
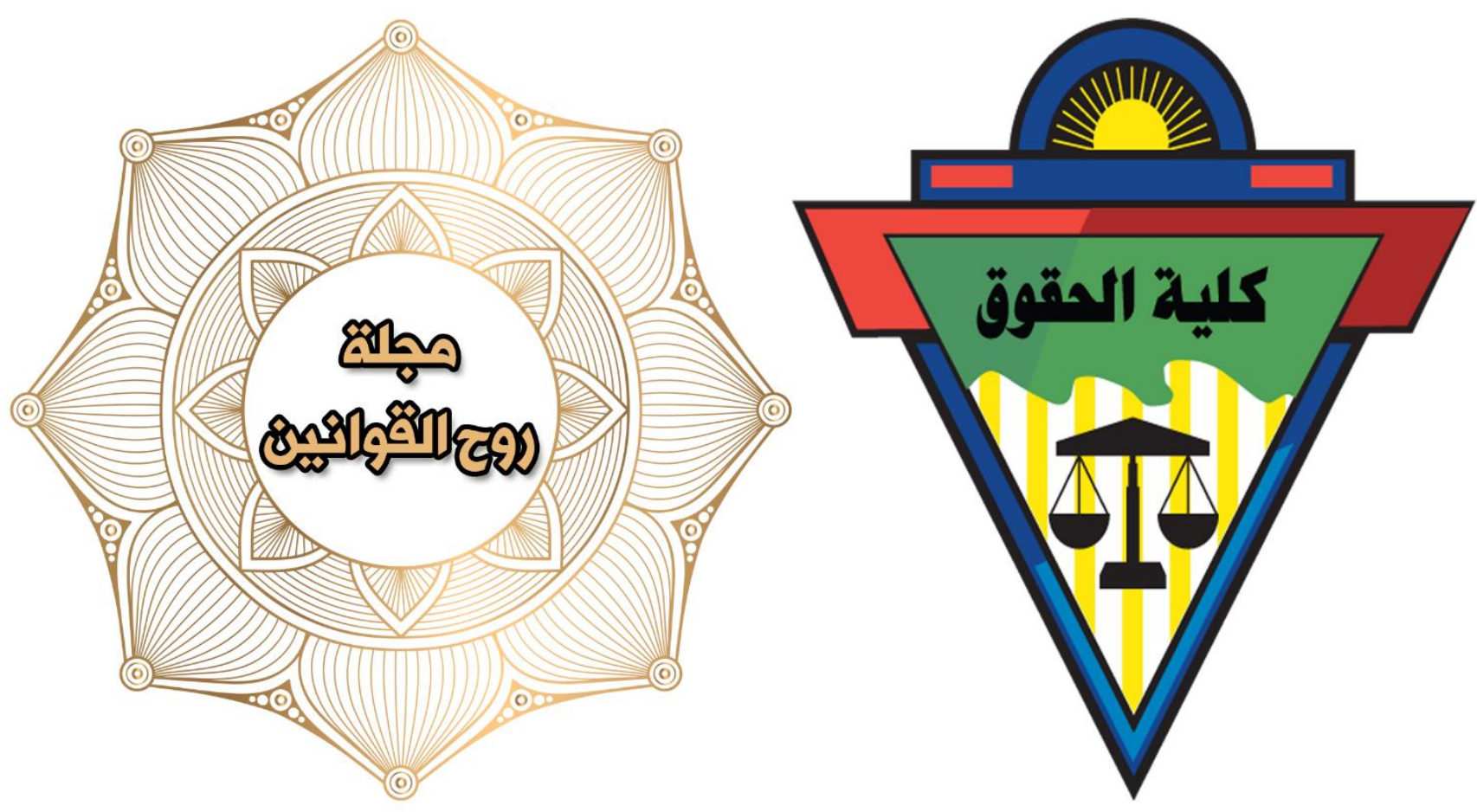

العنوان : الإنتمان الضريبي وآثارة الإقتصادية والمالية "دراسة مقارنة" . الناشر : مجلة روح القوانين - كلية الحقوق - جامعة طنطا .

$$
\begin{aligned}
& \text { المؤلف : إبراهيم عبد العزيـز النجـــار. } \\
& \text { المجلد : الأول . المالم } \\
& \text { العدد : الثامن و الثمانون . } \\
& \text { محكمة : نعم. }
\end{aligned}
$$

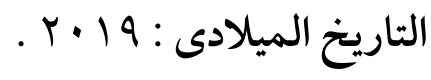

$$
\begin{aligned}
& \text { الشهر : أكتوبر · }
\end{aligned}
$$

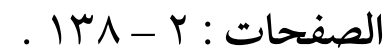

$$
\begin{aligned}
& \text { مواضيع : الإيتمان الضريبى · } \\
& \text { (C) } 19 \text { ـ مجلة روح القوانين - جميع الحقوق محفوظة . }
\end{aligned}
$$


الأصل في الإتتمان الضريبي، أو الخصم Tax Credit أنه نظام تسمح به بهاه

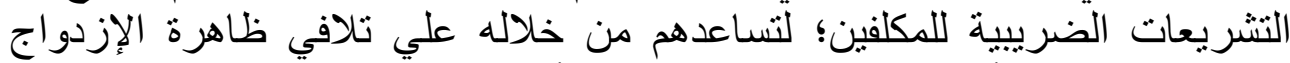

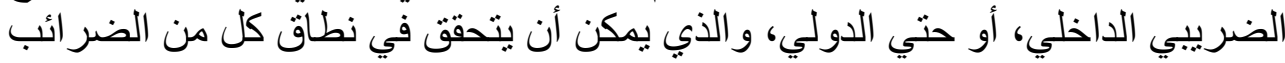

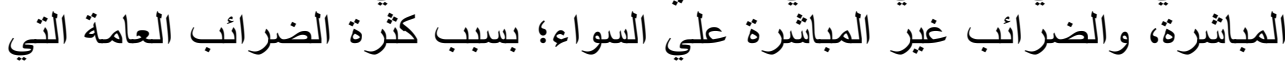

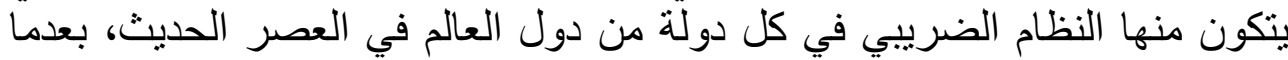

أصبحت الضريبة العامة هي المعين الأكبر لتمويل الموازنات العيات العامة للدول المختلفة.

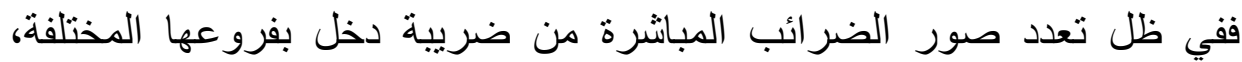

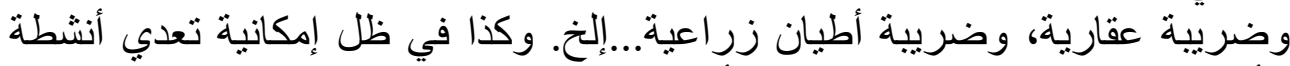

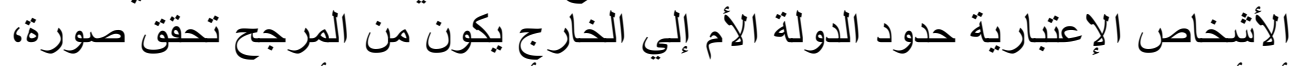

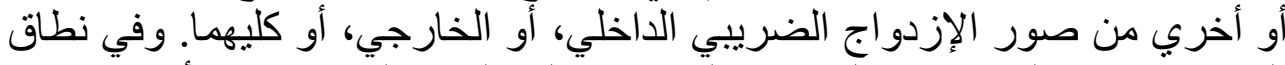

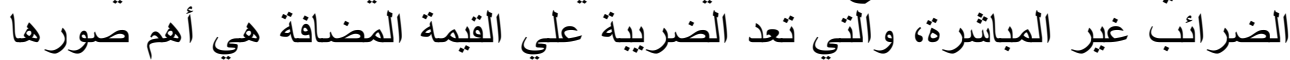

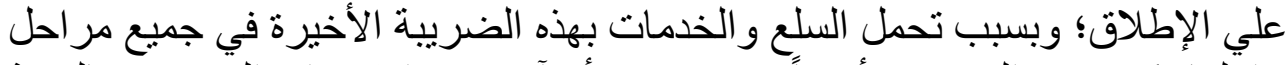

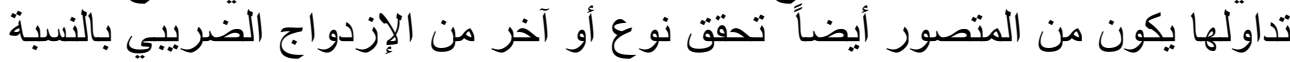

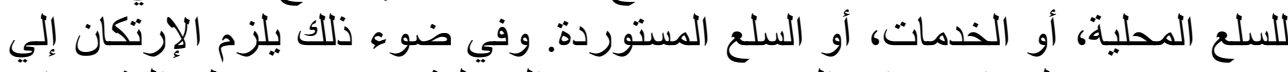

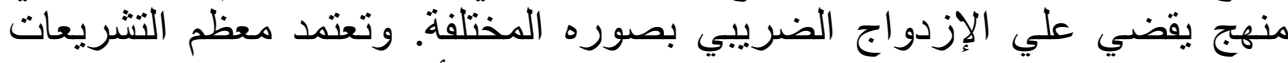

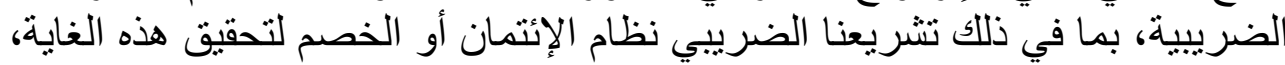

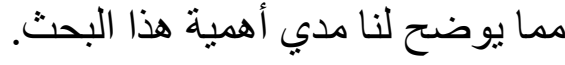

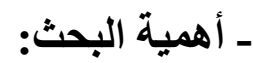

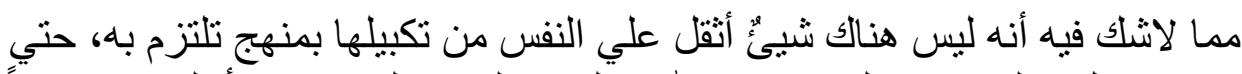

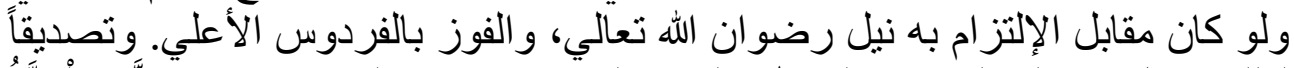

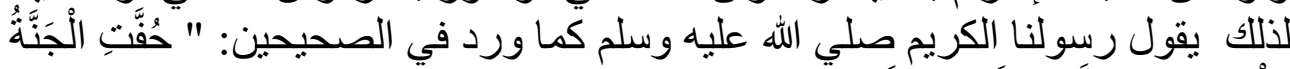

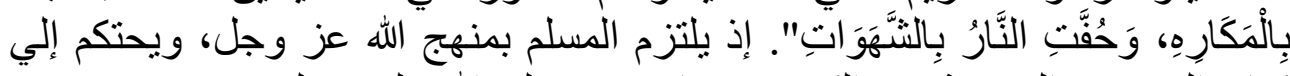

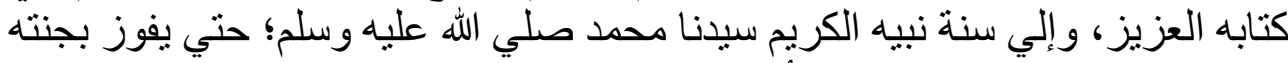

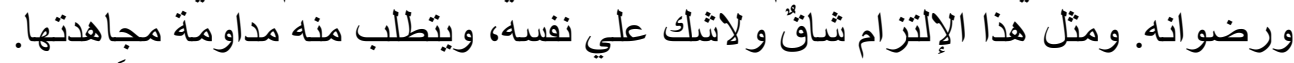

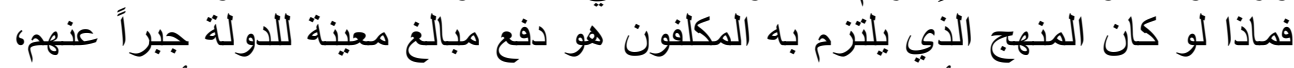

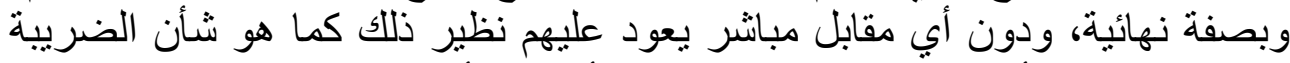

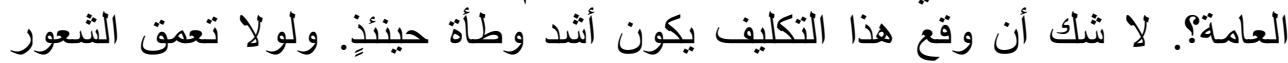

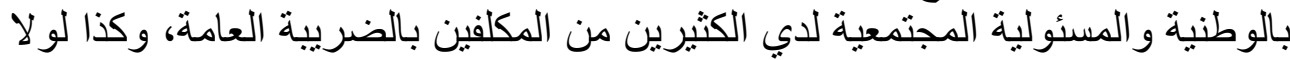

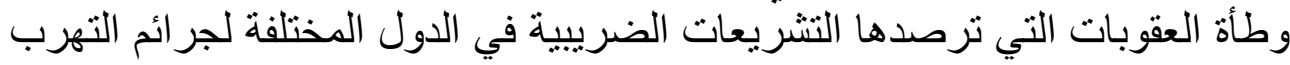

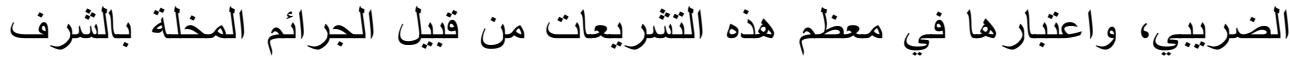

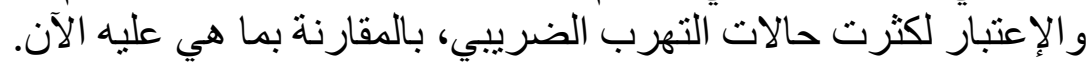

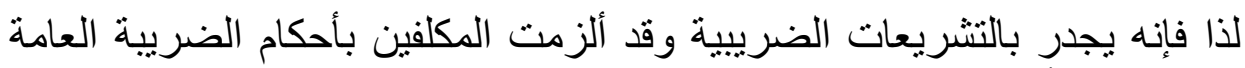

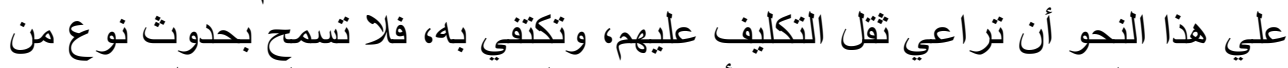
الإزدواج الضريبي. ومن هنا تبدو أهمية هذا البحث. إذ يرنو إلي تناول موضوع 


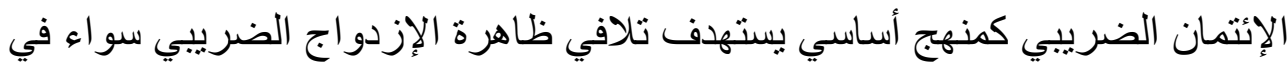

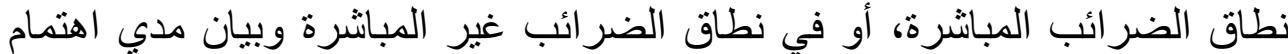

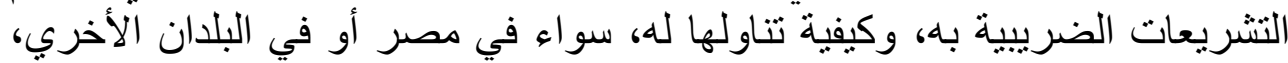

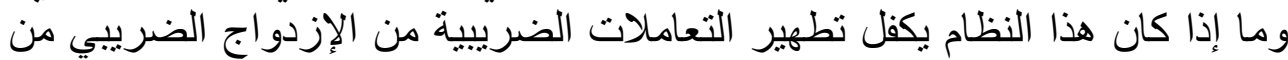

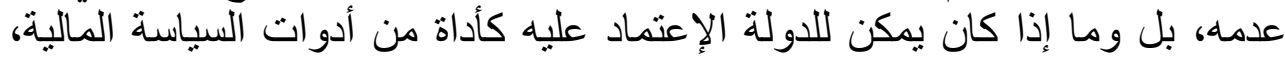

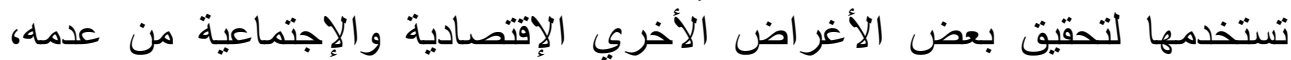
و الوقوف علي الآثار الإقتصادية والمالية لتطبيق هذا النظام.

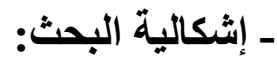

تتمثل الإنشكالية الرئيسة لهذا البحث، في ضوء ماسبق، في التعرض لماهية نظام

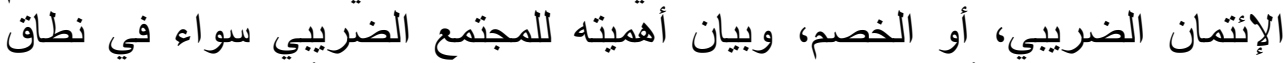

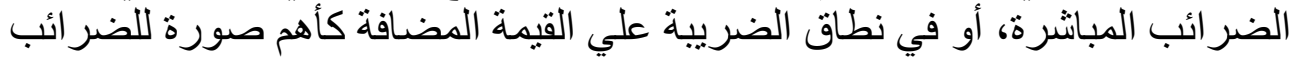

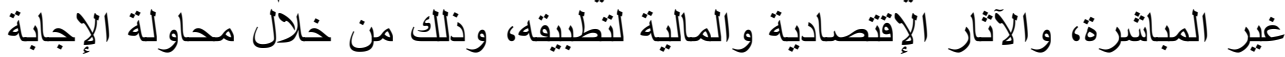

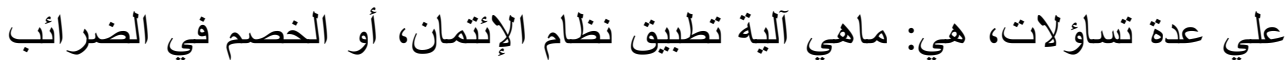

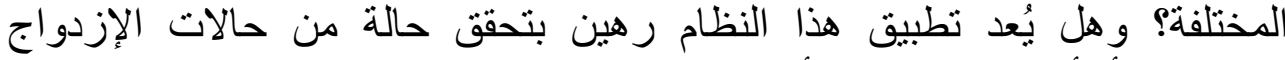

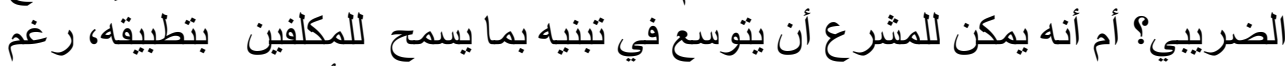

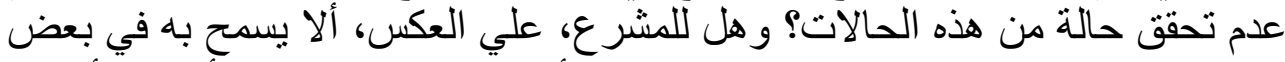

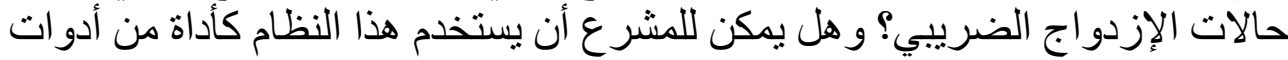

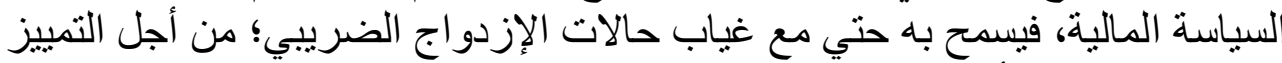

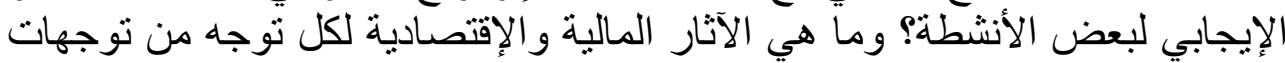

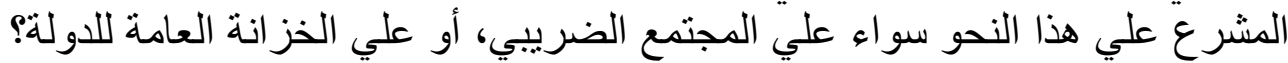

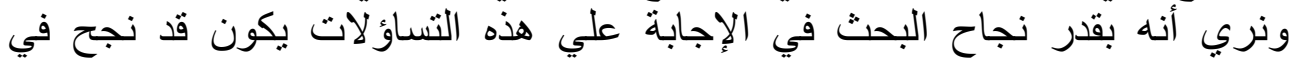

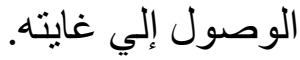

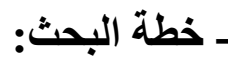

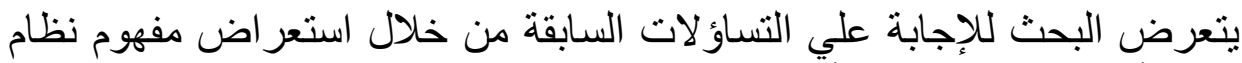

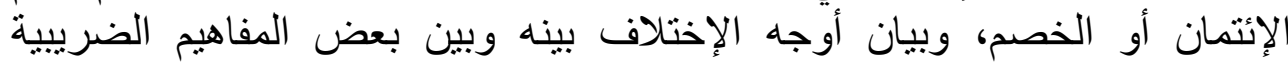

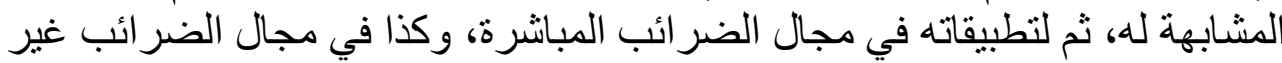

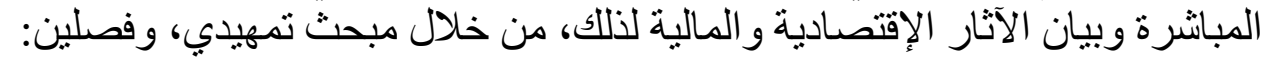

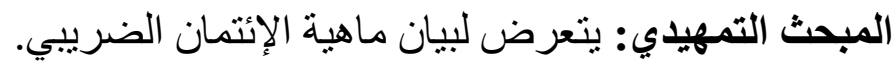

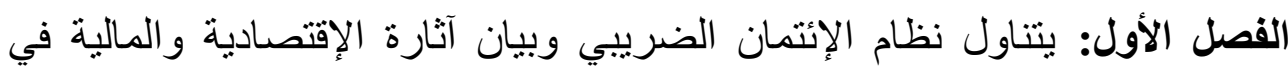
نطاق الضر ائب المباثرة، سو اء ضريبة الدخل، أو الضريبة علئ رأن أس المال.

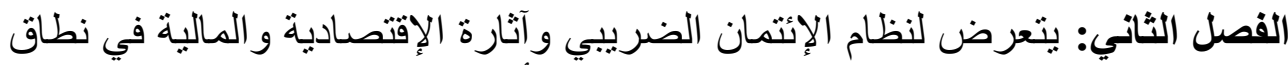
الضريبة علي القيمة المضافة باعتبار ها الصورة الأهم للضر ائب غير المبانشرة. 


\section{ماهية الإنتمان الضريبي}

المبحث التمهيدي

أولاً: تعريف الإنتمان الضريبي:

الإئتمان الضريبي، أو الخصم Tax Credit عبارة عن نظام يسمح به التشريع

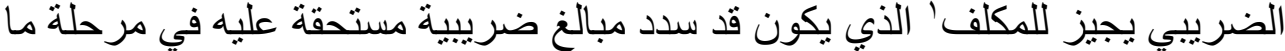

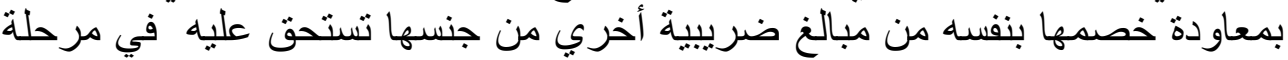

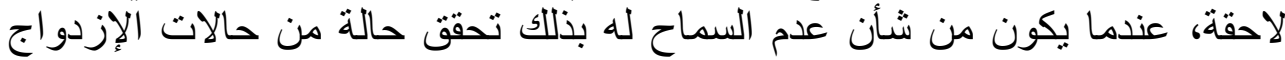

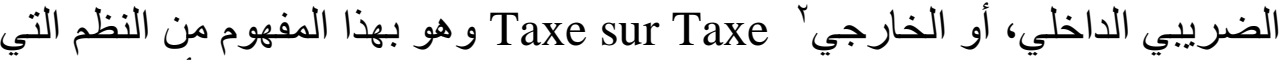
تستخدمها التشريعات الضريبية سواء في نطاق الضرائب المباشرة الضرأ أو في نطاق

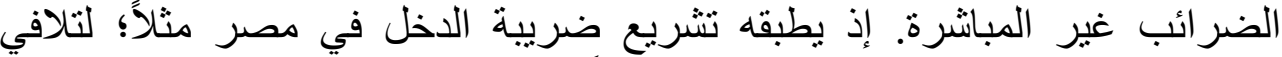

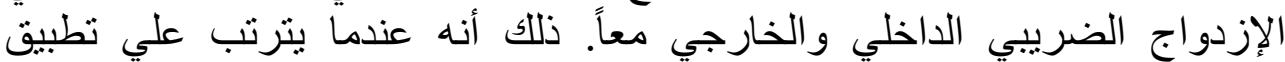
التشريعات الضريبية المختلفة خضوع المادة الواحدة لأكثر من ضريية من ذات

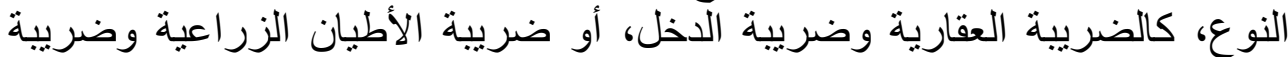

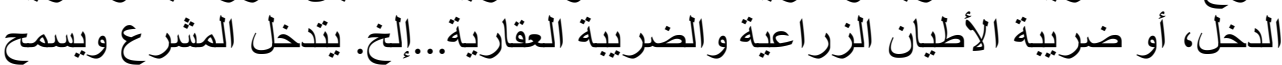

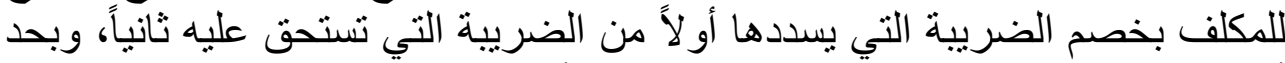

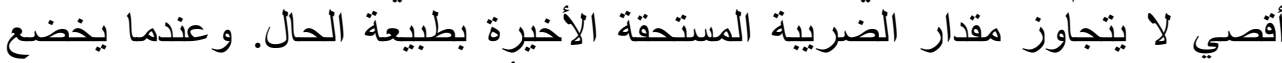

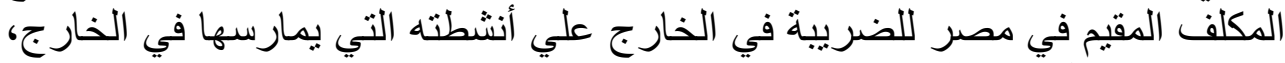

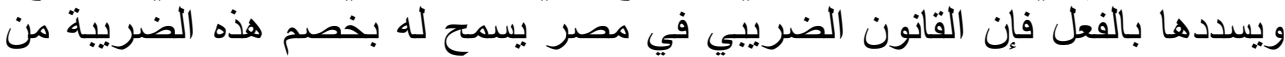

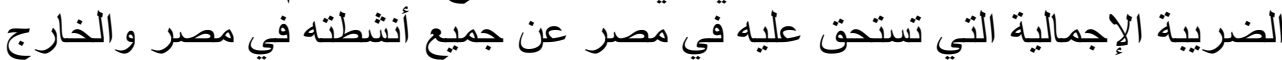
(خصم الضريبة الأجنبية)؛ من أجل تلافي الإزدو الإجي الضرية الضريبي الدولي.

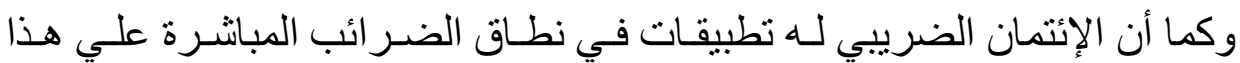

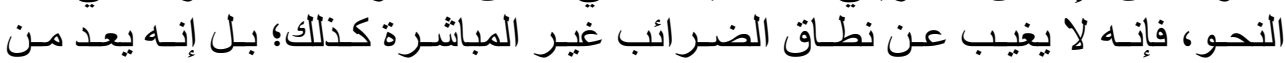

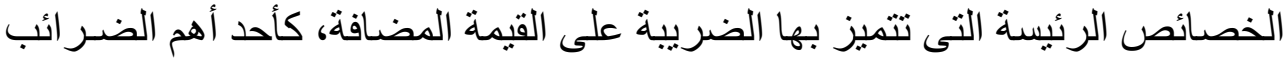

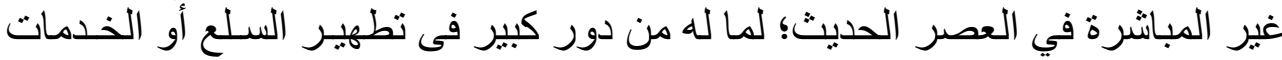

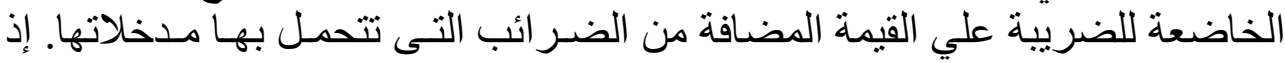

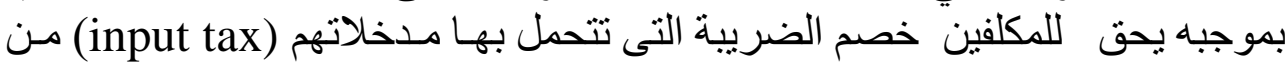

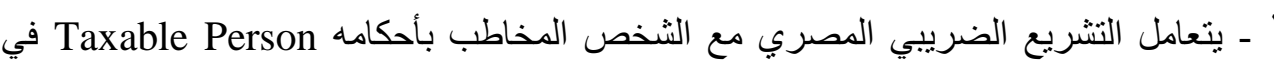

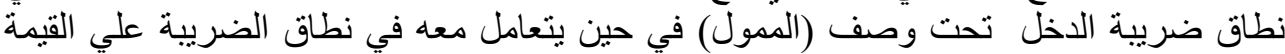

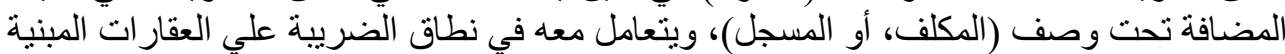

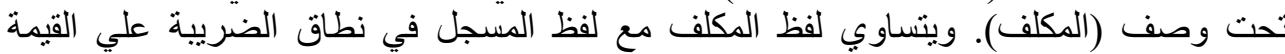

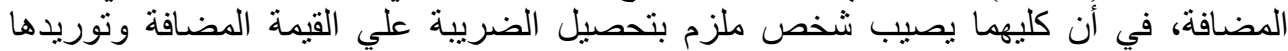

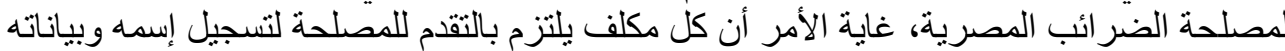

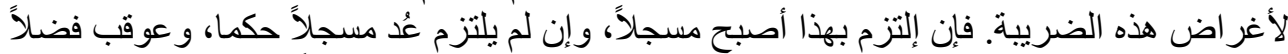

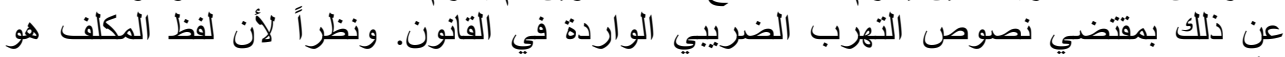

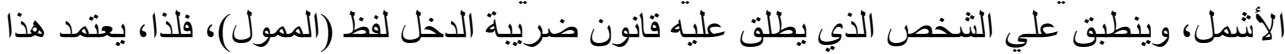

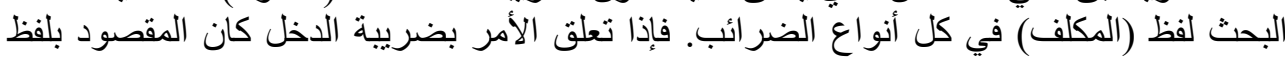
المكلف الثخص الذي يطلق عليه قانون ضريبة الدخل لفظ الفر (المدول). r - Andre Muller " L'assiette rèelle de la taxe sur la valeur Ajoutee " thèse du doctorat, Dallaz, paris, 1970 , p. or. 
الإئتمان الضر يبي وآثارة الإقتصادية والمالية "دراسة مقارنة"

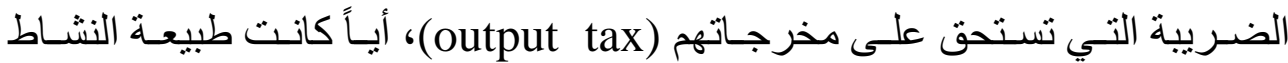

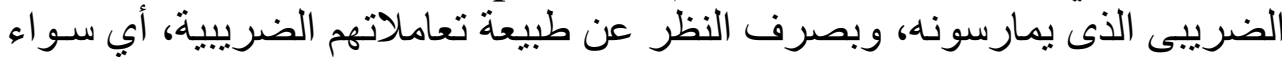

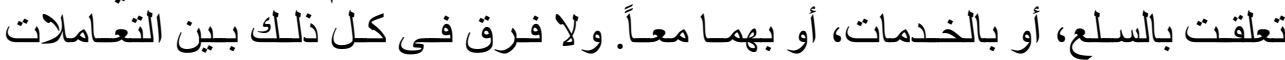
الضريبية التي تتعلق بالسلع المحلية وتللك التى تتصل بالسل السلع المستوردة.

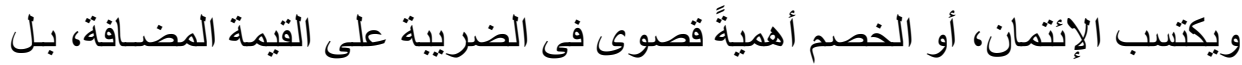

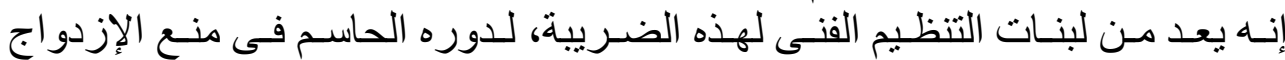
الضريبى. ولذا حاول مشروع التوجيه السادس (Sixth Directive) للسوق اللسوق الأوربية

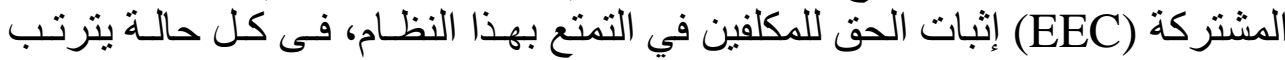

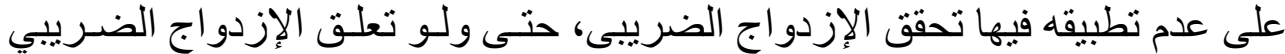

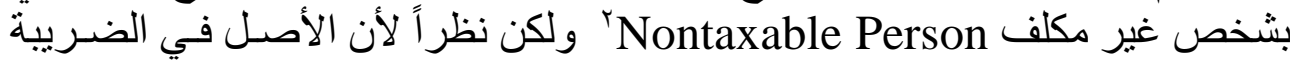

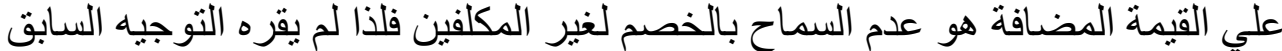

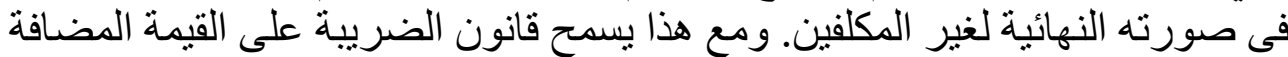

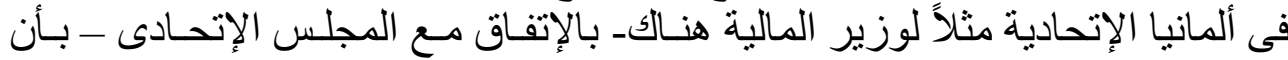

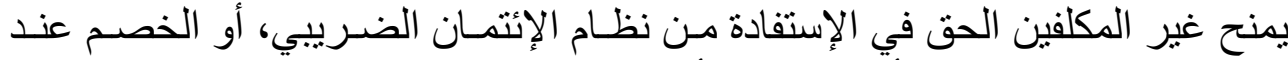

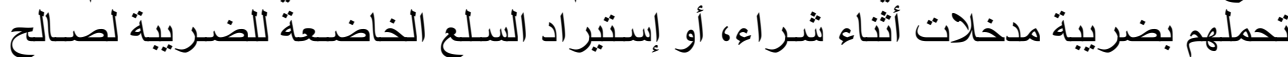

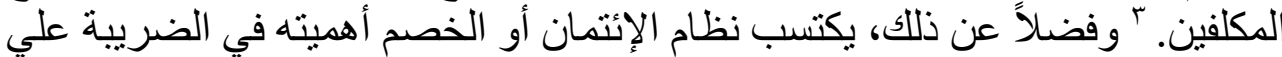

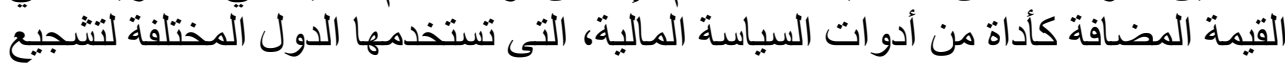

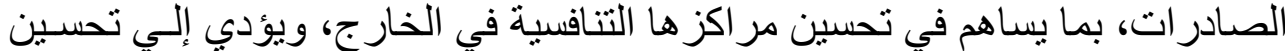

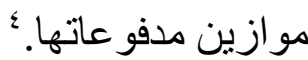

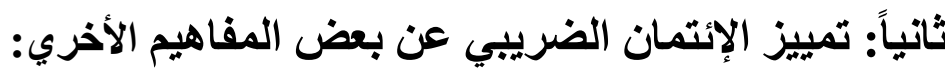

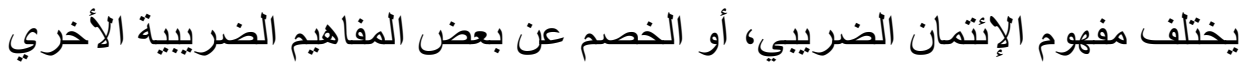

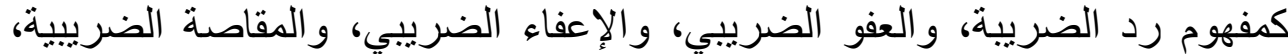

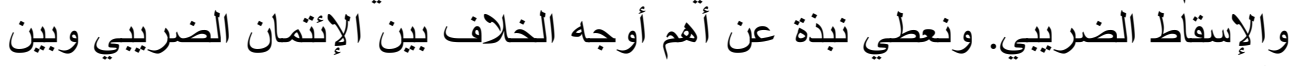

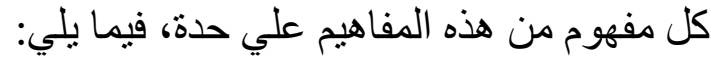
(1) - تمييز الإنتمان الضريبي عن رد الضريبة:

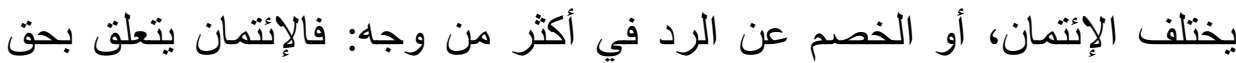

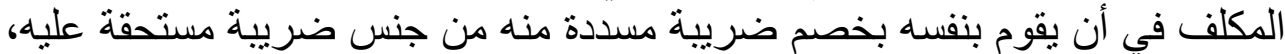
بهدف تلافي الإزدواج الضريبي، في حين يتعلق الرد بضريبة زن زائدة مستحقة للمكلف

' - Gerard tourinie; La politique friscale sous la ${ }^{\circ}$ e Repulilique, paris , 1910, pp. IrV $-1 \% \Lambda$.

$\checkmark$ - Dennis Parkinson, Value Added Tax in the E E C, Graham \& trotman L T d , London, 1911.p.rr.

r ـ انظر فى تفاصيل ذلك : المادة (0/0) من قانون الضريبة على القيمة المضافة فى ألمانيا الإتحادية.

¿ - Alan A. Tait, value Added Tax international, practice and problems, 1911 internatinal Monetary .Fund, Washington, D.C. 1911. p. 9 . 
للدي الإدارة الضريبية، ويعجز المكلف عن الحصول عليها بنفسه، فتتدخل الإدارة الضريبية لردها إليه. وتوجد أمثلة عديدة لنظام رد الضريبة سواء في نطاق ضريبة الدخل، أو في الضريبة علي القيمة الضئة المضافة:

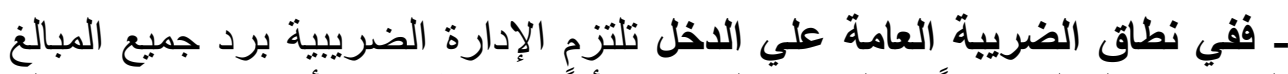

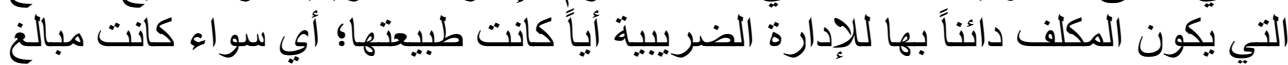

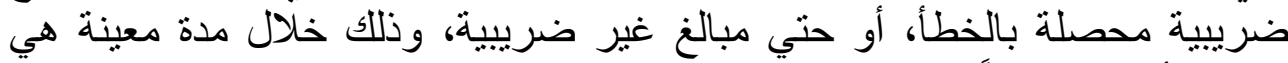

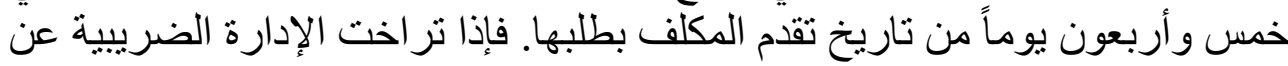

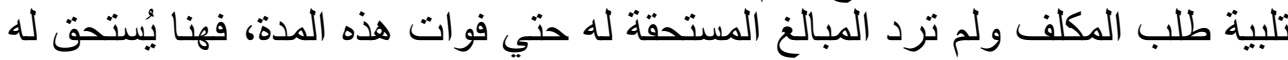

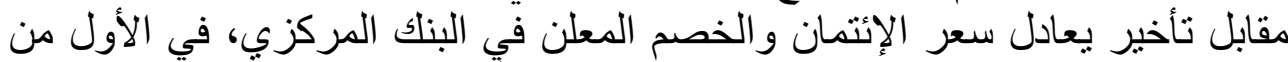

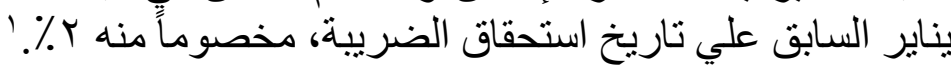

وحسناً فعل المشرع إذ سوي في الحكم بين مقابل التأخير المستحق لمصلحة

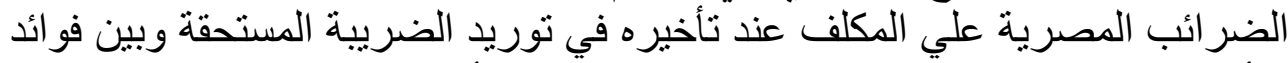

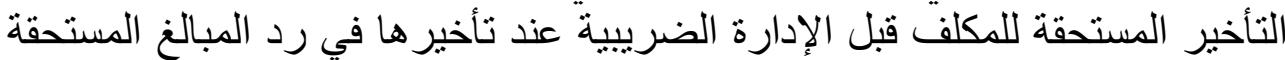

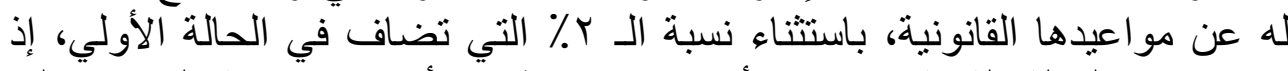
تخصم في الحالة الثانية؛ بحسبان أنها تحسب نظير اعني الأعباء الإدارية التي تتحملها

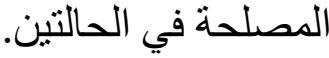

ويسري نظام رد الضريبة كذلك علي الضريبة المدفوعة علي الأصول الر أسمالية

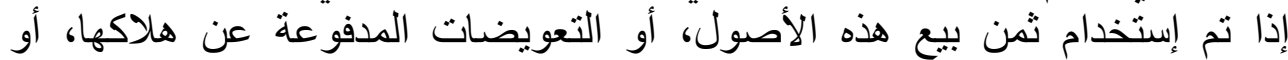
الإستيلاء عليها بالكامل لثراء أصناء أصول جديدة خلال ذات ذات السنة المالية التي يتم فيها

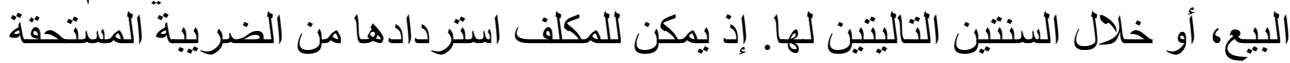

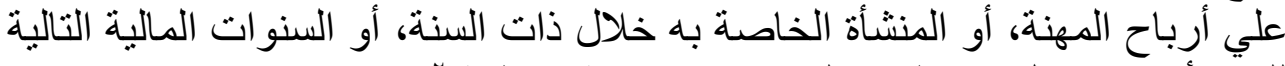

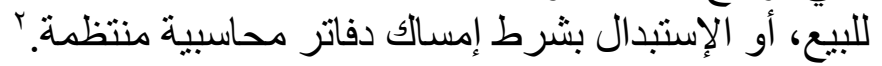

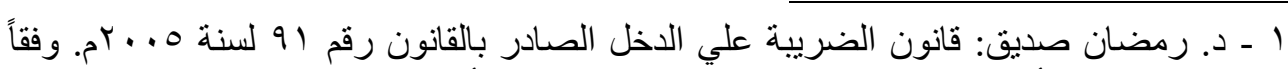

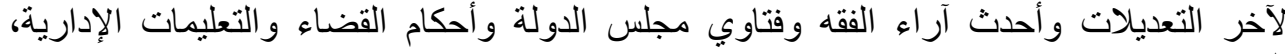

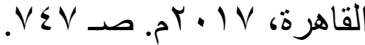

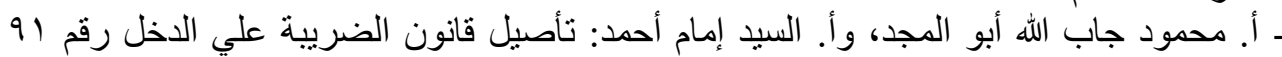

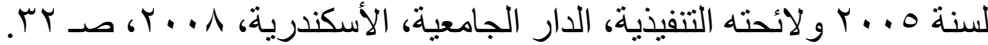

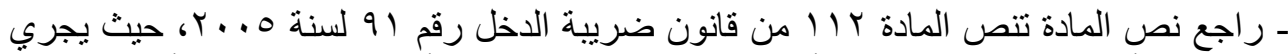

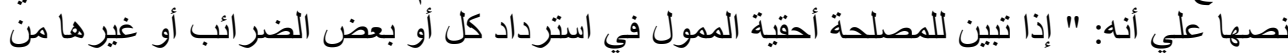

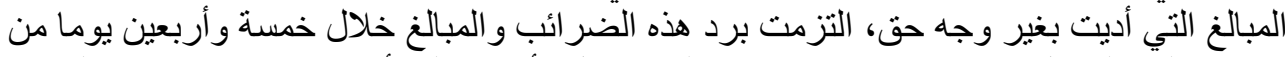

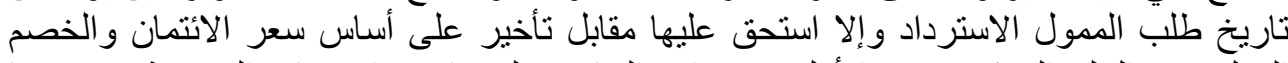

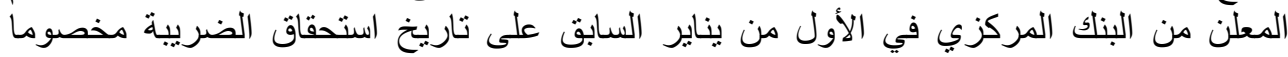

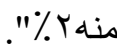
r ـ ـ د. أمين السيد لطفي: تحليل وتقييم الحو افز و الإعفاءات الضريبية مع مدخل لقياس عو ائدها

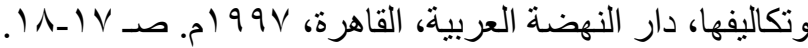


الإيتمان الضريبي وآثارة الإقتصادية والمالية "دراسة مقارنة"

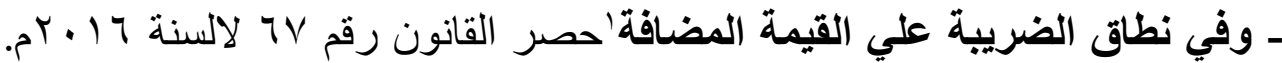

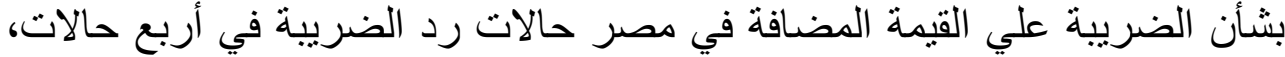

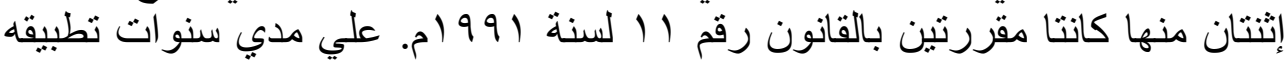

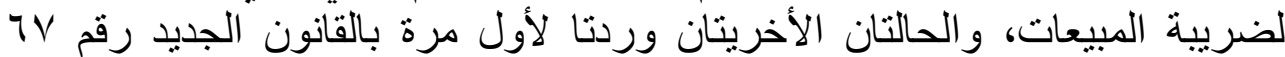

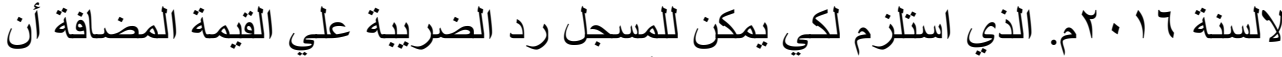

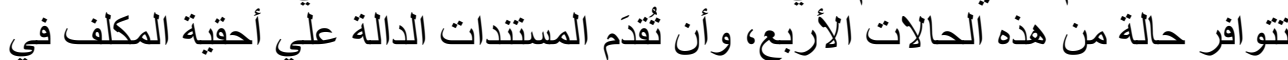

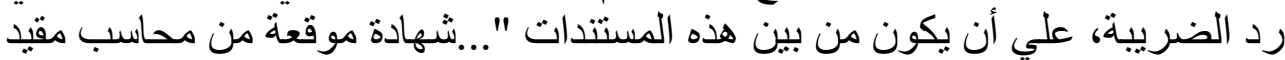

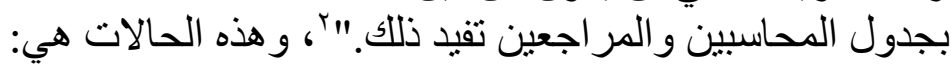

أـ الضريبة المسددة بطريق الخطأ: ذلك أنه إذا قام المسجل بسداد مبالغ مالية للإدارة

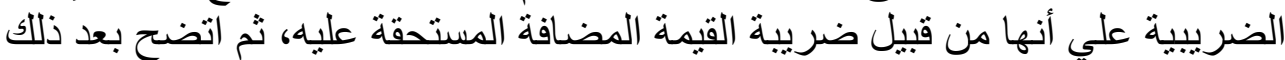

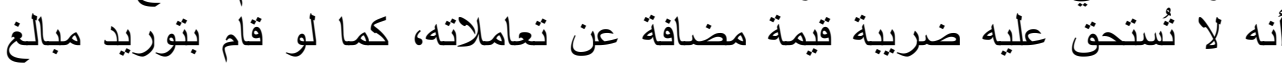

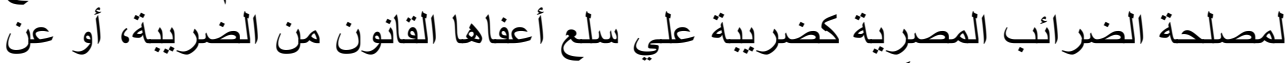

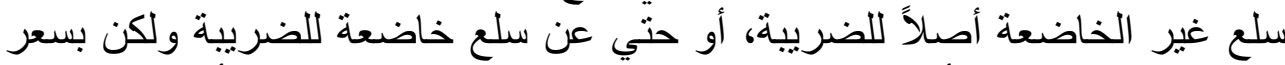

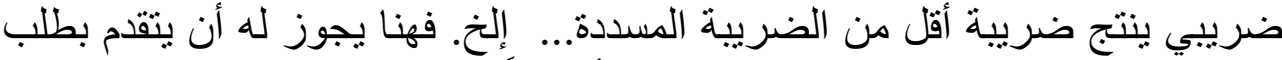

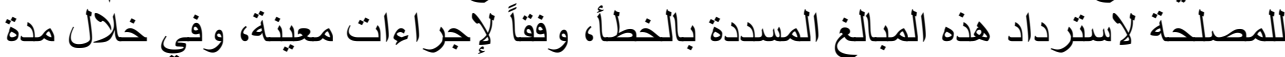

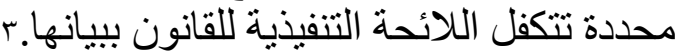

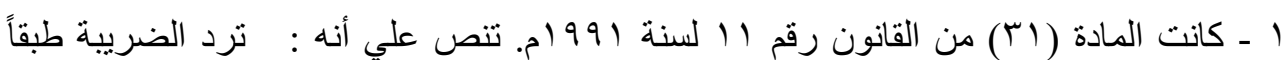

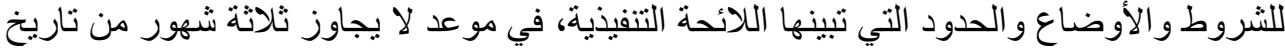

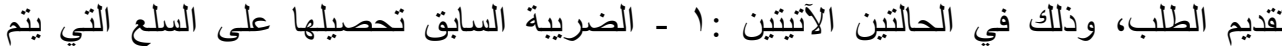

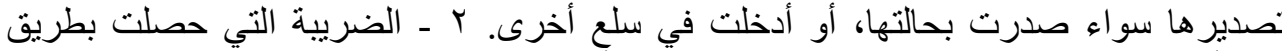

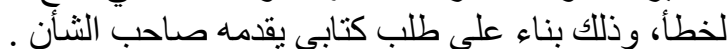

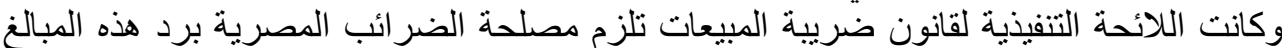

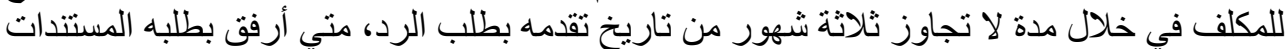

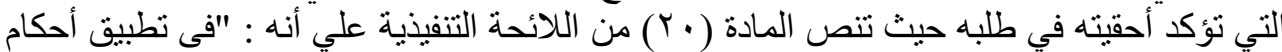

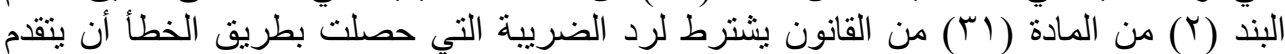

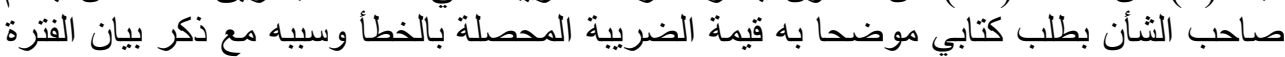

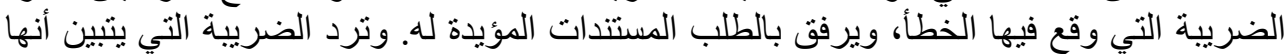

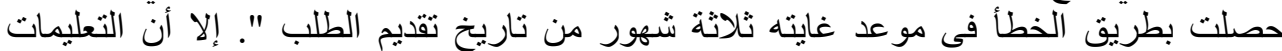

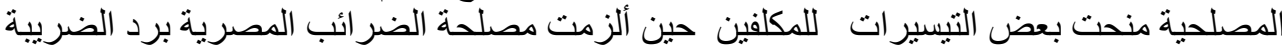

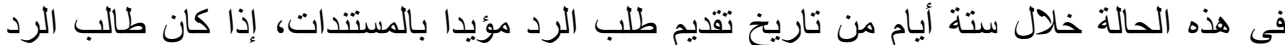

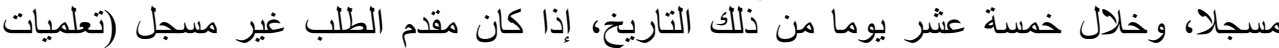
الإجر اءات رقم 10 لسنة 990 ام الصادر عن المصلحة).

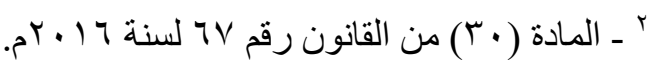

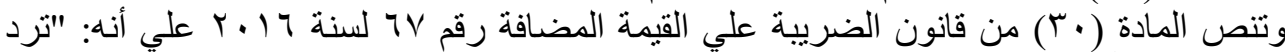

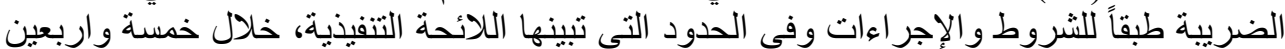

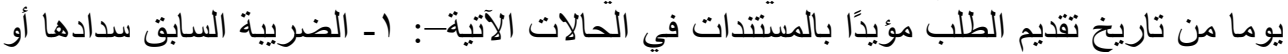

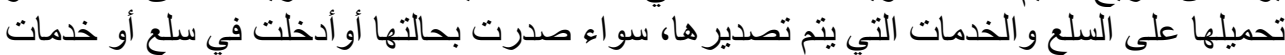

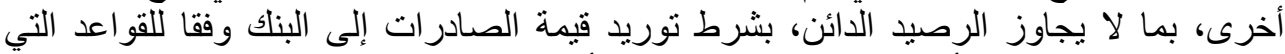

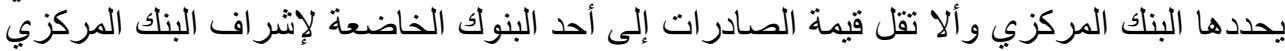
وفقا للضوابط التي تحددها اللائحة التنفيذية وذللك كله بشرط الا تقل قيمة الصـادرات عن قيمة الترات 
بـ الضريبة المسددة في حالة التصدير: الأصل أنه يجوز للمسجل خصم الضريبة الصدية

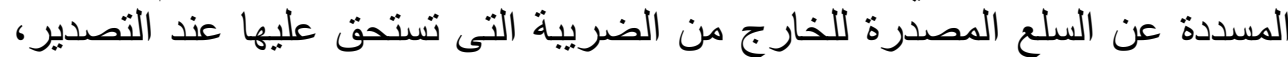

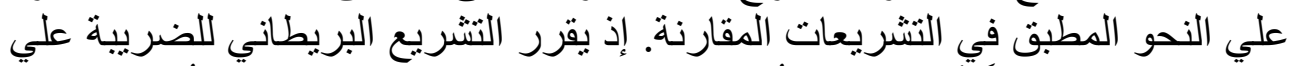

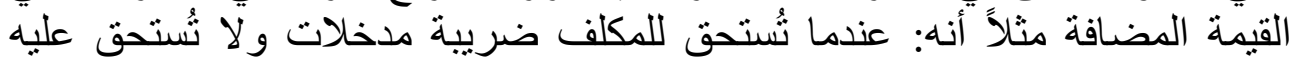

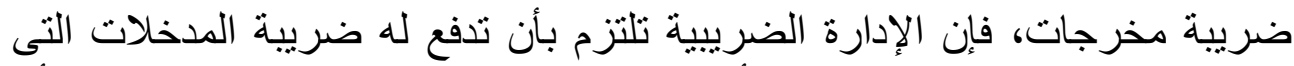

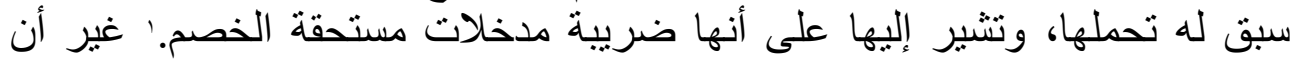

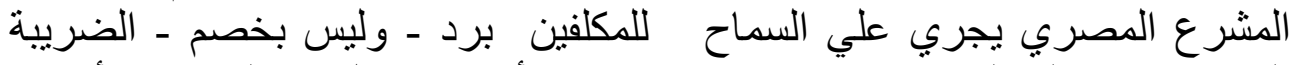

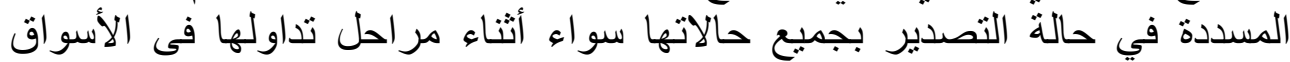

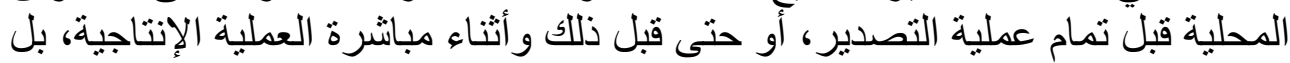

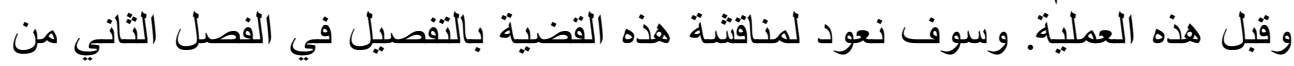

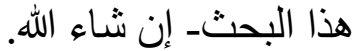

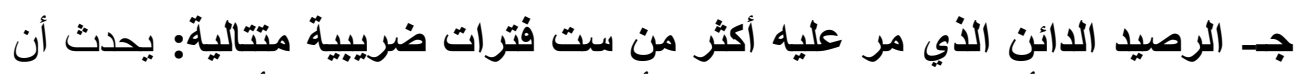

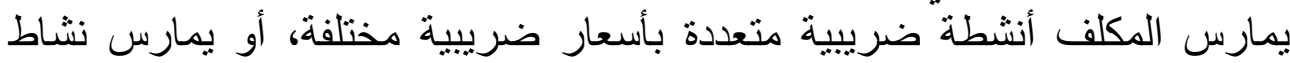

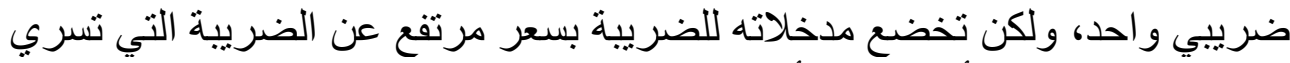

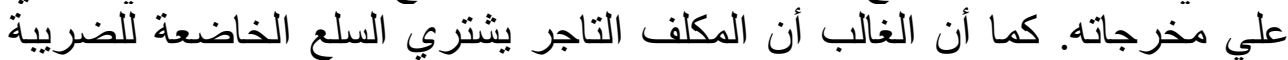

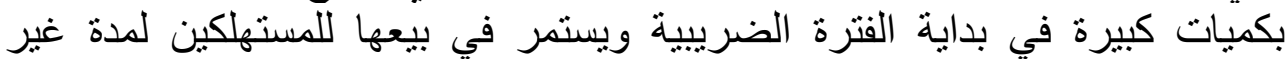

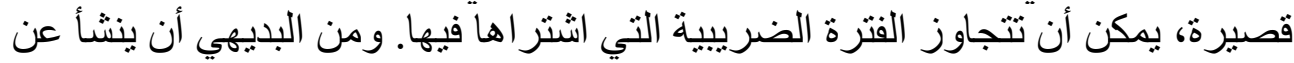

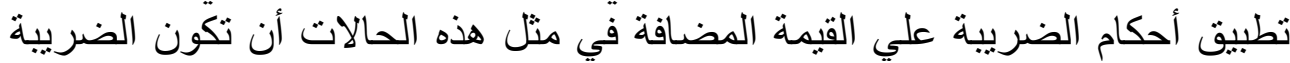

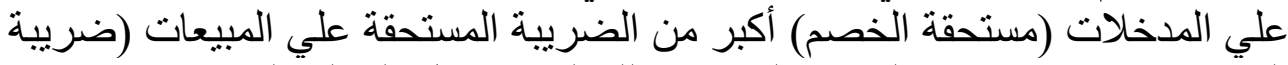

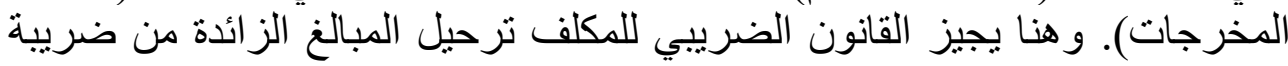

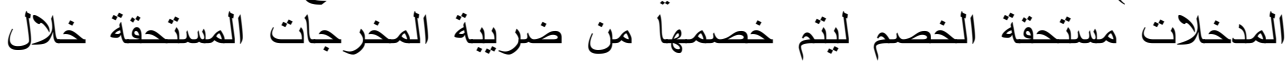

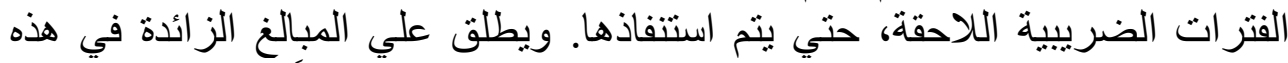

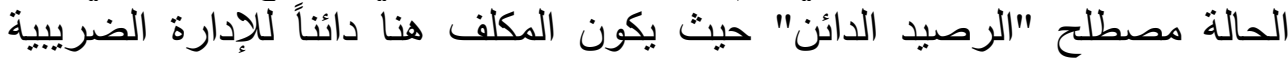

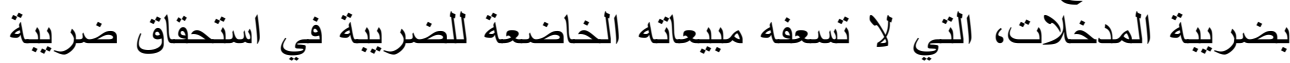

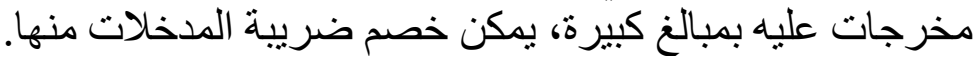

ولم يكن يحق للمكلفين في ظل تطبيق أحكام ضريبة المبيعات بالقانون رقم

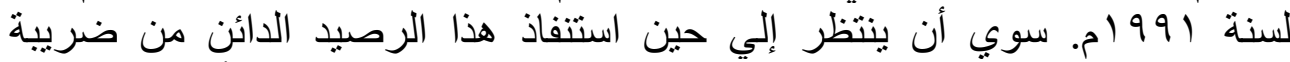

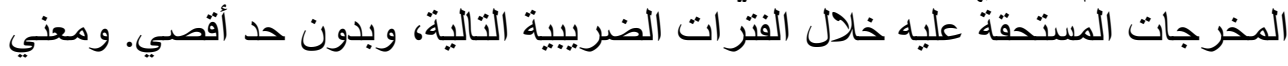

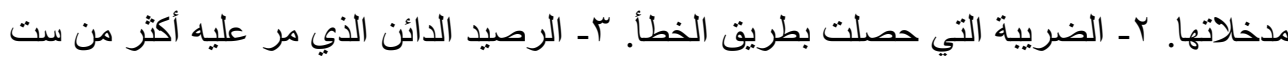

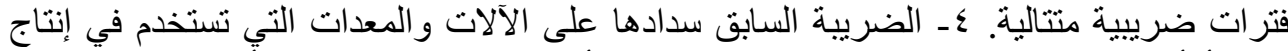

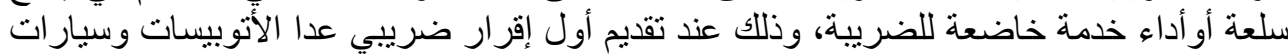

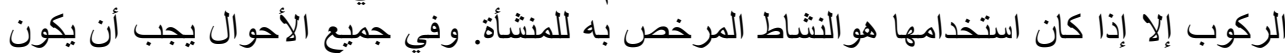

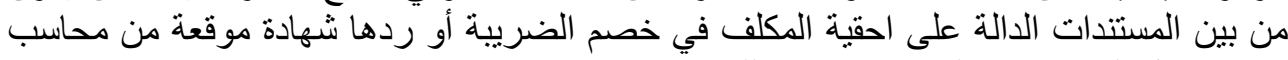
مقيد بجدول المحاسبين والمر اجعين تفيد ذللك."

' - Look: Art. No. ro/ r , since it states that: " If ... nooutput tax is due at the end of the period , ... the amaunt of the credit shall be paid to the taxable person by. the commissioners ; and an amount which is due under thirs subection is referred to in this Act as a "VAT credit" 
الإعتمان الضريبي وآثارة الإقتصادية والمالية "دراسة مقارنة"

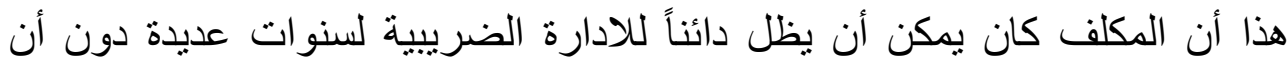

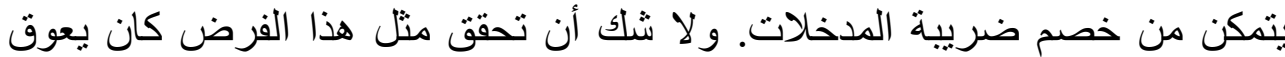

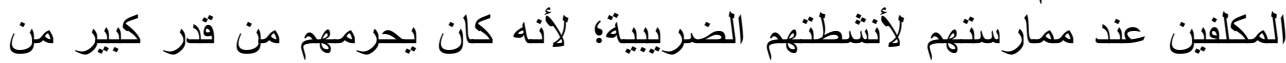

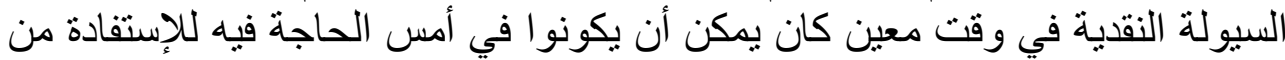

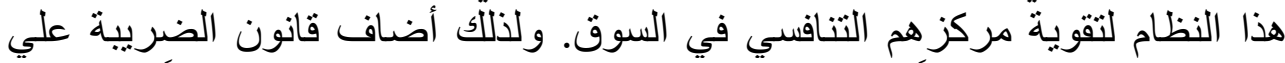

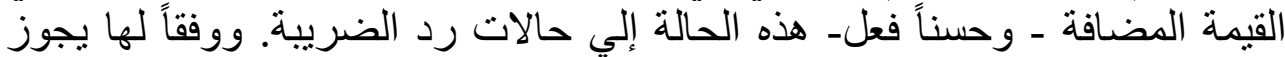

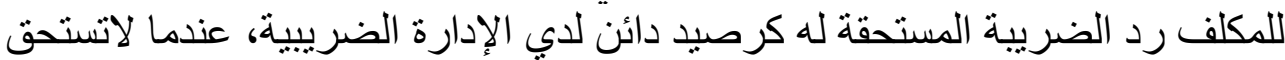

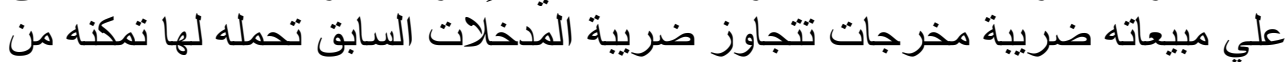

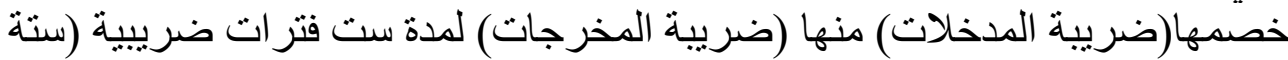
شهور ميلادية) متتالية.

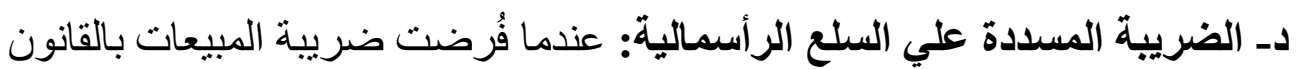

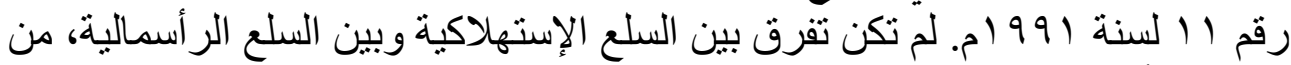

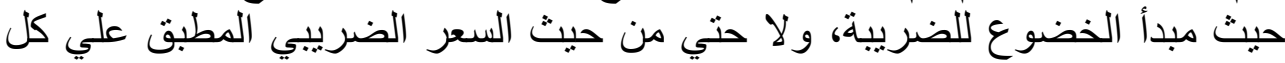

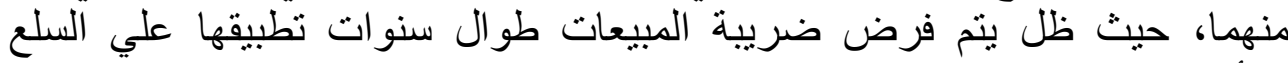

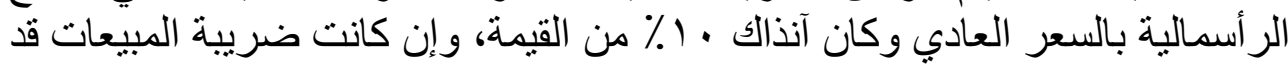

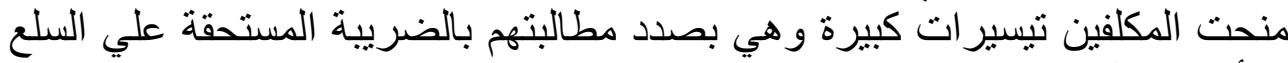

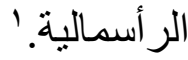

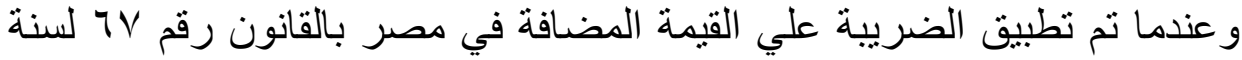

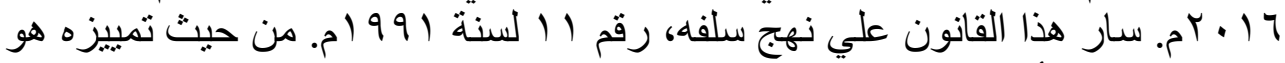

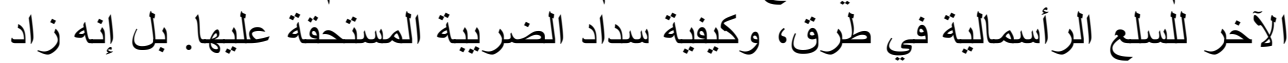

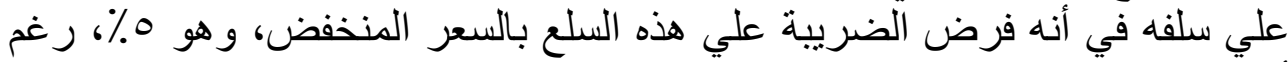

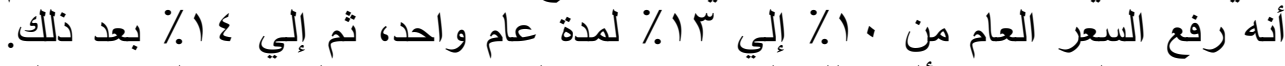

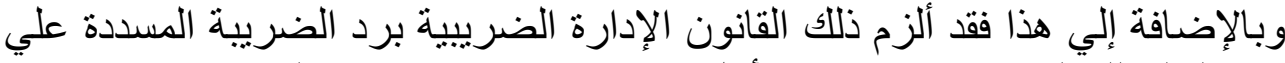

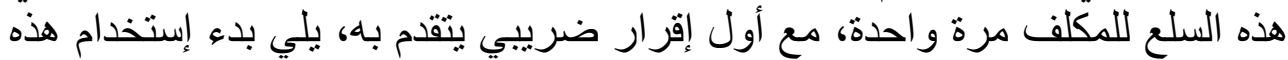

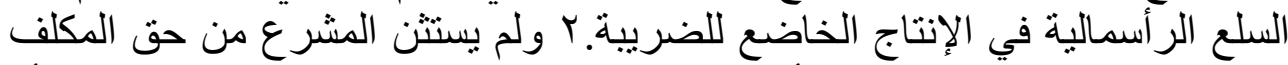

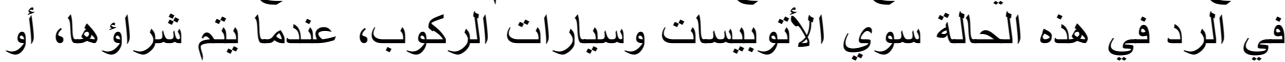

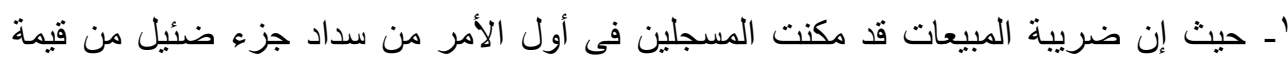

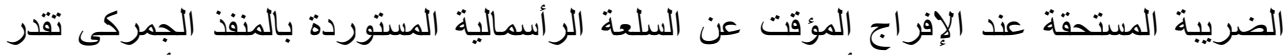

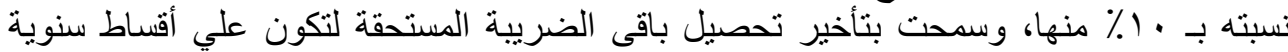

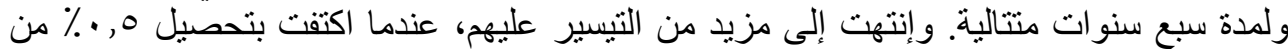

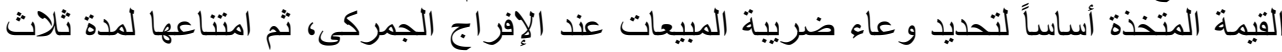

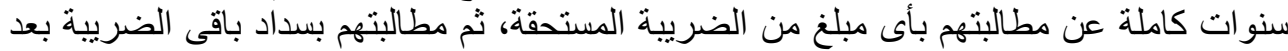

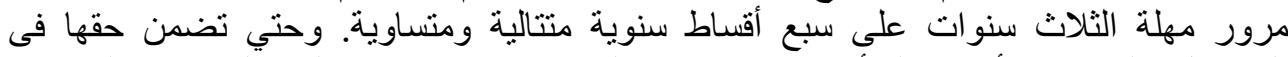

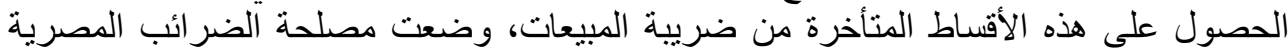

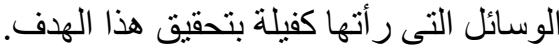

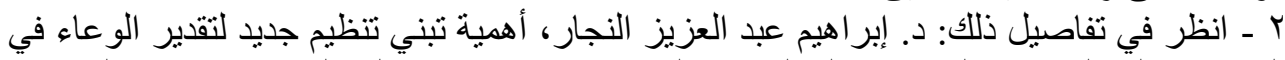
الضريبة علي العقار ات المبنية، مجلة البحوث القانية العانونية والاقتصـادية، كلية الحقوق الهية - جامعة المنوفية،

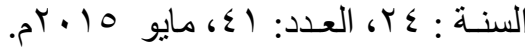




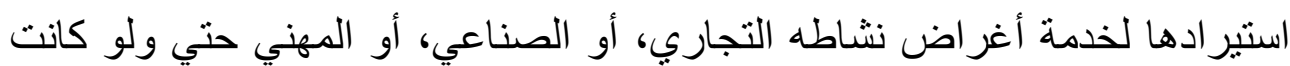

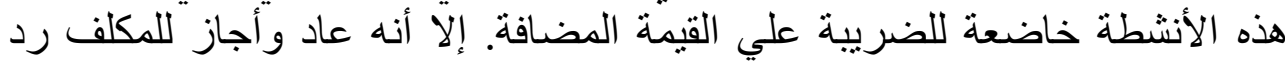

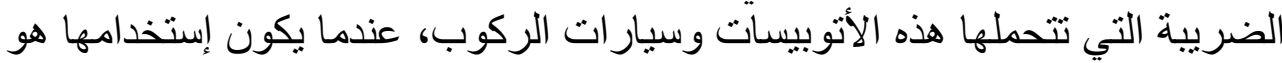

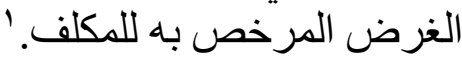

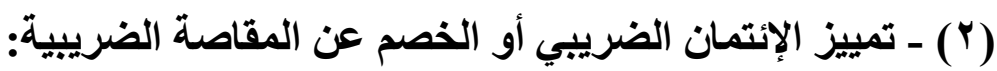

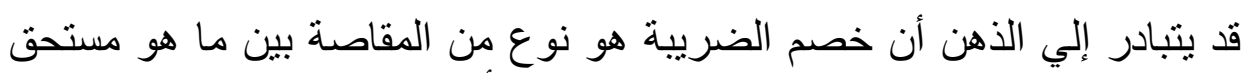

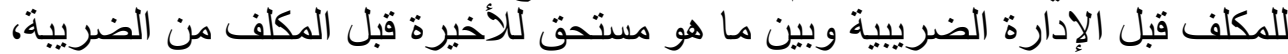

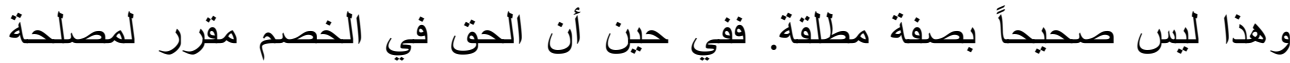

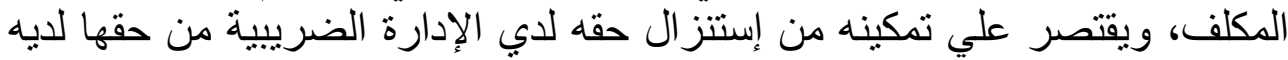

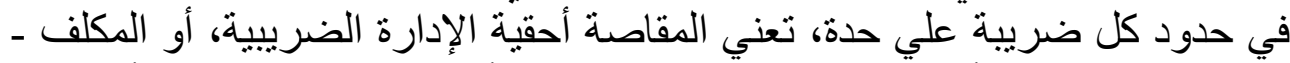

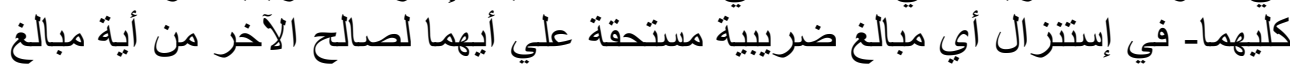

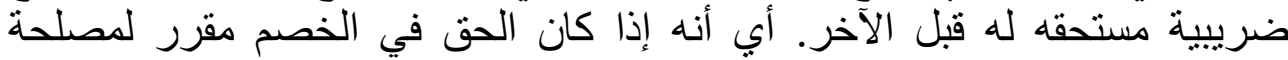

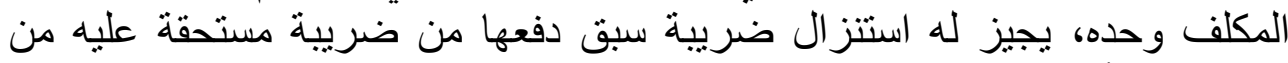

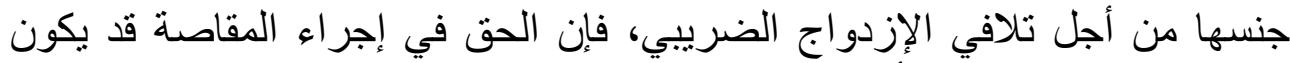

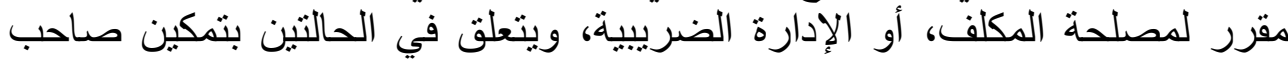

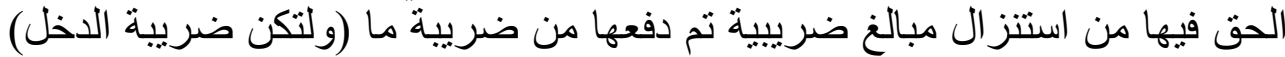

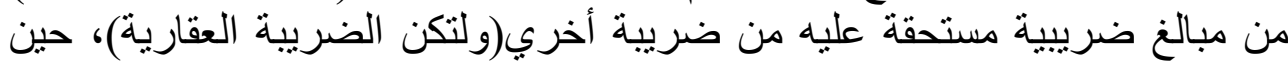

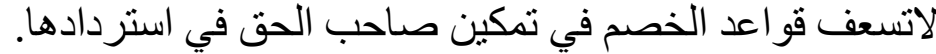

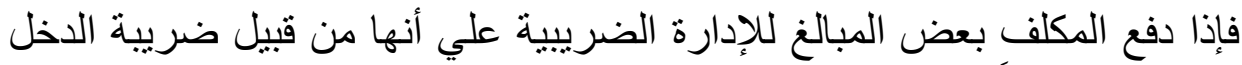

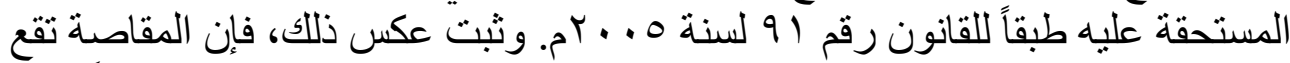

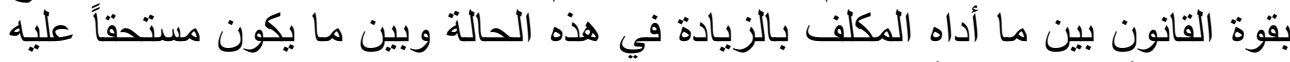

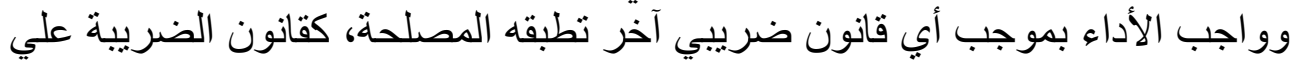

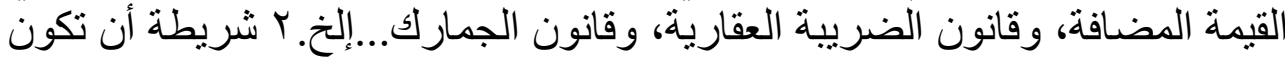

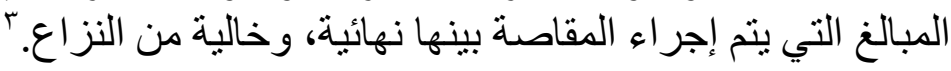

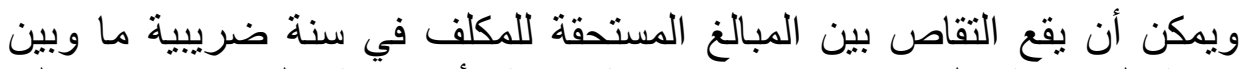

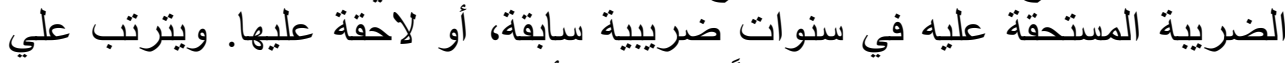

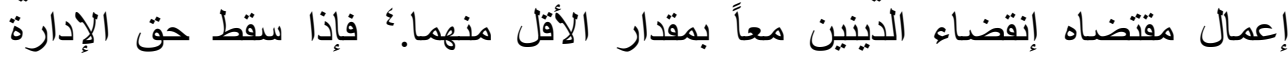

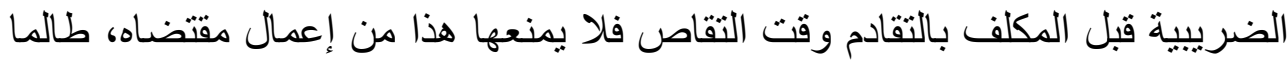

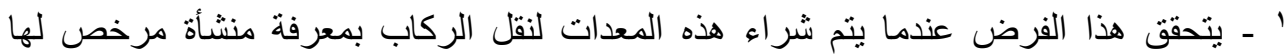

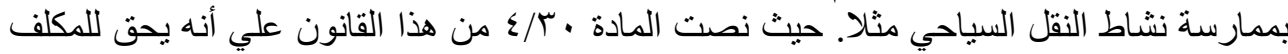

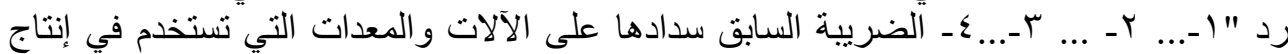

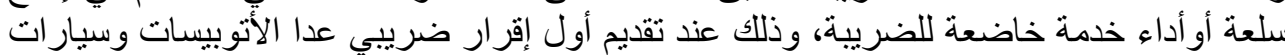

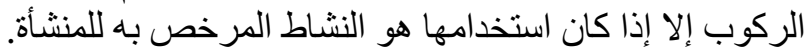

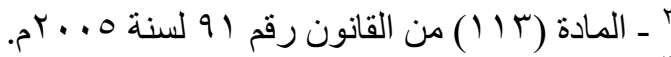

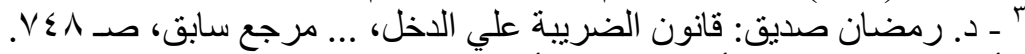

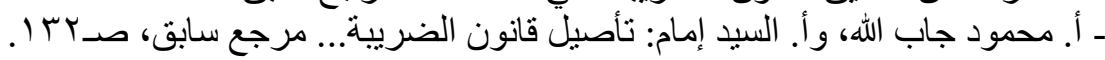

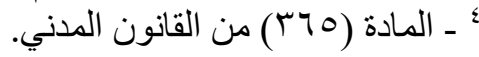


الإيتمان الضريبي وآثارة الإقتصادية والمالية "دراسة مقارنة"

أن مدة التقادم لم تكن قد اكتملت وقت نشوء الحق في التقاص. غير أن جواز المقاصة

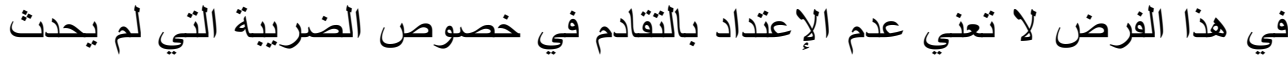

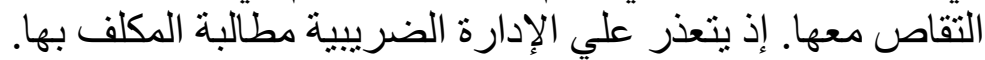

فإذا كان المكلف هو من يريد إجراء المقاصة، فيكون له تعبين نوع الضريبة التي التهاي

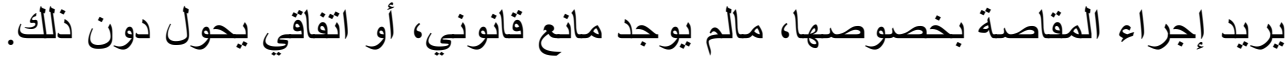

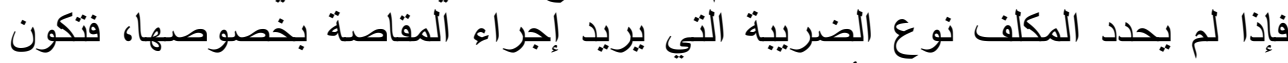

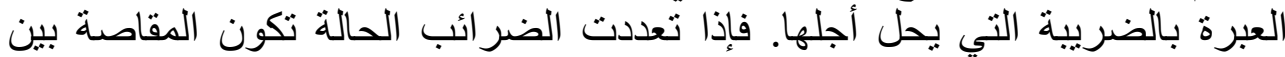

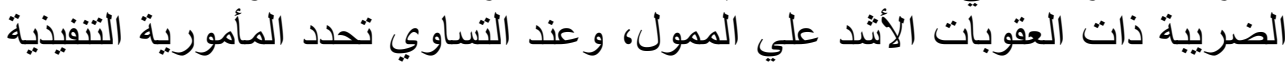

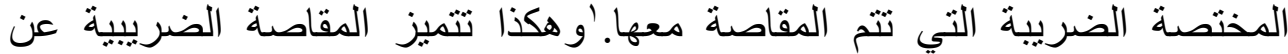

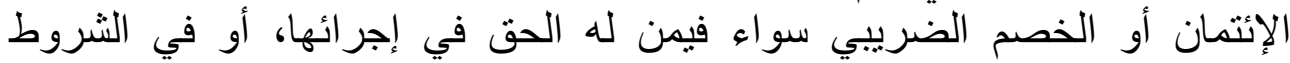
و الضو ابط التي تحكم كل منهما.

\section{(r) - تمبيز الإئتمان أو الخصم عن الإسقاط الضريبي:}

تكاد تجمع التشريعات الضريبية المختلفة علي أنه يمكن اسقاط دين الضريبة العامة الإنة

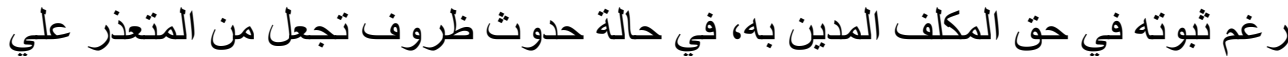

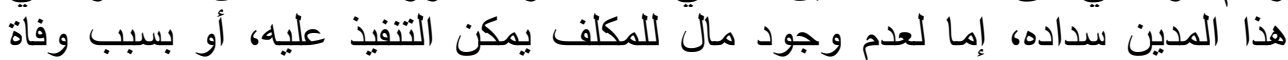

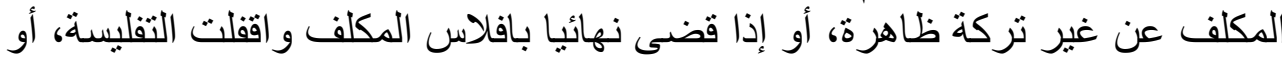

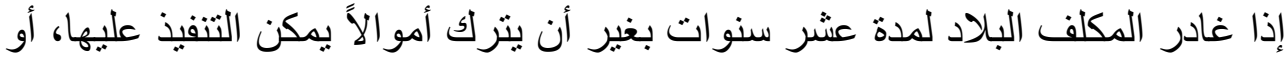

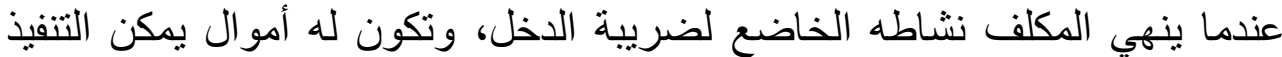

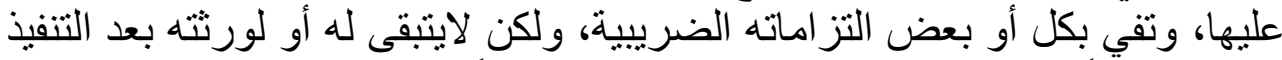

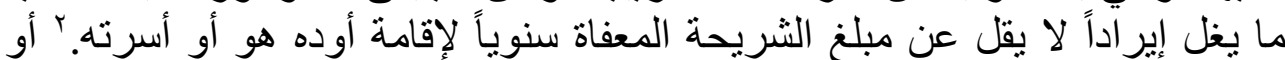

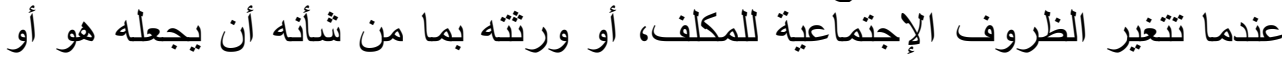

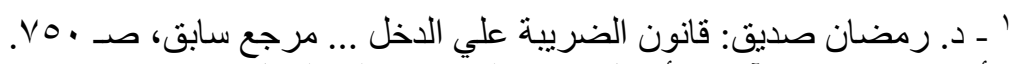

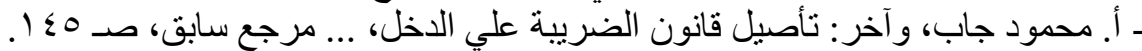

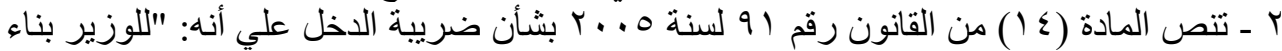

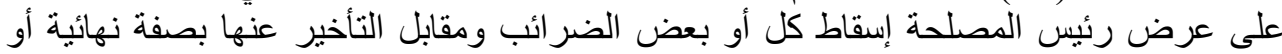

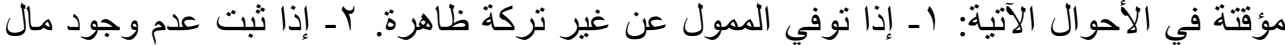

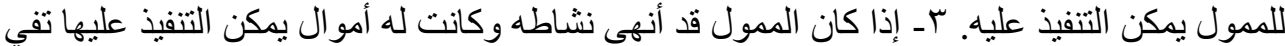

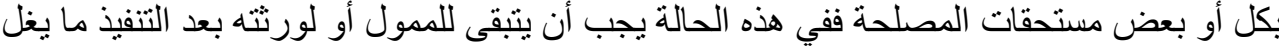
إير ادا لا يقل عن من ـ...0 جنيه سنويا.

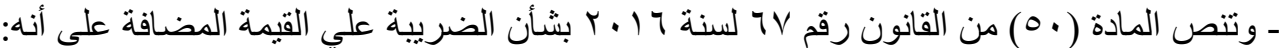

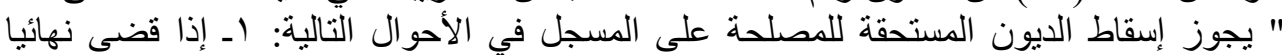

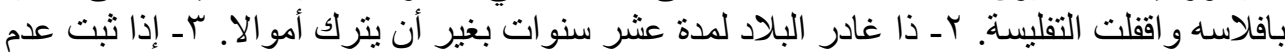

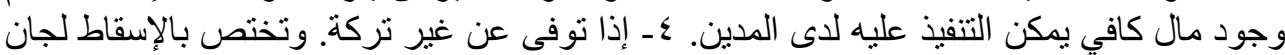

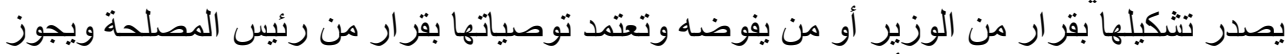
سحب قرار الإسقاط إذا تبين أنه قام على سبب غير الفير صحيح، وتحدد اللائحة التنفيذية قو اعد تشكيل 
ورثثه غير قادرين على الوفاء بدفع الضريبة المستحقة علي عقار اته المبنية، أو ما في

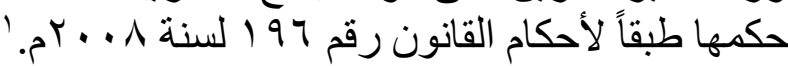

إذ الفرض نكون - في جميع هذه الصور- إزاء ضريبة مستحقة علي المكلف، فئه

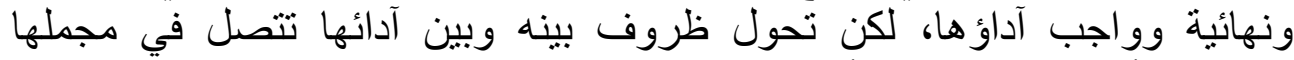

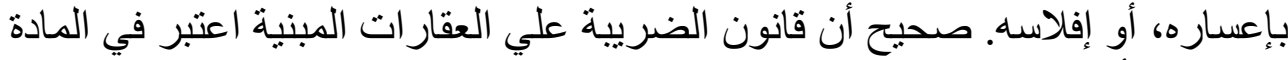

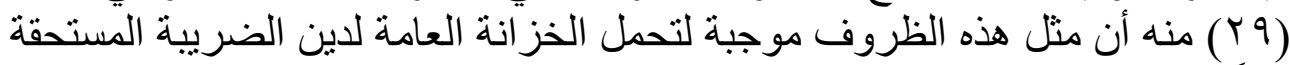

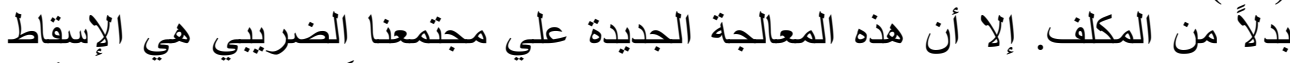

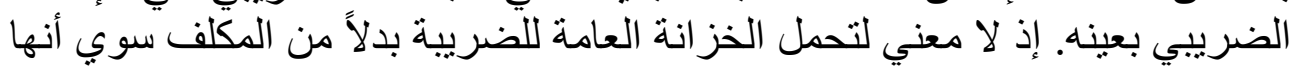

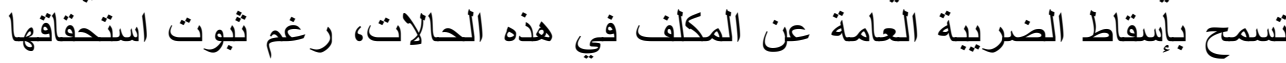
عليه.

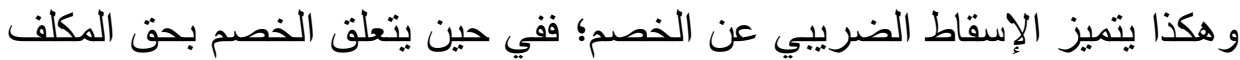

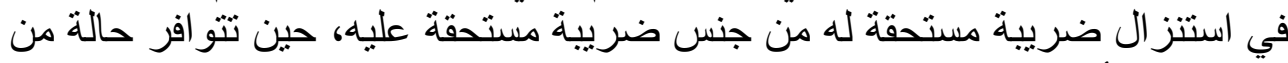

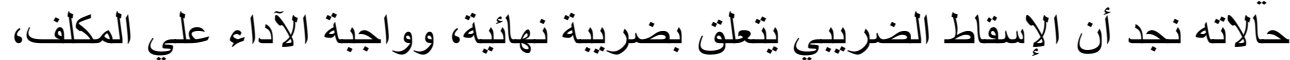

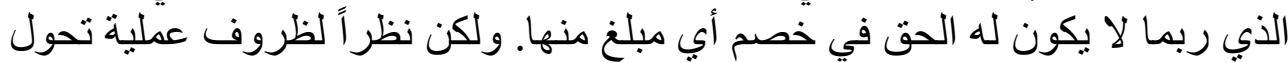

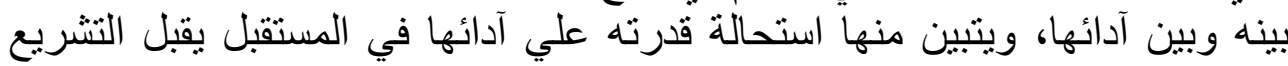

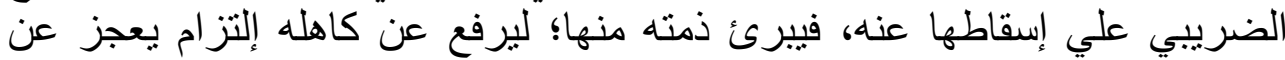

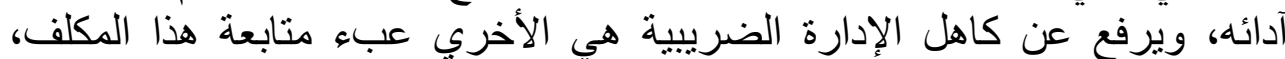
ومطالبته إدارياً، أو قضائياً بضريبة يستحيل عليه آداؤها، ومن ثم يستحيل عليها لأيها

تحصيلها.

(๕) - تمييز الإتتمان عن العفو الضريبي:

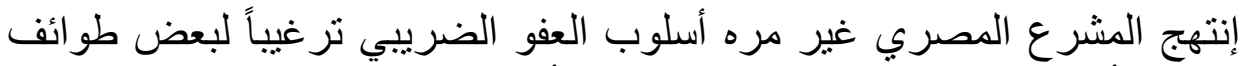

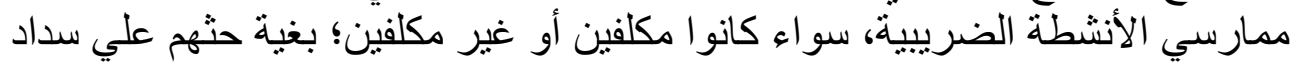

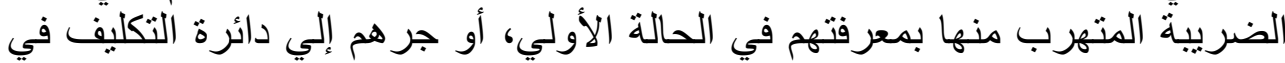

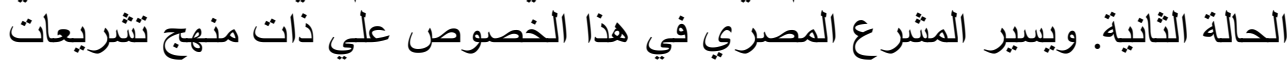
بعض الدول المتقدمة، والنامية على السواء مثل الولائات الئل المتحدة، وفرنسا، وتركيا،

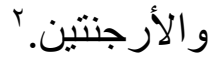

ومقتضي العفو الضريبي أن تقوم الإدارة الضريبية ـ بترخيص تشريعي- بإعفاء الإنياء

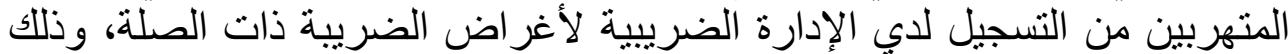

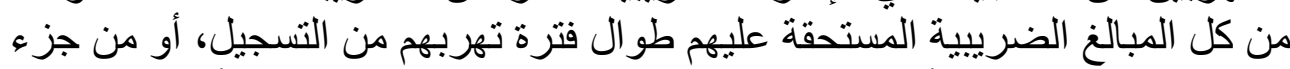
كبير من هذه المبالغ، أو من العقوبات المقررة علي التهرب منها، أو تطبيق هذه النه

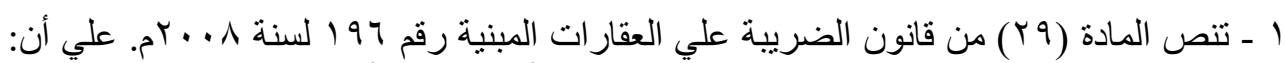

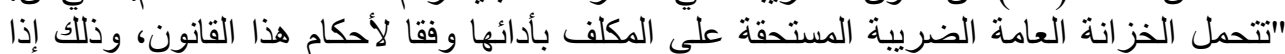

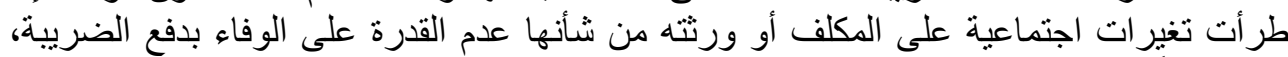
وذلك طبقاً لما تحدده اللائحة التنفيذية".

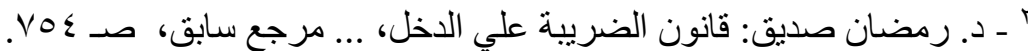

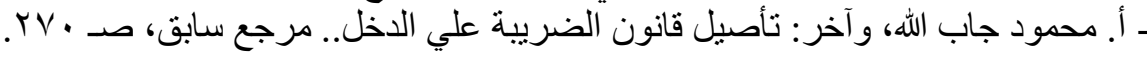




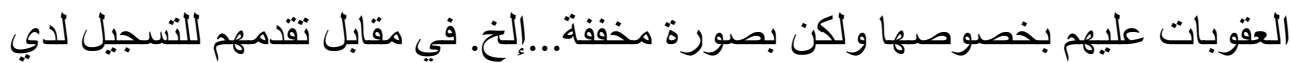

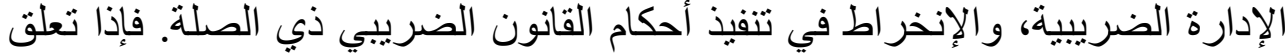

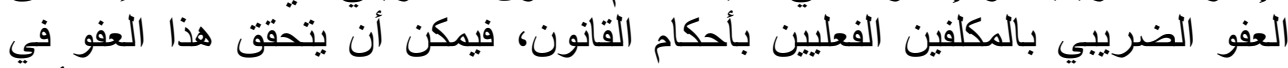

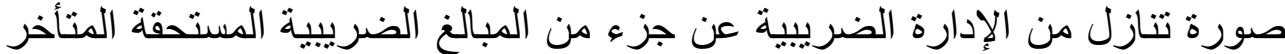

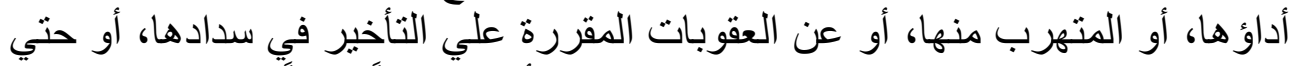

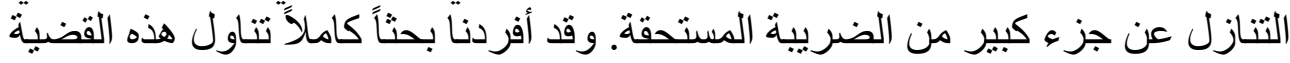

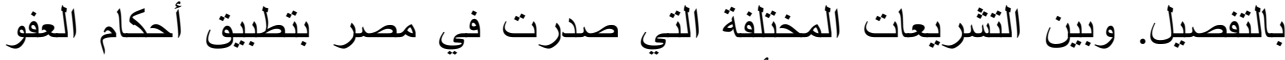

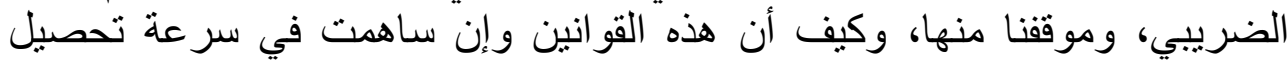

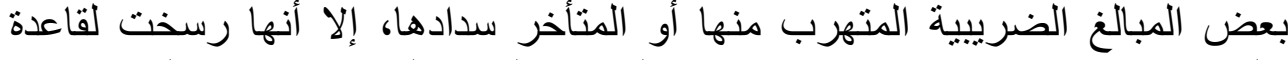

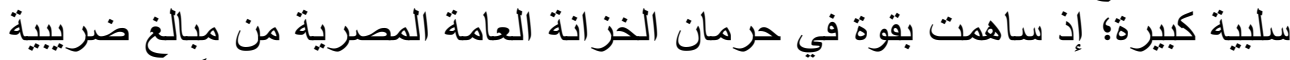

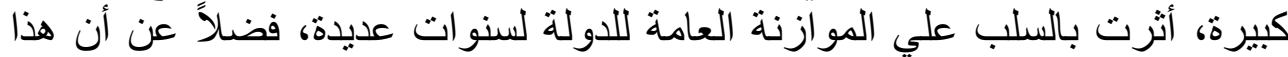

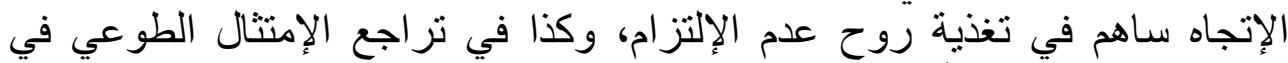

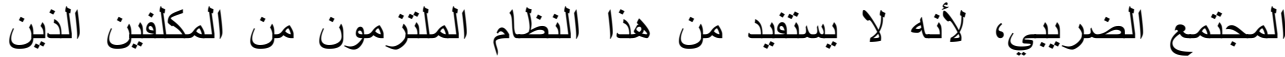

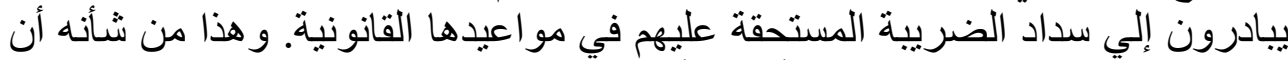
يجعل نظام العفو الضريبي مسئو لاً رئيساً عن تفضيل غير الفير الملتزمين من المكلفين علي

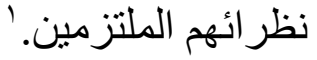

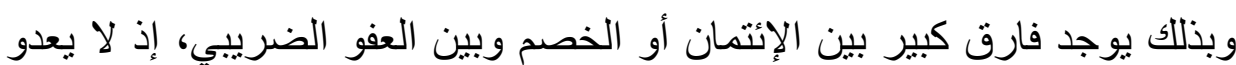

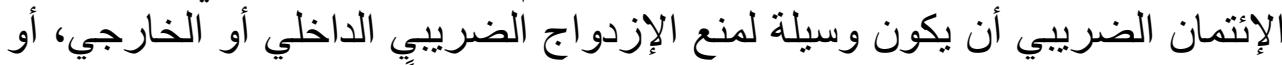

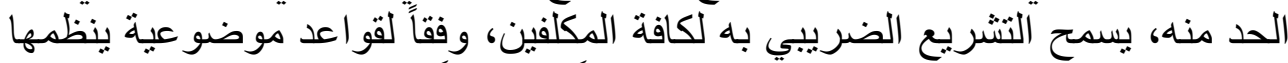
التشريع الضريبي تجعل إستخدام هذا النظام حقاً مشرو عاً للمكلفين.

\section{(॰) - تمييز الإتتمان أو الخصم عن الإعفاء:}

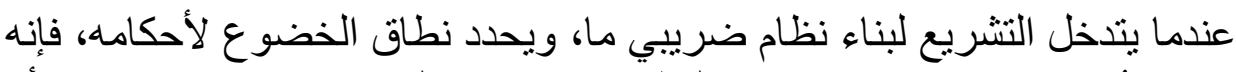

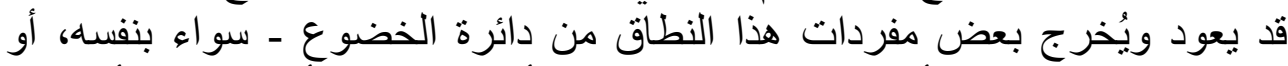

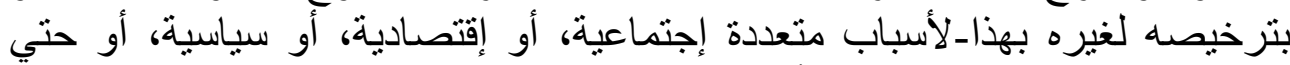

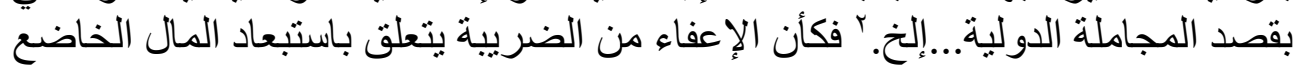

1 ـ راجع : د.إبراهيم عبد العزيز النجار: تأملات في المرحلة الإدارية لنظر المنازعات الهات الضريبية،

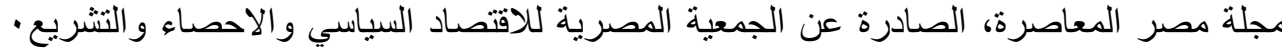

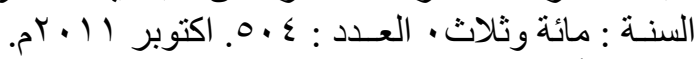

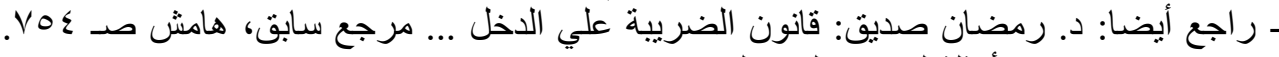

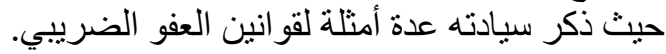

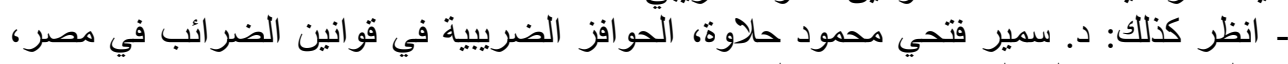

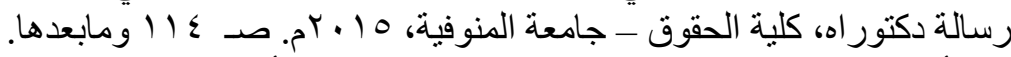

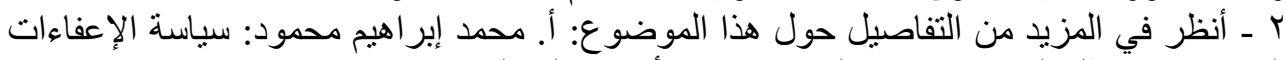

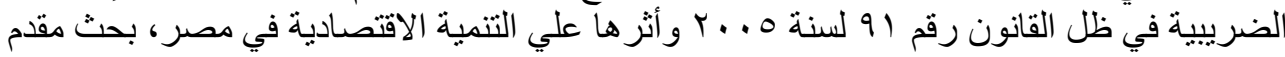

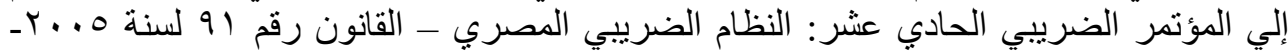




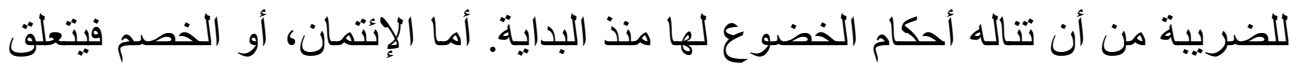

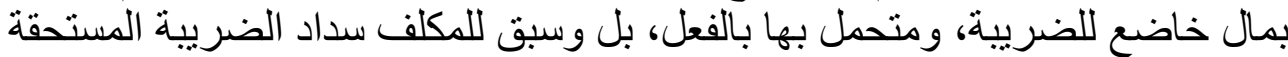

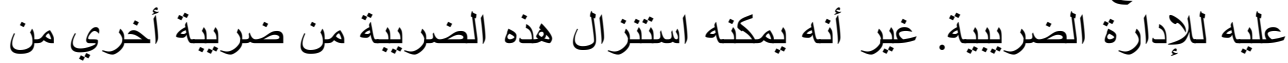

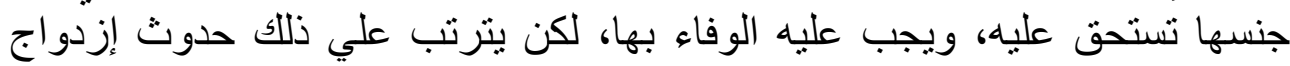
ضريبي علي المكلف يسعفه الخصم في تلافيه و التخلص منهـ.

و علي ذللك برد الإئتمان أو الخصم علي الضريبة ذاتها، وبستند الأساس في تبنيه

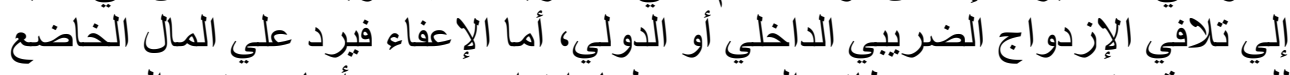

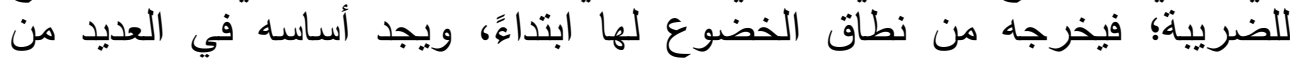

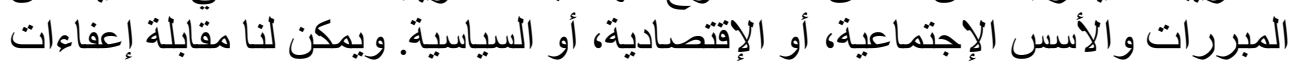

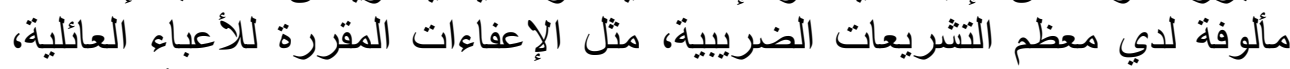

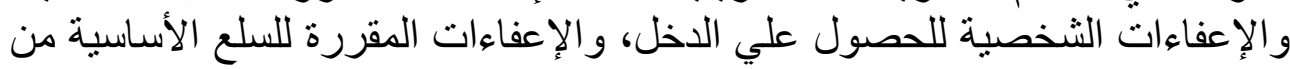

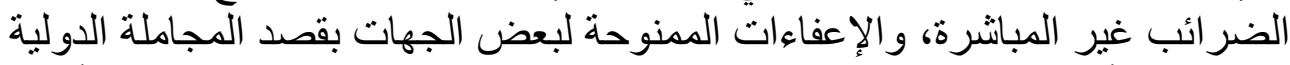

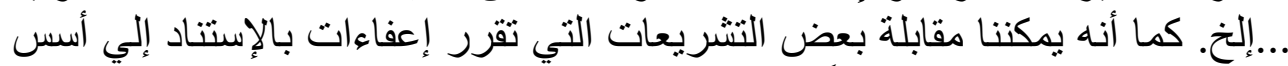
غير مألوفة كذللك، من ذلك مثناًا:

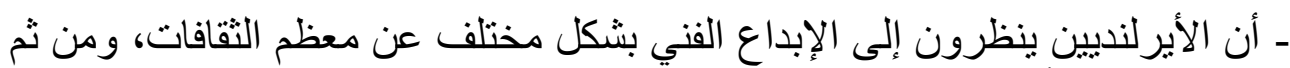

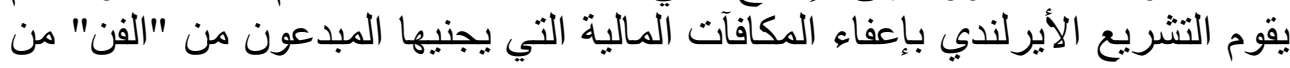
الضريبة.

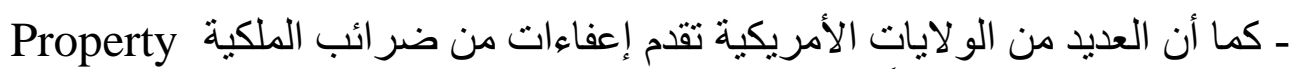
Tax

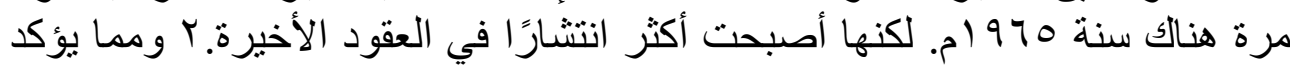

المشكلات ومعوقات التطبيق ومقترحات الحلول،الجمعية المصرية للمالية العامة و الضر ائب، المجلد

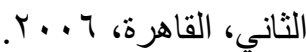

- S.O'ConnoraTerrence M.O'Connorbc: Tax exemption as a marketing tool: The Irish Republic and profits derived from artistic creativity. Journal of Business Research, Volume ${ }^{r}$, Issue $1 \cdot$, October $r \ldots q$, Pages $1 \ldots r_{-}$ 1... T. P.Y. .

-RICHARD L. PFISTER: A REEVALUATION OF THE JUSTIFICATIONS FOR PROPERTY TAX EXEMPTION, Indiana University, India, PUBLIC FINANCE QUARTERLY, Vol. ₹ No. ₹,

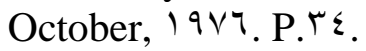

-James M. Poterba: TAX REFORM AND THE MARKET FOR TAXEXEMPT DEBT, NBER WORKING PAPER SERIES, Working Paper No. rq.. NATIONAL BUREAU OF ECONOMIC RESEARCH, USA, Massachusetts, Cambridge, MA · r 1 ґ, March $19 \wedge 9$.p. $r$ r.

$r$ - H. Spencer Banzhaf Ryan Mickey Carlianne and E. Patrick: AGEBASED PROPERTY TAX EXEMPTIONS, Working Paper, NATIONAL BUREAU OF ECONOMIC RESEARCH, Cambridge, MA. • ri r^. USA, January Y. 19. P. Y. 
الإيتمان الضريبي وآثارة الإقتصادية والمالية "دراسة مقارنة"

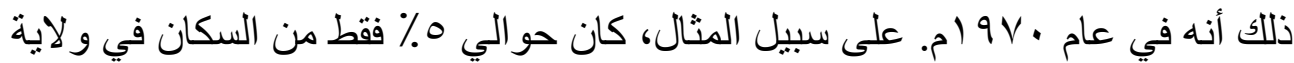

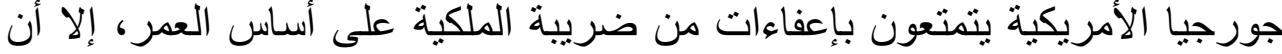
هذه النسبة ارتفعت اليوم لتصل إلي أكثر من ـ ــ من عدد سكان الو لاية.

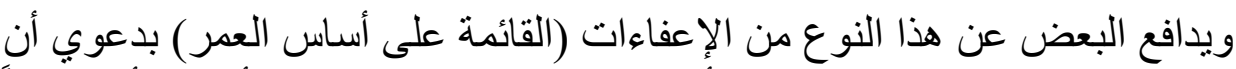

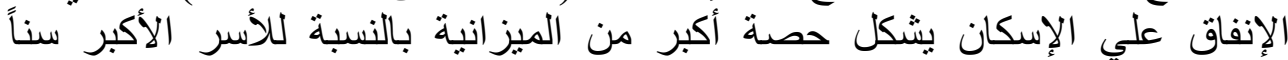

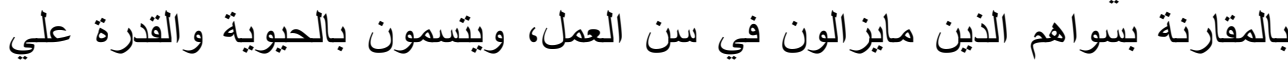
الكسب، و أن العديد من هذه الأسر قد دفع إلى المجتمع لسنوات فئن عديدة، ويحق له مقابلة

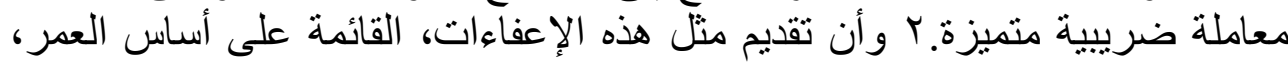

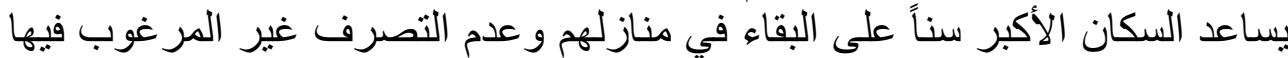

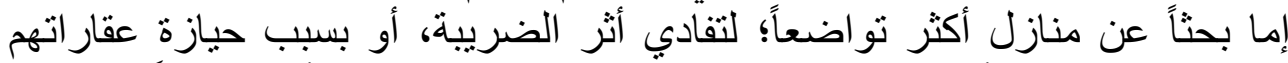

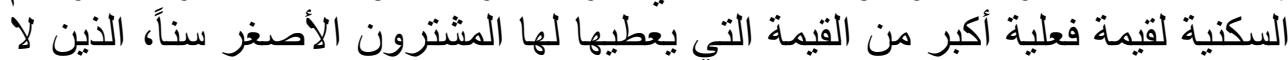
يستفيدون من هذه الإعفاءات.

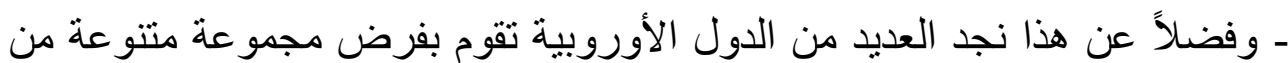

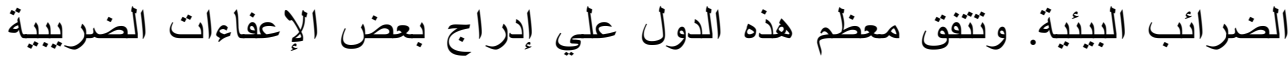

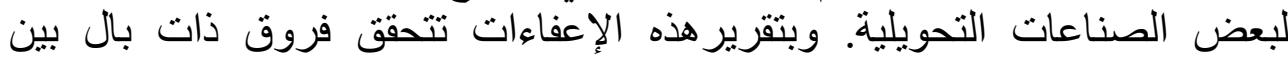

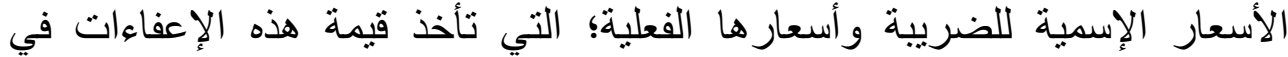
الإعتبار.ء لذا اعترضت بعض القطاعات علي فرض ضر ائب بيئية علي أنشطتها،

-James M. Poterba: TAX REFORM AND THE MARKET FOR TAX-

EXEMPT DEBT, ..., Op. Cit.p. $r \varepsilon$.

' - H. Spencer Banzhaf Ryan Mickey Carlianne and E. Patrick: AGEBASED PROPERTY TAX EXEMPTIONS, .., Op. Cit .p. P. $Y$.

- James Alm: The Role of Tax Exemptions and Credits, Tulane University Economics Working Paper Series, New Orleans, USA, Working Paper 10Y7, December Y.10. P.11.

$r$ - H. Spencer Banzhaf Ryan Mickey Carlianne and E. Patrick: AGEBASED PROPERTY TAX EXEMPTIONS, .., Op. Cit .p. $r$.

- RICHARD L. PFISTER: A REEVALUATION OF THE JUSTIFICATIONS FOR PROPERTY TAX EXEMPTION,.., Op. Cit.p. ro.

$r$ - H. Spencer Banzhaf Ryan Mickey Carlianne and E. Patrick: AGEBASED PROPERTY TAX EXEMPTIONS, ..., Op. Cit .p. $r$.

-James M. Poterba: TAX REFORM AND THE MARKET FOR TAXEXEMPT DEBT, ..., Op. Cit.p. Yo.

- - James Alm: The Role of Tax Exemptions and Credits,..., Op. Cit .p. Ir.

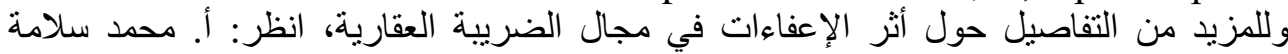

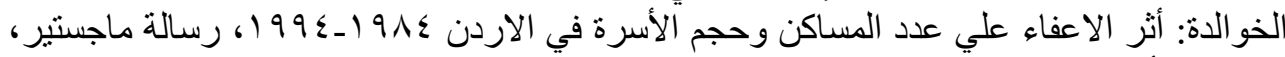

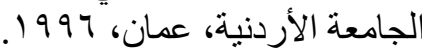

- PAUL EKINS and STEFAN SPECK: Competitiveness and Exemptions From Environmental Taxes in Europe, Environmental and Resource 
بما يجعلها في أوضاع تنافسية ضعيفة بالمقارنة بالقطاعات المعفاة منها، غير أن

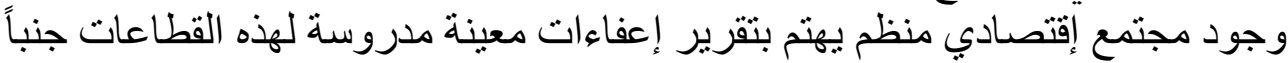

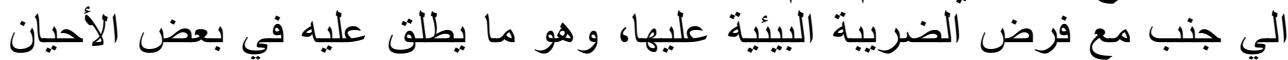
إصطلاح الضرائب البيئية، يسفر عن فوائد لهذه القطاعات، في صالح قدراتها

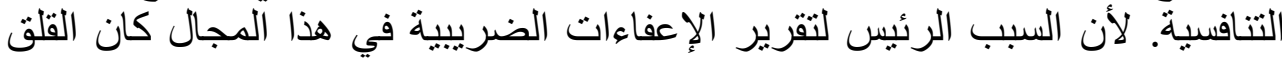
من تأثير الضر ائب البيئية على القدر ات التنافية لإنية للقطاعات الإنتاجية.

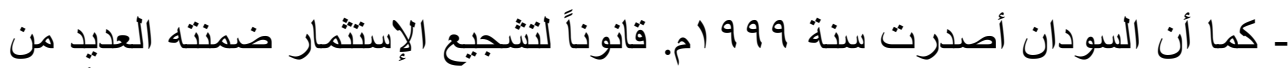

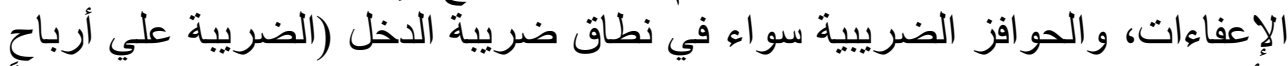

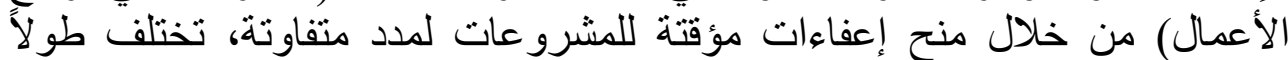

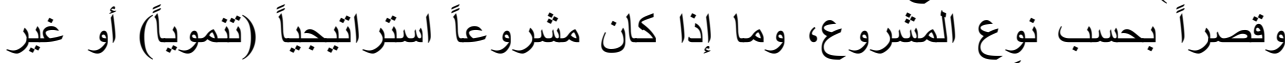

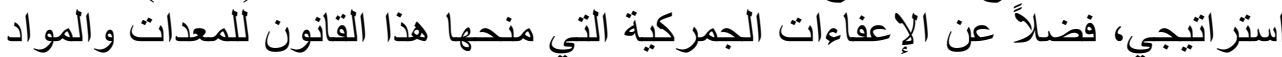

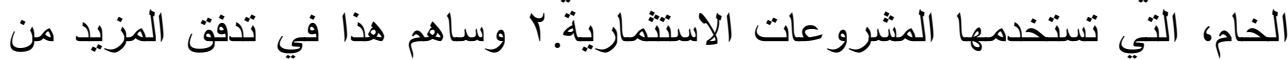

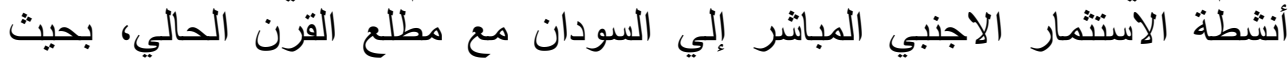

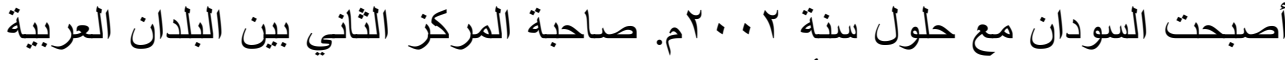
من حيث توجه الاستثمار الأجنبي المباشر إليها، بنسبة بلغت الته الاستثمار ات المباثرة في البلدان العربية، وإن كانت هذه النسبة قد انخفضت في سنة

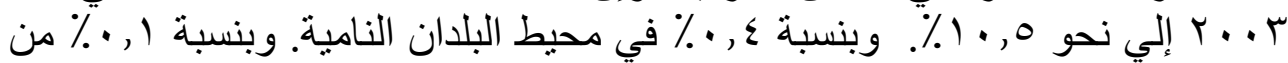

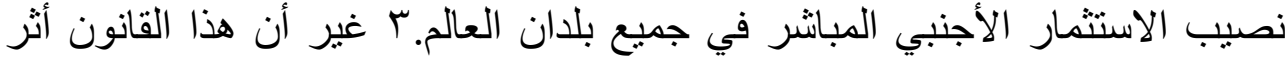

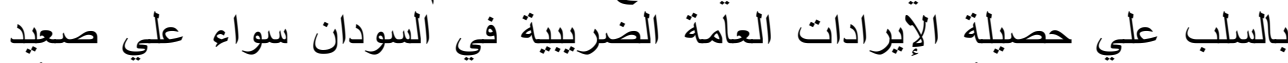

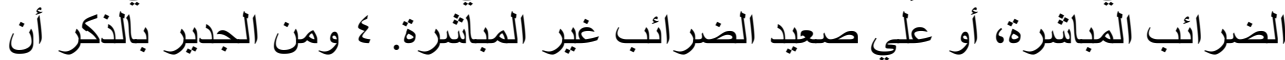

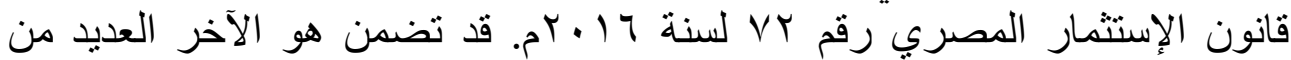
الإعفاءات الضريبية لتشجيع الإستثمار.

Economics 1r: rч9_r97, 1999. (c) 1999 Kluwer Academic Publishers. Printed in the Netherlands, April $199 \wedge$. p. $r \vee \cdot$

- James Alm: The Role of Tax Exemptions and Credits,..., Op. Cit .p. $r \cdot$.

' - PAUL EKINS and STEFAN SPECK: Competitiveness and Exemptions From Environmental Taxes in Europe..., Op. Cit. p. rv

- James Alm: The Role of Tax Exemptions and,..., Op. Cit .p. rr.

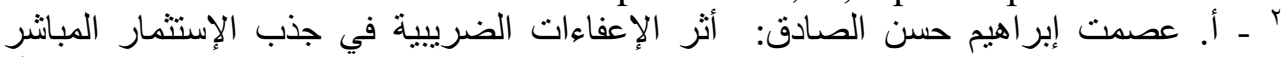

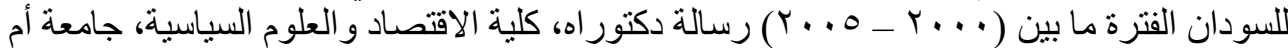

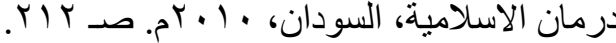

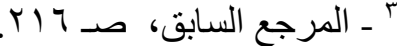

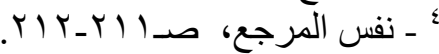
• ـ للمزيد من التفاصيل حول أثز الإعفاءات علي الحصيلة الضرييية، راجع:

Harry G.: Enacting Dividend Exemption and Tax Revenue, International Taxation, Washington, DC $r \cdot r \cdot$. National Tax Journal, Vol. LIV, No. $\varepsilon$. Pp. $\wedge 11-\wedge r v$.

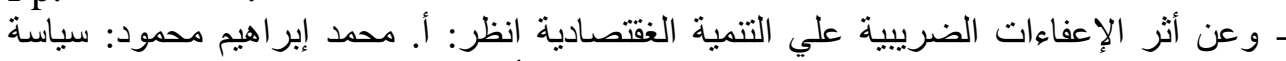

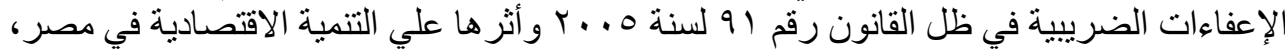


وفي معرض تقييم الآثار التنافسية الرئيسة لسياسات الإعفاءات التي تعتنقها

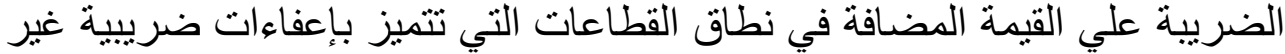

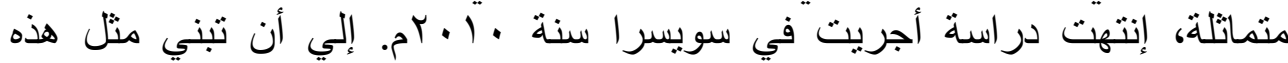

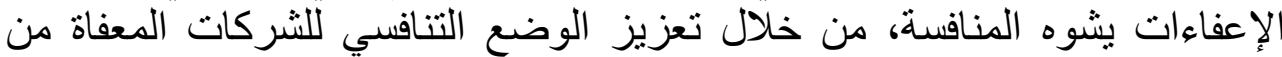

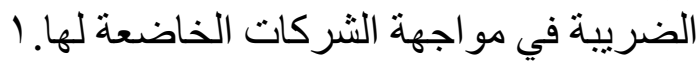

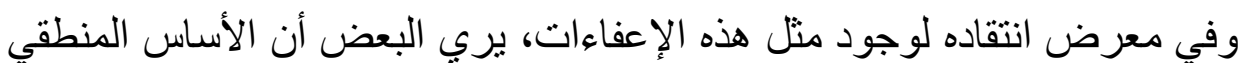

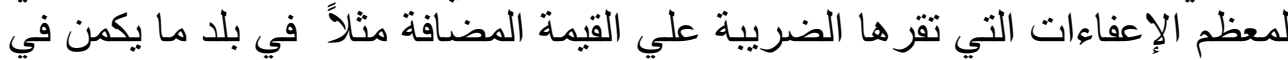

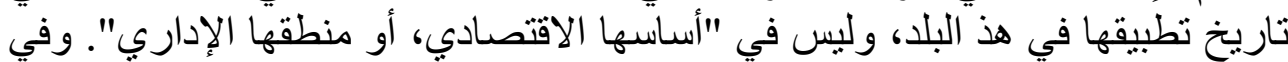

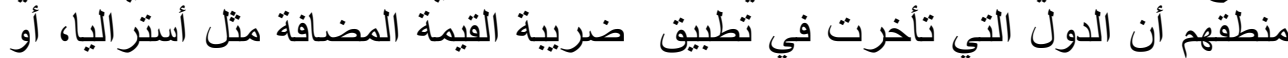

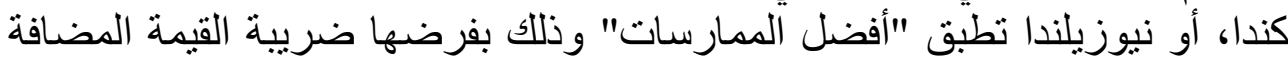

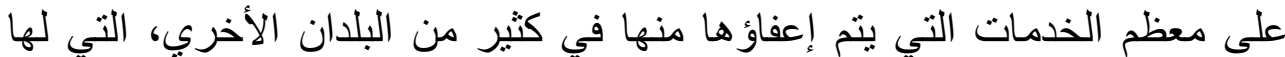

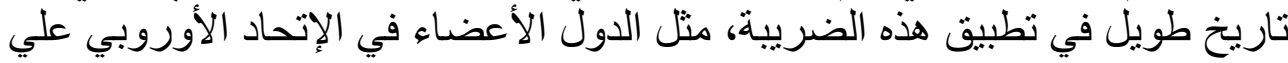

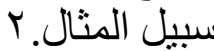

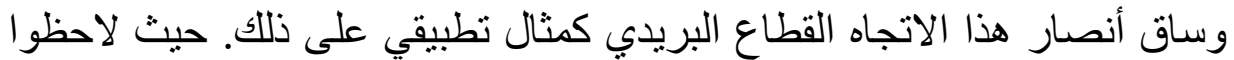

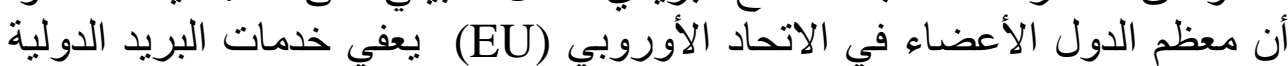
s universal postal services provided by the incumbent Operator

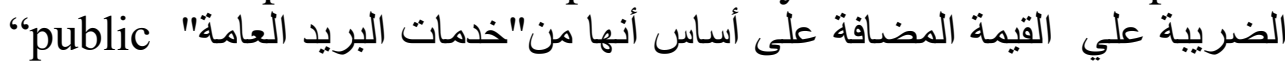
postal service." بالسعر الأساسي(standered rate)؛ مما يؤدي إلي تحمل مقدمي هذه الخدمات الخدات

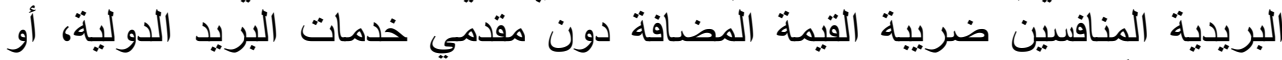

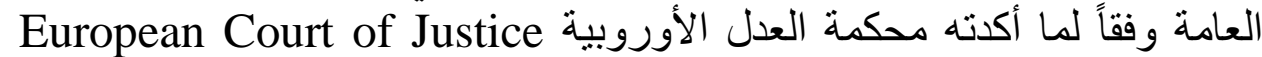
(ECJ)

بحث مقدم إلي المؤتمر الضريبي الحادي عشر: النظام الضريبي المصري ـ القانون رقم 91 لسنة

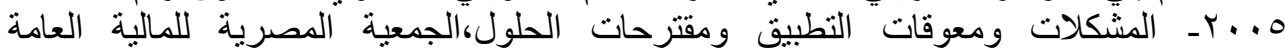

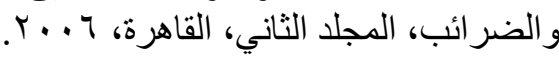

1 - Helmut Dietl, Christian Jaag, Markus Lang, Urs Trinkner; Competition and Welfare Effects of VAT Exemptions, Working Paper No. ${ }^{1} r \mathrm{r}$,October $r \cdot 1 \cdot$. Working Paper Series ISSN $17 \% \cdot-110 \mathrm{~V}$, Institute for Strategy and Business Economics, University of Zurich, Switzerland, $r \cdot 1 \cdot P . r$.

- James Alm: The Role of Tax Exemptions and..., Op. Cit. p. rr.

-Harry Grubert: Enacting Dividend Exemption and Tax Revenue, International Taxation, Washington, DC $r \cdot r r \cdot$. National Tax Journal, Vol. LIV, No. ร. P. ^)1.

$r$ - Helmut Dietl, Christian Jaag, Markus Lang, Urs Trinkner; Competition and Welfare Effects of VAT Exemptions,... Op. Cit. p. ${ }^{r}$.

- James Alm: The Role of Tax Exemptions and..., Op. Cit.p. $r \varepsilon$.

- RICHARD L. PFISTER: A REEVALUATION OF THE JUSTIFICATIONS FOR PROPERTY TAX..., Op. Cit .p. r $r$.

-Harry G.: Enacting Dividend Exemption and Tax ..., Op. Cit .p. $\wedge$ ।I. 
القيمة المضافة المطبقة في البلدان الأعضاء بالاتحاد الأوربي، طبقاً للتوجيهات

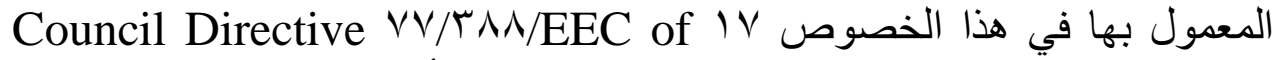

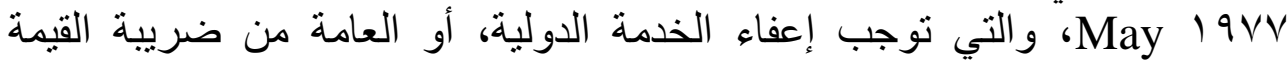

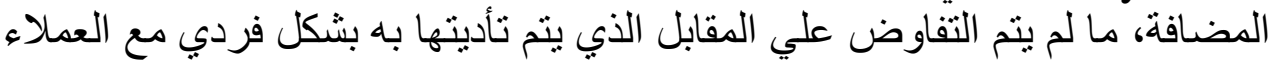
universal service tariffs are VAT exempt unless prices are individually negotiated with customers

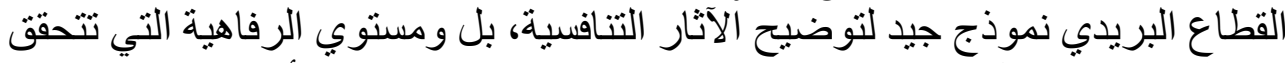

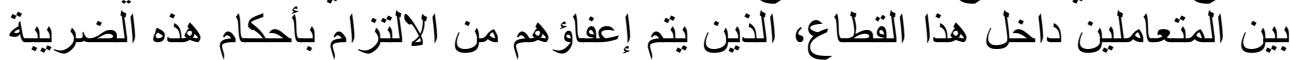

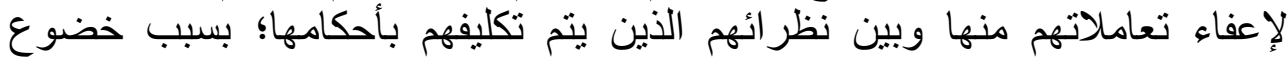
تعاملاتهم لها. وهكذا تختلف صور الإعفاء من الضريية، وتتعدد بتعدد الأسس التي يستند إليها

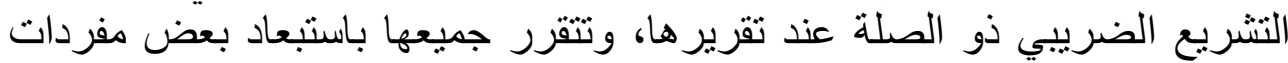

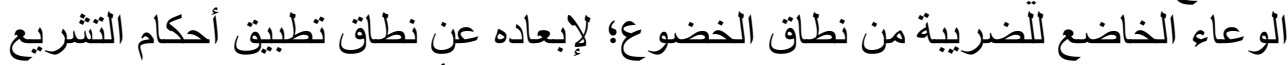

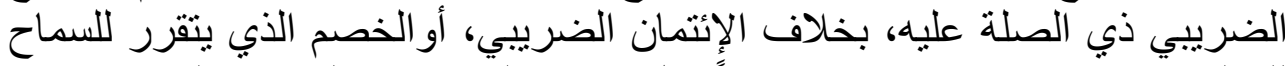

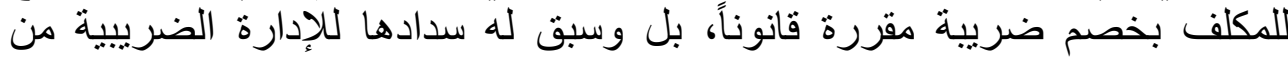

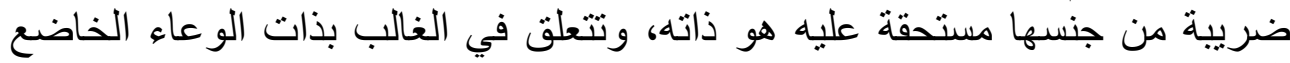
للضريبة.

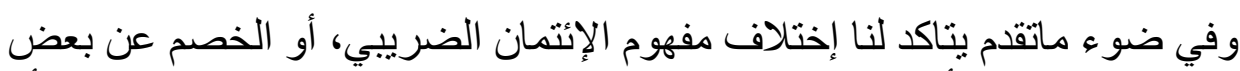

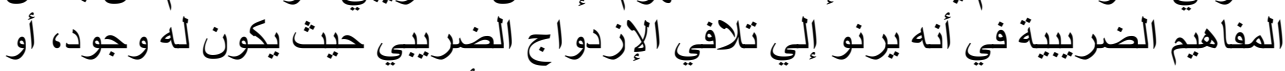

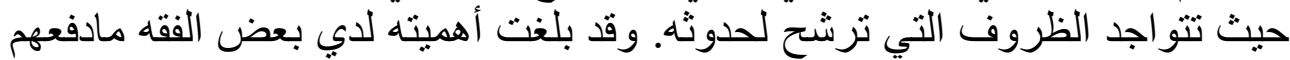

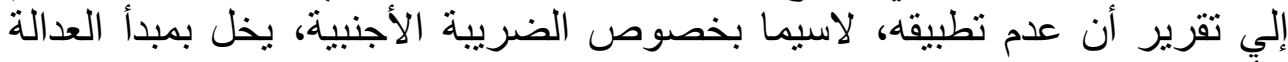

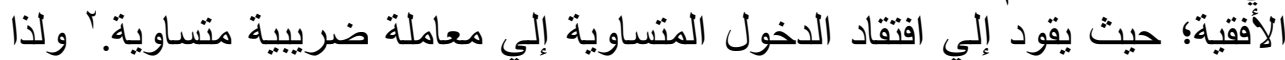

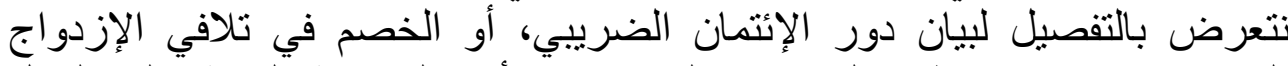

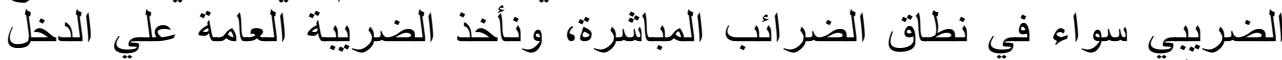

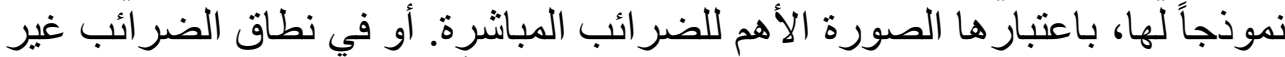

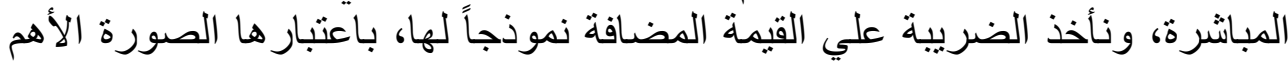

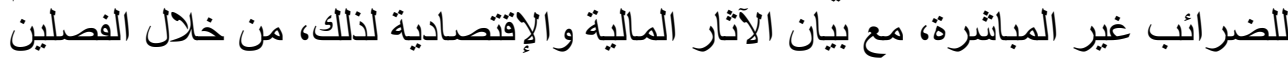
التاليين.

'-Helmut Dietl, Christian Jaag, Markus Lang, Urs Trinkner; Competition and Welfare Effects of VAT Exemptions,... Op. Cit .p. r.

- James Alm: The Role of Tax Exemptions and..., Op. Cit .p. rv.

-Harry G.: Enacting Dividend Exemption and Tax,..., Op. Cit .p. ^) 1 . ؟ ـ د. رمضان صديق: تفسير وتطبيق إتفاقيات تجنب الإزدواج الضريبي،... مرجع سابق، صد9 ؛. 


\section{الفصل الأول}

\section{الإنتمان الضريبي وآثارة الإقتصادية والمالية في نطاق الضر ائب المباشرة}

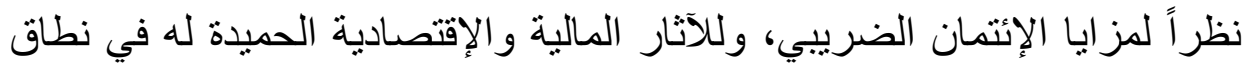

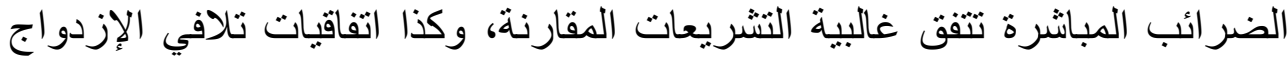

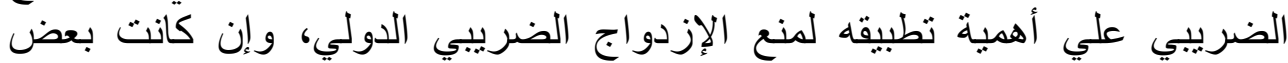

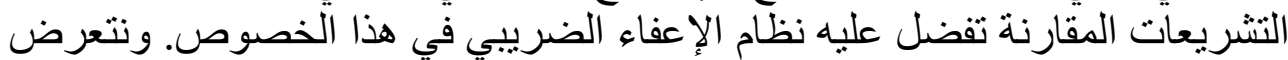

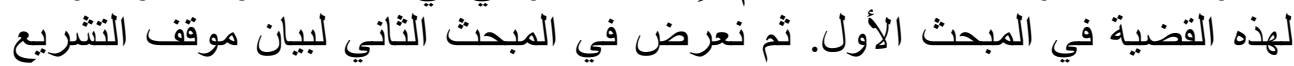

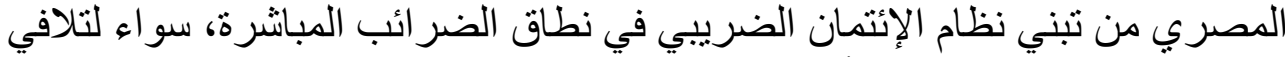
الإزدواج الضريبي الداخلي، أو الخارجي وبيان الآثار المالية، و الإقتصادية لذلتلك.

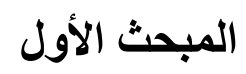

\section{دورالإنتمان في تلافي الازدواج الضريبي في النظم المقارنة بالمقارنة بالإعفاء الماء}

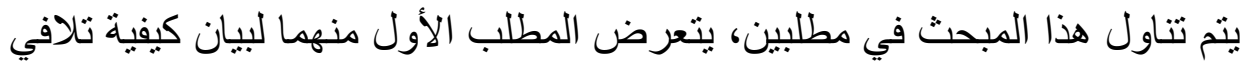

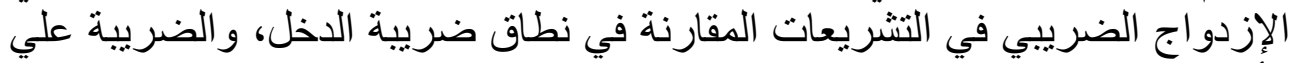

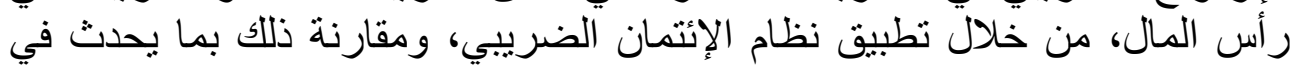

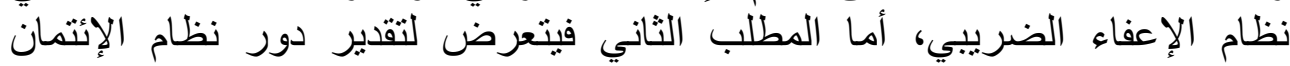
الضريبي في تلافي الإزدواج الضريبي ومقارنته في ذلإلك بنظام الإعفاء، والآثار الإقتصادية و المالية لذللك.

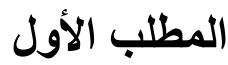 \\ كيفية تلافي الإزدواج الضريبي بتطبيق نظام الإنتمان بالمقارنته بالإعفاء}

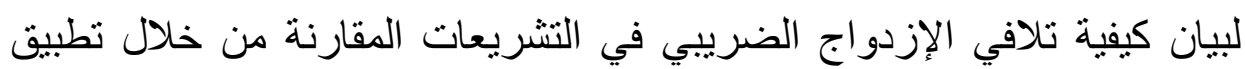

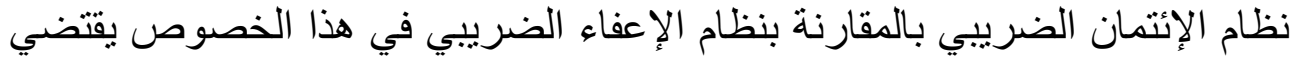

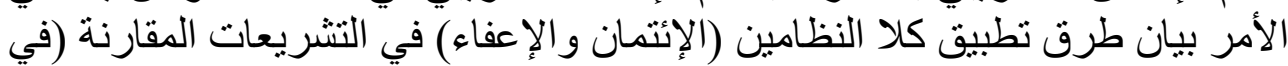

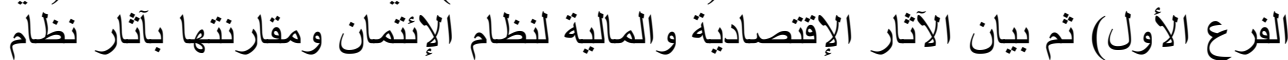
الإعفاء في التشريعات الدقارنة كذلك ( في الفرع الثاني).

\section{القرع الأول}

\section{طرق تطبيق نظام الإنتمان ومقارنتها بالإعفاء في التشريعات المقارنة}

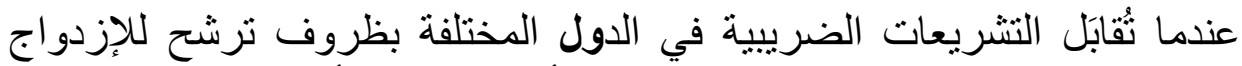

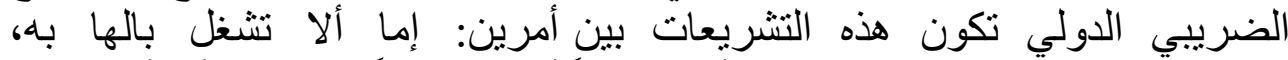

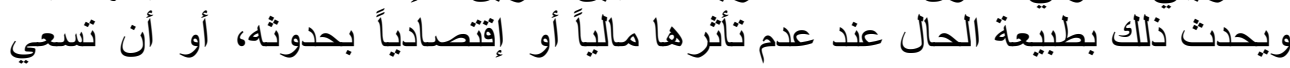


جاهدة إلي تلافيه، وهذا هو الأصل، في ظل انفتاح العالم، وتحرك رؤوس الأمو ال بين

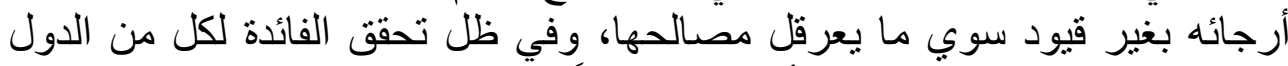
المصدرة والدول المستوردة لر أس المال معاً، من وراء تلاء تلافي ظاهرة الإزدواج

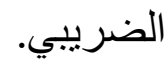

ومن المعلوم أن الإزدواج الضريبي علي نوعين: قانوني juridical double taxation الإتفاقيات الدولية والتشريعات الدقارنة هو الإدو اج الضريبي القانوني، لا الإقتصادي.

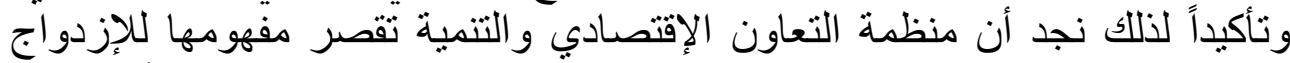

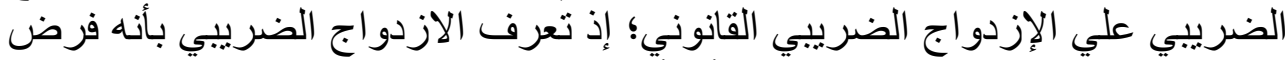

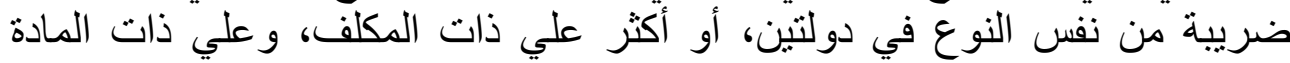

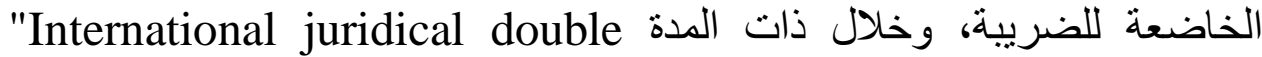
taxation can be generally defined as the imposition of comparable taxes in two (or more) States on the same taxpayer in respect of the same subject matter and for identical periods." ${ }^{r}$

' - راجع في التفاصيل عن مفهوم كلا النو عين:

$r$ - OECD ( r • I $\varepsilon)$, Model Tax Convention on Income and on Capital:

Condensed Version $Y .1 \leq$,OECD Publishing .P. 9 .

ـ وقد أبرمت هذه الإتفاقية (الاتفاقية الضريبية النموذجية لدول منظمة التعاون الاقتصادي و التنمية

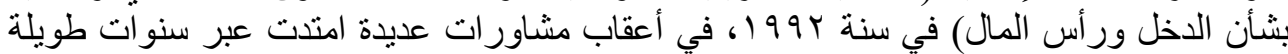

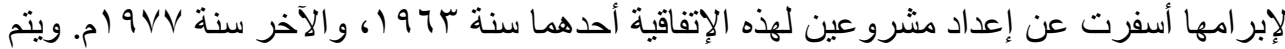

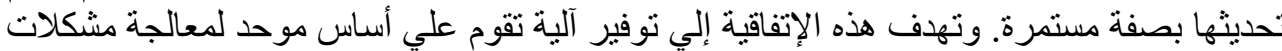

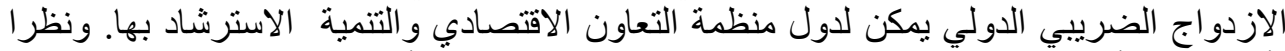

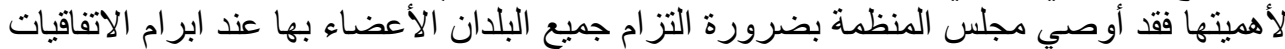

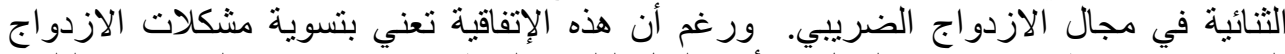

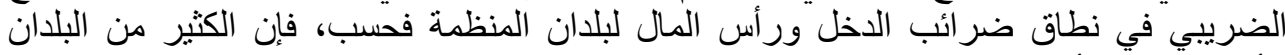

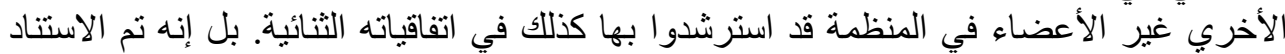

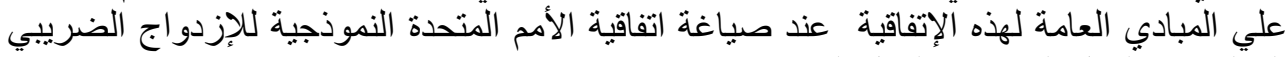

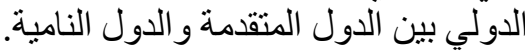

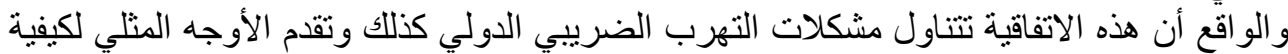

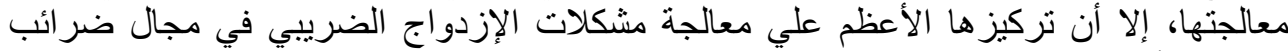

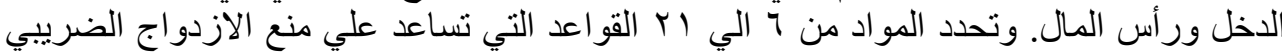

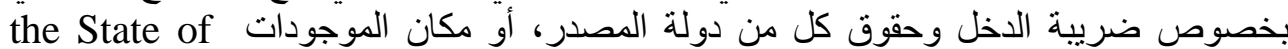
source or situs بخصوص الضريبة علي رأس المال. راجع في تأكيد ذلك:

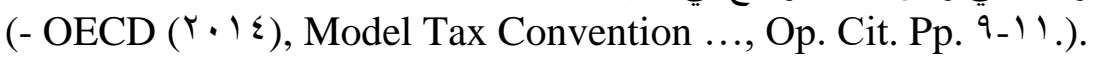

- RICHARD L. PFISTER: A REEVALUATION OF THE JUSTIFICATIONS FOR PROPERTY TAX..., Op. Cit .p. $\leqslant \cdot$

- James Alm: The Role of Tax Exemptions and..., Op. Cit .p. ץ l. -JOHANNES BECKER \& CLEMENS F.: CORPORATE TAX POLICY AND INTERNATIONAL MERGERS AND ACQUISITIONS - IS THE 
الإئتمان الضريبي وآثارة الإقتصادية والمالية "دراسة مقارنة"

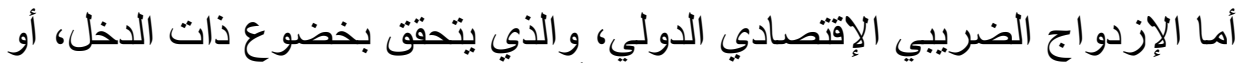

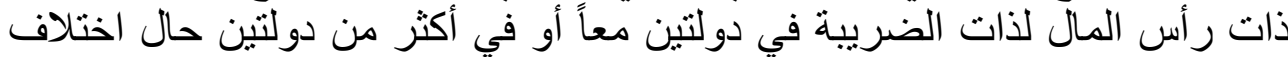

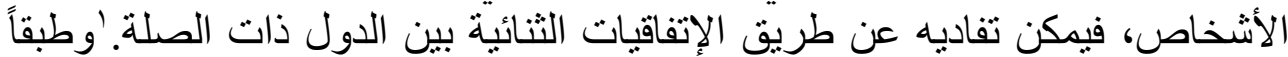

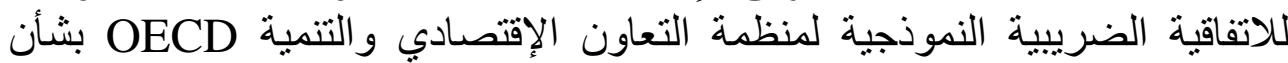

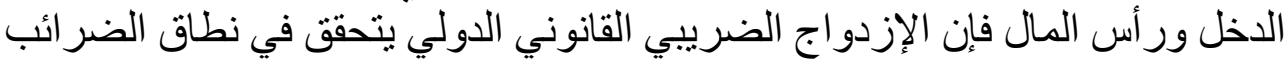

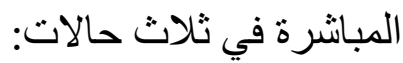

الحالة الأولي: إذا خضع دخل الثخص فأو أو رأسماله للضريبة في أكثر من دولة في آن

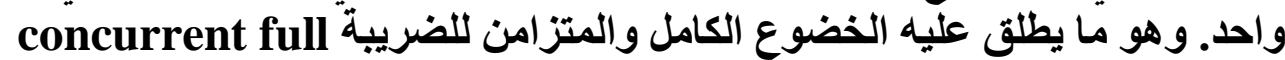
liability to tax

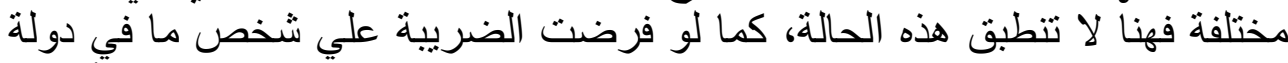

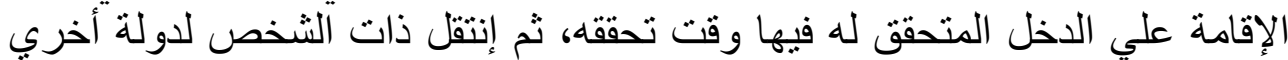

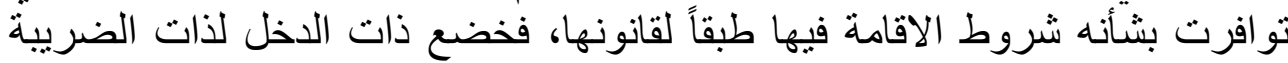

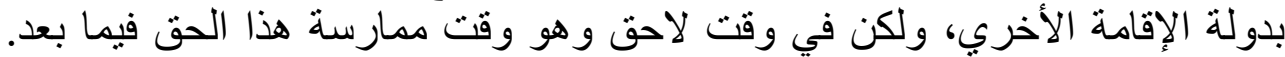

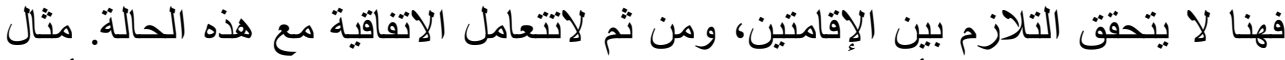

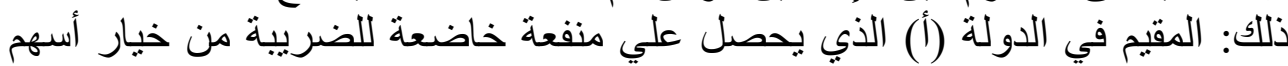

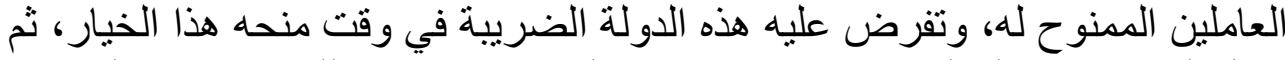

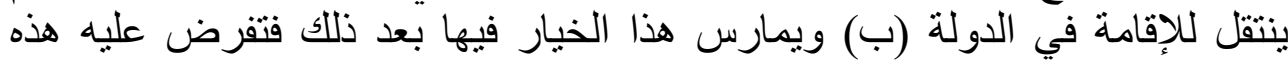
الدولة هي الأخري (ب) ذات الضريبة في وقت ممارسة هذا الحق.

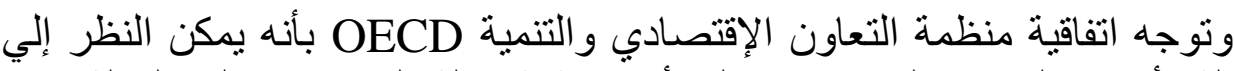

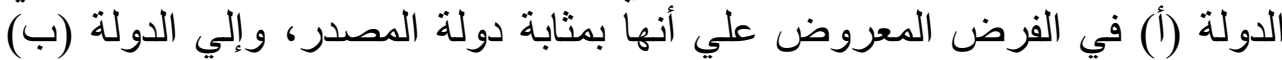

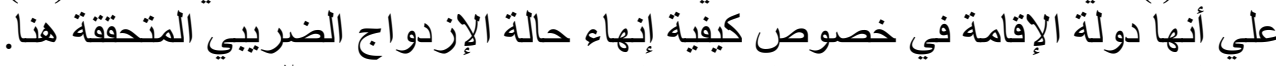

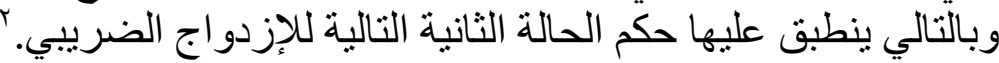

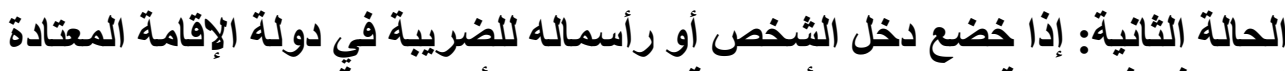

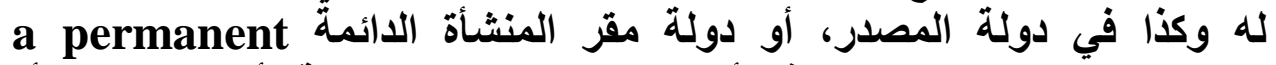

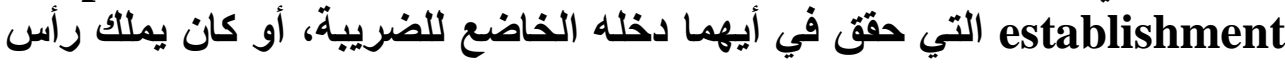

TAX EXEMPTION SYSTEM SUPERIOR? CESIFO WORKING PAPER

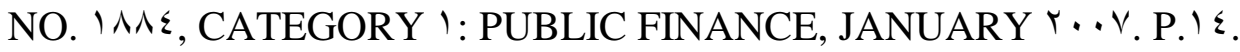

- Lawrence W. Kenny- University of Florida and Stanley L. WinerCarleton University: Tax Systems in the World: An Empirical Investigation into the importance of Tax Bases, Collection Costs, and Political Regime, May Y...'.P. 'I.

' - OECD ( $(\cdot) \varepsilon)$, Model Tax Convention..., Op. Cit.p. ${ }^{r} r$.

$r$ - OECD $(r \cdot 1 \varepsilon)$, Model Tax Convention ..., Op. Cit .p. $r$ r $\varepsilon$.

- James Alm: The Role of Tax Exemptions and Credits, ..., Op. Cit .p. r^.

- Lawrence W. Kenny- University of Florida and Stanley L. WinerCarleton University: Tax Systems in the World: An Empirical Investigation into the importance of Tax Bases, Collection Costs, and Political Regime, May T.... P. Ir. 


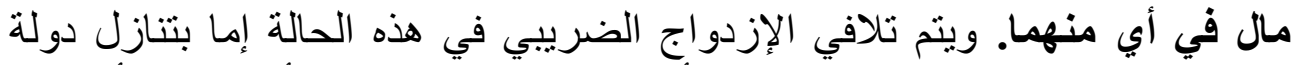

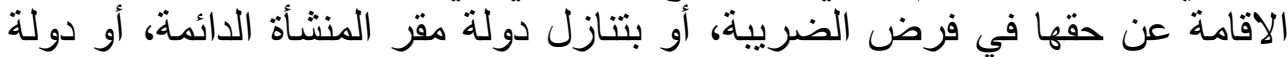

المصدر عن ذلك، ويمكن أن يتقاسم الدولتان الحق في فرض الضرية الضية.

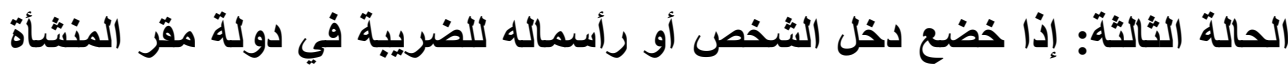

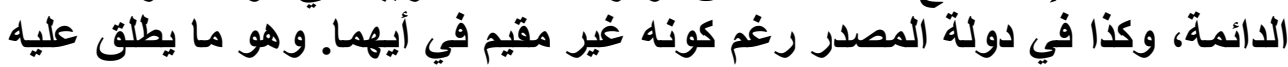

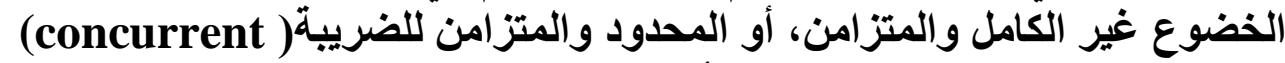

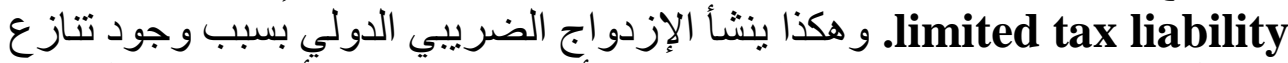

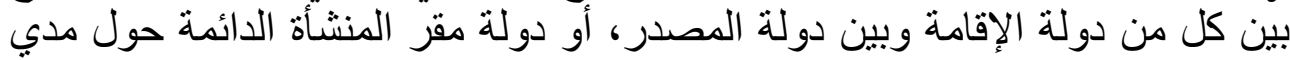

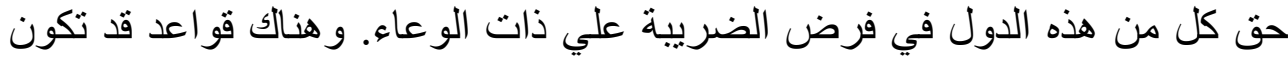
مستقرة لتنظيم هذا الموضو عي فن من هذه القو اعد:

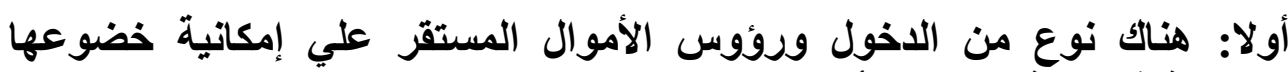

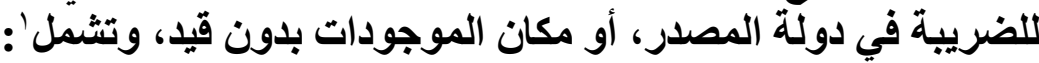

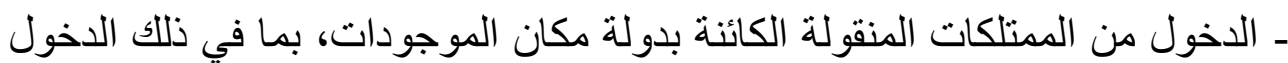

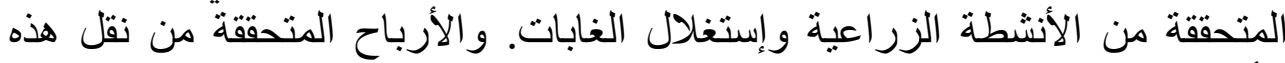

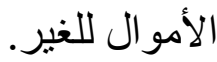

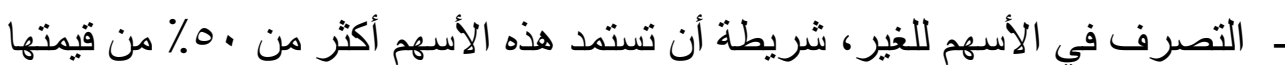

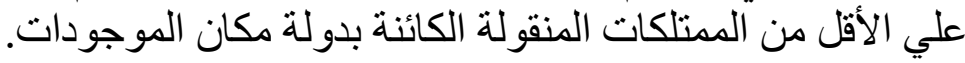

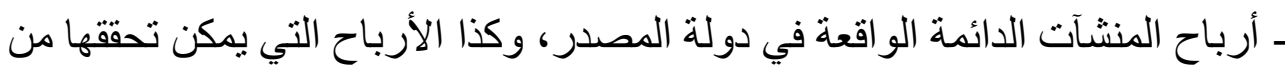
بيع تلك المنشآت الدائمة للغير.

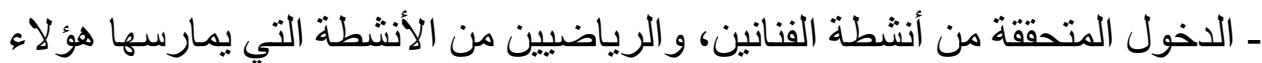

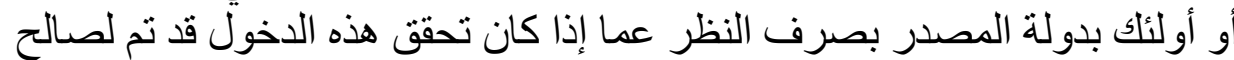
الفنانين أو الرياضيين، أو لأشخاص آخرين. ـ ـ مكافآت أعضاء مجالس إدارة الثركات التي يحصلون عليها من شركات كائنة بدولة

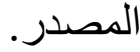

' - OECD ( $(\cdot 1 \varepsilon)$, Model Tax ..., Op. Cit .pp. $11-1$ T.

-James M. Poterba: TAX REFORM AND THE MARKET FOR TAXEXEMPT DEBT, ..., Op. Cit .p. rv. 
ثانيا: هناك نوع من الدخول يمكن خضوعها لضريبة محدودة في دولة المصدر، ومن

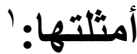

1ـ أرباح الأسهم: بشرط أن تكون ملكية الأسهم التي يتم الحصول علي أرباحها غير

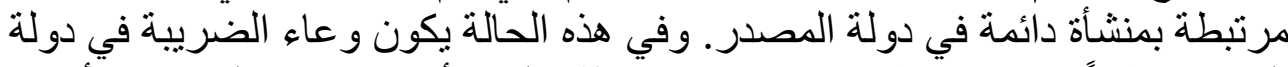

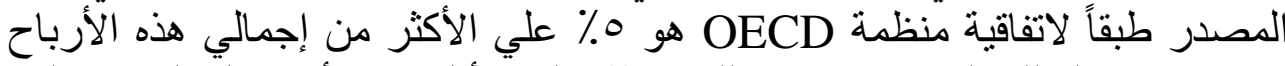

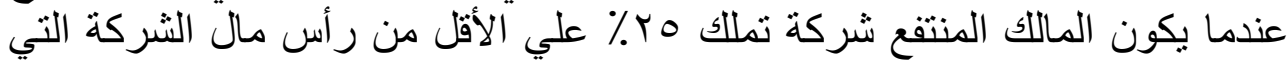

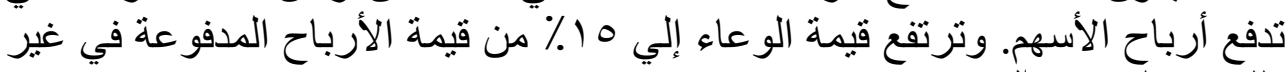

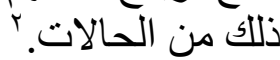

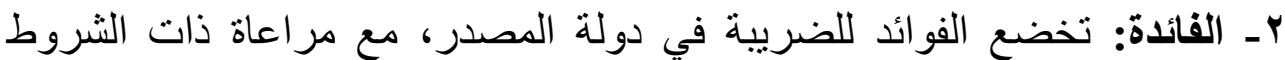

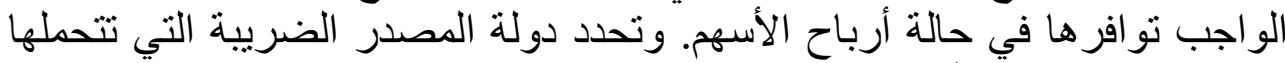

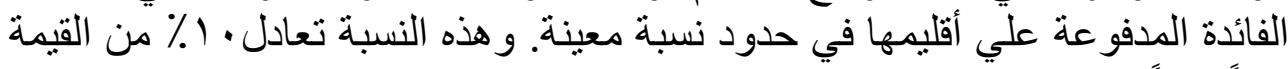

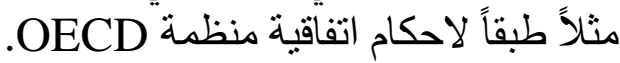

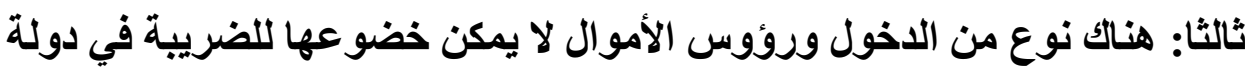

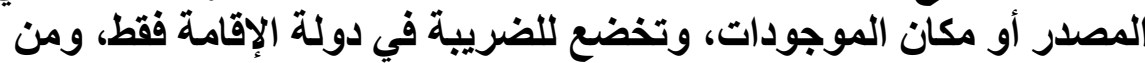

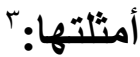

ـ ـ الإتاو ات، و الأرباح المتحققة من نقل ملكية الأسهم و السندات. ـ ـ المعاثات التي يحصل عليها المتقاعدون في القطاع الخاص.

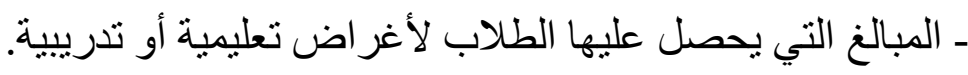
ـ ـ رأس المال الواقع في صورة أسهم أو أور اق مالية.

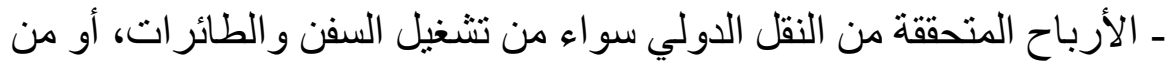

' - OECD ( $(\uparrow, 1 \varepsilon)$, Model Tax Convention ..., Op. Cit .p. ${ }^{\prime}$.

-JOHANNES BECKER \& CLEMENS FUEST: CORPORATE TAX POLICY AND INTERNATIONAL MERGERS AND ACQUISITIONS IS THE TAX EXEMPTION SYSTEM SUPERIOR? CESIFO WORKING PAPER NO. $\backslash \wedge \wedge$, CATEGORY ${ }^{\prime}$ : PUBLIC FINANCE, JANUARY $\uparrow \cdots \vee$. P.17.

' - في المعاملة الضريبية لأرباح الأسهم تفصيلاً، انظر: د. أمين السيد لطفي: تحليل وتقييم الحوافز

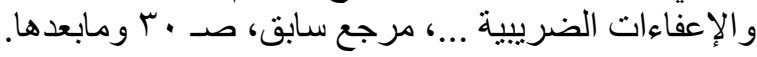

$r$ - OECD (r. I \&), Model Tax Convention ..., Op. Cit. pp. Ir-lr.

- Lawrence W. Kenny- University of Florida and Stanley L. WinerCarleton University: Tax Systems in the World..., Op. Cit.p. 10.

-JOHANNES BECKER \& CLEMENS FUEST: CORPORATE TAX POLICY AND INTERNATIONAL MERGERS AND ..., Op. Cit.p. ${ }^{\prime}$.

- CLAUDIO A. AGOSTINI and MARIEL C. SIRAVEGNA: EFECTOS DE LA EXENCION TRIBUTARIA ..., Op. Cit .p. $\leftleftarrows$. 


$$
\begin{aligned}
& \text { تشغيل القوارب في الممرات الداخلية. }
\end{aligned}
$$

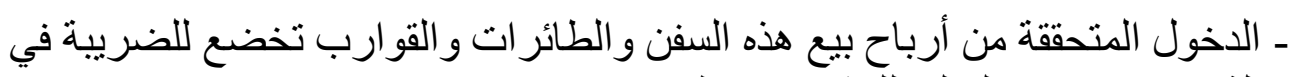

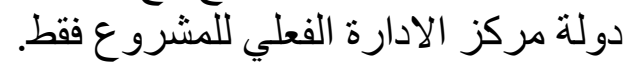

ـ الأرباح التجارية التي تحصل عليها منشأة دائمة في دولة المصدر. إذ لإدة لا تخضع للضريبة سوي في دولة الإقامة فقط. وفي ضو ذو ذلك:

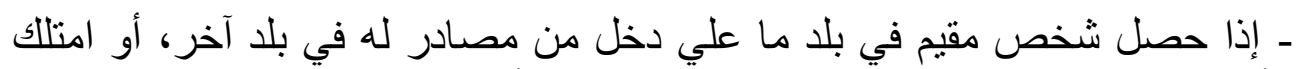

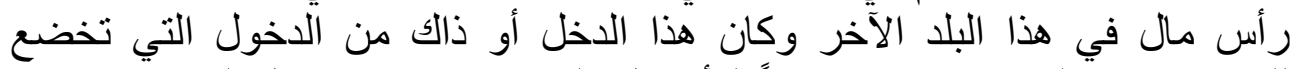

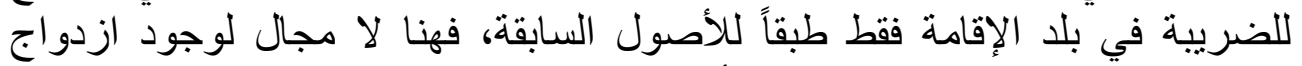

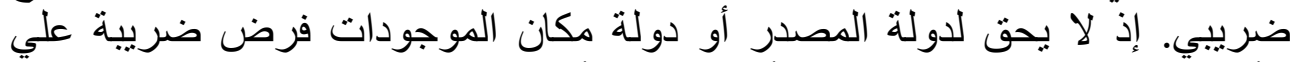

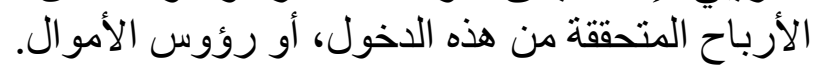

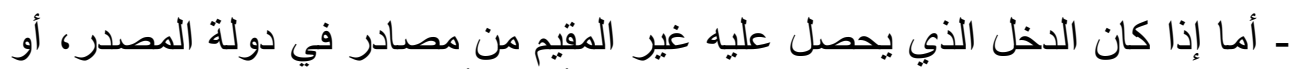

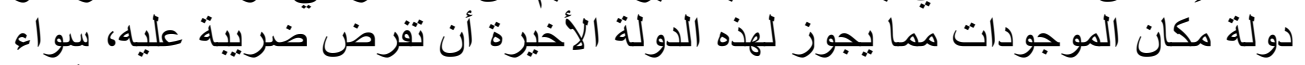

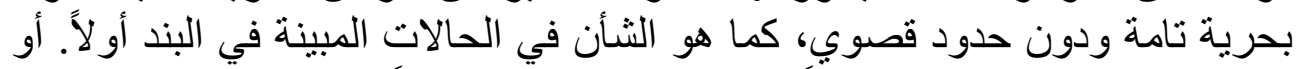

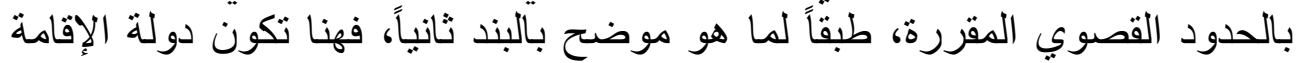

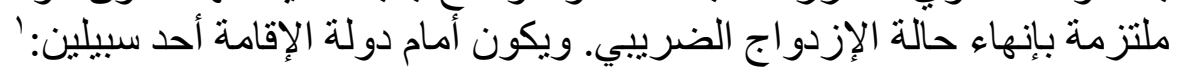
السبيل الأول: الإيتمان الضريبي: credit method وبموجب هذه الطريقة يكون

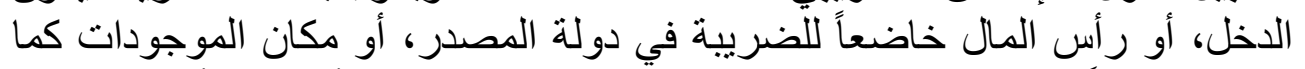

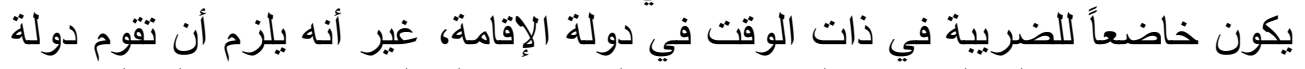

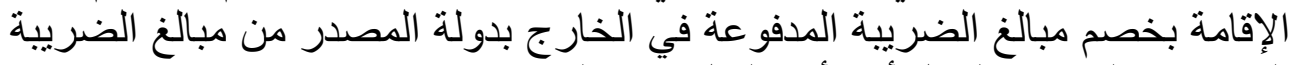

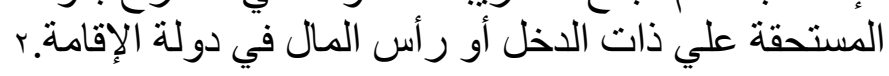

' - Where, on the contrary, income or capital may, in accordance with the Convention, be taxed with or without limitation in the State of source or situs, the State of residence has the obligation to eliminate double taxation. This can be accomplished by one of the following two methods:

- exemption method: income or capital that is taxable in the State of source or situs is exempted in the State of residence, but it may be taken into account in determining the rate of tax applicable to the taxpayer's remaining income or capital;

- credit method: income or capital that is taxable in the State of source or situs is subject to tax in the State of residence, but the tax levied in the State of source or situs is credited against the tax levied by the State of residence on such incomeor capital.( OECD $(\uparrow \cdot \mid \varepsilon)$, Model Tax Convention ..., Op. Cit .p. ${ }^{1 \%}$.)

r - Loc. Cit .p. I $\leqslant$.

-James M. Poterba: TAX REFORM AND THE MARKET FOR TAXEXEMPT DEBT, ..., Op. Cit .p. $\curlyvee$ ^. 
الإيتمان الضريبي وآثارة الإقتصادية والمالية "دراسة مقارنة"

السبيل الثاني: الإعفاء الضريبي: exemption method حيث تقوم دولة الإقامة

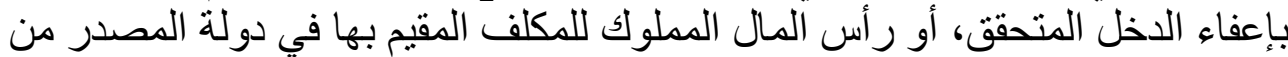

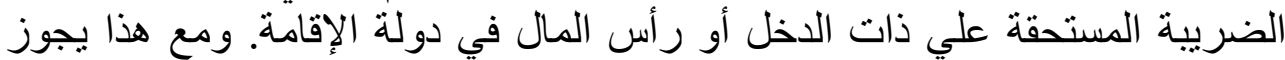

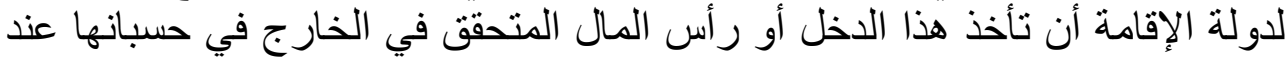

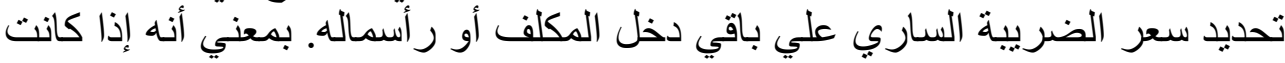

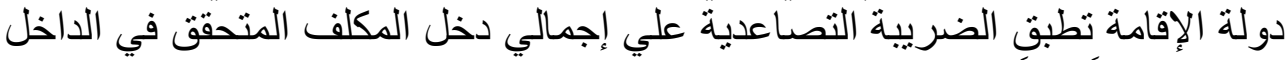

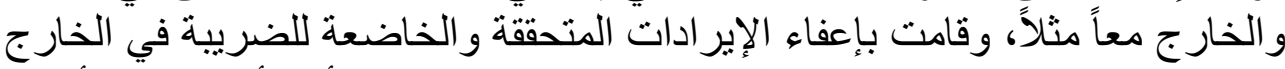

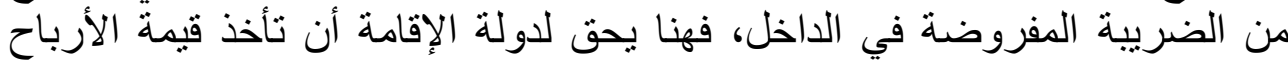

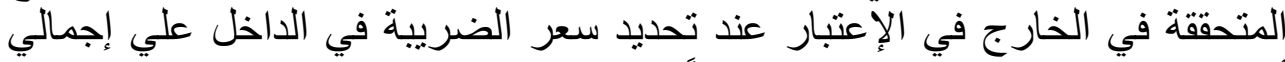
أرباحة المتحققة في الداخل و الخار جار معاً.'

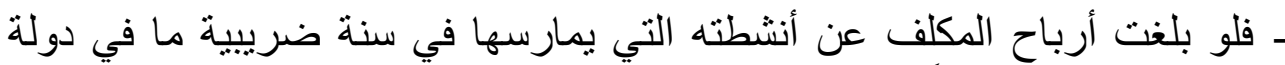

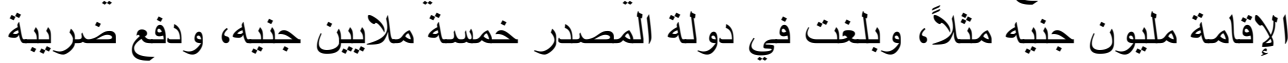

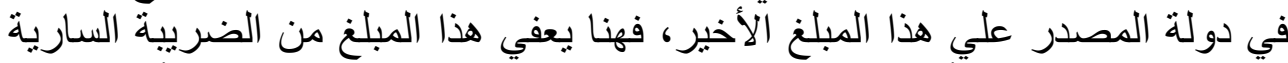

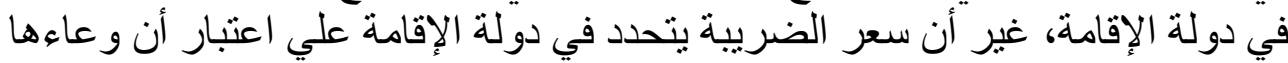

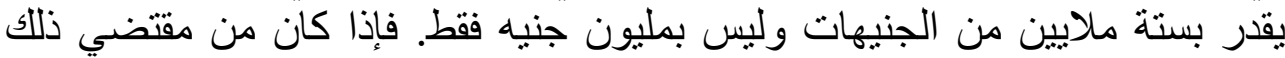

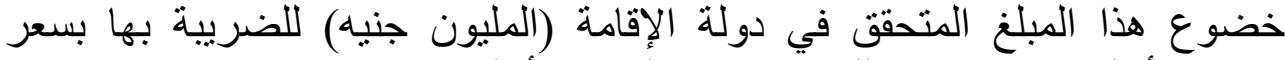
ضريبي أعلي، فهنا يخضع للضريبة بهذا السعر الأعلي.

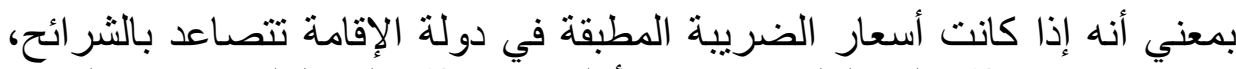

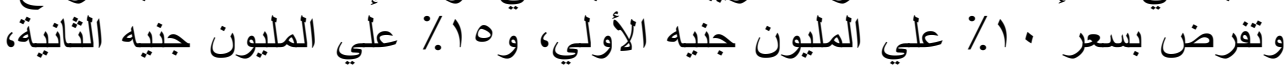

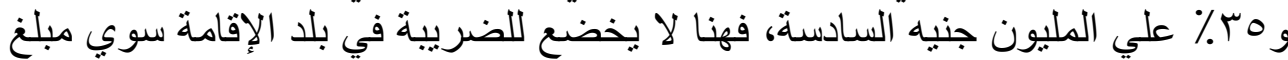

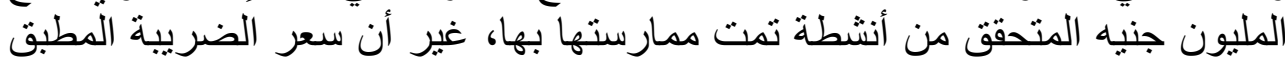

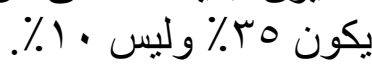

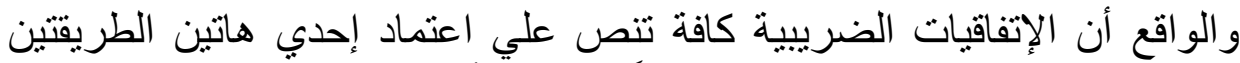

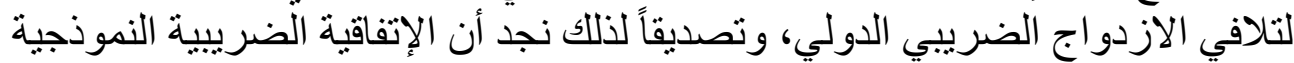

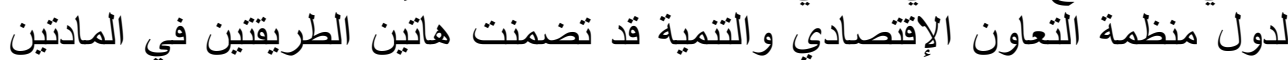

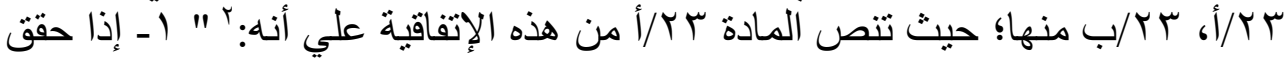

- James Alm: The Role of Tax Exemptions and Credits, ..., Op. Cit.p. ${ }^{\text {} \wedge}$. -CLAUDIO A. and MARIEL C. : EFECTOS DE LA EXENCION TRIBUTARIA A LAS GANANCIAS ..., Op. Cit.p. $\leqslant$.

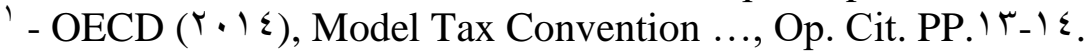

- Lawrence W. Kenny- University of Florida and Stanley L. WinerCarleton University: Tax Systems in the World: ..., Op. Cit .p. IV. -James M. Poterba: TAX REFORM AND THE ..., Op. Cit .p. r^. ' - يجري نص هذه المادة علي النحو التالي: " "). Where a resident of a Contracting State derives income or owns capital which, in accordance with the provisions of this Convention, may be taxed in the other Contracting State, the first-mentioned State shall, subject to the provisions of paragraphs $r$ and $r$, exempt such income or capital from tax. 


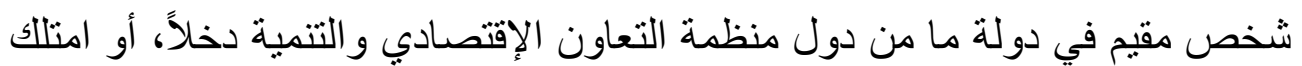

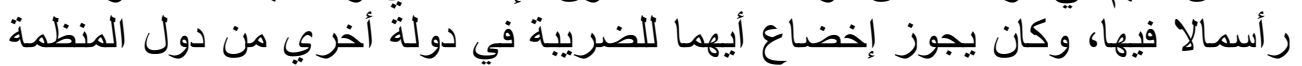

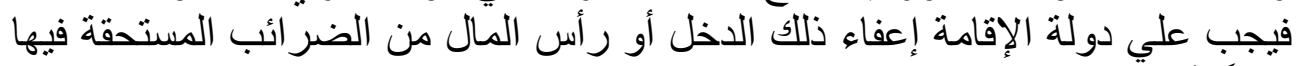

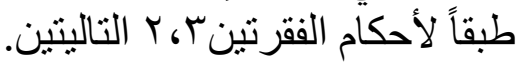

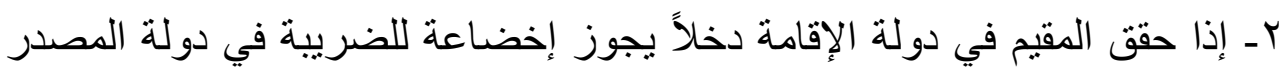

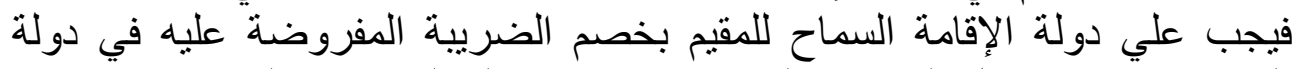

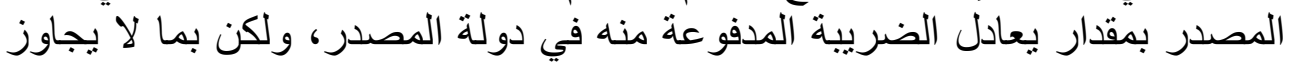
ذللك الجزء من الضريبة المحتسب في دولة الإقامة علي الدخل المتحقق في دولة لهنة المصدر.

r- و إذا تم إعفاء دخل المقيم من بعض ضريبة الدخل، أو رأس المال في دولة

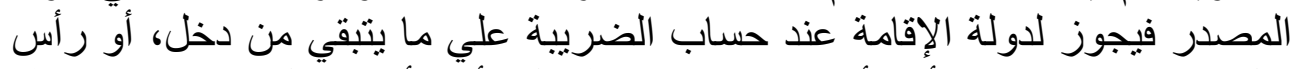

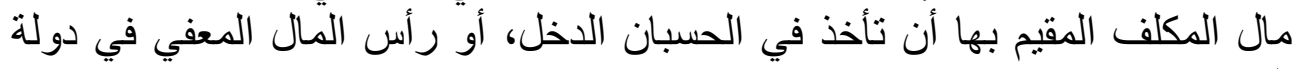
المصدر.

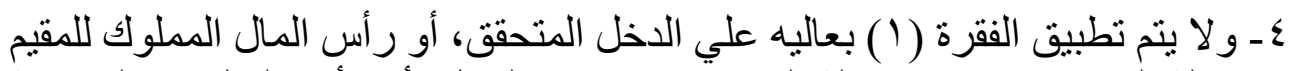

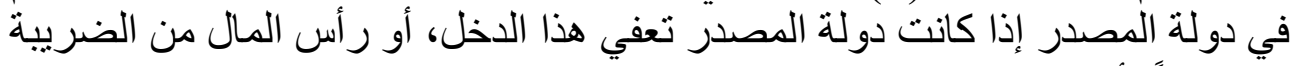

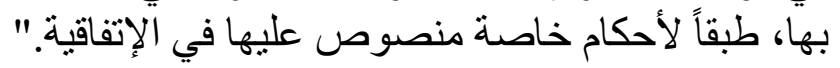

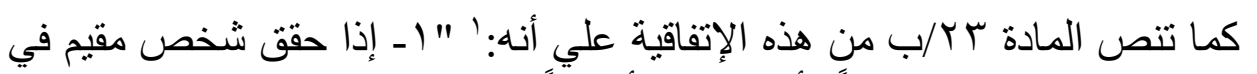

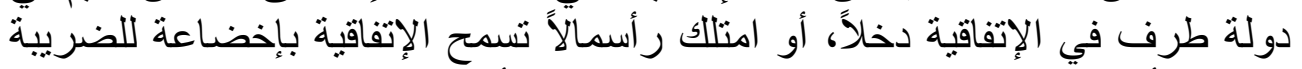

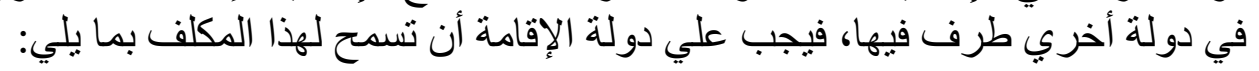

$r$. Where a resident of a Contracting State derives items of income which, in accordance with the provisions of Articles 1. and 1', may be taxed in the other Contracting State, the first-mentioned State shall allow as a deduction from the tax on the income of that resident an amount equal to the tax paid in that other State. Such deduction shall not, however, exceed that part of the tax, as computed before the deduction is given, which is attributable to such items of income derived from that other State.

$r$. Where in accordance with any provision of the Convention income derived or capital owned by a resident of a Contracting State is exempt from tax in that State, such State may nevertheless, in calculating the amount of tax on the remaining income or capital of such resident, take into account the exempted income or capital.

$\varepsilon$. The provisions of paragraph ' shall not apply to income derived or capital owned by a resident of a Contracting State where the other Contracting State applies the provisions of this Convention to exempt such income or capital from tax or applies the provisions of paragraph $r$ of Article $1 \cdot$ or 11 to such income." (Look: OECD ( $\left.\Upsilon_{\cdot}\right) \varepsilon$ ), Model Tax Convention on Income and on Capital...op. cit. p. ${ }^{\kappa}$.)

$$
\text { ' ـ تنص هذه المادة علي مايلي: }
$$


الإيتمان الضريبي وآثارة الإقتصادية والمالية "دراسة مقارنة"

أـ خصم ضريبة الدخل التي يتحملها المقيم في الدولة الأخري من ضريبة الدخل المستحقة عليه في دولة الإقامةً.

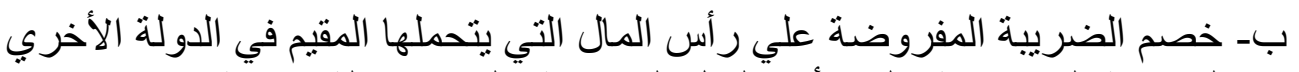
من الضريبة المفروضة علي رأس المال المستحقة عليه في دولة الإقامة.

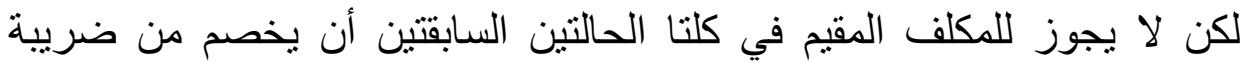

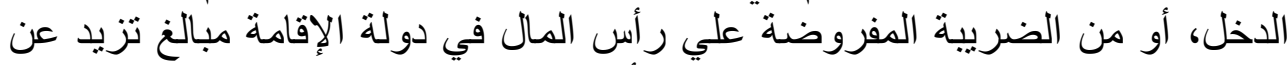
مبالغ الضريبة الدفروضة عليه في الدولة الأخري.

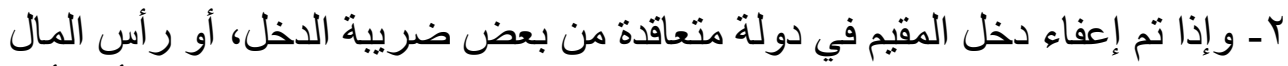

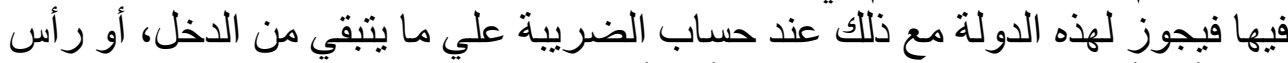
المال أن تأخذ في الحسبان قيمة الدخل أو رأس المال المعفي."

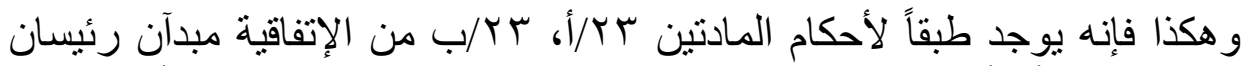

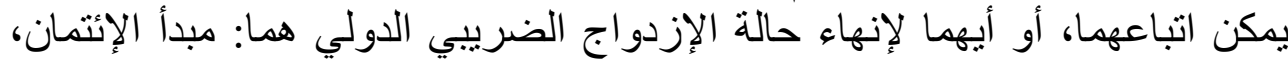
ومبدأ الإعفاء.

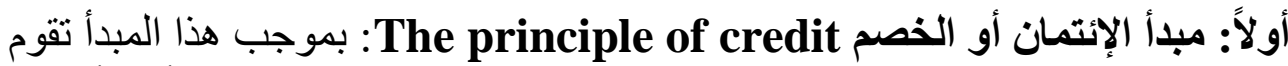

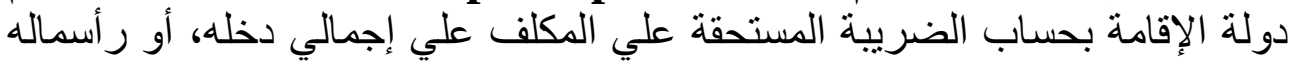

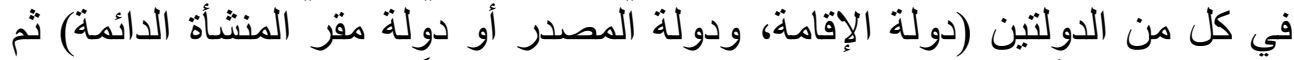

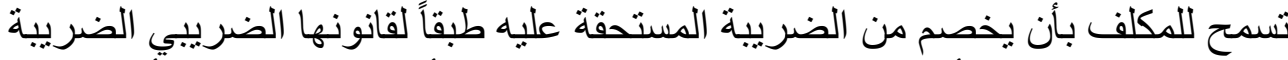
المدفو عة في الدولة الأخري.' وتفضل الدول المصدرة لر أس المال هذا المبدأ؛ بحسبان الفرية

"). Where a resident of a Contracting State derives income or owns capital which, in accordance with the provisions of this Convention, may be taxed in the other Contracting State, the first-mentioned State shall allow:

a) as a deduction from the tax on the income of that resident, an amount equal to the income tax paid in that other State;

b) as a deduction from the tax on the capital of that resident, an amount equal to the capital tax paid in that other State. Such deduction in either case shall not, however, exceed that part of the income tax or capital tax, as computed before the deduction is given, which is attributable, as the case may be, to the income or the capital which may be taxed in that other State.

$r$. Where in accordance with any provision of the Convention income derived or capital owned by a resident of a Contracting State is exempt from tax in that State, such State may nevertheless, in calculating the amount of tax on the remaining income or capital of such resident, take into account the exempted income or capital." ." (Look: OECD (ץ.) $\varepsilon$ ), Model Tax Convention on Income and on Capital...op. cit. p. ${ }^{r}$.)

' - OECD ( $(\cdot \mid \varepsilon)$, Model Tax Convention ..., Op. Cit .p. $r$ r .

- James Alm: The Role of Tax Exemptions and ... Op. Cit .p. « ).

- CLAUDIO A. AGOSTINI and MARIEL C. SIRAVEGNA: EFECTOS DE LA EXENCION TRIBUTARIA ..., Op. Cit .p. $\leqslant$. 
أنه يؤدي إلي عدم التمييز بين رؤوس الأموال الوطنية عند استثمارها في الخارج

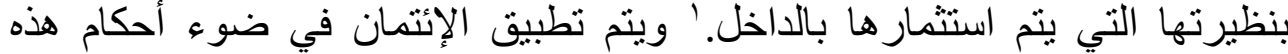
الإتفاقية بإحدي طريقتين، تألفهما معظم التشريعات التئن المقارنة:

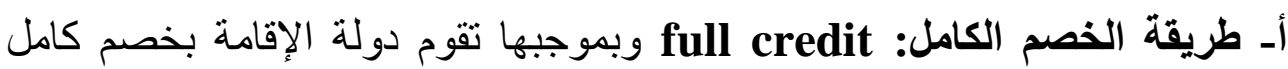
الضريبة الددفوعة في الدولة الأخري من الضريبة المستحقة علي ذات الاخل أل أو رأس

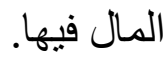

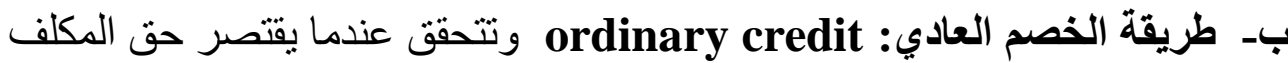

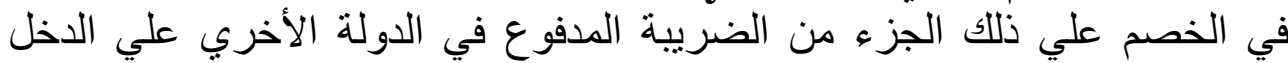

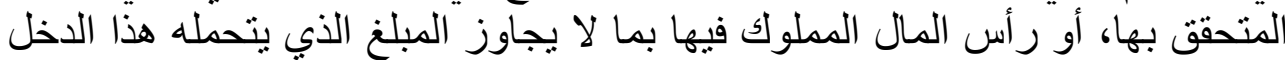
كضريبة طبقاً لسعر الضريبة الساري في دولة الطيالة الإقامة.

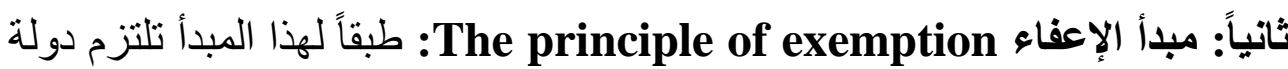

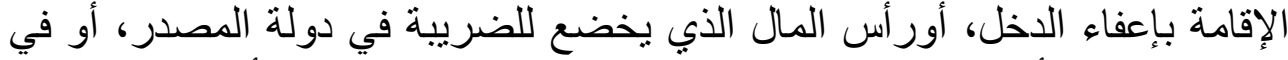

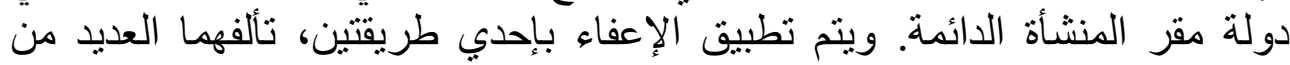

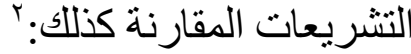

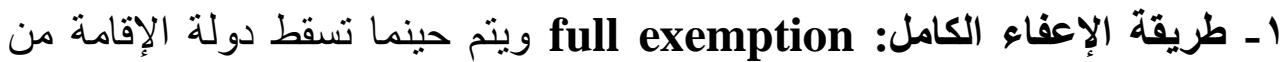

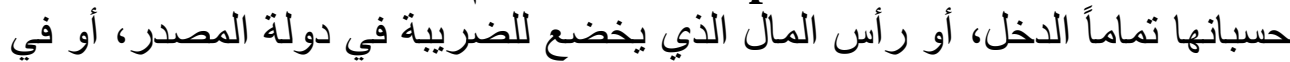
دولة مقر المنشأة الدائمة.

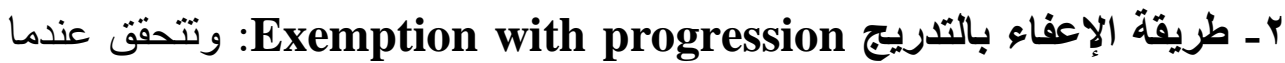

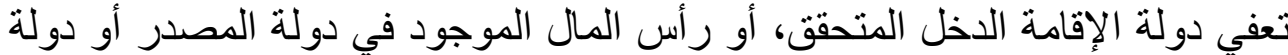

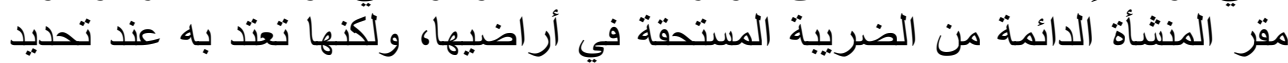

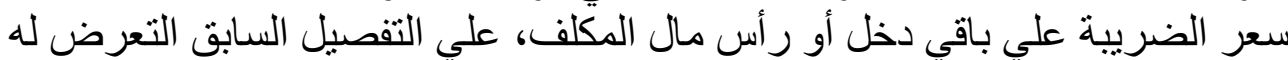

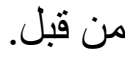

وعندما تتبني دولة ما تطبيق نظام الإتتمان الضريبي بطريقة من الطريقتين

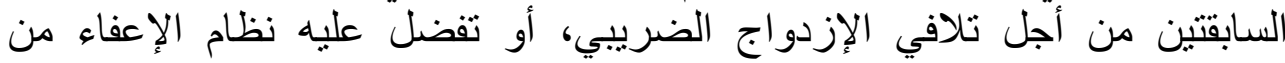

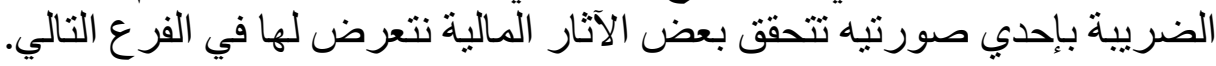

-James M. Poterba: TAX REFORM AND THE MARKET FOR TAXEXEMPT DEBT, ..., Op. Cit .p. rq.

$$
\begin{aligned}
& \text { - ـراجع في تفاصيل ذلك: د. رمضان صديق: تفسير وتطبيق إتفاقيات تجنب الإزدو اج }
\end{aligned}
$$

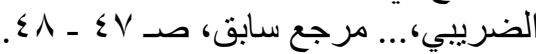

$r$ - OECD ( $(\cdot 1 \varepsilon)$, Model Tax Convention ..., Op. Cit .p. rr $r$.

- James Alm: The Role of Tax Exemptions and ..., Op. Cit .p. $\leqslant$ r.

- Lawrence W. Kenny- University of Florida and Stanley L. Winer-

Carleton University: Tax Systems in the World: ..., Op. Cit .p. $1 \wedge$. 


\section{الفرع الثاني}

\section{الآثار المالية للإنتمان في مقابلة الإعفاء في التشريعات المقارنة}

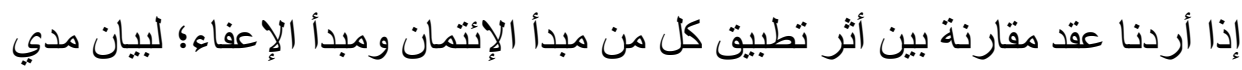

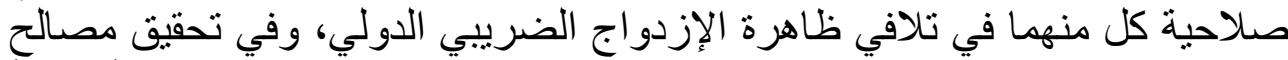

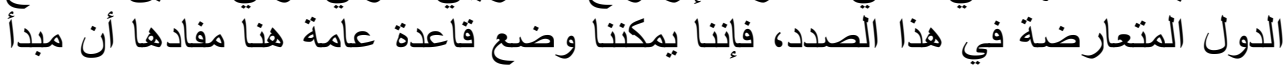

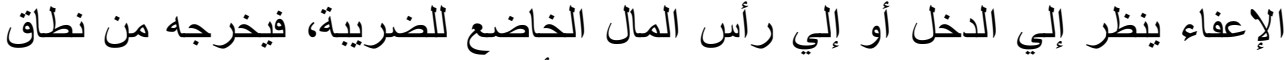

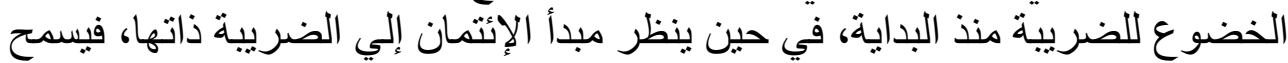

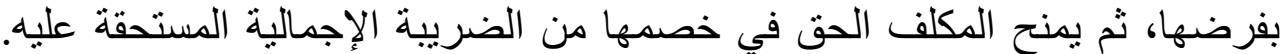
ونسوق فيما يلي مثالاً توضيحياً لبيان ذلك: فئل

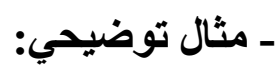

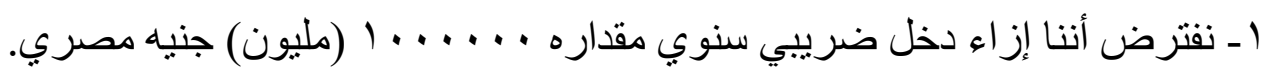

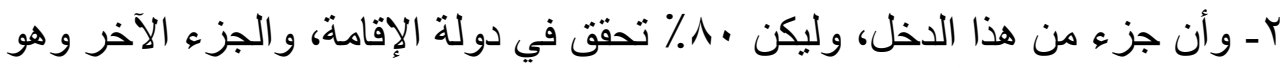

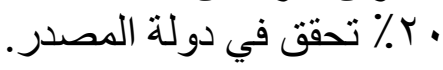

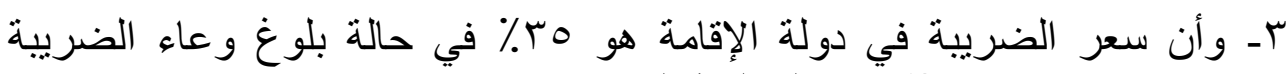

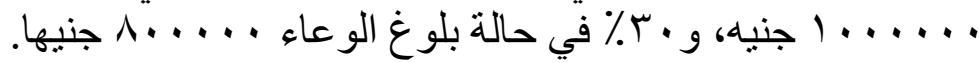

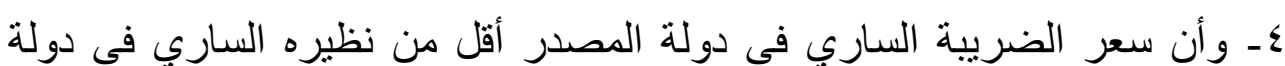

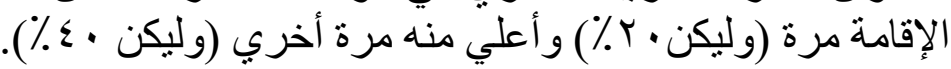

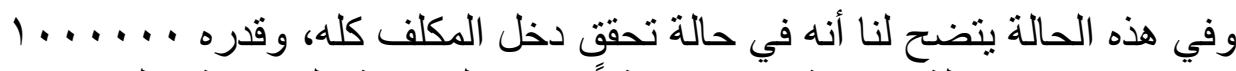

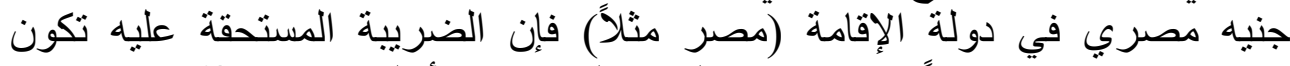

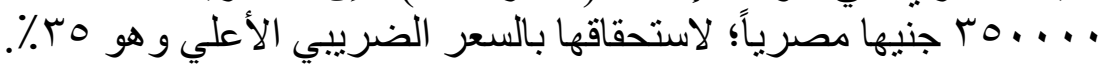

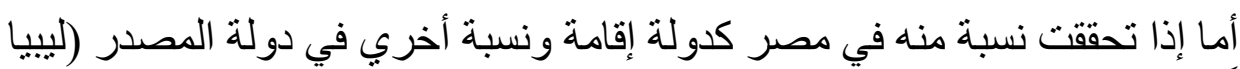

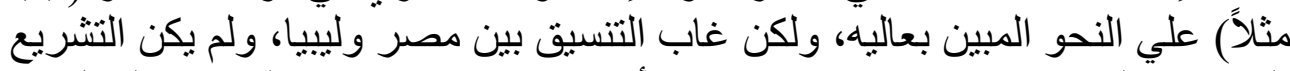

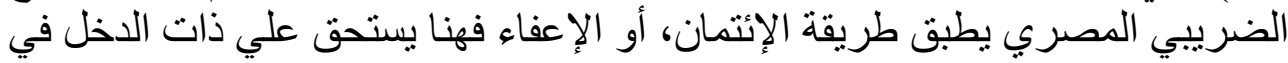

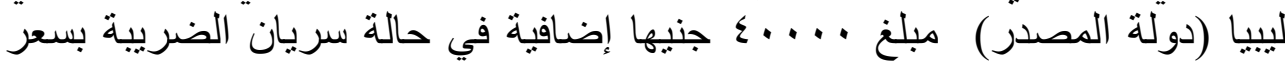

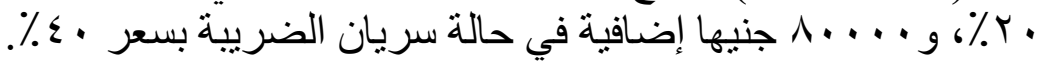

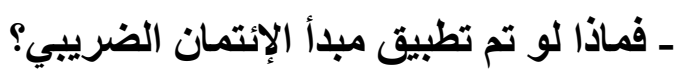

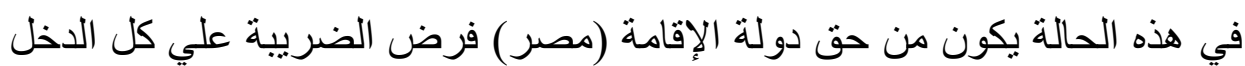

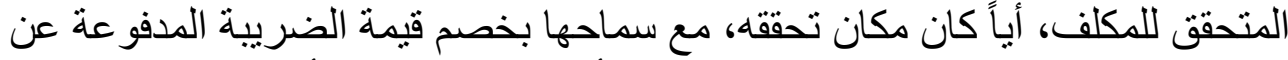

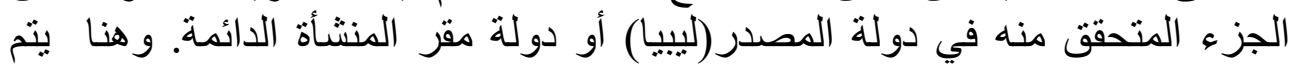
تطبيق طريقة الإنتمان ألضريبي، أو الخصم بإحدي صورنين:

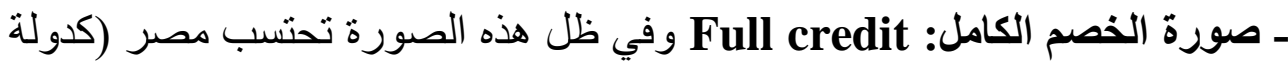

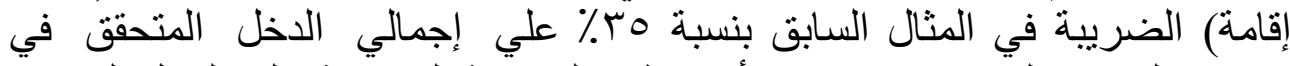

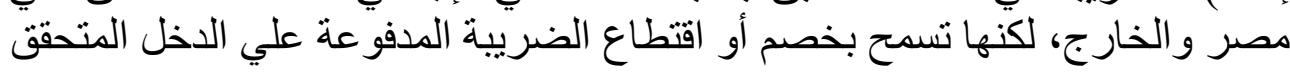


في دولة الصصدر (ليبيا) من إجمالي الضريبة المستحقة في مصر علي إجمالي الدخل الضريبي في مصر وليييا' . ويمكن توضيح هذه الحالة من خلال الجدول التالي: التيا:

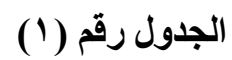

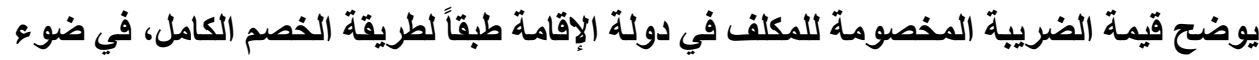

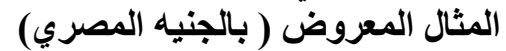

\begin{tabular}{|c|c|c|c|}
\hline الضريبة المستحقة & سعر الضريبة & وعاء الضريبة & البيان \\
\hline ro.... & $\%$ & $1 \ldots \ldots$ & الضريبة في دولة الإقامة(مصر) \\
\hline$\varepsilon \ldots$ & • • • ( في الحالة الأولي) & \multirow[t]{2}{*}{ r..... } & \multirow[t]{2}{*}{ الضريبة في دولة المصدر(ليبيا) } \\
\hline A.... & • . ؛ ( في الحالة الثانية) & & \\
\hline . . . . هـ (في الحالة الأولي) & & & \multirow[t]{2}{*}{ إجمالي الضريبة } \\
\hline . . . . ه ب (في الحالة الثانية) & & & \\
\hline . . . . . (في الحالة الأولي) & & & \multirow{2}{*}{ قيمرة الإتمان الممنوح من دولة الإقامة } \\
\hline 1 . . . . . (في الحالة الثانية) & & & \\
\hline . . . . . إ (في الحالة الأولي) & & & \multirow[t]{2}{*}{ صافي الضريبة } \\
\hline F . . . . & & & \\
\hline
\end{tabular}

ـ صورة الخصم العادي: Ordinary credit وفي ظل هذه الصورة تحسب دولة

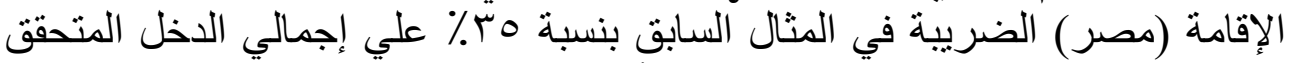

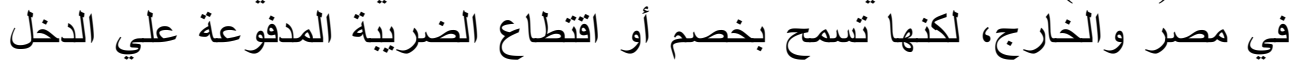

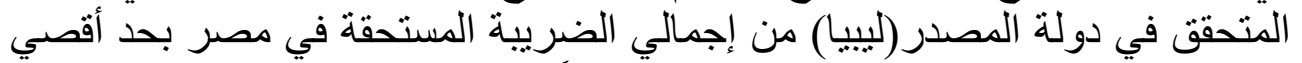

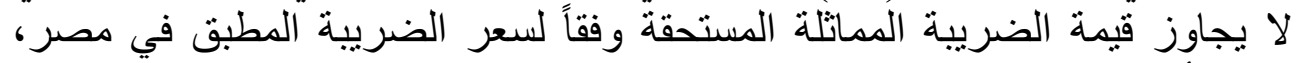

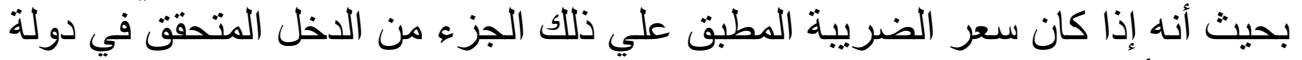

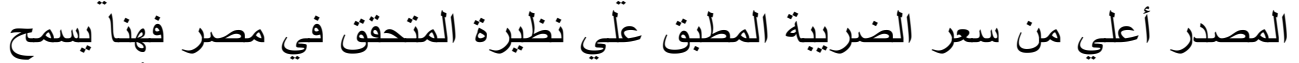

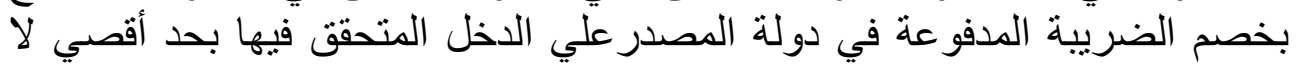

' - OECD $(\uparrow \cdot 1 \varepsilon)$, Model Tax Convention on Income and on Capital: Condensed Version $r$. I \&, OECD Publishing. P. rY^.

-JOHANNES BECKER \& CLEMENS FUEST: CORPORATE TAX POLICY AND INTERNATIONAL MERGERS AND ACQUISITIONS IS THE TAX EXEMPTION SYSTEM SUPERIOR? CESIFO WORKING PAPER NO. $\backslash \wedge \wedge$, CATEGORY 1 : PUBLIC FINANCE, JANUARY $r \cdots \vee$. P.Y.

- Lawrence W. Kenny- University of Florida and Stanley L. WinerCarleton University: Tax Systems in the World: An Empirical Investigation into the importance of Tax Bases, Collection Costs, and Political Regime, May T...'. P. 19.

- James Alm: The Role of Tax Exemptions and Credits, Tulane University Economics Working Paper Series, New Orleans, USA, Working Paper $10 r 7$, December r.10. 


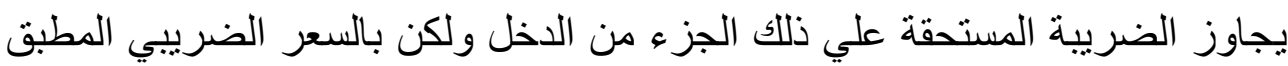

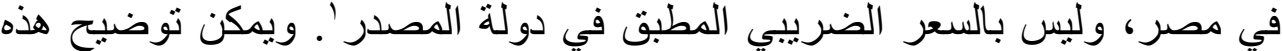

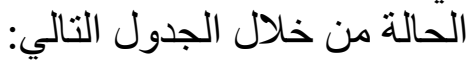

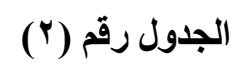

يوضح قيمة الضريبة المخصومة للمكلف في دولة الإقامة طبقاً لطريقة الخصم العادي، في ضوء المثال المعروض (بالجنيه المصري)

\begin{tabular}{|c|c|c|c|}
\hline الضريبة المستحقة & سعر الضريبة & وعاء الضريبة & 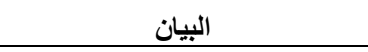 \\
\hline ro.... & $\%$ & $1 \ldots \ldots$ & الضريبة في دولة الإقامة(مصر) \\
\hline$\varepsilon \ldots$ & 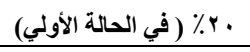 & \multirow{2}{*}{$r \ldots .}$. & \multirow{2}{*}{ الضريبة في دولة المصدر(ليبيا) } \\
\hline A.... & ـ ـ ٪ (في الحالة الثانية) & & \\
\hline . . . . ؛ (في الحالة الأولي) & & & \multirow{2}{*}{ قيمة الإتتمان المصنوح من دولة } \\
\hline V . . . . . (في الحالة الثانية) & & & \\
\hline 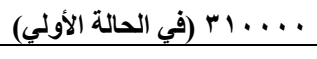 & & & \multirow{2}{*}{ صافي الضريبة المستحقة في دولة } \\
\hline . . . . . . (في الحالة الثانية) & & & \\
\hline 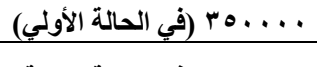 & & & \multirow{2}{*}{ إجمالي الضريبة المدفوعة من } \\
\hline . . . . ب ب (في الحالة الثانية) & & & \\
\hline
\end{tabular}

و هكذا يتضح الفرق بين تطبيق كل حالة من حالتي الإتتمان السابقتين، و أثر ها علي الإني

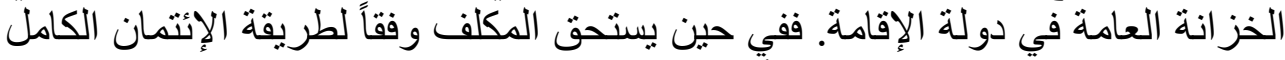

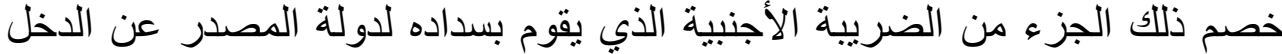

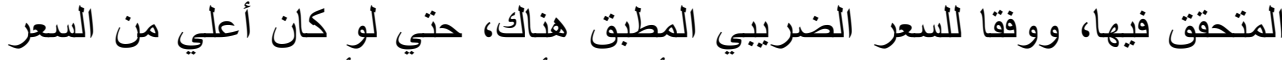

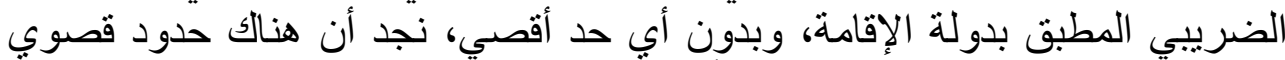

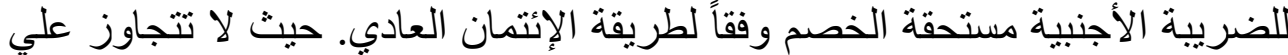
الإطلاق قيمة الضريية التي تستحق علي ذات الاخل، فيما لو كان متحققاً في دولة لإنة

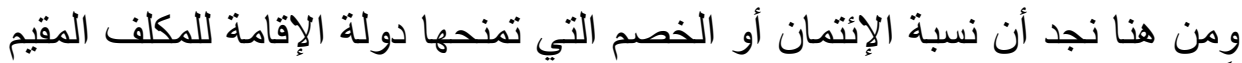

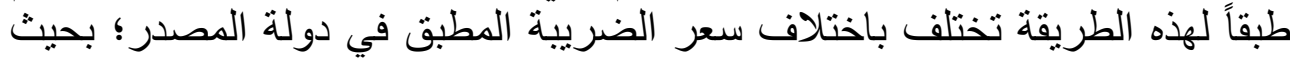

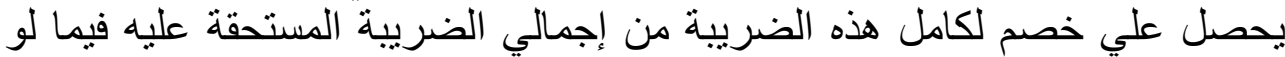

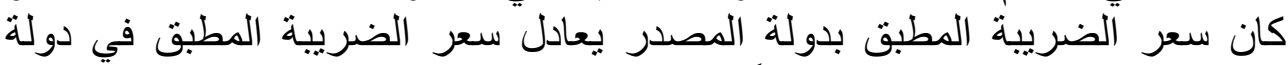

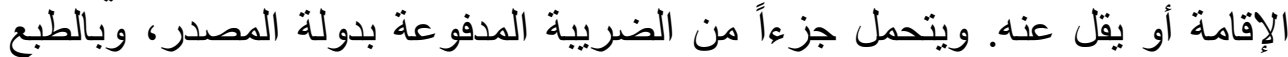

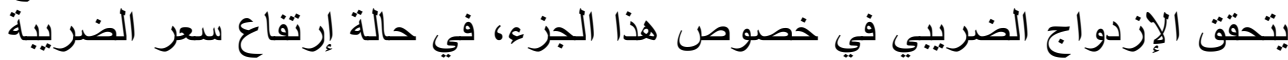
المطبق بها عن سعر الضريية المطبق بدولة الإقامة.

' - OECD ( $(\cdot 1 \varepsilon)$, Model Tax Convention ..., Op. Cit .p. rr^. -James M. Poterba: TAX REFORM AND THE MARKET FOR TAXEXEMPT DEBT... Op. Cit .p. ${ }^{\digamma} \cdot$ 
فكأن الحد الأدني للضريبة التي يدفعها المكلف علي إجمالي دخله الضريبي

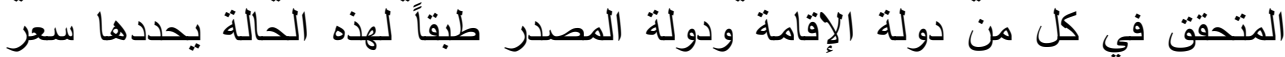

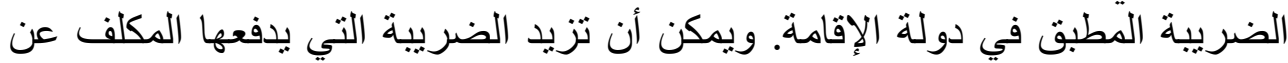

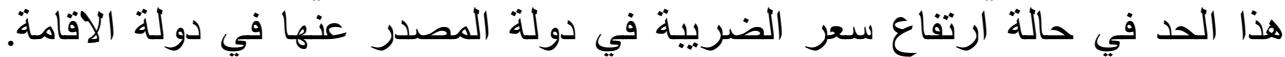

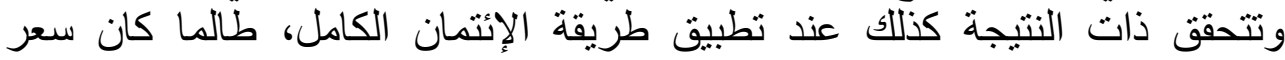
الضريبة المطبق في دولة الإقامة مانحة الإئتمان أعلي من سعر الضرية الإنية المطبق في دولة المصدر.

فإذا كانت الضريبة المستحقة علي الاخل المتحقق في دولة المصدر أعلي من

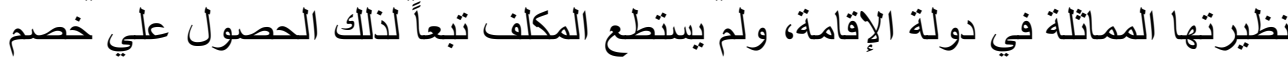

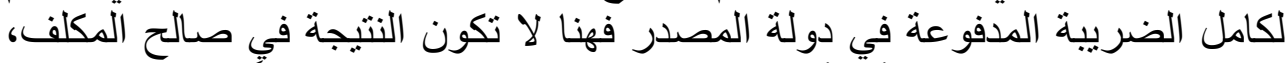

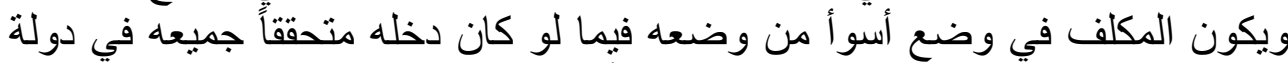

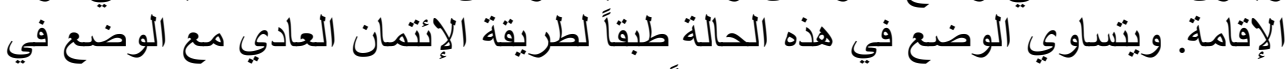

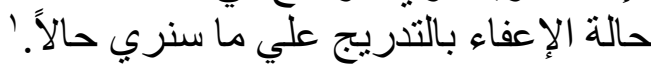

ـ أما لو تم تطبيق مبدأ الإعفاء الضريبي: ففي هذه الحالة يقتصر حق مصر كدولة

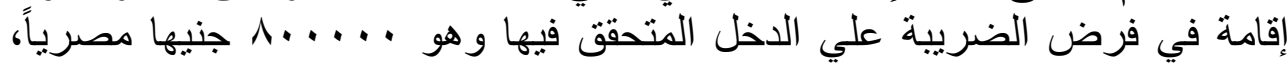
غير أن السعر الضريبي الذي يتم تطبيقه يختلف باختلاف طريقة الإعفاء المطبقة: ـ فقي حالة الإعفاء الكامل: Full exemption تكون الضريبة المستحقة علي

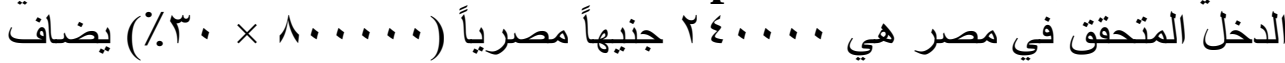

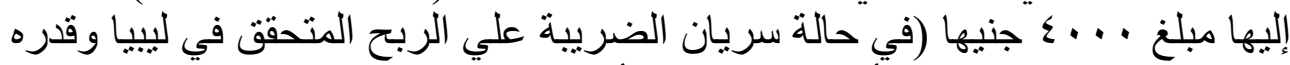

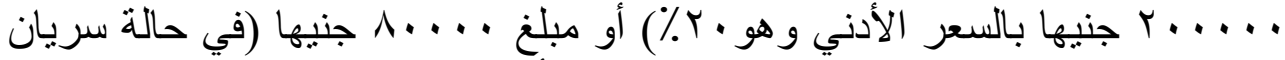

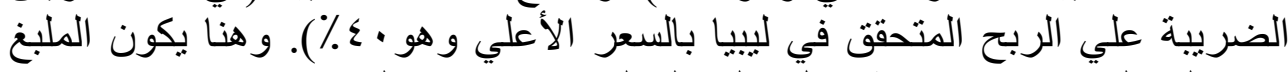

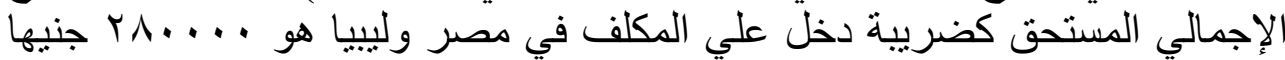

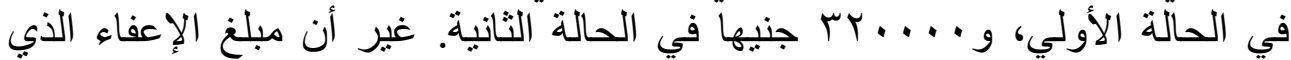

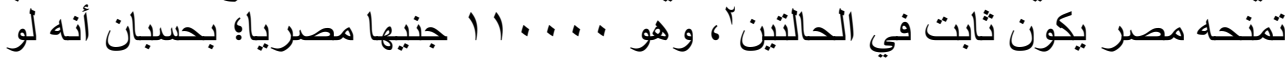

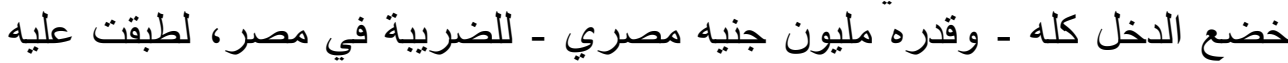

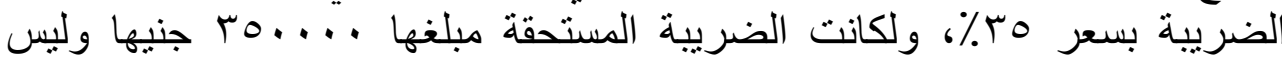

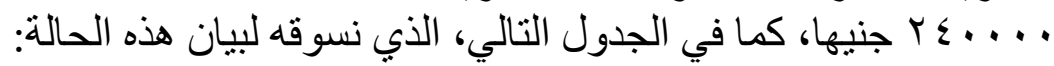

'-OECD $(\uparrow \cdot \mid \varepsilon)$, Model Tax Convention on Income and on Capital: Condensed Version $r \cdot 1 \leqslant$, OECD Publishing. P.r $r q$.

-JOHANNES BECKER \& CLEMENS F. : CORPORATE TAX POLICY AND INTERNATIONAL MERGERS ..., Op. Cit .p. $r$ l.

- Lawrence W. Kenny- University of Florida and Stanley L. WinerCarleton University: Tax Systems in the World: ..., Op. Cit .p. $r \cdot$.

$r$ - OECD $(r \cdot \mid \varepsilon)$, Model Tax Convention ..., Op. Cit .p. rrv.

- Lawrence W. Kenny- University of Florida and Stanley L. WinerCarleton University: Tax Systems in the World: ..., Op. Cit .p. Y I.

- James Alm: The Role of Tax Exemptions and Credits, p. $\leqslant 0$. 


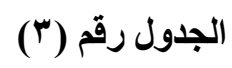

يوضح قيمة الإعفاء الممنوح للمكلف من دولة الإقامة ( بالجنيه المصري)

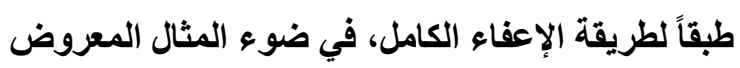

\begin{tabular}{|c|c|c|c|}
\hline الضريبة المستحقة & سعر الضريبة & وعاء الضريبة & البيان \\
\hline$r \varepsilon \ldots$ & $\%$. & $\wedge \ldots$. & الضريبة في دولة الإقامة (مصر) \\
\hline$\leq \ldots$ & 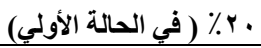 & \multirow[t]{2}{*}{$r \ldots .}$. & \multirow[t]{2}{*}{ الضريبة في دولة المصدر( ليبيا) } \\
\hline$\wedge \ldots$ & • ـ ٪ ( في الحالة الثانية) & & \\
\hline · . . . . في الحالة الأولي) & & & \multirow[t]{2}{*}{ إجمالي الضريبة } \\
\hline 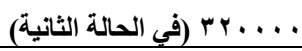 & & & \\
\hline . . . . 11 (في الحالتين) & & & قالإقامة (مصر) الإعاء الممنوح من دولة \\
\hline
\end{tabular}

ـ أما في حالة الإعفاء بالتدريج: Exemption with progression فهنا يطبق

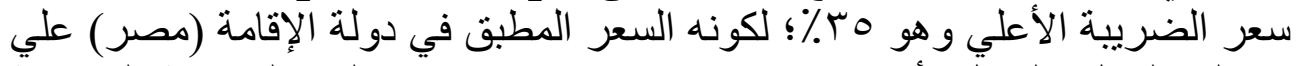

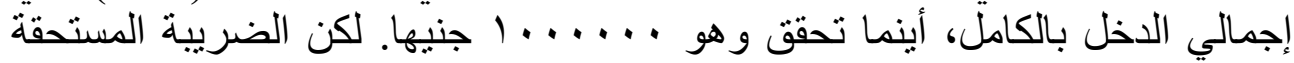

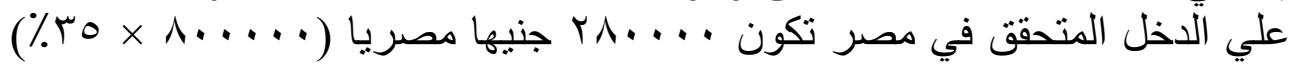

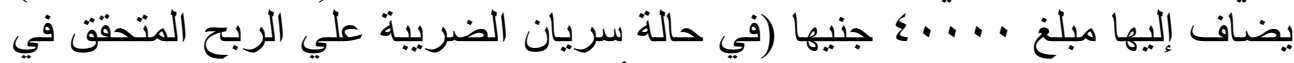

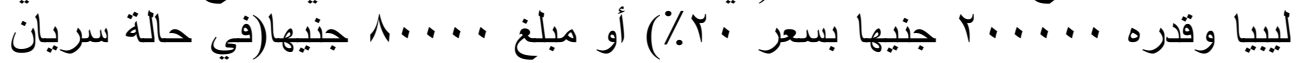

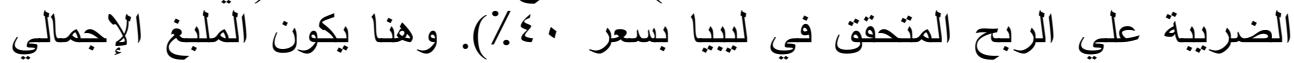

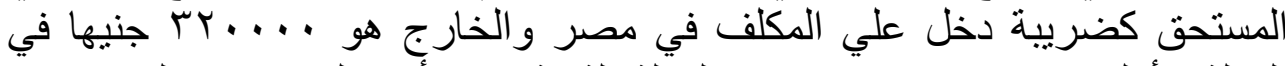

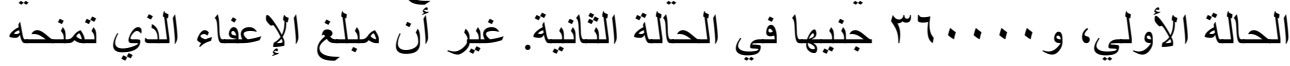

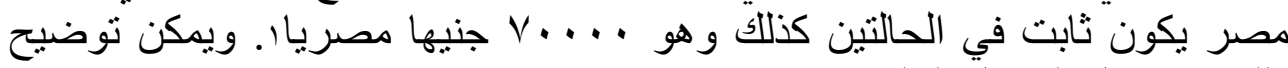

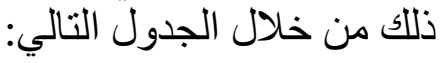

' - OECD ( $.1 \varepsilon)$, Model Tax Convention ..., Op. Cit .p. r ${ }^{\top}$.

-James M. Poterba: TAX REFORM AND THE MARKET FOR TAXEXEMPT DEBT, ..., Op. Cit .p. ${ }^{r}$.

-JOHANNES BECKER \& CLEMENS FUEST: CORPORATE TAX POLICY AND INTERNATIONAL MERGERS AND ACQUISITIONS IS THE TAX EXEMPTION SYSTEM SUPERIOR..., Op. Cit .p. ${ }^{r}$. 


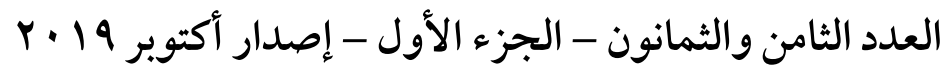

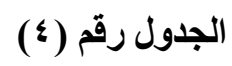

يوضح قيمة الإعفاء الممنوح للمكلف من دولة الإقامة ( بالجنيه المصري)

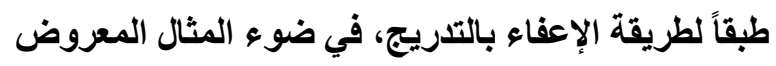

\begin{tabular}{|c|c|c|c|}
\hline الضريبة المستحقة & سعر الضريبة & وعاء الضريبة & البيان البيان \\
\hline r^... & $\%$ & $\wedge \ldots$. & الضريبة في دولة الإقامة \\
\hline$\leq \ldots$ & • . . . ( في الحالة/لأولي) & \multirow[t]{2}{*}{$r \ldots}$. & \multirow{2}{*}{ الضريبة في دولة } \\
\hline$\wedge \ldots$ & . ـ ؛ ( في الحالة لثانية) & & \\
\hline 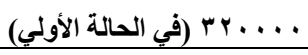 & & & \multirow[t]{2}{*}{ إجمالي الضريبة } \\
\hline . . . . . ب (في الحالة الثانية) & & & \\
\hline 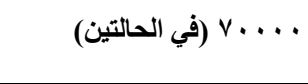 & & & قيمة الإعفاء الممنوح من دولة \\
\hline
\end{tabular}

و هكذا يتضح لنا أن سعر الضريبة في دولة المصدر لليبيا) لا يؤثر علي مقدار مبلغ

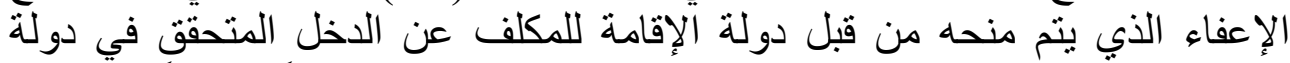

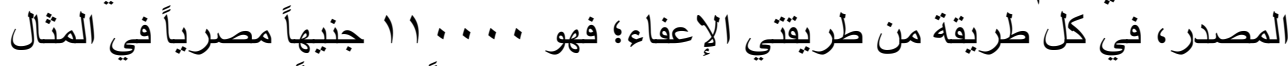

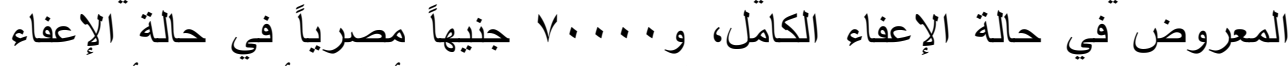

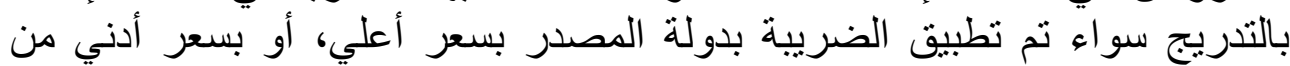

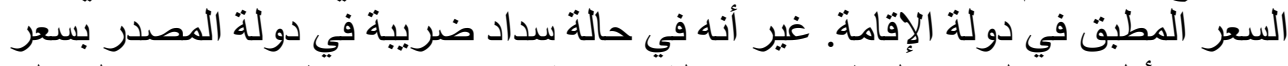

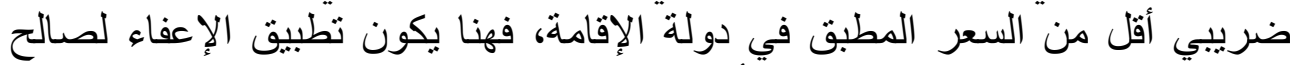

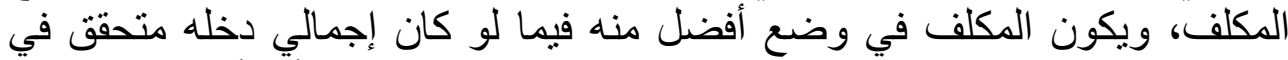

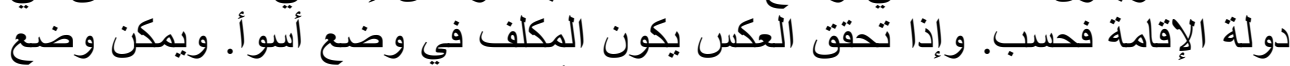

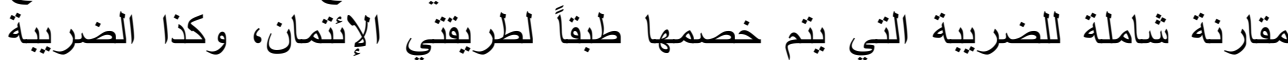

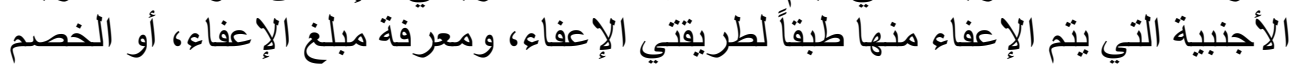

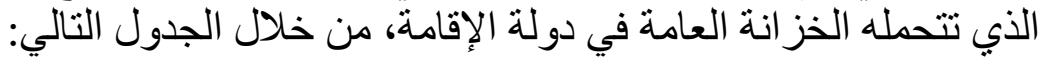




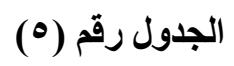

مقارنة بين المبالغ المعفاة والمخصومة طبقاً للطرق الأربع السابقة (بالجنيه الدصري)

\begin{tabular}{|c|c|c|c|c|c|c|c|}
\hline \multicolumn{2}{|c|}{ دولة الإقامة التي تتحملها } & \multicolumn{2}{|c|}{ بلضة الإقامة التي يتحملها الدكلف } & \multicolumn{2}{|c|}{ بلاولة المصدة المدفوعة } & \multirow{2}{*}{\multicolumn{2}{|c|}{ الموقـــــف }} \\
\hline 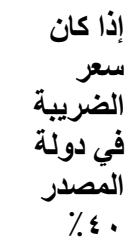 & الضعر الدرانة & الضّا كايبة سعة بدولة & 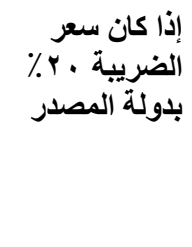 & 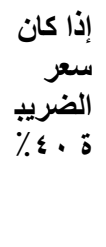 & إذإكانة & & \\
\hline & - & ro.... & ro.... & & - & \multicolumn{2}{|c|}{ بأكمله في دولة تحقة الإخاملة } \\
\hline - & - & $\leqslant \mu \ldots$ & $r a \ldots .$. & A.... & $\{\ldots$ & الإلطفايق أو & 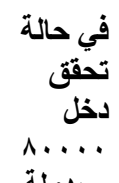 \\
\hline $11 \ldots$. & $11 \ldots$. & rr.... & rı.... & $\wedge \ldots$ & $\{\ldots$ & الإلكاءك & 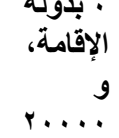 \\
\hline v.... & $v \ldots$. & $r+\ldots . .$. & rr.... & A.... & $\{\ldots$ & الإعفاءي & البصدر \\
\hline$\wedge \ldots$ & $\varepsilon \ldots$ & ro.... & ro.... & $\wedge \ldots$ & $\{\ldots$ & ألأأتمان & \\
\hline v.... & $\varepsilon \ldots$ & $r+\ldots$. & ro.... & $\wedge \ldots$ & $\{\ldots$ & الالآتمان & \\
\hline
\end{tabular}

وهكذا تتساوي الضريبة التي تتحملها دولة الإقامة في حالة تطبيق الإعفاء

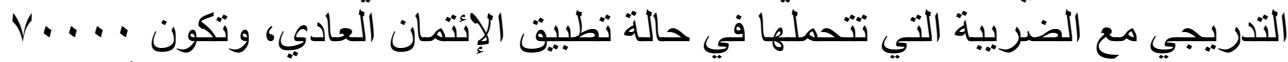

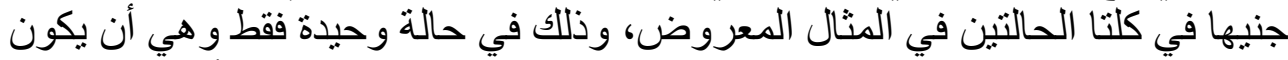

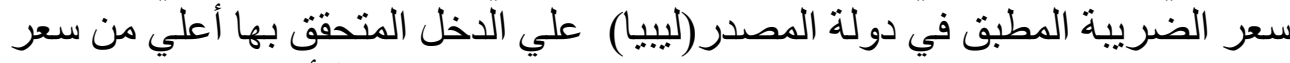

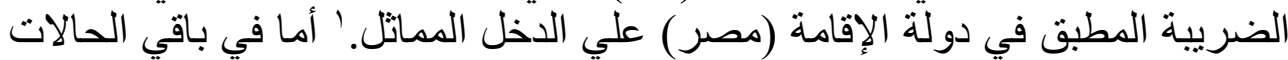

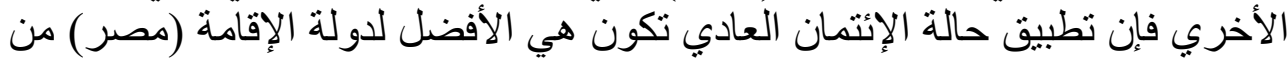

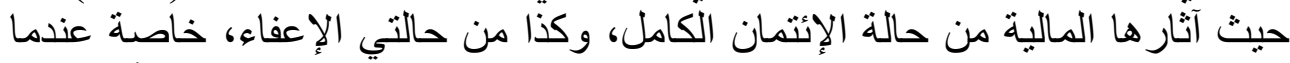

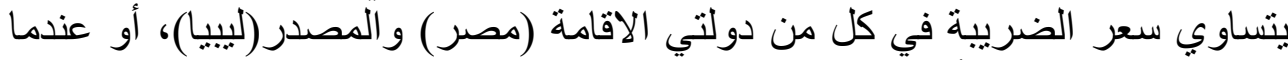

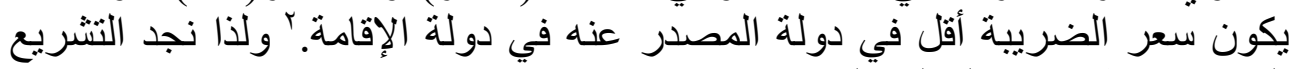
المصري يطبق هذه الحالة علي ما سنري فيما بعد.

' - OECD ( $(.) \varepsilon)$, Model Tax Convention ..., Op. Cit .p. rrq.

- James Alm: The Role of Tax Exemptions and Credits, p. $\{$ ?

$r$ - OECD $(r \cdot 1 \varepsilon)$, Model Tax Convention ..., Op. Cit .p. $r$ rq. 
وتتضمن إتفاقية منظمة التعاون الاقتصادي والتنمية OECD كلا هذين المبدأين

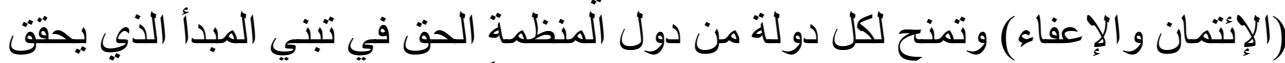

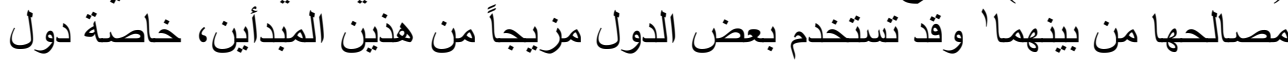

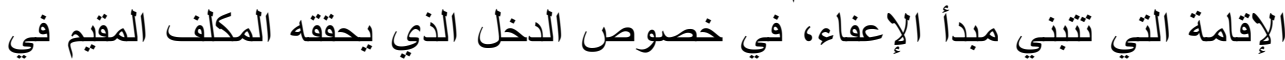

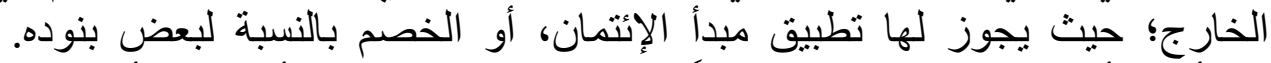

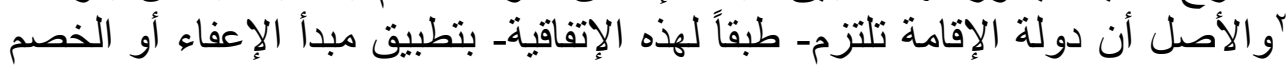

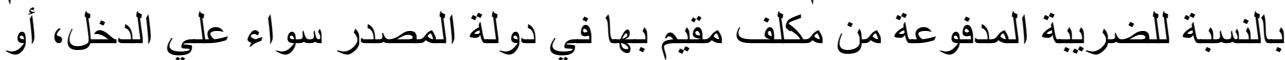

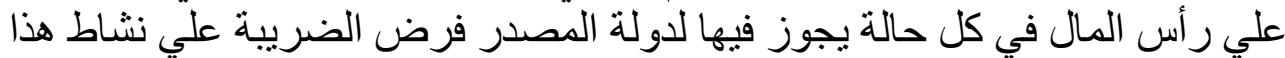
المكلف بها. ولا يشترط أن تقوم دولة المصدر بفرض الضريبة بالفعل، بل يكفي أن في في

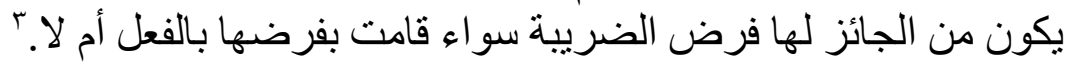

$$
\text { المطلب الثاني }
$$

\section{دور نظام الإئتمان في تلافي الازدواج الضريبي ومقارنته بالإعفاء}

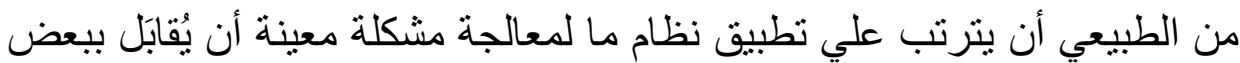

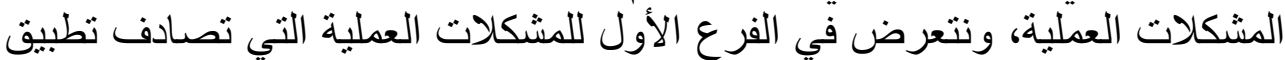

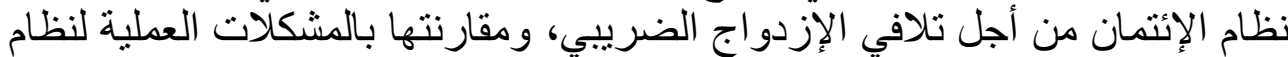

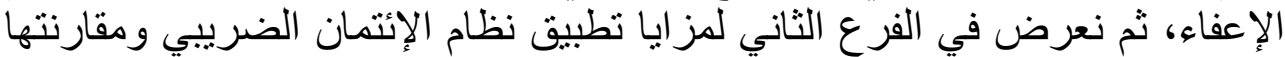

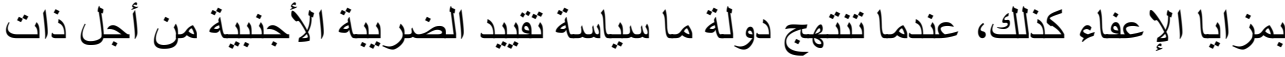

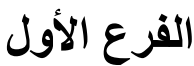

\section{المشكلات العملية لتطبيق الإئتمان ومقارنتها بمشكلات الإعفاء}

تثور بعض المشكلات العملية بسبب إختلاف الفلسفات والأسس التي تقوم عليها

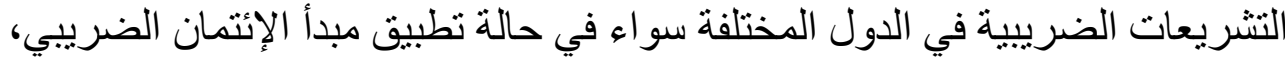
أو عند تبني مبدأ الإعفاء الضريبي، الإولي نعرض لبعضها فيما يلي:

-James M. Poterba: TAX REFORM AND THE MARKET FOR TAXEXEMPT DEBT, ..., Op. Cit .p. rr.

' - OECD (r.। $\varepsilon)$, Model Tax Convention ..., Op. Cit .p. r rq.

- James Alm: The Role of Tax Exemptions and ..., Op. Cit.p. $\leqslant$.

$r$ - OECD ( $r \cdot 1 \varepsilon)$, Model Tax Convention ..., Op. Cit .p. r $r q$.

-JOHANNES BECKER \& CLEMENS FUEST: CORPORATE TAX POLICY ..., Op. Cit.p. rY.

$r$ - OECD ( $r \cdot 1 \varepsilon)$, Model Tax Convention ..., Op. Cit .p. ${ }^{r q}$.

-James M. Poterba: TAX REFORM AND THE MARKET FOR TAXEXEMPT DEBT, ..., Op. Cit .p. $r \varepsilon$. 
أولاً: بعض المشكلات العملية لتطبيق مبدأ الإنتمان أو الخصم:

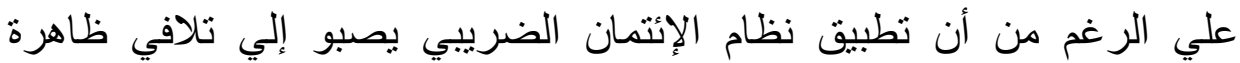

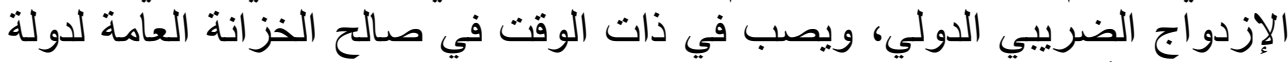

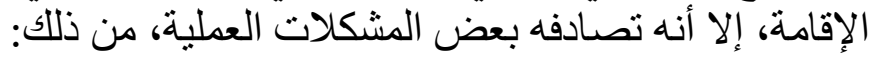

\section{1 - الحد الأقصي للإنتمان أو الخصم:}

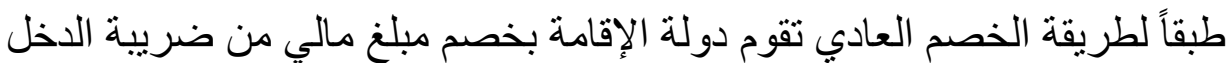

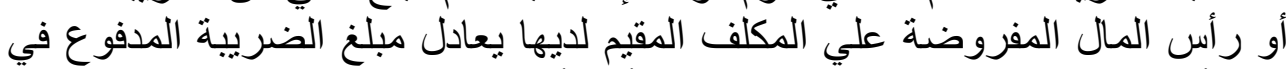

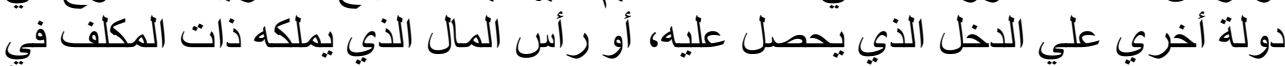

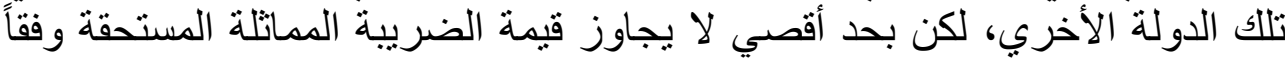
لسعر الضريبة المطبق في دولة الإقامة، كما سبق أن ذكرنا. restricted to the appropriate proportion of its own tax.

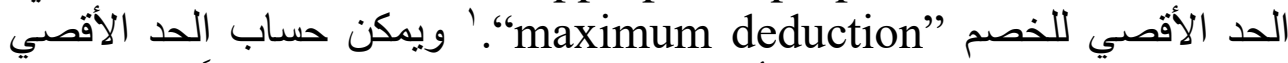

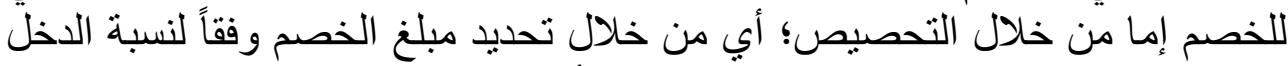

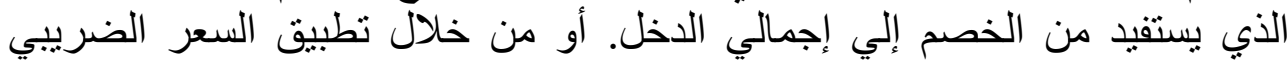

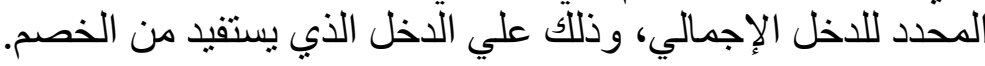

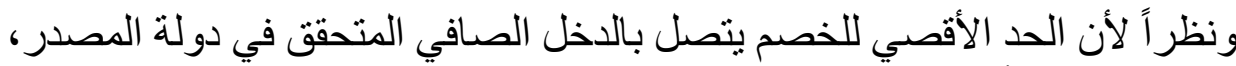

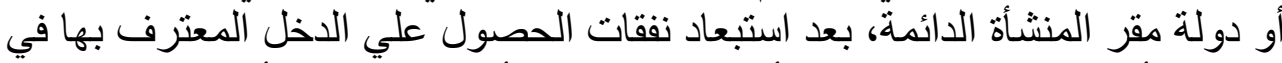

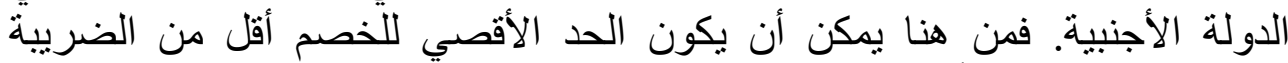
الأجنبية المدفو عة فعلاً.

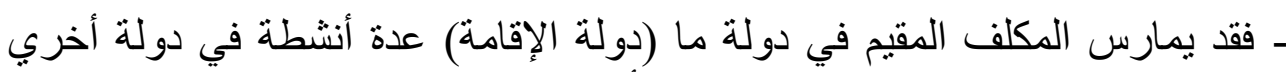

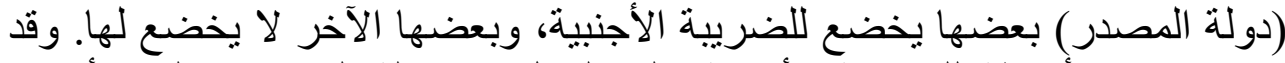

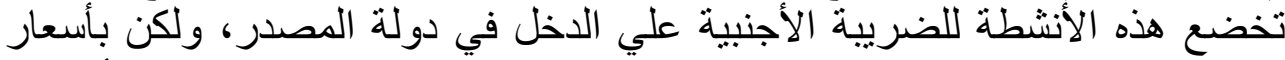

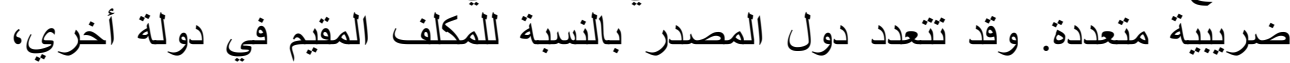

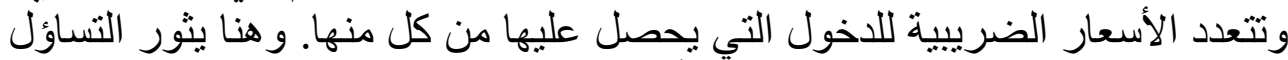

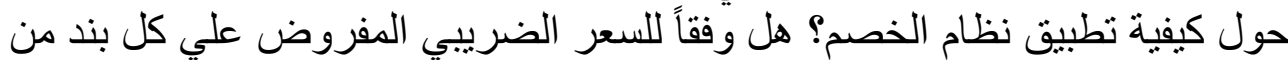

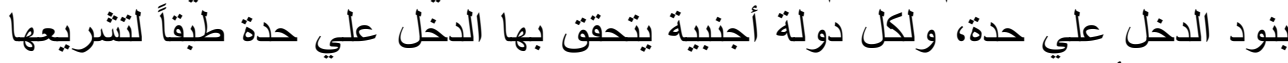

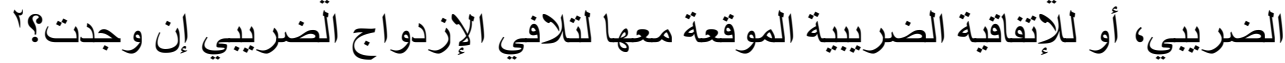

' - OECD ( $(\cdot 1 \varepsilon)$, Model Tax Convention ..., Op. Cit .p. $r \varepsilon$.

- James Alm: The Role of Tax Exemptions and..., Op. Cit .p. ₹v.

-JOHANNES BECKER \& CLEMENS FUEST: CORPORATE TAX POLICY ..., Op. Cit .p. rr.

$r$ - OECD $(r \cdot 1 \varepsilon)$, Model Tax Convention ..., Op. Cit .p. $r \varepsilon$ ).

-JOHANNES BECKER \& CLEMENS FUEST: CORPORATE TAX POLICY ..., Op. Cit .p. $r \varepsilon$.

- James Alm: The Role of Tax Exemptions and ..., Op. Cit .p. $\leqslant$ v. 


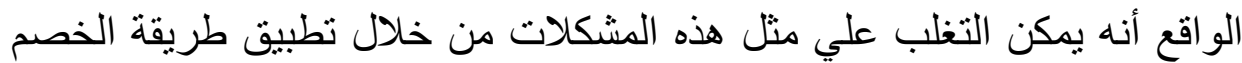

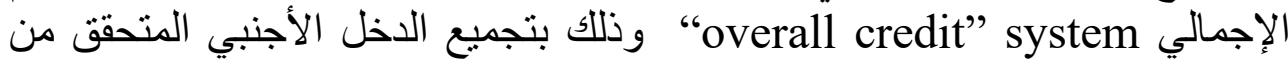

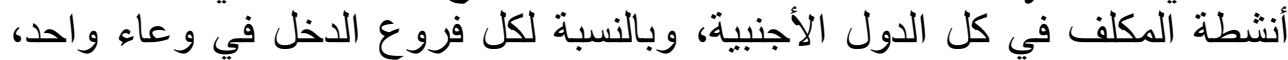

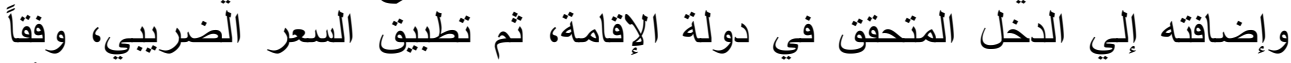

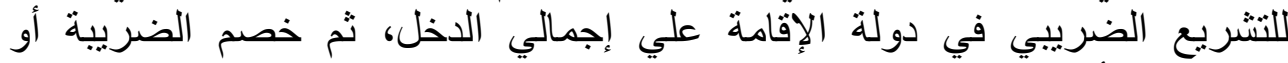
الضر ائب الأجنيية المدفو عة بالفعل من الضريبة المستحقة الإجمالية علي المكلف.

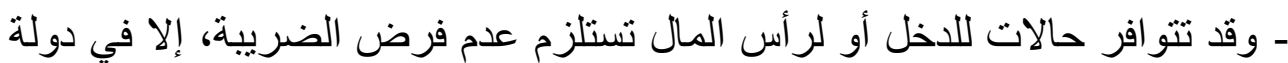

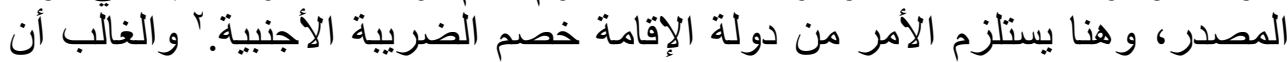
تتعرض التشريعات الضرييية لمشكلات خصم الضريبة الأجنبية وطريقة تجاوز ها.

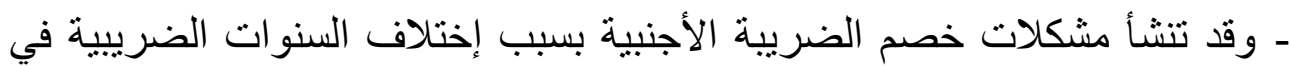

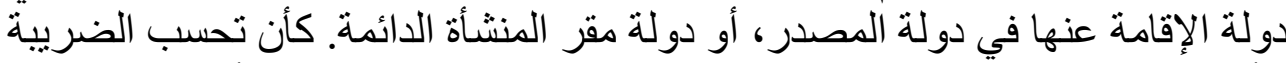

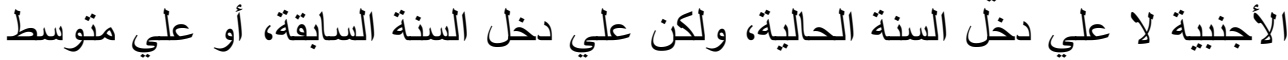

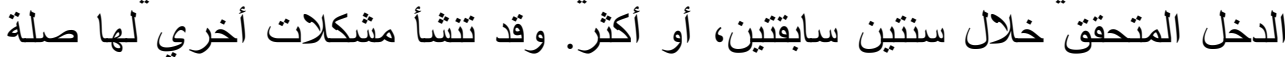

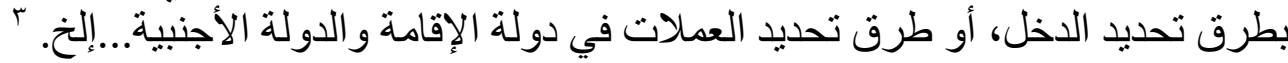

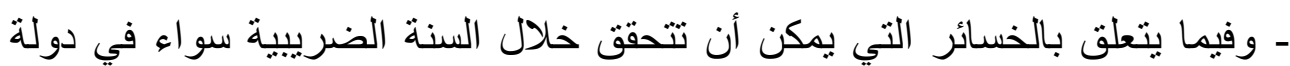

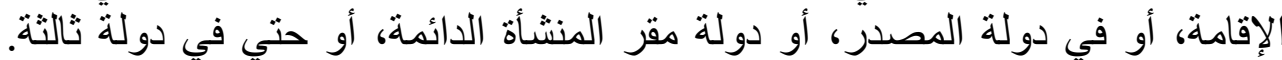

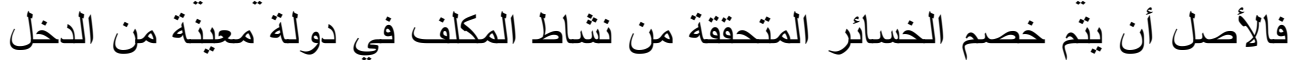

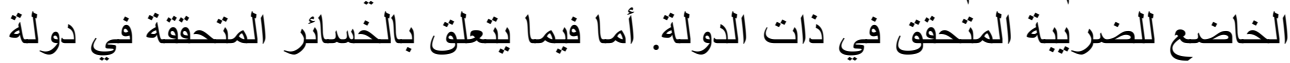

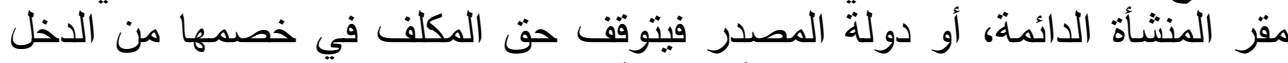

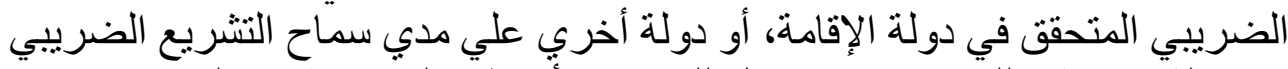

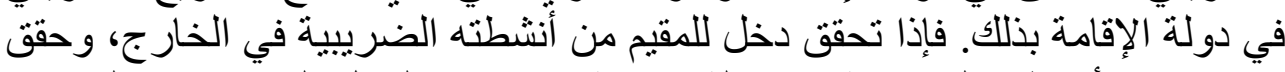

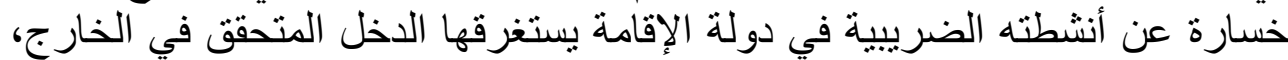

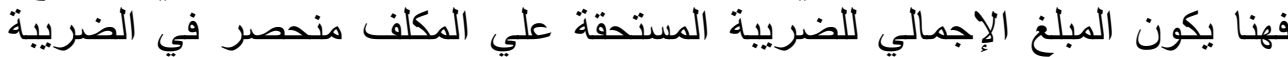

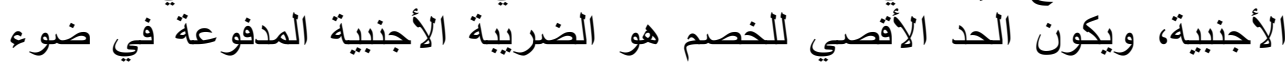
السعر الضريبي المطبق علي إجمالي دخل المكلف. الأفر

' - OECD ( $(\cdot 1 \varepsilon)$, Model Tax Convention ..., Op. Cit p. $r \leqslant$ r.

- James Alm: The Role of Tax Exemptions and ..., Op. Cit.p. «^.

$r$ - OECD ( $r \cdot \mid \varepsilon)$, Model Tax Convention ..., Op. Cit .p. $r \cdots$.

-James M. Poterba: TAX REFORM AND THE MARKET FOR TAXEXEMPT DEBT, ..., Op. Cit .p. ro.

${ }^{r}$ - OECD $(r \cdot 1 \varepsilon)$, Model Tax Convention ..., Op. Cit .p. $r \xi\ulcorner$.

- James Alm: The Role of Tax Exemptions and..., Op. Cit .p. ₹१.

-JOHANNES BECKER \& CLEMENS FUEST: CORPORATE TAX POLICY ..., Op. Cit .p. ro.

- OECD $(r \cdot 1 \varepsilon)$, Model Tax Convention ..., Op. Cit .p. $r \leqslant 0$.

-James M. Poterba: TAX REFORM AND THE MARKET FOR TAXEXEMPT DEBT, ..., Op. Cit .p. ro. 


\section{r- بإمكانية معاملة الفو ائد بذات معاملة أرباح الأسهر:}

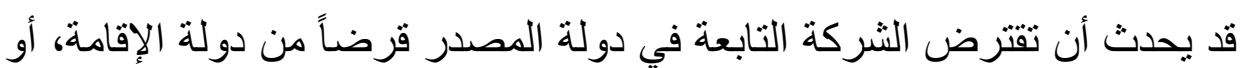

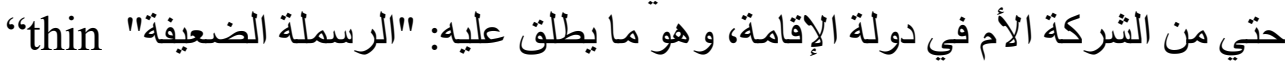

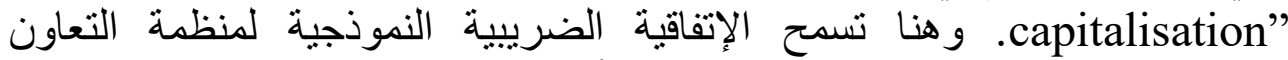

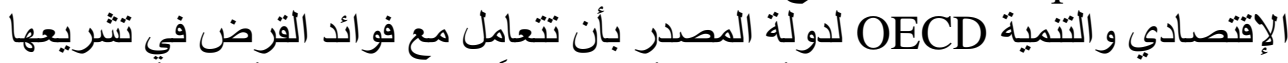

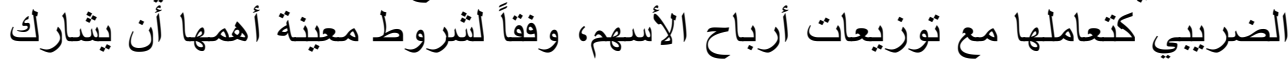

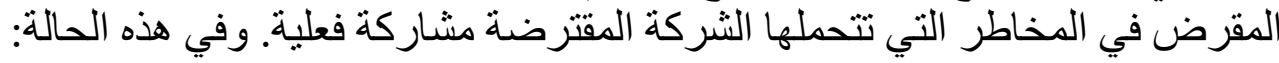

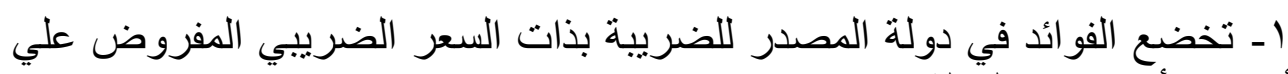

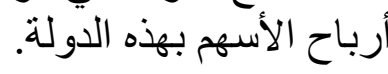

r ـ كما تدخل هذه الفو ائد في أرباح الثركة المقرضة الثة الخاضعة للضريبة.

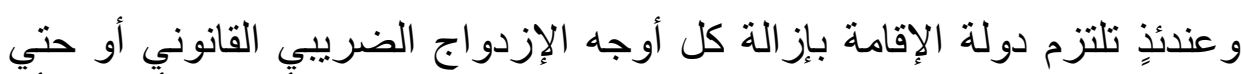

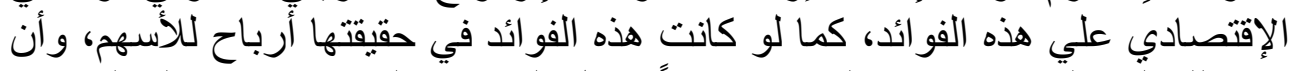

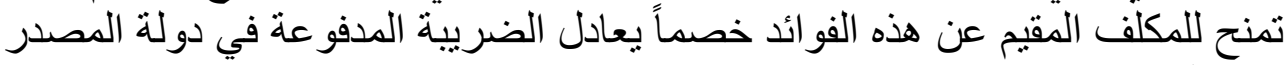
عنها.

\section{r- مشكلات شركات التوصية البسيطة:}

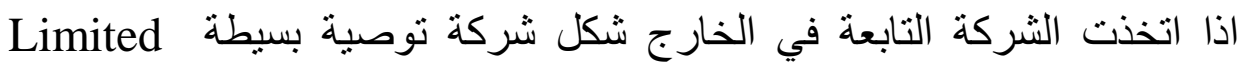

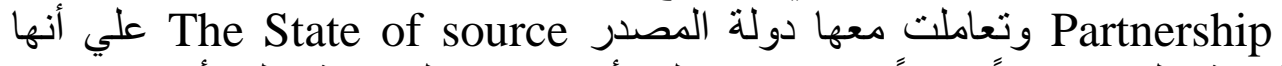

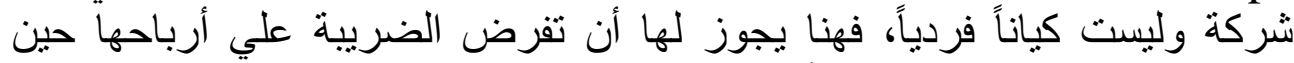

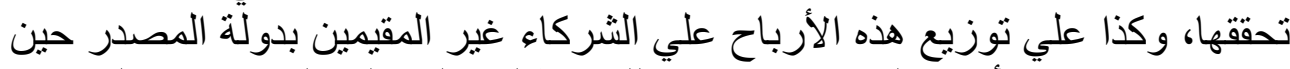

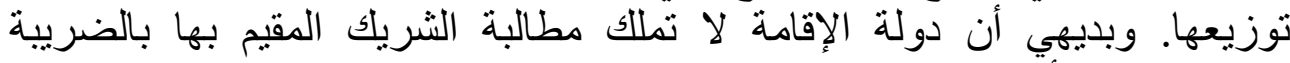

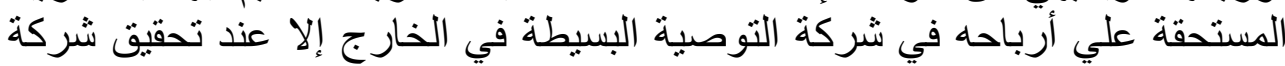

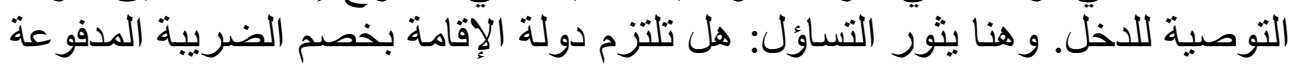

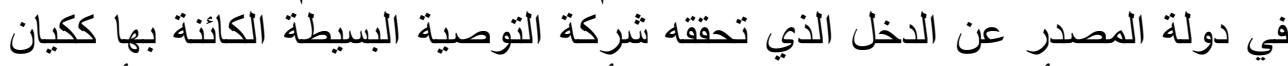

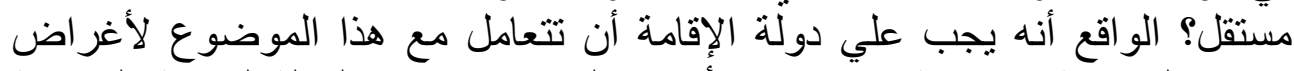

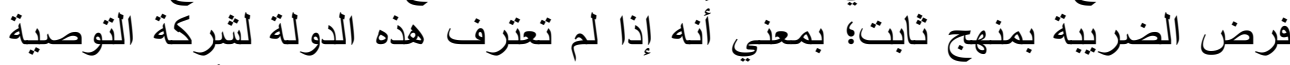

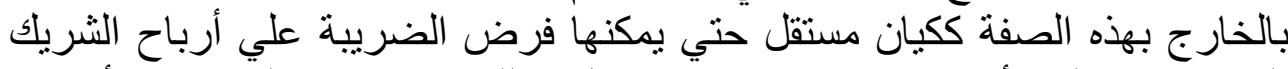

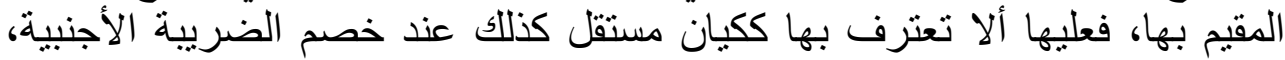

$$
\text { وتسمح بخصم الضريبة المدفو عة من الثريك في في الخان الخارج. }
$$

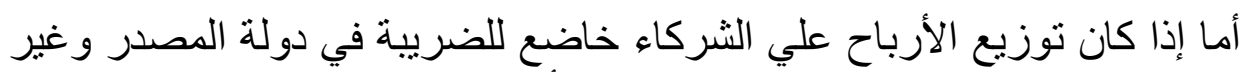
خاضع للضريبة في دولة الإقامة، فمن البديهي ألا توجد ضريبة للاهية تستحق الخصم في

' - OECD ( $(\cdot 1 \varepsilon)$, Model Tax Convention ..., Op. Cit .p. $r \varepsilon \varepsilon$.

- James Alm: The Role of Tax Exemptions and ..., Op. Cit .p. ๑ • .

-JOHANNES BECKER \& CLEMENS FUEST: CORPORATE TAX POLICY AND INTERNATIONAL MERGERS AND ACQUISITIONS IS THE TAX EXEMPTION SYSTEM SUPERIOR? ..., Op. Cit. P.Yฯ 
هذه الحالة. ويجب التفرقة هنا بين واقعة توليد الأرباح الخاضعة للضريبة بمعرفة

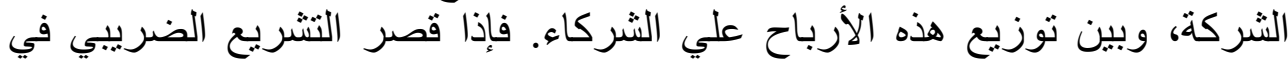

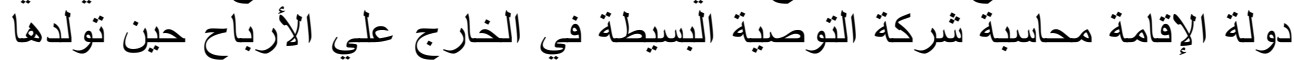
فحسب، فلا يمكن مطالبة دولة الإقامة بالضريية التي يتم دفعها علي الأرباح الموزعة الإحة

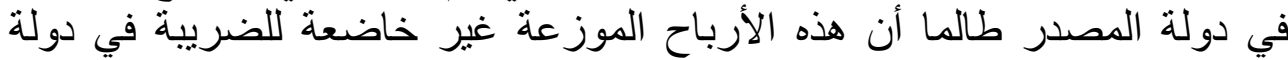

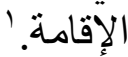

$$
\text { ؛ ـ خصم الضريبة علي رأس المال: }
$$

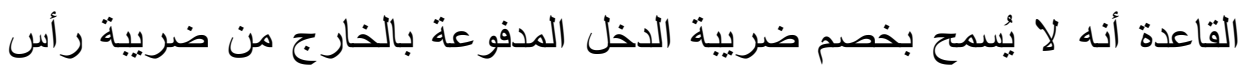

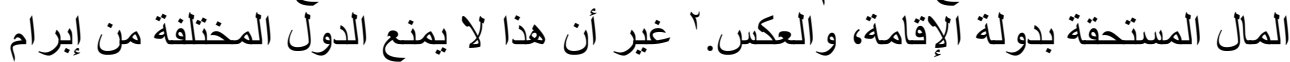

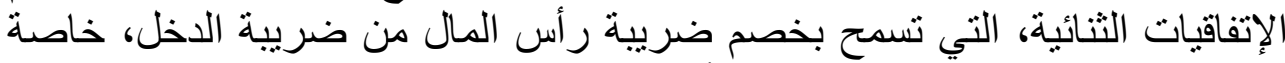
في الحالات التي تقترب فيها ضريبة رأس المال من طبيعة ضريبة الفية الدخل. هـ تقييد الضريبة:

قد تشترط دولة المصدر في تشريعاتها الضريبية، أو في الإتفاقيات الضريبية التي

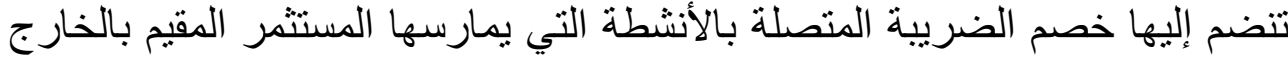

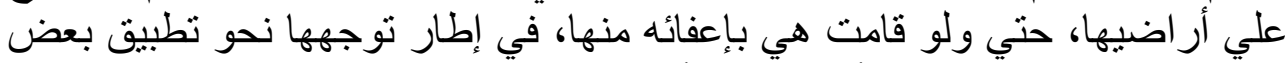

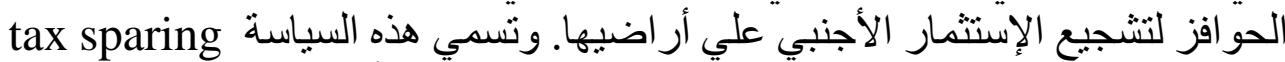

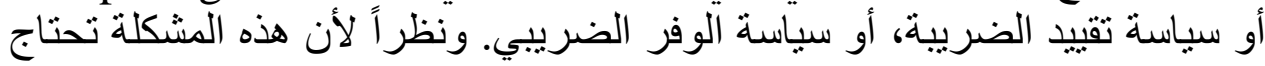

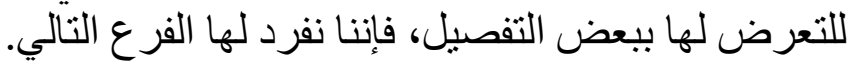
ثاتياً: بعض المشكلات العملية لتطبيق طريقة الإعفاء الضريبي:

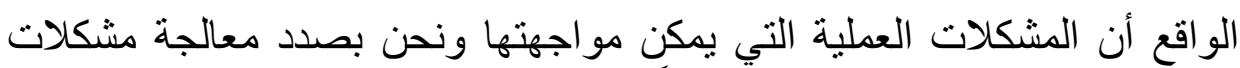

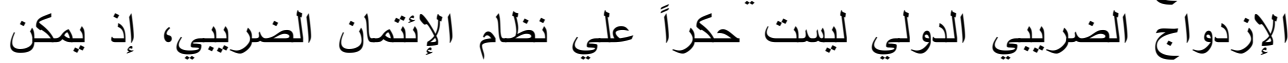

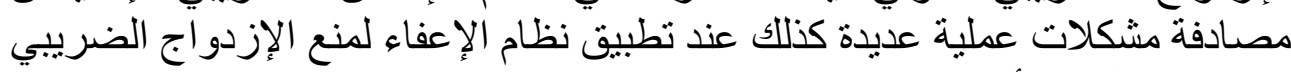
الدولي، ولعل من أهم هذه المشكلات مائهة مايلي:

1 - مقار الإعفاء: Amount to be exempted

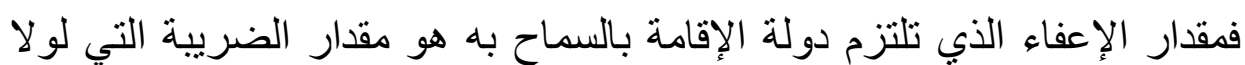

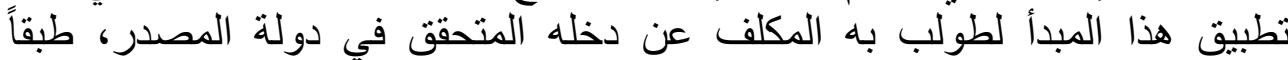

' - OECD ( $(\cdot 1 \varepsilon)$, Model Tax Convention ..., Op. Cit. pp. $r \leq \varepsilon-r \leqslant 0$.

- James Alm: The Role of Tax Exemptions and ..., Op. Cit .p. ${ }^{\circ 1}$.

-JOHANNES B \& CLEMENS FUEST: CORPORATE TAX POLICY ..., Op. Cit .p. $r \cdot$.

- Lawrence W. Kenny- University of Florida and Stanley L. WinerCarleton University: Tax Systems in the World: ..., Op. Cit .p. r).

$r$ - "credit is to be allowed for income tax only against income tax and for capital tax only against capital tax." ( OECD $\left(\Upsilon_{\bullet}\right) \varepsilon$ ), Model Tax Convention ..., Op. Cit.p. $r \leqslant 0$.) 
الإئتمان الضر يبي وآثارة الإقتصادية والمالية "دراسة مقارنة"

لتشريعها الضريبي. ومن هنا يختلف مقدار الإعفاء من الضريبة المدفو عة في الخارج

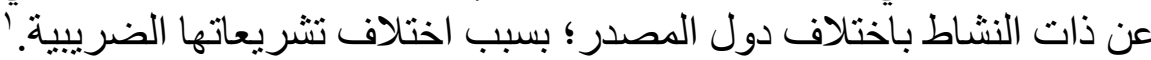

فمن المعلوم أن الضريبة تستحق علي الدخل الصافي، بعد خصم نفقات الحصول

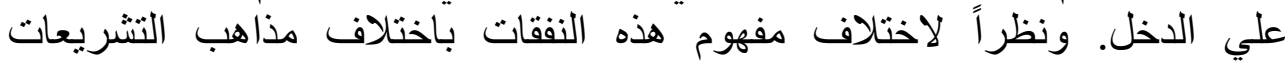

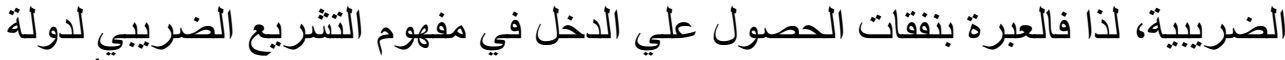

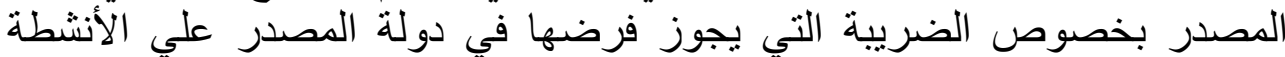

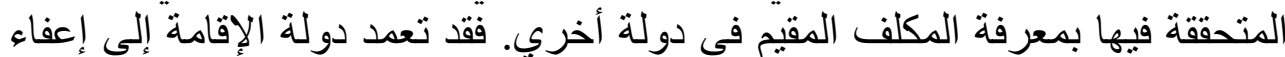

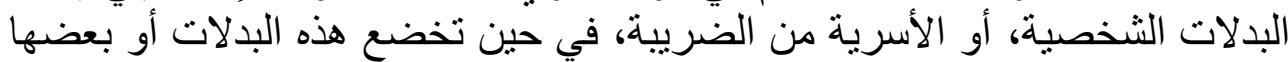

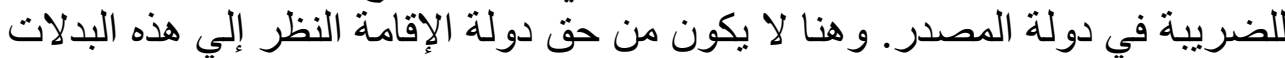

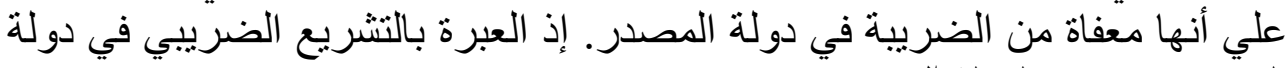

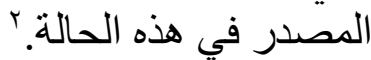

Y ـ المعاملة الضريبية للخسائر: Treatment of losses

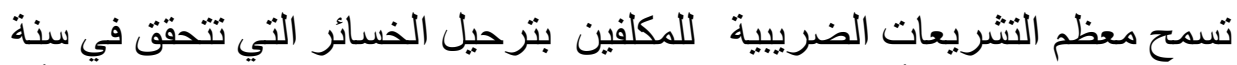

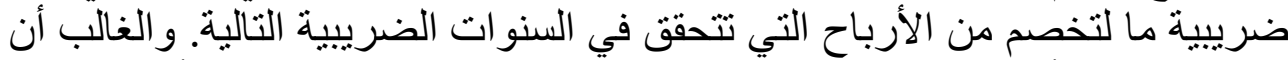

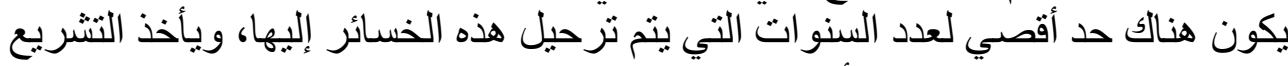

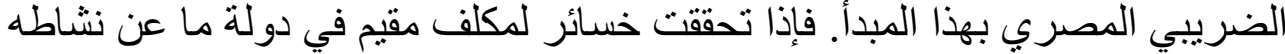

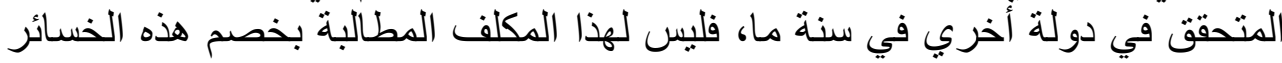

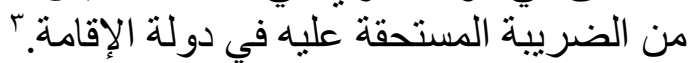

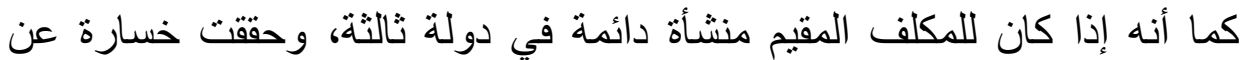
أنشطتها في هذه الدولة، فليس لها خصم هذه الخسارة من الأرباح المتحققة في دولة التها

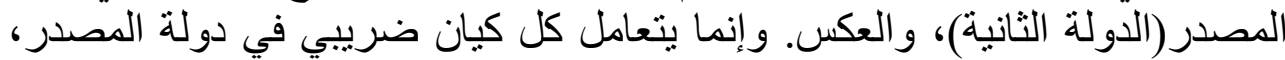
ودولة مقر المنشأة الدائمة علي حدة. ومن البديهي أنه لن يلحق المكلف النف المقيم ضرر

' - OECD (ץ. I $\varepsilon)$, Model Tax Convention ..., Op. Cit .p.

- Lawrence W. Kenny- University of Florida and Stanley L. WinerCarleton University: Tax Systems in the World: ..., Op. Cit .p. Yr.

-JOHANNES BECKER \& CLEMENS FUEST: CORPORATE TAX POLICY ..., Op. Cit .p. $r \cdot$.

$r$ - OECD $(r, \varepsilon)$, Model Tax Convention ..., Op. Cit .p. $r^{r}$.

- Lawrence W. Kenny- University of Florida and Stanley L. WinerCarleton University: Tax Systems in the World: ..., Op. Cit .p. r r.

$r$ - OECD (r.ls), Model Tax Convention ..., Op. Cit .p. rrv.

- Lawrence W. Kenny- University of Florida and Stanley L. WinerCarleton University: Tax Systems in the World: ..., Op. Cit .p. Yo.

-James M. Poterba: TAX REFORM AND THE MARKET FOR TAXEXEMPT DEBT, ..., Op. Cit .p. ז־.

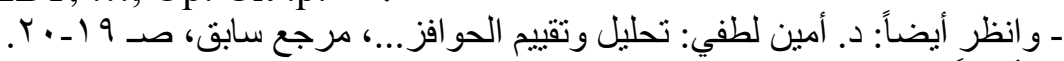

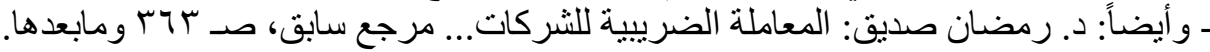


من هذه المعاملة، طالما أن التشريع الضريبي في دولة الإقامة سوف يأخذ في الإعتبار

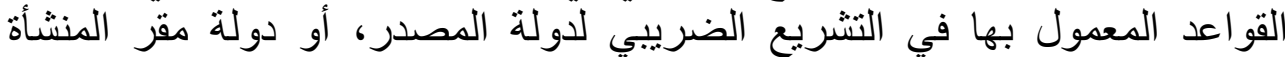

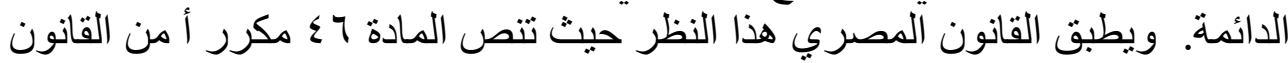

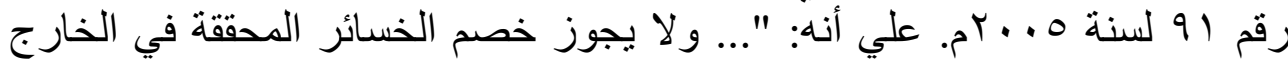

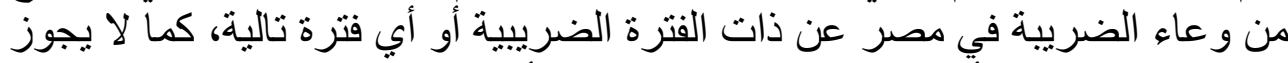

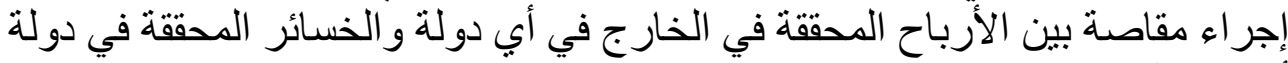

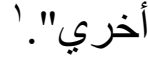

المبر أن هذا لا يمنع من إمكانية أن يضع قانون دولة الإقامة في الحسبان الخسائر

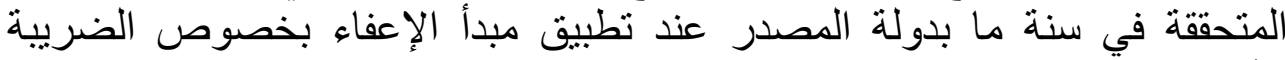

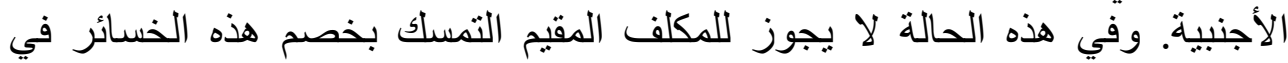

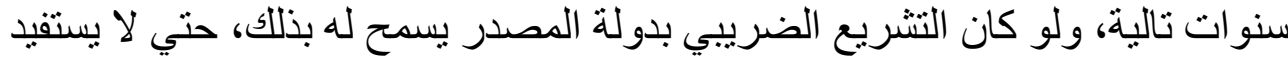

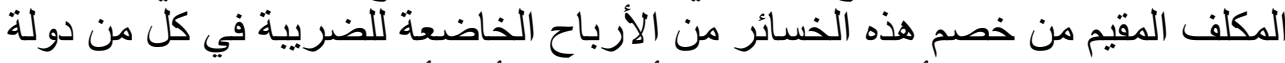

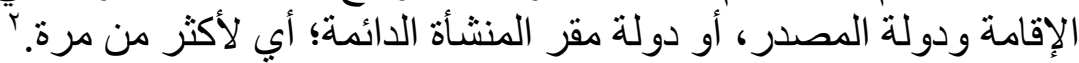

T- المعاملة الضريبية للاخل المتبقي بعد حد الإعفاء: Taxation of the rest حيث تألف القوانين الضريبية إعفاء مبالغ معينة من الدخول of the income

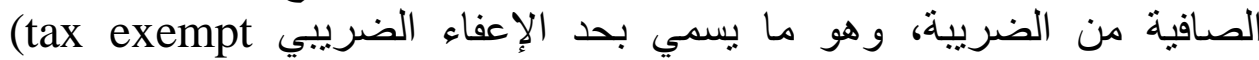

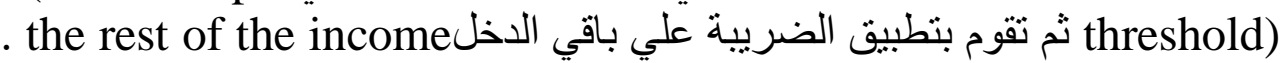

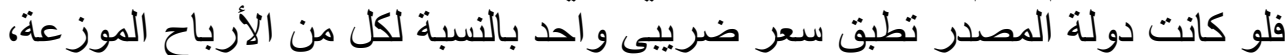

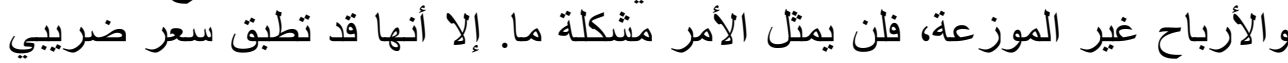

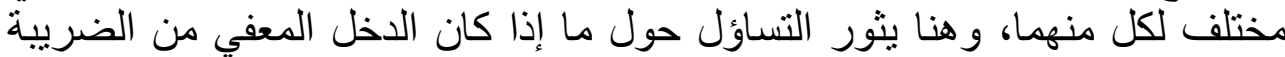

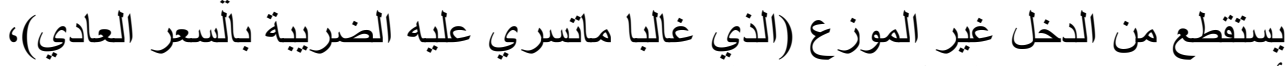

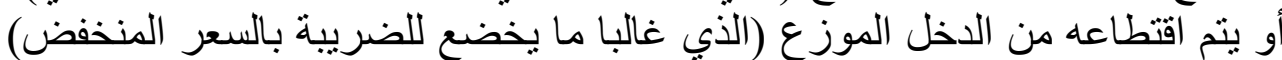

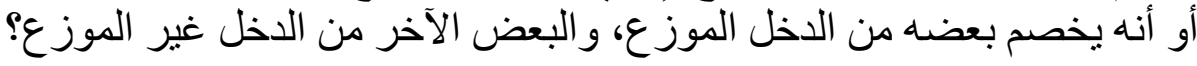

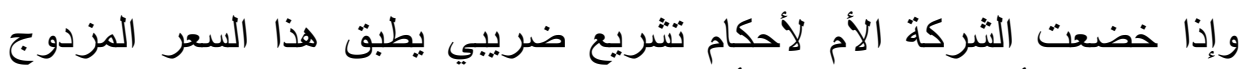

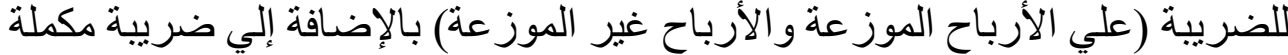

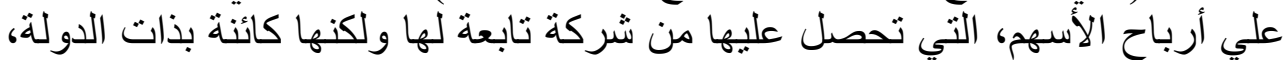

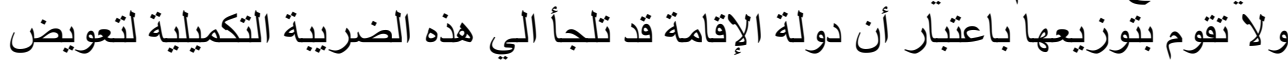

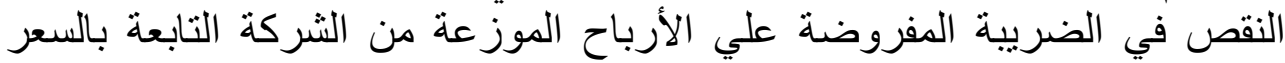

' - OECD (ץ.। $)$ ), Model Tax Convention ..., Op. Cit .p. rrv.

- Lawrence W. Kenny- University of Florida and Stanley L. WinerCarleton University: Tax Systems in the World: ..., Op. Cit .p. ro.

${ }^{r}$ - OECD $(r \cdot 1 \varepsilon)$, Model Tax Convention ..., Op. Cit .p. $r$ rr.

-James M. Poterba: TAX REFORM AND THE MARKET FOR TAXEXEMPT DEBT, ..., Op. Cit .p. rv.

- James Alm: The Role of Tax Exemptions and ..., Op. Cit.p.or. 
الإيتمان الضريبي وآثارة الإقتصادية والمالية "دراسة مقارنة"

الأدني، فكيف يمكن إنهاء هذه المشكلات؟ الواقع أنه لا سبيل لذلك، إلا من خلال

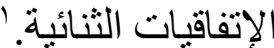

وفيما يتعلق بالضريبة علي أرباح الأسهم، وفو ائد السندات فالأصل أن دولة الإقامة الإنة

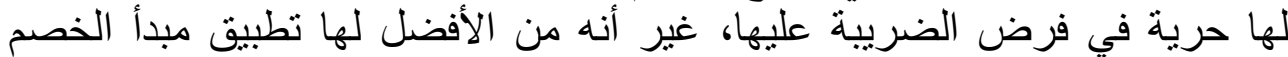

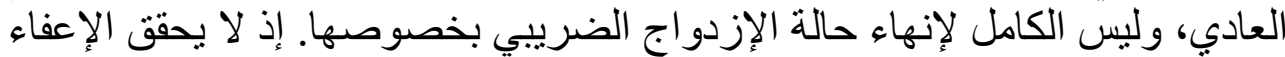
عدالة في هذه الحالة؛ لأنه يتضمن حالة تنازل دولة الإقامة عن كامل الضريبة لدولة الإنة

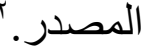

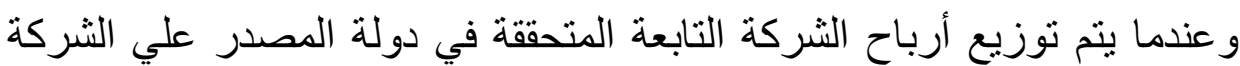

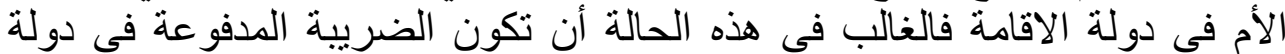

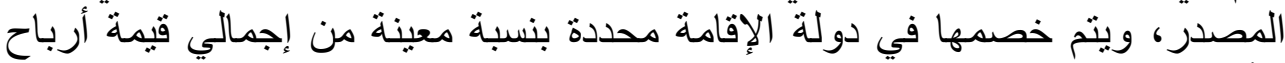
الأسهم، وقد حددت الإتفاقية الضرييية النموذجية لدول منظمة الإنة التعاون الإقتصادية

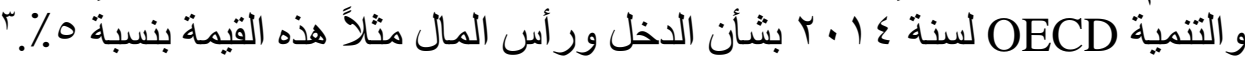
ومثل هذه الأحكام وإن كانت نساهم في منع الازدو اج الضران الضريبي القانوني، إلا أنها

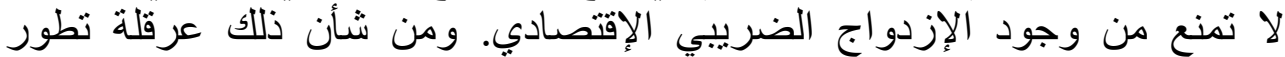

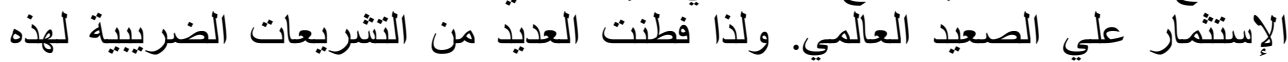

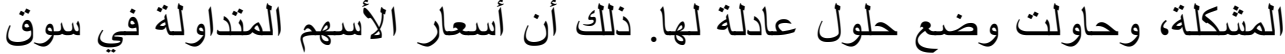

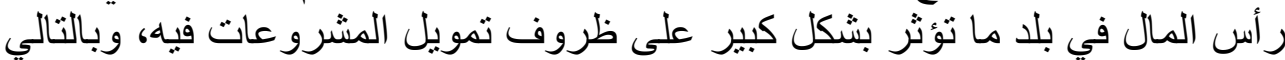

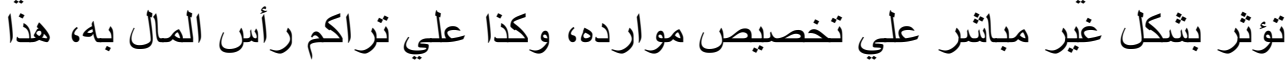

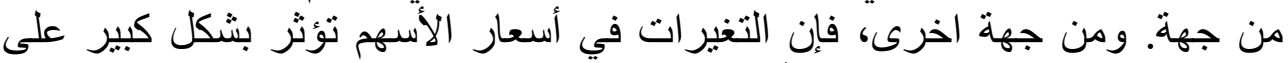

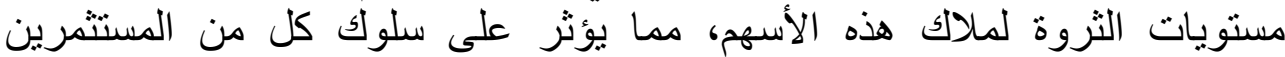

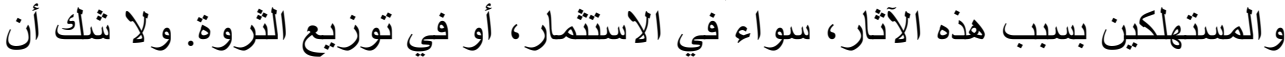

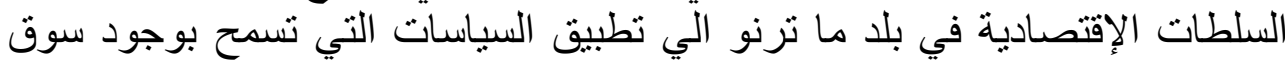

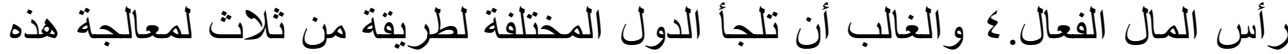

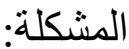

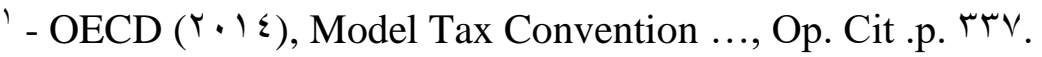

- Lawrence W. Kenny- University of Florida and Stanley L. WinerCarleton University: Tax Systems in the World: ..., Op. Cit .p. rr.

-JOHANNES BECKER \& CLEMENS FUEST: CORPORATE TAX POLICY AND INTERNATIONAL MERGERS ..., Op. Cit .p. ${ }^{r}$.

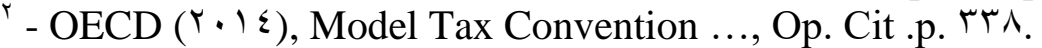

- CLAUDIO A. AGOSTINI and MARIEL C. SIRAVEGNA: EFECTOS DE LA EXENCION TRIBUTARIA A LAS GANANCIAS DE CAPITAL EN EL PRECIO DE LAS ACCIONES EN CHILE, ..., Op. Cit .p. r ${ }^{\circ}$.

$r$ - OECD (r.1 $)$, Model Tax Convention ..., Op. Cit .p. rr^.

- James Alm: The Role of Tax Exemptions and ..., Op. Cit .p. or.

$\varepsilon$-CLAUDIO A. AGOSTINI and MARIEL C. SIRAVEGNA: EFECTOS DE LA EXENCION TRIBUTARIA ..., Op. Cit .p. ro. 
العدد الثامن والثمانون - الجزء الأول - إصدار أكتوبر 19

1- طريقة الإعفاء بالتدريج: Exemption with progression بحيث تعفي

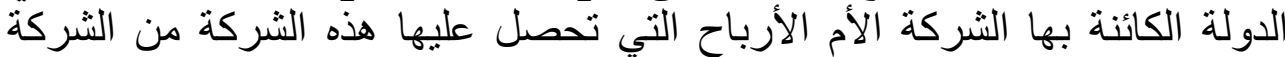

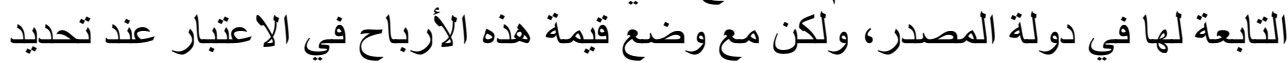

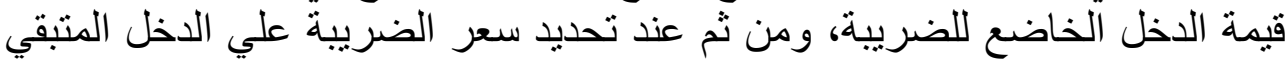
في دولة الإقامة. وقد سبق بيان أحكام ذلكان.

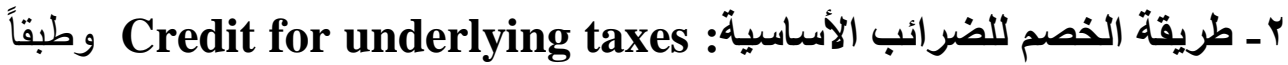

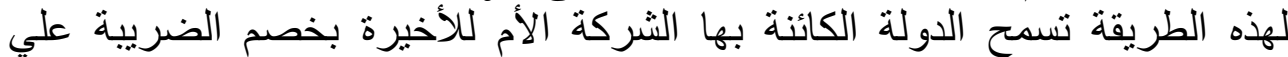

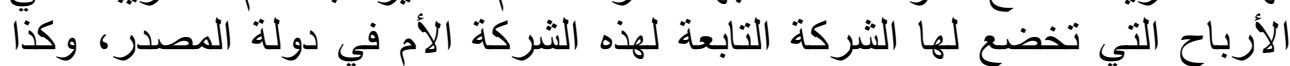

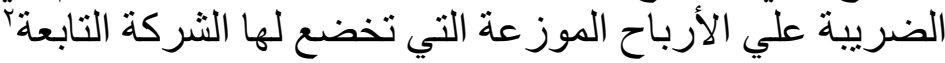

r- ذات طريقة التعامل مع الثركة التابعة المحلية: Assimilation to a holding in a domestic subsidiary

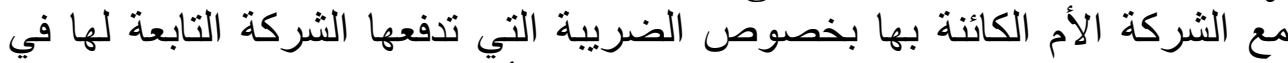

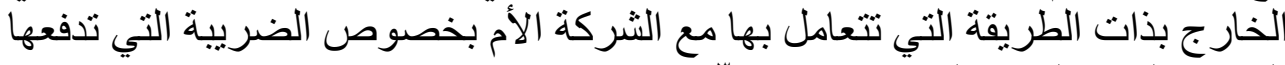
الثركة التابعة لها بدولة الإقامة ذاتها.

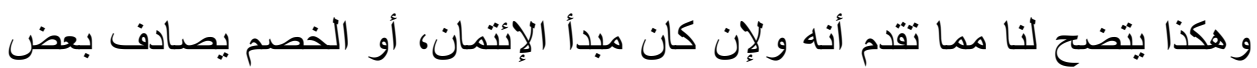

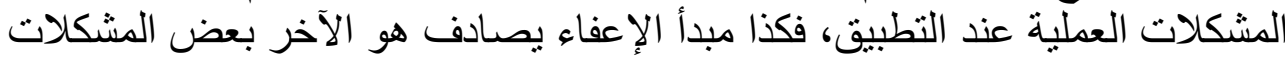

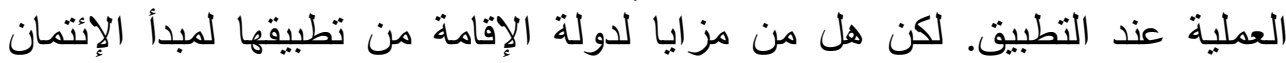

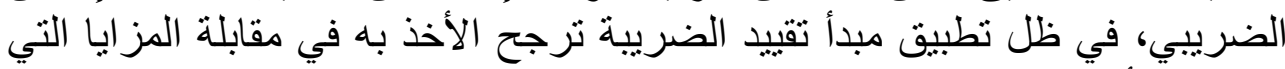
يحققها مبدأ الإعفاء في هذا الفرض؟ ين ينعرض الفرع النتالي لبيان ذلك. الفرع الثاني

\section{مزايا تطبيق الإنتمان في ظل مبدأ تقييد الضريبة ومقارنتها بمزايا الإعفاء}

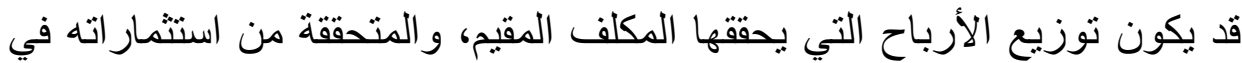

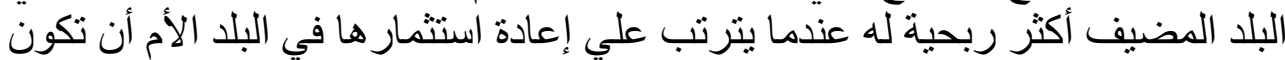

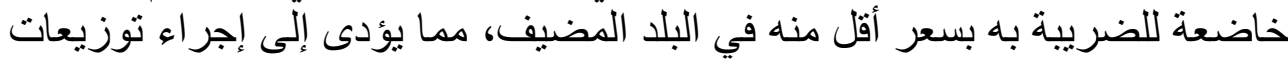

- Lawrence W. Kenny- University of Florida and Stanley L. WinerCarleton University: Tax Systems in the World: ..., Op. Cit .p. YV.

1 - OECD (r. $\mid \varepsilon)$, Model Tax Convention ..., Op. Cit .p. rrq. -JOHANNES BECKER \& CLEMENS FUEST: CORPORATE TAX POLICY AND INTERNATIONAL MERGERS ..., Op. Cit .p.

- James Alm: The Role of Tax Exemptions and ..., Op. Cit .p. or.

$r$ - OECD (r. I $\varepsilon)$, Model Tax Convention ..., Op. Cit .p. rrq.

- Lawrence W. Kenny- University of Florida and Stanley L. WinerCarleton University: Tax Systems in the World:..., Op. Cit .p. $r \wedge$.

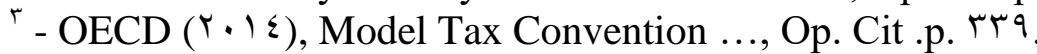

-JOHANNES BECKER \& CLEMENS FUEST: CORPORATE TAX POLICY ..., Op. Cit .p. $r \varepsilon$. 


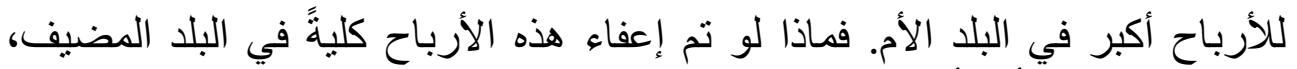

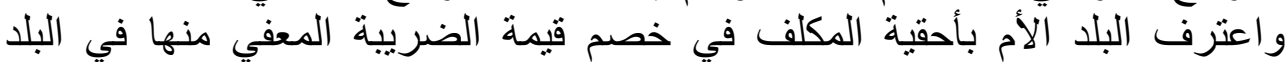

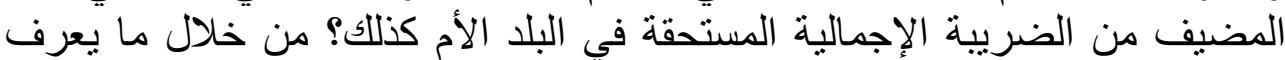

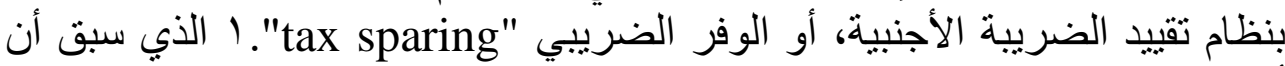

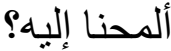

تستخدم البلدان النامية العديد من الأدوات الضريبية لتوفير اليبئة الجاذبة للاستثمار

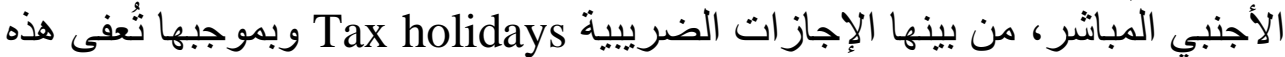

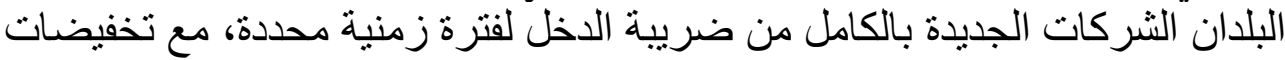

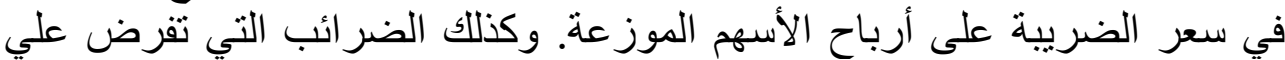

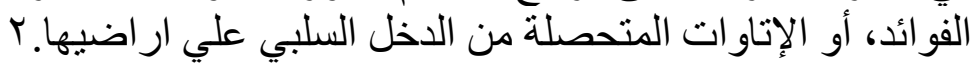

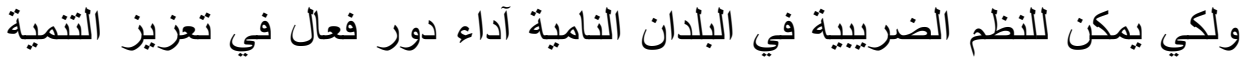

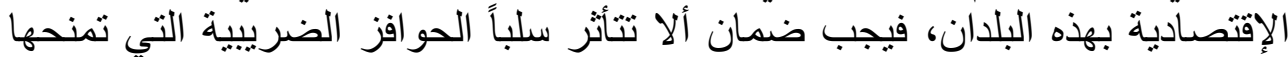

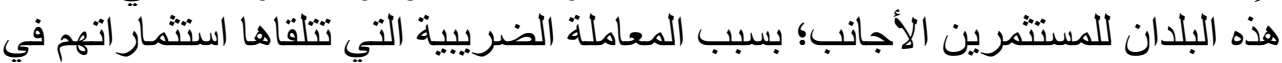

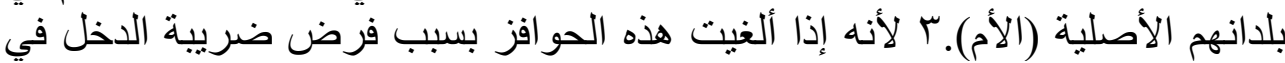

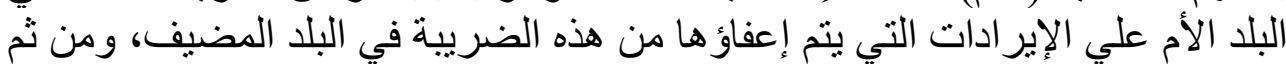

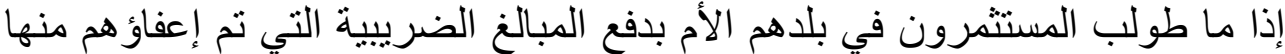

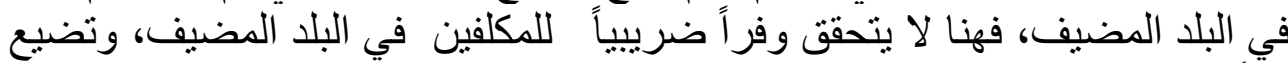

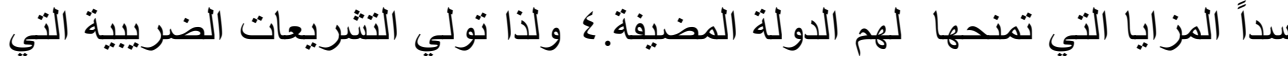
تطبق نظام الإنتمان في مواجهة الضريبة الأجنبية أهمية خاصة لهذه الحالة، ويطلق

- Celine Azemar and Andrew Delios: The Tax Sparing Provision Influence: A Credit versus, ..., Op. Cit .p. r.

- Lawrence W. Kenny- University of Florida and Stanley L. WinerCarleton University: Tax Systems in the World: An ..., Op. Cit .p. Ү^.

$r$ - Celine Azemar and Andrew Delios: The Tax Sparing Provision Influence: A Credit versus, ..., Op. Cit .p. $r$.

- CLAUDIO A. AGOSTINI and MARIEL C. SIRAVEGNA: EFECTOS DE LA EXENCION TRIBUTARIA A LAS ..., Op. Cit .p. ${ }^{\wedge}$.

${ }^{r}$ - Celine A.r and Andrew D.: The Tax Sparing Provision Influence: A Credit versus, Exempt Investors Analysis, ..., Op. Cit .p. r.

-JOHANNES BECKER \& CLEMENS FUEST: CORPORATE TAX POLICY AND INTERNATIONAL MERGERS ..., Op. Cit .p. $r \varepsilon$.

- Lawrence W. Kenny- University of Florida and Stanley L. WinerCarleton University: Tax Systems in the World: ..., Op. Cit .p. rq.

- Celine Azemar and Andrew Delios: The Tax Sparing Provision Influence: A Credit versus, Exempt ..., Op. Cit .p. r.

- Lawrence W. Kenny- University of Florida and Stanley L. WinerCarleton University: Tax Systems in the World: ..., Op. Cit .p. IV. 


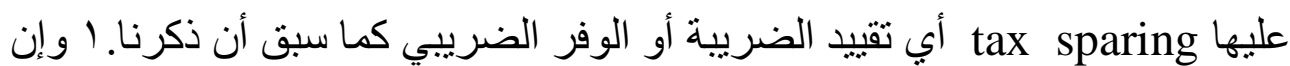

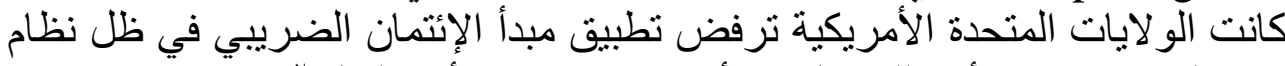

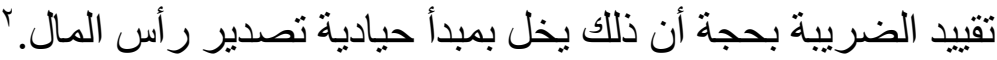

- عيوب نظام تقييد الضريبة:

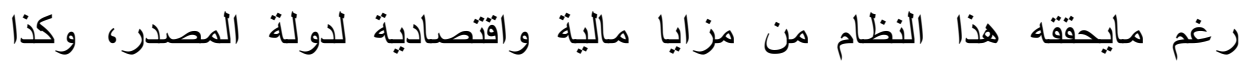

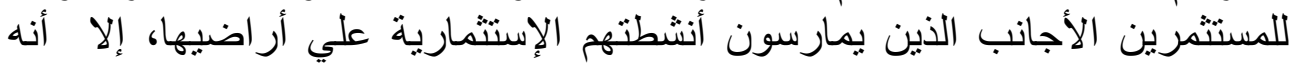

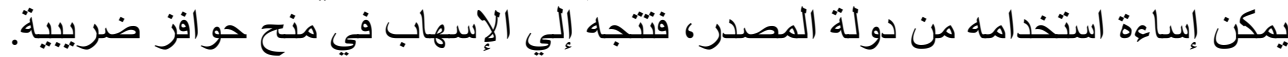

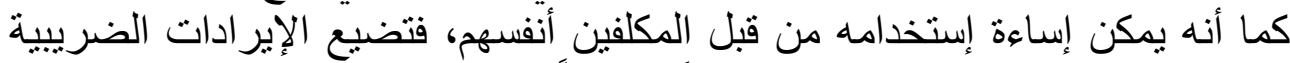

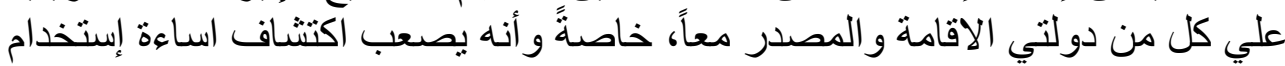

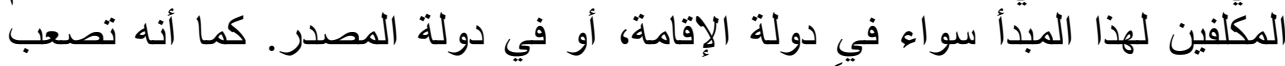

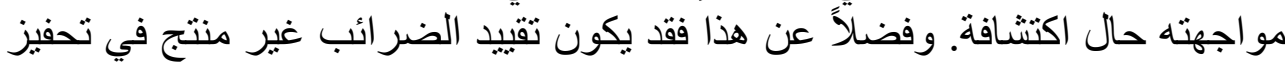

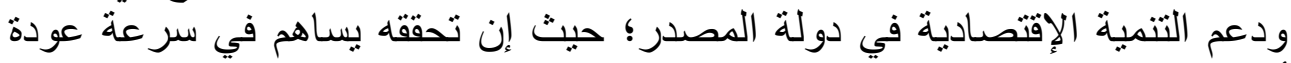

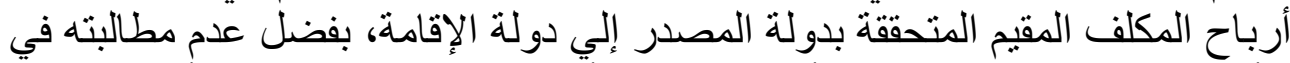

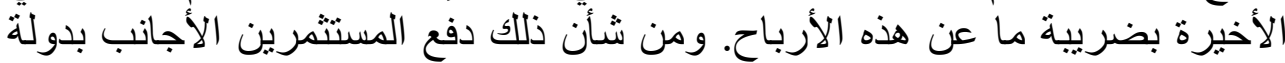

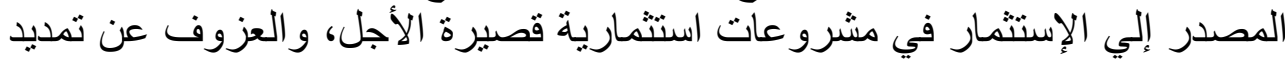

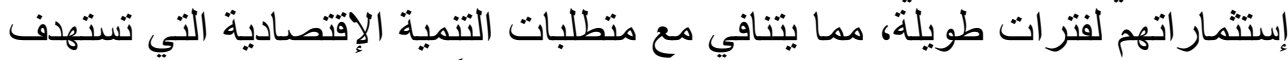

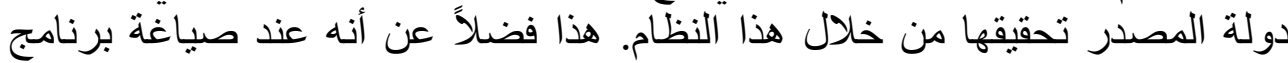

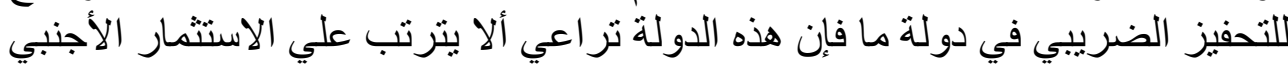

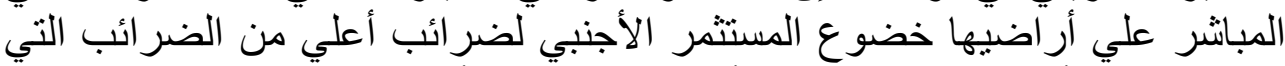

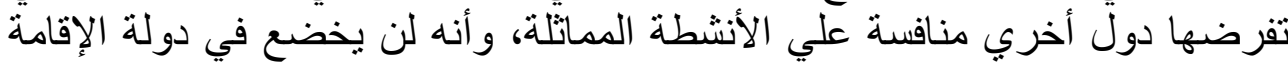

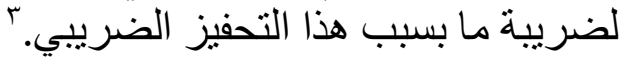

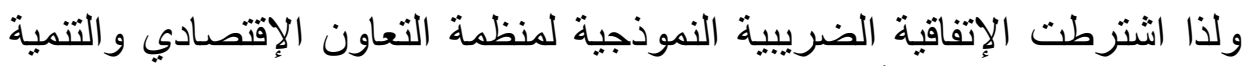

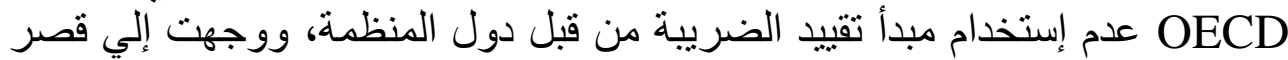

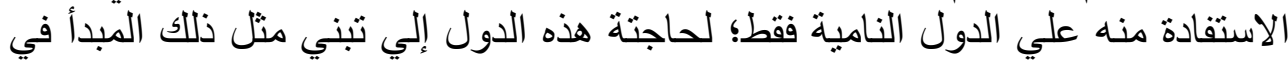
مر احل التنمية التي تمر بها. that tax sparing should be considered

- Celine Azemar and Andrew Delios: The Tax Sparing Provision Influence: A Credit versus, Exempt ..., Op. Cit .p. P. ' .

ـ يطلق البعض علي هذا البدأ :" التوفير الضريبي" (د. رمضان صديق: تفسير وتطبيق إنفاقيات

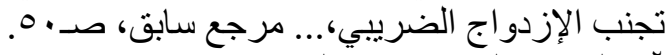

$$
\begin{aligned}
& \text { ' ـ المرجع السابق، نفس الموضع. }
\end{aligned}
$$

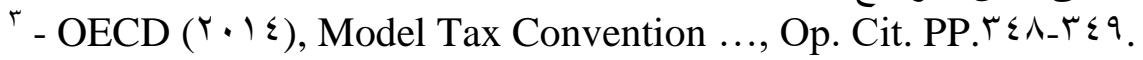

-James M. Poterba: TAX REFORM AND THE MARKET FOR TAXEXEMPT DEBT, ..., Op. Cit .p. rq.

- Lawrence W. Kenny- University of Florida and Stanley L. WinerCarleton University: Tax Systems in the World: ..., Op. Cit .p. $r$. 
الإيتمان الضريبي وآثارة الإقتصادية والمالية "دراسة مقارنة"

only in regard to States the economic level of which is considerably below that of OECD member States.'

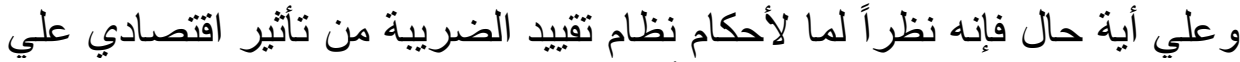

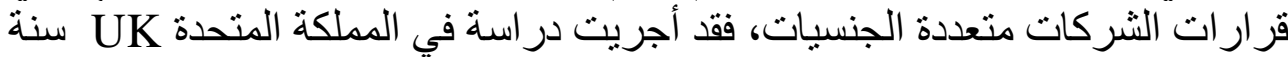

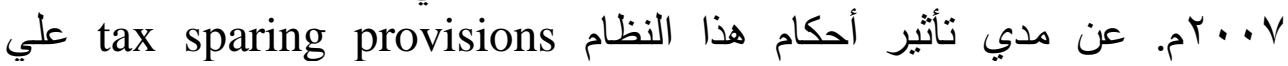

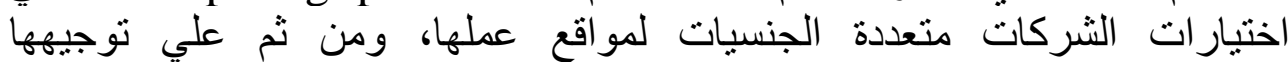

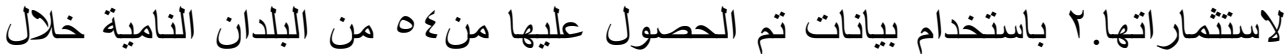

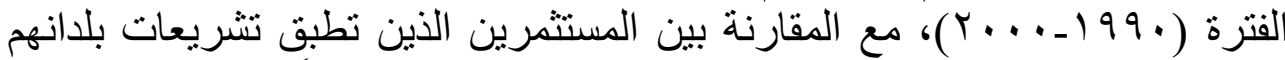

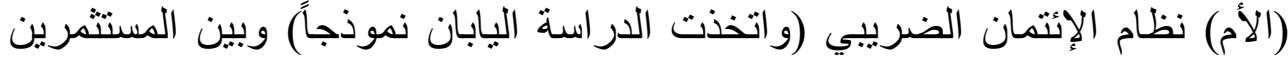

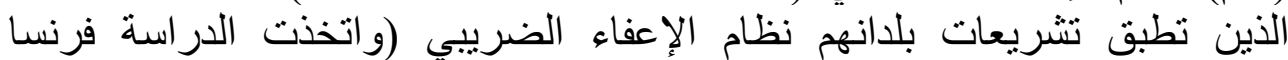

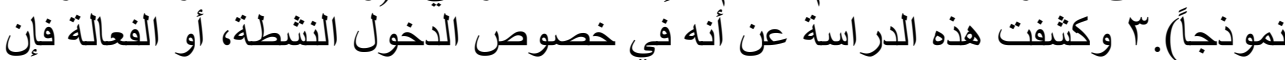

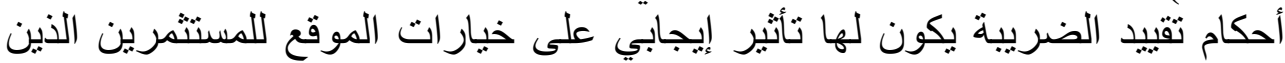

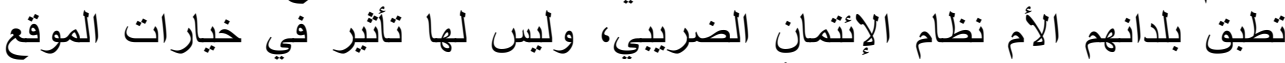
للمستثمرين الذين تطبق بلدانهم الأم نظام الإعفاء الضرئي ولئي.

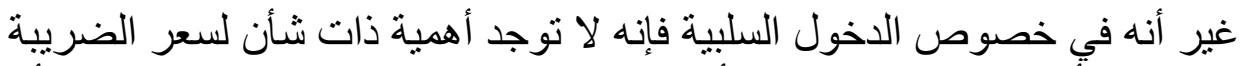

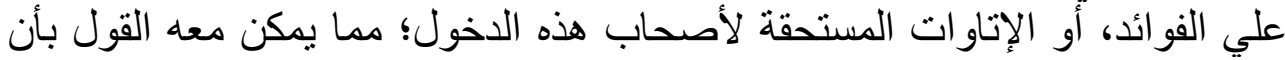

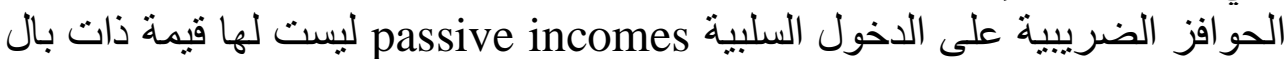

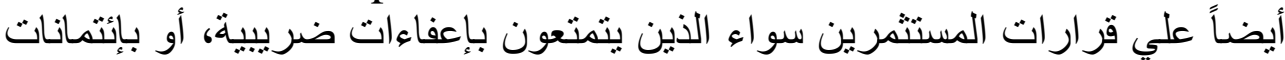
ضريبية عند إصدار قرار اتهم باختيار أماكن ممارسة أنشطتهم الاستثمارية.

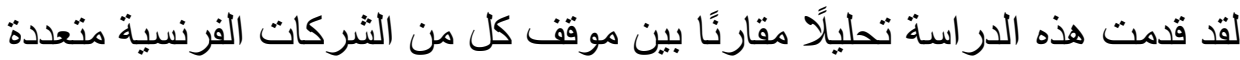

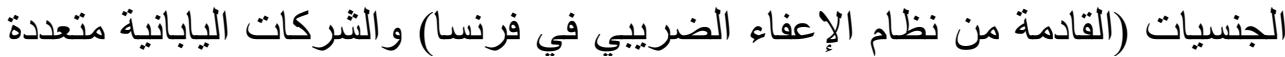

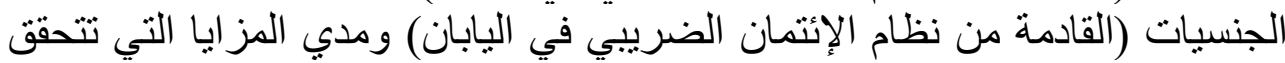

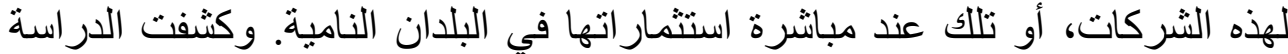

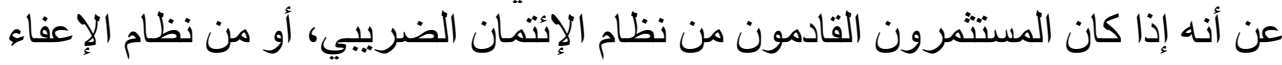

' - OECD ( $(., \varepsilon)$, Model Tax Convention ..., Op. Cit .p. $r \leqslant 9$.

-JOHANNES BECKER \& CLEMENS FUEST: CORPORATE TAX POLICY AND INTERNATIONAL MERGERS AND ..., Op. Cit .p. ${ }^{r V}$.

$r$ - Celine Azemar and Andrew Delios: The Tax Sparing Provision Influence: A Credit versus, Exempt ..., Op. Cit .p. P. '.

- Lawrence W. Kenny- University of Florida and Stanley L. WinerCarleton University: Tax Systems in the World: ..., Op. Cit .p. $1 \wedge$.

$r$ - Celine Azemar and Andrew Delios: The Tax Sparing Provision Influence: A Credit versus, Exempt Investors ..., Op. Cit .p. '.

- " "Second, we find that tax sparing provisions have a favorable impact on the location choices of credit investors and have no influence on the location choices of exempt investors." Celine Azemar and Andrew Delios: The Tax Sparing ..., Op. Cit. P. '.

- Ibid. Loc. Cit. 


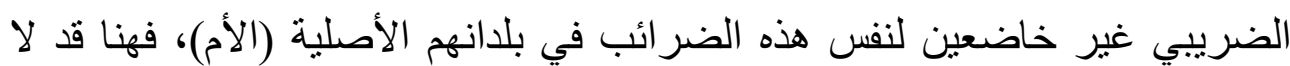
يستجيب هؤ لاء، أو أولئك للحو افز المنونة من قبل البل فيلد المضيف.

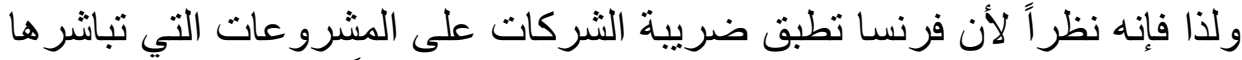

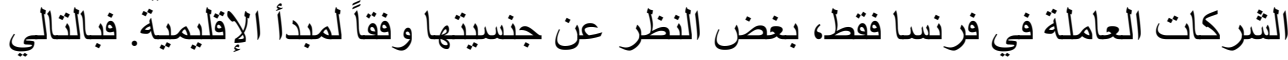

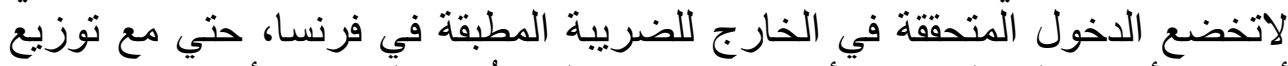

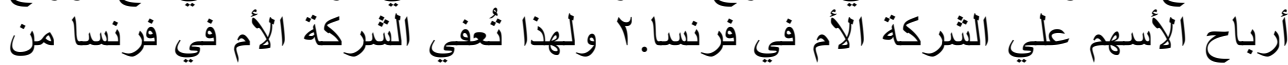

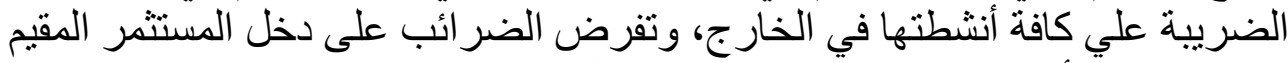

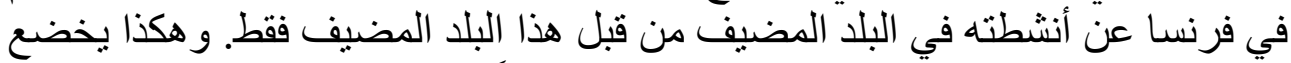

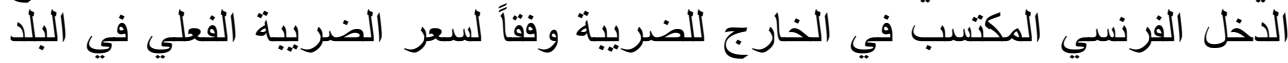
المضيف. فإذا تم إعفاؤه، فلا يطالب بضريبة ما في لإني فرنسا.

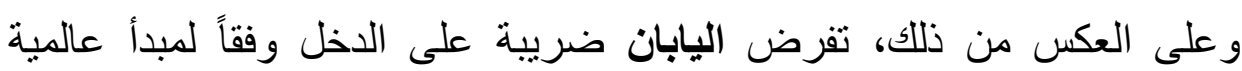

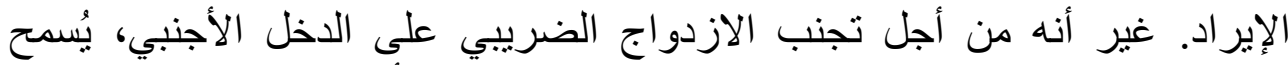

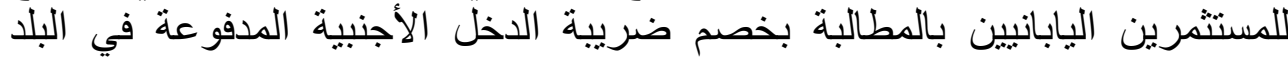

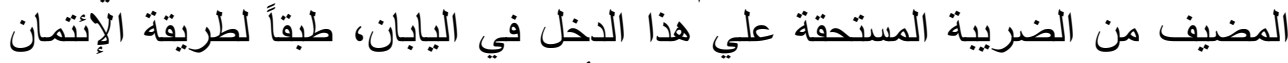

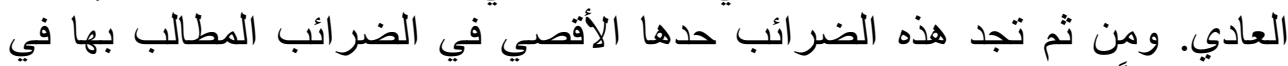

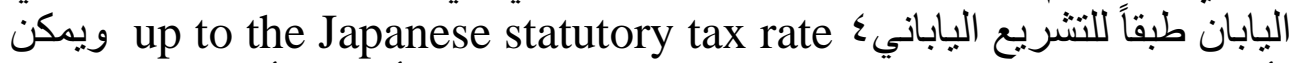
تأجيل الضر ائب اليابانية home taxes حنى العادة توزيع أرباح الأسهم علي الثركة

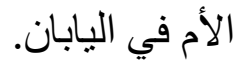

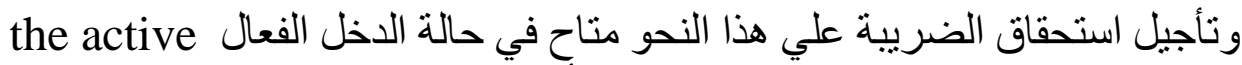

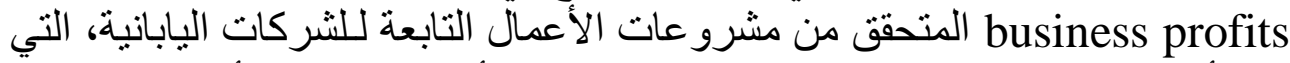

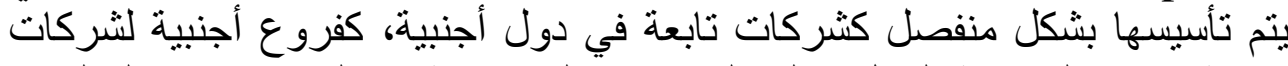

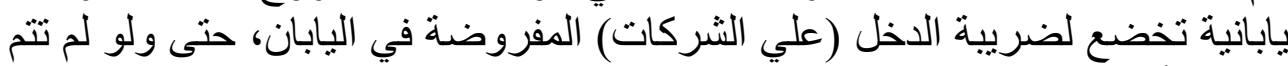

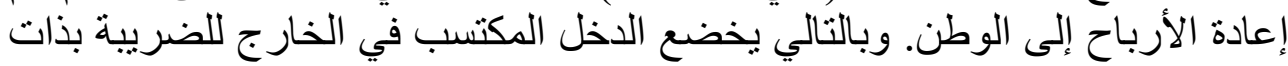

- Lawrence W. Kenny- University of Florida and Stanley L. WinerCarleton University: Tax Systems in the World: ..., Op. Cit .p. $1 \wedge$.

' - Celine Azemar and Andrew Delios: The Tax Sparing Provision Influence: A Credit versus, Exempt Investors ..., Op. Cit .p. P.๑.

-JOHANNES B. \& CLEMENS FUEST: CORPORATE TAX POLICY ..., Op. Cit .p. $\Upsilon^{\wedge}$.

$r$ - Celine Azemar and Andrew Delios: The Tax Sparing Provision ..., Op. Cit .p. ${ }^{\circ}$.

- Ibid. Loc. Cit.

- James Alm: The Role of Tax Exemptions ..., Op. Cit .p. 00 .

- Celine Azemar and Andrew Delios: The Tax Sparing Provision ..., Op. Cit .p. ${ }^{\circ}$. 
الإيتمان الضريبي وآثارة الإقتصادية والمالية "دراسة مقارنة"

سعر الضريبة المطبق في اليابان بالنسبة لفرع الثركة اليابانية في الخارج. الفإذا قام

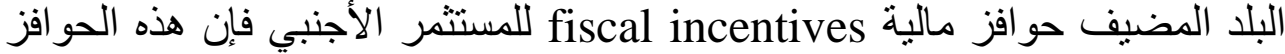

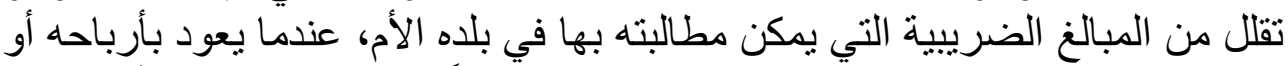

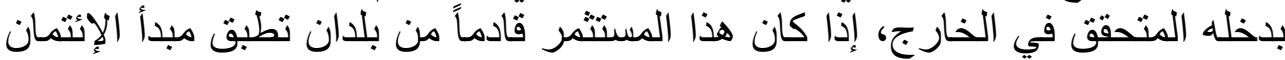

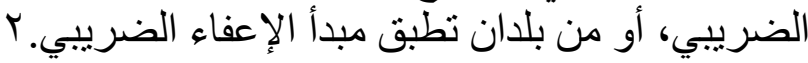

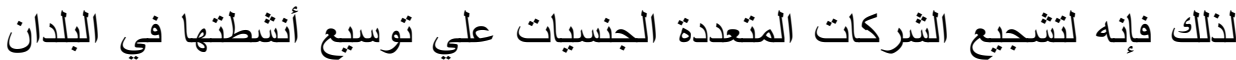

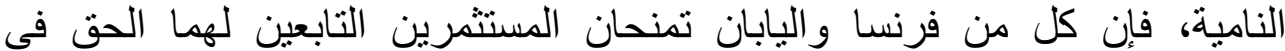

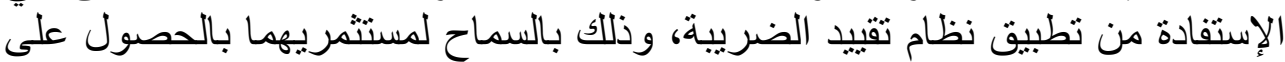

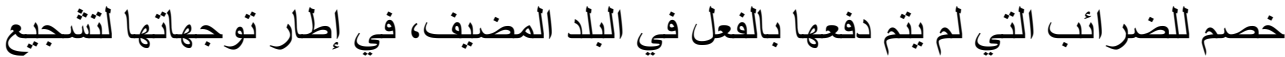

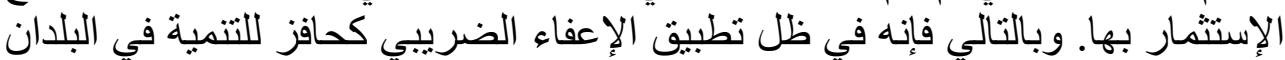

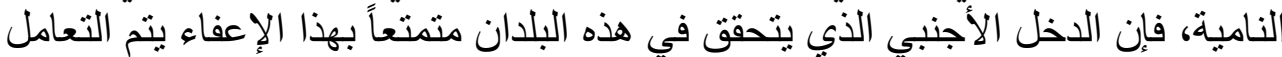

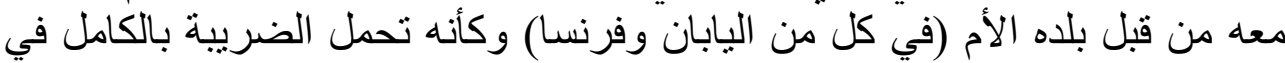

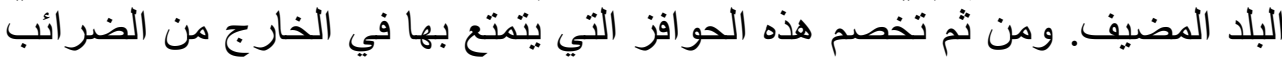

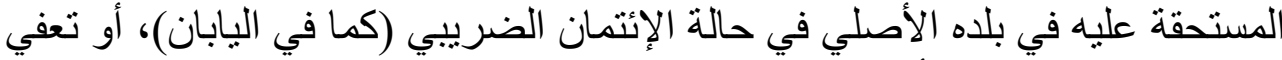

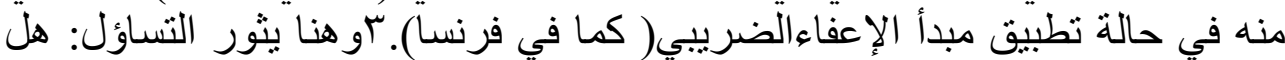

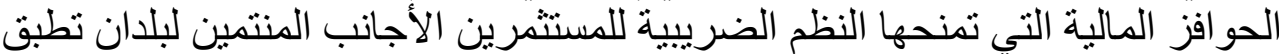

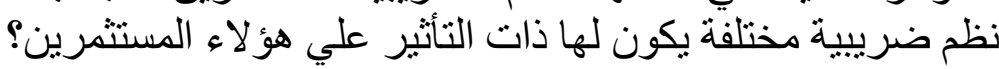
أثر تقييا الضريبة على المستثمرين في نظامي الإتثمان والإعفاء:

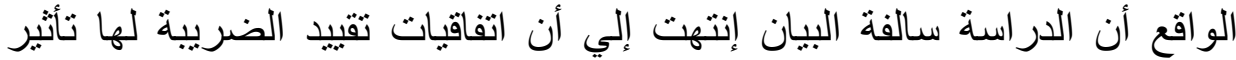

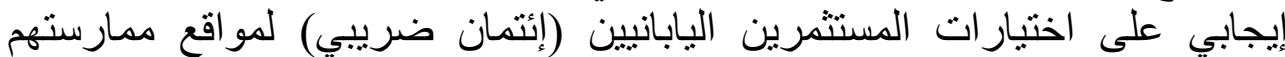

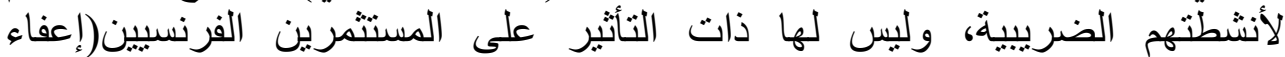

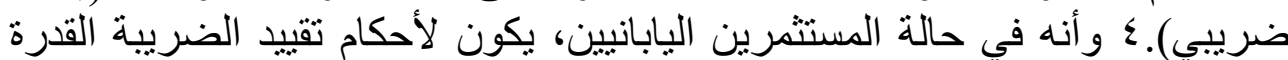

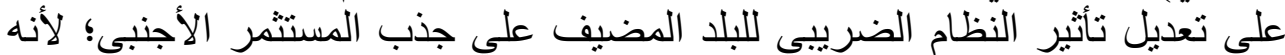

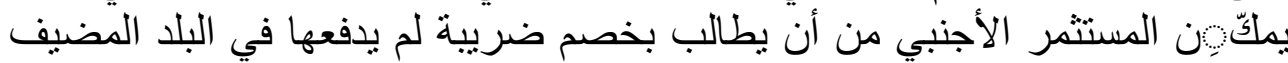

- Lawrence W. Kenny- University of Florida and Stanley L. WinerCarleton University: Tax Systems in the World: ..., Op. Cit .p. 19.

' - Celine Azemar and Andrew Delios: The Tax Sparing..., Op. Cit .p. ๑ .

- Lawrence W. Kenny- University of Florida and Stanley L. WinerCarleton University: Tax Systems in the World: ..., Op. Cit .p. 19.

$\checkmark$ - Celine Azemar and Andrew Delios: The Tax ..., Op. Cit .p. ${ }^{\circ}$.

- James Alm: The Role of Tax Exemptions ..., Op. Cit.p. 00

- Lawrence W. Kenny- University of Florida and Stanley L. WinerCarleton University: Tax Systems in the World: ..., Op. Cit .p. 10.

r - Celine Azemar and Andrew Delios: The Tax Sparing..., Op. Cit. P. \. -James M. Poterba: TAX REFORM AND ..., Op. Cit .p. rq.

¿ - Celine Azemar and Andrew Delios: The Tax Sparing ..., Op. Cit .p. `.

- Lawrence W. Kenny- University of Florida and Stanley L. WinerCarleton University: Tax Systems in the World: ..., Op. Cit .p. $r \cdot$. 


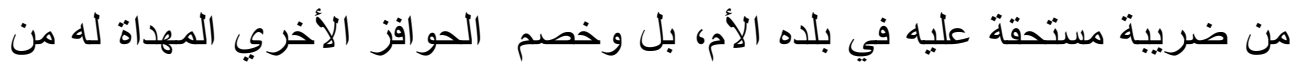
النظام الضريبي في البلد المضيف. ا

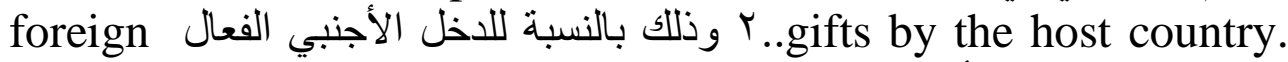
ractive

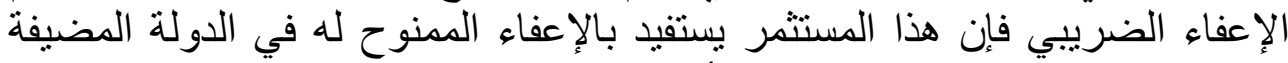

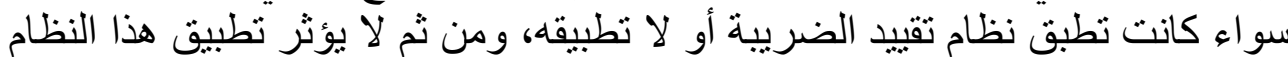

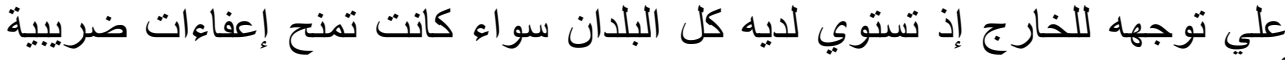

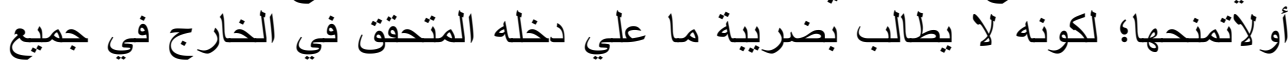

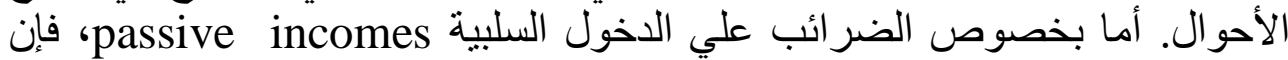

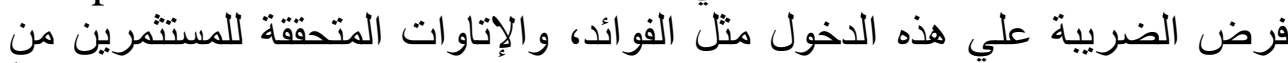

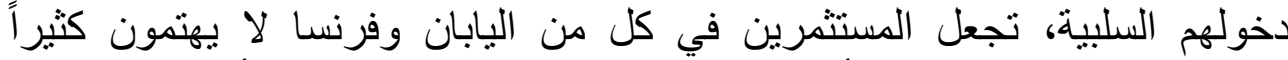
بوجهته و هم بصدد ممارسة أنشطة الدخل السلبي؛ بسبب علئ عدم نجاعة أحكام نظام تقييد الضريبة في هذا الخصوص. فوص.

ونظراً لأهمية أحكام تقييد الضريبة، فقد وقعت جميع دول منظمة التعاون

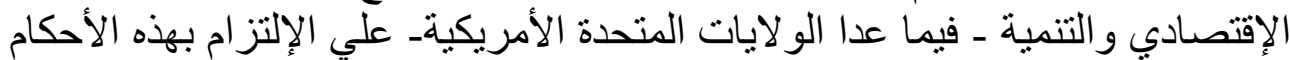

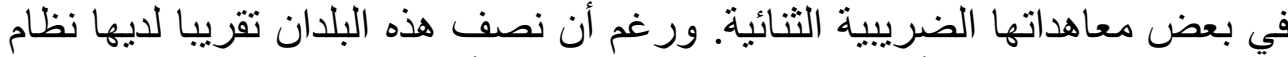

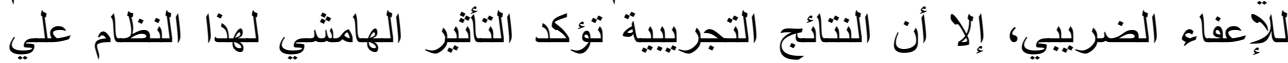
جاذبية المستثرين القادمين من هذه البلدان.0 ورغم مزايا نظام تقييد الضريبة

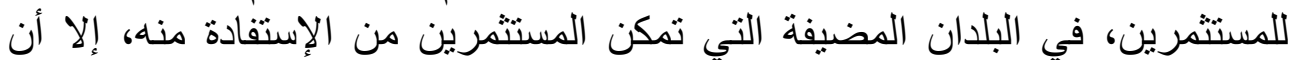

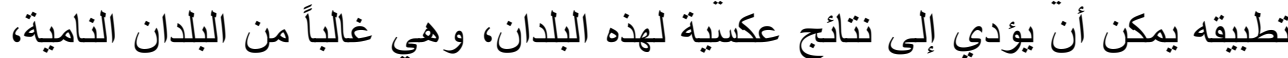

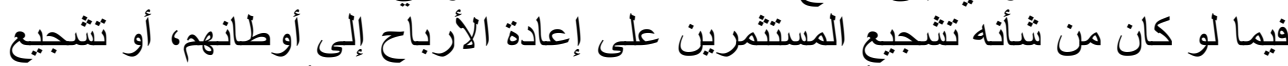

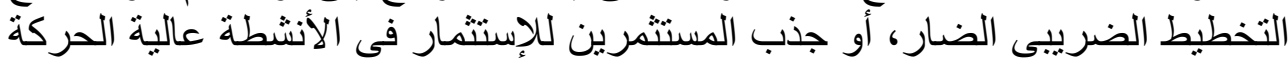

' - Celine Azemar and Andrew Delios: The Tax Sparing ..., Op. Cit .p. ${ }^{\circ}$. - James Alm: The Role of Tax Exemptions ..., Op. Cit .p. ${ }^{\circ}$.

$\checkmark$ - Celine Azemar and Andrew Delios: The Tax Sparing ..., Op. Cit .p. ^^.

$r$ - Celine Azemar and Andrew Delios: The Tax Sparing Provision Influence: A Credit versus ..., Op. Cit .p. V.

- James Alm: The Role of Tax Exemptions ..., Op. Cit .p. ov.

- Celine Azemar and Andrew Delios: The Tax Sparing Provision Influence: A Credit versus ..., Op. Cit .p. ${ }^{\circ}$.

- Lawrence W. Kenny- University of Florida and Stanley L. WinerCarleton University: Tax Systems in the World: ..., Op. Cit .p. r).

- Celine Azemar and Andrew Delios: The Tax Sparing Provision Influence: A Credit versus ..., Op. Cit .p. ${ }^{\circ}$.

- James Alm: The Role of Tax Exemptions ..., Op. Cit.p. ${ }^{\circ 7}$

-James M. Poterba: TAX REFORM AND THE MARKET FOR TAXEXEMPT DEBT, ..., Op. Cit .p. $\_$• 
التي يمكنها الإنتقال من بلد إلى آخر، عندما تنتهي صلاحية الحوافز الضرييية بالبلا

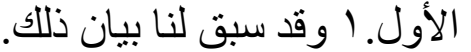

\section{المبحث الثاني}

\section{دور نظام الإنتمان في تلافي الازدواج الضريبي في التشريع المصري}

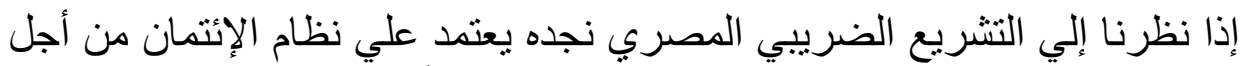

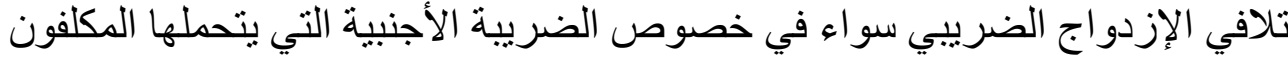

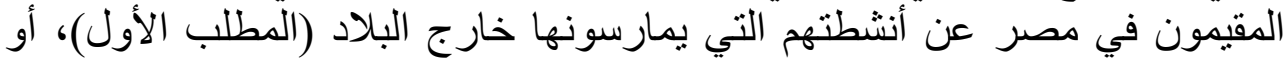
بالنسبة للضريبة التي تتحملها انشطنهم الضريبية في الداخل (المطلب الثاني).

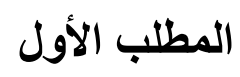

\section{دور نظام الإنتمان في تلافي الإزدواج الضريبي الدولي}

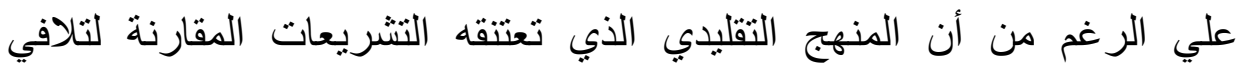

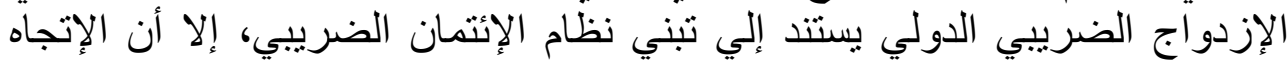

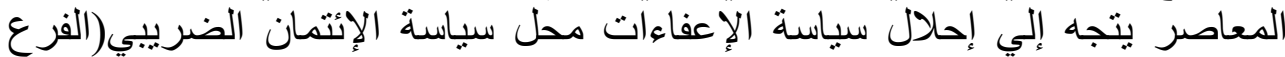

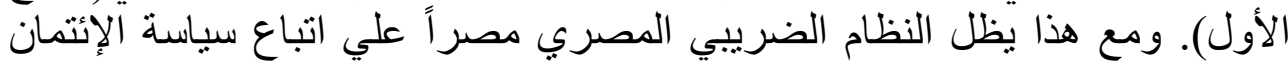

$$
\text { الضريبي لتحقيق هذا الهدف (فرع ثان). }
$$

\section{التحول العالمي للإعفاء من الضريبة الأجنبية بـلاً من خصمها}

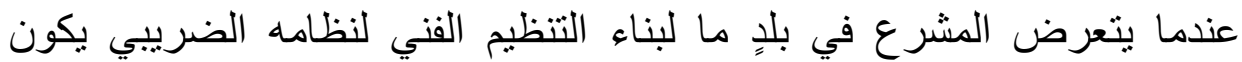

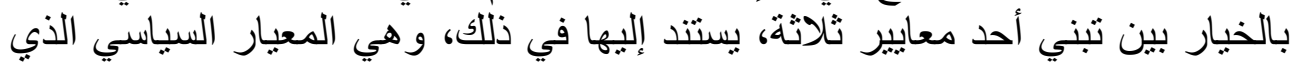

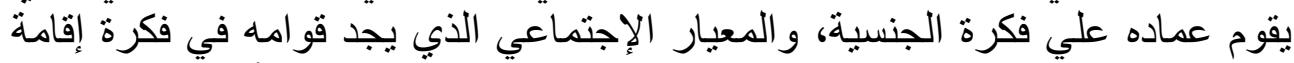

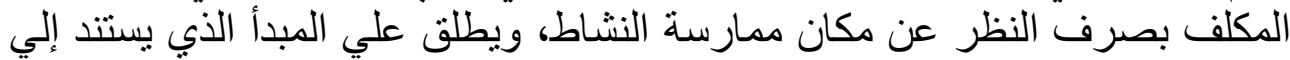

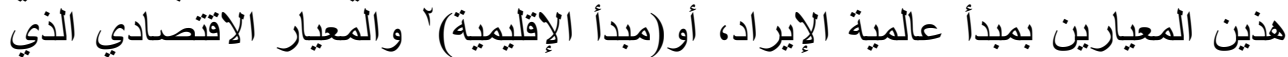

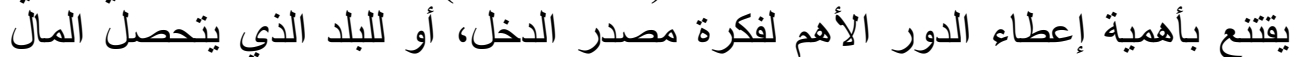

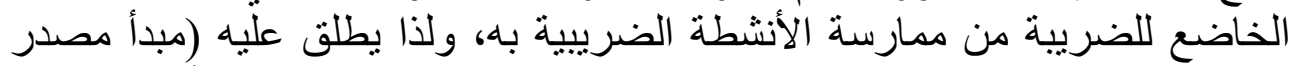

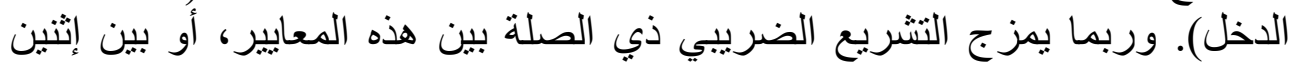

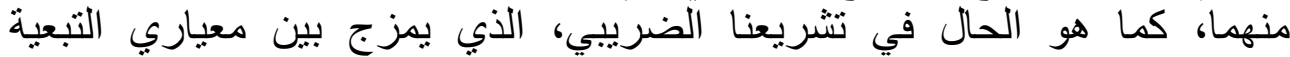

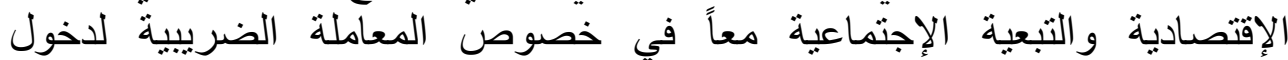

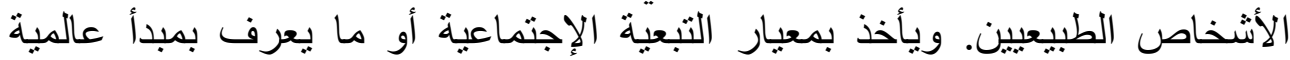

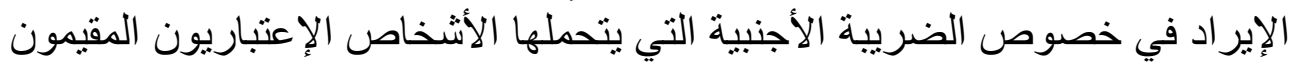

- Celine Azemar and Andrew Delios: The Tax Sparing Provision Influence: A Credit ..., Op. Cit .p. $r$ \&.

'ـ راجع في المزيد من التفاصيل حول هذا المبدأ: د. رمضان صديق محمد: المعاملة الضريبية اللثركات الإستخر اجية، ... مرجع سابق، صـ 97 ومابعدها. 
في مصر عن أنثطتهم الضريبية في الخارج، علي النحو الذي نتناوله في الفرع التاللي. والأصل أن التشريع الضريبي ذا الصله له مطلق الحريه فيما ينتهجه في هذا

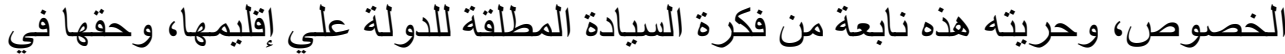

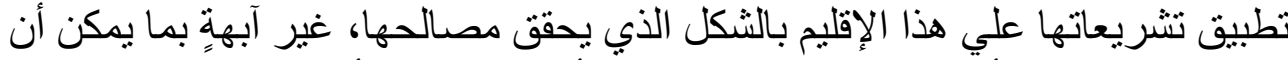

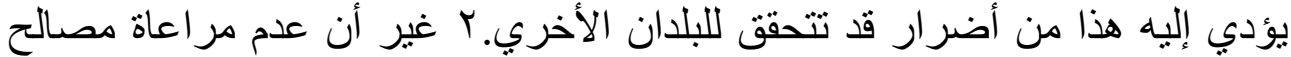

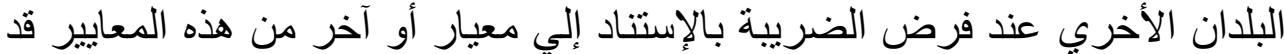
ينعكس بالسلب علي مظاهر النثاط الإقتصادي بالبلا صاحب الإلت التشريع نفسه.

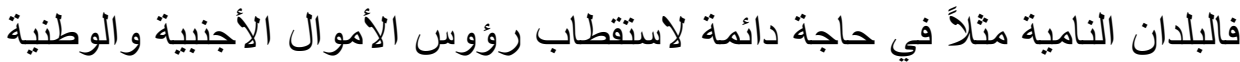

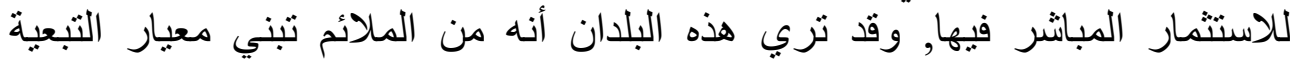

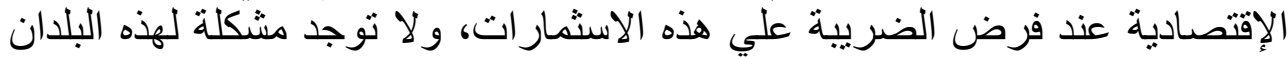

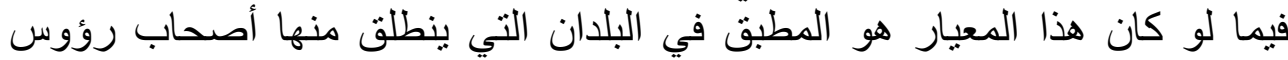

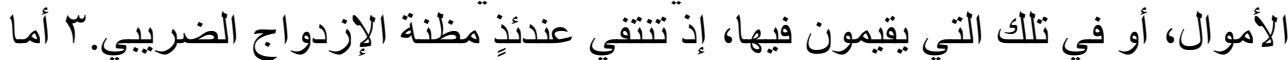

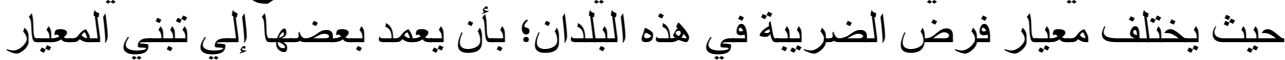

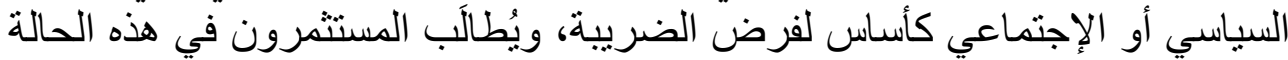

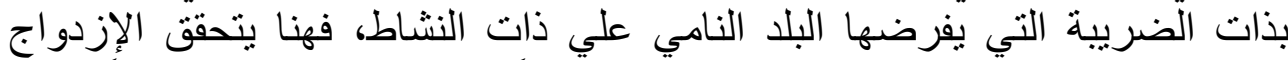

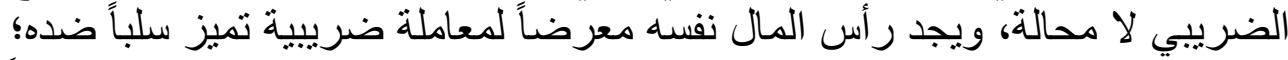

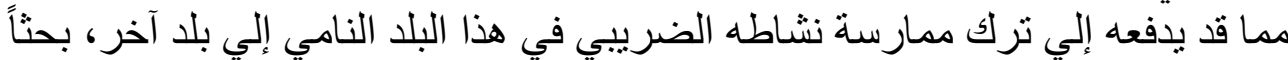

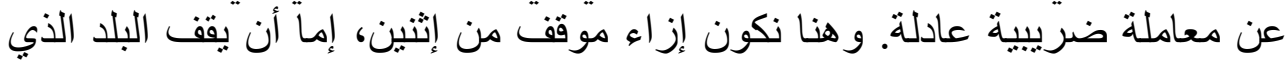

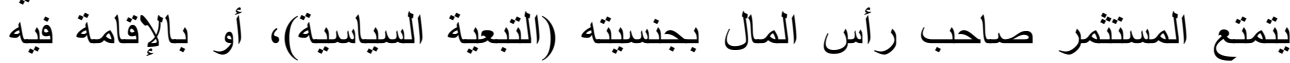

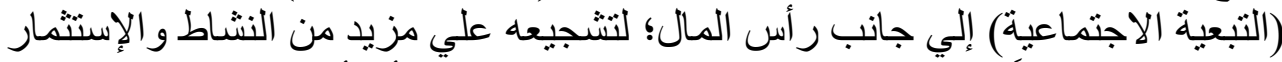

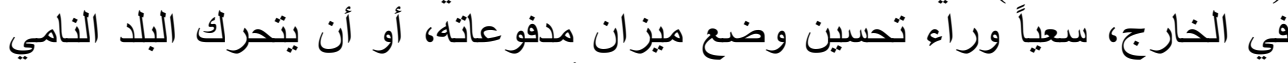

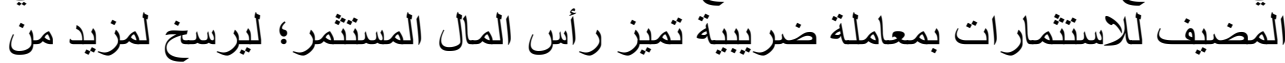

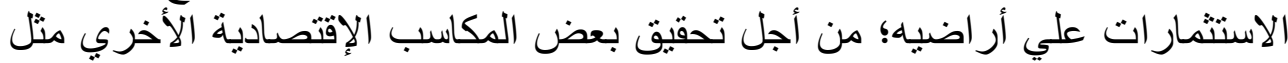

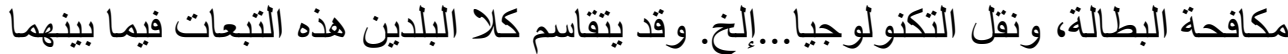

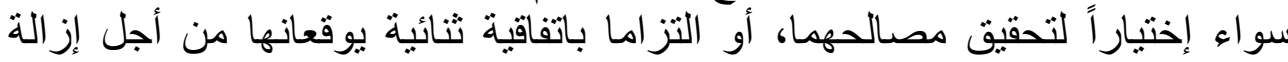
الازدو اج الضريبي في مثل هذه الظروف.

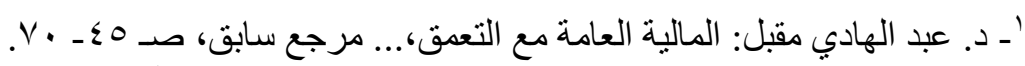

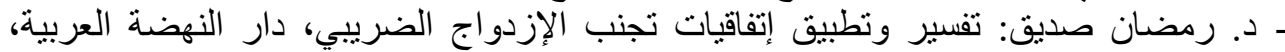

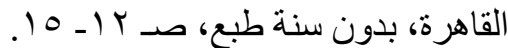

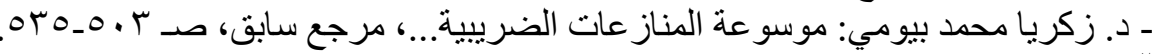

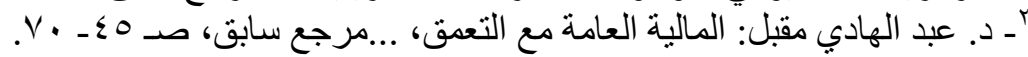

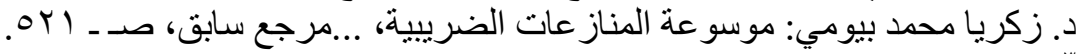

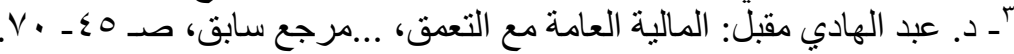

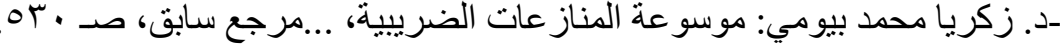

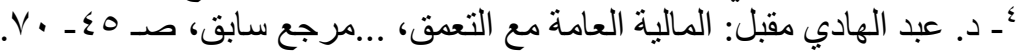


الإعتمان الضريبي وآثارة الإقتصادية والمالية "دراسة مقارنة"

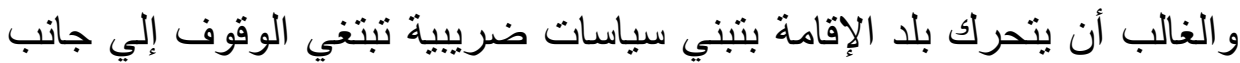

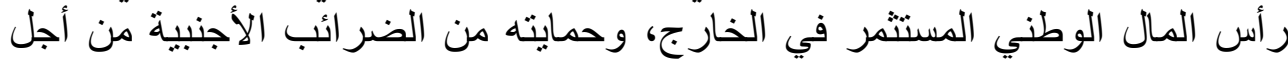

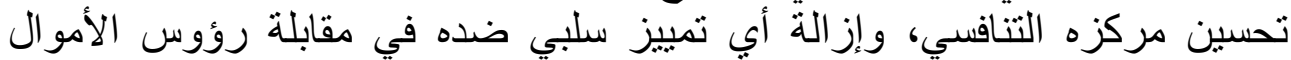

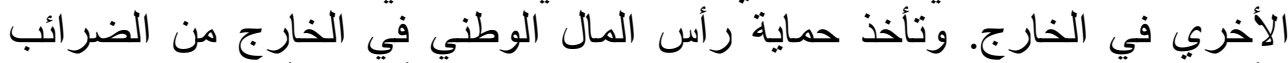

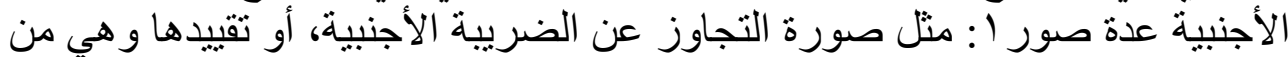

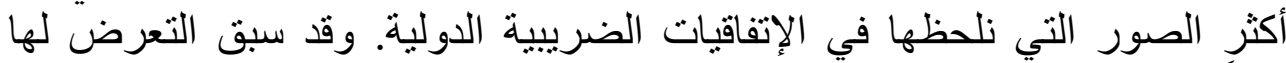

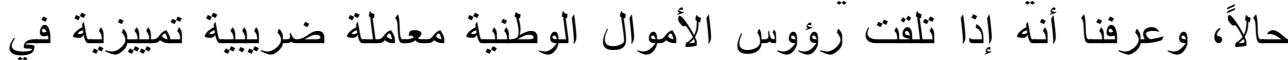

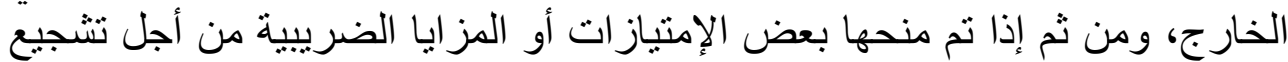

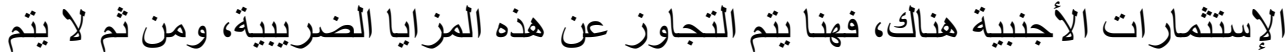

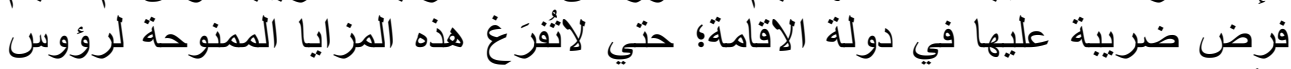
الأمو ال الوطنية في الخارج من مضدونها.

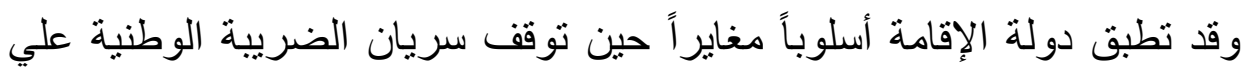

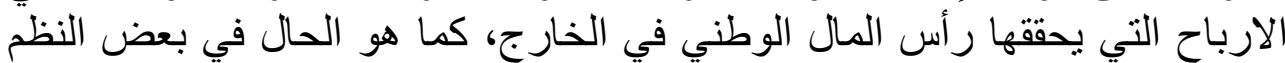

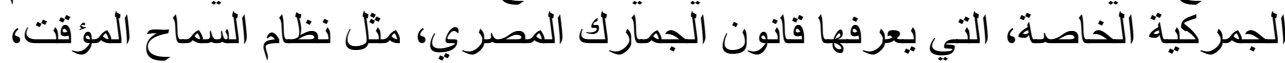

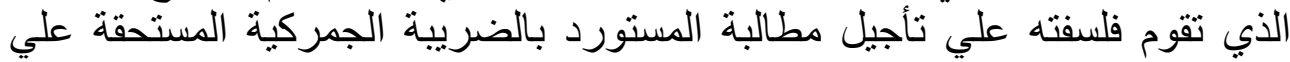

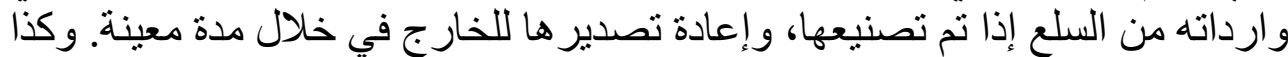

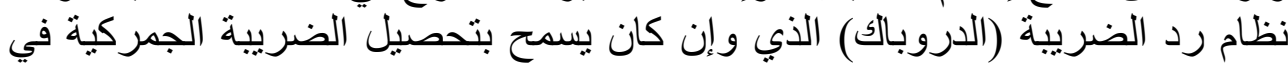

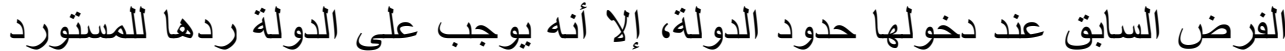
مرة أخري، عند إعادة تصدير ها خلال مدة معينة.

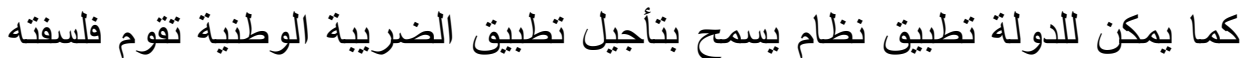

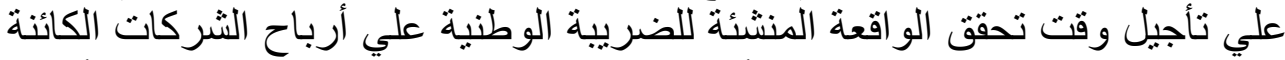

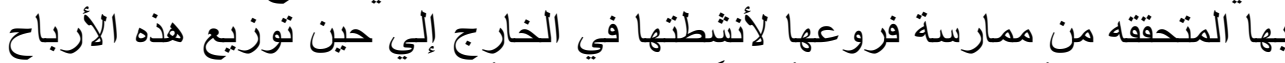

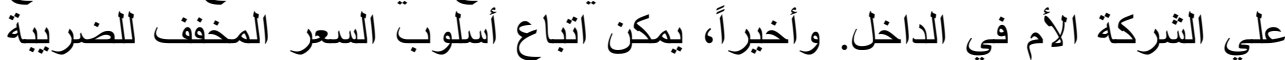

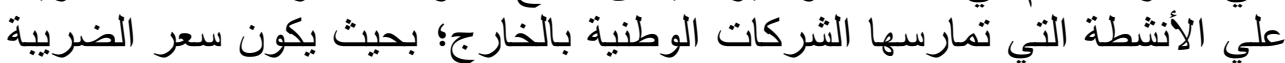
علي هذه الأنشطة منخفضاً عن سعر الضريبة المطبق علي الخئ الأنشطة المماتلة في

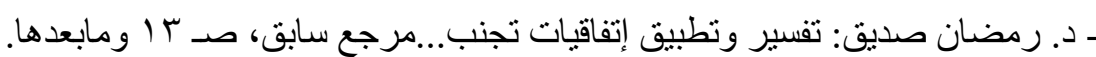

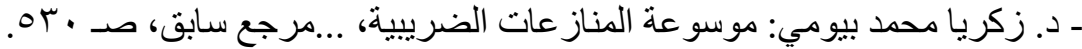

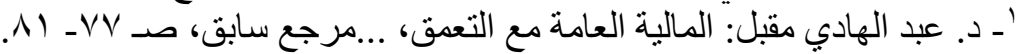

-Harry G.: Enacting Dividend Exemption and Tax Revenue, International Taxation, Washington, DC r.r r •. National Tax Journal, Vol. LIV, No. .

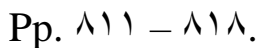

-JOHANNES BECKER \& CLEMENS FUEST: CORPORATE TAX POLICY ..., Op. Cit. P. ${ }^{q}$

-PAUL EKINS and STEFAN SPECK: Competitiveness and Exemptions From Environmental Taxes in Europe, Environmental and Resource Economics 1r: rq9_r97, 1999. (c) 1999 Kluwer Academic Publishers. Printed in the Netherlands, April $199 \wedge . p . r \vee \cdot$ 
غير أن أهم الأساليب أو السياسات التي يمكن لدولة الإقامة اتباعها من أجل الإنل

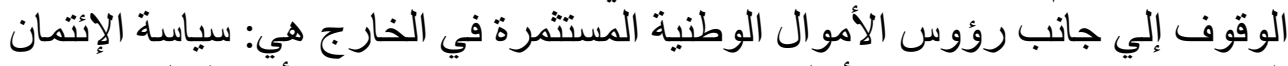

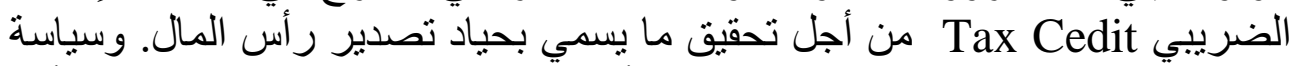
الإعفاء الضريبي Tax Exemption من أجل تحقيق ما بسي بحي بحياد إستيراد رأس

\section{ـ فكرة الحياد الضريبي والمصالح المالية للاولة:}

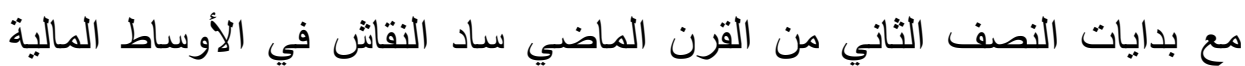

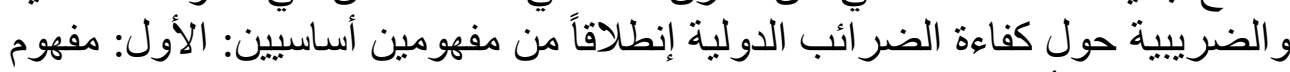

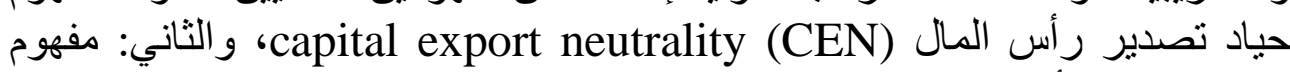
حياد استير اد رأس المال (CIN)

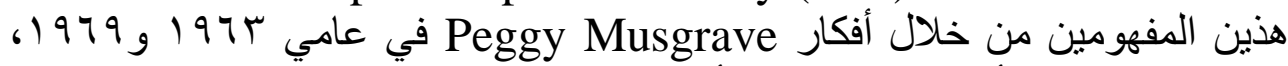

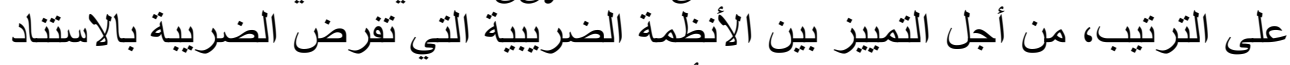

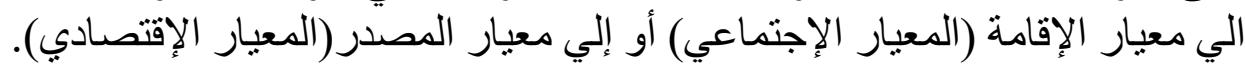

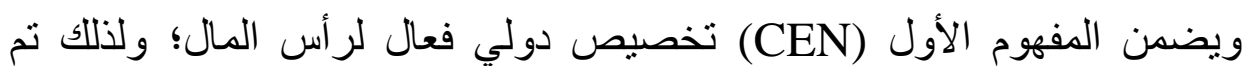

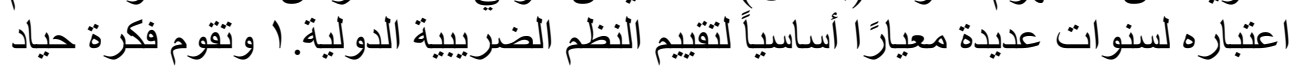

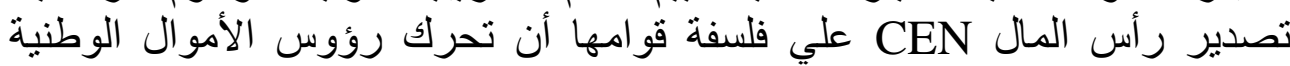

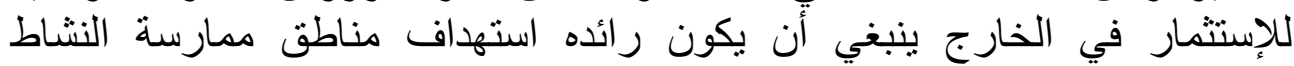

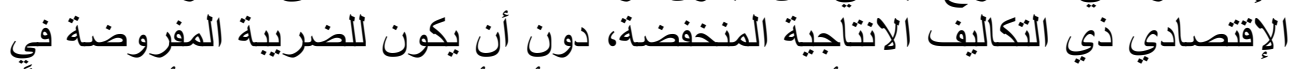

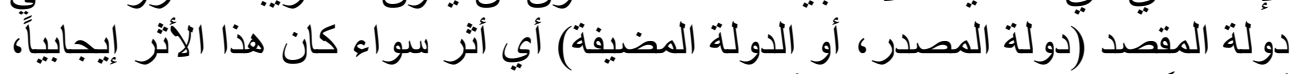

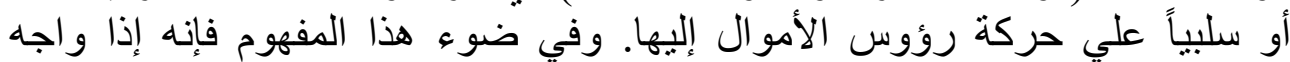

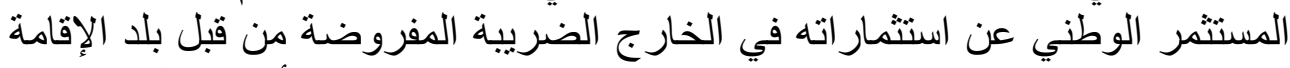

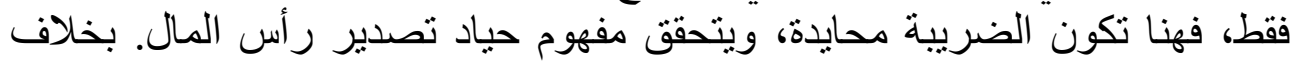

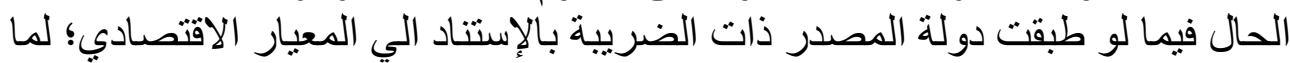

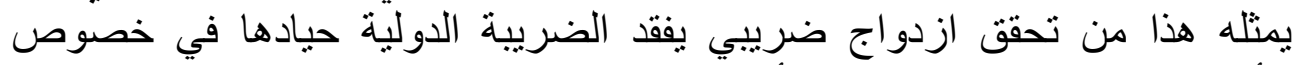

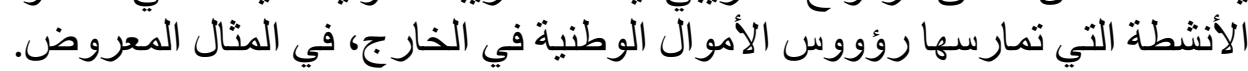

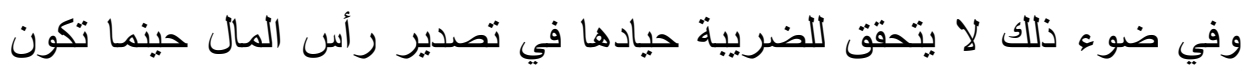

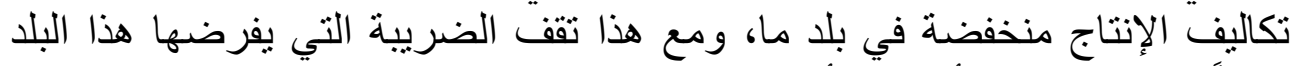

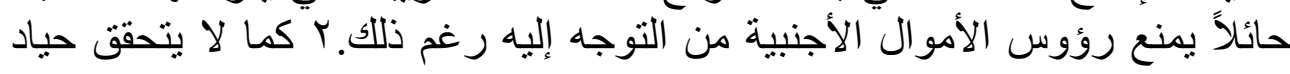

'- Peter Egger, Valeria Merlo, Martin Ruf \& Georg Wamser: Consequences of the New UK Tax Exemption ...Op. Cit. P. r.

-PAUL E. and STEFAN SPECK: Competitiveness and ..., Op. Cit. P.rY).

- Harry G.: Enacting Dividend Exemption and ..., Op. Cit. Pp. 110 - ᄉ 1 4 .

- Lawrence W. Kenny- University of Florida and Stanley L. WinerCarleton University: Tax Systems in the World: ..., Op. Cit. P. rr.

'- Peter Egger, Valeria Merlo, Martin Ruf \& Georg Wamser: Consequences of the New UK Tax Exemption ..., Op. Cit. P. Y.

-PAUL E. and STEFAN S.: Competitiveness and ..., Op. Cit. P. rVr. 
تصدير رأس المال أيضاً حينما يكون هناك أكثر من بلا يمكن لرأس المال الوطني

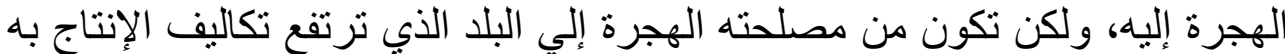

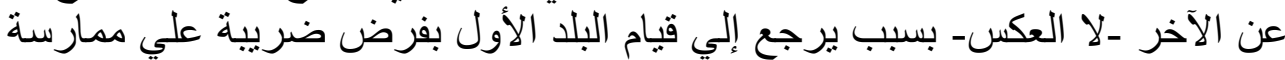

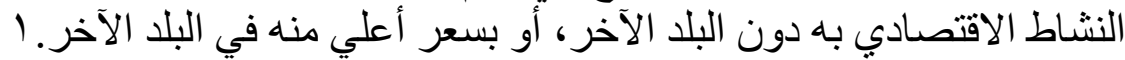

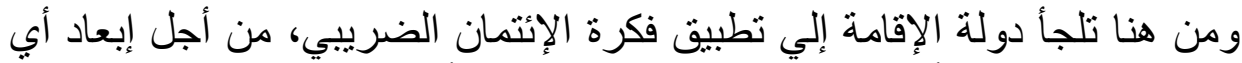

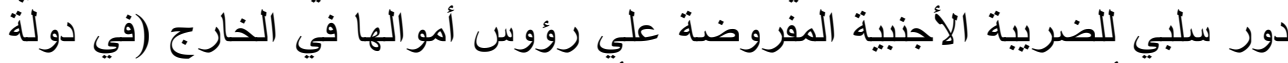

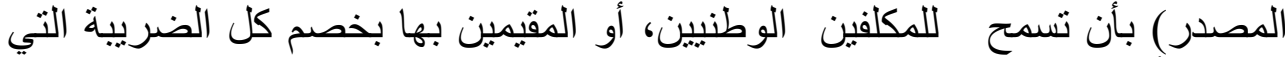

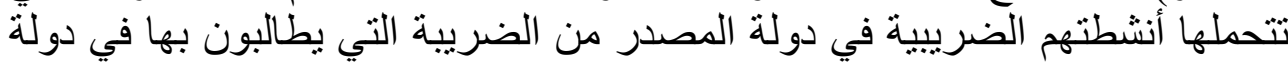

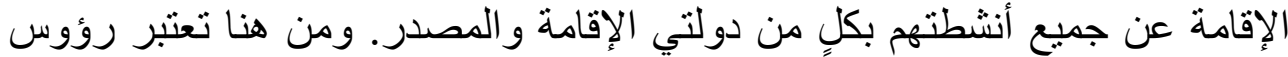

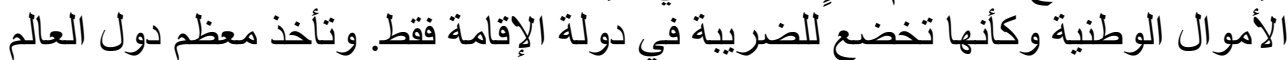

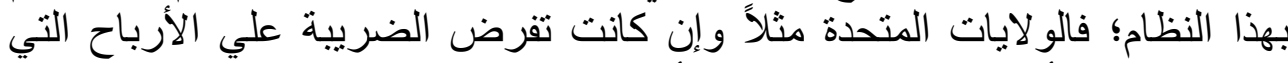

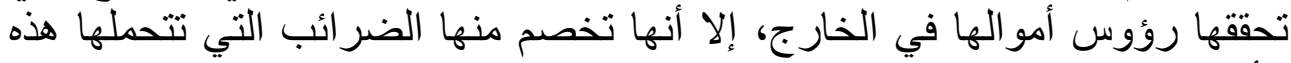

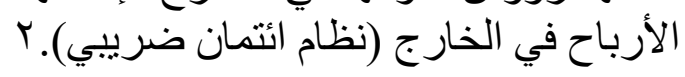

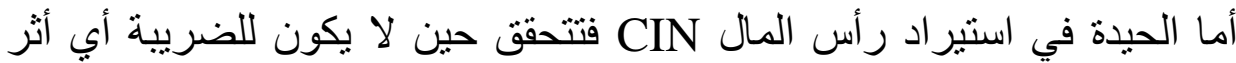

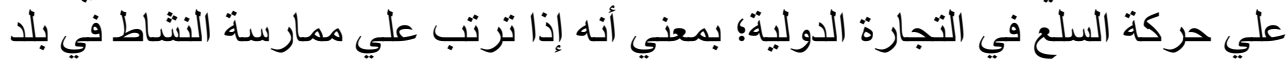

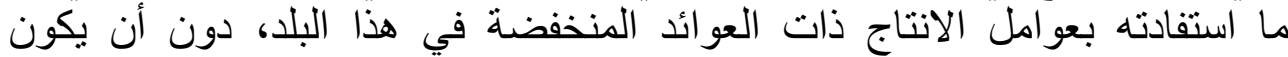

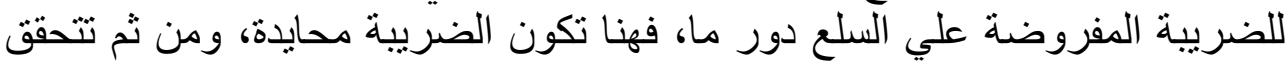

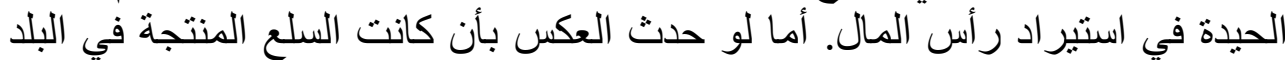

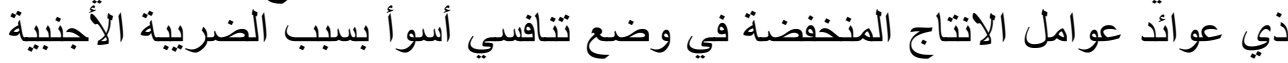

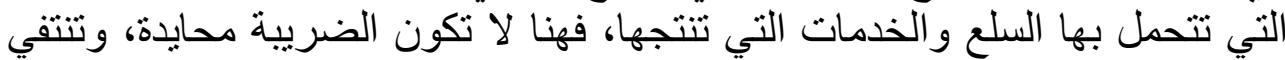

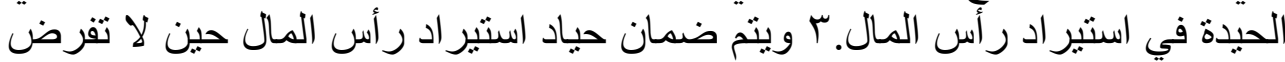

- Harry G.: Enacting Dividend Exemption and Tax..., Op. Cit. P. ^ґ•.

' - Peter Egger, Valeria Merlo, Martin Ruf \& Georg Wamser: Consequences of the New UK Tax Exemption ..., Op. Cit. P. r.

-JOHANNES BECKER \& CLEMENS FUEST: CORPORATE TAX POLICY AND INTERNATIONAL MERGERS AND ACQUISITIONS IS THE TAX EXEMPTION SYSTEM SUPERIOR? ..., Op. Cit. P. ¿ •

$r$ - Peter Egger, Valeria Merlo, Martin Ruf \& Georg Wamser: Consequences of the New UK Tax Exemption ..., Op. Cit. P. Y.

$$
\text { - د. رمضان صديق: تفسير وتطبيق إتفاقيات تجنب الإزدو اج ... مرجع سابق، صد.0. }
$$

- Lawrence W. Kenny- University of Florida and Stanley L. Winer-

Carleton University: Tax Systems in the World: ..., Op. Cit. P. r.

- Harry Grubert: Enacting Dividend Exemption ..., Op. Cit. P. Arr.

-PAUL E. and STEFAN S.: Competitiveness ..., Op. Cit. P. rV

$r$ - Peter Egger, Valeria Merlo, Martin Ruf \& Georg Wamser: Consequences of the New UK Tax Exemption ..., Op. Cit. P. r.

-PAUL E. and STEFAN S.: Competitiveness ..., Op. Cit. P. rVo. 
علي الاستثمار ات الوطنية في الخارج سوي الضريبة في دولة المصدر فقط، و لا

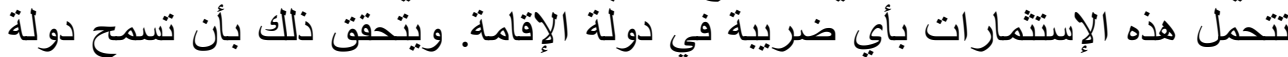

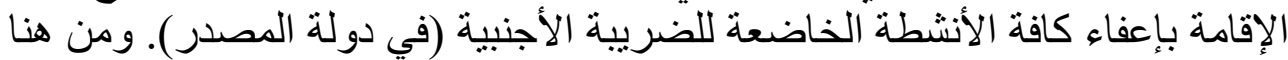

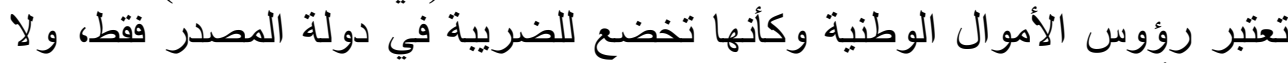
تتحمل بأية ضريبة في دولة الإقامة (نظام الإعفاء الضريبي).

و هكذا تقوم سياسة الإئتمان الضريبي علي فلسفة قوامها أن دولة الإقامة حين تفرض الضريبة علي النشاط الضريبي الذي تتم ممارسته في الخارج (طبقاً لمعيار

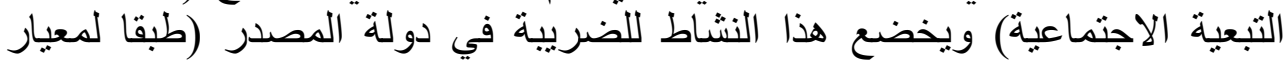

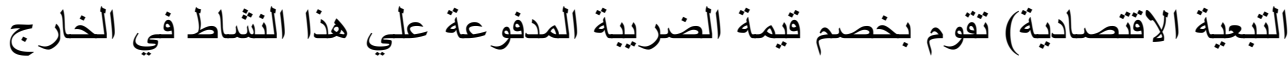

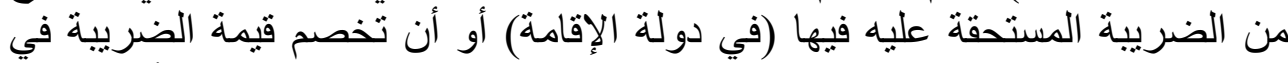

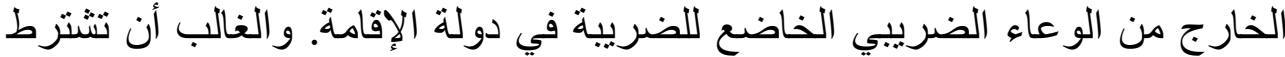

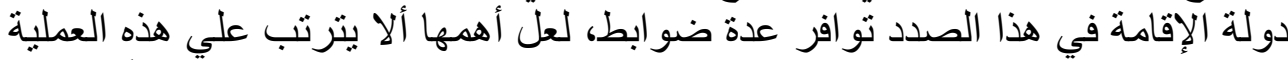

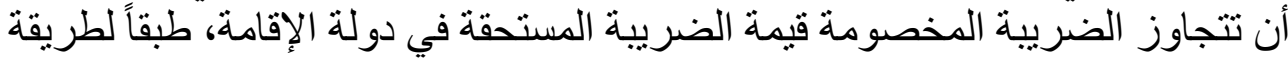

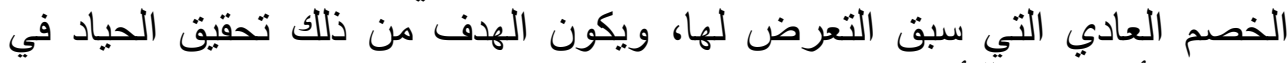

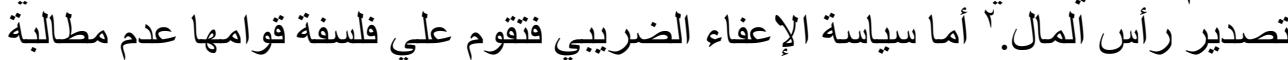

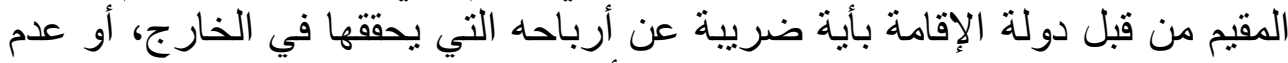

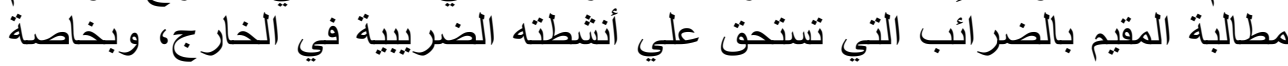

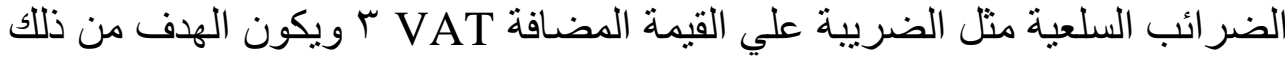
تحقيق الحياد في استير اد رأس المال.

و الواقع أنه منذ أن صاغ مسجريف نظريته في هذا الخصوص (س7 9 (1979 197 ) و هذان المعيار ان ( حياد تصدير رأس المال وحياد استير اد رأس المال) تتم مناقتتهما

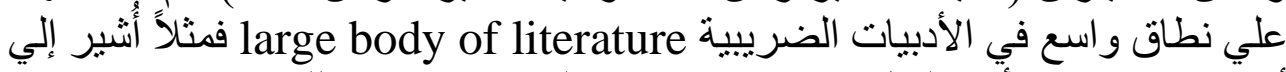

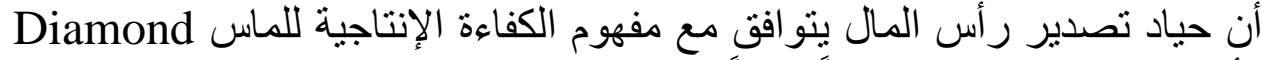

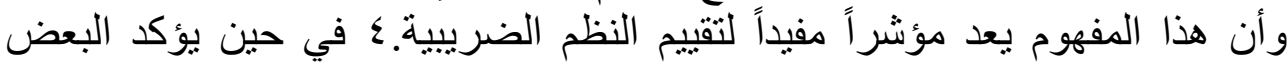

- Lawrence W. Kenny- University of Florida and Stanley L. WinerCarleton University: Tax Systems in the World..., Op. Cit. P. $r \leqslant$.

'- Peter Egger, Valeria Merlo, Martin Ruf \& Georg Wamser: Consequences of the New UK Tax Exemption ..., Op. Cit. P. Y.

-PAUL E. and STEFAN S.: Competitiveness..., Op. Cit. P. rV

- Harry Grubert: Enacting Dividend Exemption ..., Op. Cit. P. A ro.

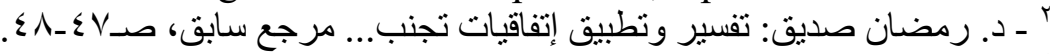

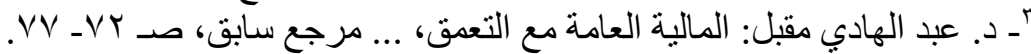

- Peter Egger, Valeria Merlo, Martin Ruf \& Georg Wamser: Consequences of the New UK Tax Exemption ..., Op. Cit. P. r.

- Lawrence W. Kenny- University of Florida and Stanley L. WinerCarleton University: Tax Systems in the World: ..., Op. Cit. P. r I.

-PAUL E. and STEFAN S.: Competitiveness and Exemptions From Environmental Taxes in Europe, ..., Op. Cit. P. r $r v$. 
الإيتمان الضريبي وآثارة الإقتصادية والمالية "دراسة مقارنة"

الآخر أن كفاءة الإنتاج لا تتصل بهذا المفهوم في المحيط الدولي بصورة مباشرة، وأن

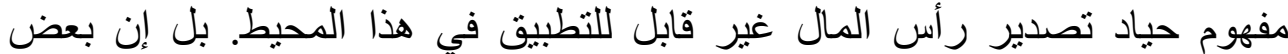

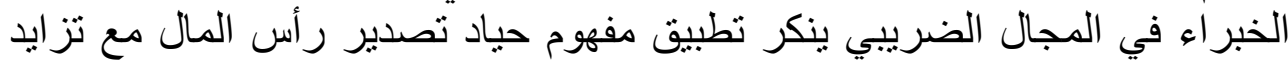

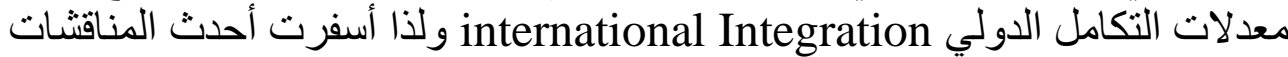

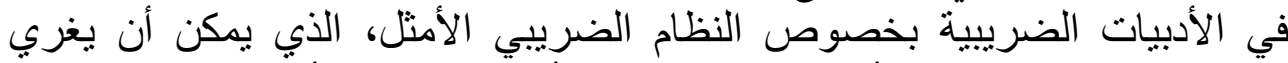

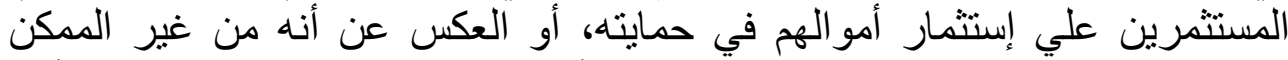

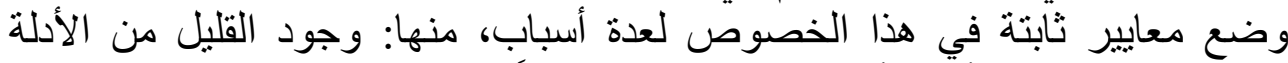

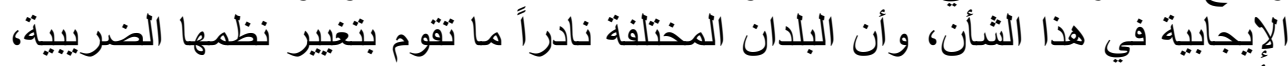

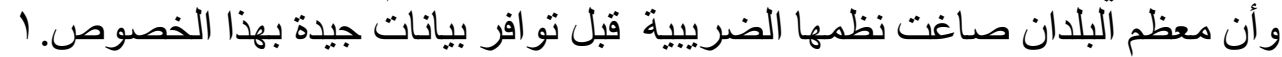

\section{ـ أفضلية نظام الإعفاء علي نظام الإنتمان الضريبي:}

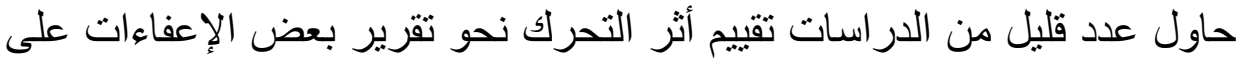

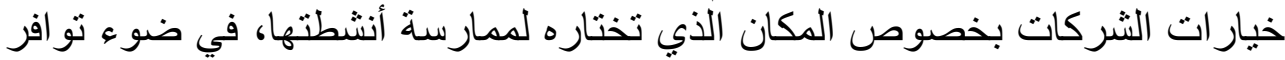

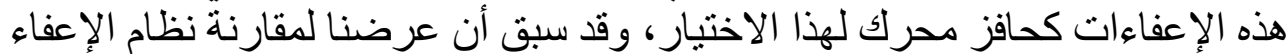

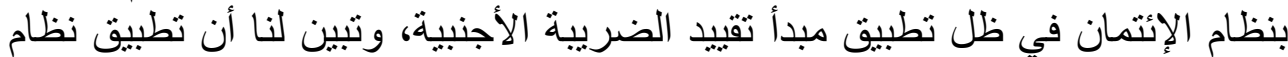

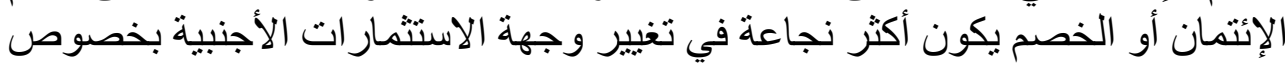
الاخل الفعال أو النشط في ظل تطبيق هذا المبدأ.

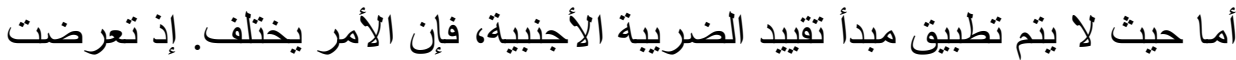

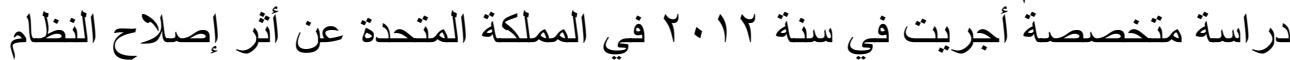

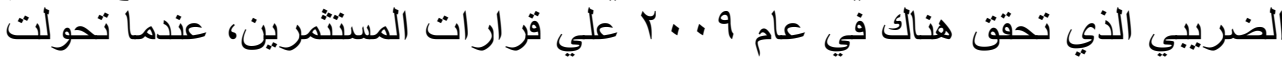

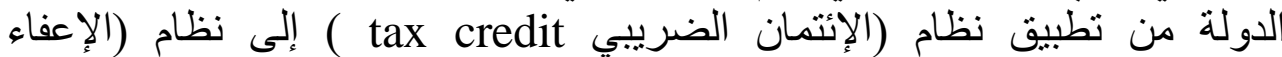

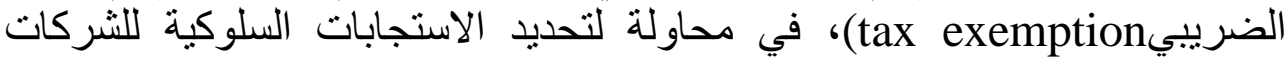

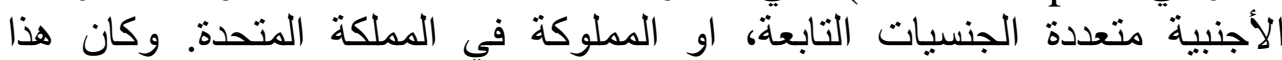

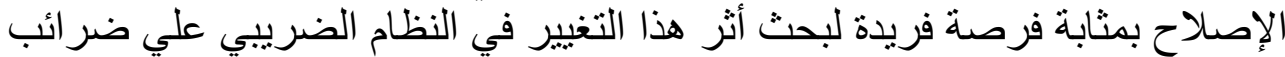

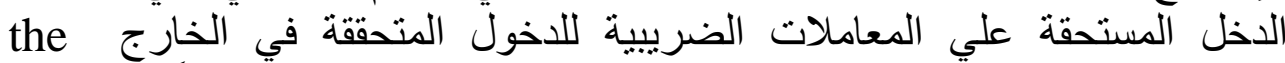

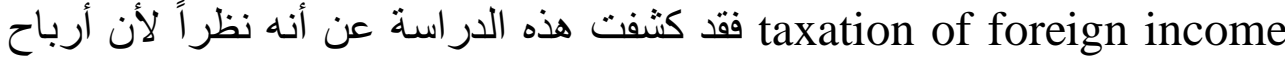

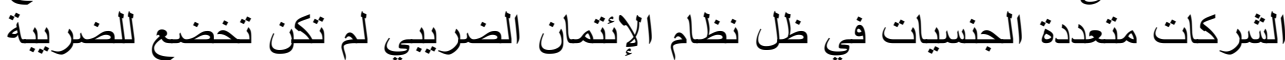

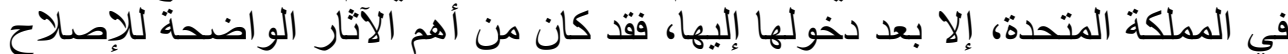

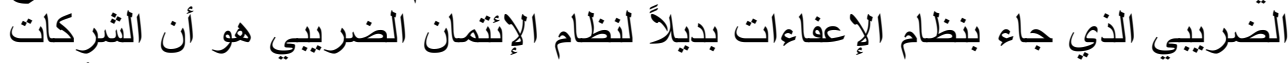

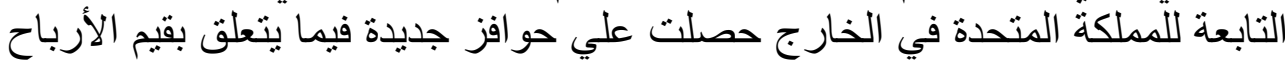
الوطنية المتحققة في الخارج بعد الإصلاح، بالمقارنة بما كان يحدث قبله. بـ ولقياس الأباح

'- Peter Egger, Valeria Merlo, Martin Ruf \& Georg Wamser: Consequences of the New UK Tax Exemption ..., Op. Cit. P. r.

- Harry Grubert: Enacting Dividend Exemption ..., Op. Cit. P. ATr.

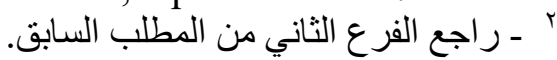

- Harry Grubert: Enacting Dividend Exemption ..., Op. Cit. P. ArY.

$\checkmark$ - Peter Egger, Valeria Merlo, Martin Ruf \& Georg Wamser: Consequences of the New UK Tax Exemption..., Op. Cit. P. r. 
الآثار الناتجة عن هذا التحول في النظام الضريبي البريطاني على ( () - سياسة توزيع

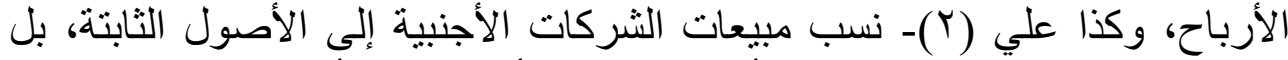

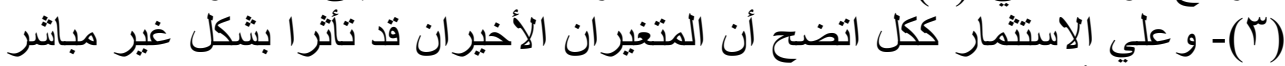

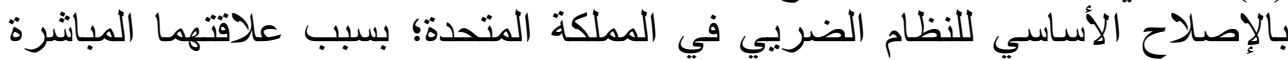
بالمتغير الأول (سياسة توزيع الأرباح علي في حملة الأسهم).

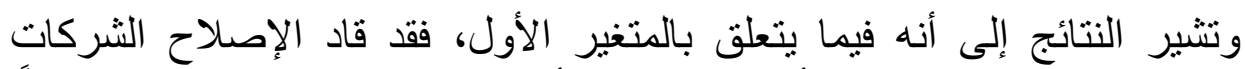

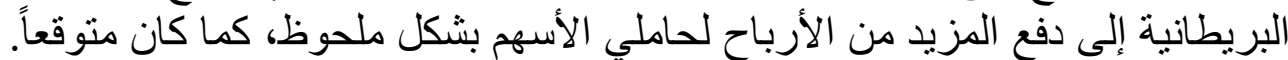

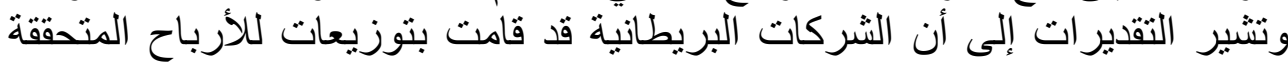

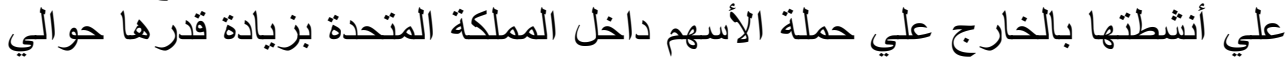
r, 10

كما تثير النتائج كذلك إلي أن متوسط الاستثمار الجديد للشركات المملوكة للمملكة

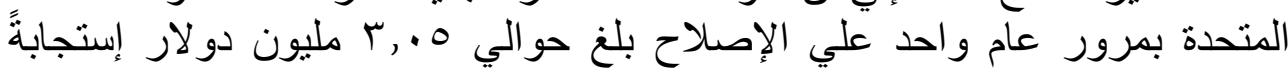

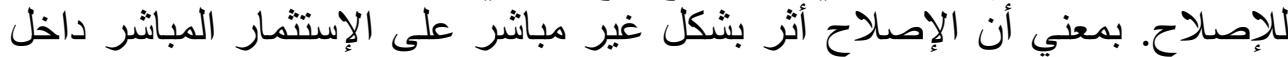

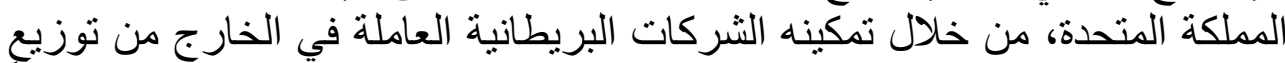

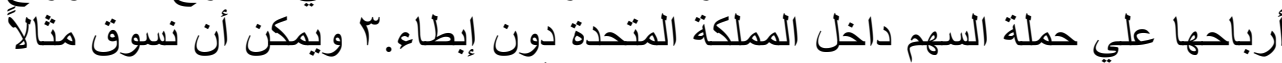

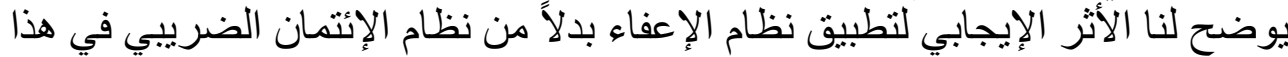

-JOHANNES BECKER \& CLEMENS FUEST: CORPORATE TAX POLICY AND INTERNATIONAL MERGERS AND..., Op. Cit. P.r ${ }^{r}$.

- Lawrence W. Kenny- University of Florida and Stanley L. WinerCarleton University: Tax Systems in the World: ..., Op. Cit. P. YV.

- Harry G.: Enacting Dividend Exemption and Tax ..., Op. Cit. P. Arv.

'- Peter Egger, Valeria Merlo, Martin Ruf \& Georg Wamser: Consequences of the New UK Tax Exemption ..., Op. Cit. P. ₹.

-JOHANNES BECKER \& CLEMENS FUEST: CORPORATE TAX POLICY AND INTERNATIONAL MERGERS AND..., Op. Cit. P.rr.

- Harry Grubert: Enacting Dividend Exemption..., Op. Cit. P. Ar.

- Lawrence W. Kenny- University of Florida and Stanley L. WinerCarleton University: Tax Systems in the World: ..., Op. Cit. P. Y^.

$r$ - Peter Egger, Valeria Merlo, Martin Ruf \& Georg Wamser: Consequences of the New UK Tax Exemption ..., Op. Cit. P. ₹.

-JOHANNES B. \& CLEMENS F. : CORPORATE TAX POLICY AND ..., Op. Cit. P. $r \varepsilon$.

- Lawrence W. Kenny- University of Florida and Stanley L. WinerCarleton University: Tax Systems in the World..., Op. Cit. P. rr.

r- Peter Egger, Valeria Merlo, Martin Ruf \& Georg Wamser: Consequences of the New UK Tax Exemption ..., Op. Cit. P. ₹.

- Harry Grubert: Enacting Dividend Exemption ..., Op. Cit. P. rrr. 
نفترض أن شركة تابعة للمملكة المتحدة وتمارس نشاطاً ضريبياً في بولندا،

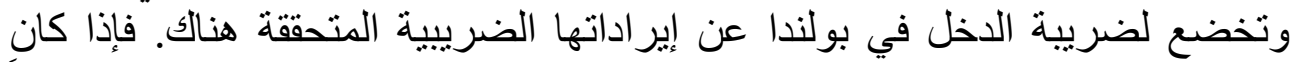

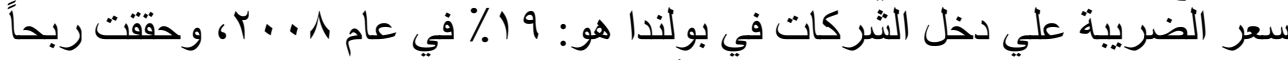

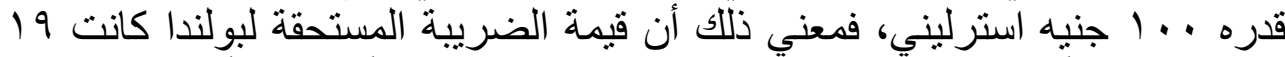

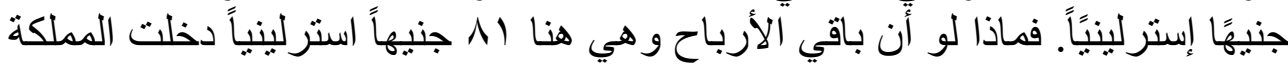

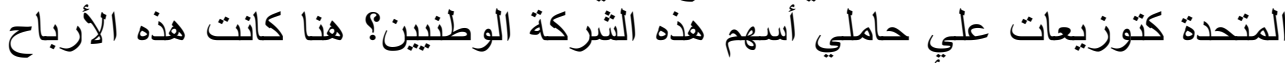

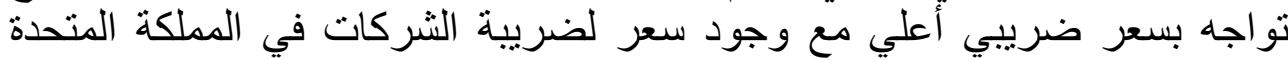

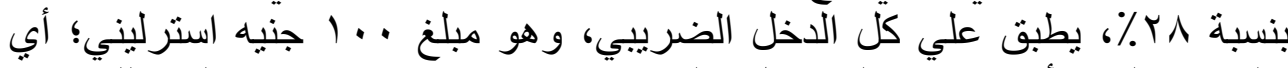

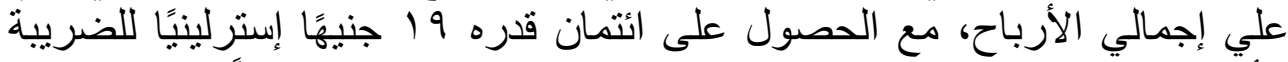

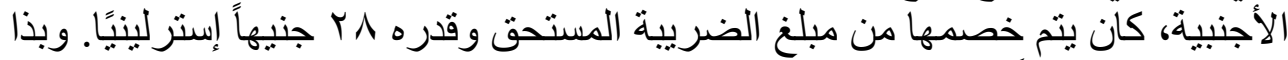

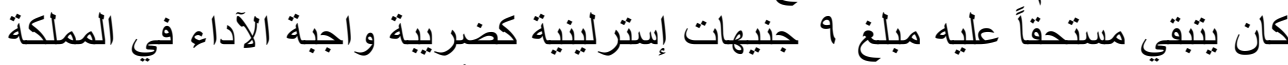

المتحدة، وكانت هذه الضريبة تستحق عند دخول تللك الأرباح إلي المملكة المتحدة.

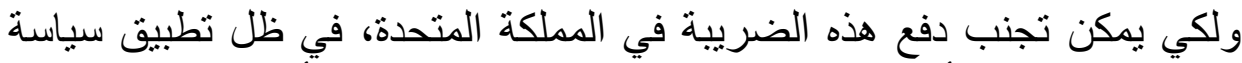

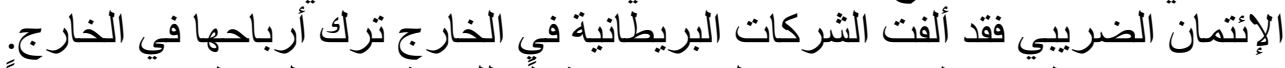

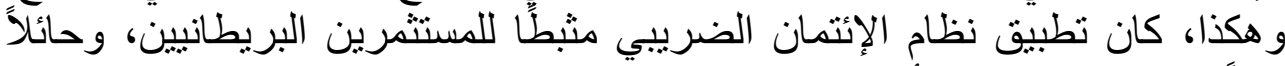

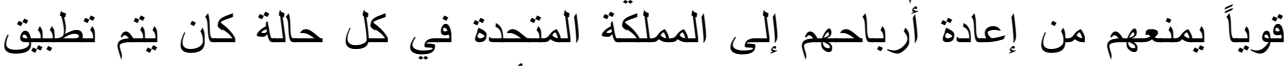

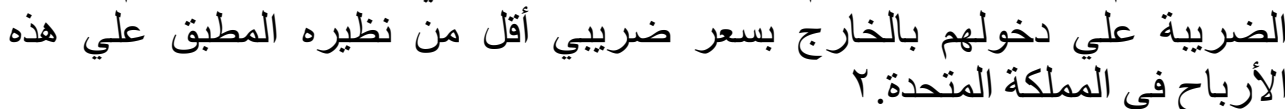

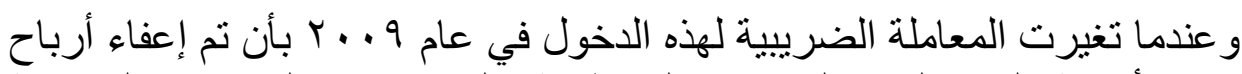

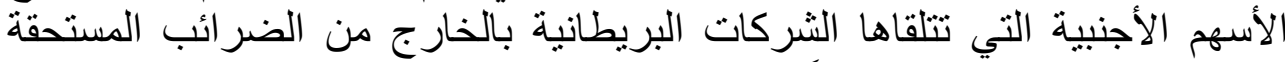

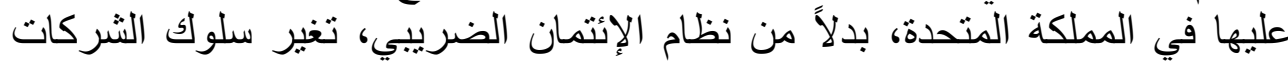

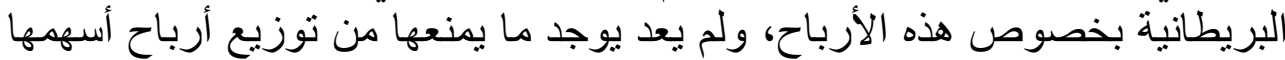

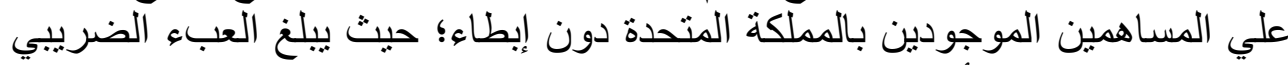

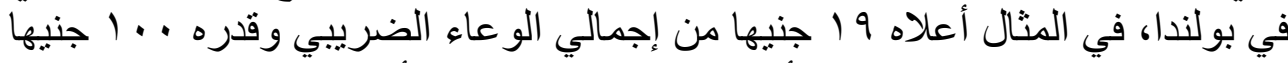

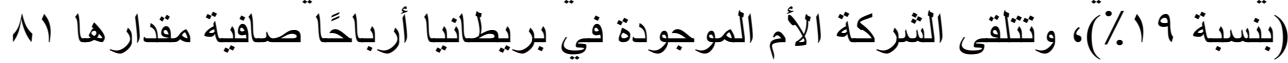

'- Peter Egger, Valeria Merlo, Martin Ruf \& Georg Wamser: Consequences of the New UK Tax Exemption..., Op. Cit. P.॰.

-JOHANNES B. \& C. F. : CORPORATE TAX POLICY ..., Op. Cit. P.r •.

- Lawrence W. Kenny- University of Florida and Stanley L. WinerCarleton University: Tax Systems in the World: ..., Op. Cit. P. Y 7 .

- Harry Grubert: Enacting Dividend Exemption ..., Op. Cit. P. Yr.

$r$ - Peter Egger, Valeria Merlo, Martin Ruf \& Georg Wamser: Consequences of the New UK Tax Exemption ..., Op. Cit. P. ^.

- Lawrence W. Kenny- University of Florida and Stanley L. WinerCarleton University: Tax Systems in the World: ..., Op. Cit. P. Y. 
جنيها بدلاً من VY جنيها كانت تتلقاها في ظل نظام الإئتمان الضريبي. ا وهكذا،

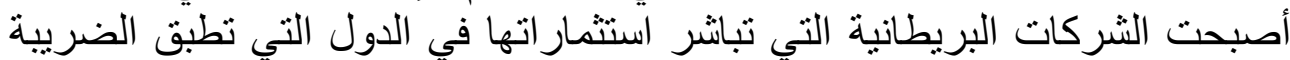

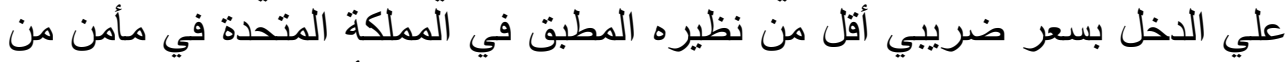

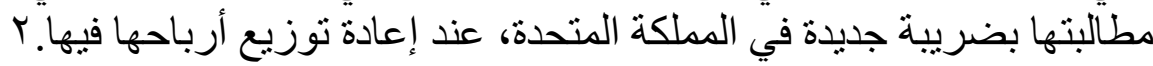
بالإضافة إلى ذلك، كانت الشركات متعددة الجنسيات المملوكة للمملكة المتحدة في

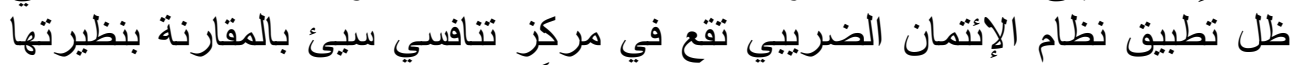

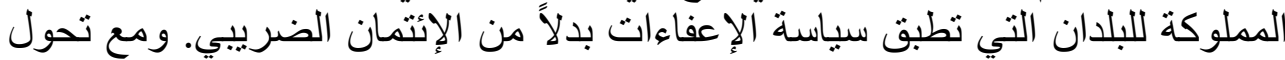

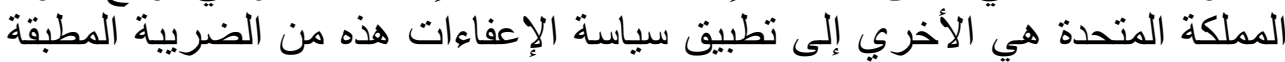
في المملكة المتحدة علي الأرباح المتحققة في الخارج إختفى هذا العيب. ـ أسباب التحول لنظام الإعفاء في المملكة المتحدة:

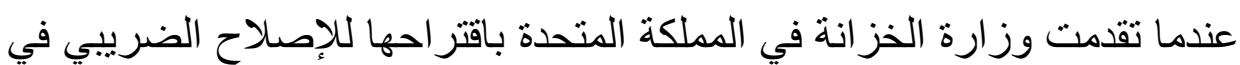

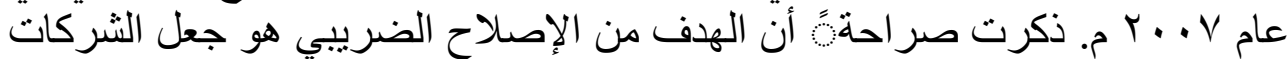

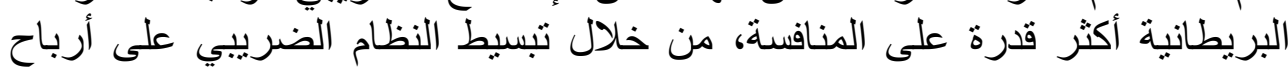

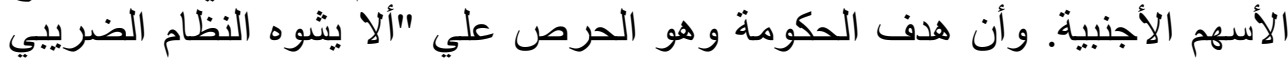

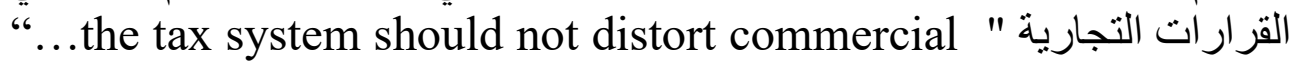
decisions"

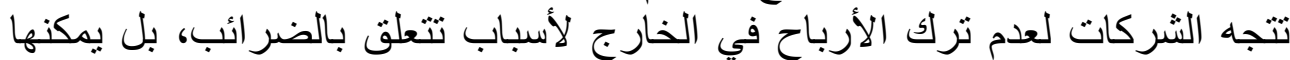

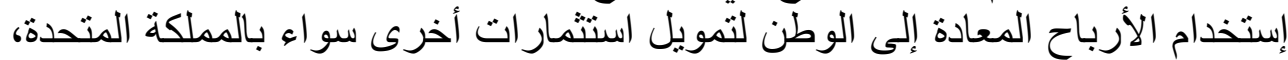

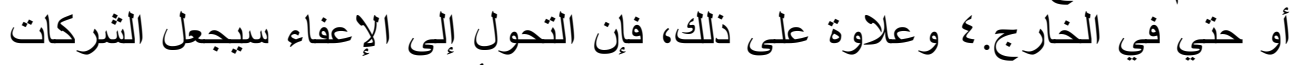

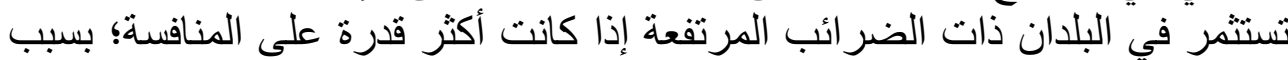

'- Peter Egger, Valeria Merlo, Martin Ruf \& Georg Wamser: Consequences of the New UK Tax Exemption ..., Op. Cit. P.॰.

- Harry Grubert: Enacting Dividend Exemption ..., Op. Cit. P. Arr.

$\checkmark$ - Peter Egger, Valeria Merlo, Martin Ruf \& Georg Wamser: Consequences of the New UK Tax Exemption ..., Op. Cit. P. `.

- Lawrence W. Kenny- University of Florida and Stanley L. WinerCarleton University: Tax Systems in the World: ..., Op. Cit. P. $r \leqslant$.

$r$ - Peter Egger, Valeria Merlo, Martin Ruf \& Georg Wamser: Consequences of the New UK Tax Exemption ..., Op. Cit. P. 7.

-JOHANNES B. \& C. F.: CORPORATE TAX POLICY ..., Op. Cit. P. ז

- Harry Grubert: Enacting Dividend Exemption and Tax Revenue, International Taxation, ..., Op. Cit. P. ^ $\mathrm{r}$.

- Peter Egger, Valeria Merlo, Martin Ruf \& Georg Wamser: Consequences of the New UK Tax Exemption ..., Op. Cit. P. 7.

- Lawrence W. Kenny- University of Florida and Stanley L. WinerCarleton University: Tax Systems in the World: ..., Op. Cit. P. Ү . 
الإئتمان الضر يبي وآثارة الإقتصادية والمالية "دراسة مقارنة"

انخفاض تكاليف الامتتال لديها، لعدم وجود التزام ضريبي إضافي عند إعادة الأرباح

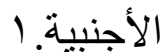

واستنتجت الحكومة البريطانية أن النظام القديم(الائتمان الضريبي) قلل على والي وجها

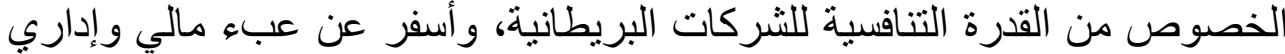

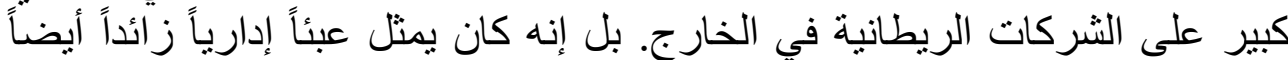

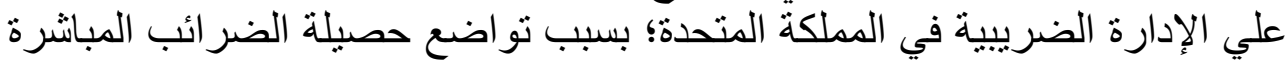
it produced only a modest amount of direct tax yield ظل تطبيق ذللك النظام (الايتمان الضريبي). وحيث كانت معظم بلدان الاتحاد

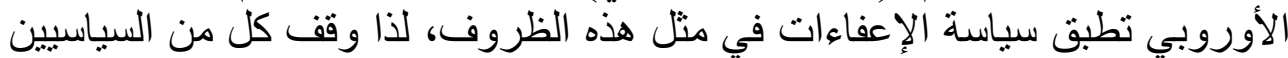

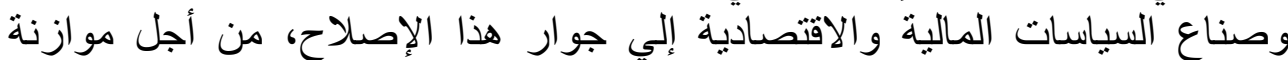

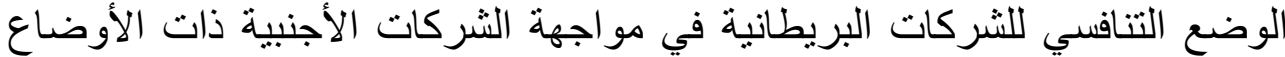

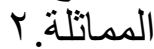

\section{الفرع الثاني \\ تطبيق نظام الإنتمان لخصم الضريبة الأجنبية في مصر}

بعد استعراضنا لمقارنة نظام الإتثمان بنظام الإعفاء كمنهجين أساسيين تتبعهيا

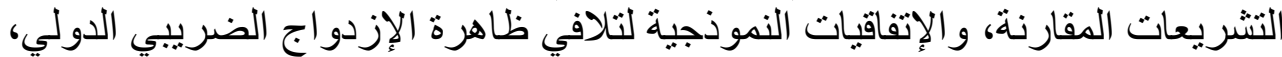

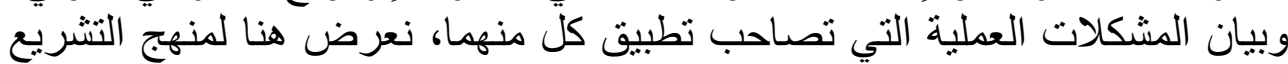

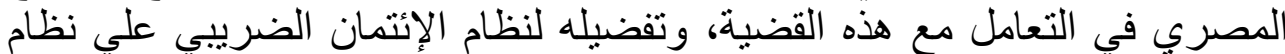

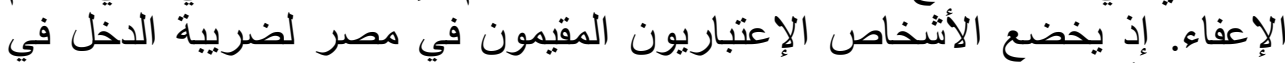

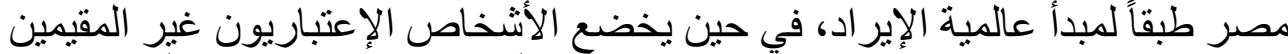

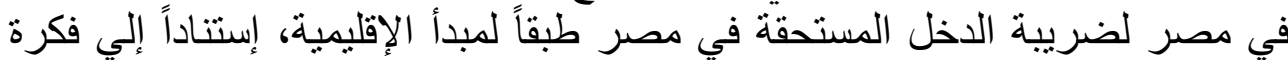
المنشأة الدائمة. ّ و عندما يحقق الممول، الذي يتخذ صورة الثخص الإعتباري المقيم

'- Peter Egger, Valeria Merlo, Martin Ruf \& Georg Wamser: Consequences of the New UK Tax Exemption ..., Op. Cit. P. 7.

- Harry Grubert: Enacting Dividend Exemption ..., Op. Cit. P. Ar).

$\checkmark$ - Peter Egger, Valeria Merlo, Martin Ruf \& Georg Wamser: Consequences of the New UK Tax Exemption ..., Op. Cit. P. \.

-PAUL E. and STEFAN S.: Competitiveness and Exemptions From Environmental Taxes in Europe, ..., Op. Cit. P. rVq.

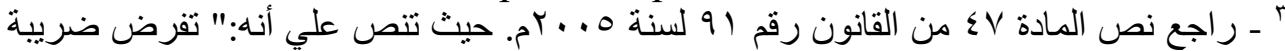

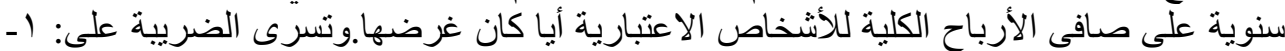

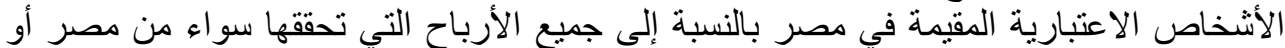

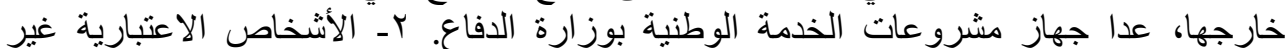

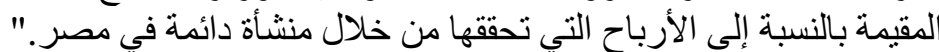

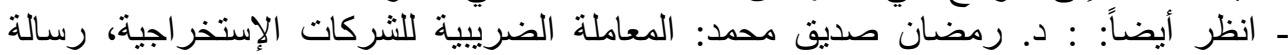

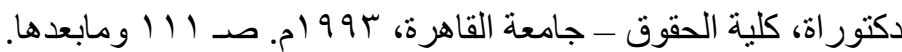

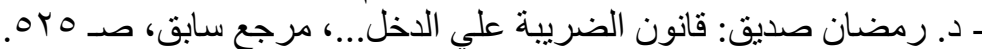

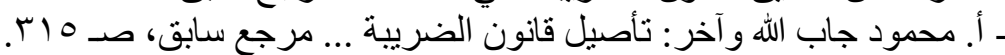




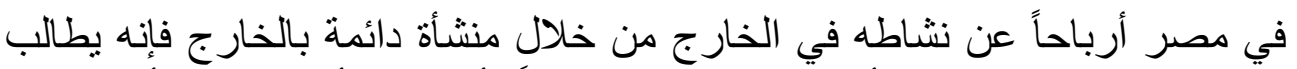

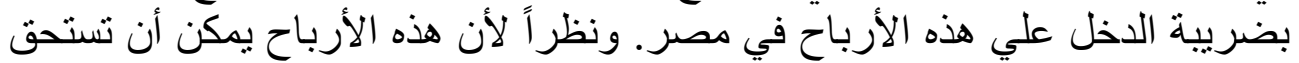

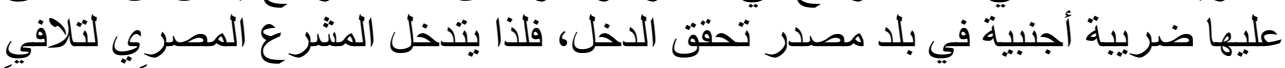

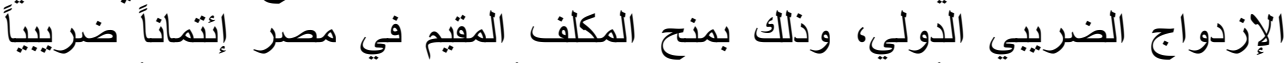

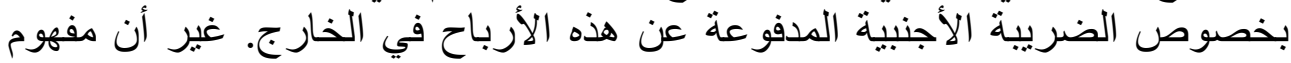

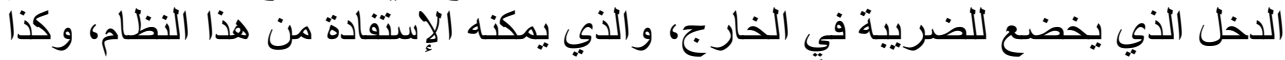
شروط تطبيق هذا النظام من الأمور التي تحتاج إلي تفصيل:

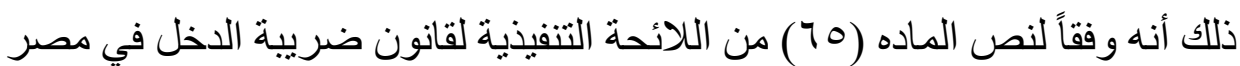

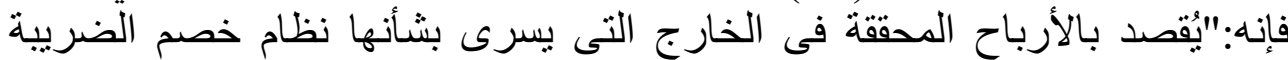

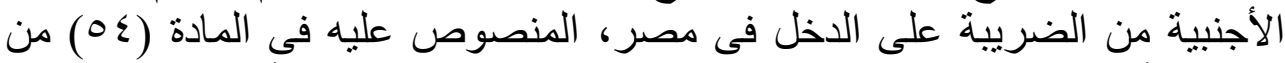

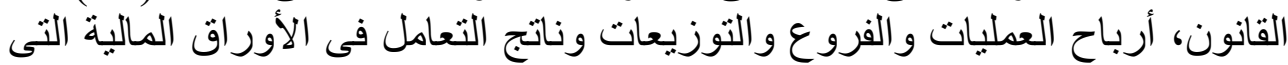

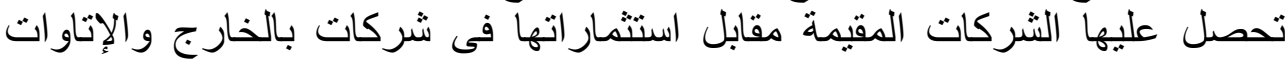

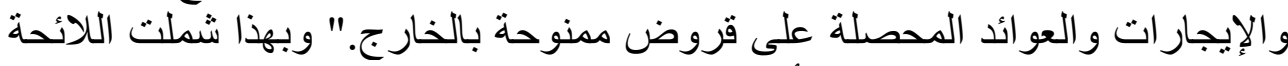

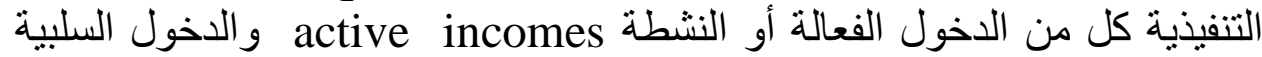
passive incomes

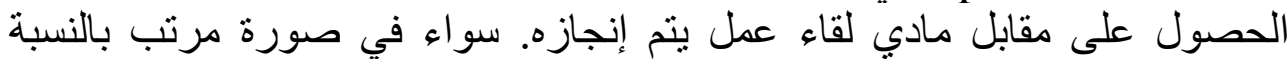

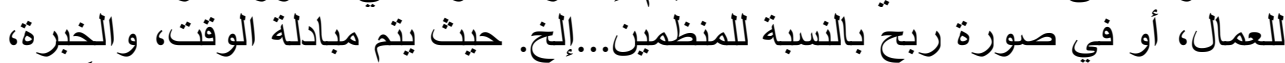

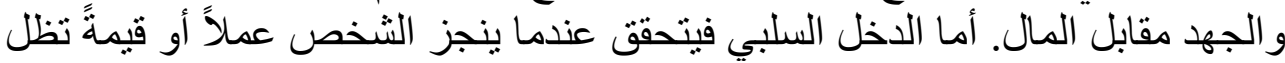

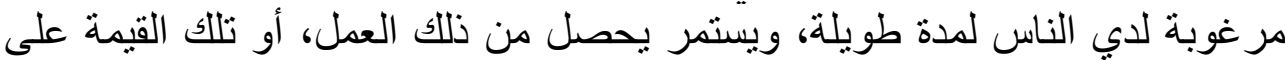

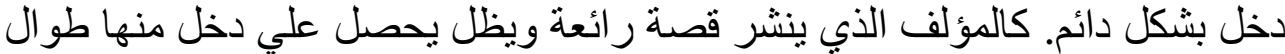

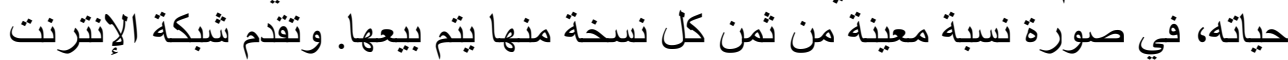

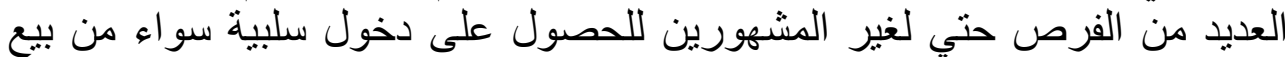

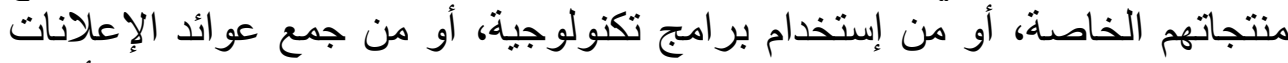

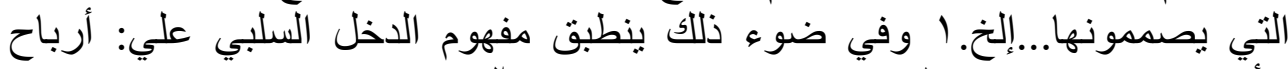

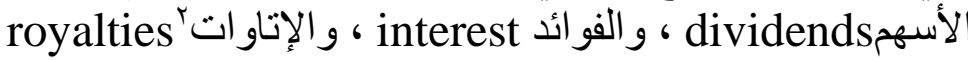

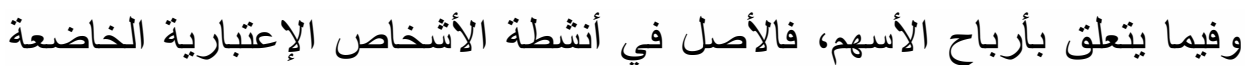

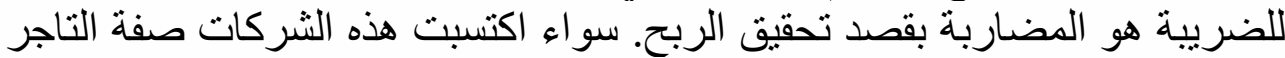

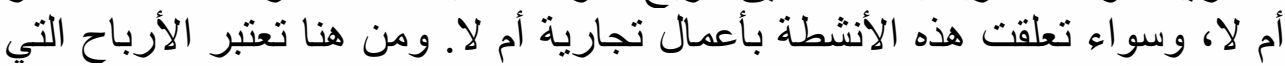

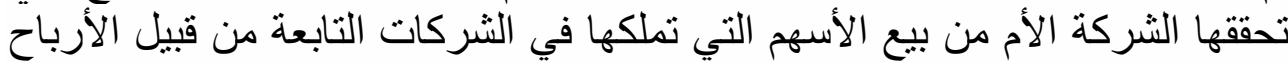

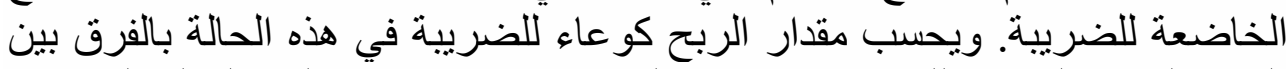

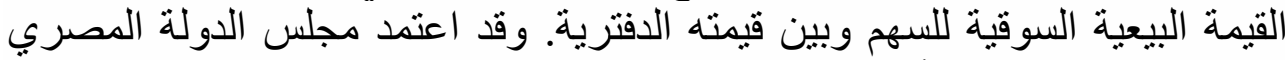

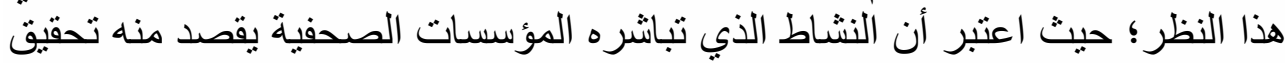
أرباح تعينها علي تحقيق أغر اضها، ولذا أفر بخضو النّوع هذه الأرباح لضريبة الذخل.

1 - https://business.tutsplus.com/ar/tutorials/what-is-passive-income-cms $r$ - "... activities which give rise to passive income, such as dividends, interest and royalties" (Look: OECD ( $\uparrow . \mid \varepsilon)$, Model Tax ..., Op. Cit. P. Y).)

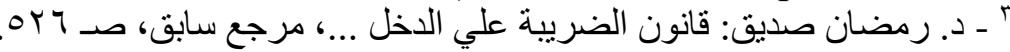


الإيتمان الضريبي وآثارة الإقتصادية والمالية "دراسة مقارنة"

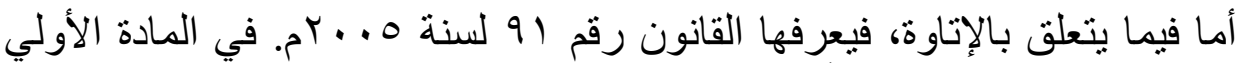

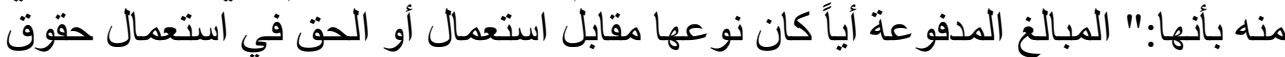

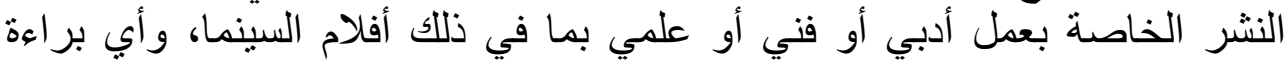

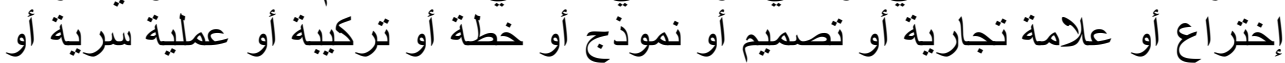

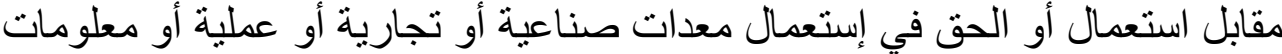

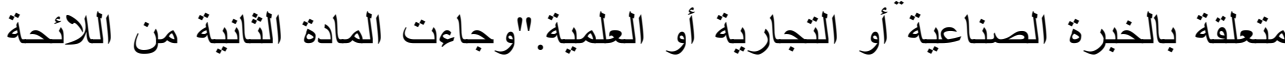

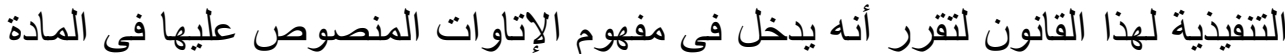

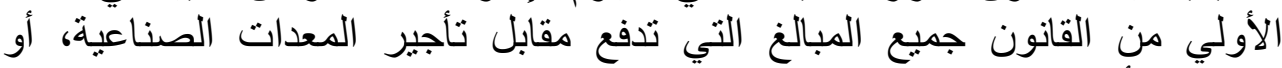

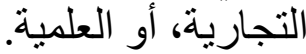

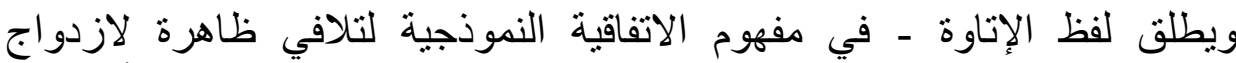

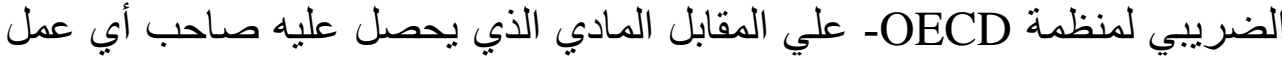

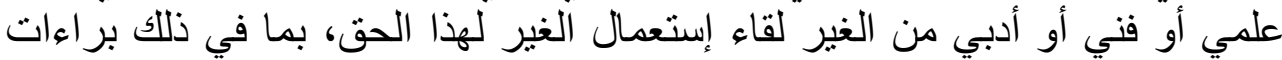

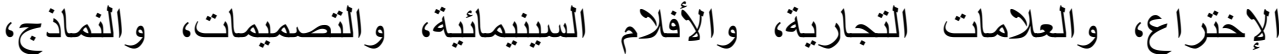

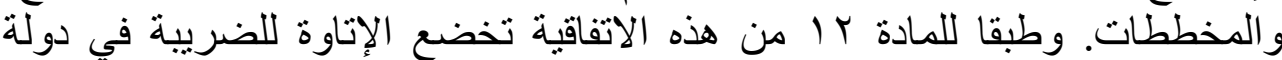

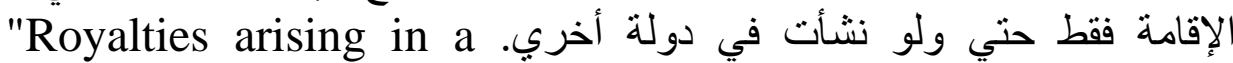
Contracting State and beneficially owned by a resident of the other Contracting State shall be taxable only in that other State."'

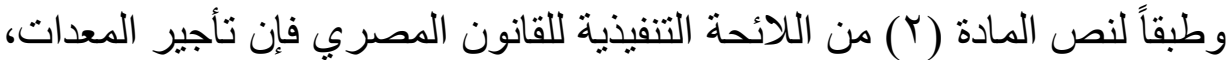

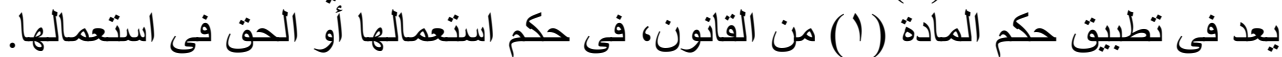

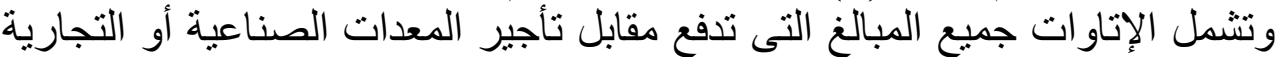

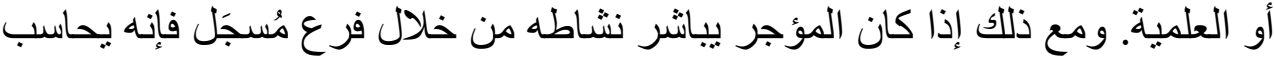
لأغر اض الضريبة باعتباره منشأة دائمة.

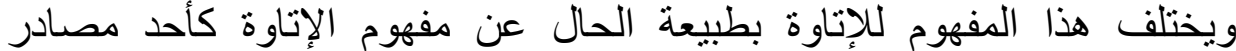

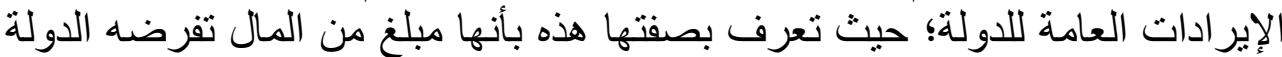

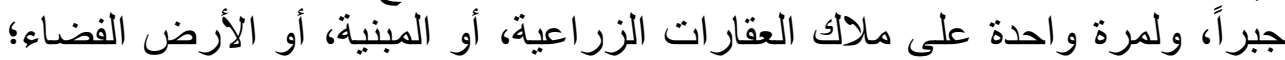

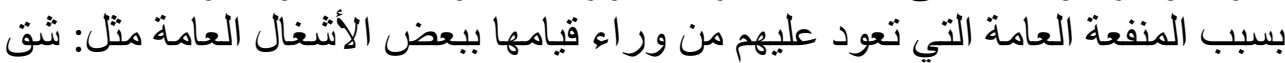

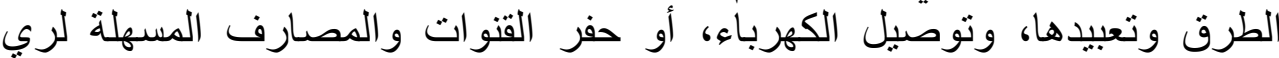

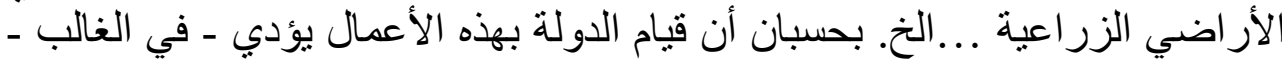

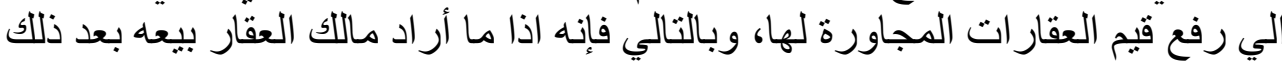

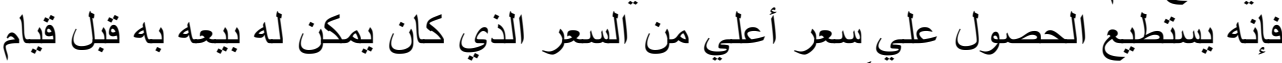

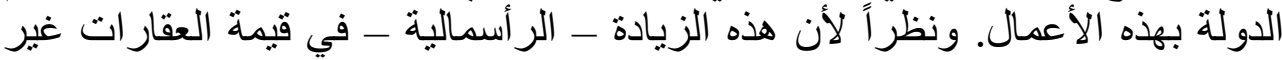

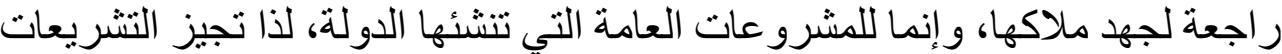

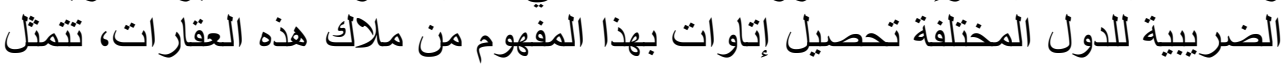
في مبالغ مالية تحددها الدولة بصفة قطعية، ولمرة واحدة. ويلتزم ملاك هذه العقار الت اتل

' - OECD ( $(\cdot 1 \varepsilon)$, Model Tax Convention ..., Op. Cit. P. $\vee$ '. $r \varepsilon$.

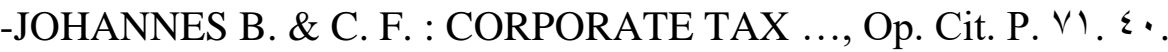


بدفعها للاولة. غير أن الإتاوات لاتتمتع بأهمية كبيرة كمورد هام أوحيوي من الموارد

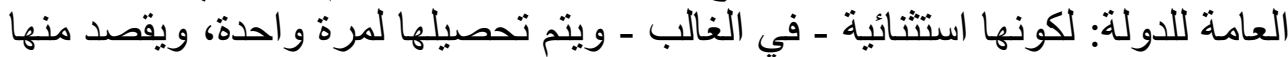

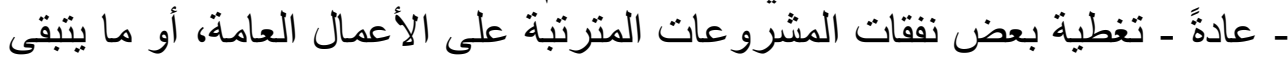
من هذه النفقات. ولذا لا تعول عليها الدول كثير أ في هذا الخصو الخصوص.

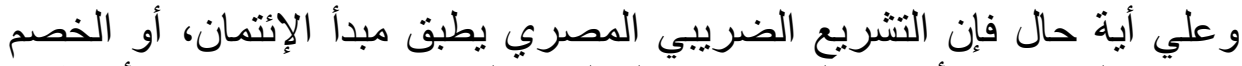

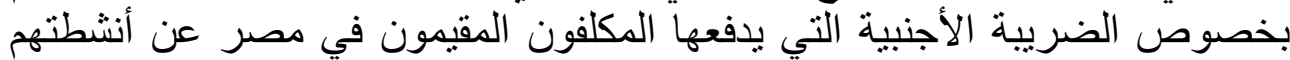

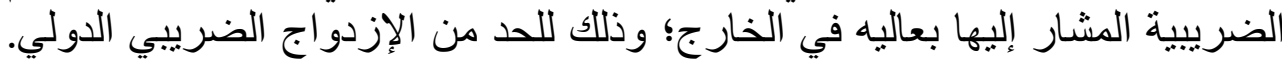
غير أنه يتطلب لتمكين المكلف من ذللك تحقق عدة شروط:

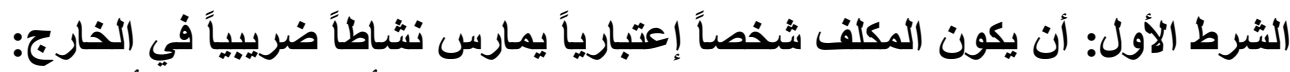

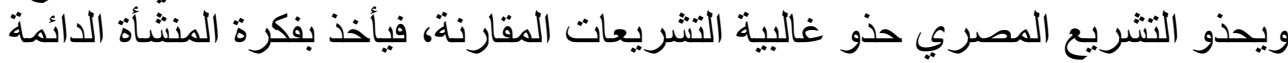
Permanent establishment

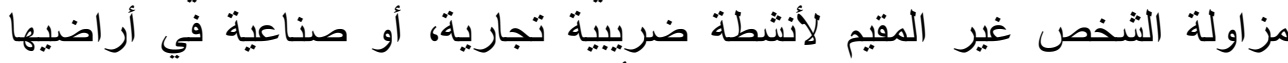

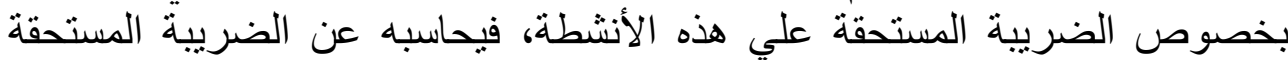

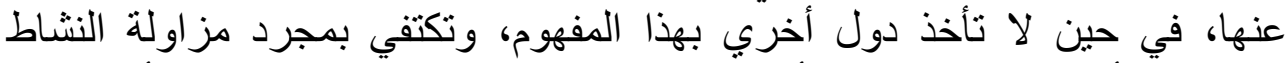

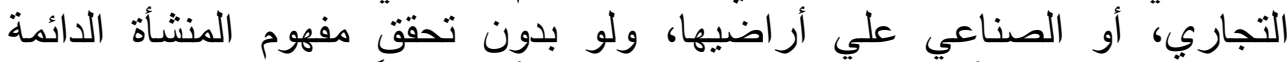

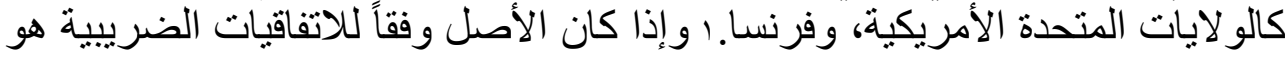

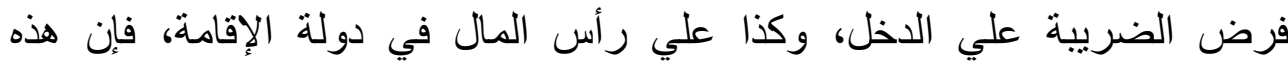

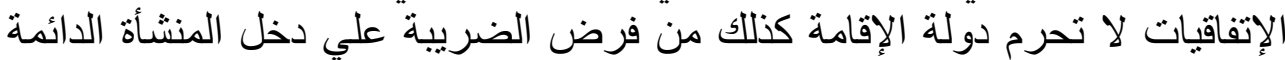

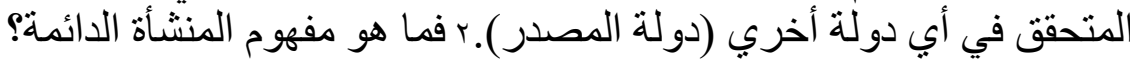

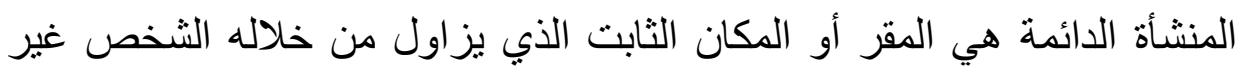

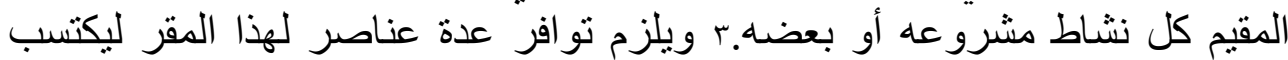
وصف المنشأة الدائمة، هي:

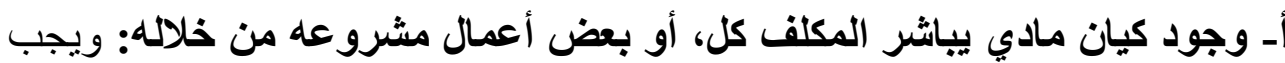

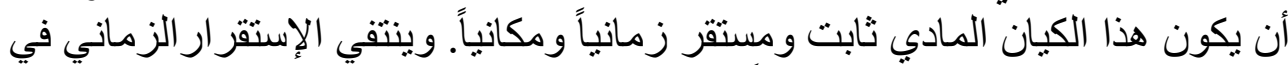

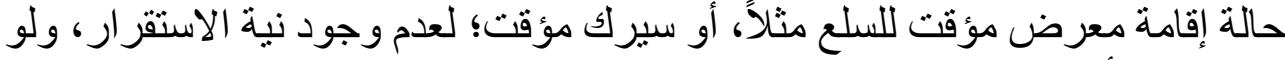

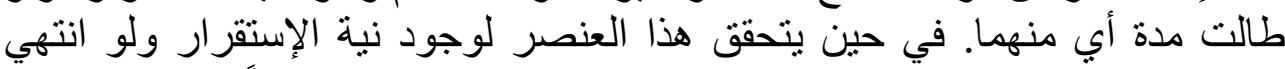

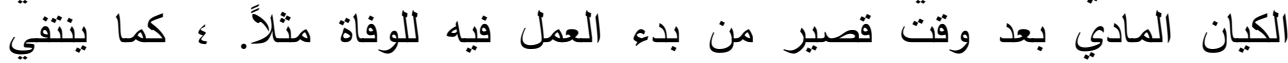

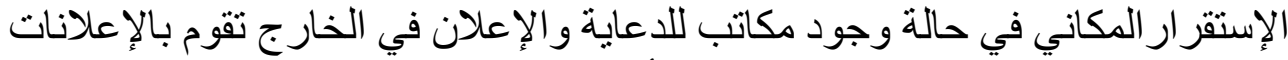

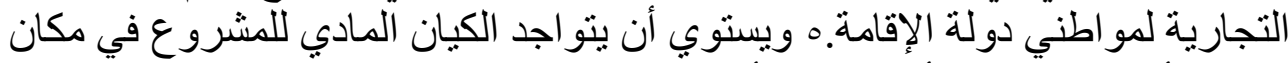

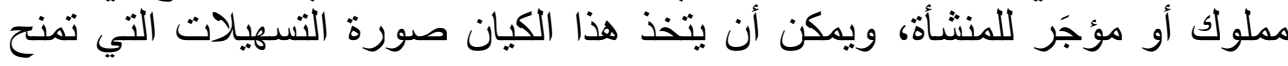

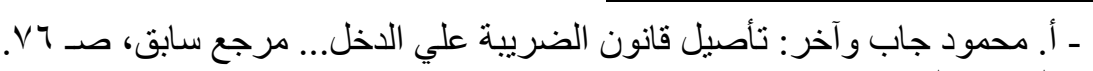

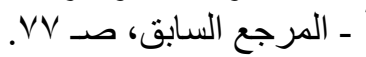

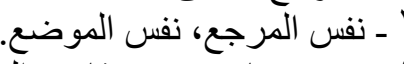

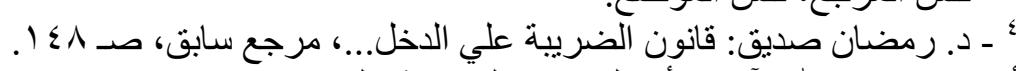

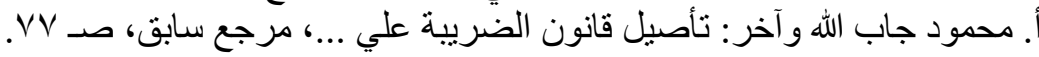

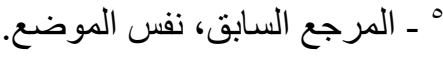


الإيتمان الضريبي وآثارة الإقتصادية و المالية "دراسة مقارنة"

للمشروع في دولة المصدر كالتصاريح، أو وجود الآلات أو المعدات التابعة له فيه.

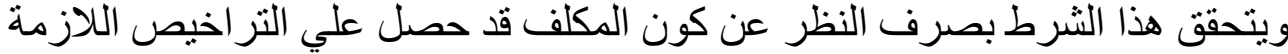

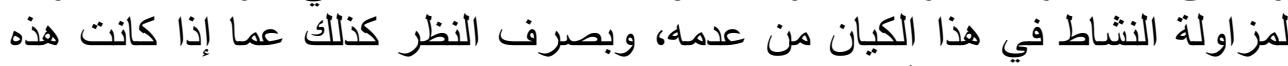
التز اخيص مطلوبة من الأساس من عدمه.

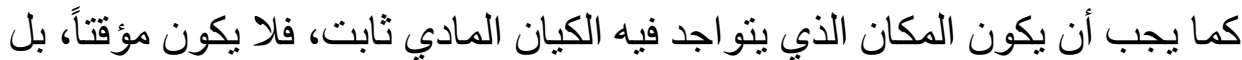

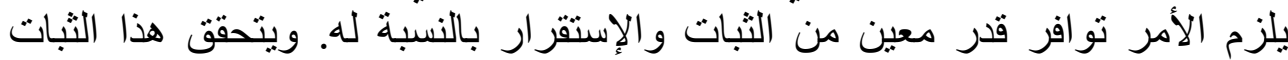

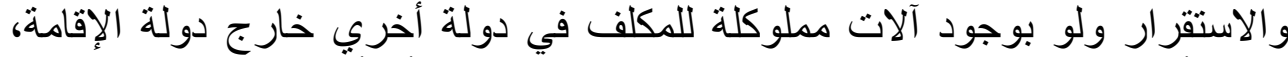

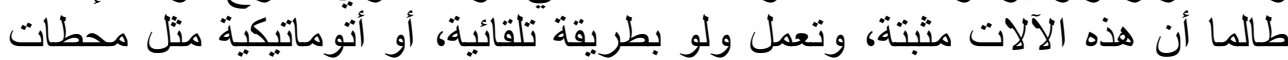

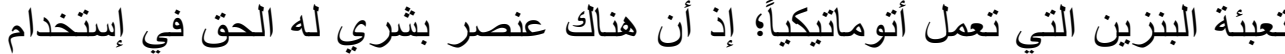
المكان الذي تتو اجد فيه هذه المحطات.

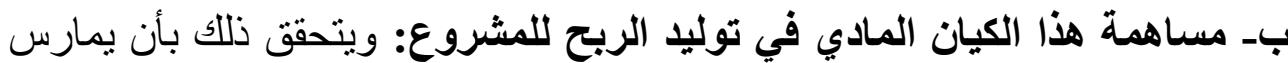

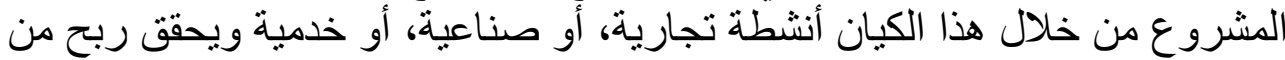

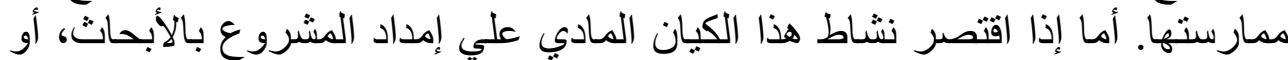

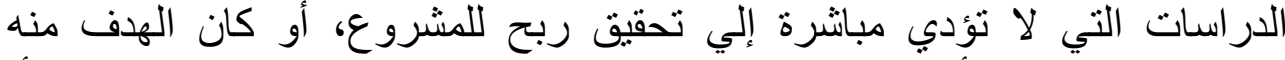

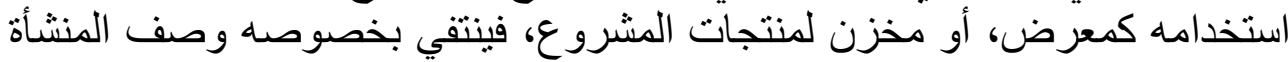

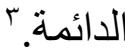

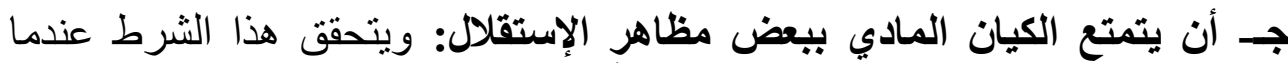

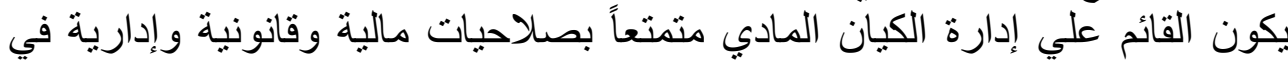
علاقته بالمنشأة الأصلية، أما إذا كان تابعاً لها، ولا يتمتع بهذه الصلاحيات فيات فينتفي فئي

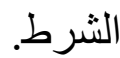

و الأصل أن تو افر هذه العناصر يقطع بتو افر صورة أو أخري للمنشأة الدائمة، فهل

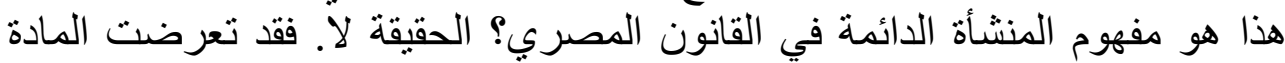

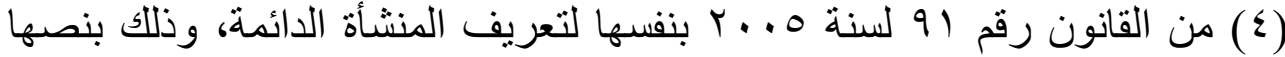

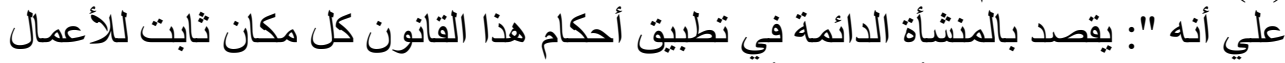

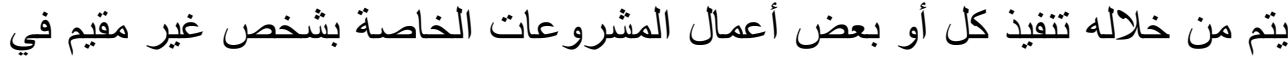

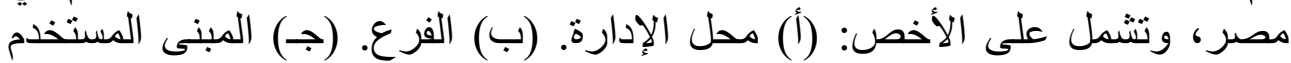

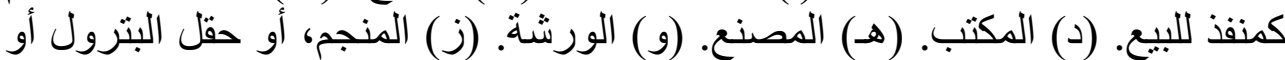

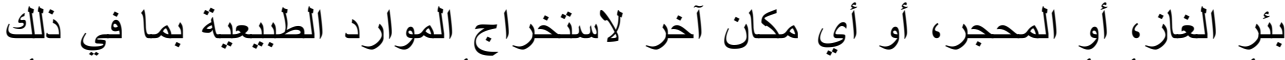

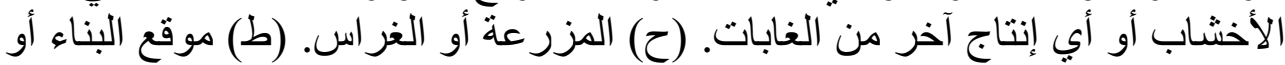

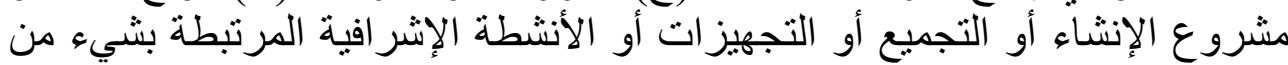

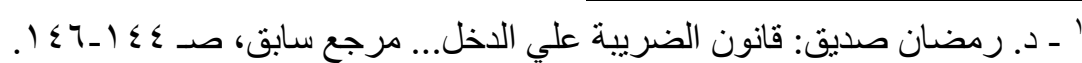

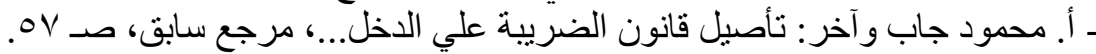

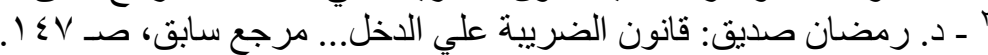

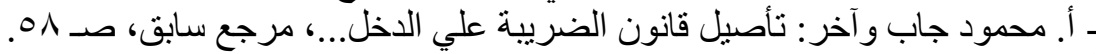

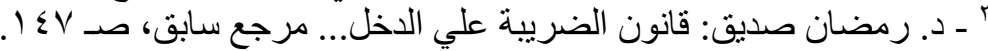

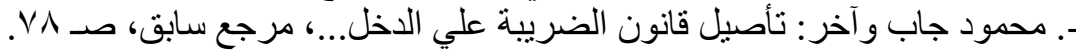




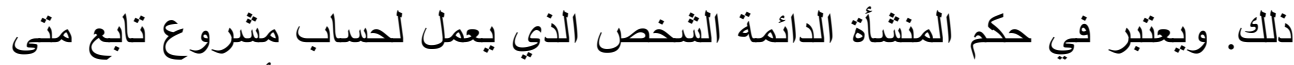

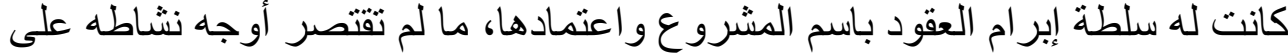

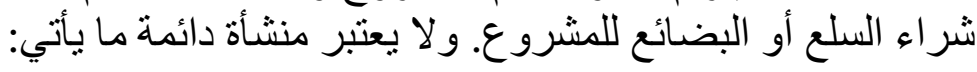

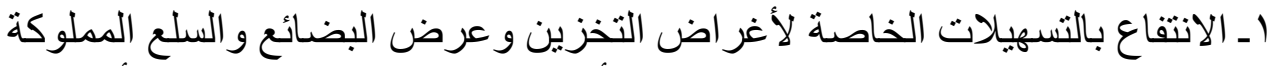

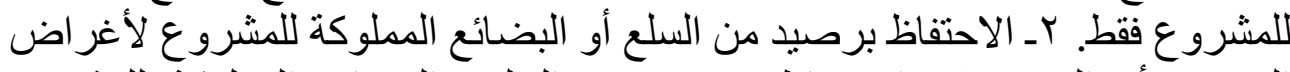

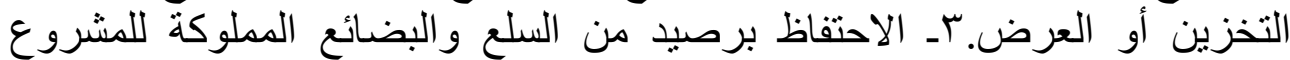

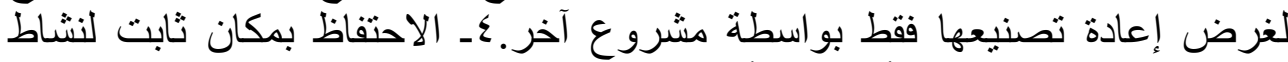

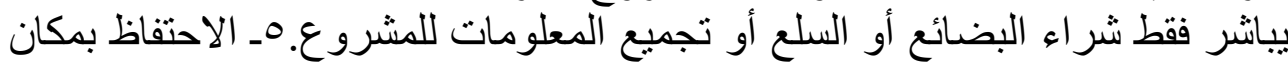

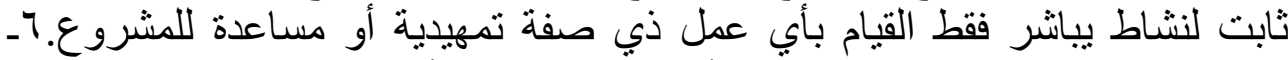

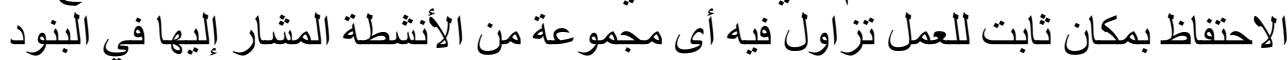

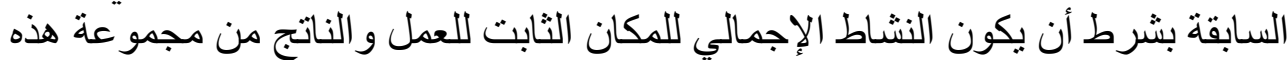

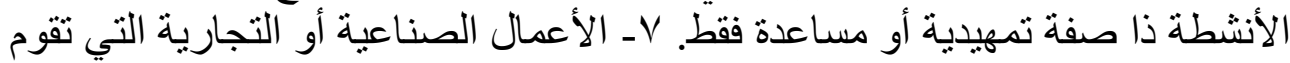

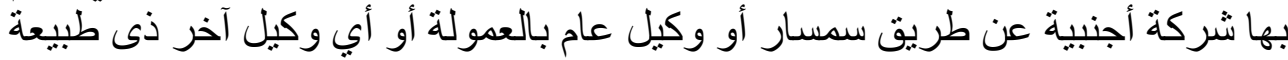

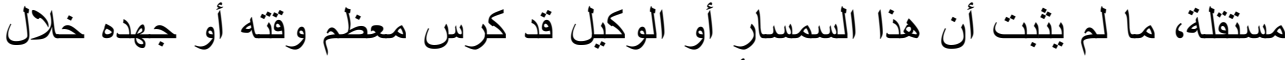

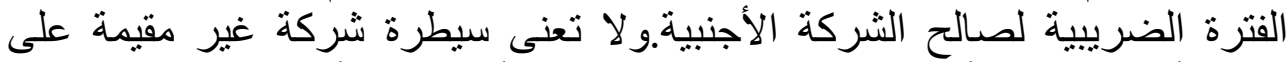

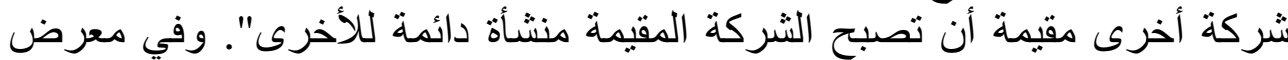

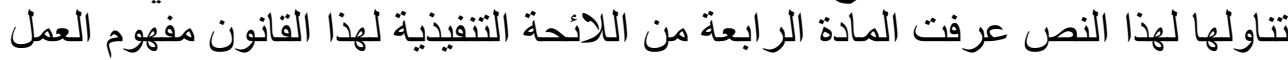
ذي الصفة التمهيدية المنصوص عليه في البند رقم (0) المشار إليه بأنه:"كل نشاط

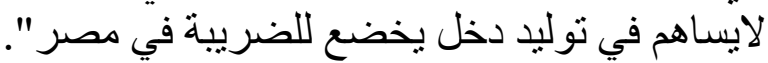

و الواقع أن المشرع المصري بهذا الإسهاب في تحديده لمفهوم المنشأة الدائمة

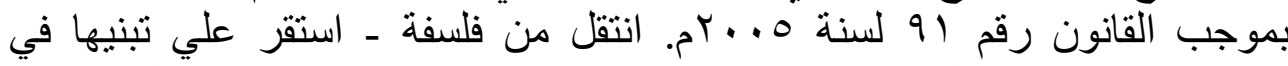

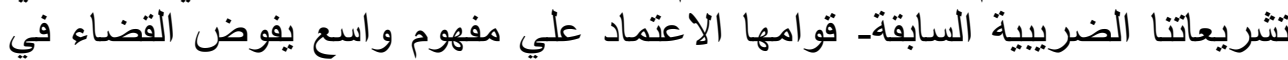

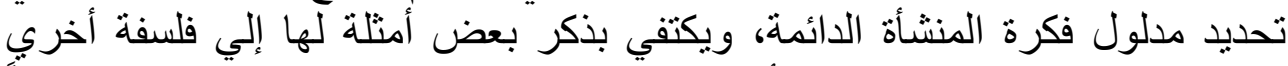

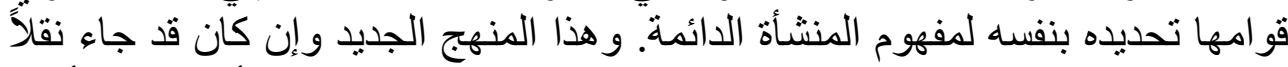

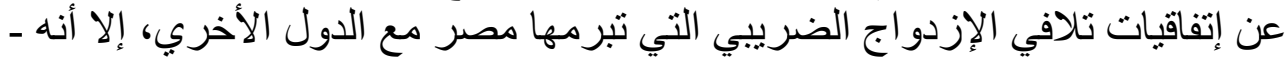

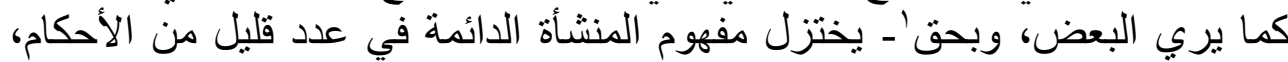

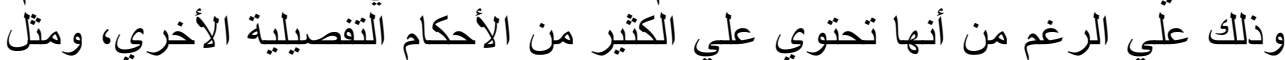

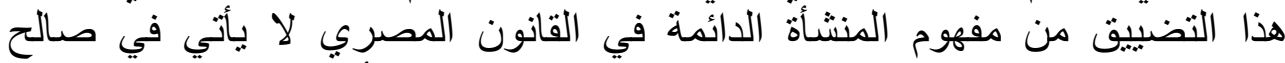

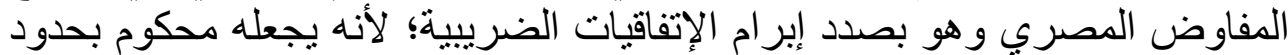

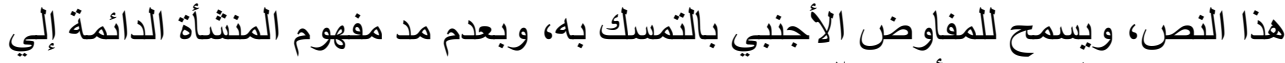
ما ور اء هذا النص من أحكام.

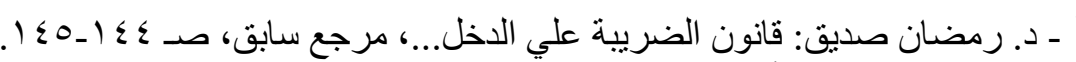

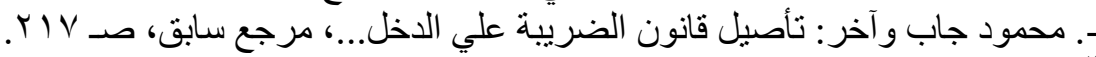

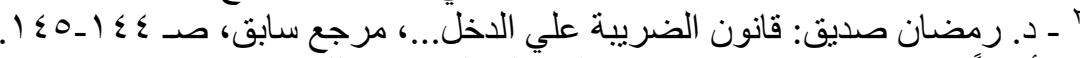

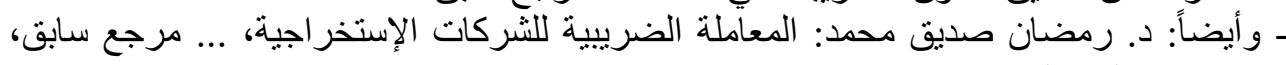


الإيتمان الضريبي وآثارة الإقتصادية و المالية "دراسة مقارنة"

الثرط الثاني: أن تكون الضريبة الأجنبية قد تم دفعها بالفعل: فإذا لم تكن قد تم دفعها

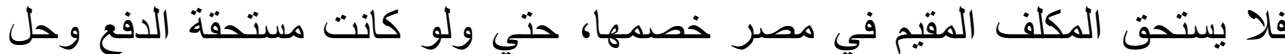

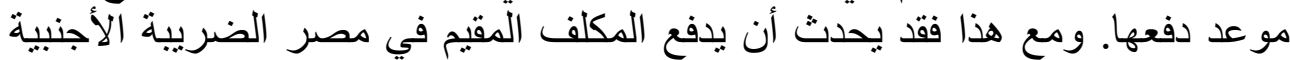

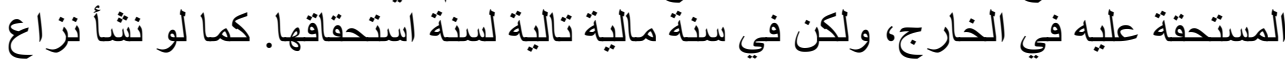

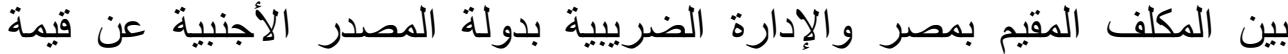

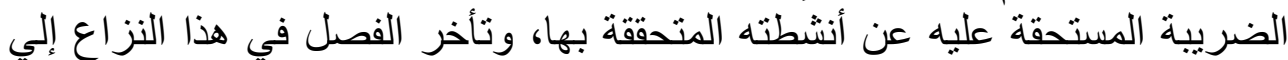

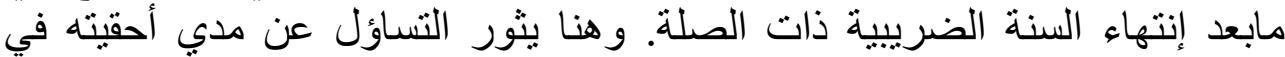

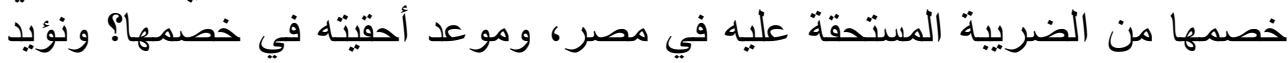

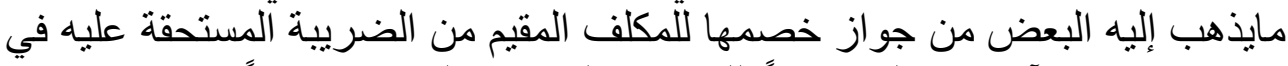

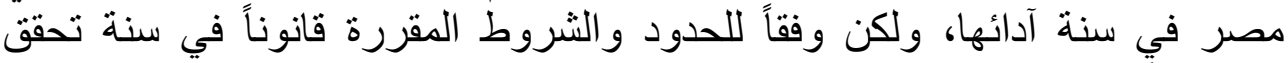
و عائها، أبي في سنة استحقاقها.'

غير أن المكلف المقيم في مصر قد يدفع الضريبة الأجنبية أولاً، ويقوم بخصمها

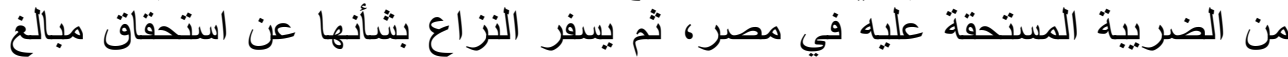

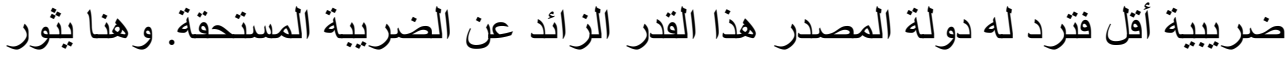

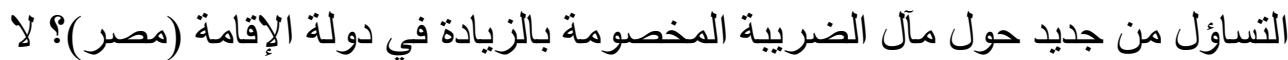

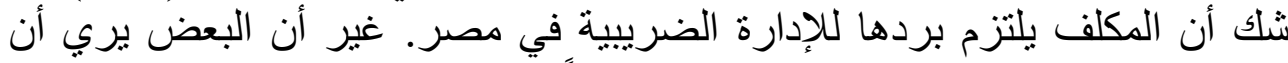

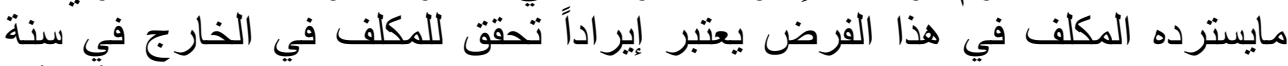

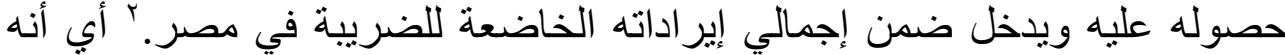

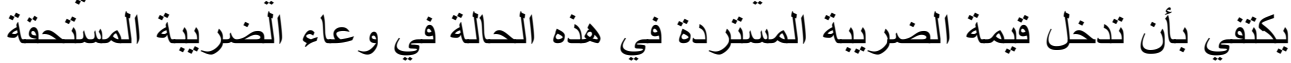

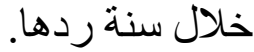

وفي ضوء هذا الثرط فإن إعفاء المكلف من الضريبة في دولة المصدر يجعله

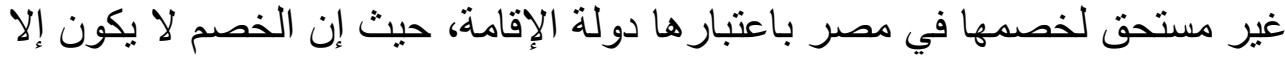

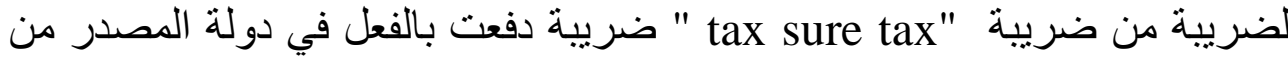

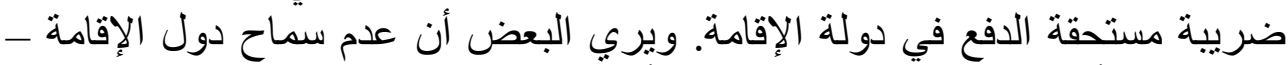

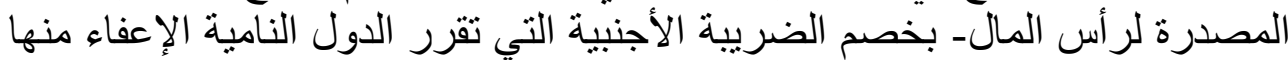

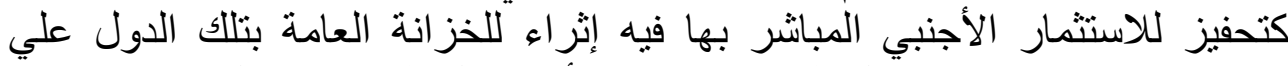

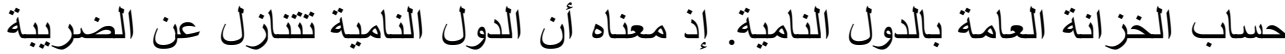

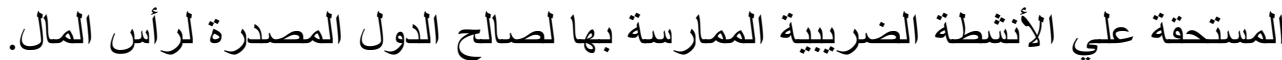

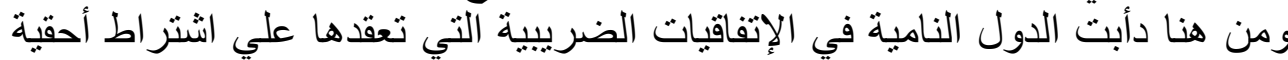

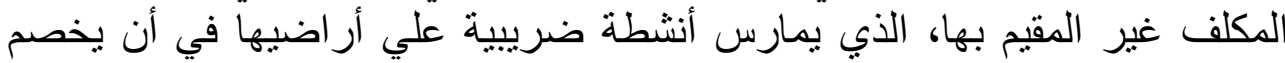
الضريبة المتعلقة بها من الضريبة المستحقة عليه في دولة الإقامة. حتي ولَّو كان قد نت

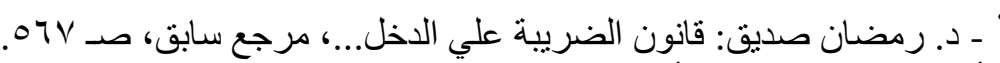

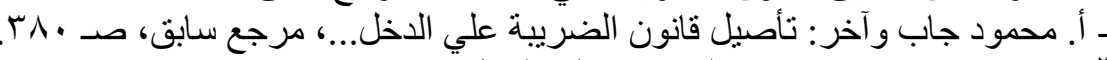

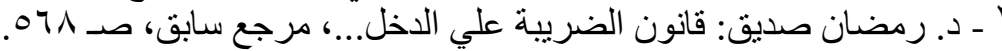

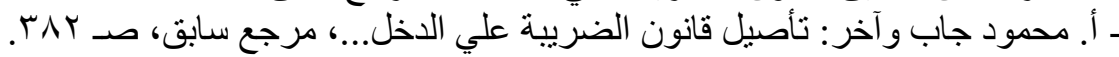


إعفاؤه من الضريية في دولة المصدر، مني تم ذلك لأغر اض التنمية الإقتصادية. وقد سبق بيان ذلك تفصيلاً عند تناولنا لمبدأ تقييد الضريبة.

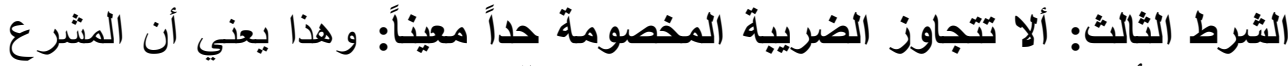

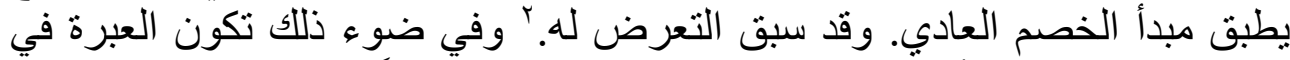

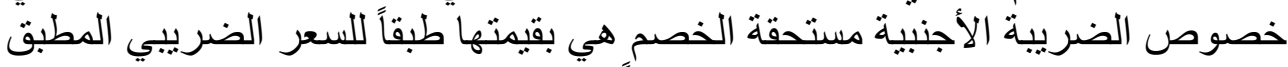

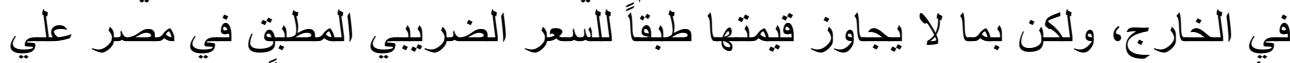

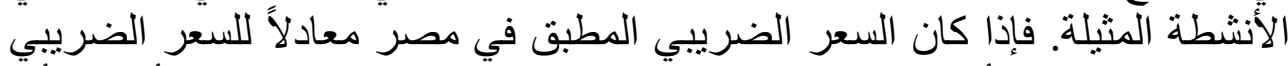

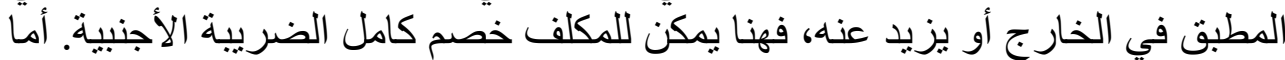

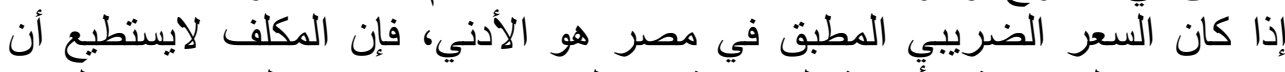

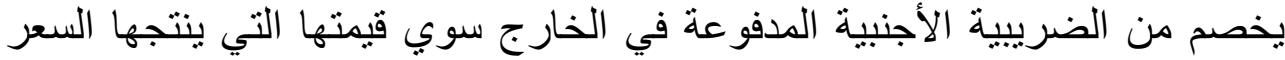

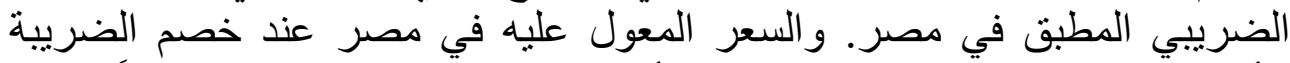

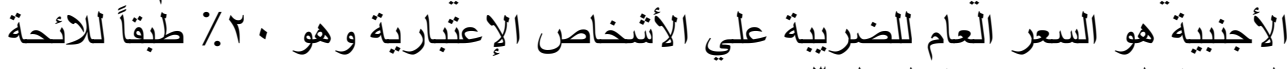

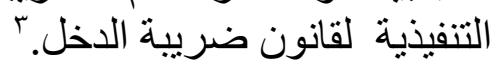

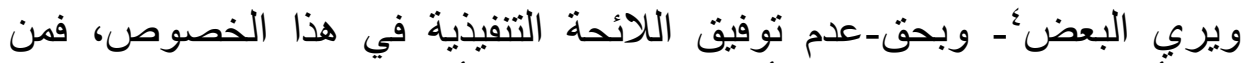

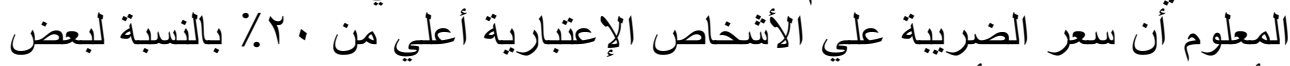

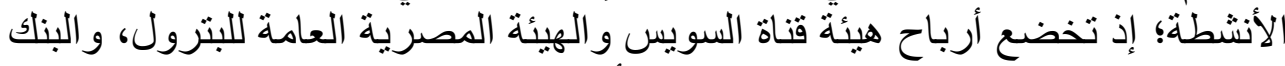

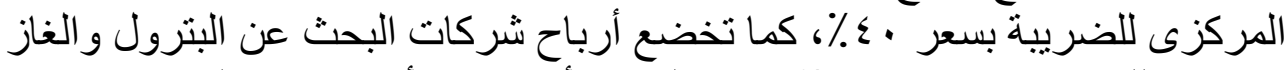

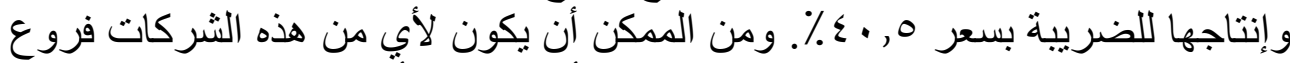

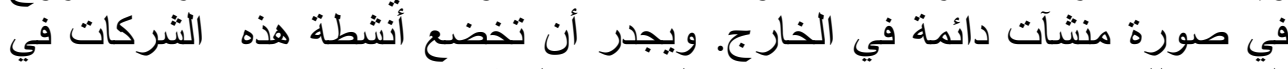

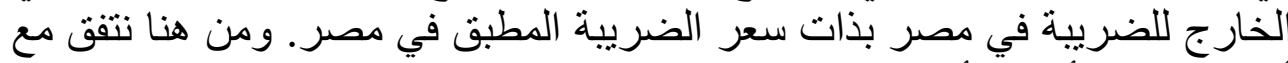
أنصار هذا الر أي في أولوية تعديل نص اللائحة التنفيذية بمأ ير اعي ذلك.

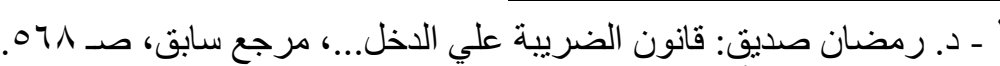

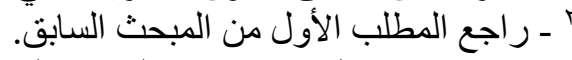

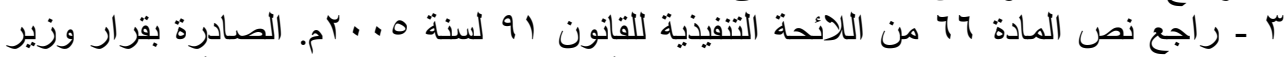

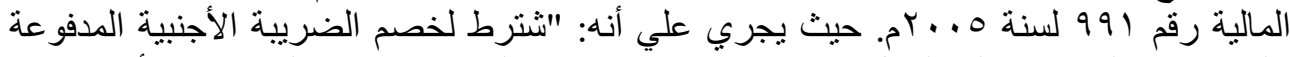

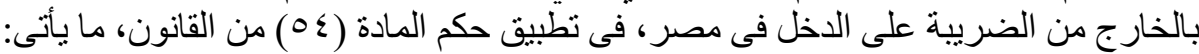

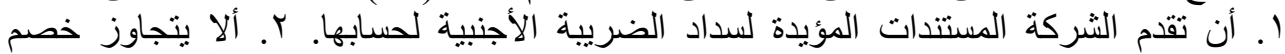

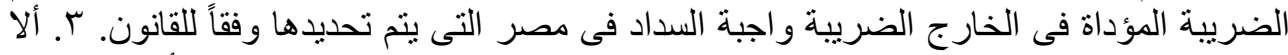

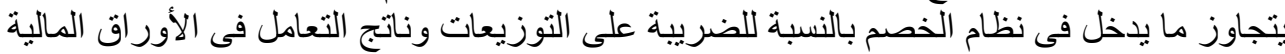

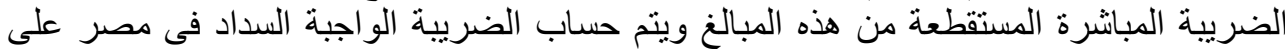

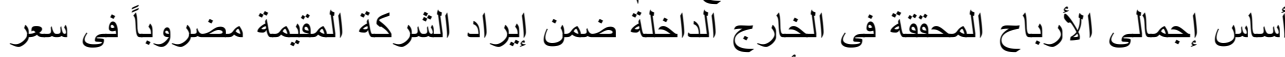

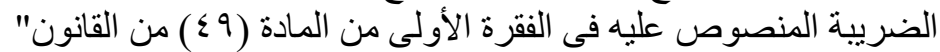

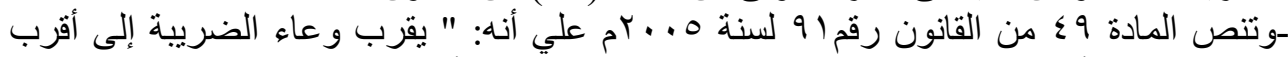

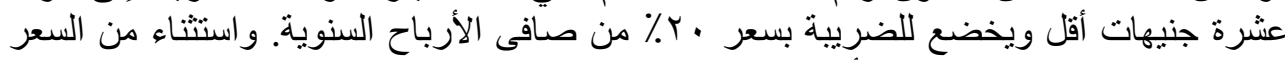

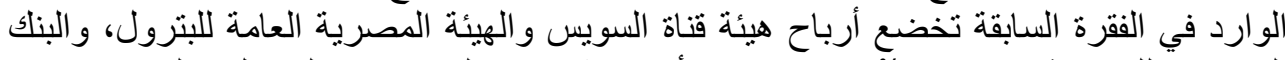

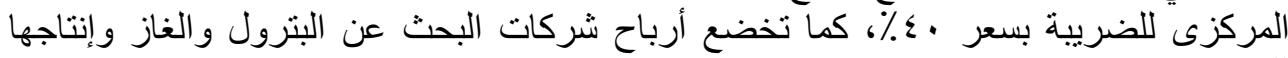

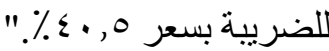
" ـ د. رمضان صديق: قانون الضريبة علي الدخل...، مرجع سابق، صـ 
الإئتمان الضريبي وآثارة الإقتصادية والمالية "دراسة مقارنة"

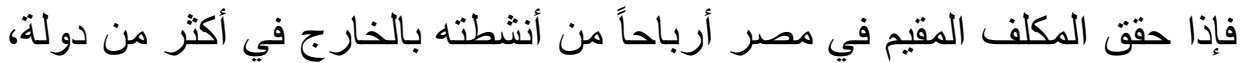

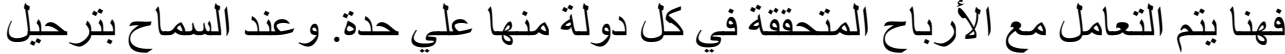

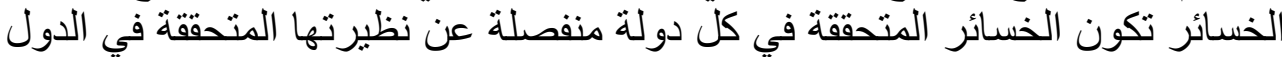

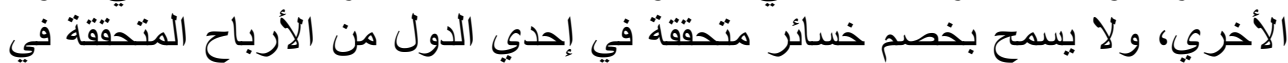
دولة أخري.' و هذا هو المعمول به في التشريعات المقارنة علي ما أسلفنا. ـأثر عدم توافر شروط خصم الضريبة الأجنبية:

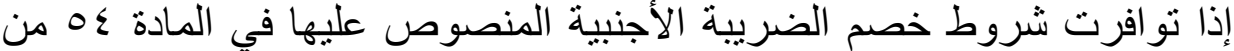

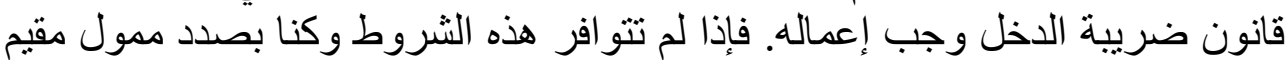

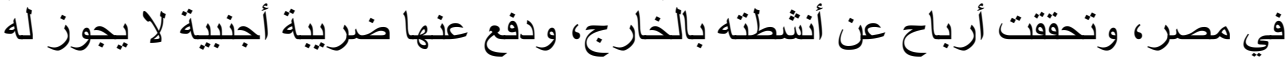

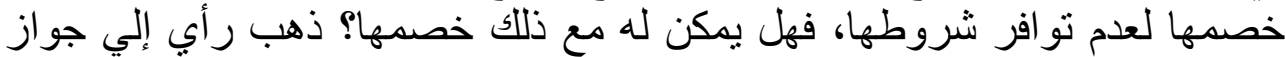

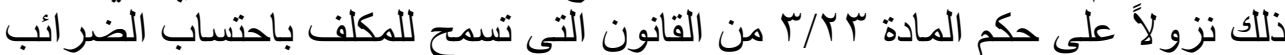

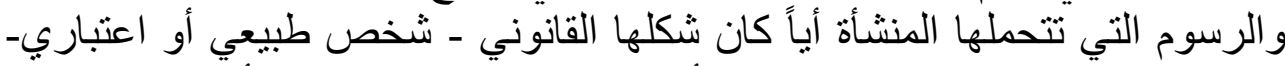

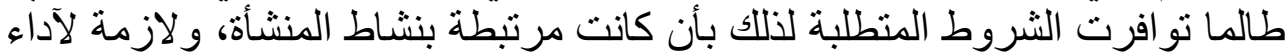

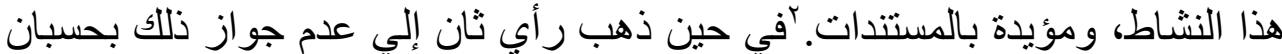

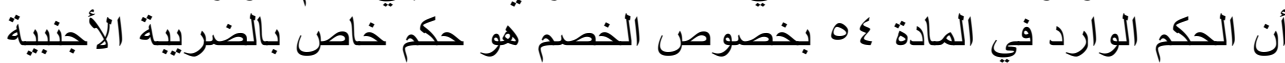

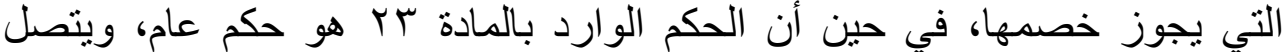

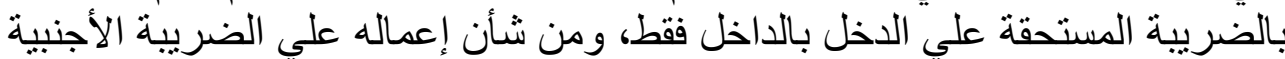

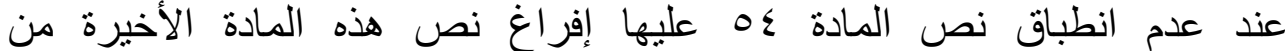

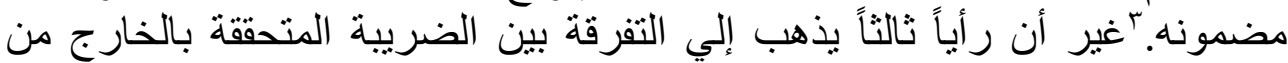

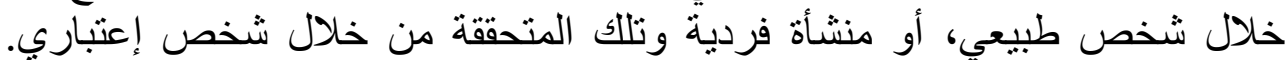

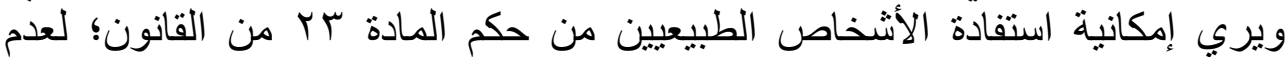

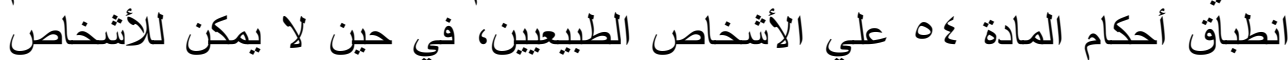

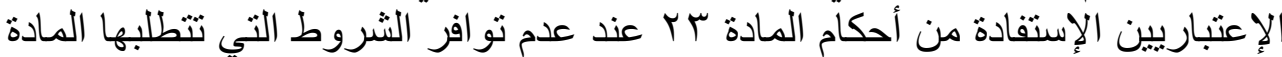

ـه من القانون. وساق أنصار هذا الر أي من أحكام قضاء الإن النقض مايؤيد منطقهر.

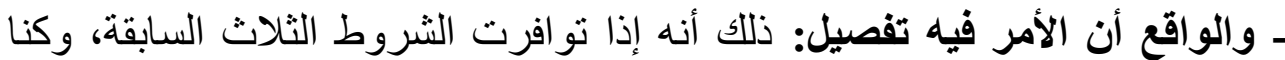

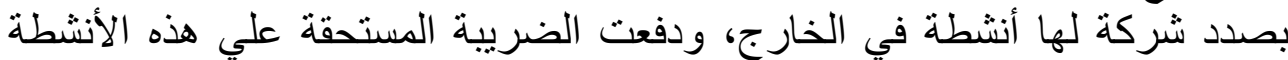

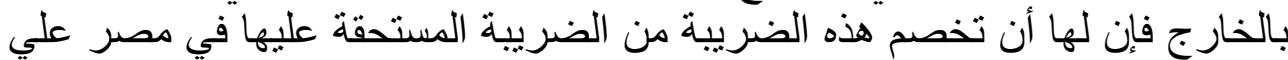

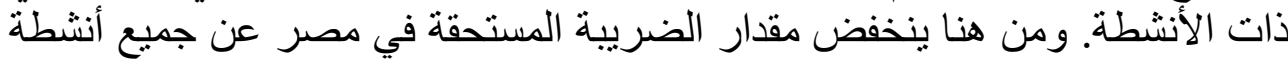

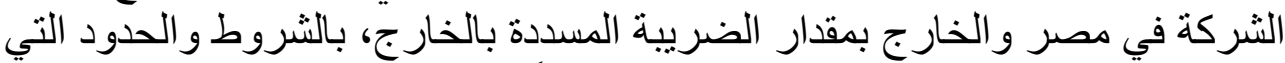

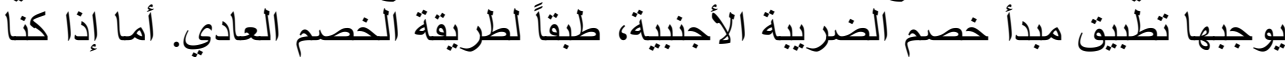
بصدد شخص طبيعي يمارس نشاطاً ضريبياً بالخارج، أو شركة تمارس نشاطية أنساً

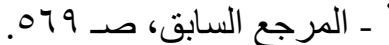

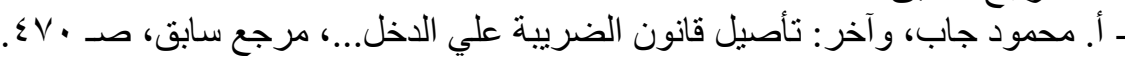

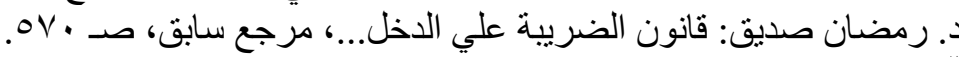

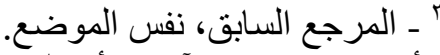

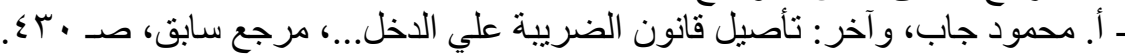

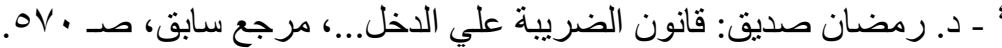


ضريبياً بالخارج ولكن لا تتو افر لها شروط خصم الضريبة الأجنبية، فهنا يمكن لكلا

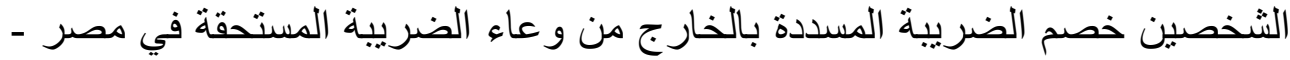
وليس من هذه الضريبة- باعتبار ها من التكاليف واجبة الخصاء الخصد. والفارق كبير بين فين

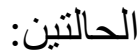

ففي حين تسمح قواعد خصم الضريبة الأجنبية المقررة بالمادة ؟0 من القانون

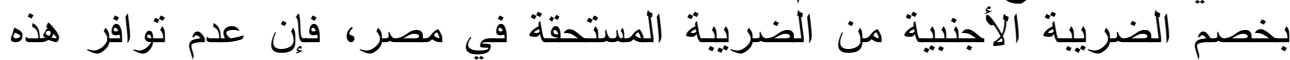

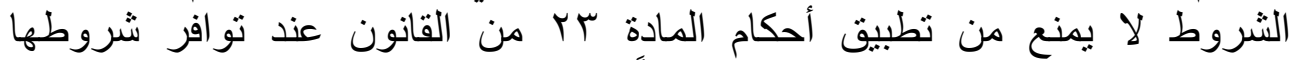

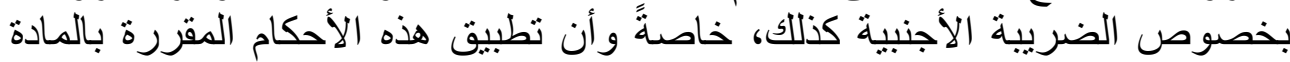

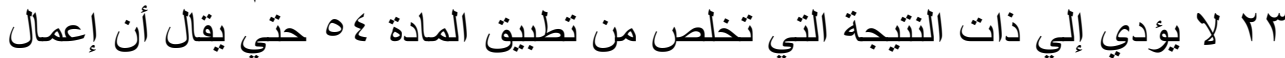

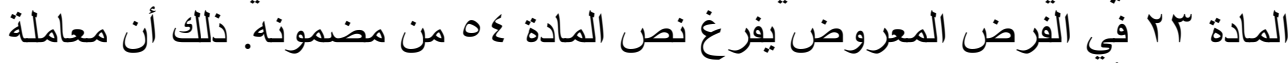

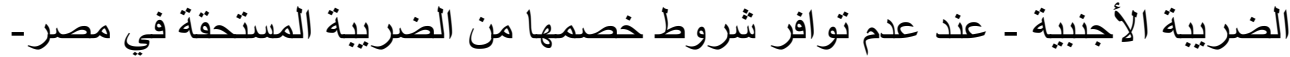

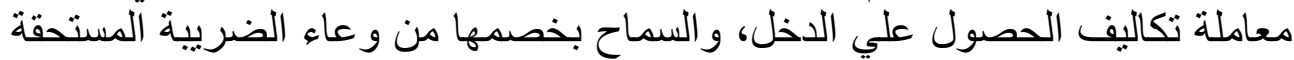

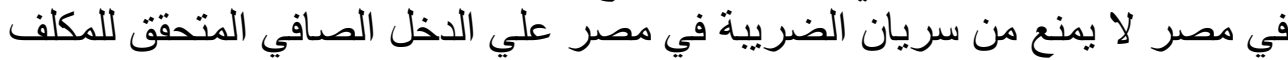

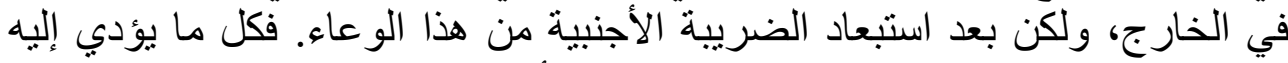

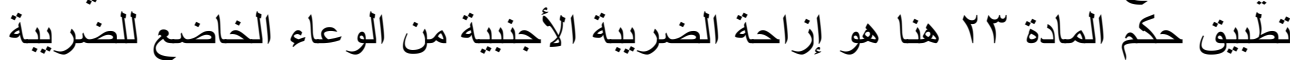

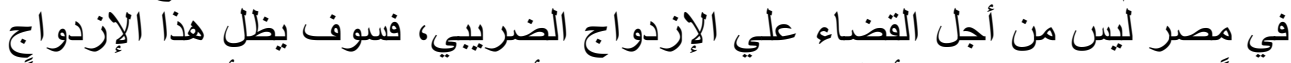
قائماً رغم ذللك، و إنما من أجل استبعاد الضريبة الأجنية الفية المدفو عة من أن تكون محلاً،

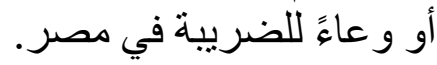

ومما لا شك فيه أن أثر كلا الحكمين علي الخزانة العامة في مصر كدولة إندامة إقامة

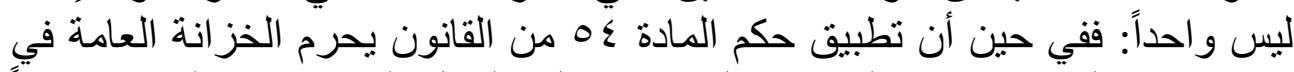

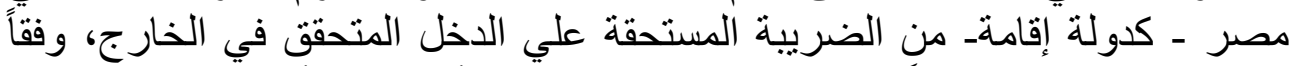

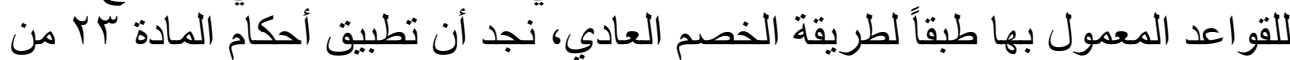

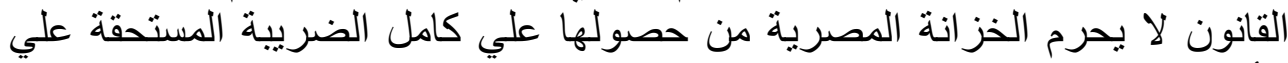

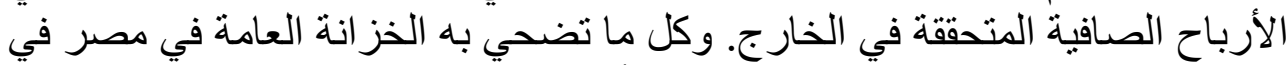

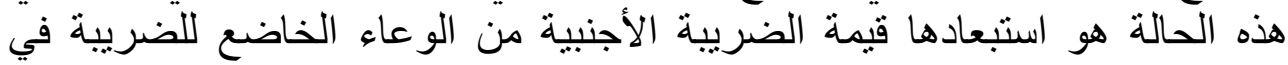

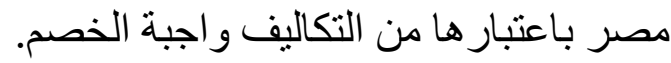
المطلب الثاني

\section{دور نظام الإنتمان في تلافي الإزدواج الضريبي الداخلي}

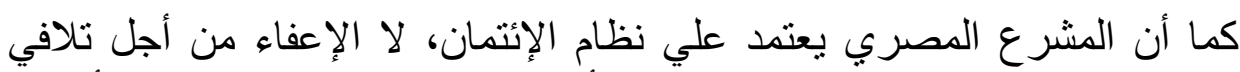

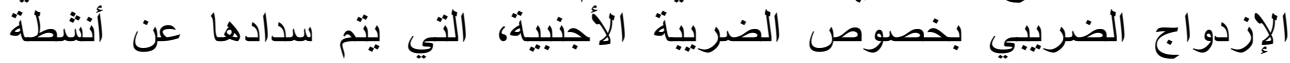

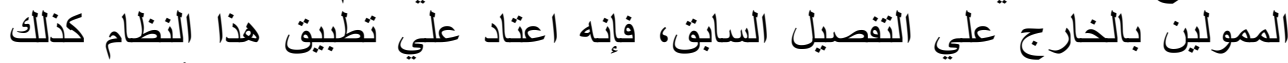

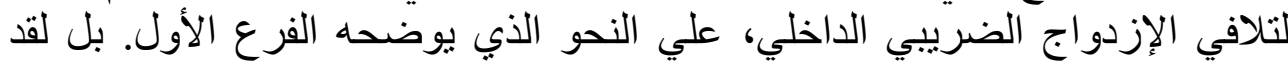

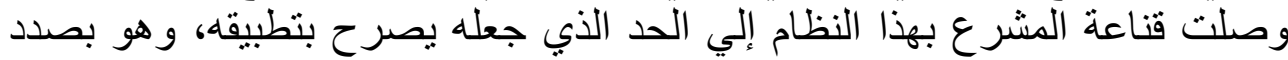

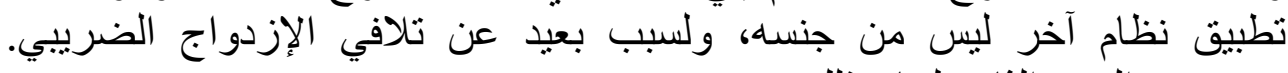
ويتعرض الفرع الثناني لبيان ذللك. 


\section{الفرع الأول}

\section{إعتيـاد المشرع علي تطبيق الإنتمـان لتلافي الإزدواج الداخلي}

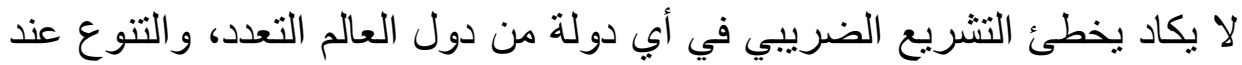

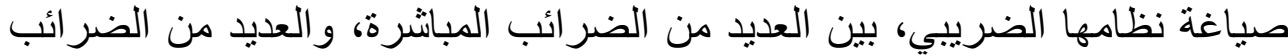

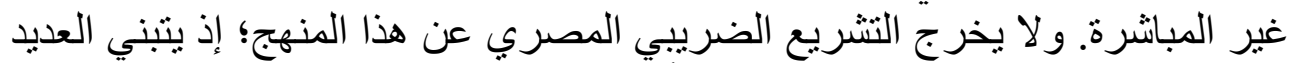

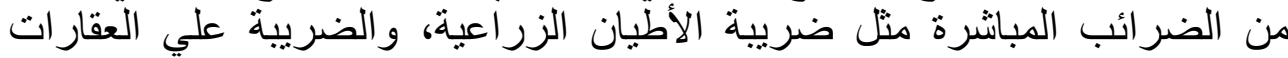

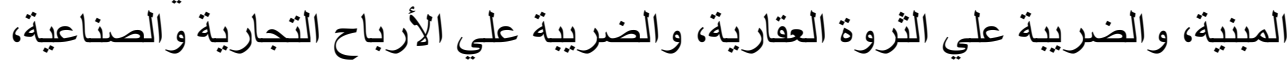

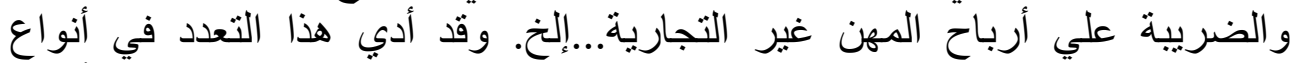

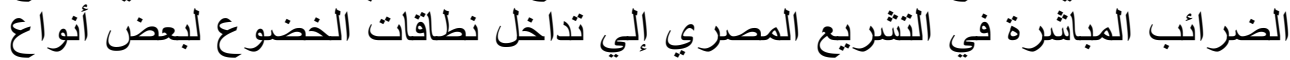

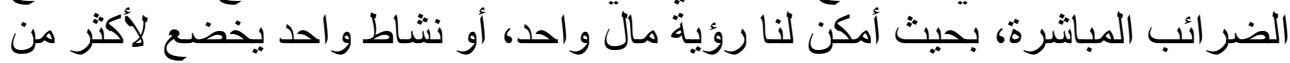

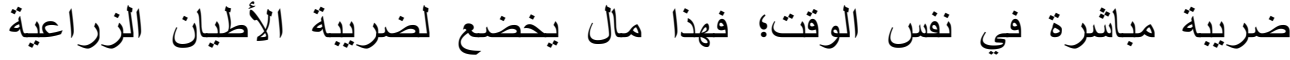

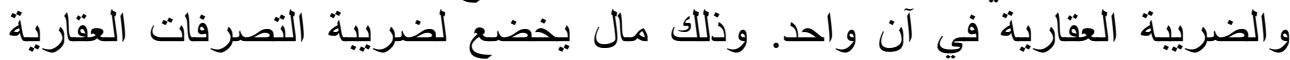

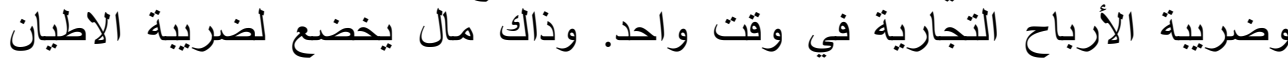

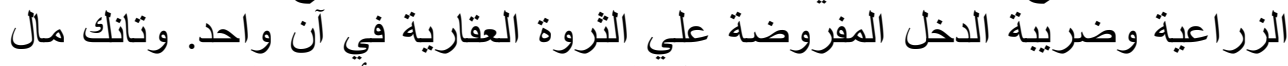

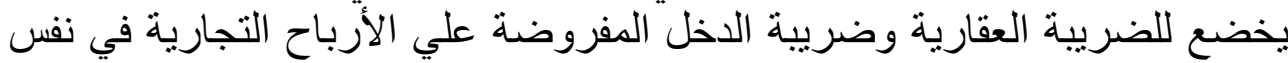

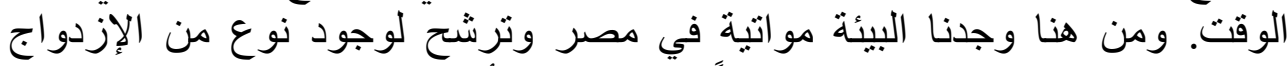

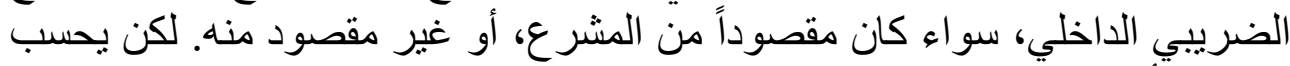

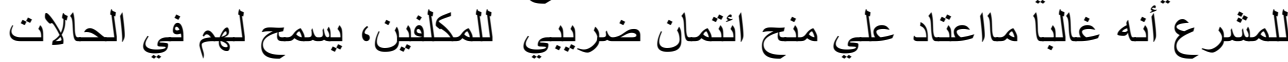

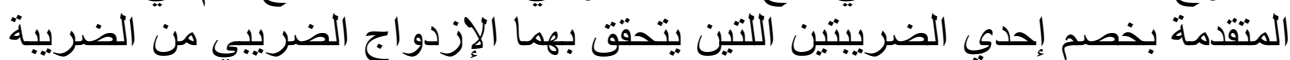

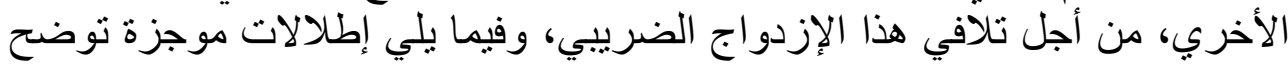
ذلك:

\section{ا ـ ضريبة الاطيان الزراعية والضريبة العقارية:}

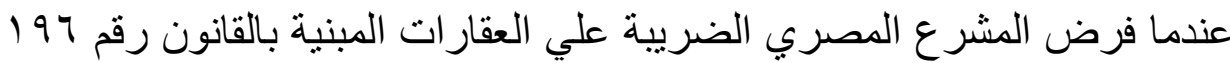

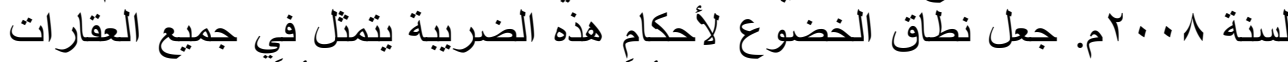

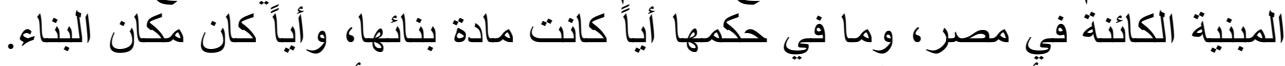

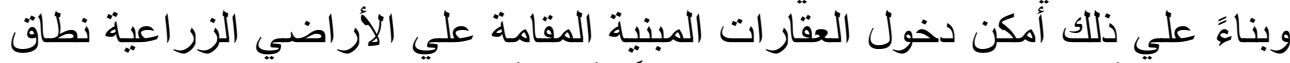

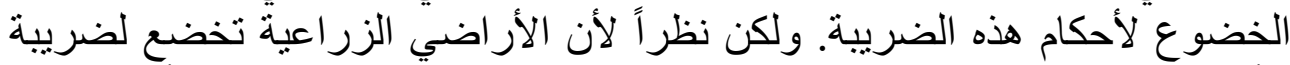

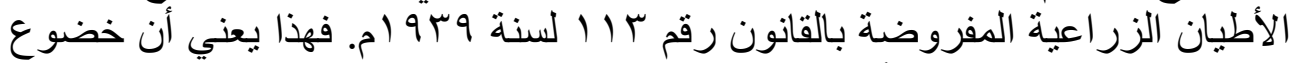

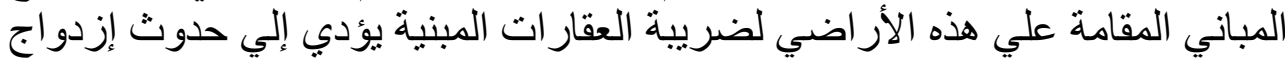

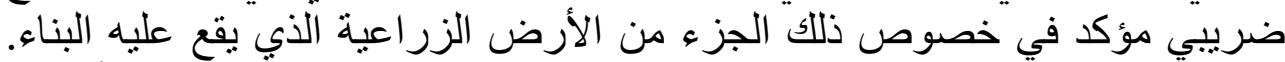

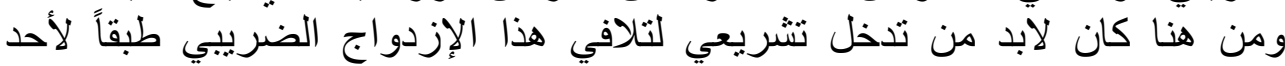

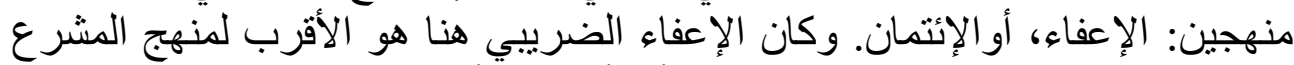

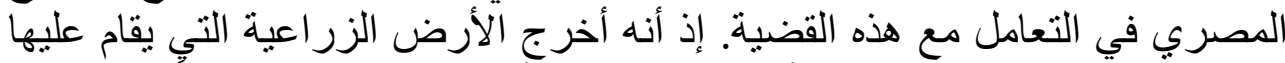

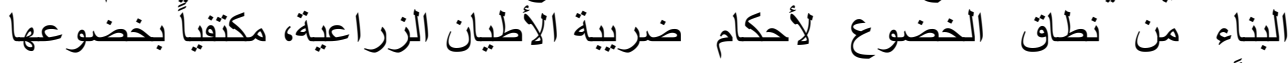
تبعاً للمبني المقام عليها للضريبة علي العقارات المبنية، بقطع النظر النظر عن صدور 


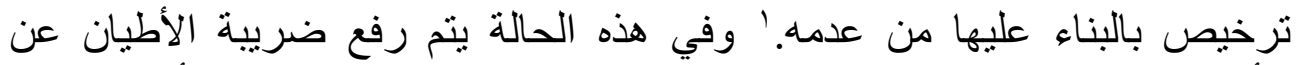

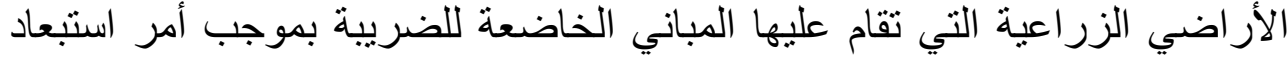

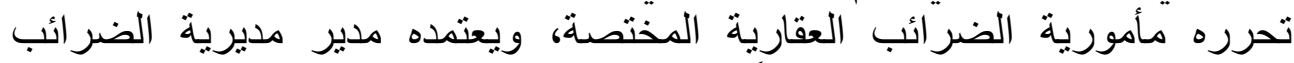

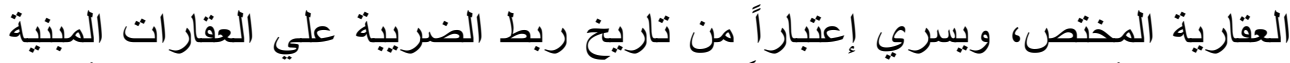

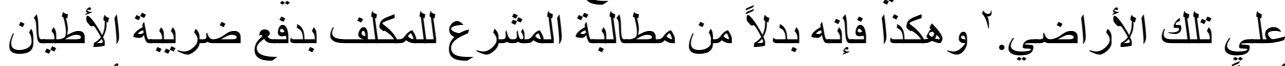

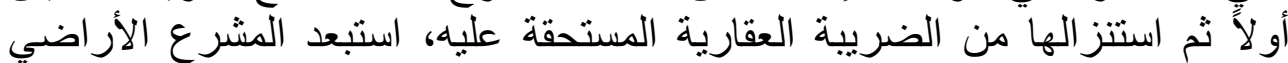

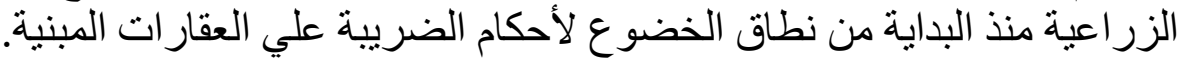

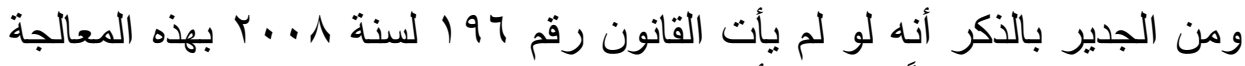

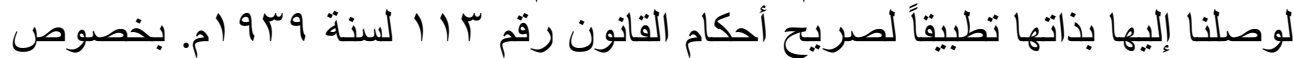

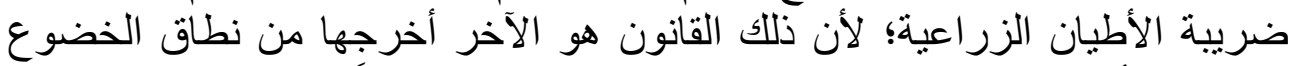

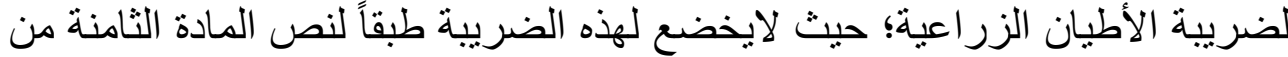

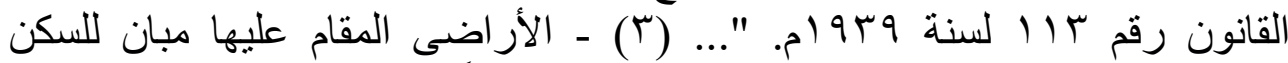

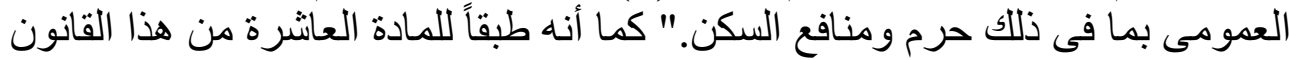

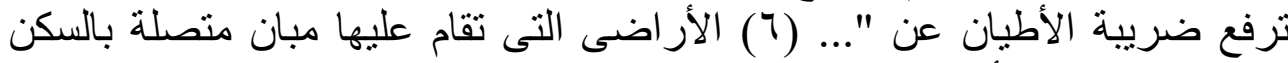

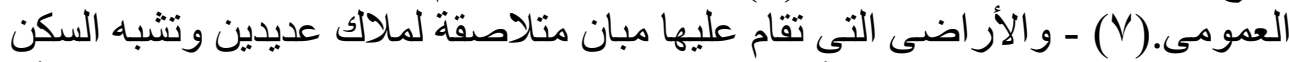

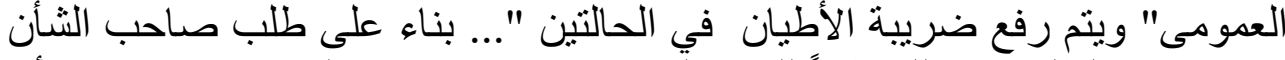

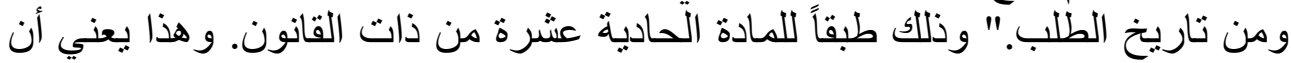

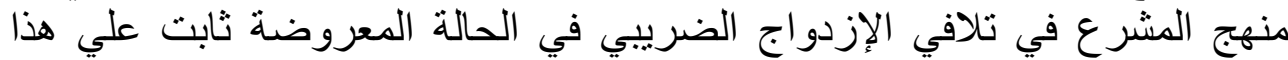
النحو منذ ثلاثينيات القرن الماضي.

\section{r - ضريبة التصرفات العقارية وضريبة الأرباح التجارية:}

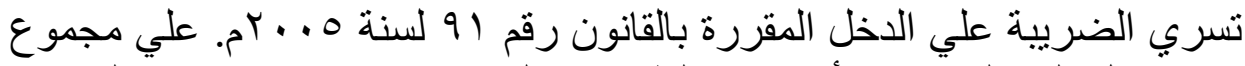

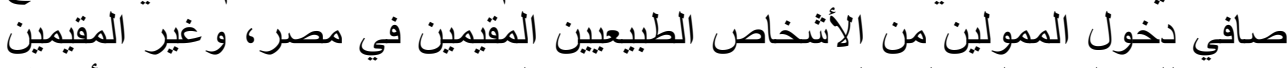

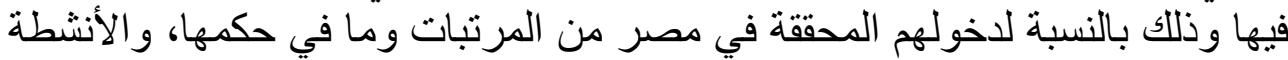

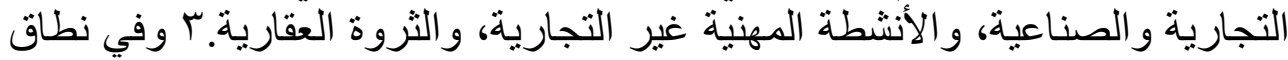

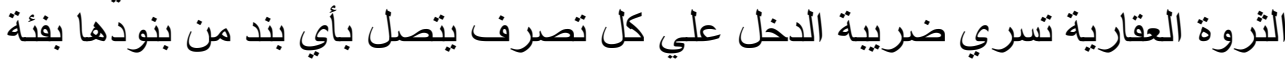

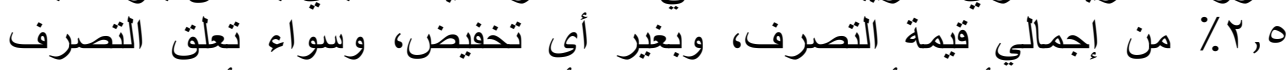
بالعقارات المبنية، أو بالأراضى الفضاء من أجل البناء عليها في أي مكان، عداء

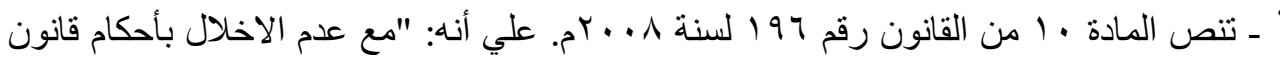

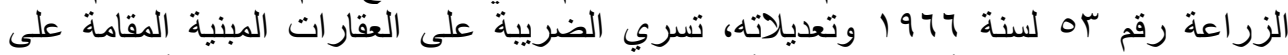

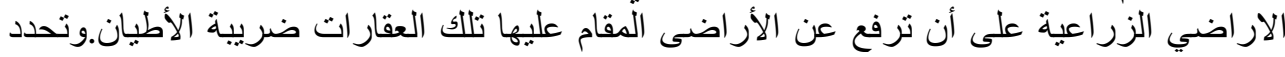

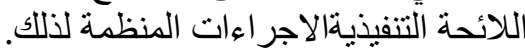

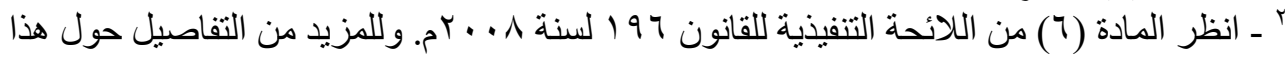

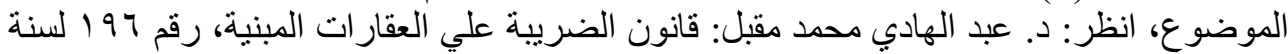

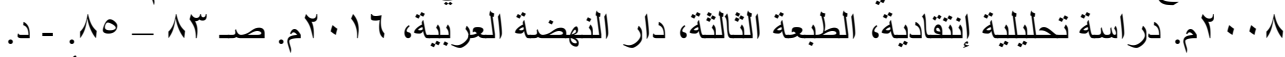

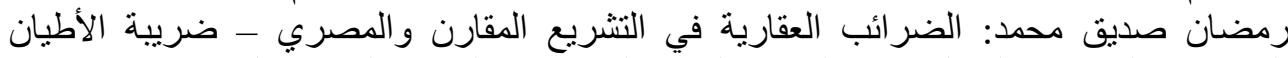

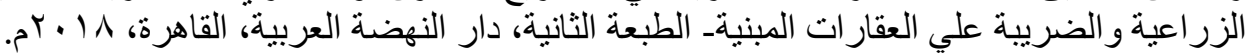

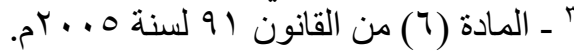


الإيتتمان الضريبي وآثارة الإقتصادية والمالية "دراسة مقارنة"

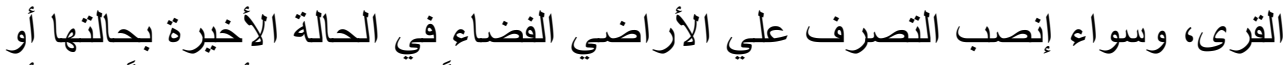

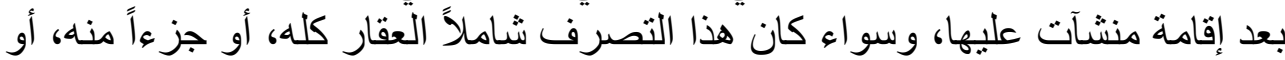

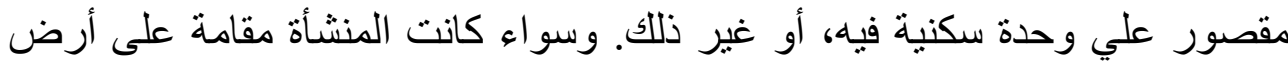

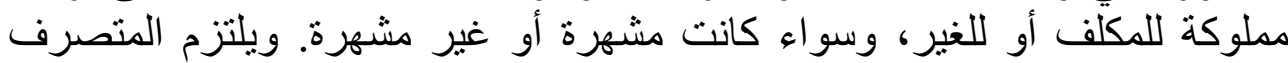

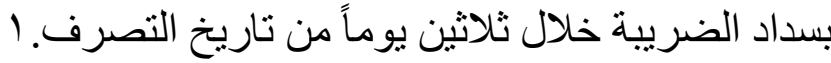

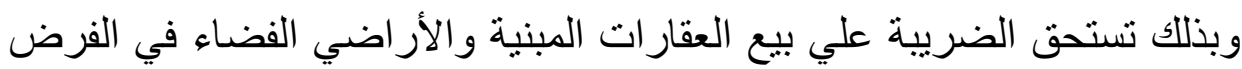

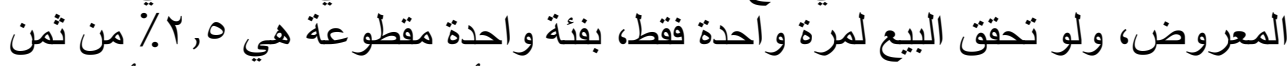

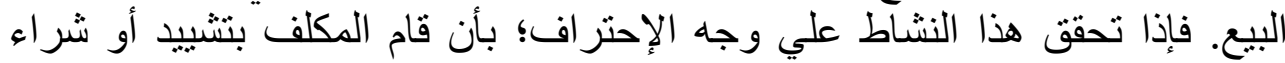

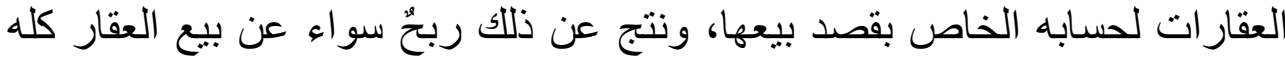

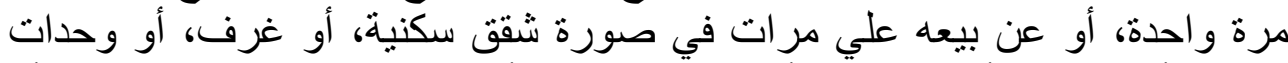

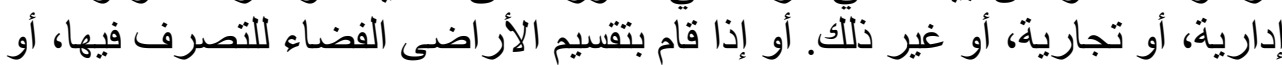

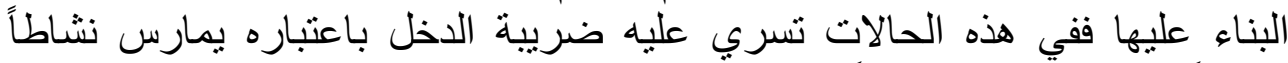
تجارياً بالسعر الدحدد قانوناً للشريحة التي يقع دخله في نطاقها، علي حسب قلئ قيمة

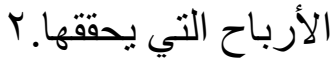

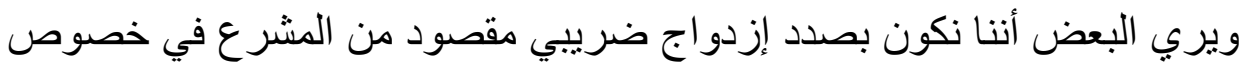

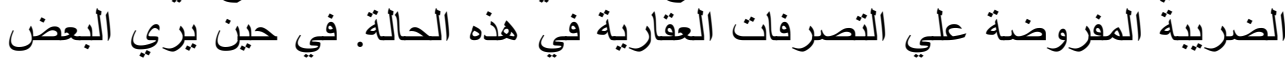

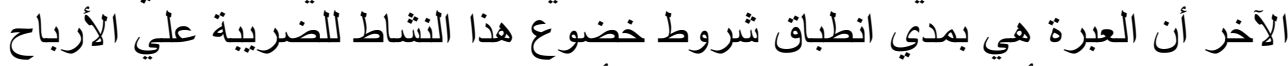

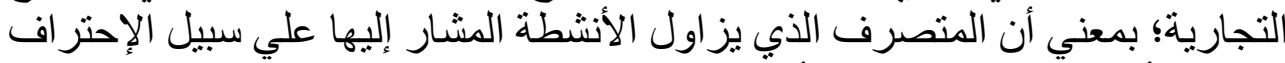

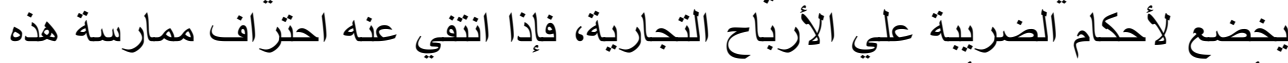

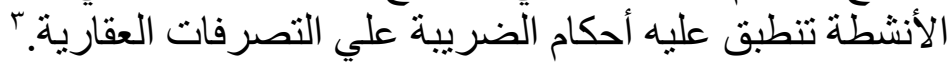

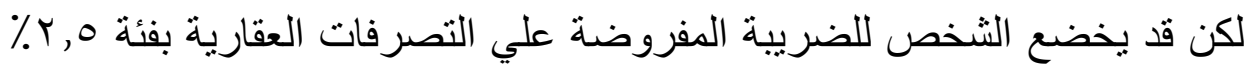

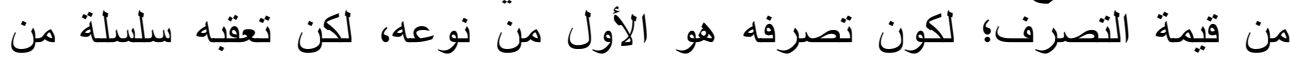

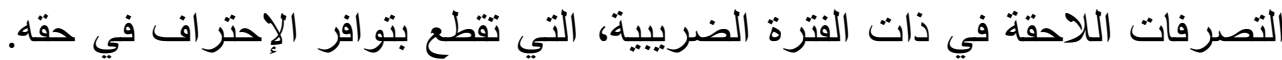

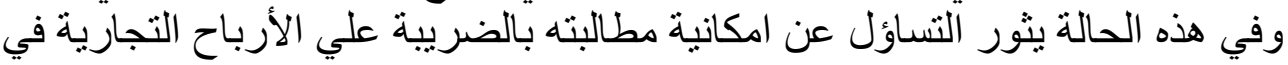

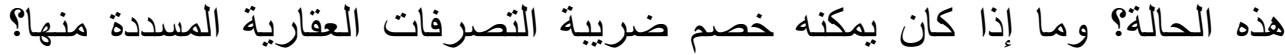

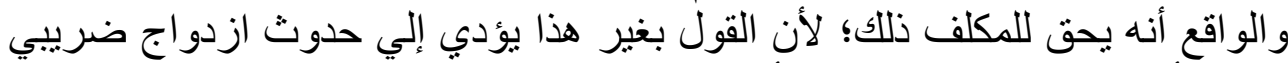

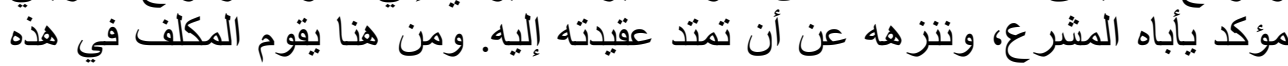

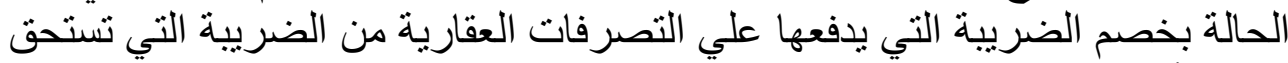

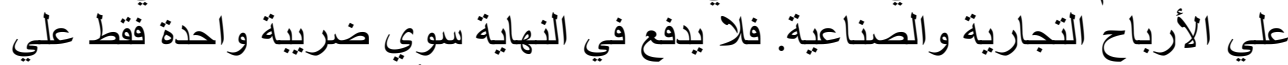
كل تصرفاته في ثروته العقارية هي الضرية لإيبة علي الأرباح التياح التجارية والصناعية

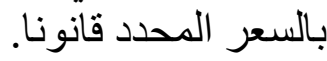

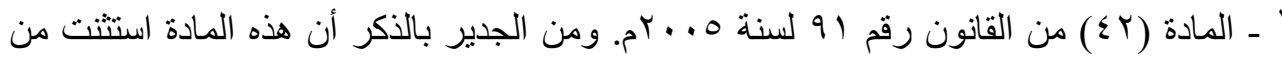

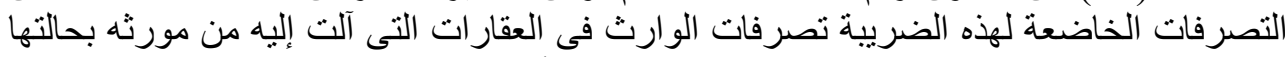

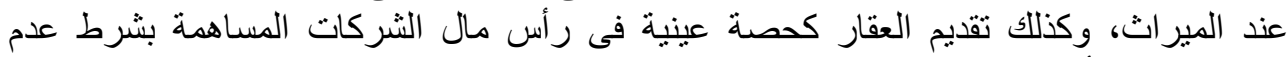

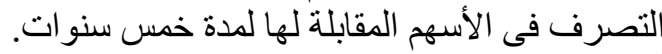

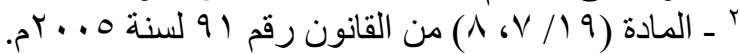

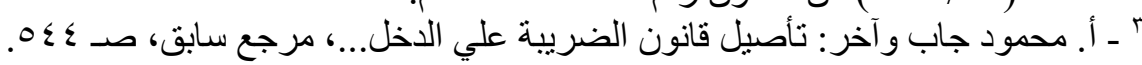




\section{rـ ضريبة الاطيان الزراعية وضريبة الاخل علي الثروة العقارية:}

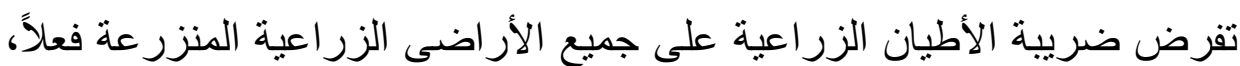

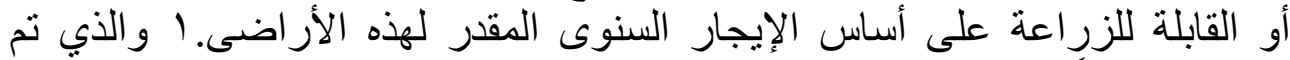

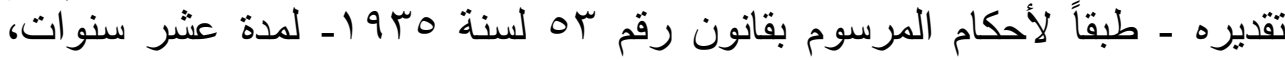

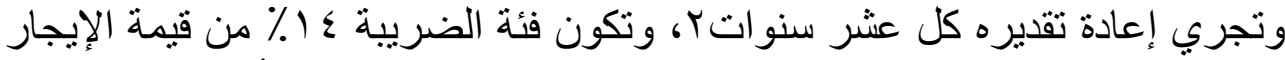

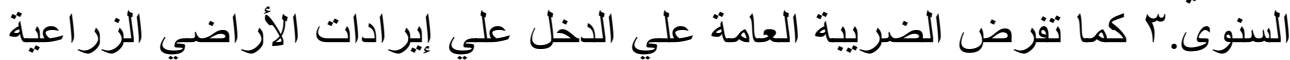

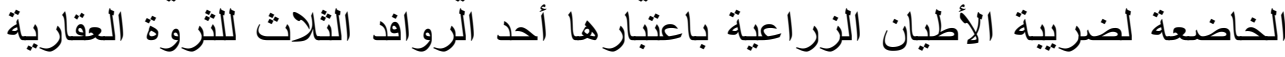

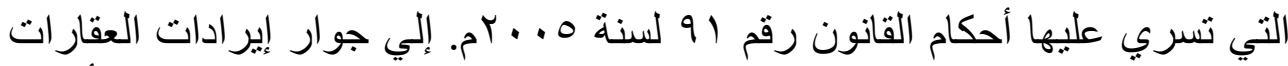

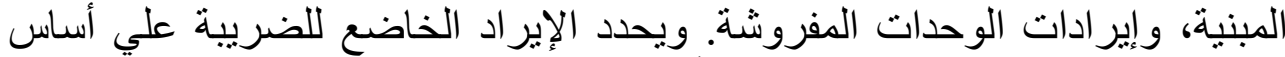

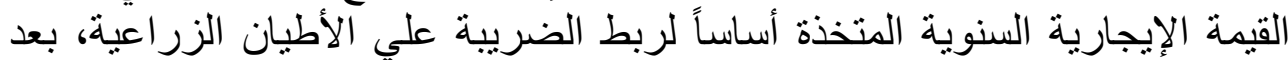

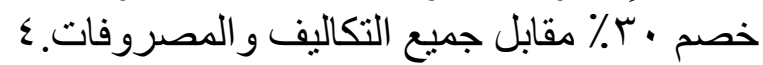

وعلي ذلك تتحمل الأراضي الزراعية الخاضعة لضريبة الأطيان الزراعية

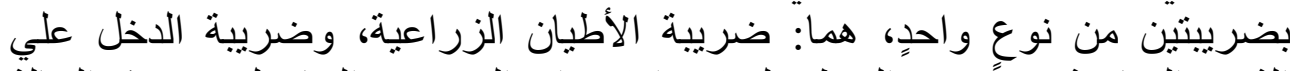

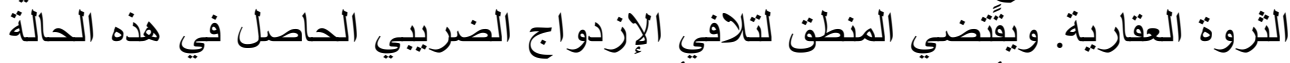

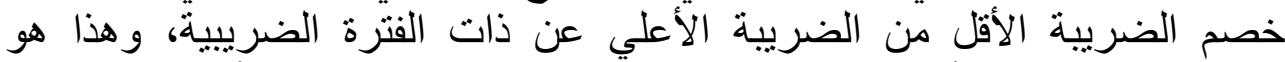

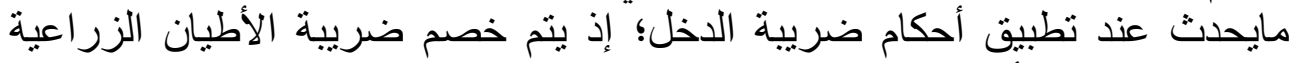

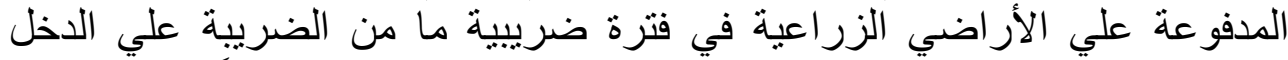

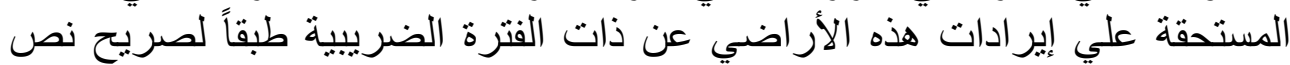

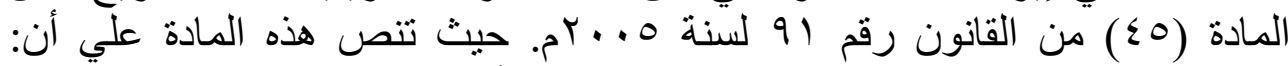

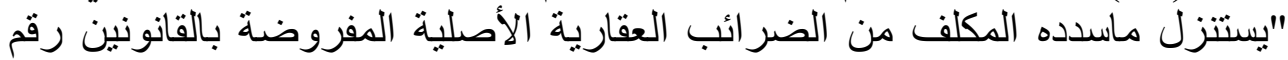

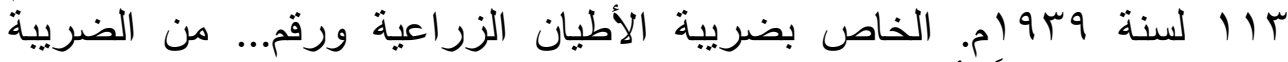

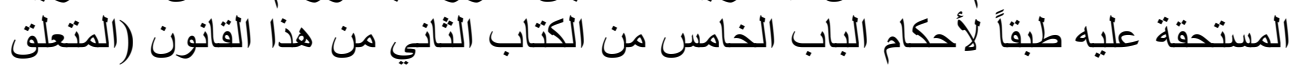

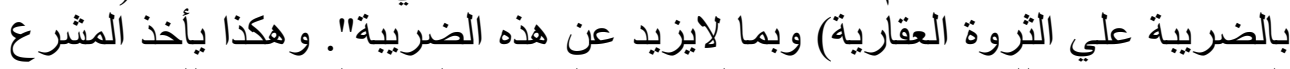

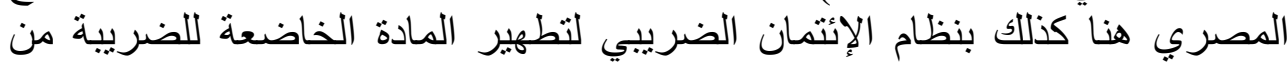

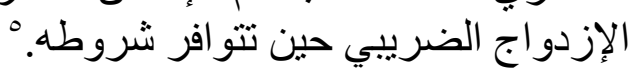

\section{ع ـ الضريبة العقارية وضريبة الاخل علي الأرباح التجارية:}

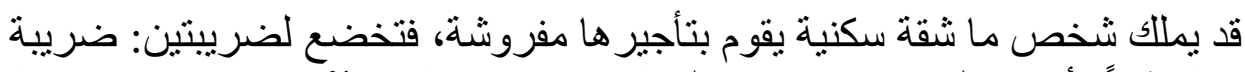

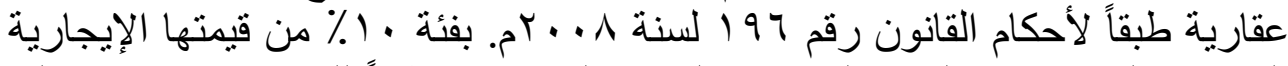

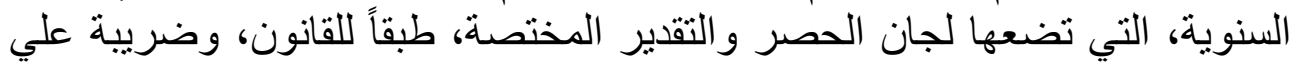

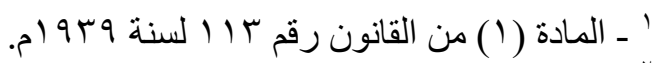

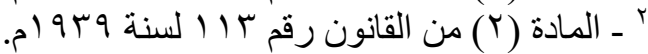

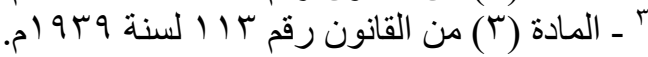

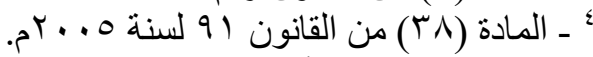

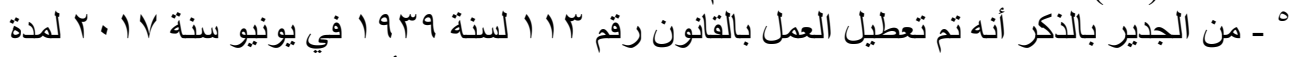

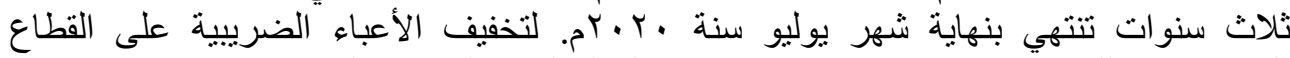

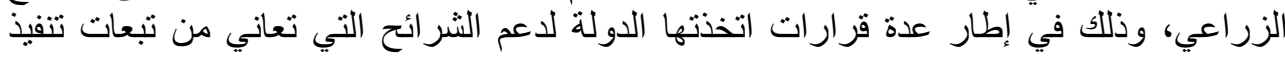
برنامج الإصلاح الاقتصادي وتقليص الدعم. 
الإيتمان الضريبي وآثارة الإقتصادية والمالية "دراسة مقارنة"

الاخل المتحقق من تأجيره هذه الثقة السكنية مفروشةًً. ومن شأن استحقاق هاتين

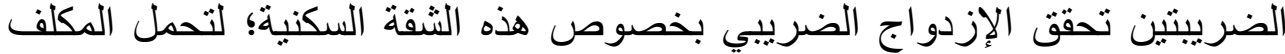

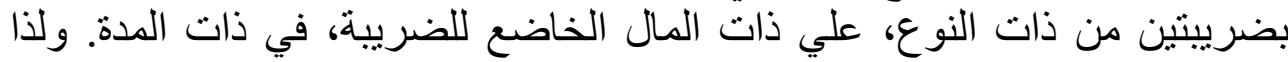

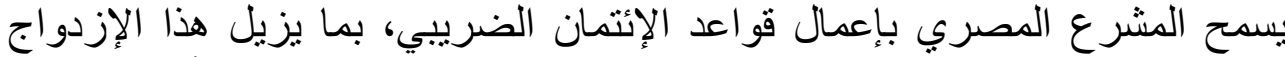

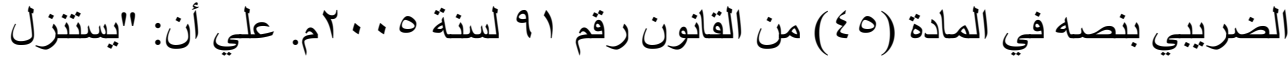

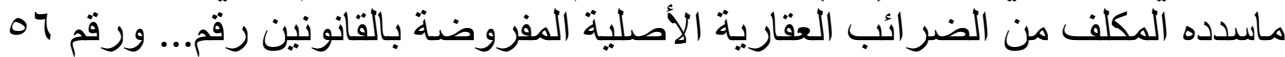

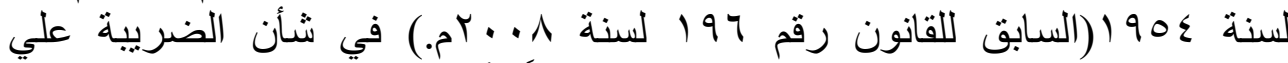

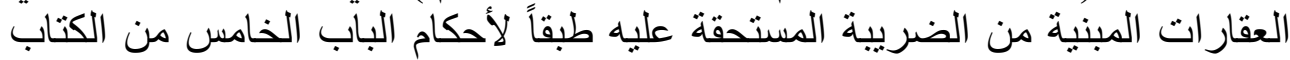

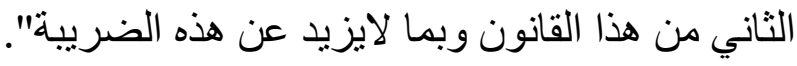

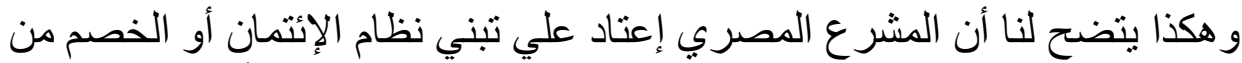

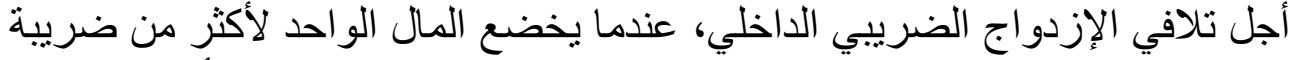

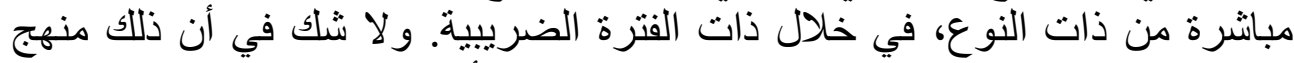

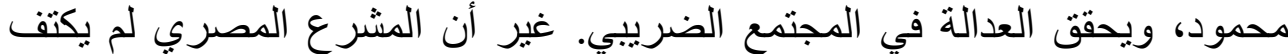

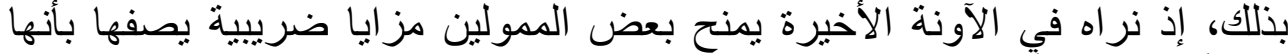

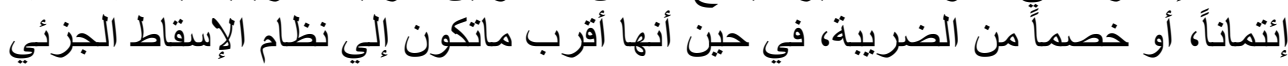
للضريبة، أو العفو الجزئي عنها، ونفرد الفرع التالي لبيان هذه الحيان الحالة.

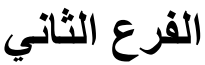

\section{تطبيق مصر ائتمان في حكم العفو لايستهـف إزدواجاً ضريبياً}

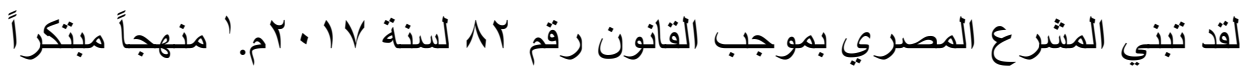

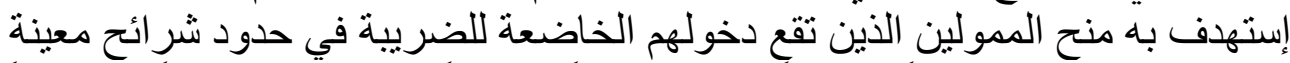

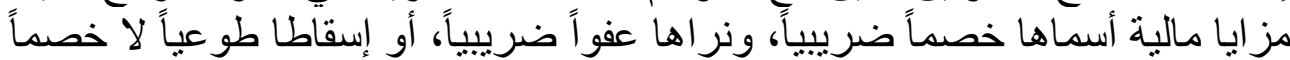

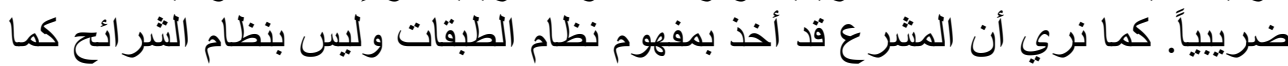

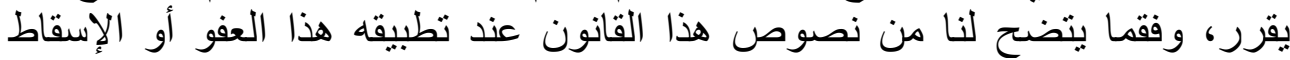

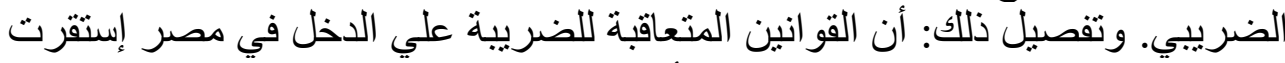

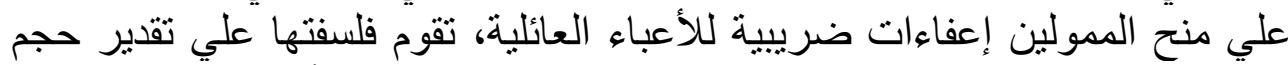

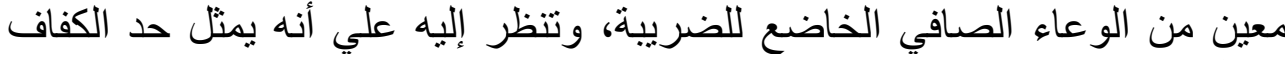

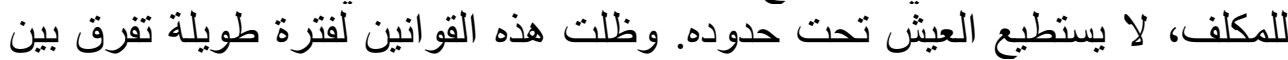

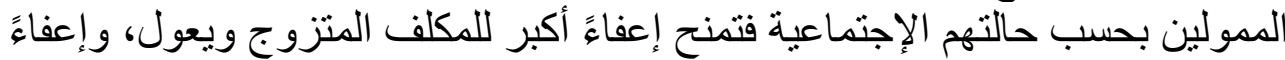

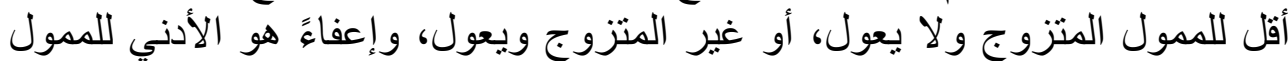

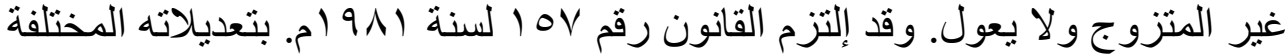

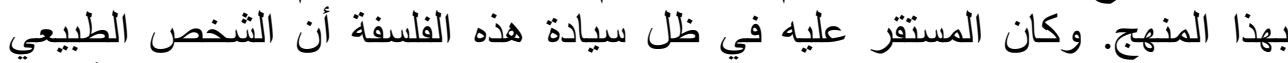

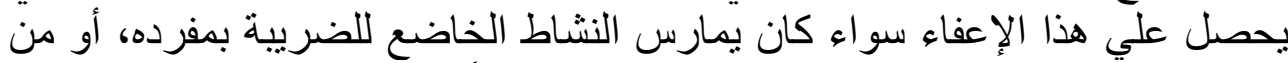

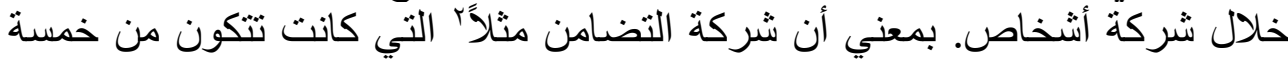

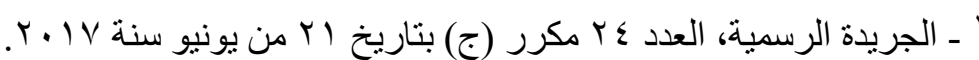

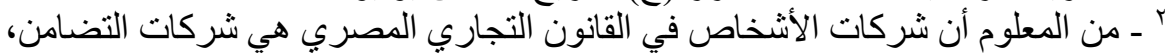
وشركات التوصية البسيطة، وشركات المحاصة. 
أشخاص، وتمارس نشاطاً يخضع لضريية الدخل، كان كل شريك بها يتمتع بهذا

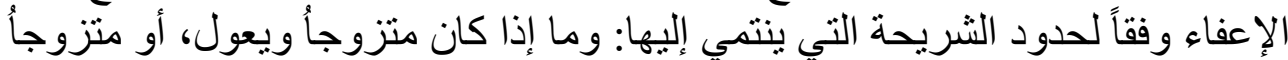

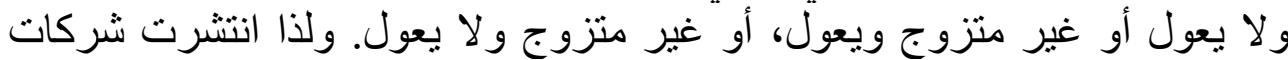

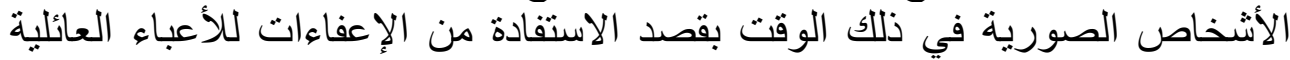

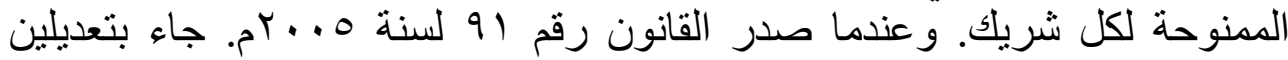

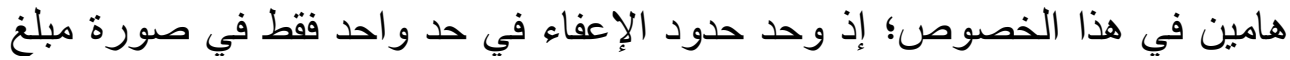
واحد ثابت' لكل شخص طبيعي مقيم بصرف النّ النظر عن حالته الإجتماعية، يتم إعفاؤه

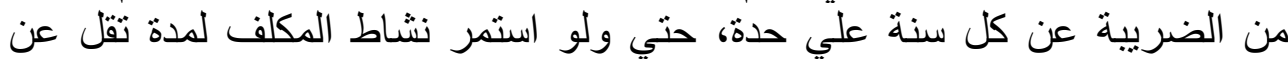

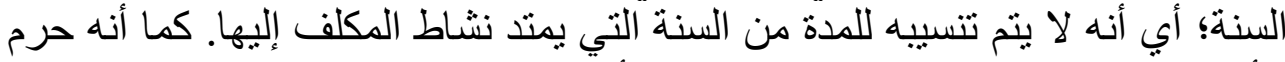

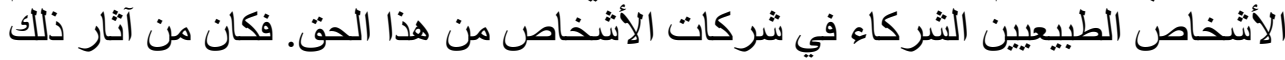

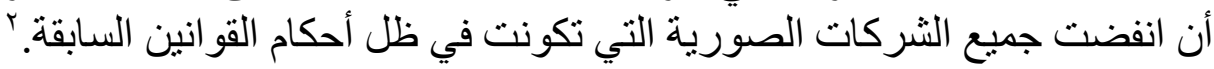

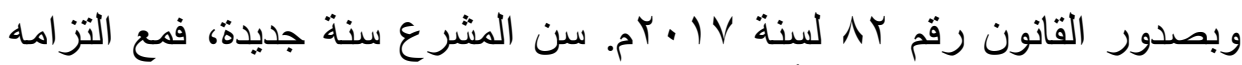

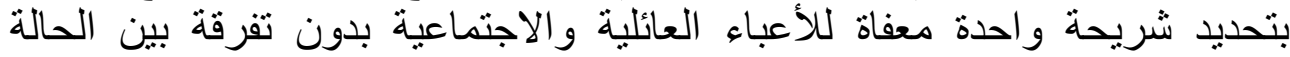

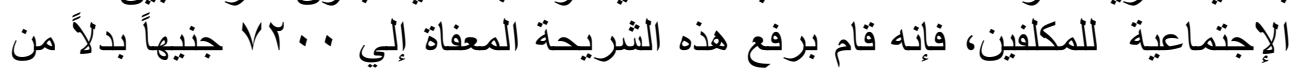

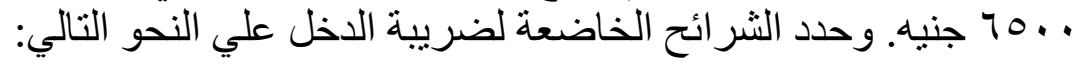
الشريحة الأولي: حتي . . Pr. جنيها، ويتم إعفاؤها من الضريبة.

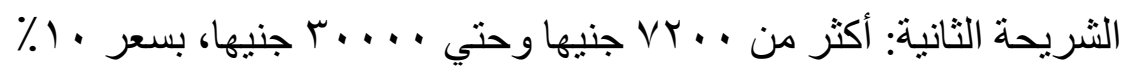

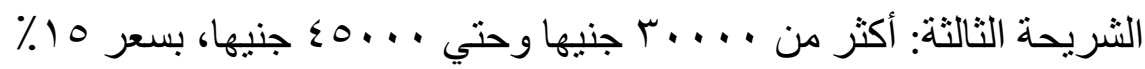

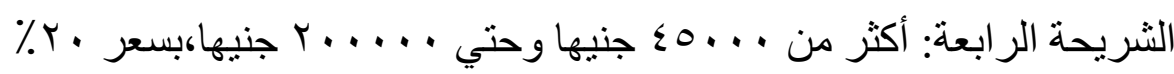

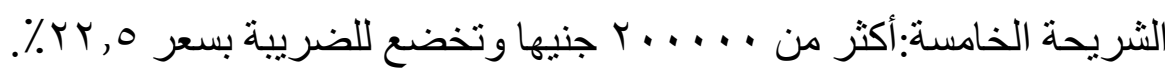

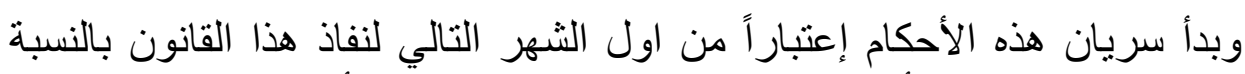

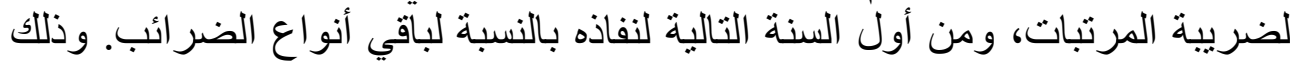

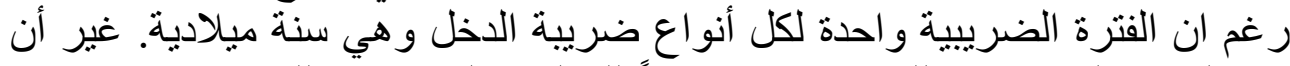

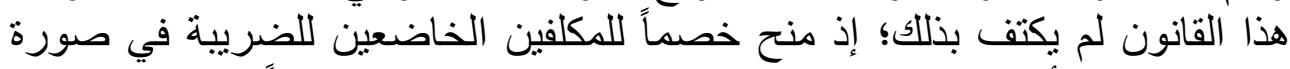
عفو ضريبي، أو إسقاط لجزء من الضراء الضريبة المستحقة، وذللك وفقاً للشرائح الثانية، و الثالثة، والر ابعة، وتدرج في هذا الخصم هو الآخر بحسب الثريحة الثران التي ينتمي اليها المول. غير أنه خلط في التطبيق بين التصاعد بالثر ائح وبين التصاعد بالّبقات.

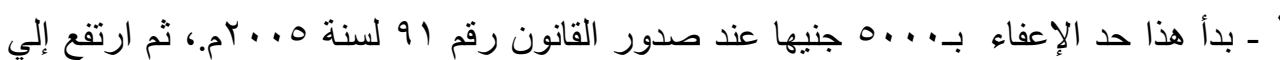

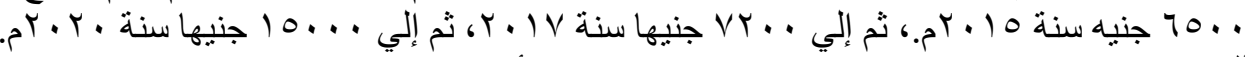

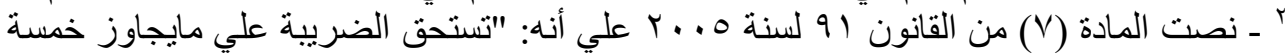

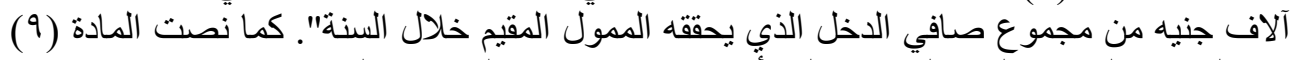

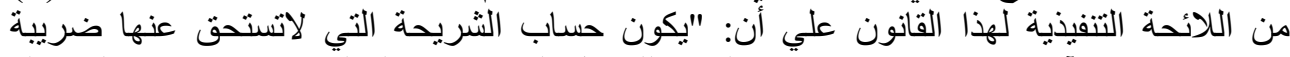

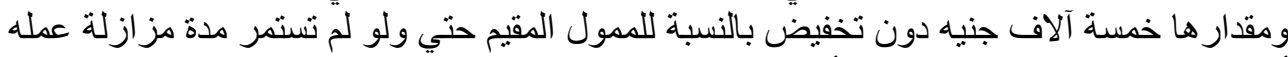
أو مز اولة نشاطه الفترة الضريبية بافية دأكملها.

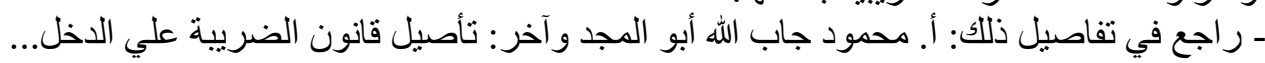
مرجع سابق، صـ 0 ـ 1 و ومابعدها. 
الإعتمان الضريبي وآثارة الإقتصادية والمالية "دراسة مقارنة"

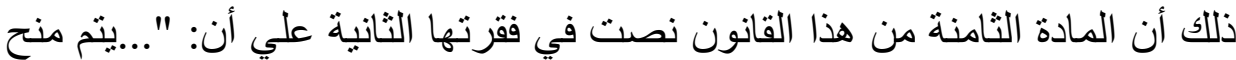

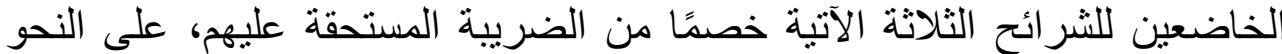

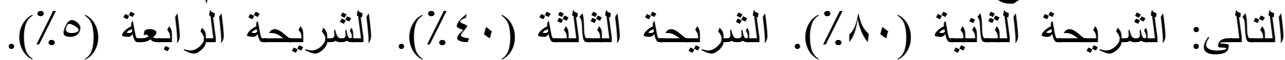

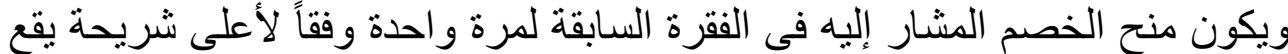

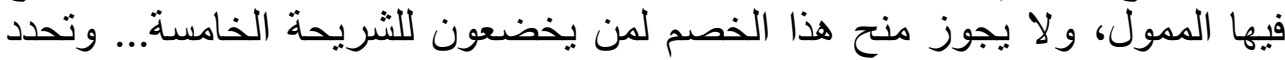

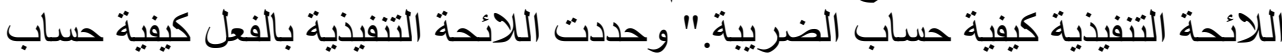

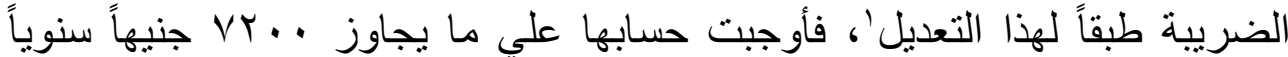

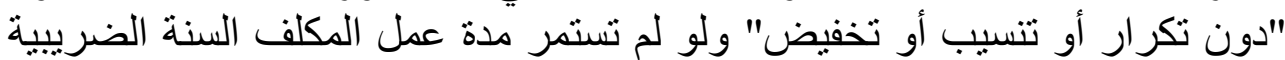

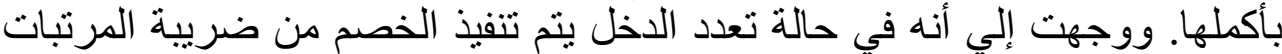

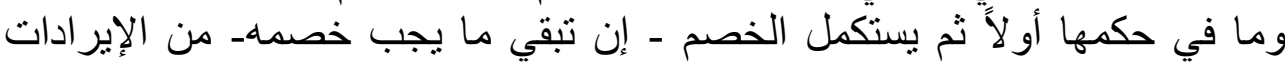

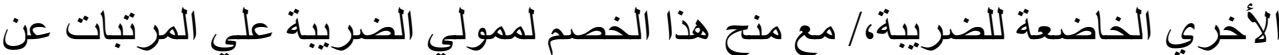

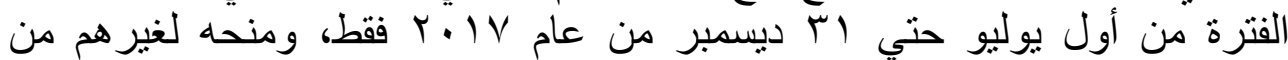

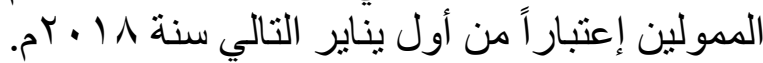

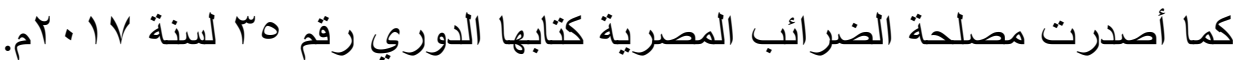

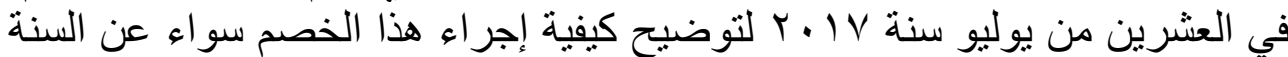

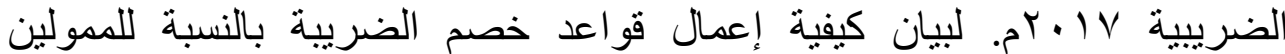

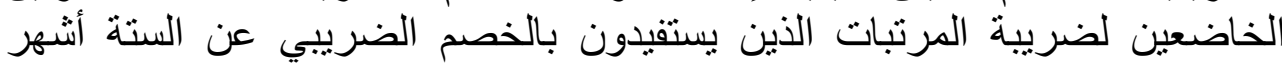

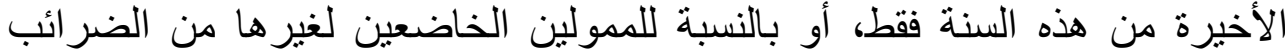

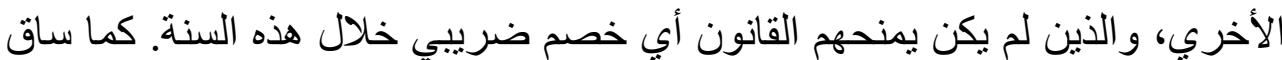

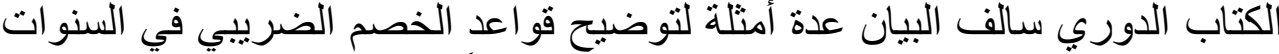

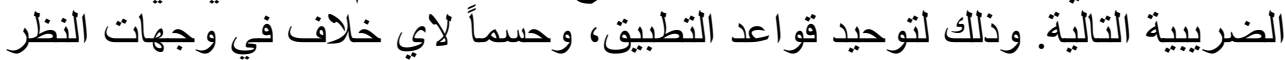

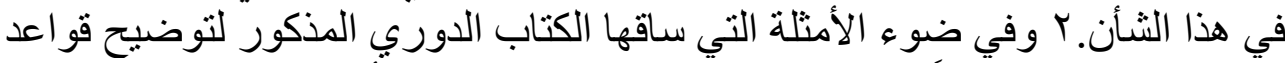

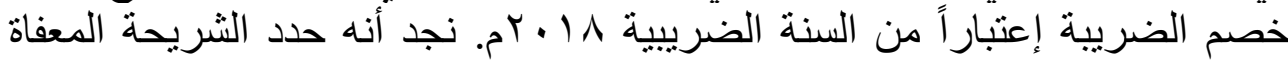

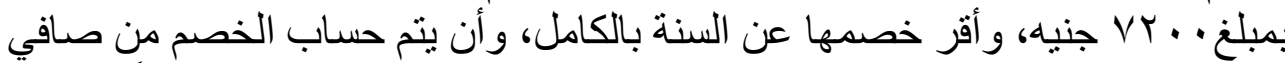

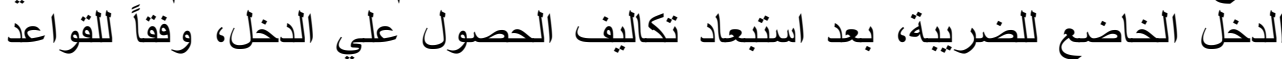

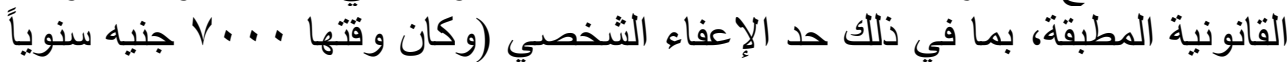

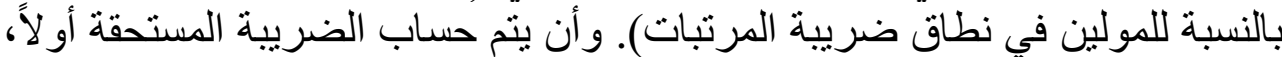

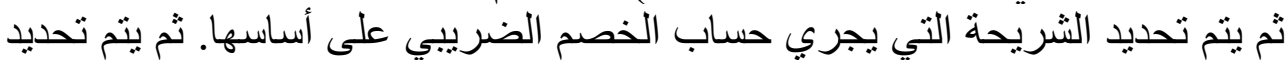

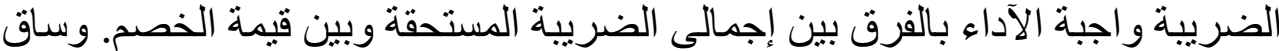

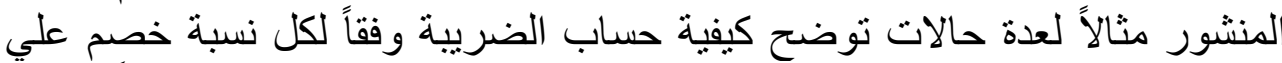

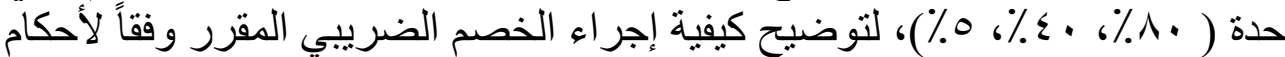
هذا القانون.

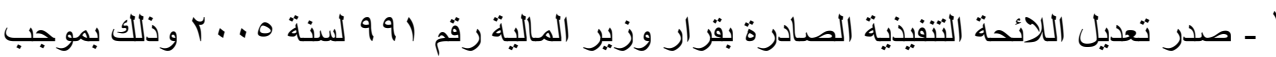

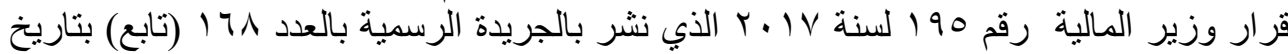

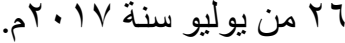

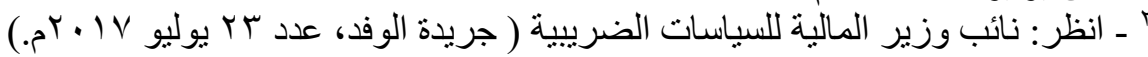




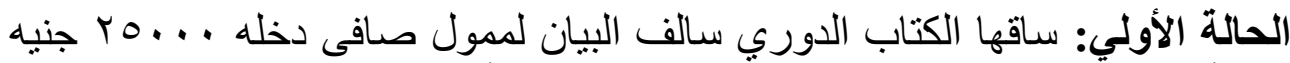

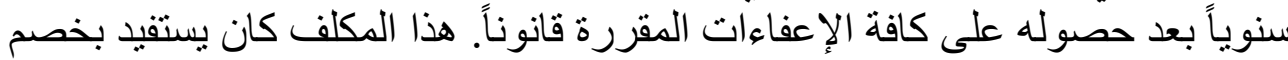

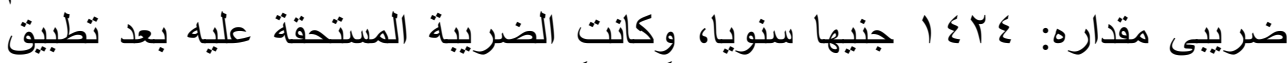

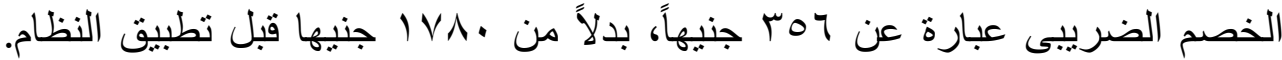
ويمكن توضيح هذه الحالة من خلال الجدول التالي:

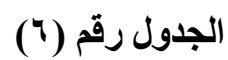

يوضح قيمة الخصم الضريبي طبقاً للثريحة الثانية

\begin{tabular}{|c|c|}
\hline | (0.... & صافي الدخل السنوي \\
\hline- & 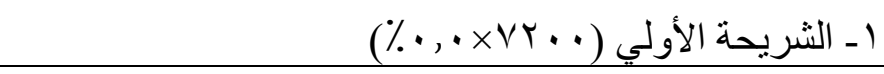 \\
\hline اجنيهاً VA. & 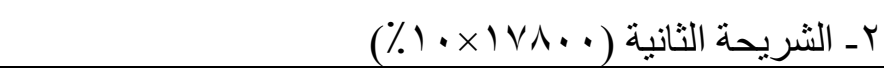 \\
\hline اجنيهاً VA. & r- إجمالي الضريبة المستحقة (1) + (r) \\
\hline الثريحة الثانية & عـ تحديد الثريحة التي يقع بها صافي الدخل الخاضع للضريبة \\
\hline$\%$. & هـ تحديد نسبة الخصم الضريبي وفقاً لهذه الثريحة (الثانية) \\
\hline (جن اجيهاً & جـ قيمة الخصم الضريبي( أو بالأحري قيمة العفو الضريبي) \\
\hline ا & V- إجمالي الضريبة المستحقة عن الفترة الضرييية=(T)-(T) \\
\hline
\end{tabular}

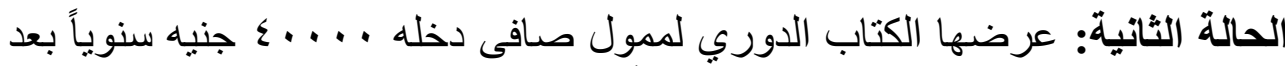

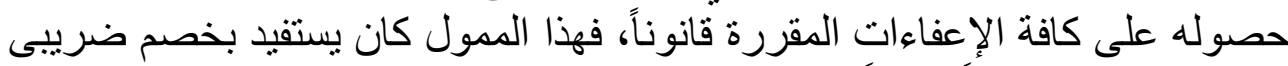

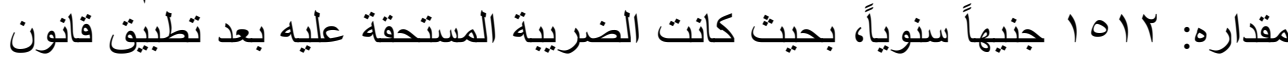

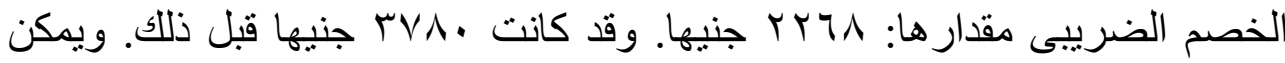
تفصيل هذه الحالة من خلال الجدول التالي:

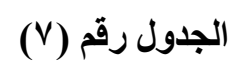

يوضح قيمة الخصم الضريبي طبقاً للثريحة الثالثة

\begin{tabular}{|c|c|}
\hline 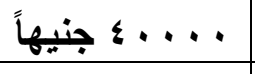 & صافي الدخل السنوي \\
\hline- & 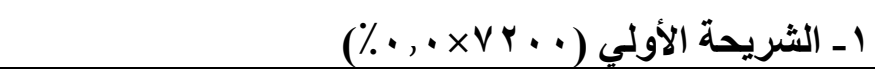 \\
\hline 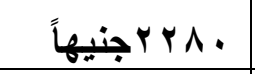 & 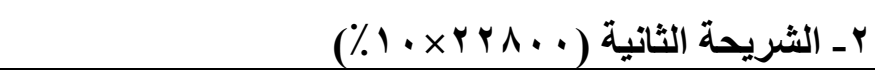 \\
\hline | اجنيهاً & 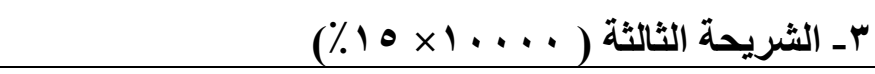 \\
\hline 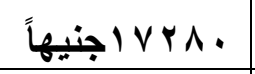 & عـ إجمالي الضريبة المستحقة (1) + (r) + (r) (r) \\
\hline 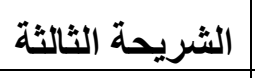 & ه ـ تحديد الثريحة التي يقع بها صافي الاخل الخاضع للضريبة \\
\hline$\%$. & דـ تحديد نسبة الخصم الضريبي وفقاً لهذه الثريحةة الثالثة) \\
\hline | & 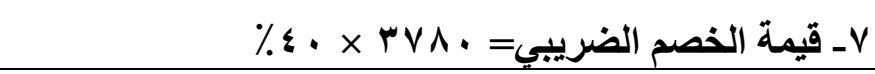 \\
\hline
\end{tabular}




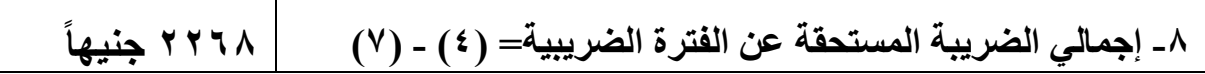

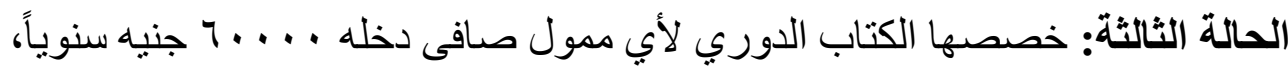
وكان يستفيد بخصم ضريبى مقداره:

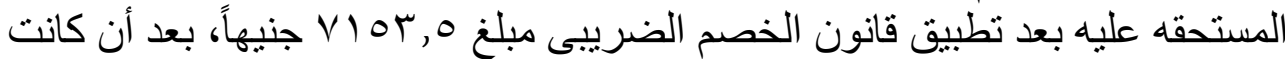
V ج Por.

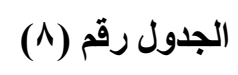

يوضح قيمة الخصم الضريبي طبقاً للثريحة الرابعة

\begin{tabular}{|c|c|}
\hline 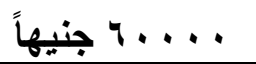 & صافي الدخل السنوي \\
\hline- & 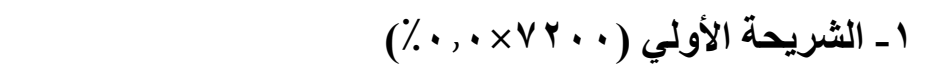 \\
\hline 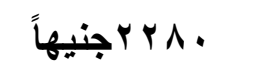 & 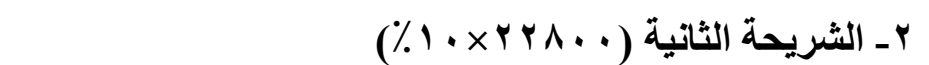 \\
\hline 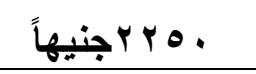 & بـ الثريحة الثالثة ( . . 10 × 10\%) \\
\hline 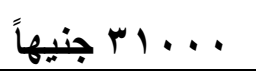 & 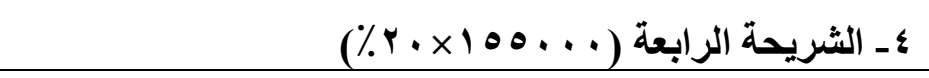 \\
\hline 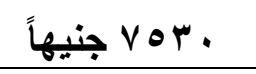 & 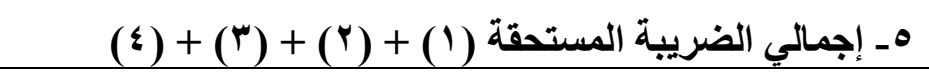 \\
\hline 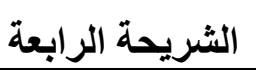 & آـ تحديد الثريحة التي يقع بها صافي الاخل الخاضع للضريبة \\
\hline$\%$ & V- تحديد نسبة الخصم الضريبي وفقاً لهذه الثريحة( الرابعة) \\
\hline 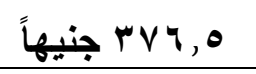 & 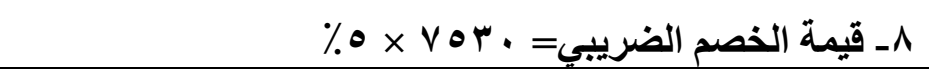 \\
\hline 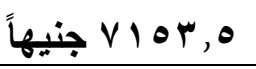 & 9- إجمالي الضريبة المستحقة عن الفترة الضريبية= (•) - (^) \\
\hline
\end{tabular}

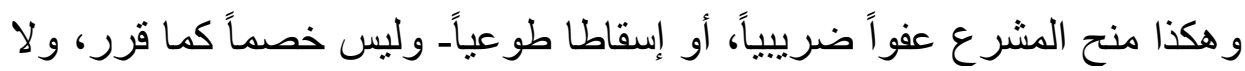

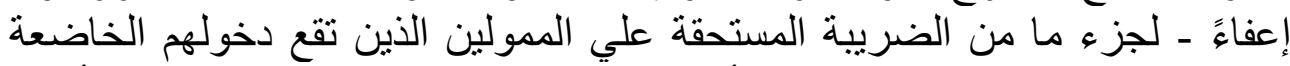

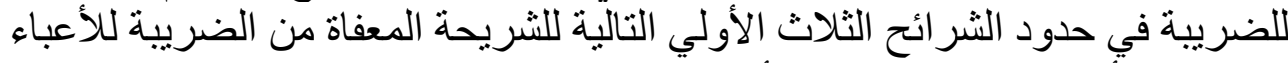

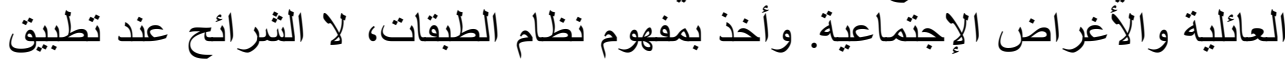

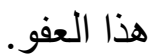

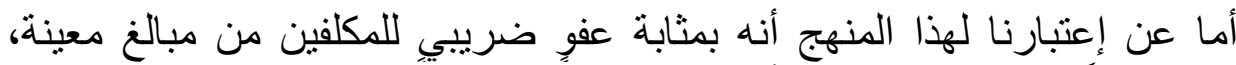

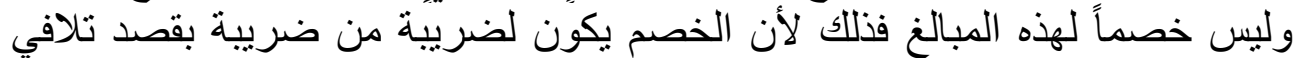

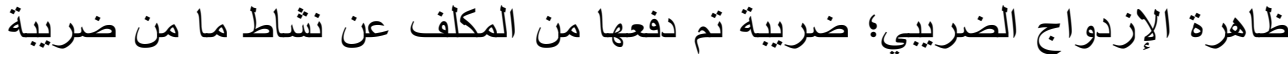

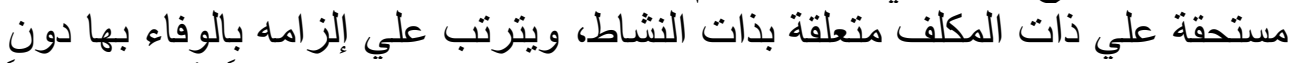

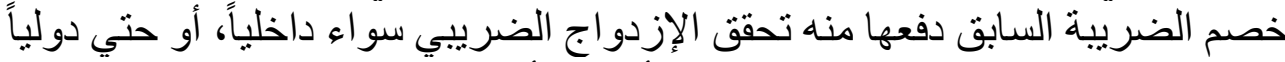

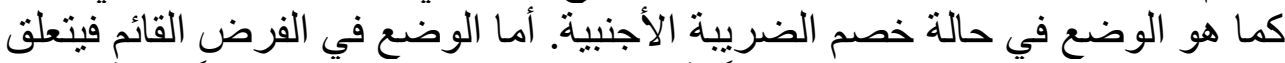

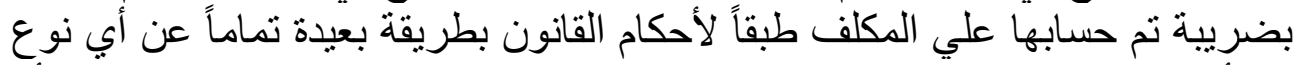

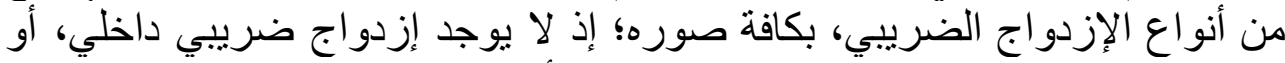

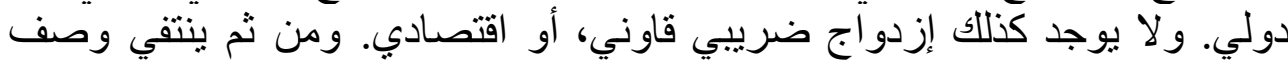
الخصم هنا للمبالغ التي يتم إسقاطها عن الممول. 


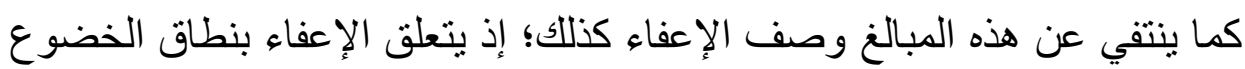

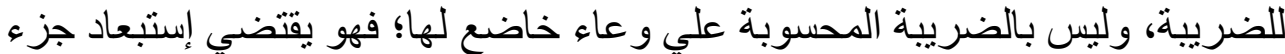

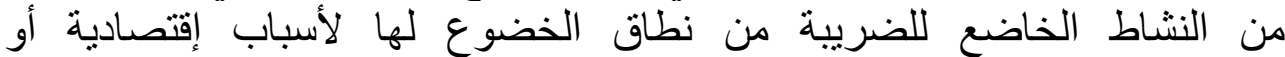

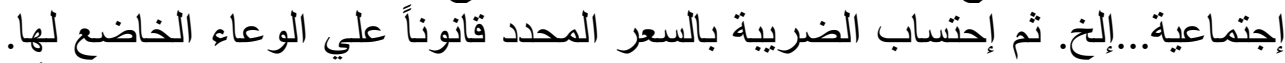

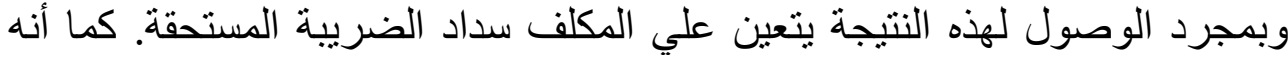

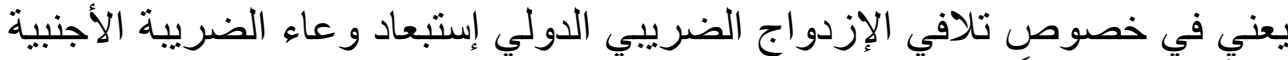
من أن يكون محلاً من جديد لضريبة الدخل المستحقة في دولة الإقامة.

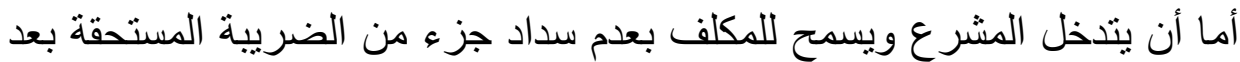

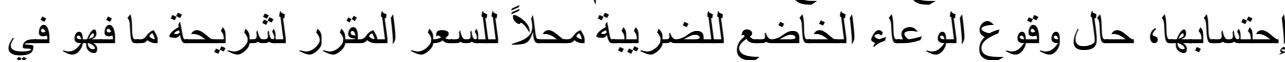

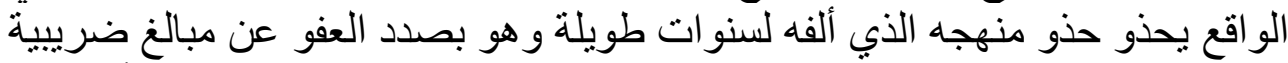

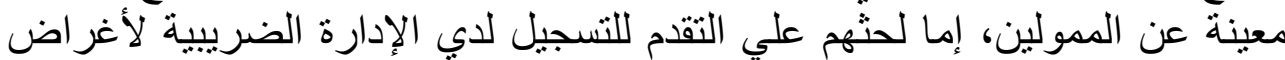

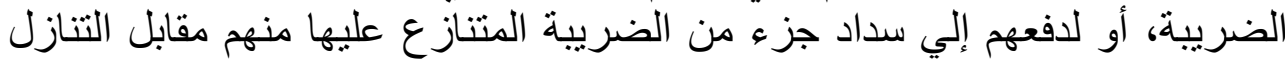

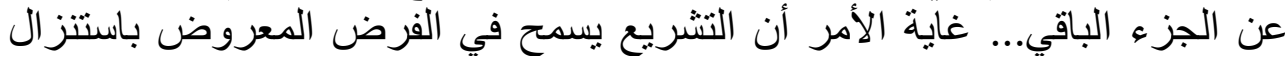

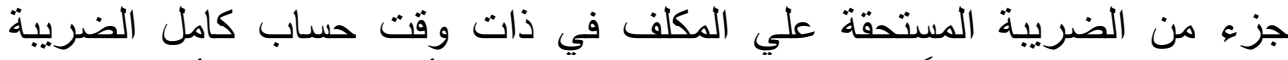

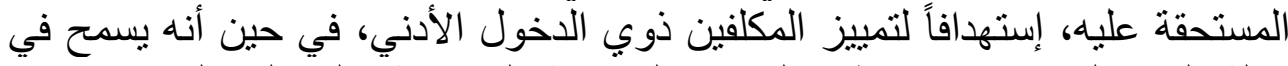
حالة العفو الضريبي بإسقاط مبالغ من الضريية المستحقة علي الممولين في وقت الته

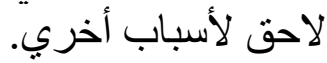

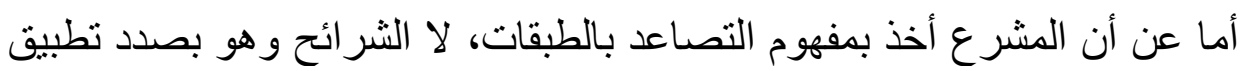

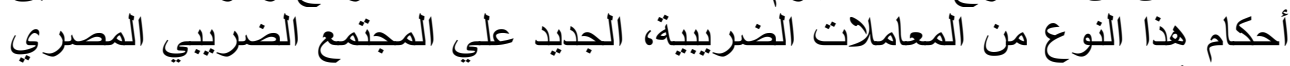

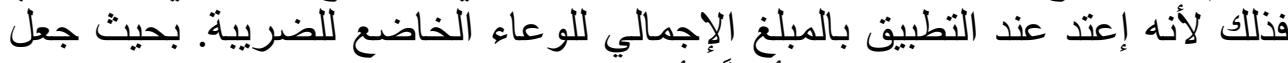

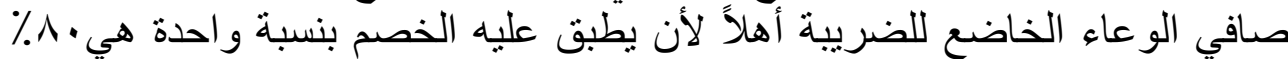

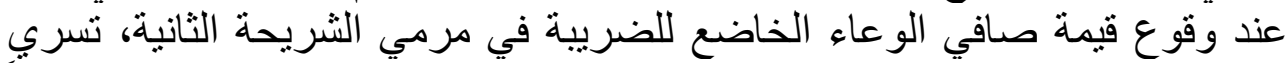

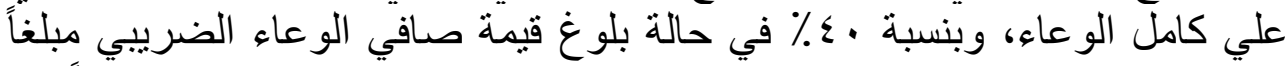

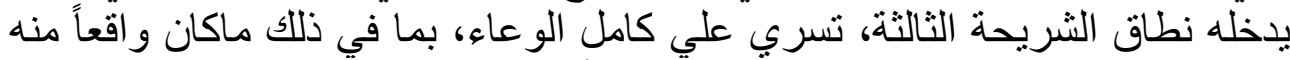

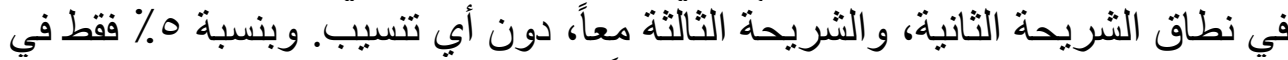

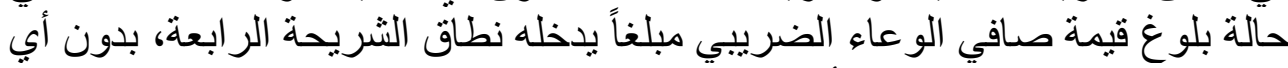

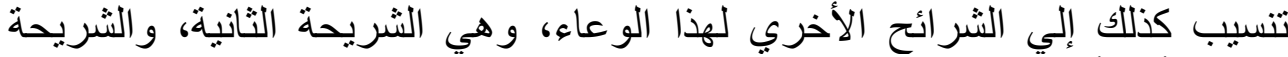

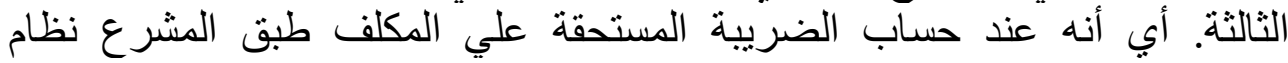

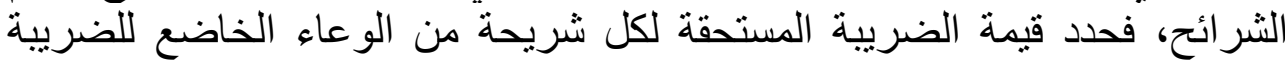

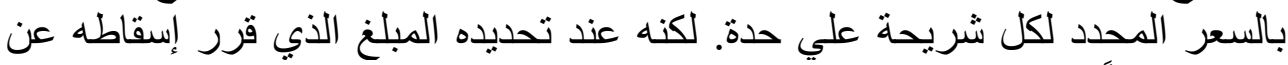

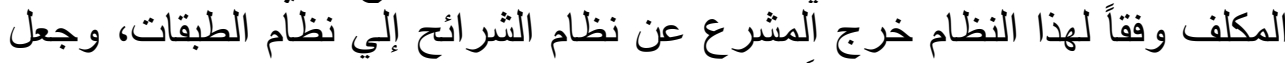

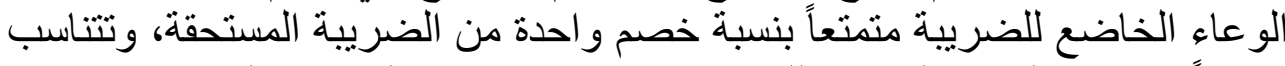

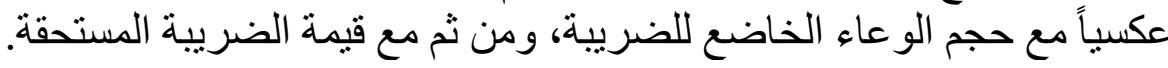

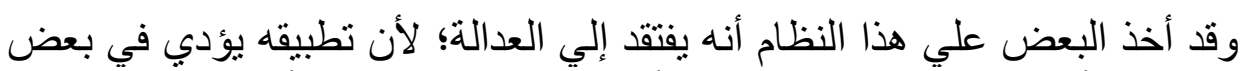

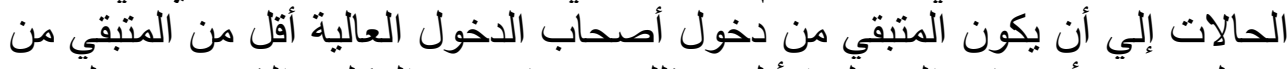

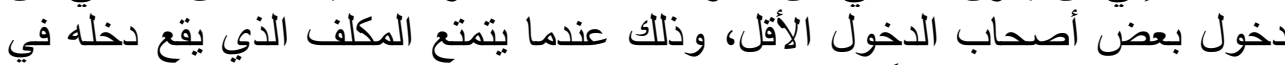

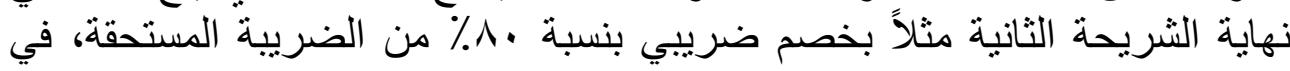




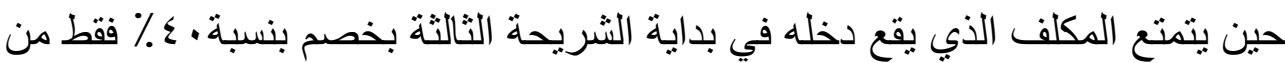

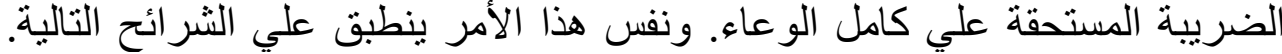

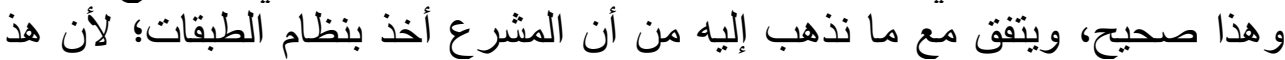

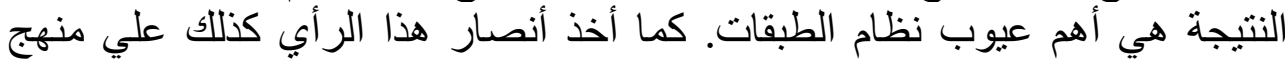

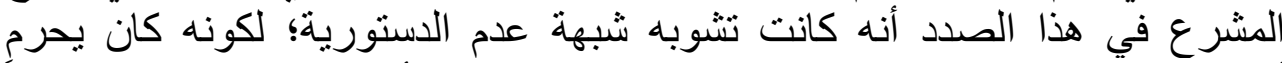

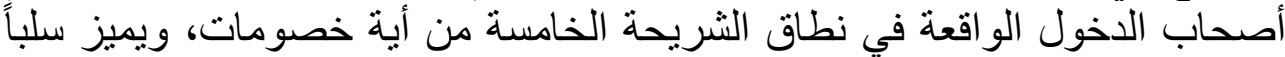
ضدهم بالمقارنة بالممولين الواقعة دخولهم الخاضعة للضريبة في نطاق الثان الثرائح

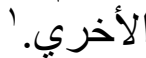

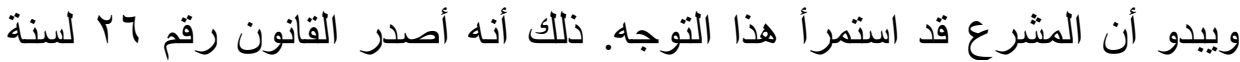

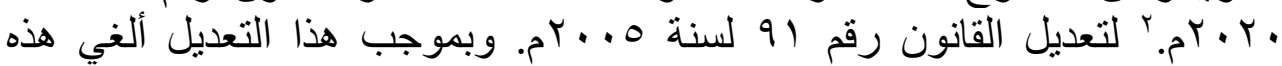

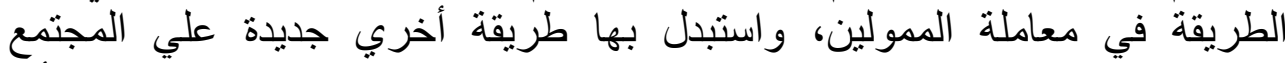

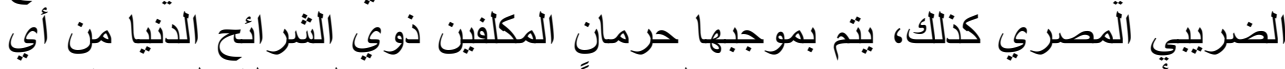

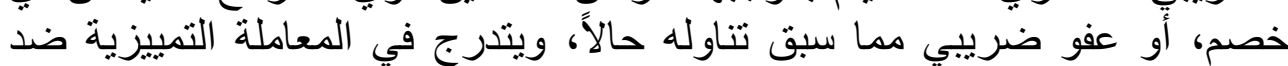

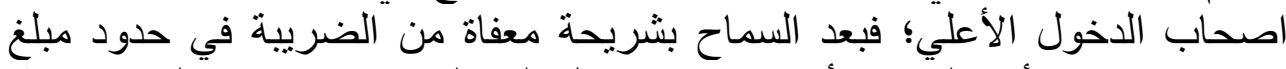

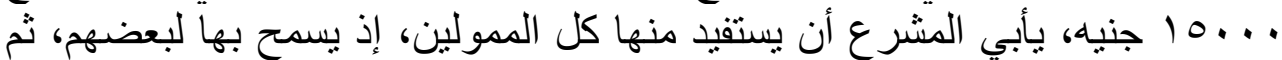

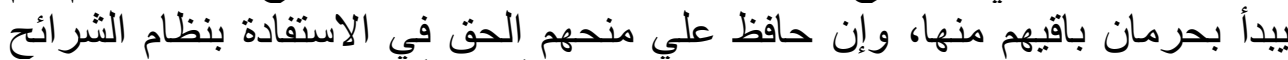

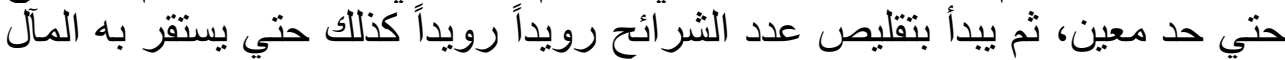

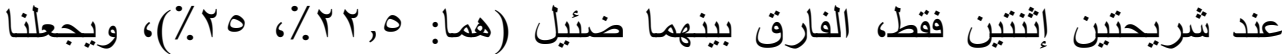
تطبيقهما وكأننا أمام نظام الطبقات، لا الثر ائح.

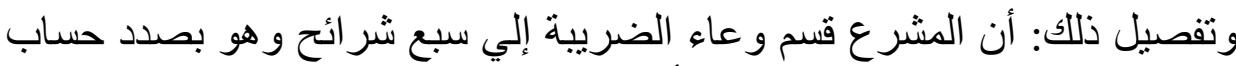

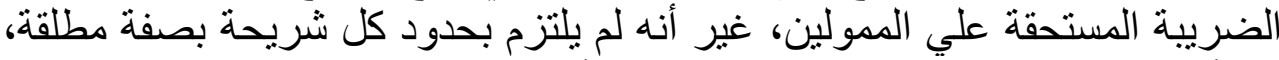

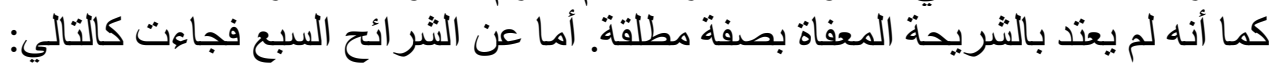
الشريحة الأولي: حتي . . 10 جنيها، وقام المشر ع بإعفائها من الضريبة.

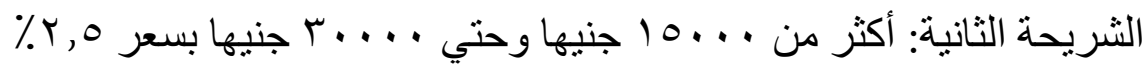

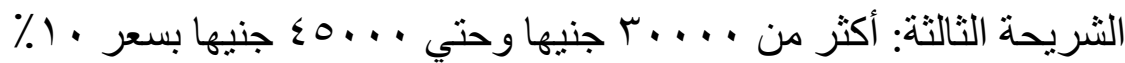

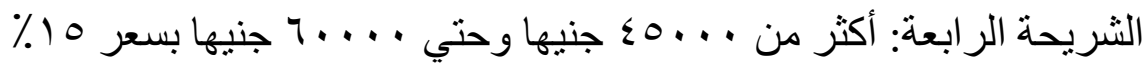

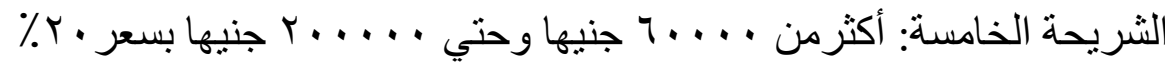

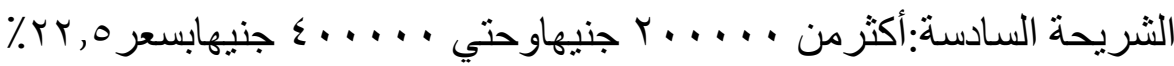

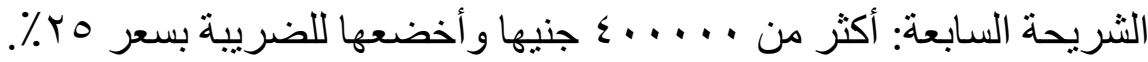

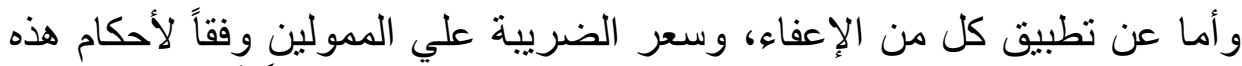

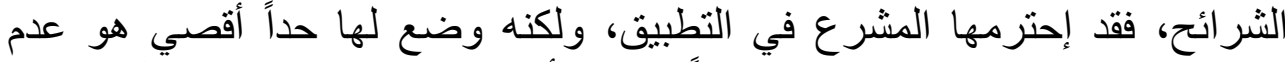

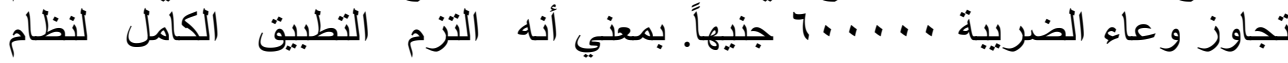

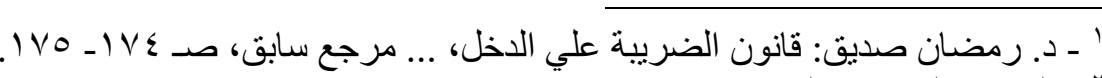

$$
\begin{aligned}
& \text { ' ـ الجريدة الرسمية، العدد }
\end{aligned}
$$




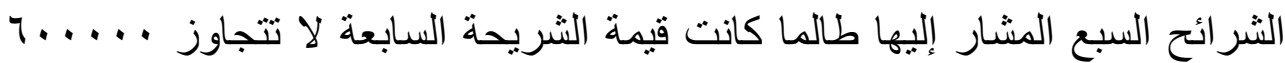

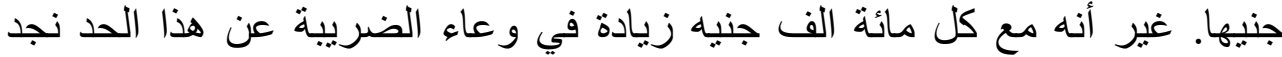
المشرع يتر اجع عن الوقوف إلي جوار الممولين.

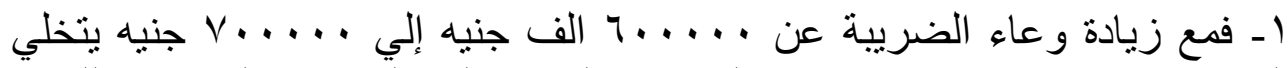

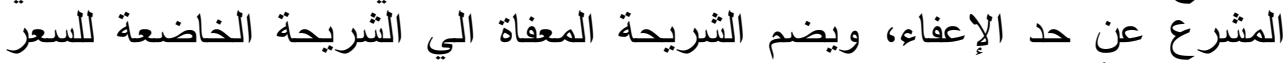

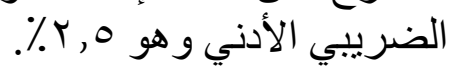

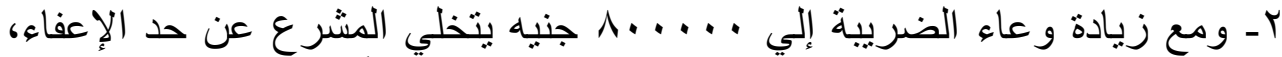

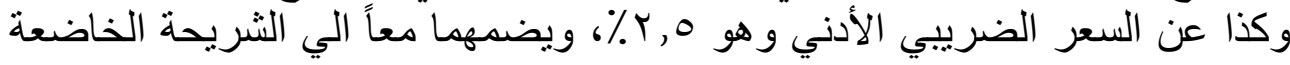

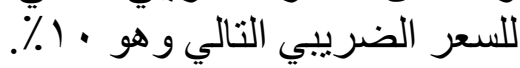

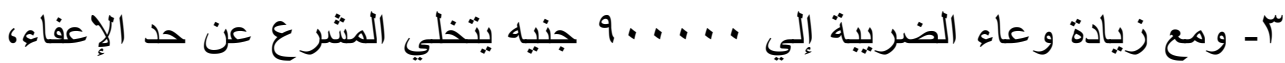

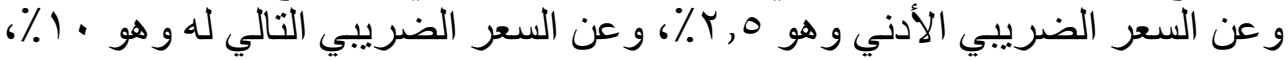

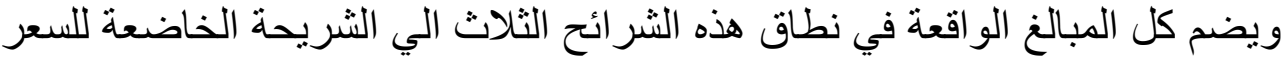

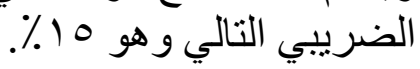

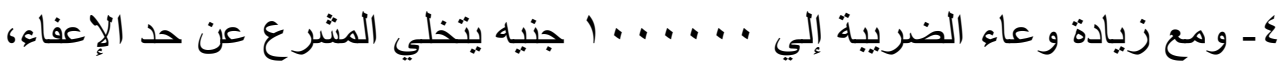

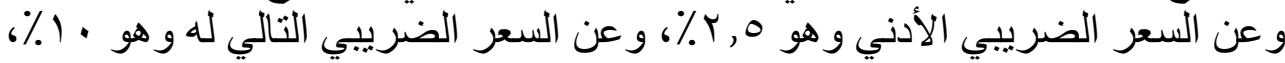

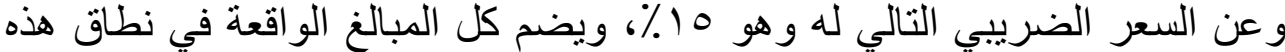

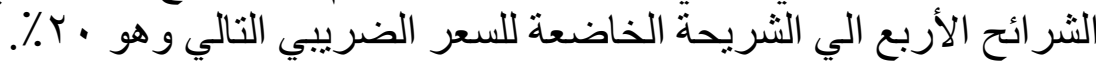

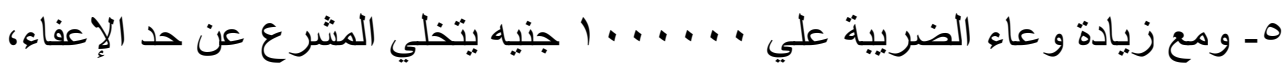

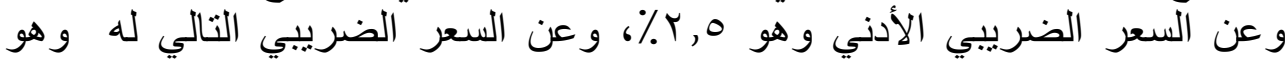

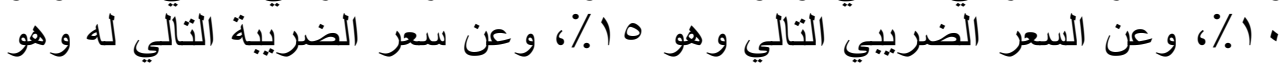

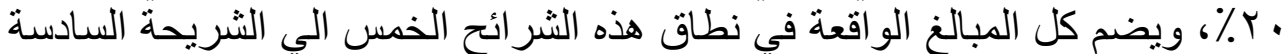

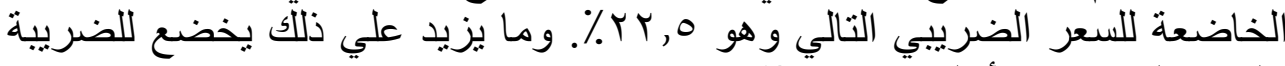

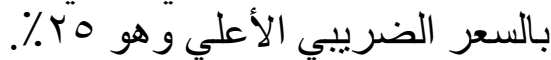

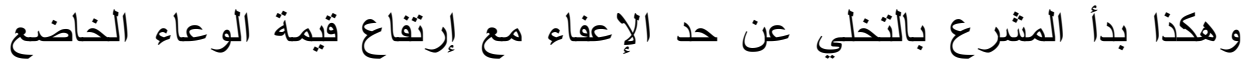

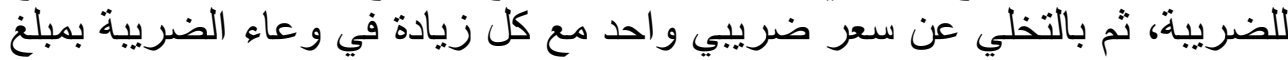

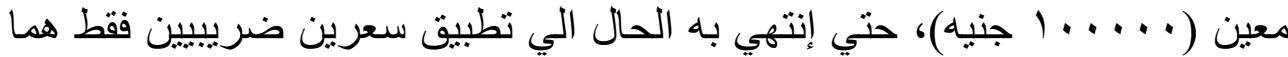

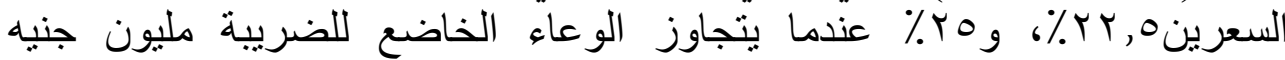

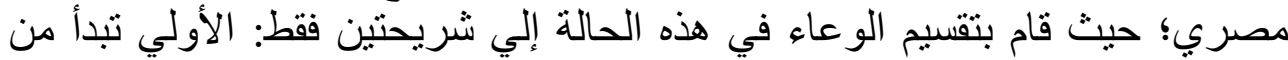

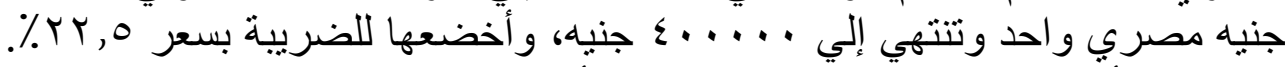

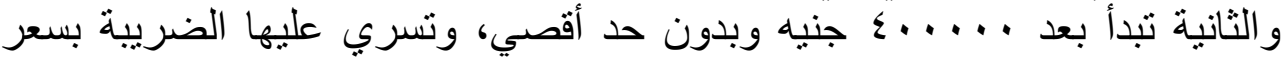
$\%$ ro

والواقع أنه لا معني لهذا المنهج الجديد في تطبيق نظام الثرائح بنكهة نظام

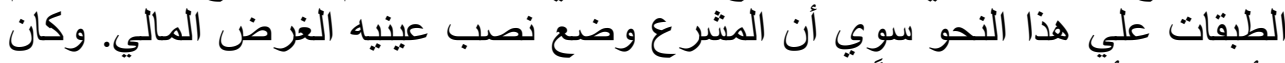

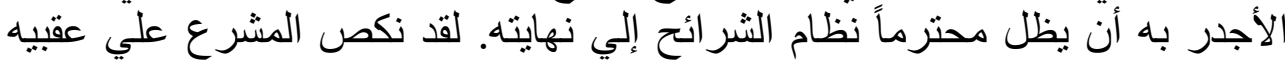

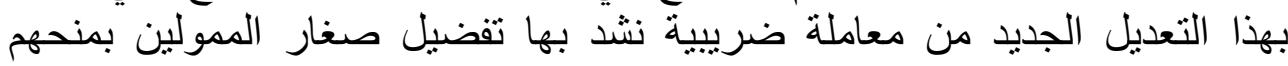


الإيتمان الضريبي وآثارة الإقتصادية والمالية "دراسة مقارنة"

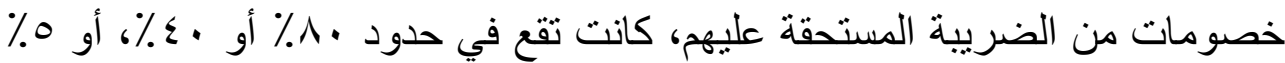

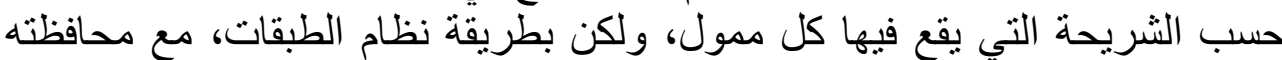

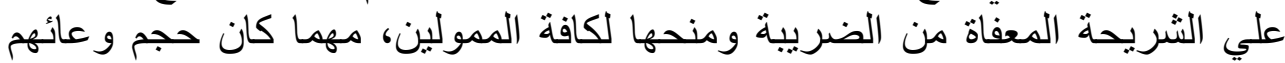

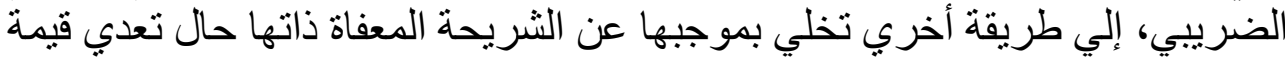

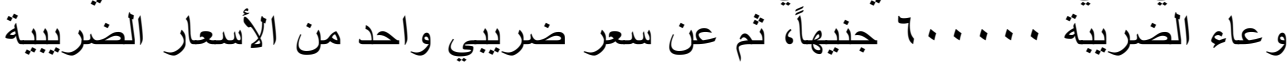

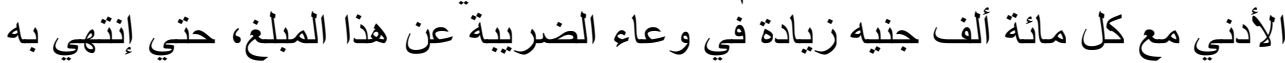

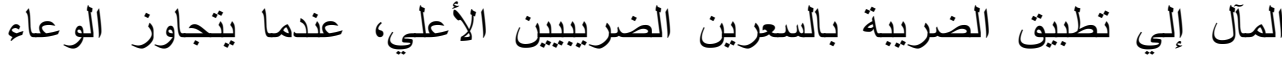
الخاضع للضريبة المليون جنيه.

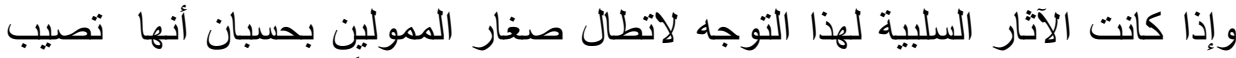

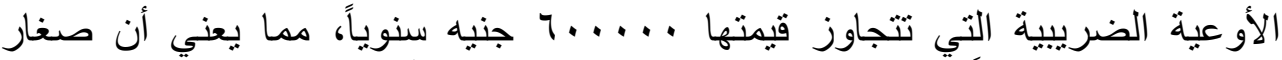

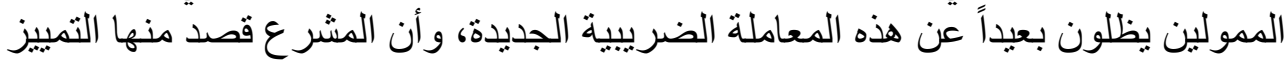

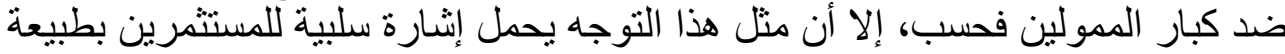

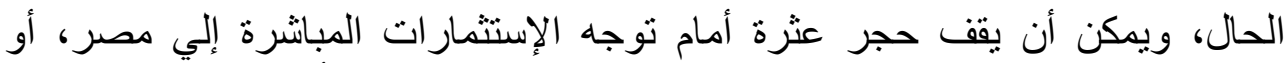

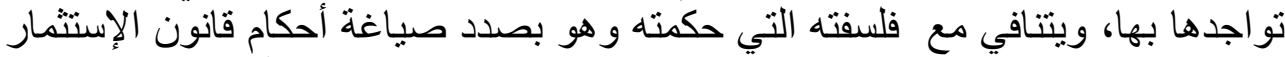

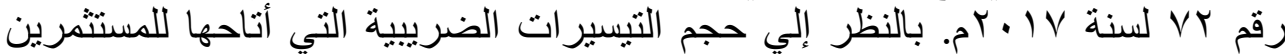

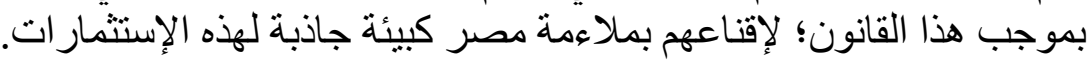

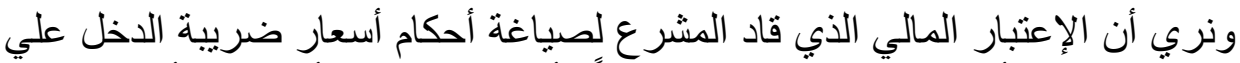

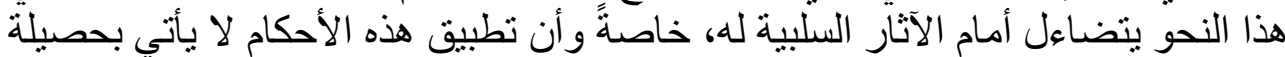

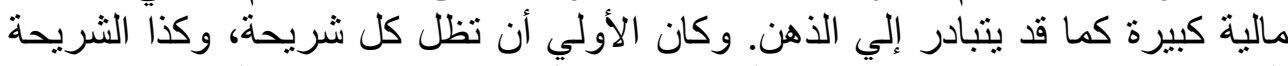

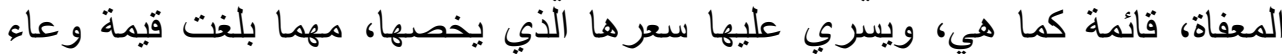

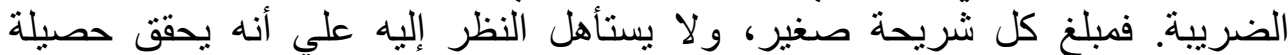
ضريبية ذات بال عند رفع سعر الضريبة المطبق عليه.

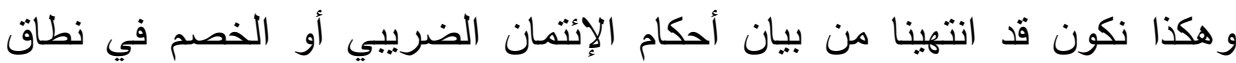

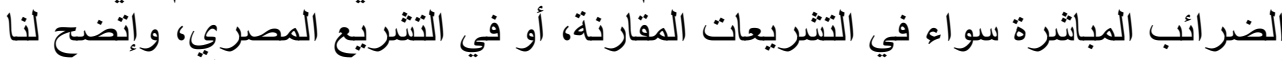

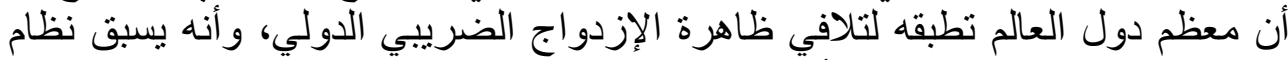

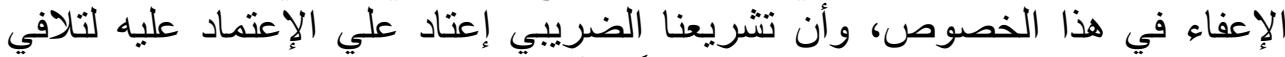

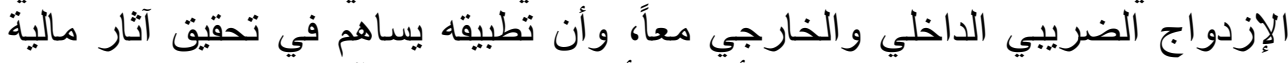

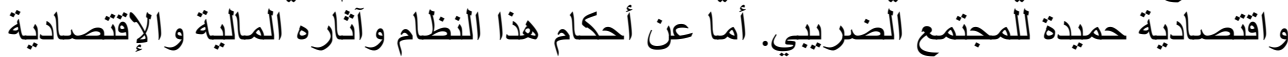

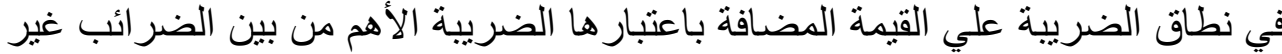

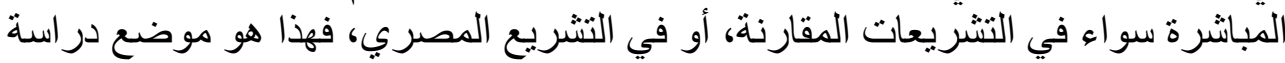

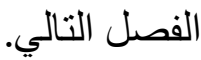

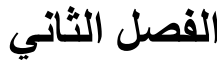

\section{الإنتمان الضريبي وآثارة الإقتصادية والمالية في نطاق الضريبة علي القيمة المضافة}

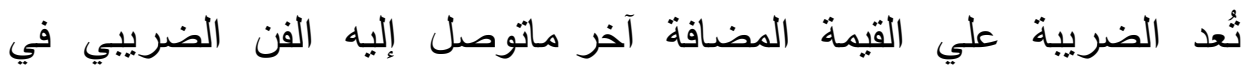
نطاق الضرائب السلعية غير المباثرة. ولعل أهم ما يميزها ها عما سبقها من ضر الئب 


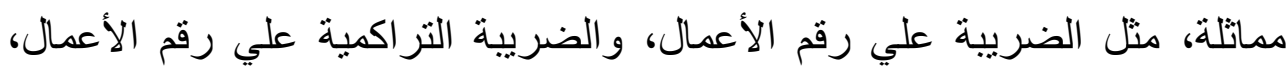

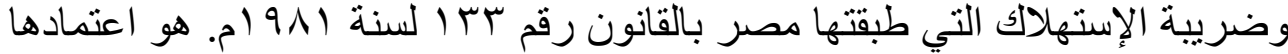

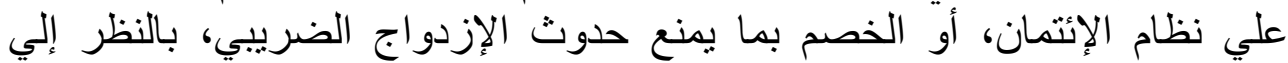

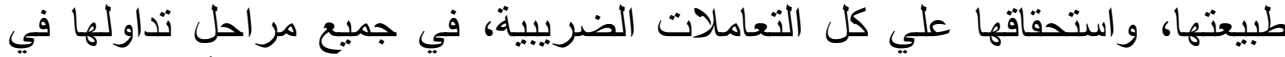

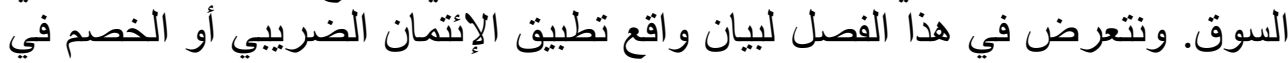

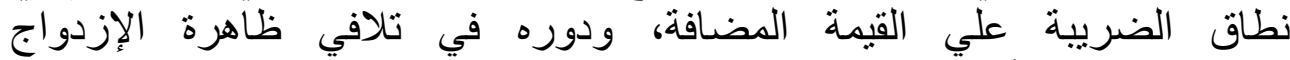

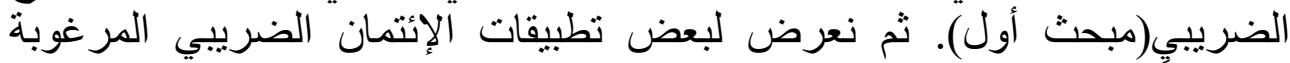
إقتصادياً في نطاق الضريبة علي القيمة المضافة (مبحث ثان).

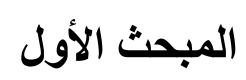

\section{علاقة الإنتمان بالإزدواج الضريبي وآثاره الإقتصادية والمالية}

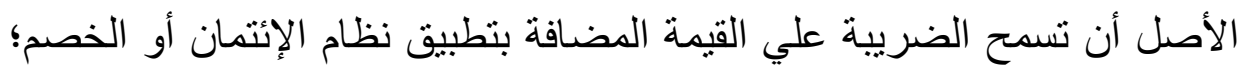

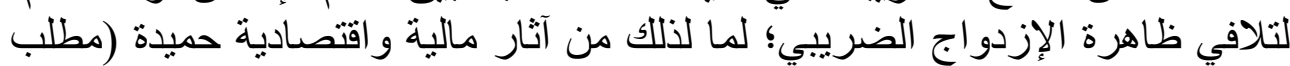

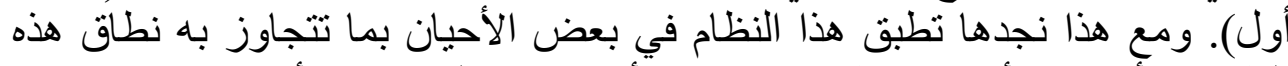

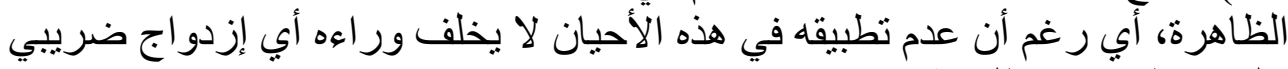

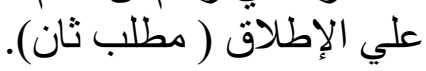

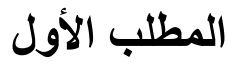

\section{تطبيق الإنتمان للحد من الإزدواج الضريبي وآثاره الإقتصادية والمالية}

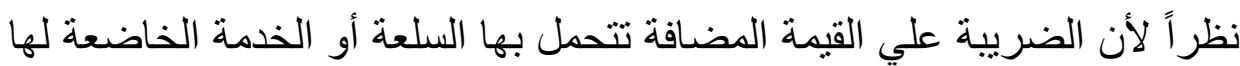

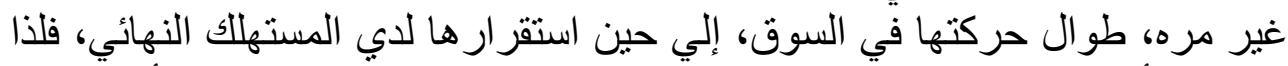

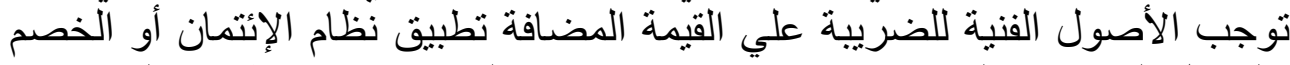

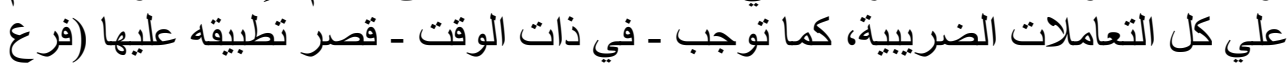

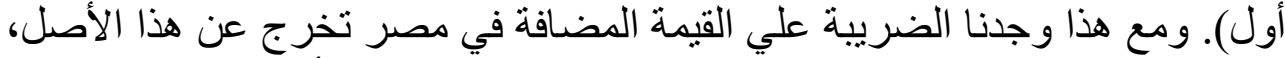

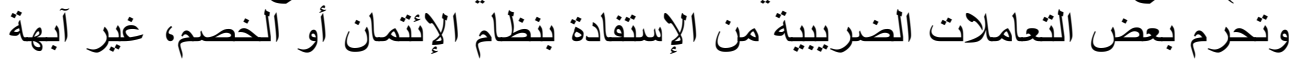
بما يخلفه ذللك من إزدو اج ضريبي مؤكد (فرع ثان).

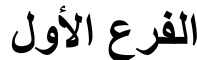

\section{الأصل: قصر تطبيق الإنتمان علي التعاملات الضريبية}

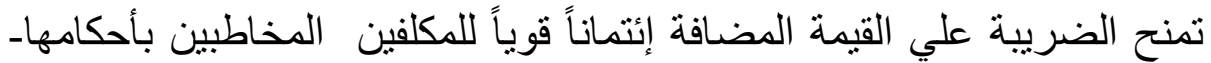

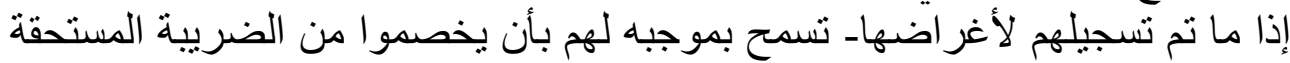

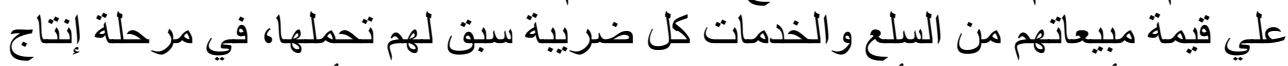

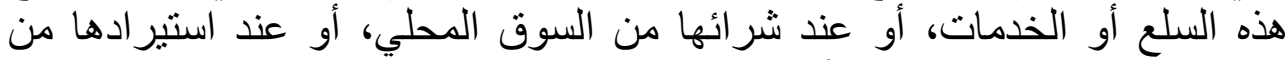

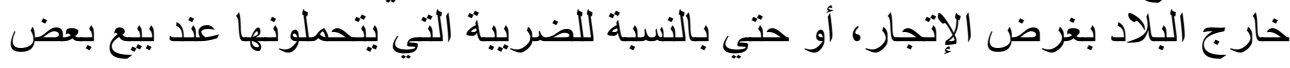


الإئتمان الضر يبي وآثارة الإقتصادية والمالية "دراسة مقارنة"

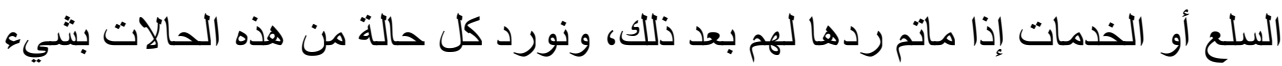
من التفصيل؛ حتي يمكننا الوقوف علي الآدآثار المالية و الإقتصادية لها.

\section{أولاً: الإنتمان أو الخصم للضريبة علي مردودات المبيعات:}

تسمح الضريبة علي القيمة المضافة في مصر للمسجل بأن يخصم من الضريبة

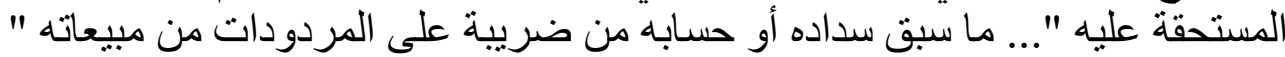

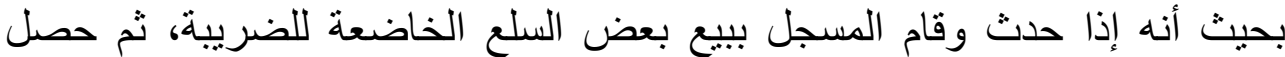

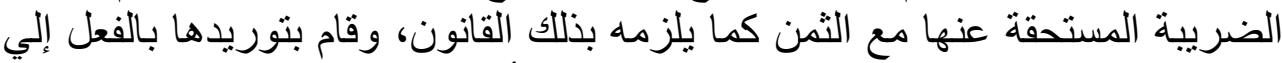

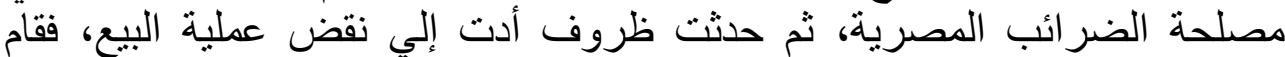

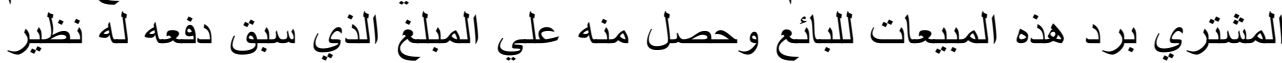

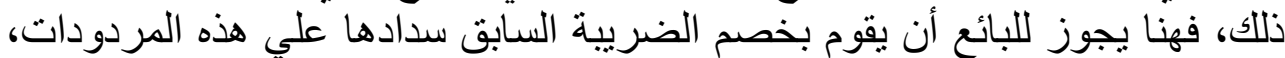
لماذا؟ لأن المبلغ السابق دفعه للبائع من المشتري، و الذي استرده المشتري بالفعل

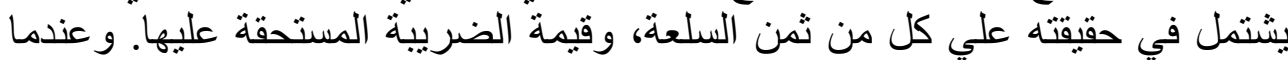

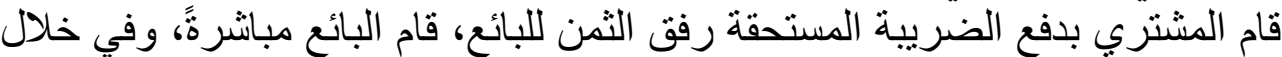

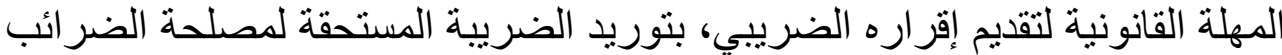

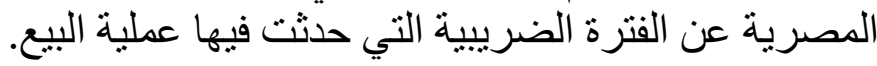

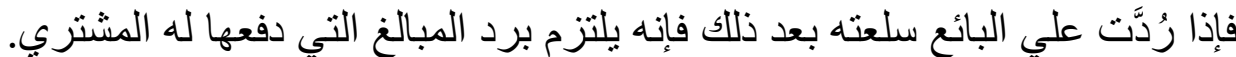
و هذه المبالغ هي ثمن السلعة بالإضافة إلي الضريبة المستحقة عليها. ولما كانئ كان البائع

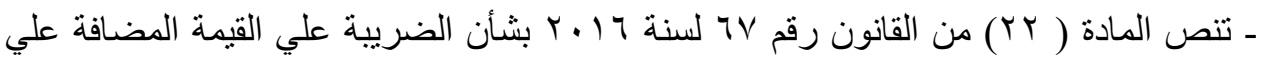

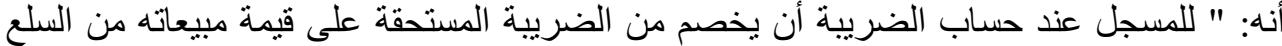

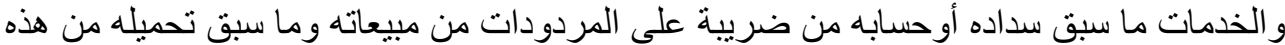

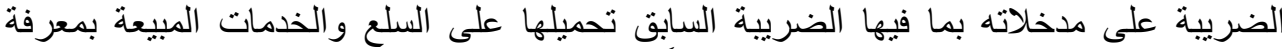

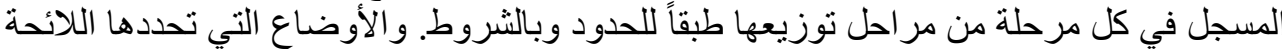

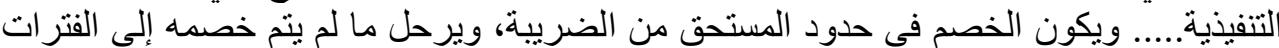

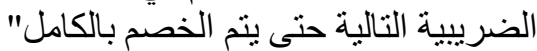

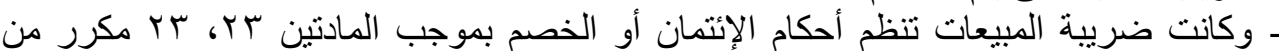

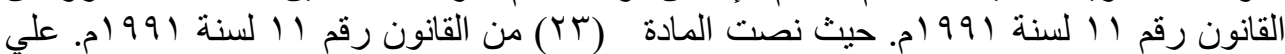

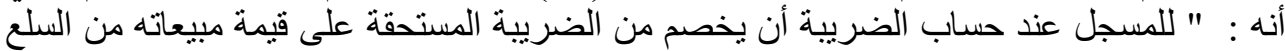

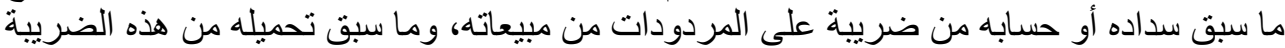

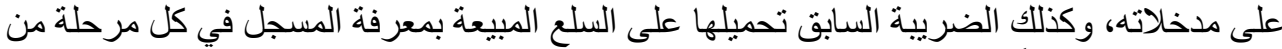

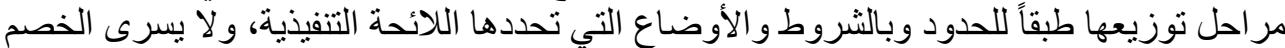

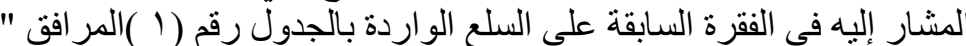

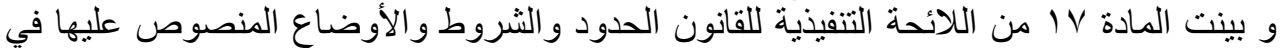

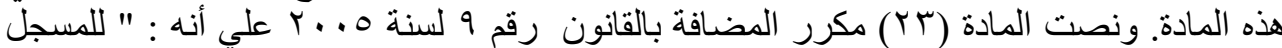

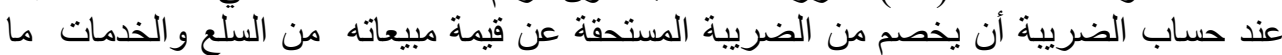

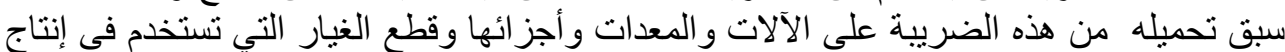

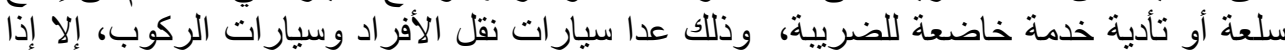

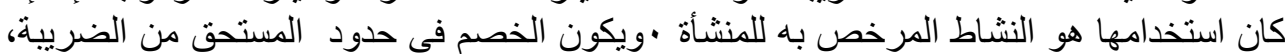

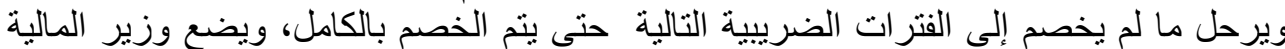
قو اعد سداد الضريبة على الآلات و المعدات الضرات الترات 
ملزم برد هذه الضريبة للمشتري في هذه الحالة، فيكون من حقه أن يستردها من

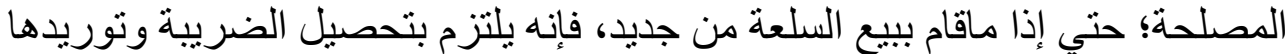

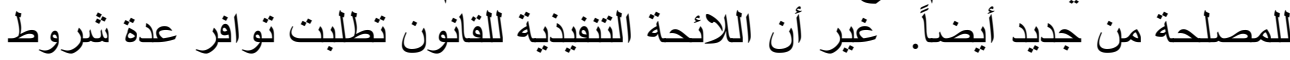

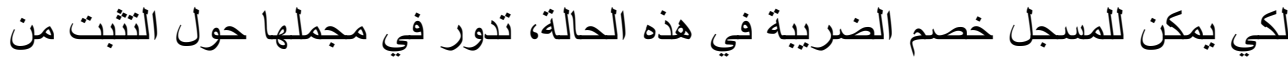

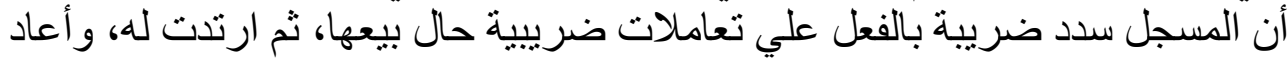

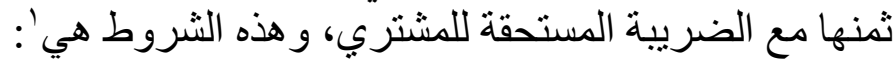

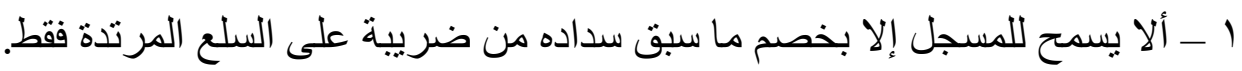

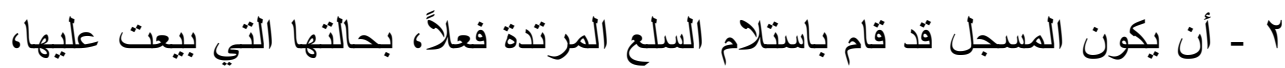

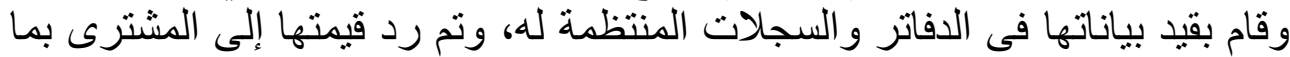

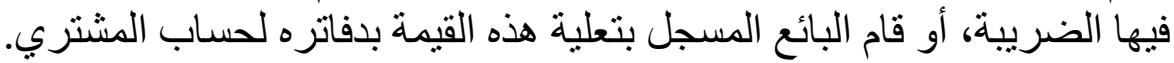

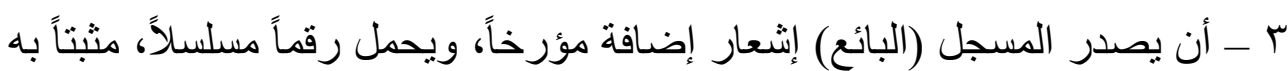

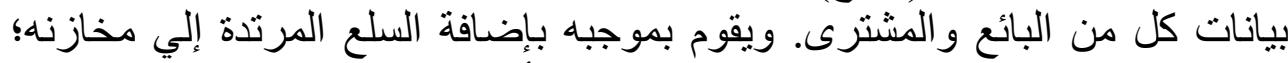
حتي يقوم بتحصيل الضريبة عليها، عند بيعها مرة أخري.

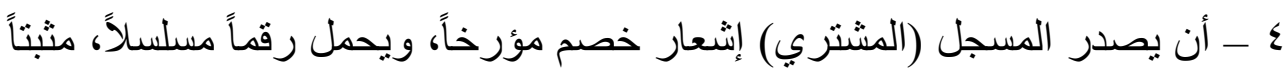

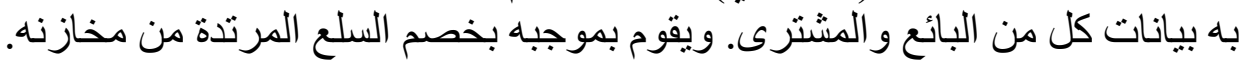

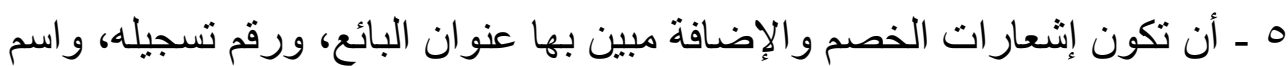

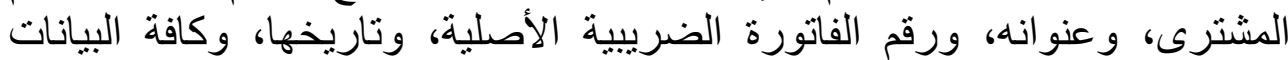

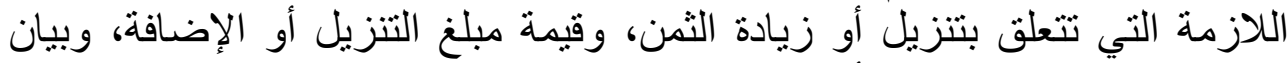
منفصل بالضريبة المستنزلة أو المضافة.

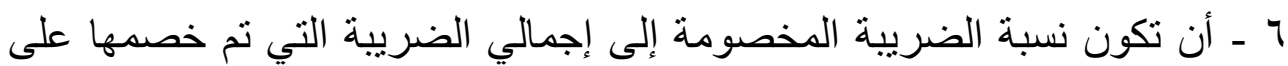
المشتريات هي نفس نسبة الضريبة التي حُملت بها السلع إلى ثمن تلك التك السلع.

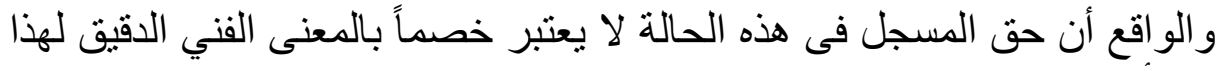

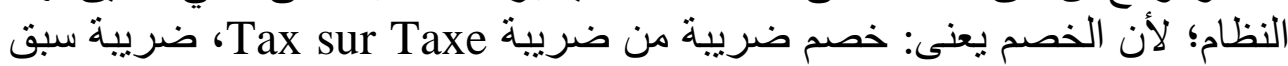

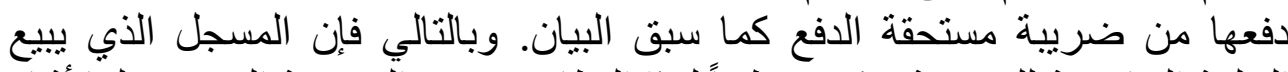

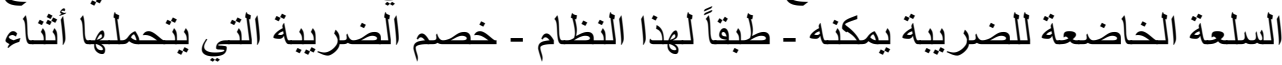

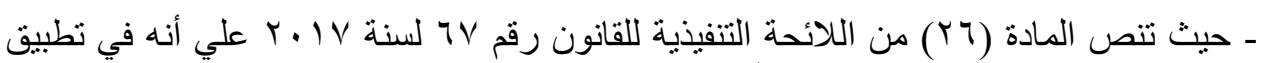

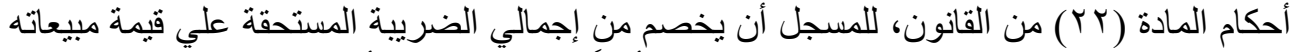

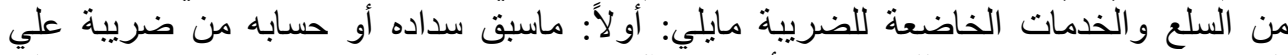

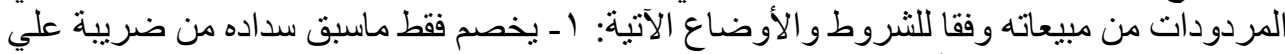

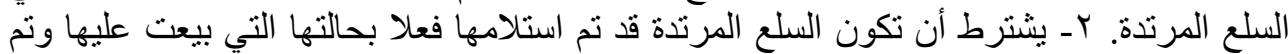

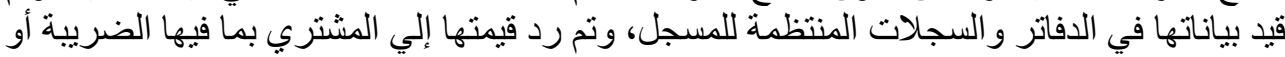

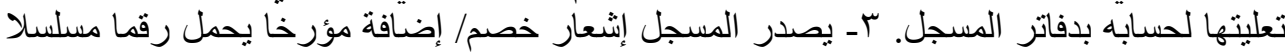

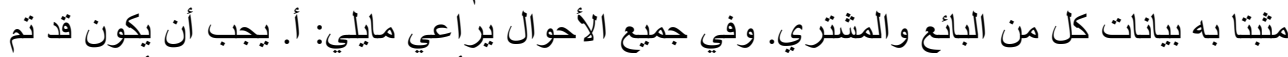

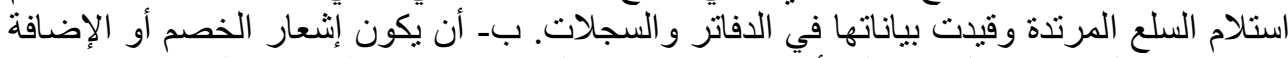

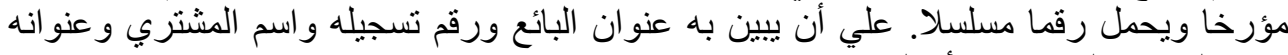
ورقم الفاتورة الضريبية الأصلية وتاريخها. 
الإيتمان الضريبي وآثارة الإقتصادية والمالية "دراسة مقارنة"

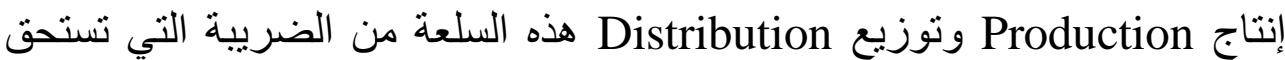

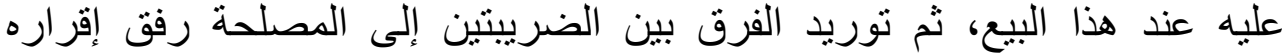

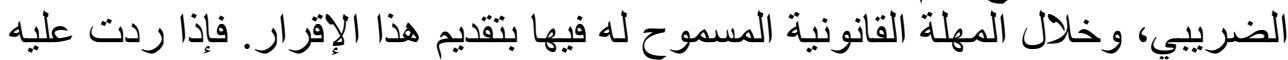

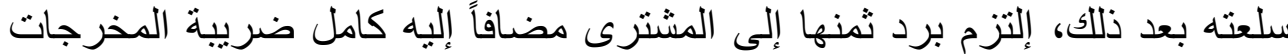
التي سبق له تحصيلها منه مع الثمن.

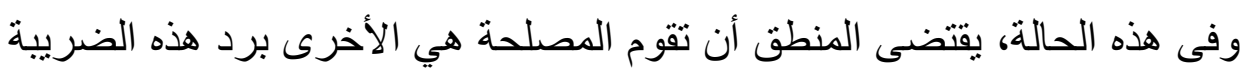

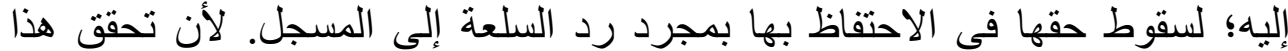

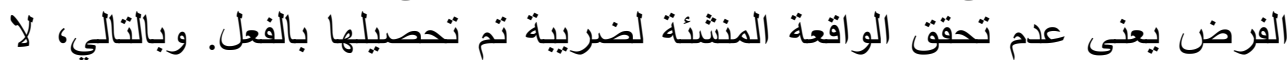

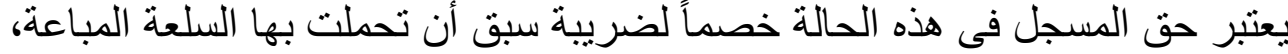

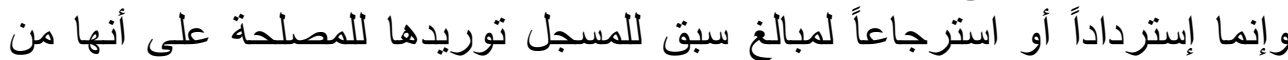

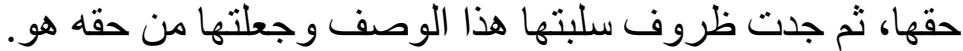

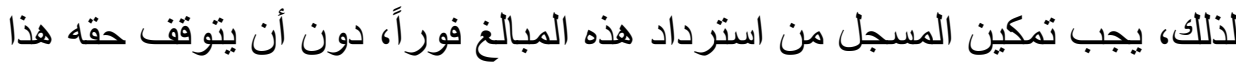

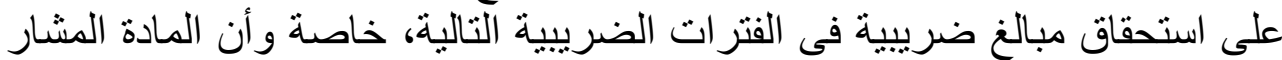

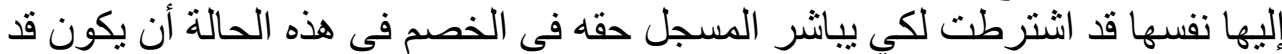

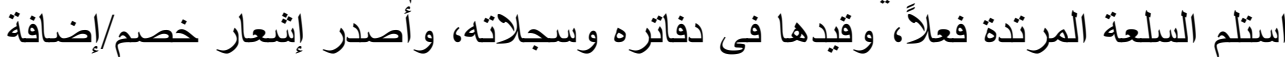

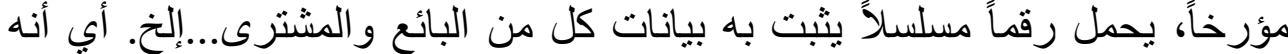

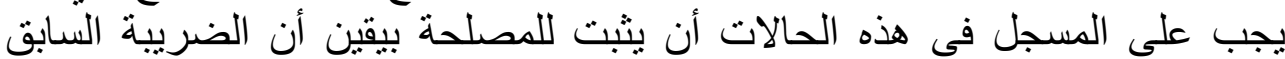

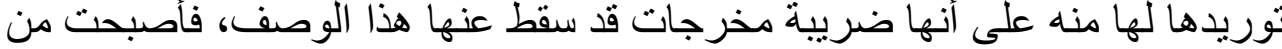

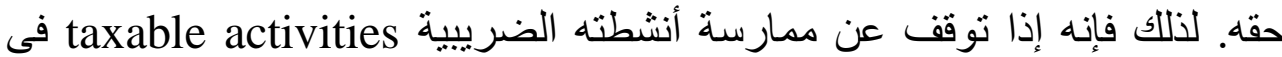

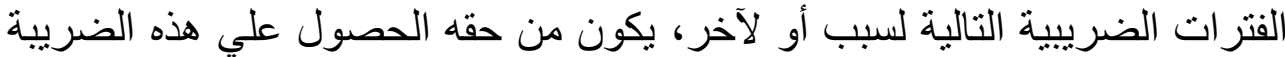

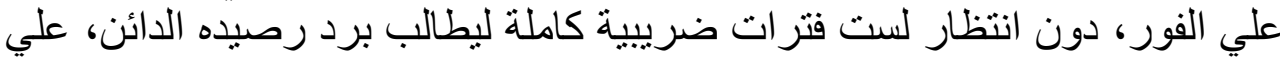
النحو الذي تعرضنا له في المبحث التمهيدي.

\section{ثنانيا: الإتثمان الممنوح للمدخلات، والمشتريات بغرض الاتجار:}

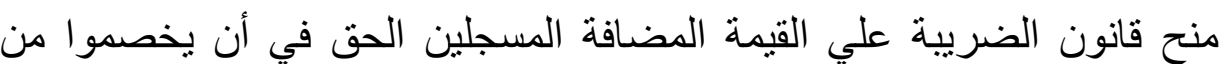

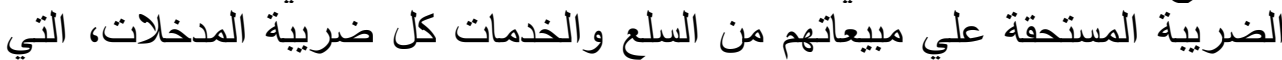

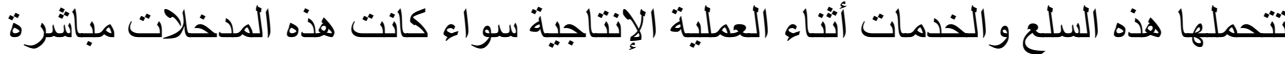

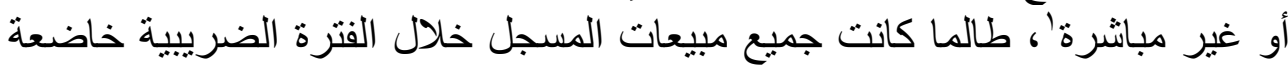

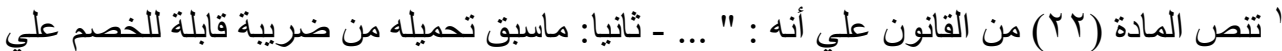

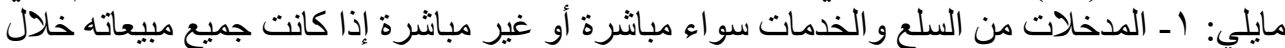

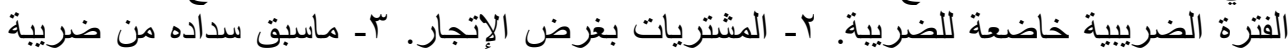

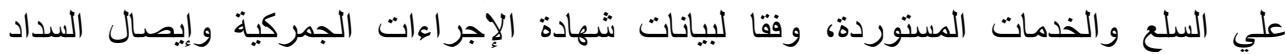

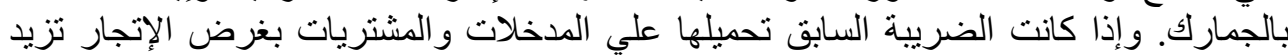

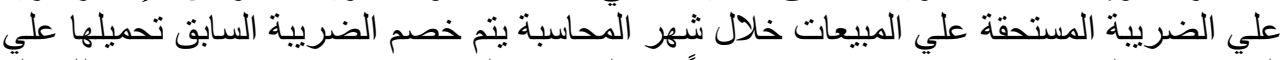
المدخلات و المشتريات بغرض الإتجار شهرياً من الضريبة المستحقة حتي يتم استنفاذها. وذللك كله شريطة حيازة المسجل فاتورة ضريبية. 


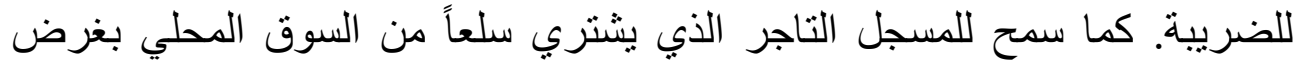

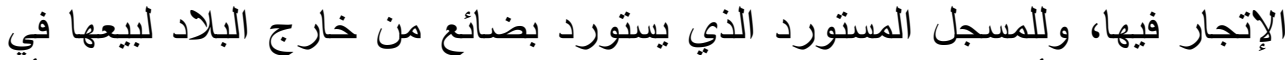

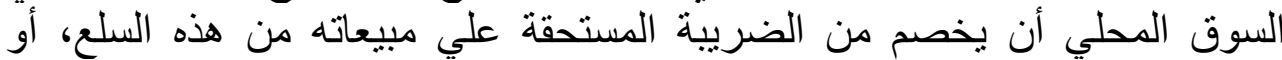

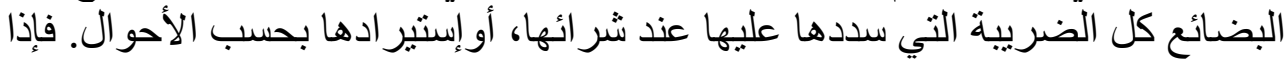

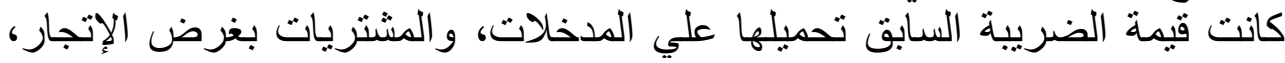

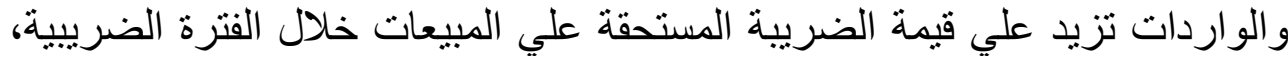

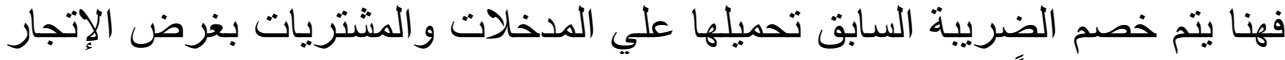

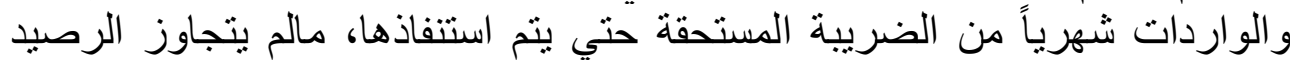

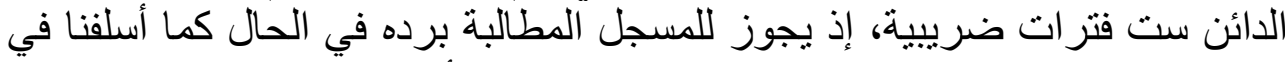

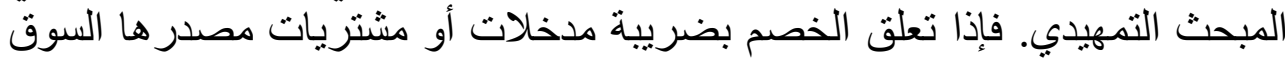

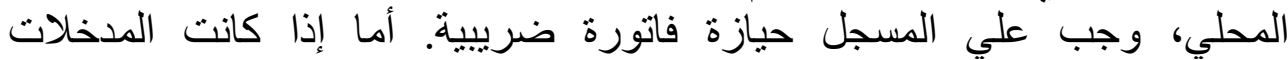

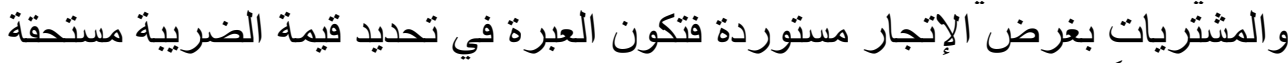

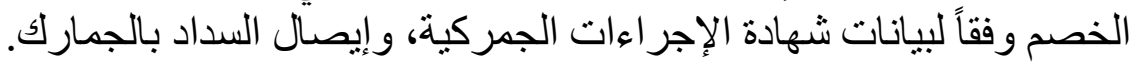

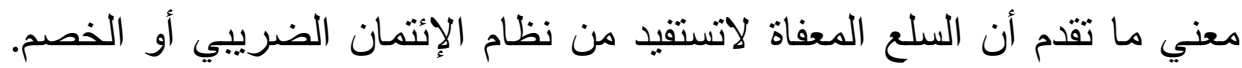

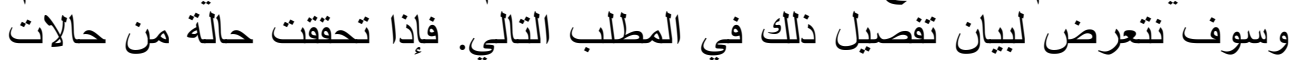

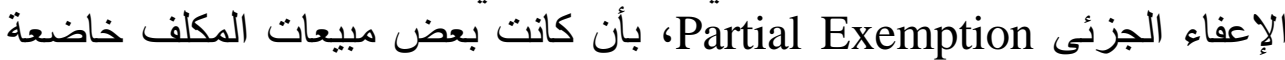

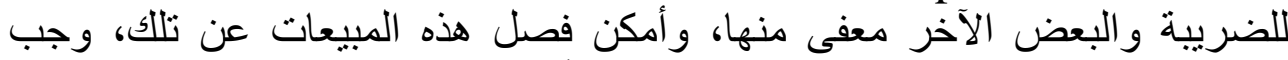

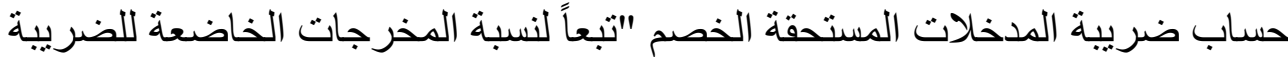

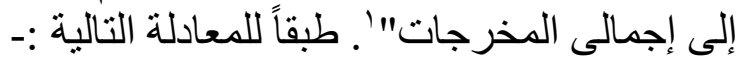
× إجمالى ضريبة الدخلات = الضريبة المستحقة الخصم. إجمالى قيمة المبيعات الخاضعة للضريبه إجمالى قيمة المبيعات الخاضعة و المعفاة

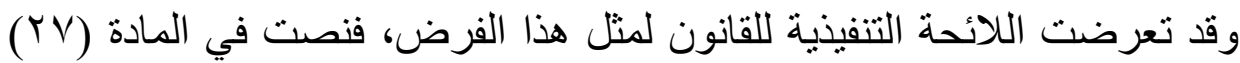

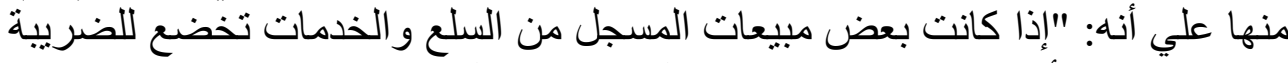

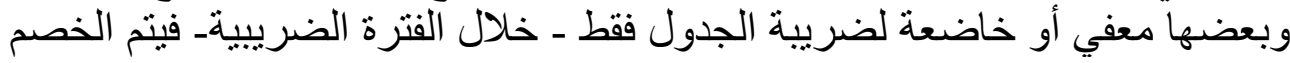

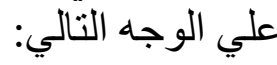

(أ)- يخصم إجمالي الضريبة علي المدخلات المتعلقة بييع السلعة أو آداء الخدمة الخاضعة للضريبة فقط سو اء تمت عملية البيع في الفترة الضريبية أو بعدها.

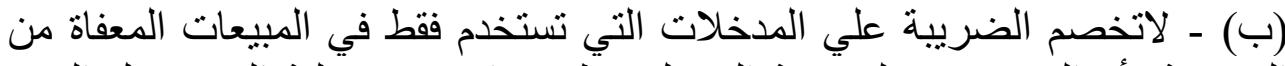
الضريبة، أو التي تخضع لضريبة الجدول فقط، سواء تمت عملية البيع خلال الفترة الضريبية أو بعدها.

- و وتعرف المادة الأولي من اللائحة التنفيذية المدخلات غير المباشرة بأنها: "تكاليف الإنتاج و التشغيل غير المباثرة، وتكاليف البيع و التوزيع، و المصروفاتهات الإدارية و العمومية". ' - المادة (V V ) من اللائحة التنفيذية للقانون. 
الإيتمان الضريبي وآثارة الإقتصادية والمالية "دراسة مقارنة"

(ج) - تخصم الضريبة علي المدخلات التي تستخدم في مبيعات بعضها خاضع للضريبة وبعضها معفي أو خاضع لضرية الضرية الجدول فقط طبقاً لنسبة المبيعات الخاضعة التهات للضريبة إلي إجمالي المبيعات.

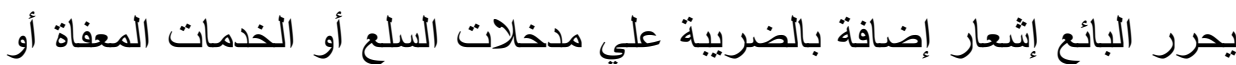

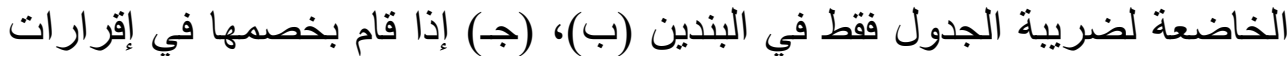

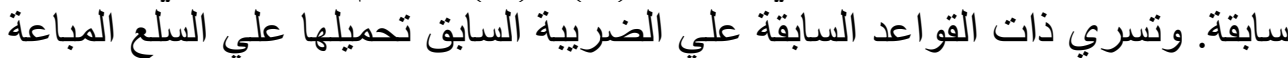
بمعرفة المسجل في كل مرحلة من مر احل التوزيع.

- Sixth Directive ومع ذلك، فإن التوجيه السادس للسوق الأوروبية المشتركة الإنه

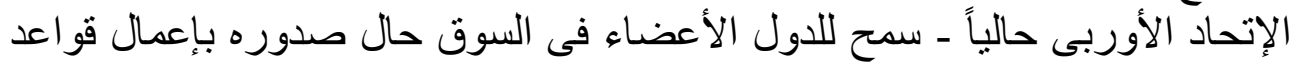

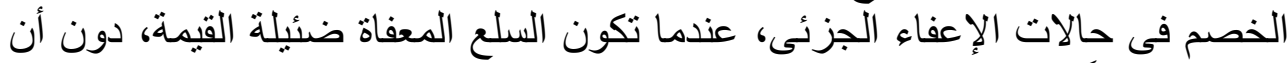

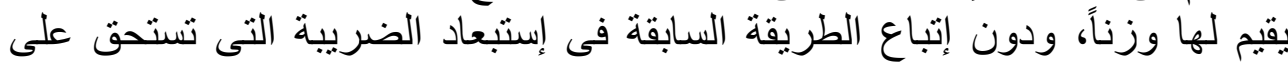

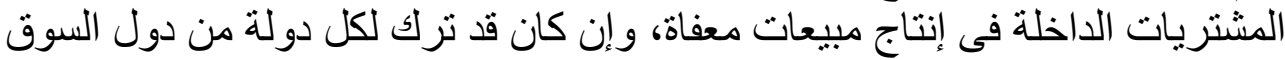

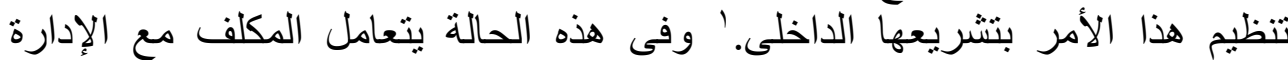

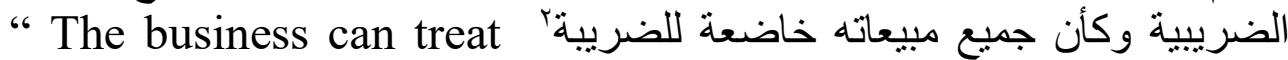
itself as fully taxable"

والأصل في التشريعات المقارنة ألا يتم إعمال المعادلة السابقة إلا بعد مرور سنة

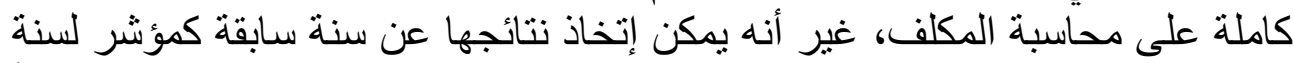
مقبلة، بشرط أن تتم تسوية أخرى فى نهاية السنة الأخيرة Final Adjustment طبلة أنساً

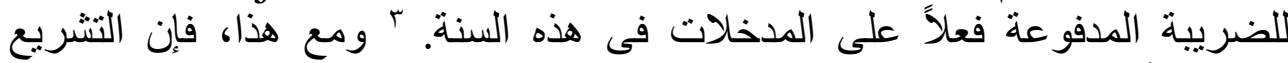

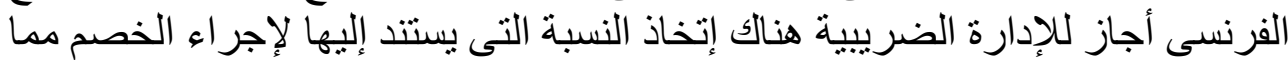

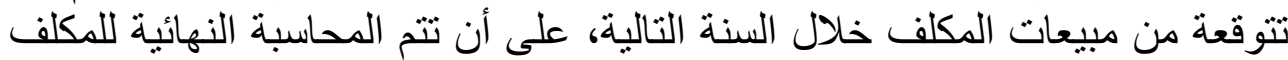

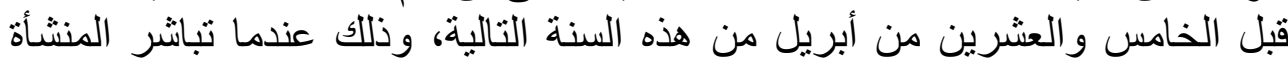

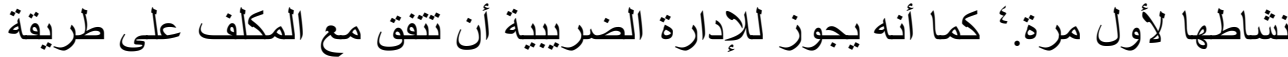

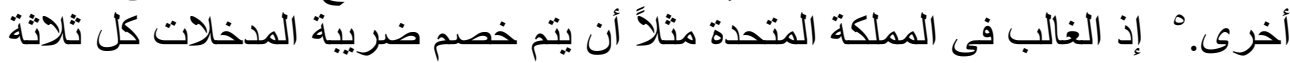

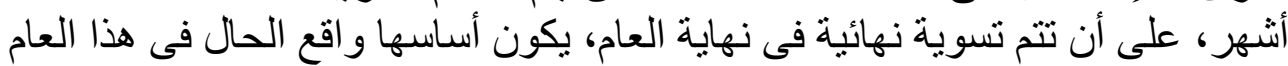

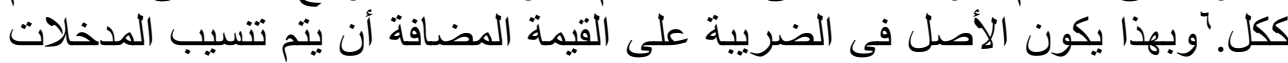

' _. ... it can be ignored, but the level of what is to be considered insignificant is left to the member states to decide " (Dennis Parkinson, op. cit. p. $r \leqslant$.

- Ernst \& Young, International VAT, op. cit. p. rr

- Dennis Parkinson, op. cit. p. ro.

- Ernst \& Young, op. cit. p. Yr).

- Ibid, p. YrY.

' Ibid, p. VY. 
التى تقبل الخصم بشكل مباشر إلى المخرجات الخاضعة للضريبة، و إستبعاد تلك التى

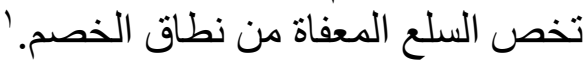
و الواقع أن ما انتهي إلبه تطور تطبيق نظام الإئتمان أو الخصم في الضريبة علي

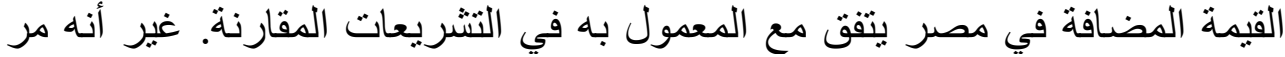

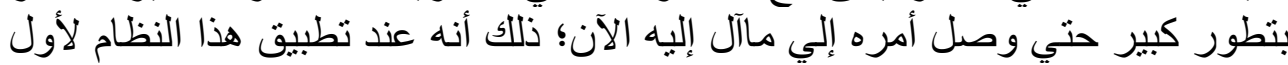

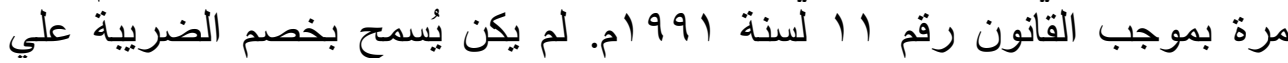

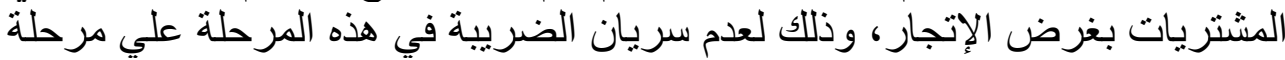

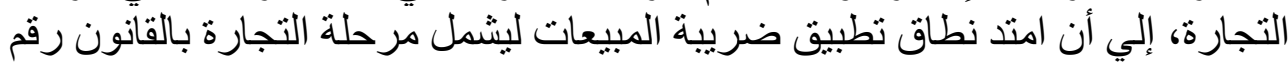

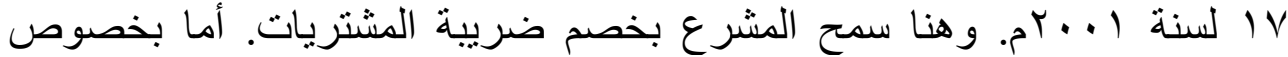

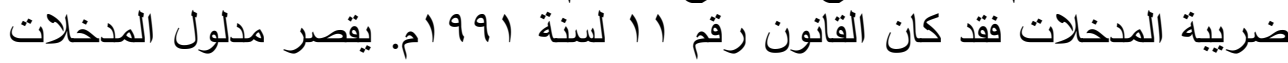
التي يُقبل خصم الضريبة المسددة عنها علي ".... السلع الوسيطة الداخلة فى إنتاج

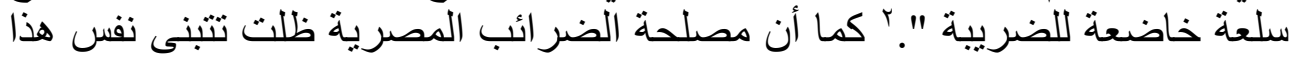

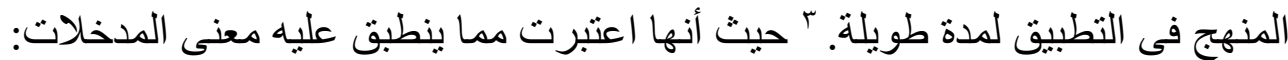

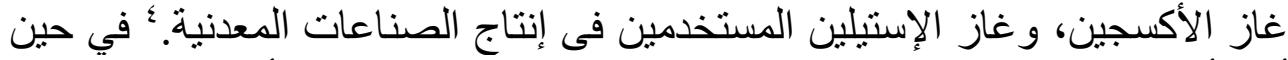

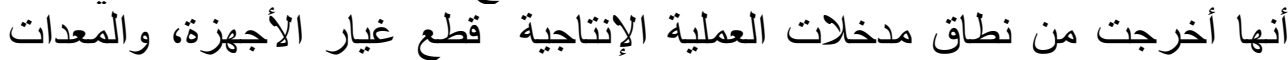

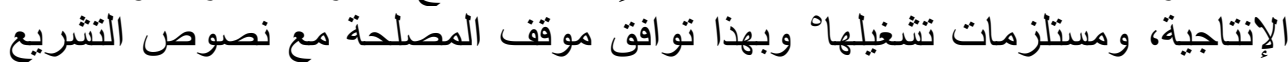

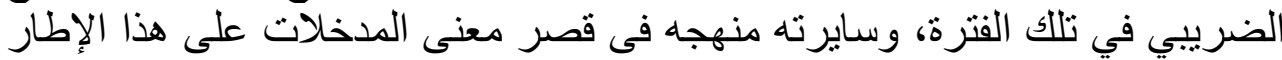
الضيق حبيس العملية الإنتاجية، المقيد بشرطين، همائها:

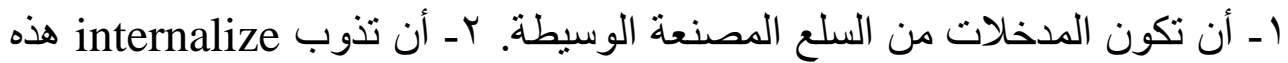

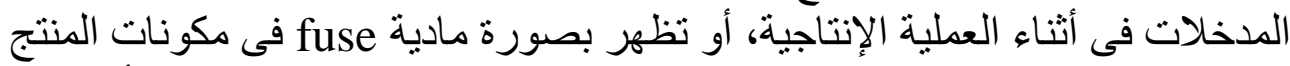

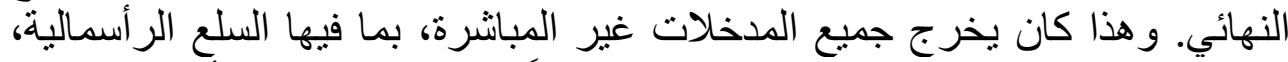

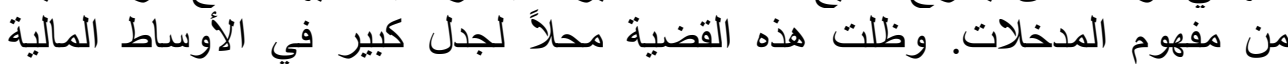
والضريبية بين مؤيد لموقف القانون ومعارض لله غير أندانه أنه عندما صدر القانون

' - " The basic principal in that, input tax must be directly attributed as for as passible to taxable activities an the one hand and exempt and non business activities on the other "

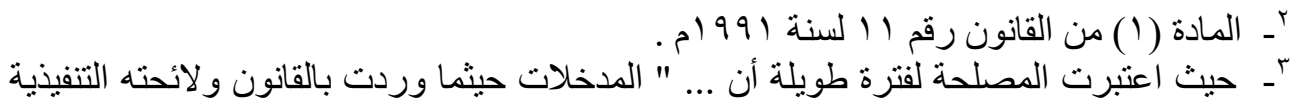
وكذللك القرارات والمنشورات والقوات العد الإجرائية التى يصدرها رئيس المصلحة لتطبيق أحكام

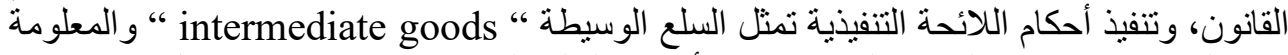

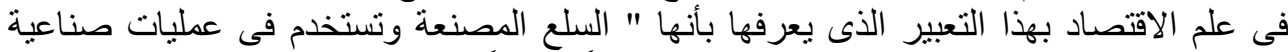

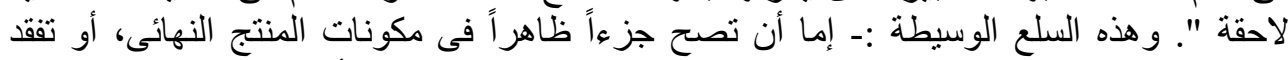

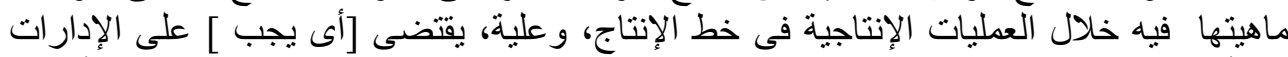

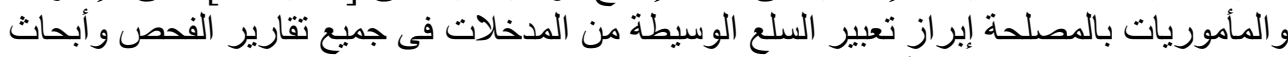

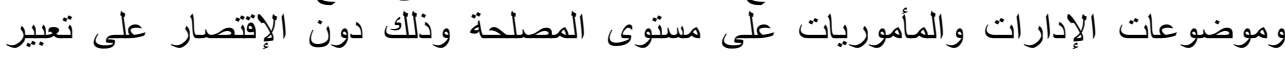

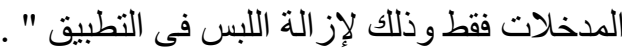

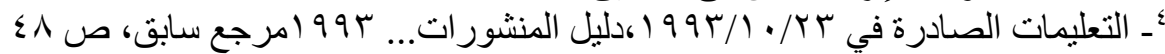

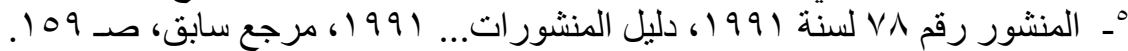


الإئتمان الضر يبي وآثارة الإقتصادية والمالية "دراسة مقارنة"

الحالي نجده - وحسناً فعل ـ أقر حق المكلفين في خصم ضريبة المدخلات بكافة

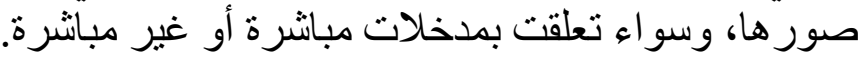

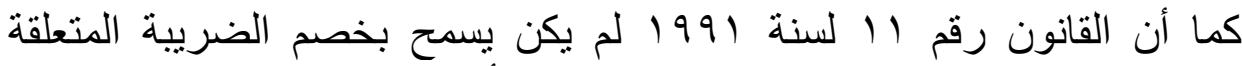

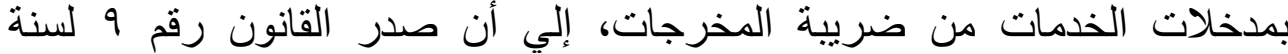

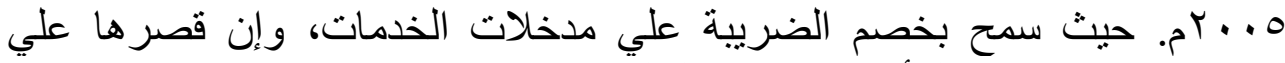

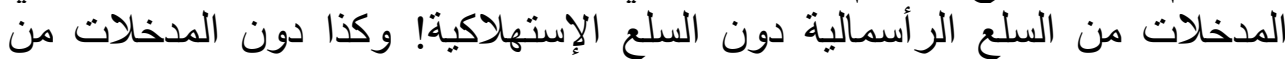

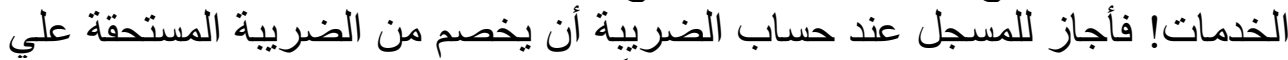

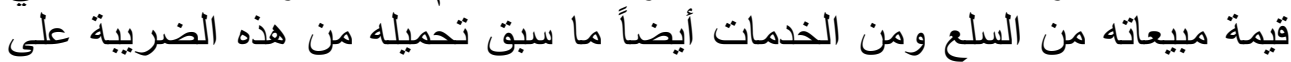
الآلات و المعدات، وأجزائها، وقطع الغيار التي تستخدم في إنتاج سلعة أو تأدية خدمة التية

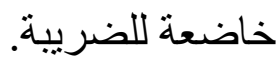

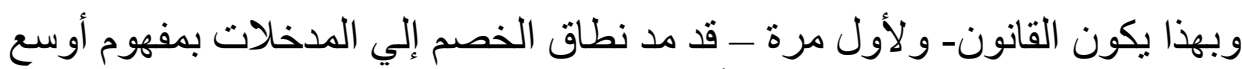

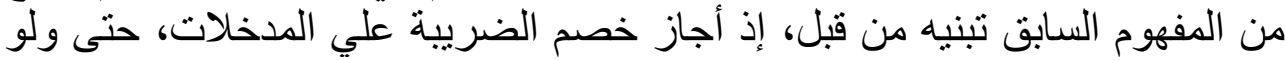

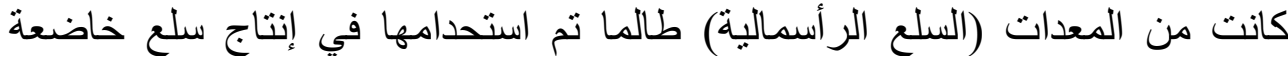

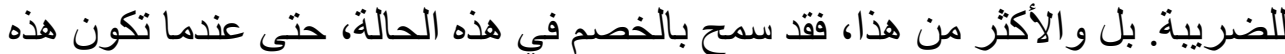

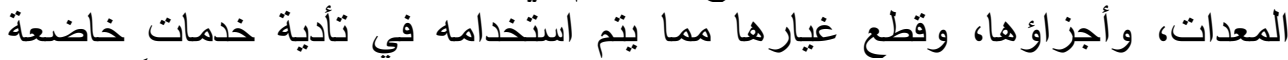

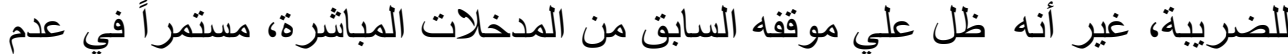

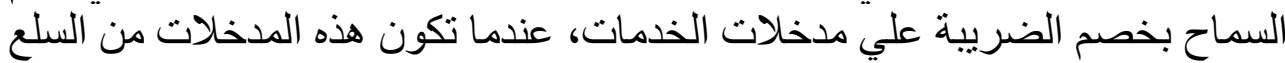

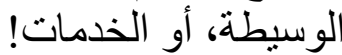

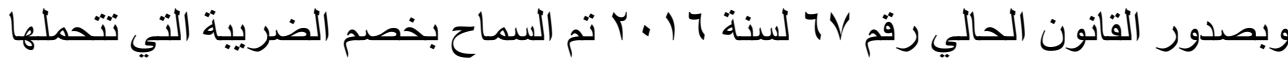

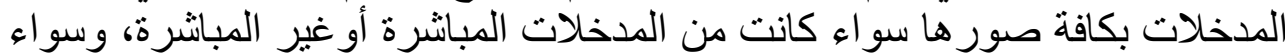
كانت من مدخلات السلع أو من مدخلات الخدمات الخاضعة الضعات للضريبة.

ـ شروط استفادة المسجل من الإتتمان أو الخصم:

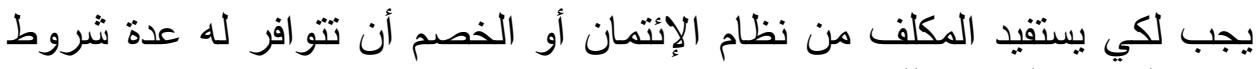
أوجبتها اللائحة التنفيذية للقانون، هي:

1 - أن يكون لدي المسجل فو اتير ضريبية بمبالغ الضريبة التي يريد خصمها.

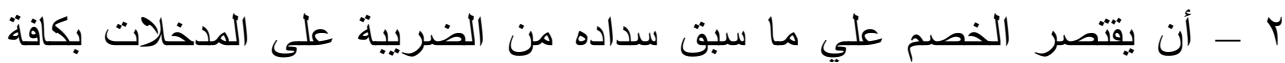

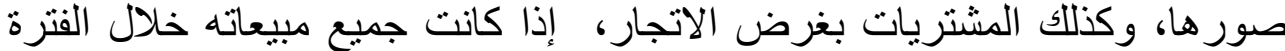
الضريبية خاضعة للضريبة.

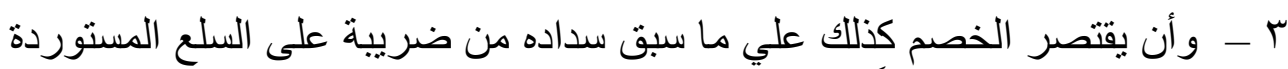
خلال الفترة الضريبية، وفقاً لبيانات شهادة الإجر اءات الجمركية. 


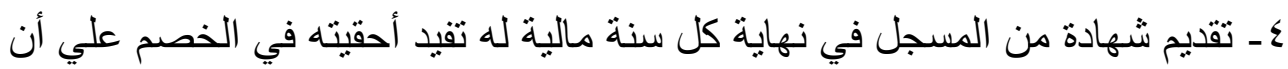

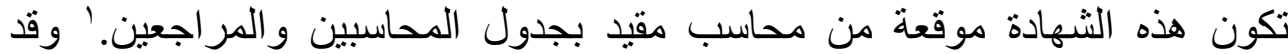

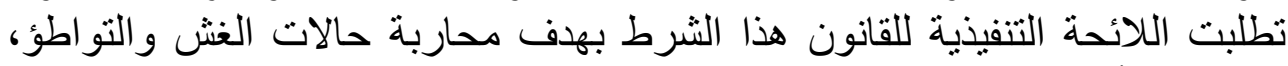
التي يمكن أن يقع فيها المسجلون.

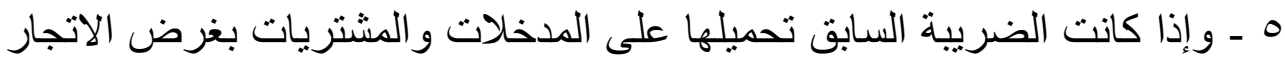

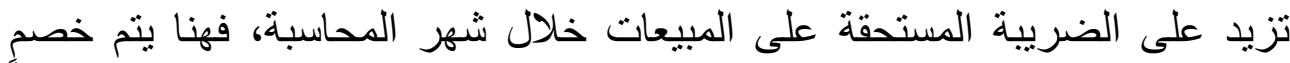
الضريبة المستحقة على المبيعات من الضريبة السابق سدادها على الضى المدخلات شهرياً

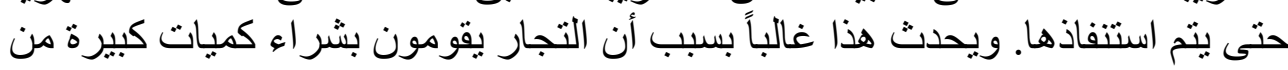

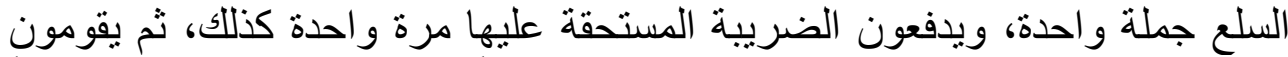

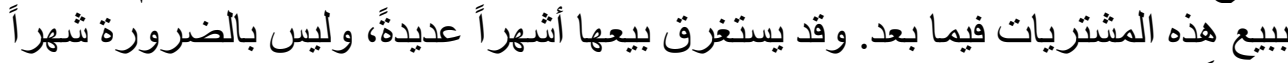

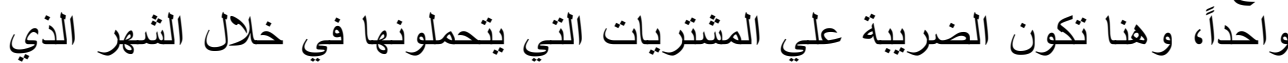

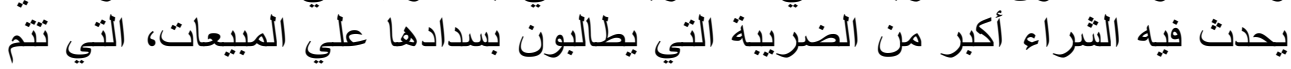

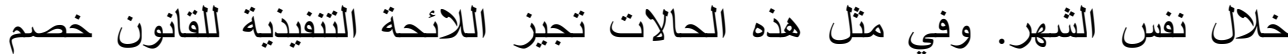

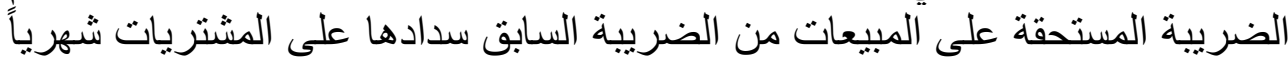

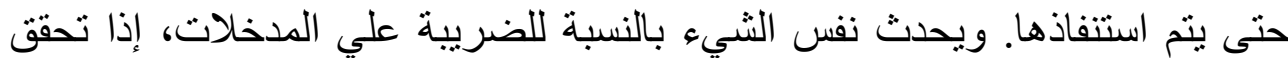
هذا الفرض للمنتجين الصناعيين.

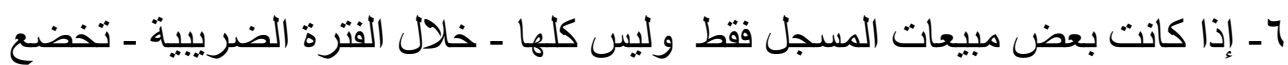

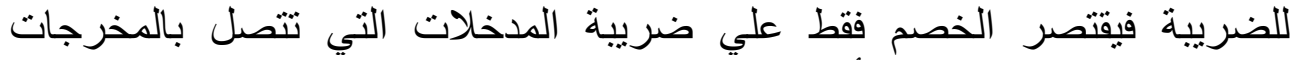
الخاضعة للضريبة كما سبق أن ذكرنا، وبناء علي ذللك يتم الخصم على الوجه التالي: لتالي:

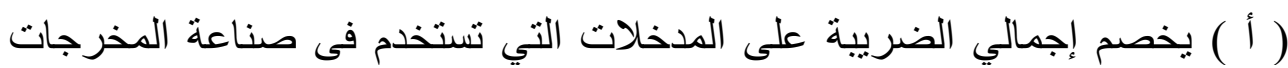
الخاضعة للضريبة، سواء تمت عملية التصنيع فى الفترة الضريبية أو بعدها.

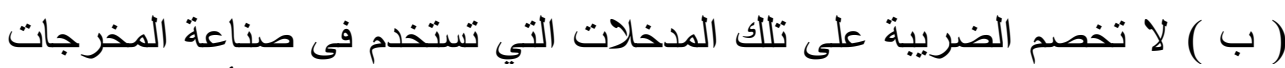
المعفاة من الضريية، سو اء تمت عملية التصنيع خلال الفترة الضريبية أو بعدها.

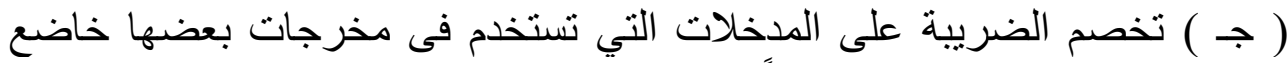

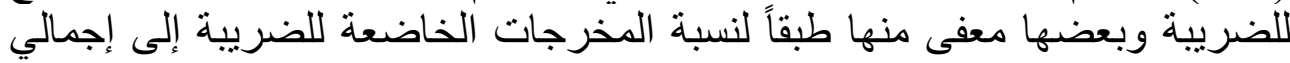

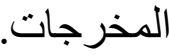

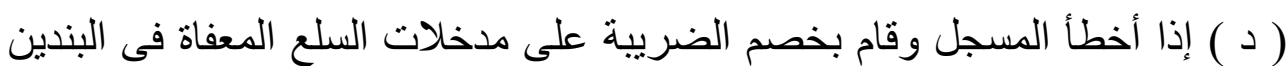

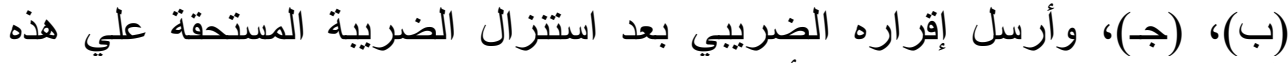

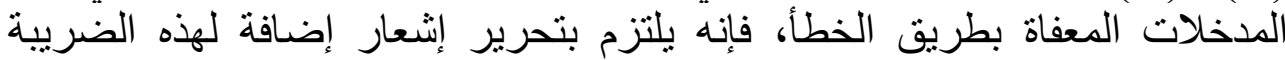

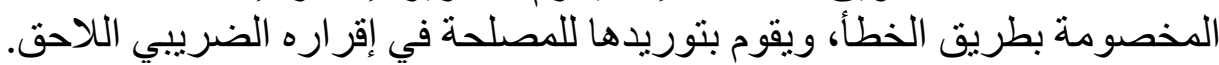

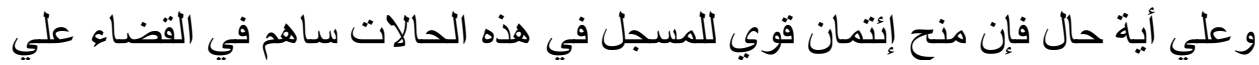

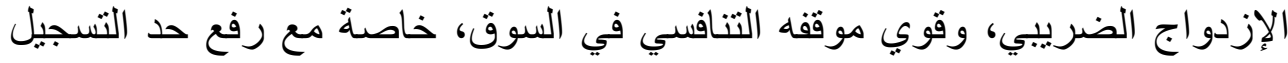

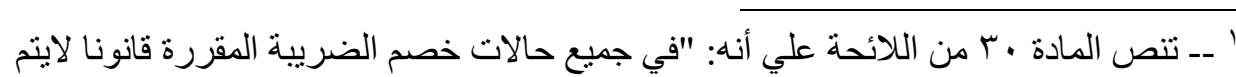

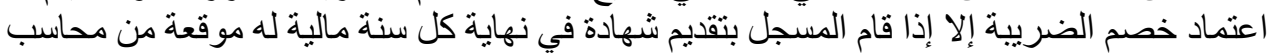
مقيد بجدول المحاسبين و المر اجعين تفيد بأحقيته في الخصم. 
الإيتتمان الضريبي وآثارة الإقتصادية والمالية "دراسة مقارنة"

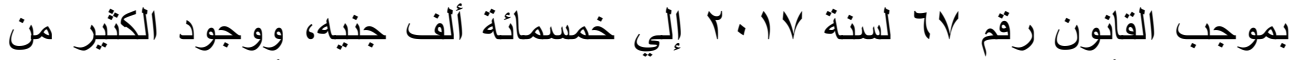
ممارسي الأنشطة الضريبية دون حد التسجيل، ومن ثم ممارستهم لأنشطتهم الضريبية

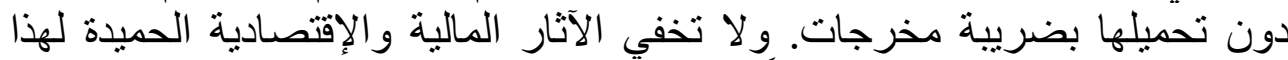

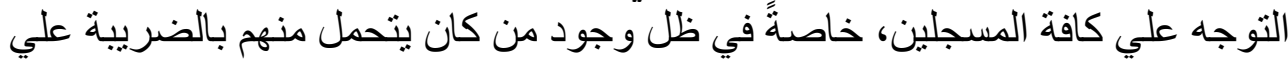

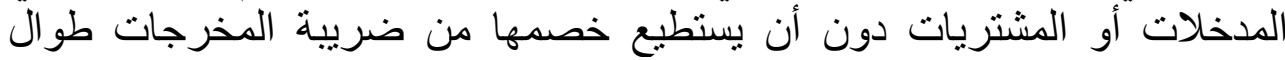

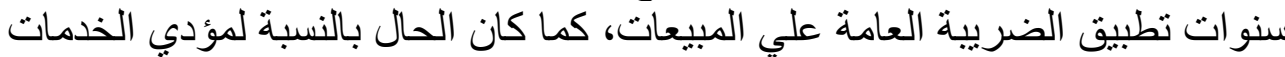
الخاضعة للضريبة.

\section{الفرع الثاني}

\section{حرمان بعض التعاملات الضريبية من الإتتمان الضريبي وآثاره الإقتصادية والمالية}

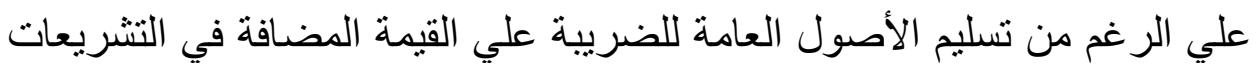
المقارنة بأحقية المكلفين في خصم ضريبة المدخلات وضريبة المشتريات التي تتصل

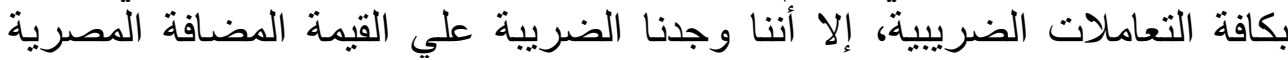

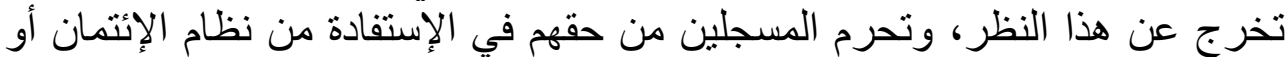

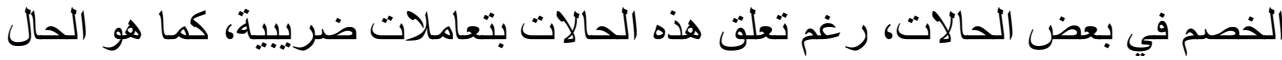

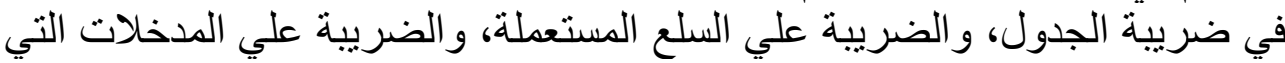
تتدرج ضمن عناصر التكلفة، ونتعرض فية علكي الكل حالة من هذه الحالات بالتفصيل فيلة فيما يلي:

\section{أولاً: السلع والخدمات الخاضعة لضريبة الجدول:}

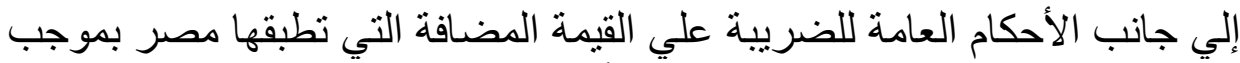

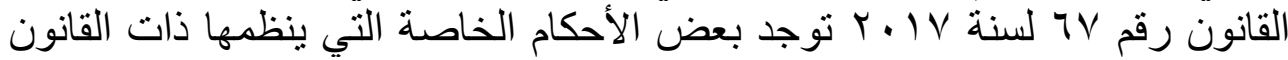

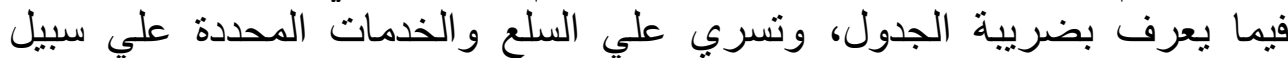

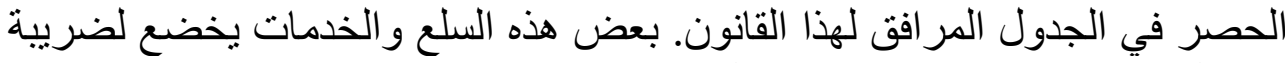

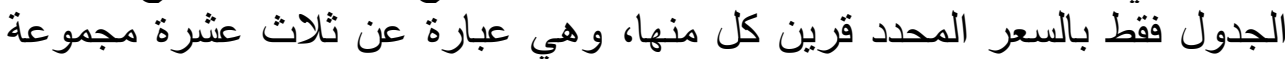

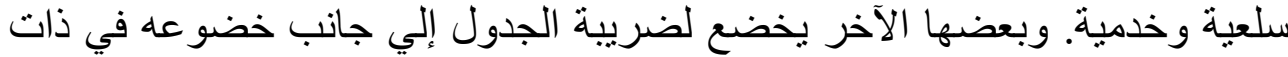

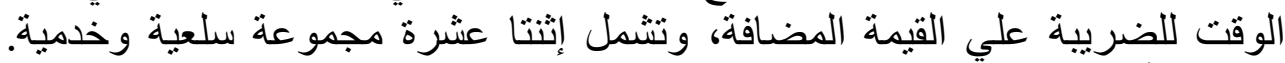

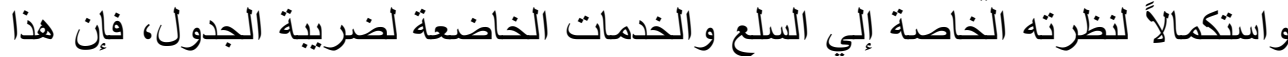

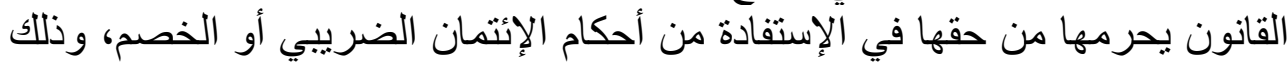

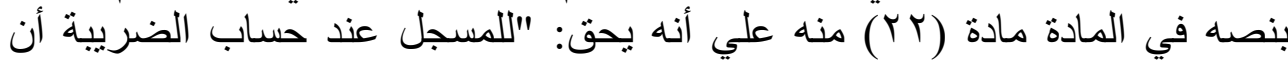

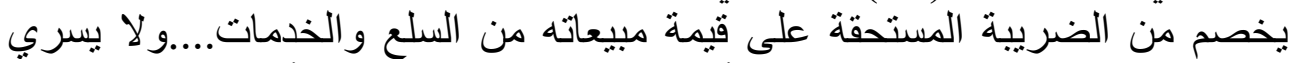

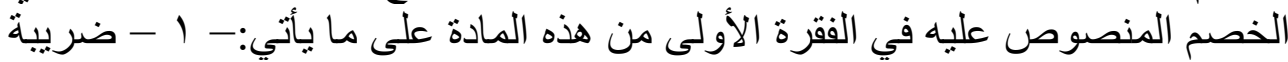

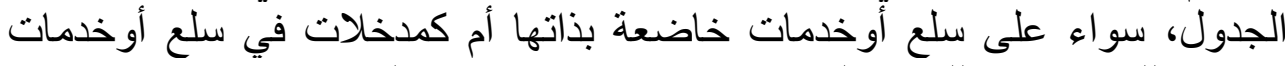
خاضعة للضريبة، وذللك فيما لم يرد به أله نص خاص في هذا القانون....." كما أن اللائحة التنفيذية لهذا القانون أكدت علي ذلك الموقف، بنصها بله في

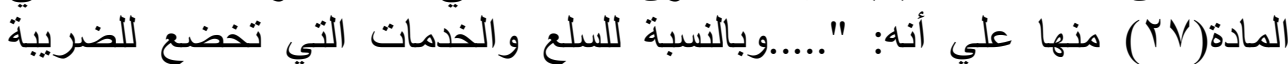

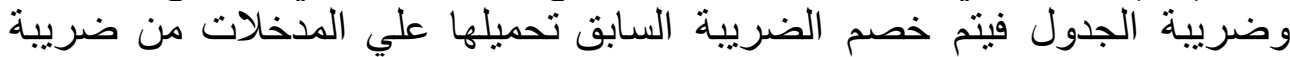

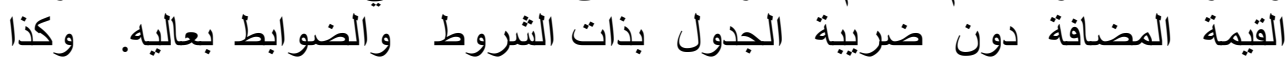




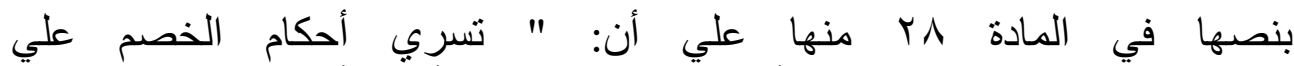

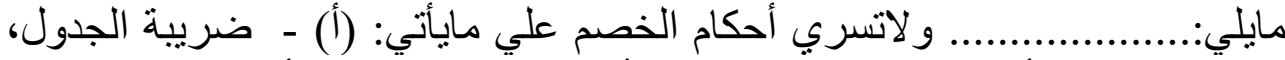
سواء علي سلع أو خدمات خاضعة بذاتها أم كمدخلات في سلع أو خدمات خاضعة

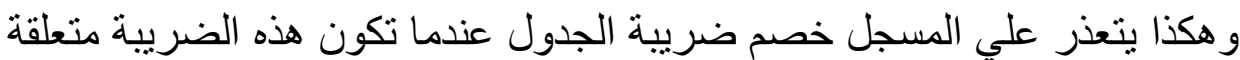

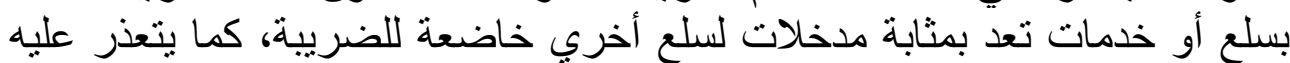

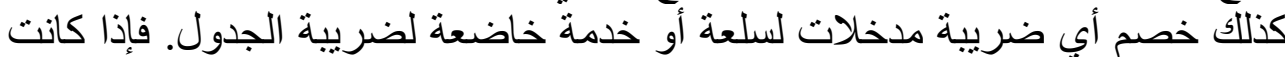

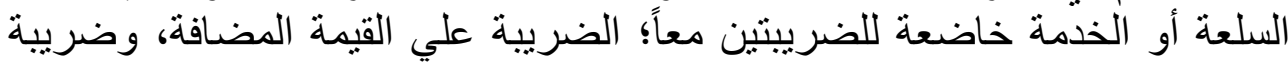

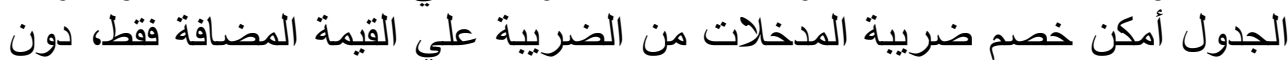

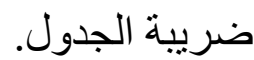

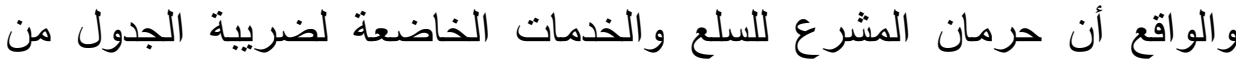

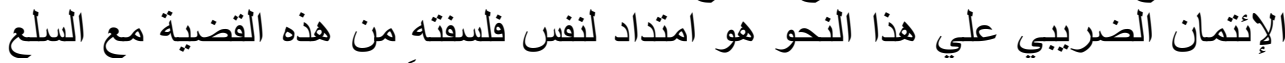

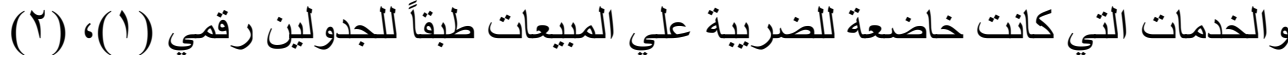

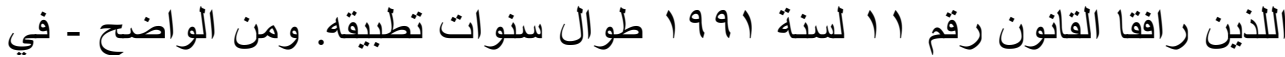

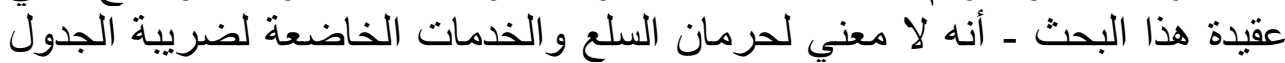

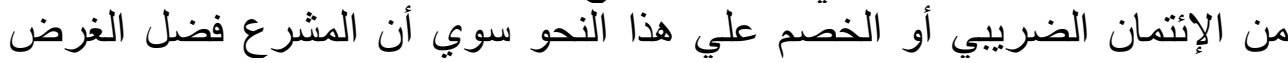

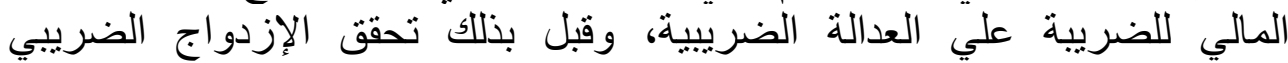

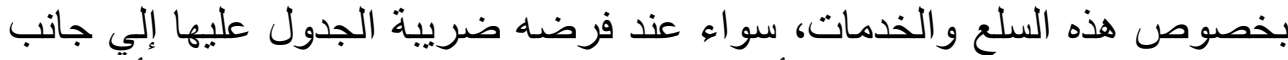

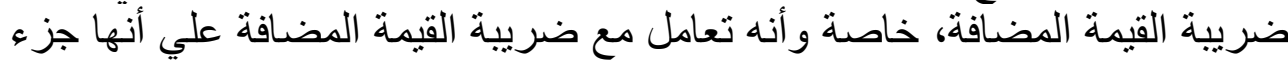

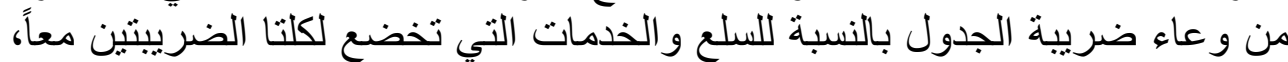

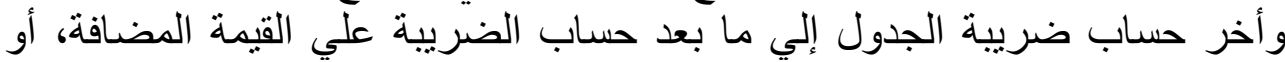

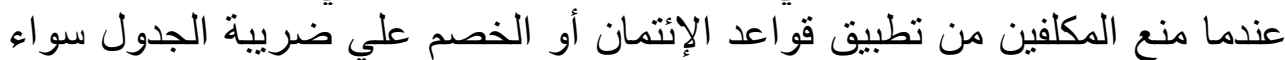

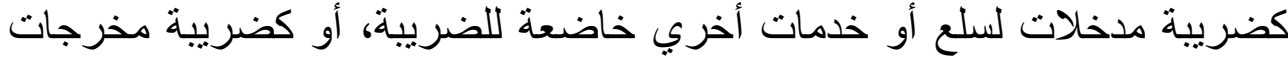

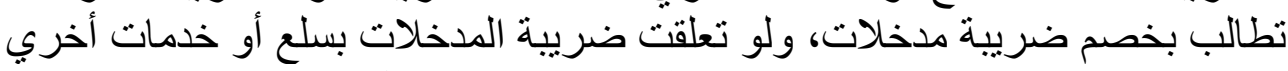

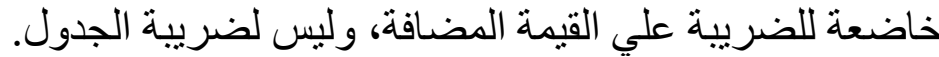

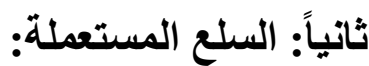

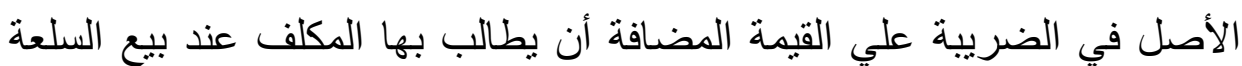

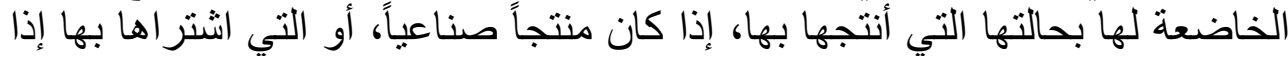

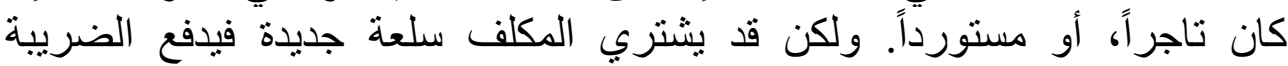

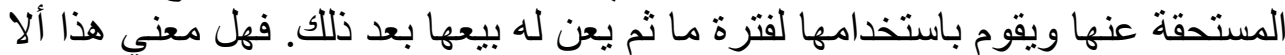

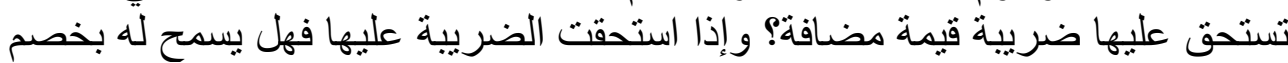
ضريبة المدخلات، أو ضريبة المشتريات؟

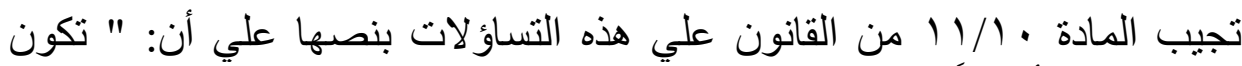

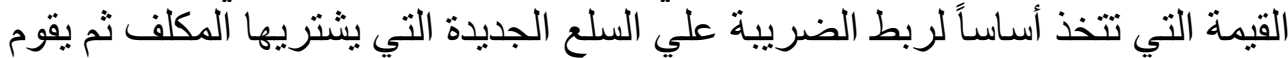

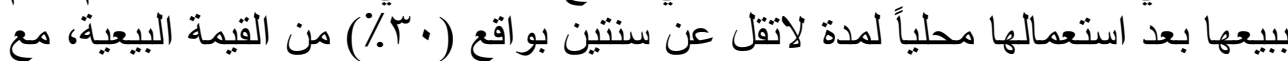
عدم إعمال قو اعد الخصم المنصوص لعليها في المادة (Y (Y) من هذا القانون عند البيع. 
الإيتمان الضريبي وآثارة الإقتصادية والمالية "دراسة مقارنة"

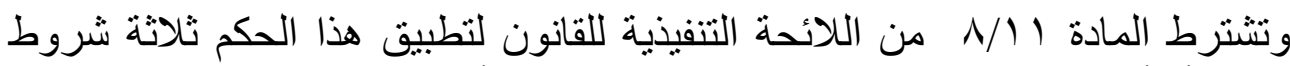

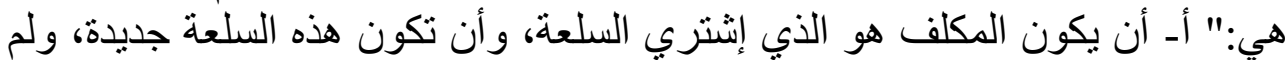

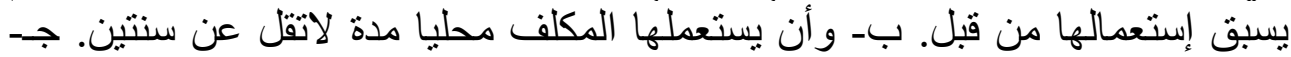

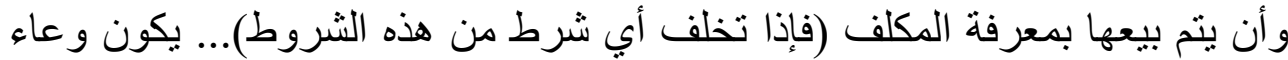
الضريبة هو كامل القيمة البيعية."

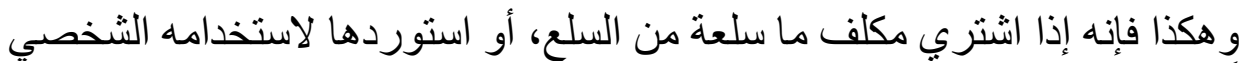

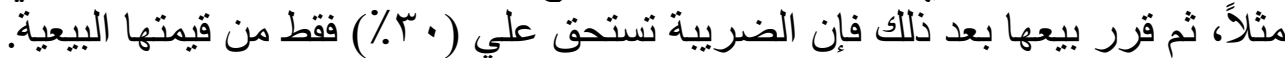

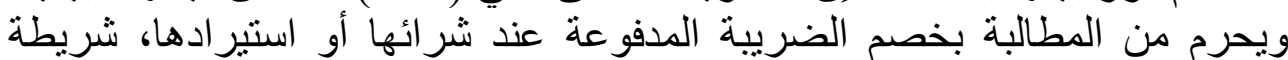

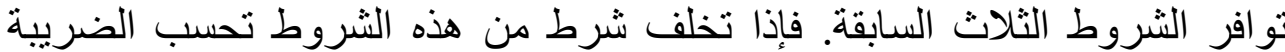

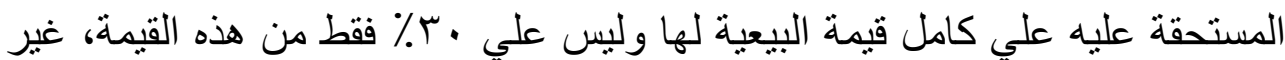

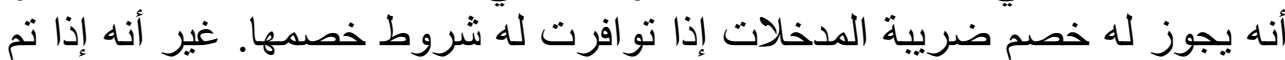

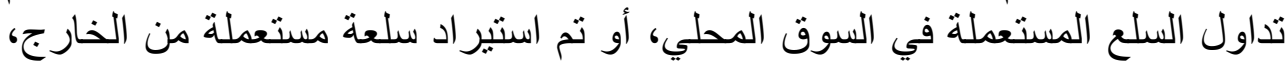

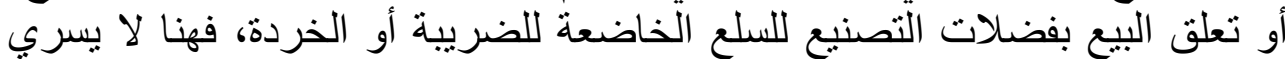

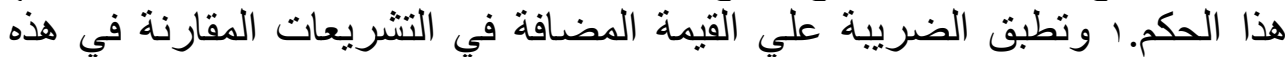

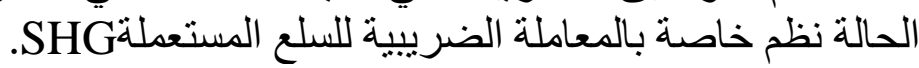

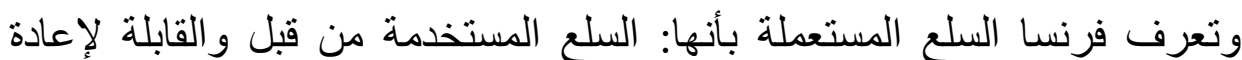

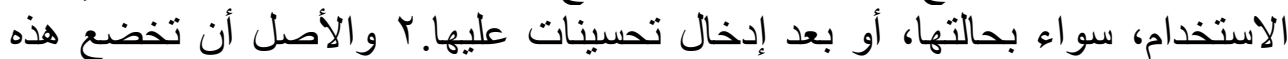

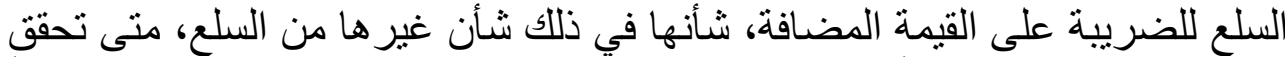

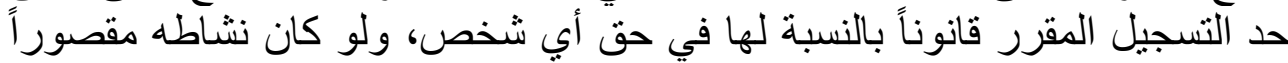

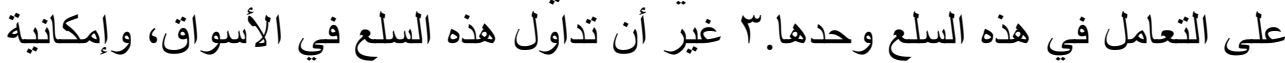

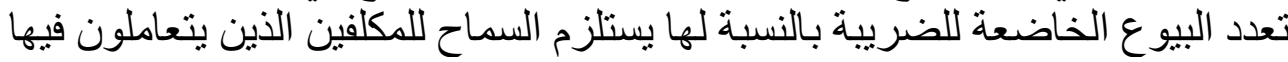

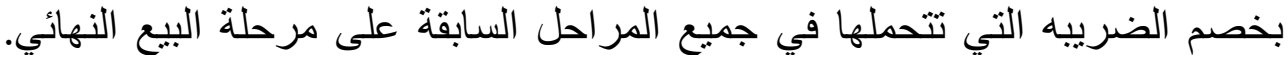

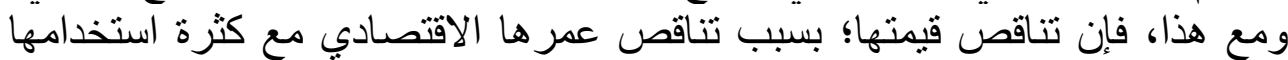

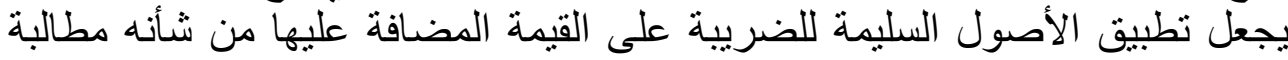

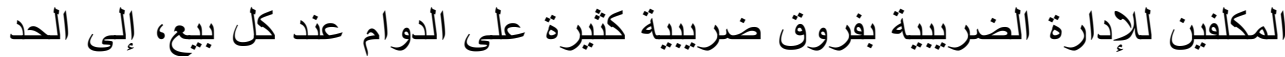

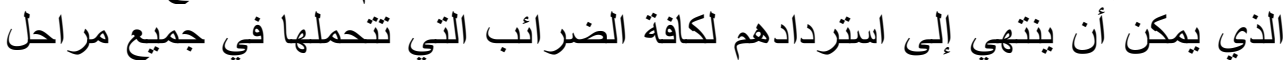

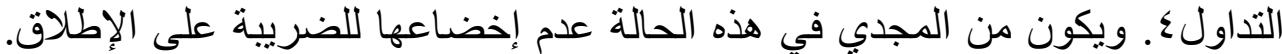

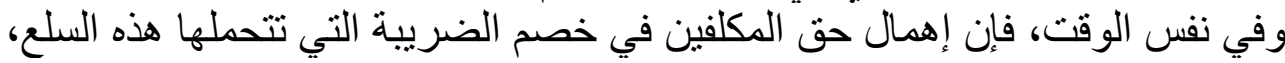

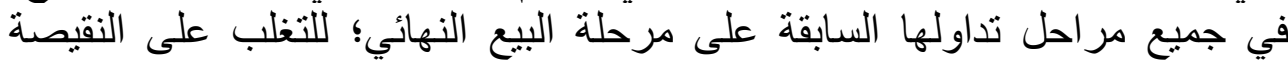

ـ تتص المادة (r؟) من القانون في فقرتها الأخيرة علي مايلي: "... و لا بسري حكم البند ذاته علي

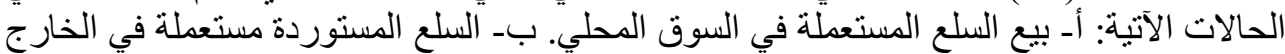

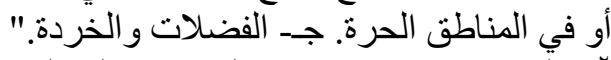

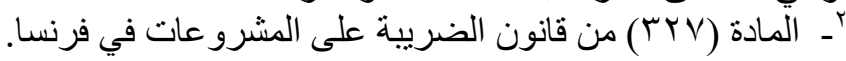

r - Edmund Tirbutt, VAT and the small business ... op.cit.p. ${ }^{\Upsilon}{ }^{\top}$.

- Encyclopedia of value Added Tax,... Op. cit.p. ${ }^{0}$. $\mathrm{V}$.

- John Brooks and Andrew Copp, How to live with VAT, Third Edition, London, 1919 ,p. 70 
السابقة من شأنه أن يؤدي إلى إلحاق عظيم الضرر بالمكلفين القانونيين و الفعليين معاً.

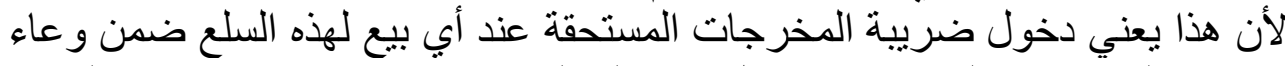

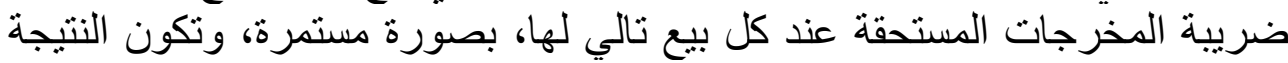

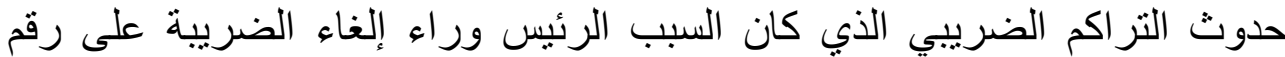

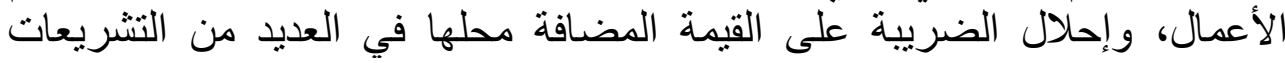

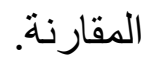

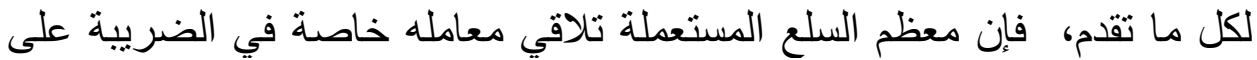

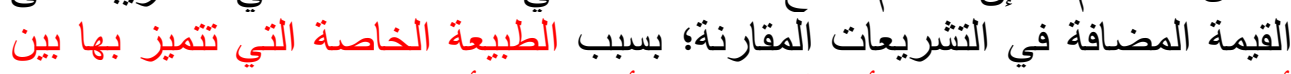

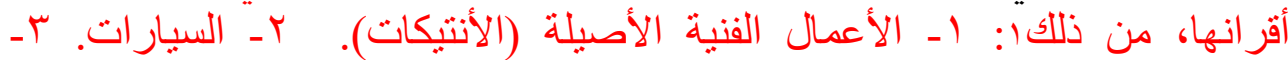

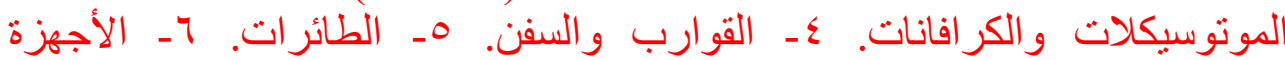

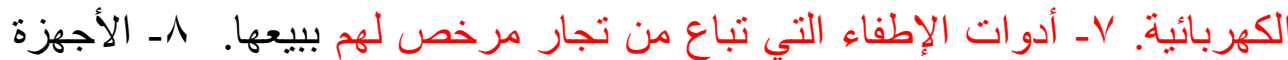

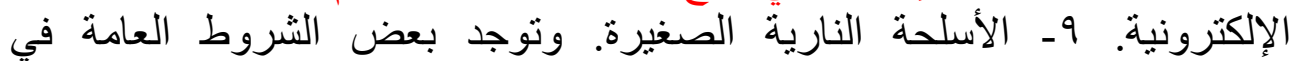

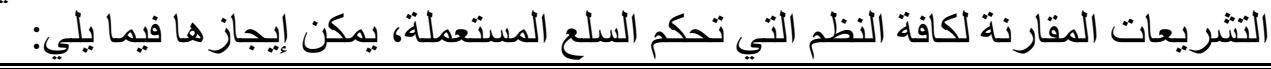

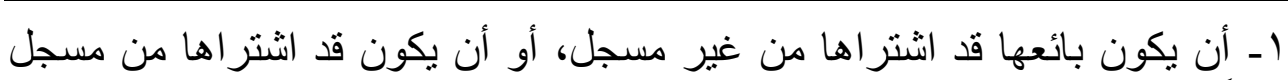
طبقاً لأحكام أحد نظم السلع المستعملة.

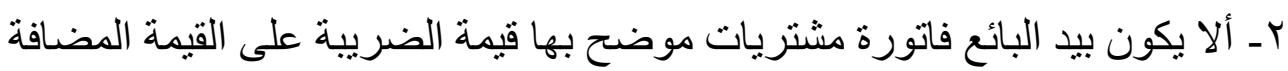

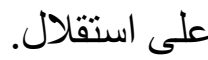
بـــ تقديم إقرار من البائع بعدم أحقيته في خصم ضريبة المدخلات عن السلعة التي

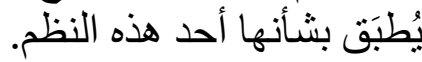

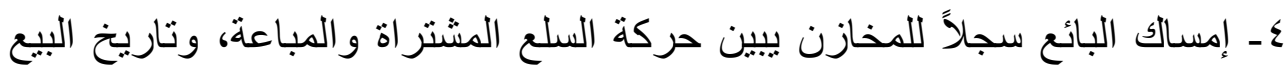

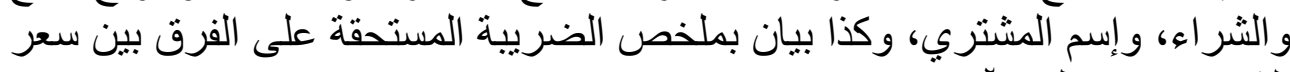

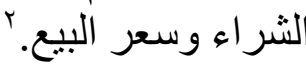

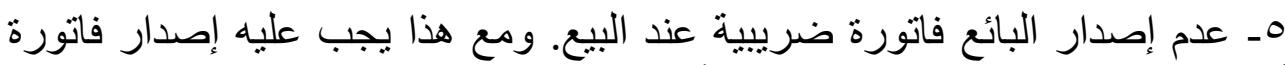

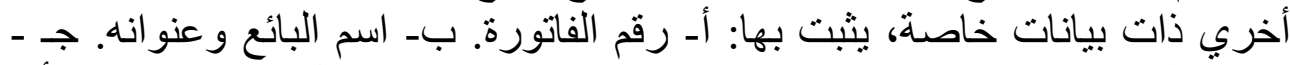

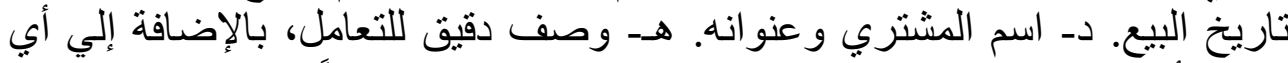

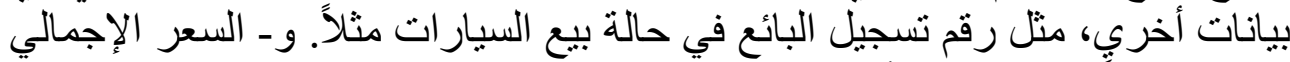

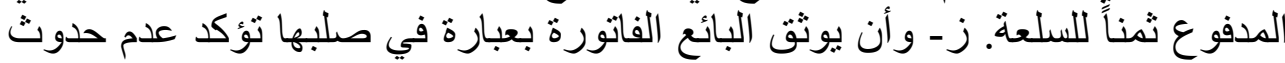

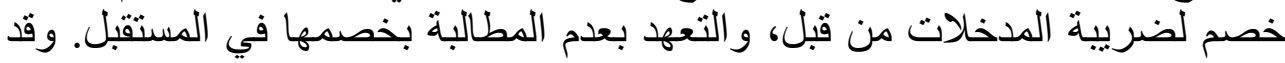

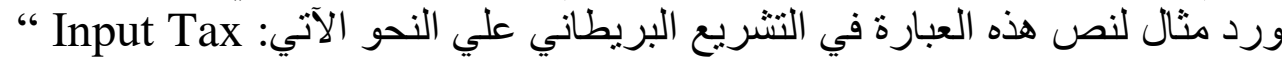
has not been and will not be claimed by me in respect of the good

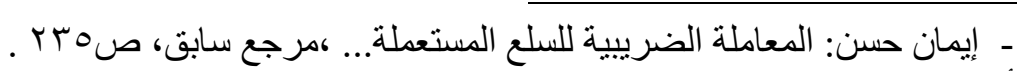

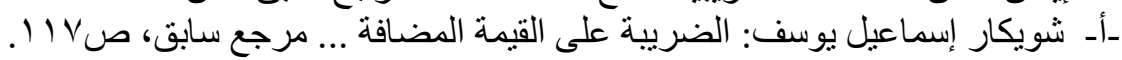

- A. Farman , PKF, tax Handbook , r... r r.. , Alled Dumfer, Great Brition, $r \cdots$, p. ov

${ }^{r}$ - John B. and Andrew C.: How to live...op.cit.p. ${ }^{\top 7}$. 
الإئتمان الضر يبي وآثارة الإقتصادية والمالية "دراسة مقارنة"

'soled in this invoice “.

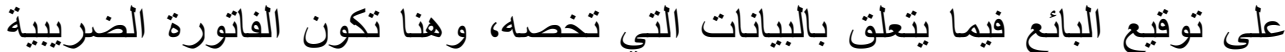
صحيحه وتعمل أنثر ها.

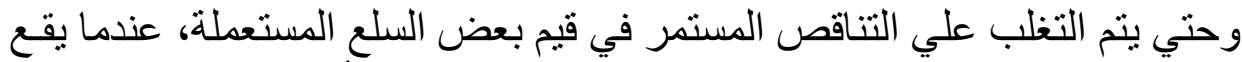

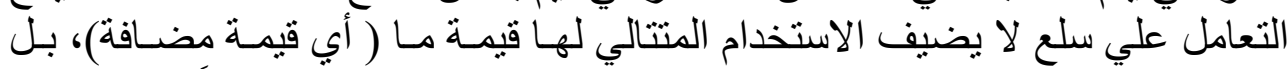

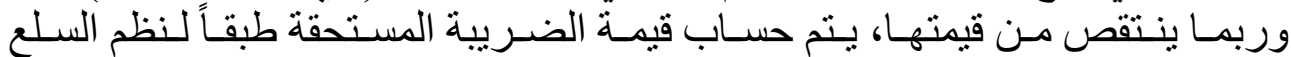

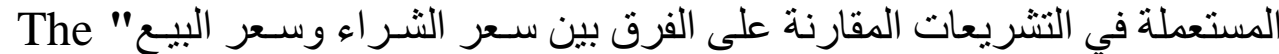
Gross Margin

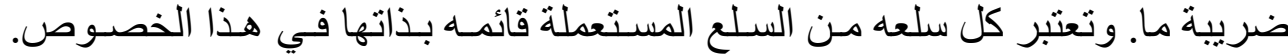

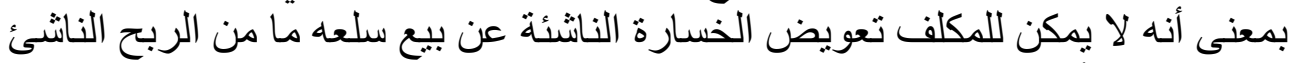

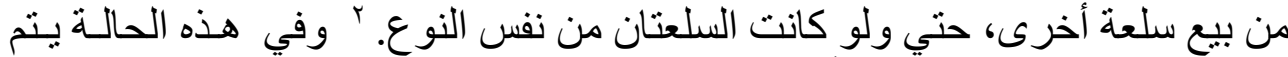
حساب الضريبة المستحقة طبقاً للمعادلة الآتية:

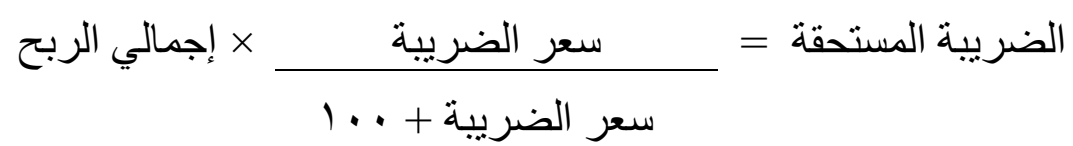

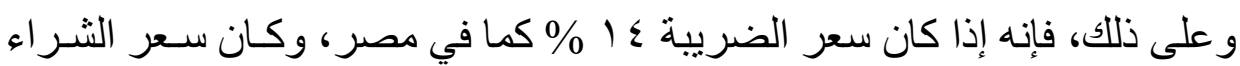
r. . .

$$
\text { الضريبة المستحقة }=\frac{1 \varepsilon}{1 \ldots+1 \varepsilon}
$$

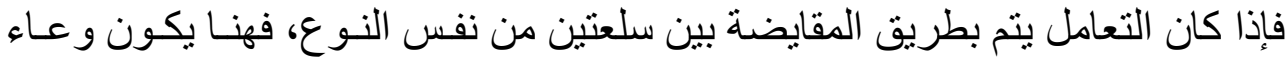

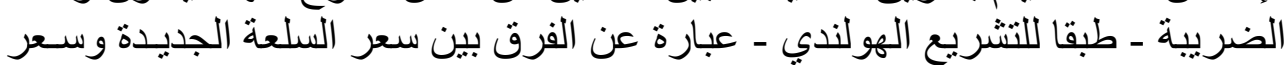

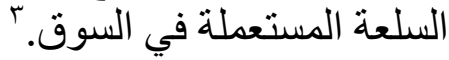

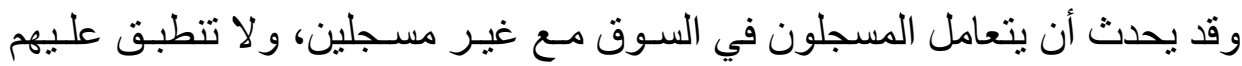

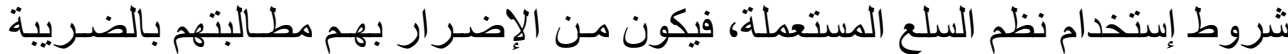

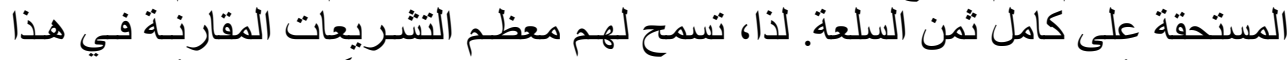

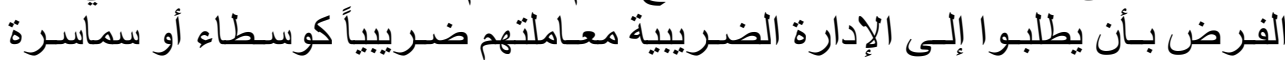

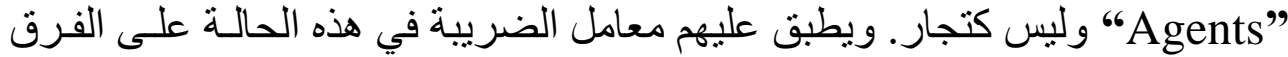

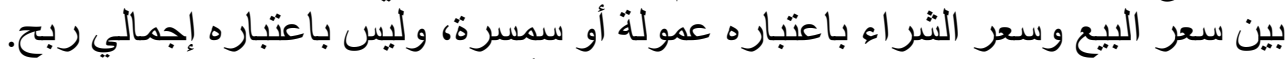

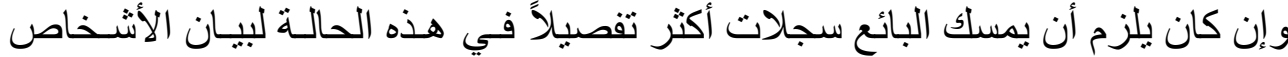

'- Ibid. Loc. cit,

ـ ـ أنظر أيضاً صـ 1^ من نفس المرجع، حيث يمكن الإطلاع على شكل هذه الفاتورة وبياناتها. $r$ - " The essential principle used is that, the user can account for VAT only on the amount by which the selling price exceeds the buying price"

(Edmund Tirbutt, VAT and ... op.cit.pp. ${ }^{\vee} \cdot-\vee /$ )

r - Ernst \& Young: International VAT ... op.cit.p. 9 \& \& p. ${ }^{r}$ r. 
الذين يتوسط بينهم، و العمولة التي يحصل عليها في نظير ذللك.' وبتطبيق هذا التيسـير

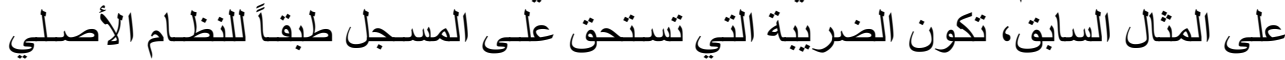

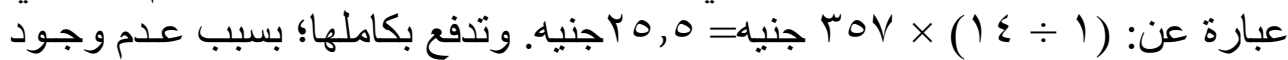

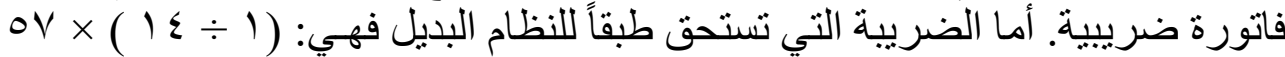
= خمسة جنيهات فقط.

و الحقيقة أننا في حاجة إلى مر اعاة القو اعد السابقة عند التعامل مع السلع المسـتعملة

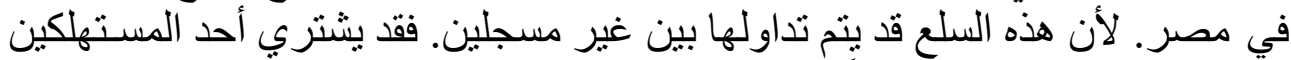

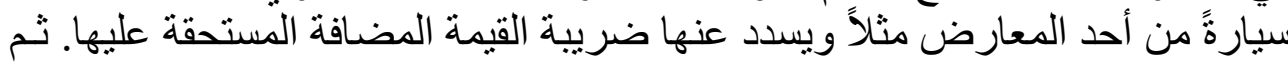
يقوم ببيعها بعد ذلك إلى تاجر مسجل. فإذا باع التاجر المسجل نفس السيارة بعد ذلكيك،

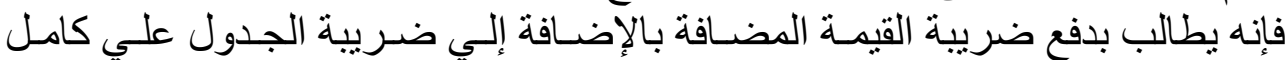
قيمتها ب. ولا يستطيع خصم ضريبة المشتريات؛ لعدم وجود فاتورة ضريبية بيده بسبب

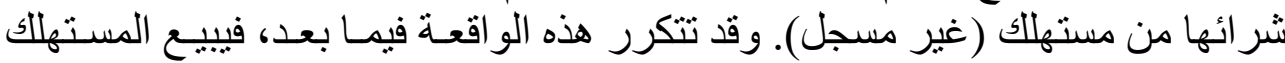

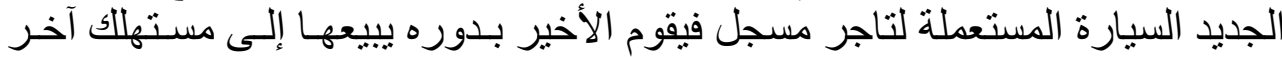

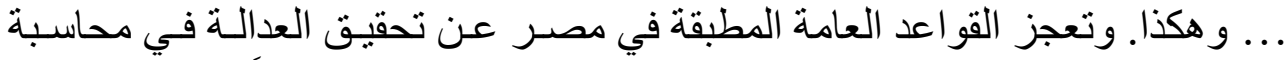

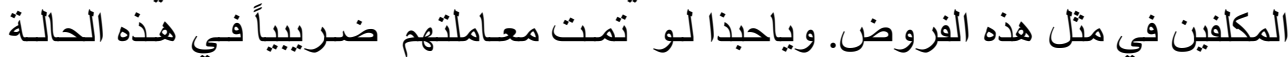
كوسطاء أو سماسرة "Agents" وليس كتجار. وتطبيق سعر الضـريبة عليهم على هئي

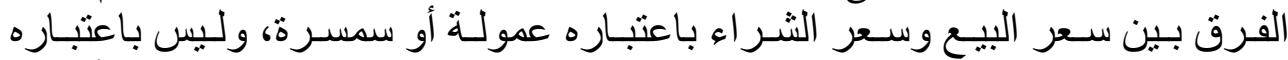
إجمالي ربح، علي النحو المعمول به في التشريعات المقارنة، علي ما أسلفنا حالاً. ثالثاً: المدخلات التي تتدرج الضريبة المسددة عنها ضمن التكلفة: الأصل أن الإئتمان أو الخصم يمنح لضريبة من ضريبة كما ذكرنا، ضريبة

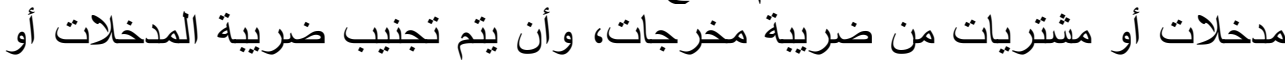

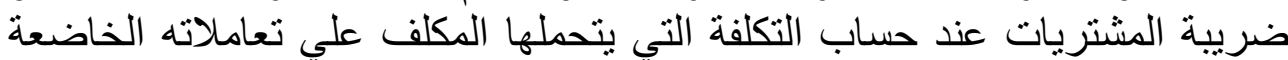
للضريبة، سو اء عند تصنيعها، أو شرائها، أو استير ادها من الخارج، أو آدائها (بالنسبة

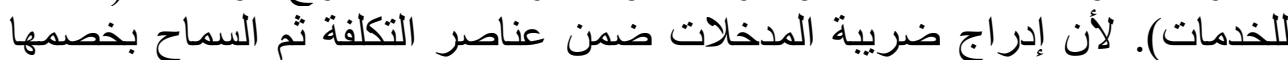

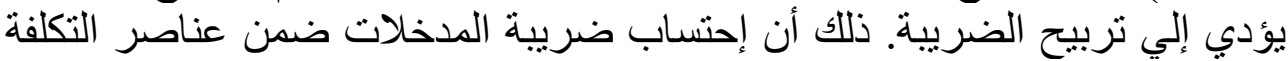

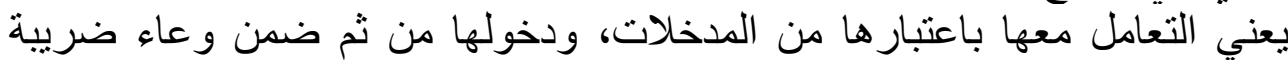

' - John B. And Andrew C., How to Live ..., op.cit.p. 79.

ـ يمكن الوقوف على المزيد من التفاصيل عن المعاملة الضريبية للسلع المستعملة من خلال

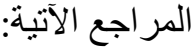

- Graham \&Trotman: The price waterhouse, A-Z of VAT, London, 1919 ,pp. 1 V4_ IV9.

-John N. Brown and Suzanne Chadwick, A guide to VAT in the UK...,

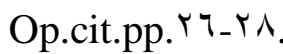

-Encyclopedia of Value Added Tax ...vol. . r.op.cit.p.0.1 V.

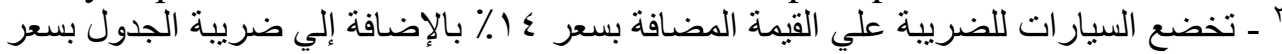

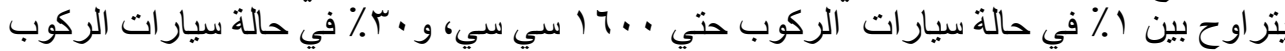

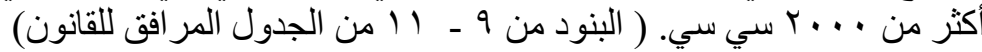


الإيتمان الضريبي وآثارة الإقتصادية والمالية "دراسة مقارنة"

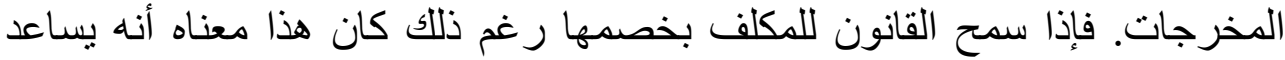

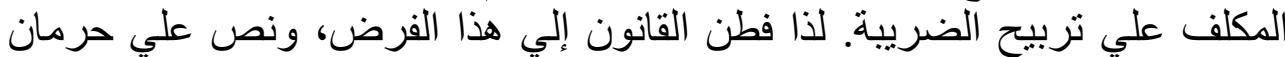
المكلف من خصم ضريبة المدخلات المدرجة ضنمن التكلفة.

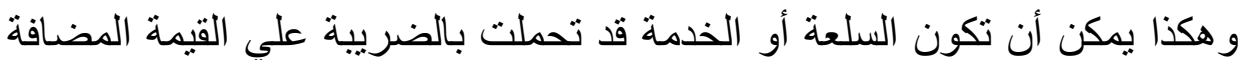

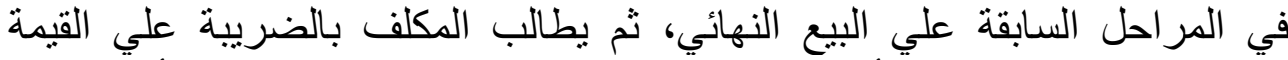

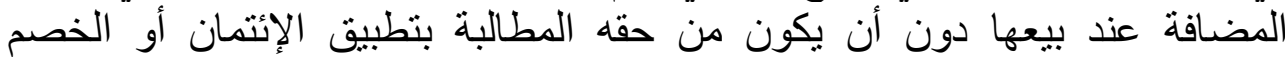

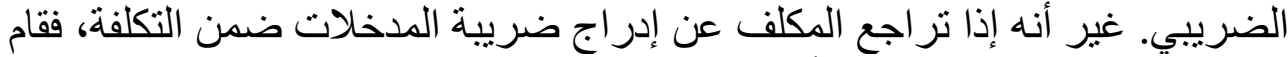

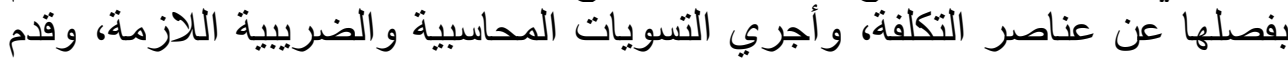

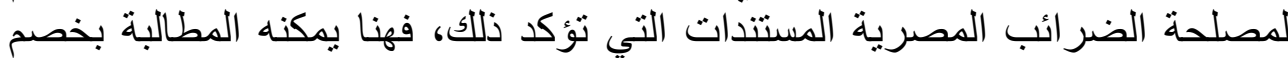

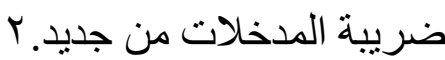

$$
\text { المطلب الثاني }
$$

\section{تطبيق الإتتمان رغم غياب الإزدواج الضريبي وآثاره الإقتصادية والمالية}

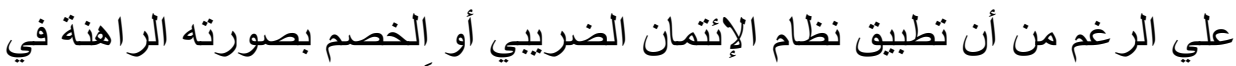

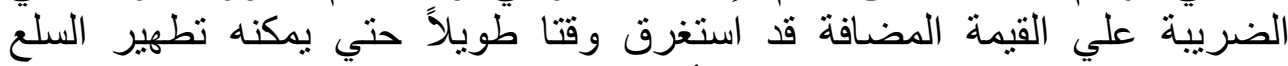

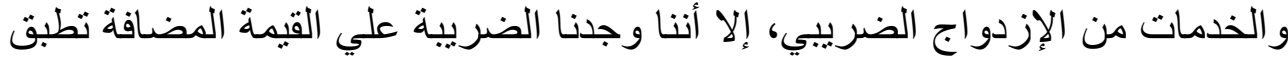

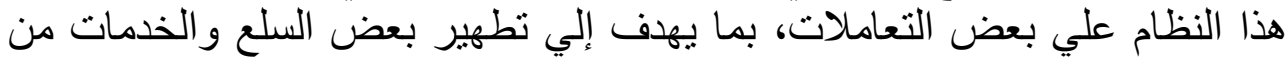

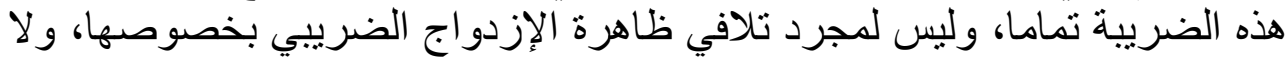

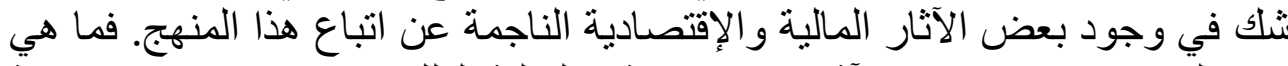

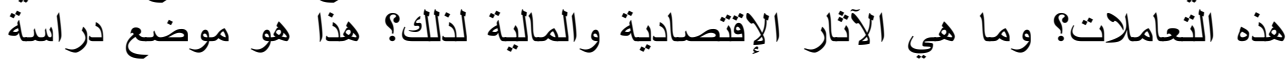

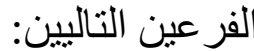

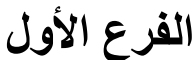

\section{أهمية تطبيق الإتتمان علي الصادرات وآثاره الإقتصادية والمالية}

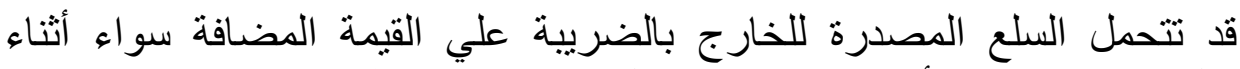

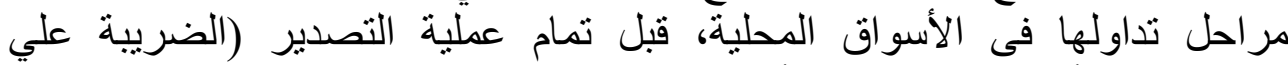

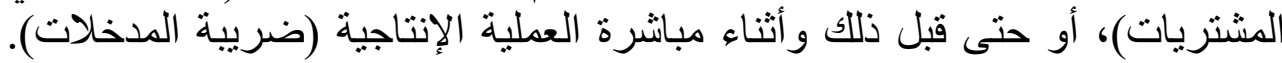

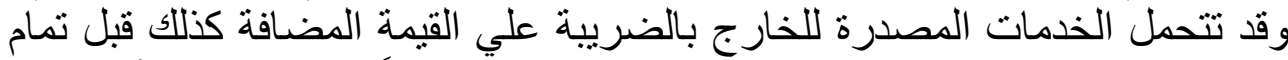

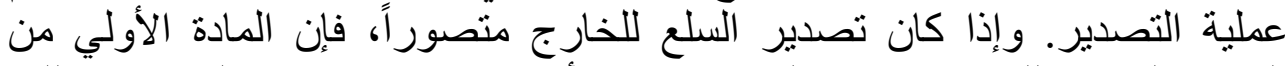

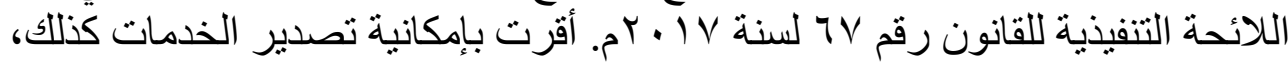

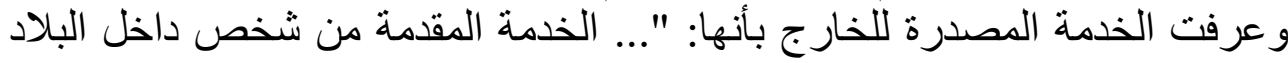

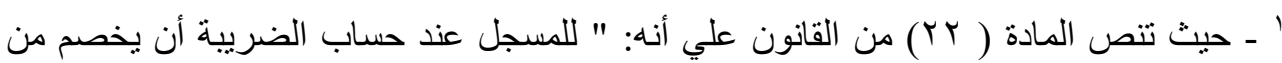

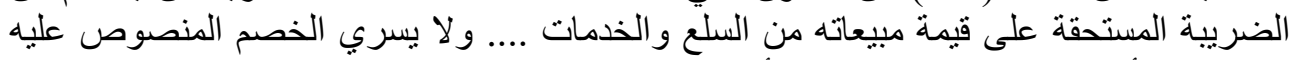

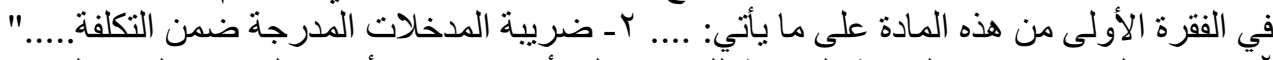

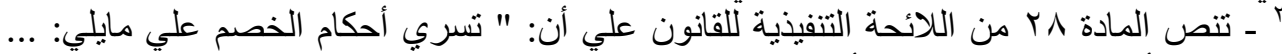

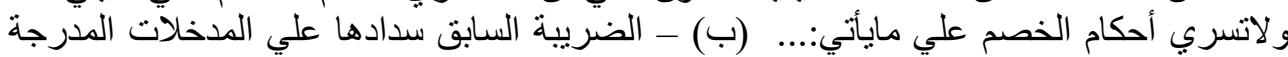
ضمن التكلفة إلا إذا أجريت التنسوية المحاسبية والضريبية اللازمة وقدم مايفيد ذلك للمصلحة.... 
إلي متلقيها في الخارج سواء نم تقديمها من شخص مقيم في مصر أو لايه منشأة دائمة

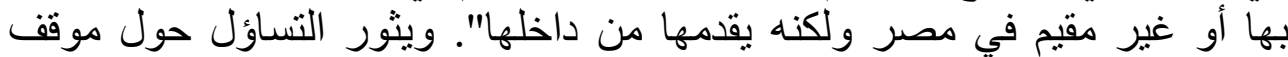

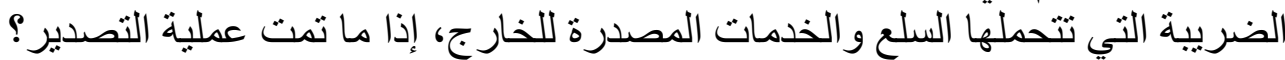
وما يثير هذا التساؤل أمران:

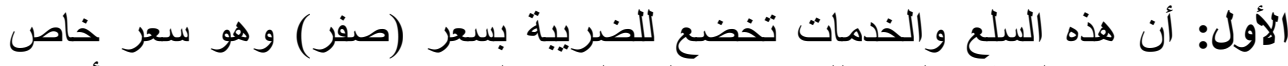

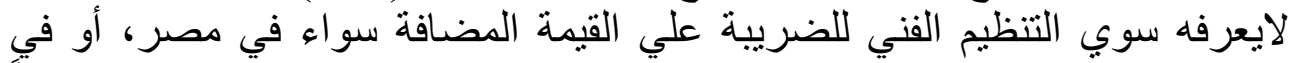

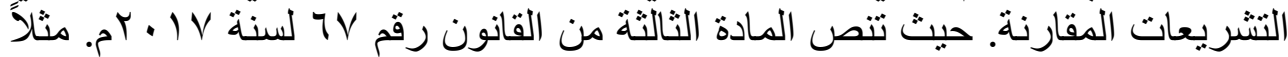

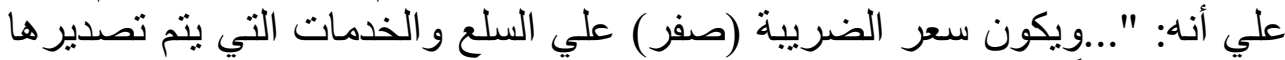

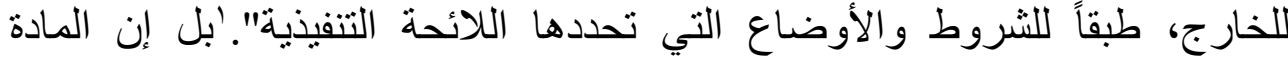

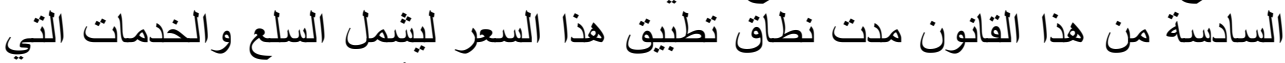

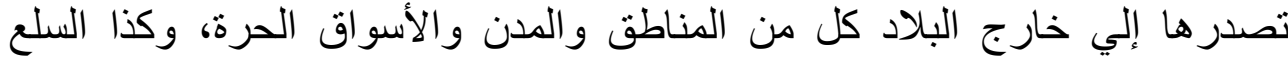
و الخدمات التي تدخل هذه الأماكن من داخل البلاد.

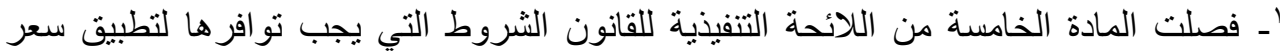

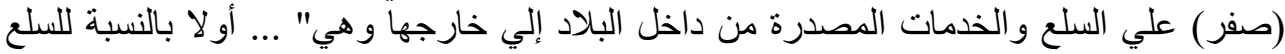

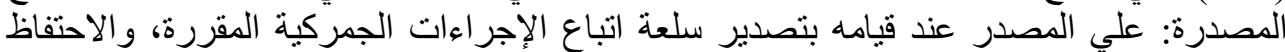

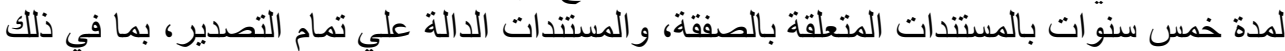

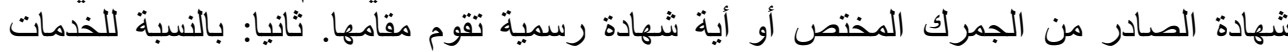

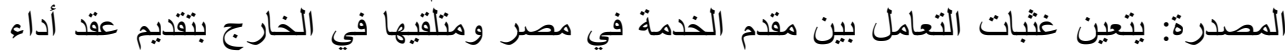

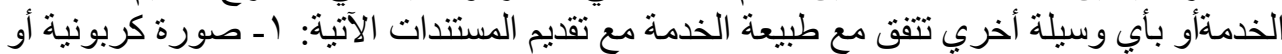

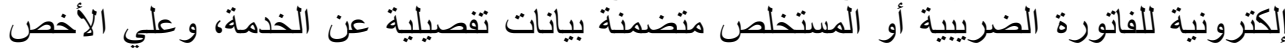

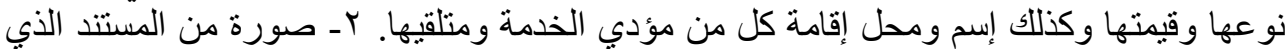

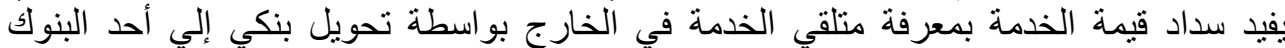

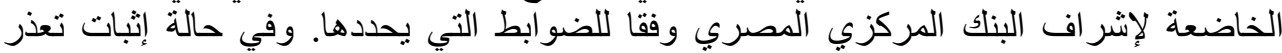

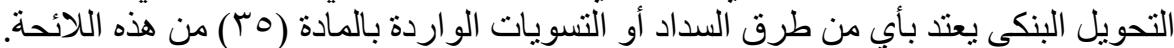

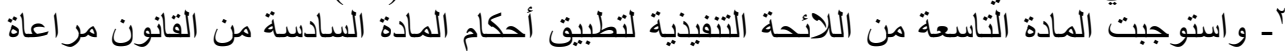

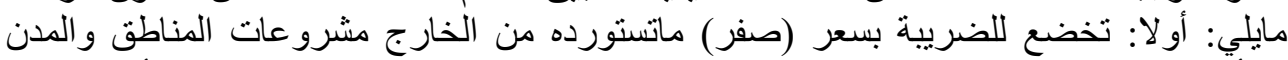

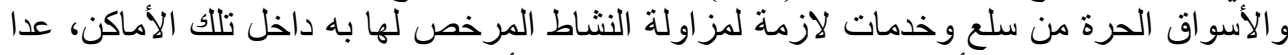

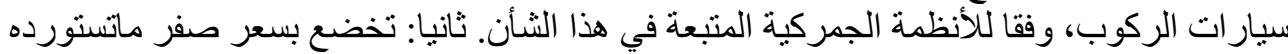

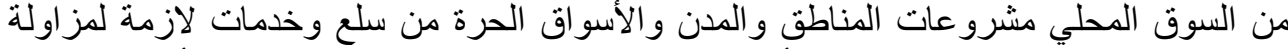

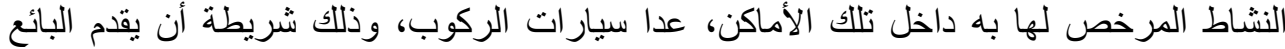

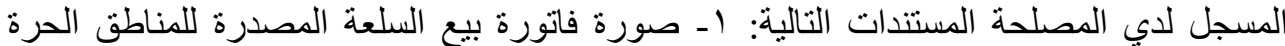

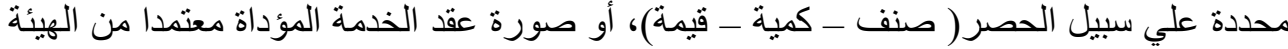

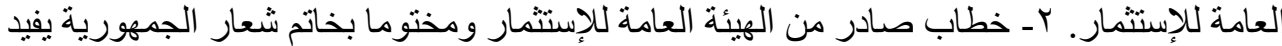

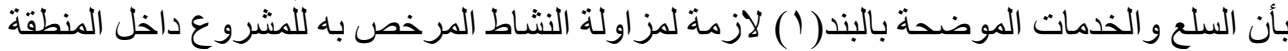

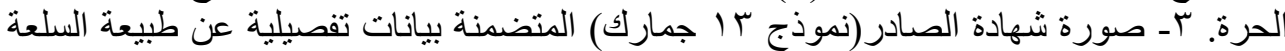

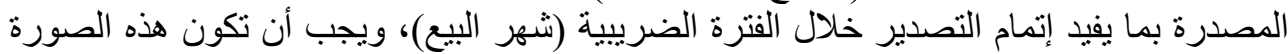

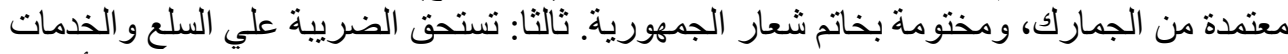

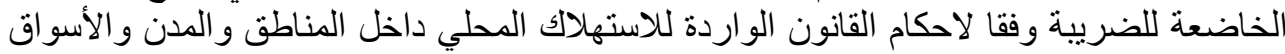

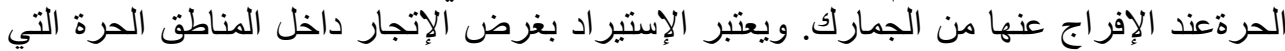

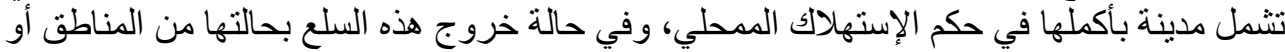


الإئتمان الضر يبي وآثارة الإقتصادية والمالية "دراسة مقارنة"

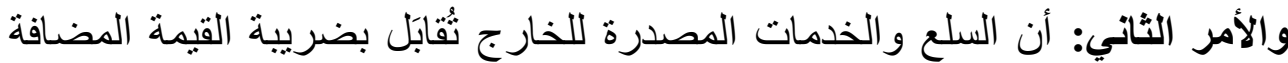

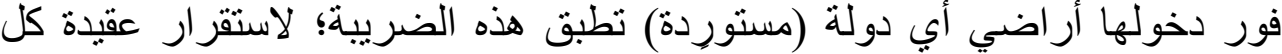

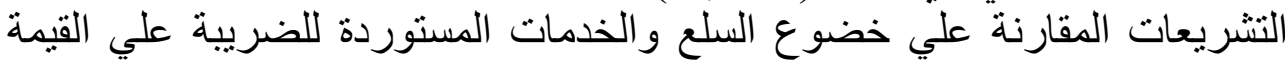
المضافة بمجرد دخولها أر اضيها، شأنها في ذلك شأن السلع و الخدمات المحلية.

وفي ضوء هذين الاعتبارين استقر التشريع الضريبي المصري منذ فجر تطبيق التبيق

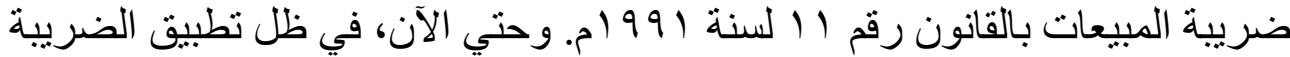

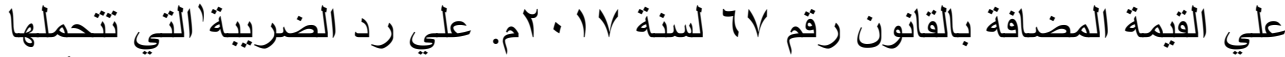

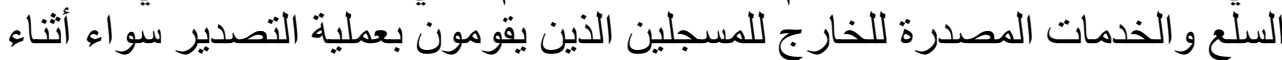

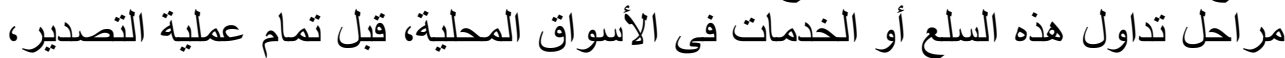

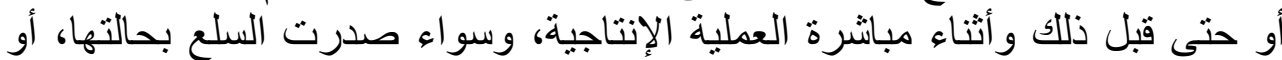

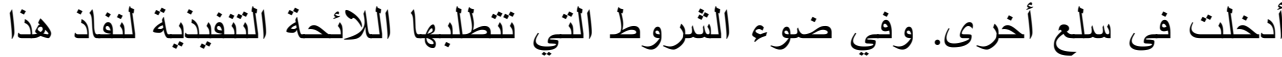

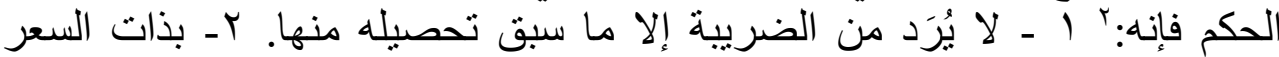

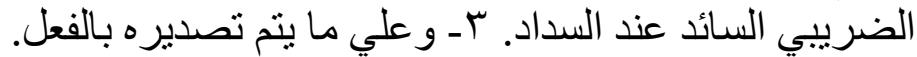
وفي عقيدة هذا البحث أنه إذا كان نظام رد الضريبة يتناسب مع الحالات الات الأخري

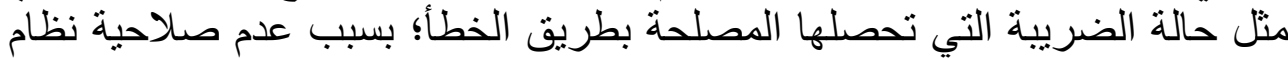

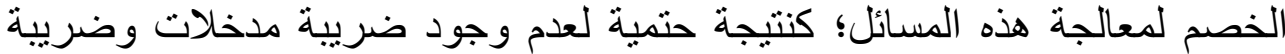

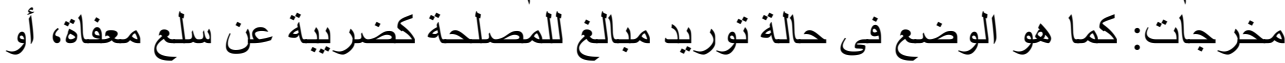

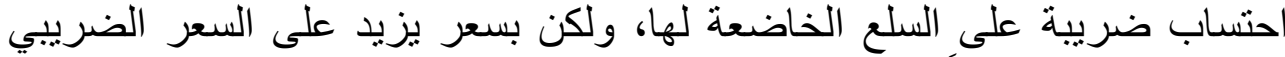

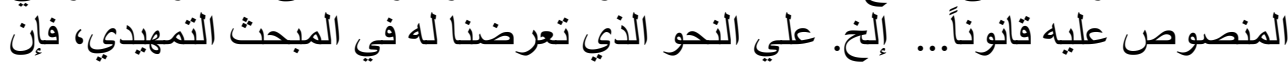

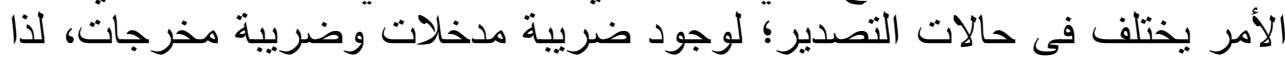

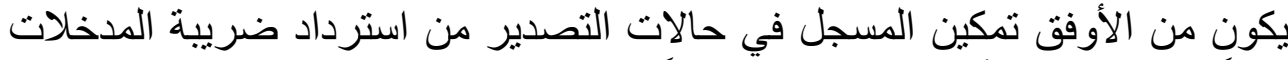

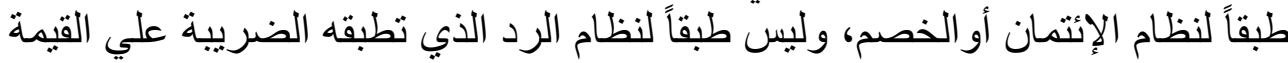

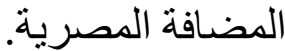

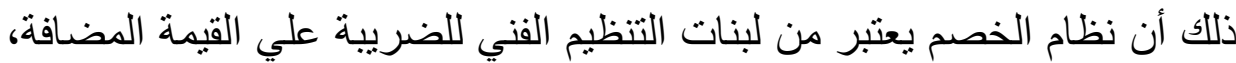

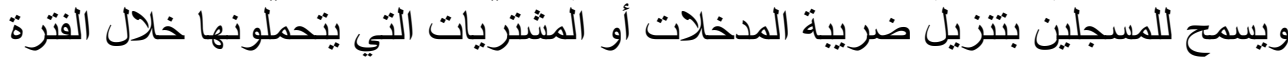

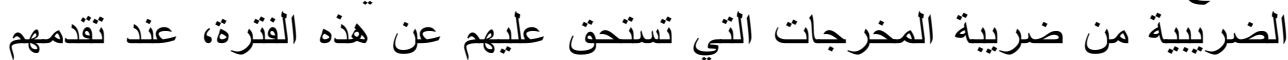
بإقراراتهم الضريبية فى الميعاد القانوني، دون أن يتقدموا بطلب مستقل إلى الإدارة

المدن أو الأسواق الحرة إلي السوق المحلي داخل البلاد لاتحسب الضريبة إلا علي قيمة الضريبة

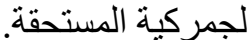

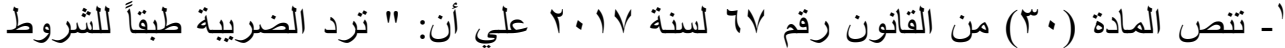

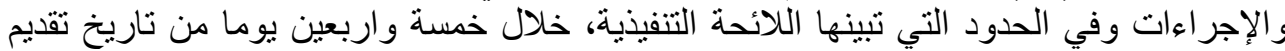

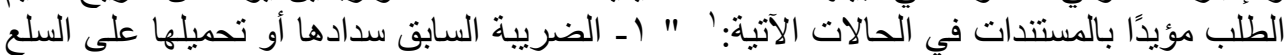

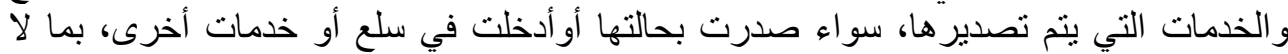

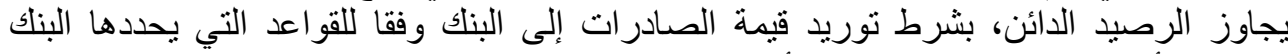

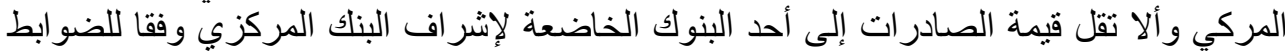

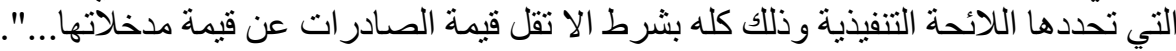
r ـ انظر في تفاصيل هذه الثروط: المادة (ب) من اللائحة التنفيذية للقانون. 
الضريبية بذلك، بخلاف نظام رد الضريبة، الذي يستوجب تقديم طلب مستقل لها لتقوم بيحثه، في ضوء الثروط التي تتطلبها اللائحة التنفيذية للقانون.

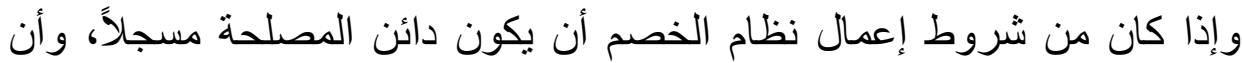

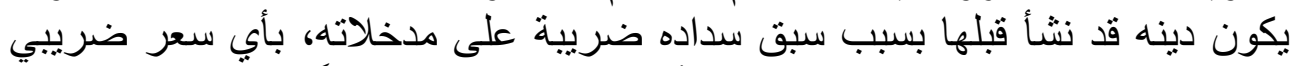

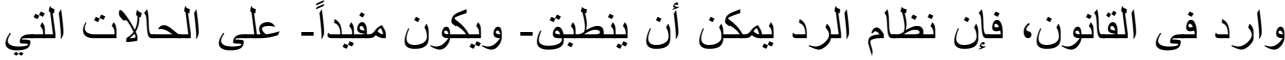

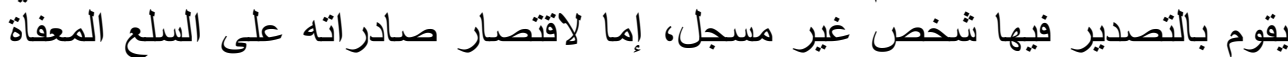
Exumptive Goods

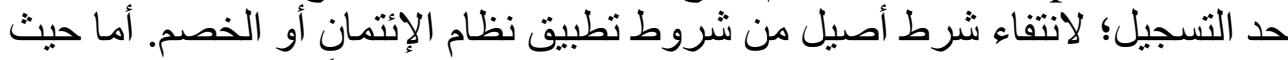

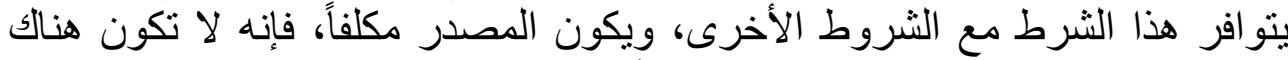

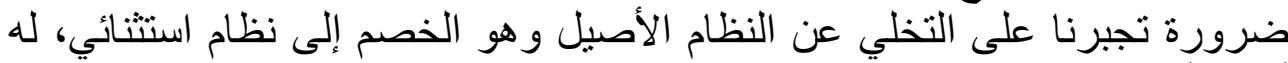
أحكام أخرى هو نظام الرد، كما هو الحال في الضريبة علي القيمة المضافة في مصر.

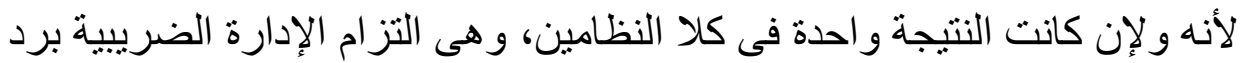

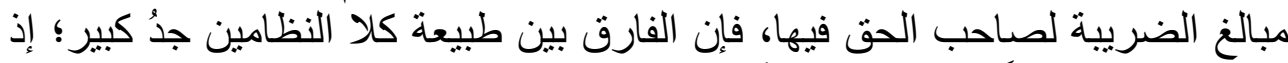

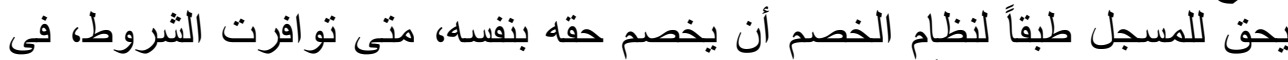

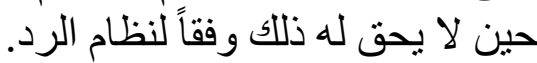

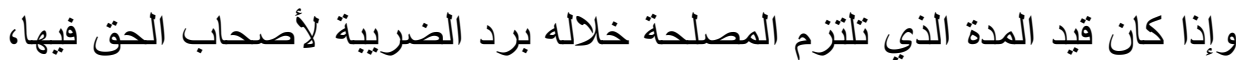

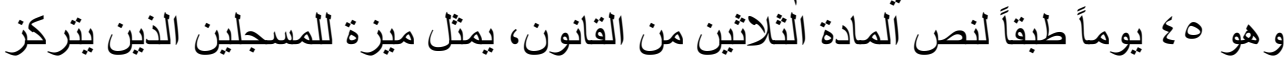

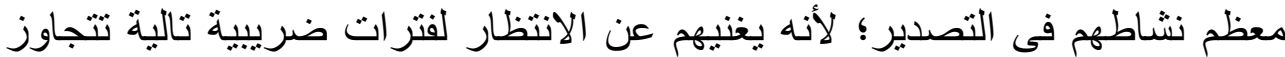

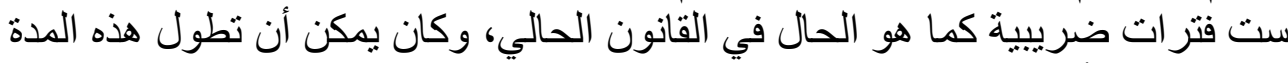

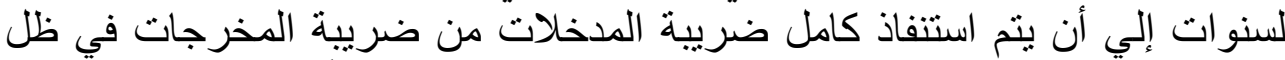

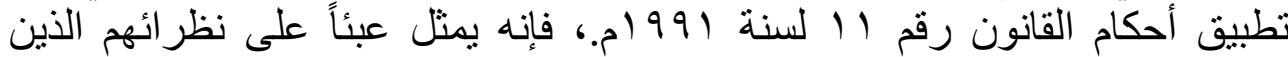

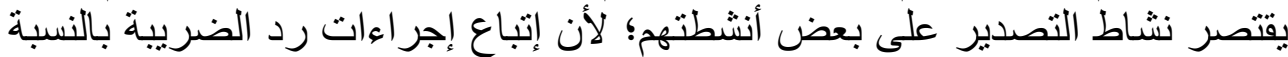

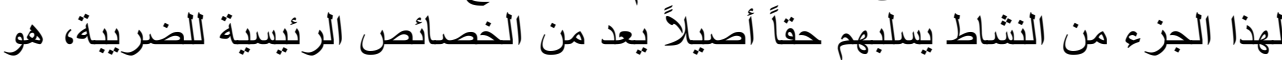

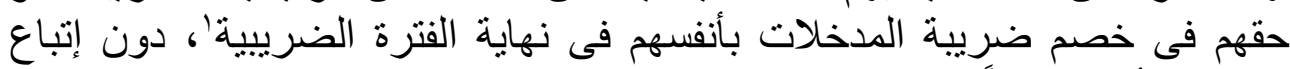

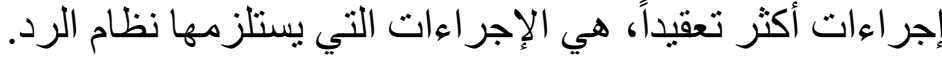

ويؤيد التشريع البريطانى للضريبة علي القيمة المضافة هذا النظر، إذهية يقرر أنهاء

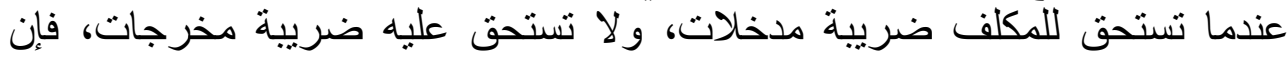

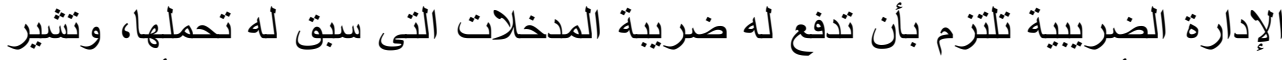

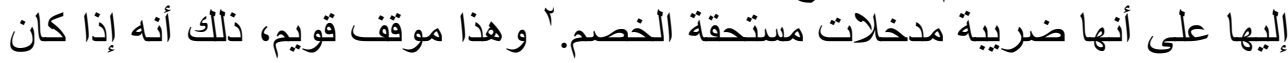

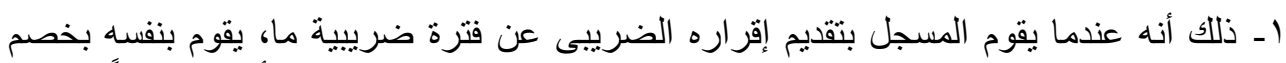

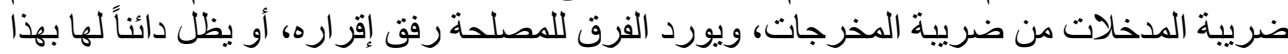

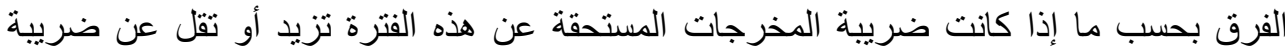

المدخلات التى تخصها.

r - Look: Art. No. ro/r, since it states that :"If ... no output tax is due at the end of the period , ... the amount of the credit shall be paid to the taxable person by. the commissioners ; and an amount which is due under this subsection is referred to in this Act as a "VAT credit". 
الإئتمان الضر يبي وآثارة الإقتصادية والمالية "دراسة مقارنة"

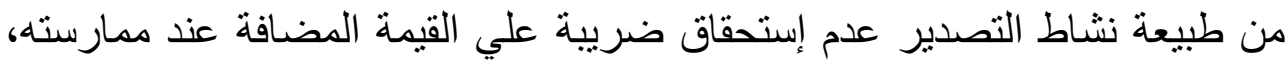

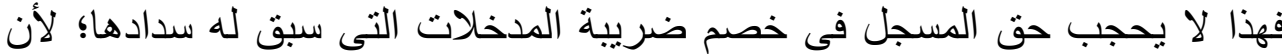

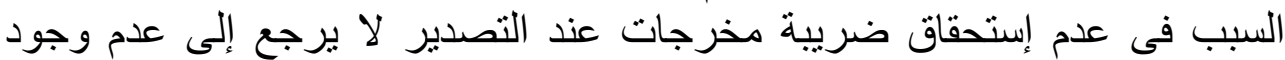

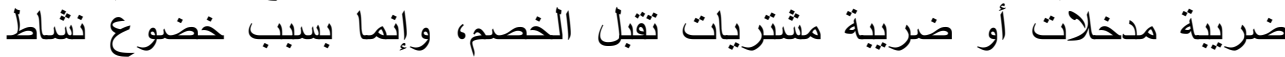

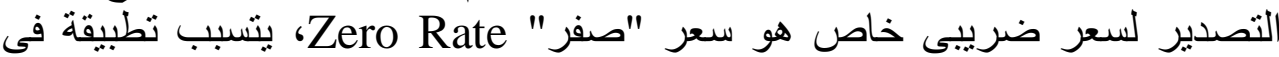
إستحقاق ضريبة مخرجات قيمتها " صفر " أيضاً.'

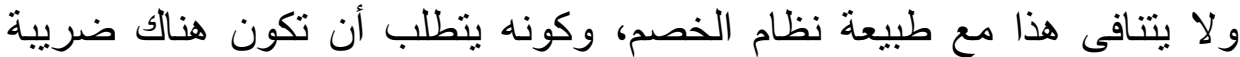

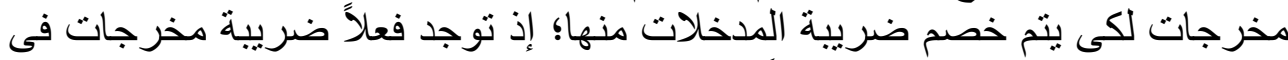

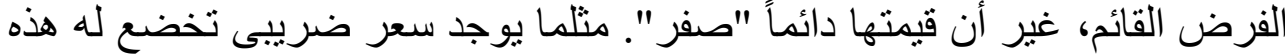

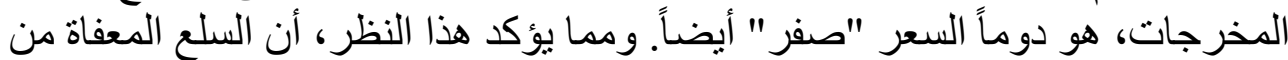

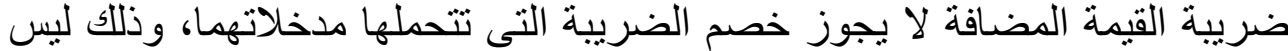

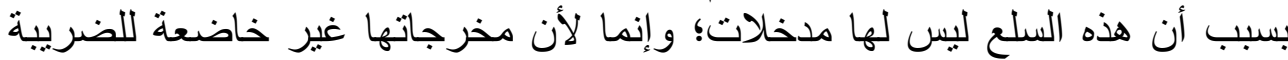

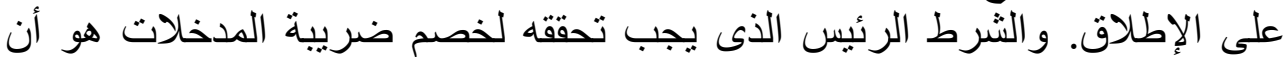

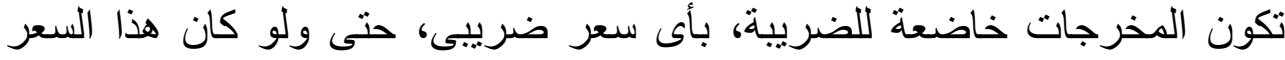

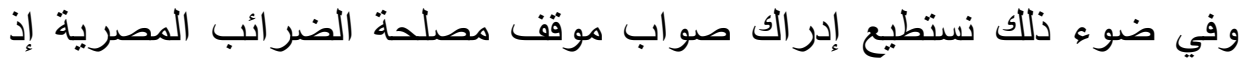
تسمح للمسجلين بخصم الضريبة التي تتحملها الصادرات في في هذه التهات الحالة؛ ذلك أنها

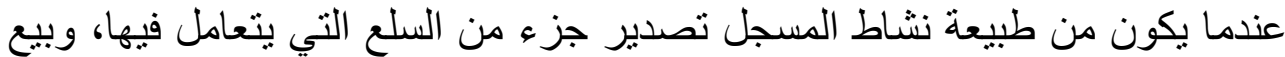

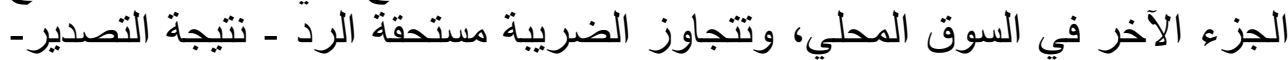

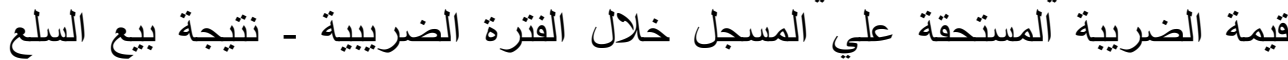

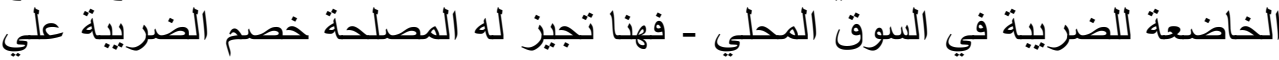

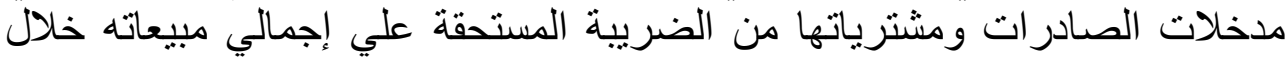

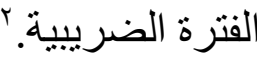

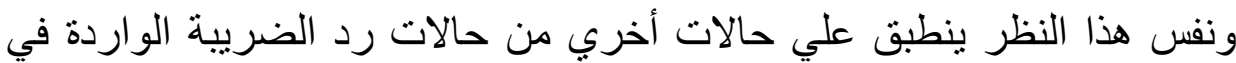

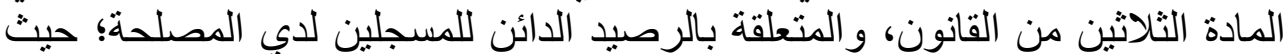
إن الأصل هو إنطباق نظام الإنتمان أو الخصم علي ضرينة لإنية الدذخلات، وضريبة لالية

$$
\text { ' - في أهمية فرض الضريبة بالسعر صفر ، أنظر : }
$$

- Paul K. and Martin F. ,: International trade effects of value Added Taxation, NBER Working paper N. rIr , National Bureau of Economic Research, Cambridge, November 1919, p. r.

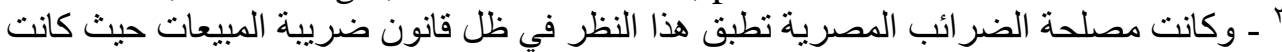

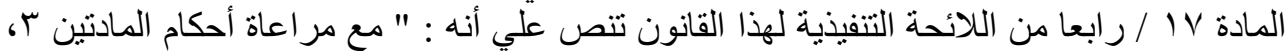

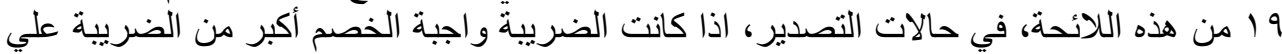

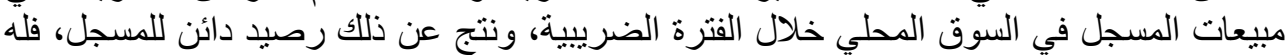

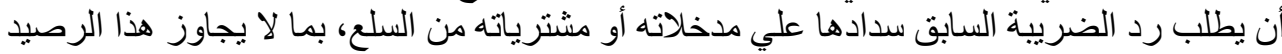

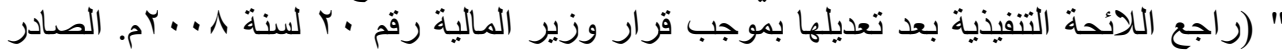

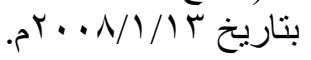


المشتريات التي تتصل بالسلع الخاضعة للضريبة، فإذا كانت قيمة الضريبة مستحقة

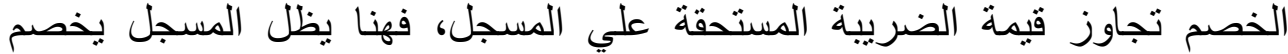
ضريبة المدخلات من ضريية المخرجات خلال الفتر الفرات الضرات الضريبية التالية، إلي أن يتم

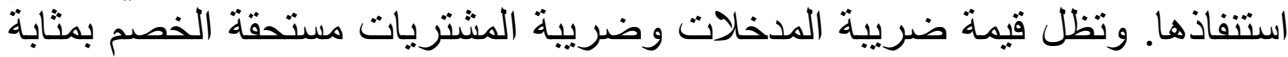

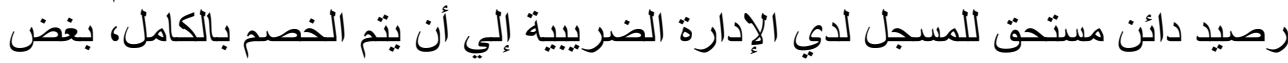
النظر عن الفترة التي يستغرقها ذللك.

وكان هذا النظر معمولاً به أثناء تطبيق ضريبة المبيعات بالقانون رقم المبات 11 لسنة

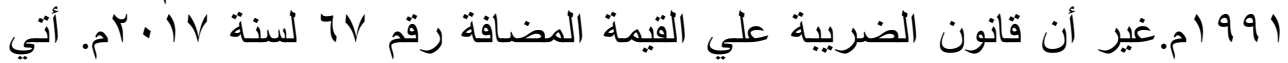

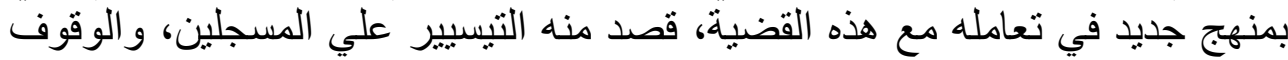

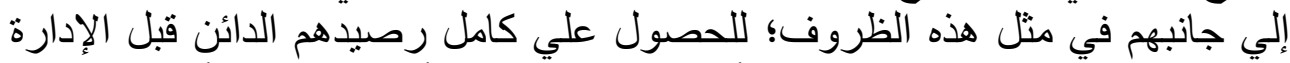

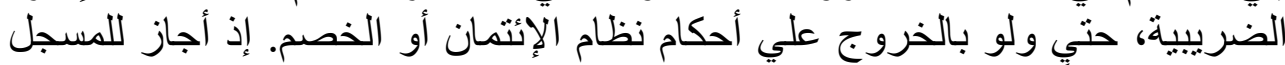

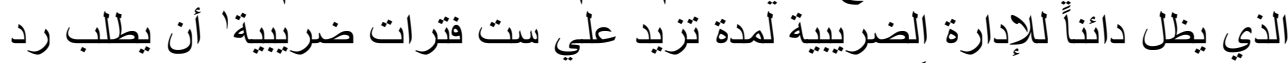

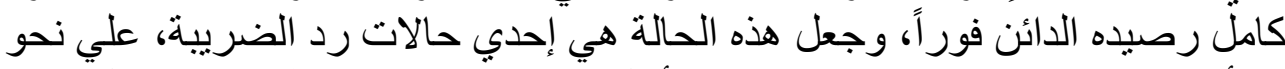

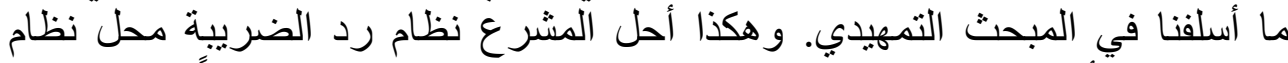

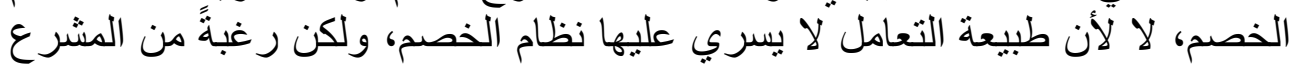
في التيسيير علي المسجلين إذا ما ترتب علي تطبيق نظام الخصم الإضرار الار بهر.

ويمكن تطبيق هذا النظر في حالة التصدير كذلك، فيكون من حق المسجلين خصم

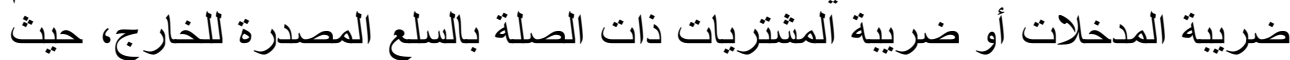

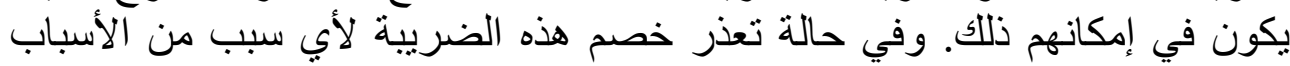

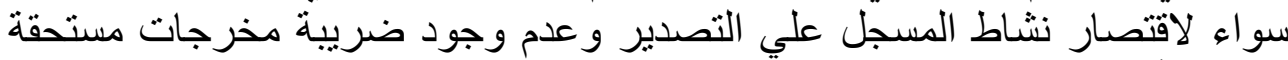

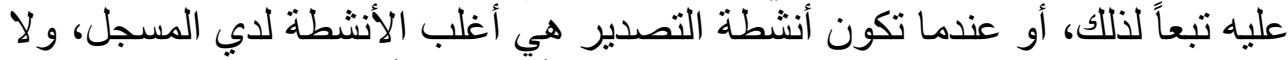

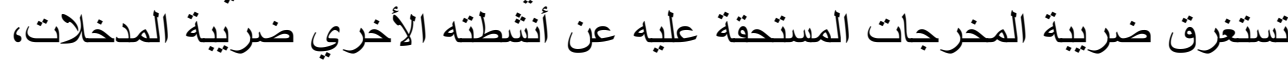

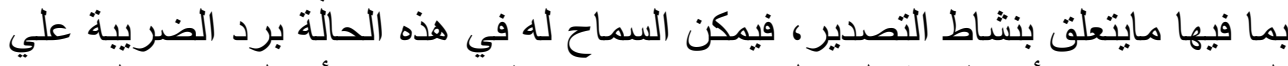

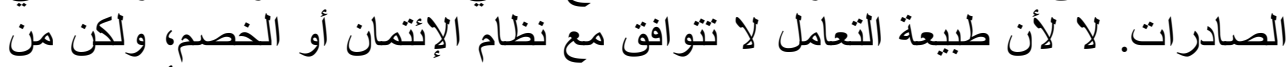

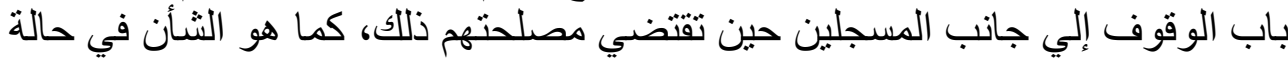

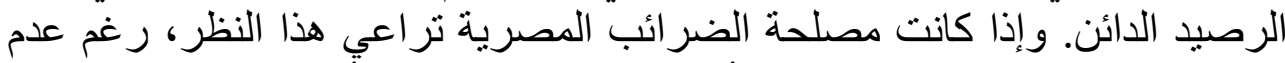

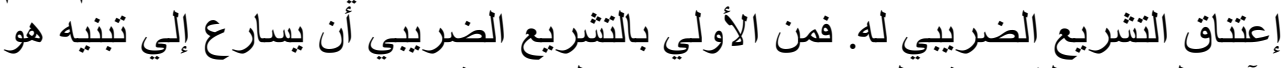

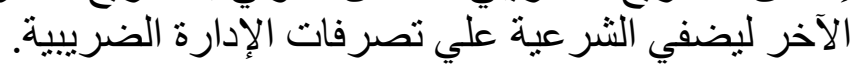

\section{الفرع الثاني}

\section{منح إئتمان ضريبي لبعض الجهات المعفاة وآثاره الإقتصادية والمالية}

الأصل أن الإئتمان أو الخصم الضريبي تسمح به الضريبة علي القيمة المضافة للمسجلين، في الحالات التي أشرنا إليها في المطلب السابق بما بمنع من تحقق لـن

$$
\begin{aligned}
& \text { ' ـ من المعلوم أن الفترة الضريبية في الضريية علي القيمة المضافة في مصر مدتها شهر ميلادي، }
\end{aligned}
$$

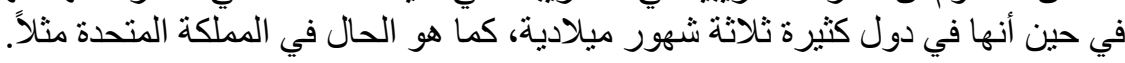


الإيتمان الضريبي وآثارة الإقتصادية والمالية "دراسة مقارنة"

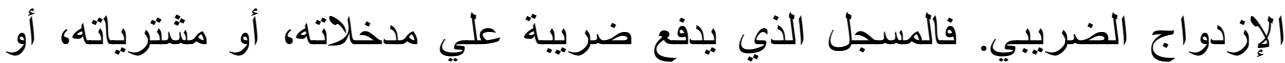

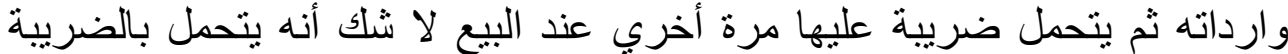

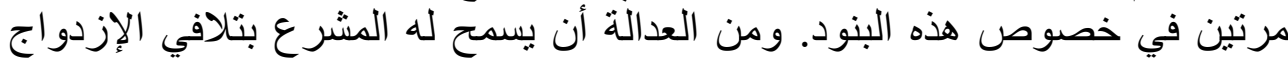

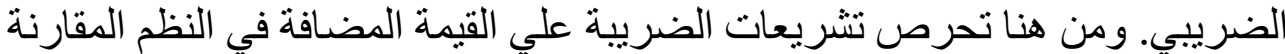
للمسجلين بالخصم في هذه الظروف.

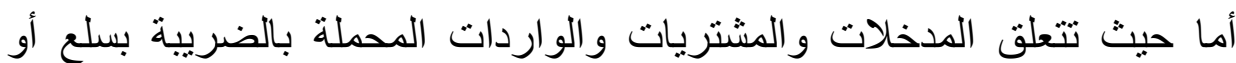

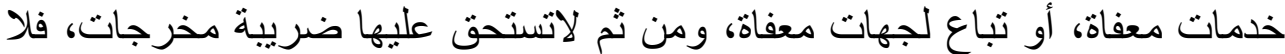

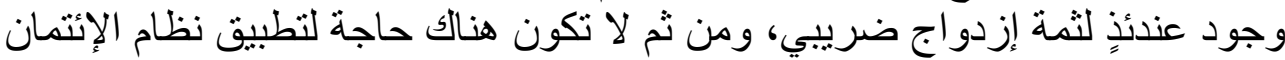

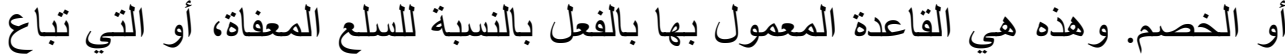

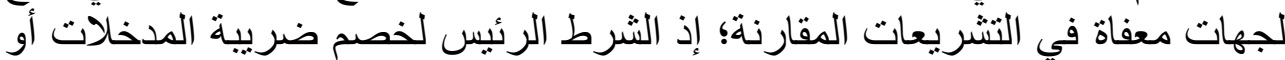

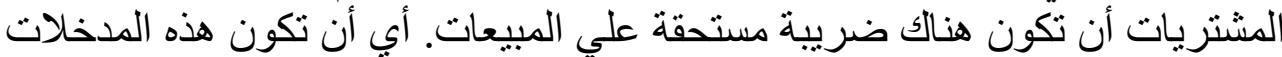

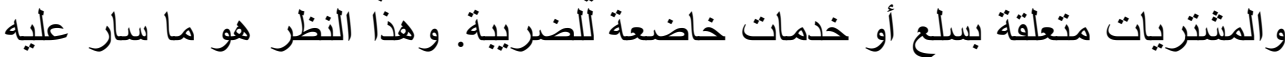

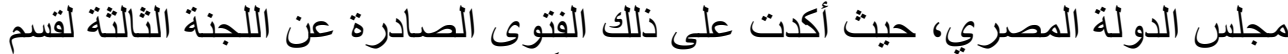

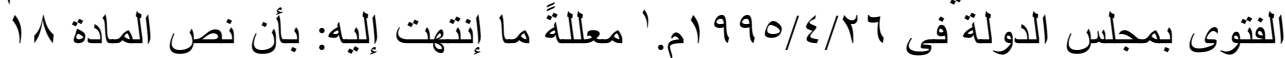

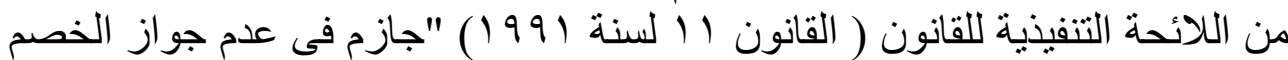

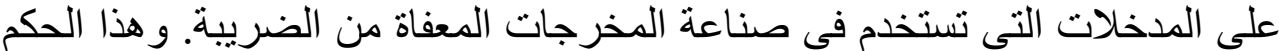

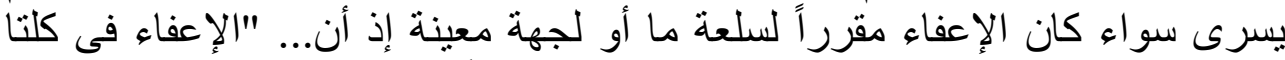

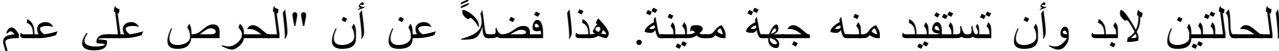

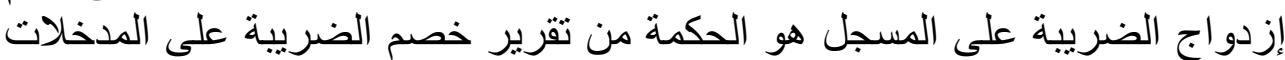

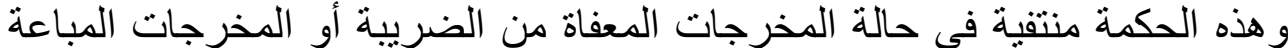

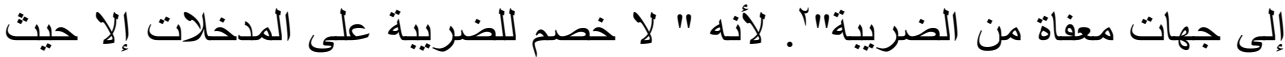
تكون هناك ضريبة تدفع" بالفعلّ".

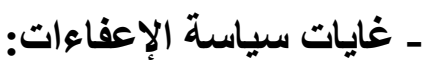

عادة ما يثور التساؤل حول أفضل تنظيم فني للضريبة علي التياعة القيمة المضافة يؤدي

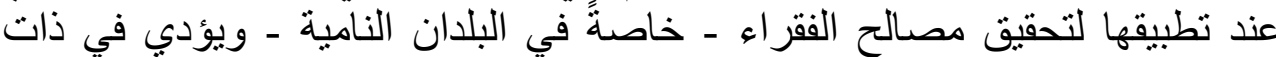

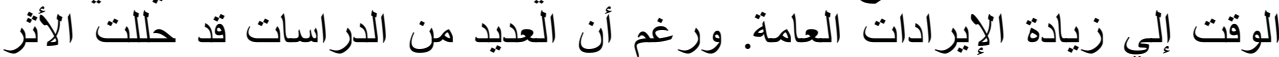

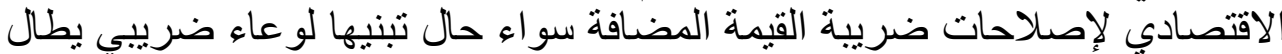

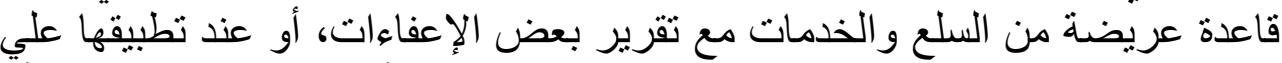

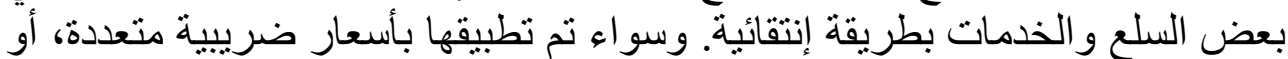
بسعر ضريبي أساسي واحد وآخر منخفض، فمما لا شك فيه أن الآثار الإجتماعية

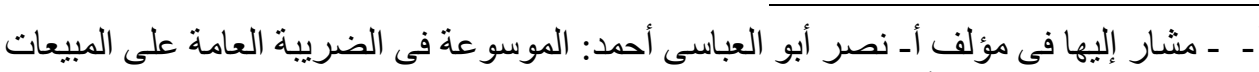

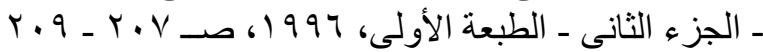

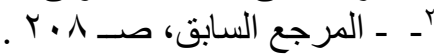

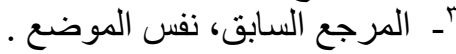


و المالية للإعفاءات التي تتضمنها هذه الضريبة تظل علي الدوام هي الثناغل الأعظم لو اضعي السياسات الضريبية.

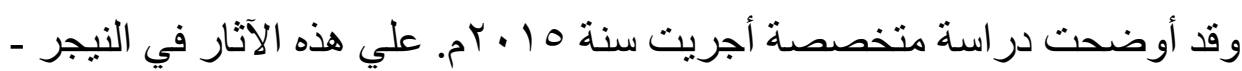

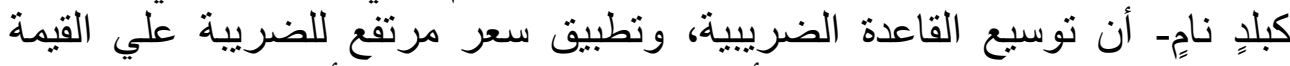

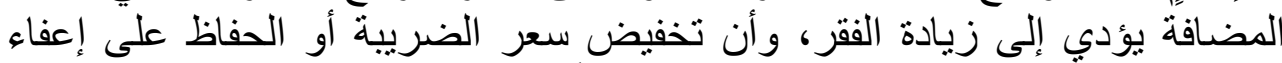

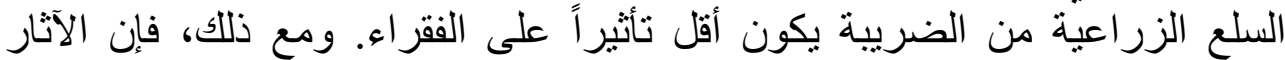

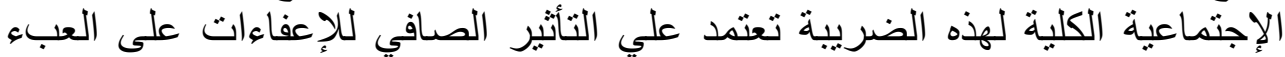
الضريبي الإضافي الذي يتحمله المنتجون، وكذا علي الطي الطلب المحلي الإجمالي.

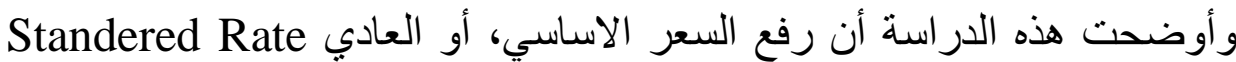

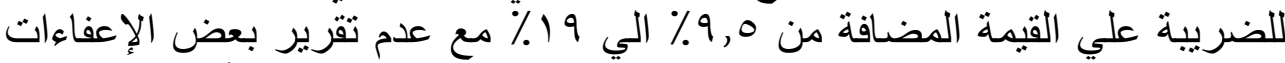

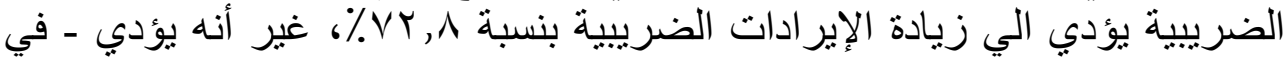
المقابل- إلي انكماش في النشاط الاقتصادي عبر القادي القطاعات الإنتاجية المختلفة (باستثناء

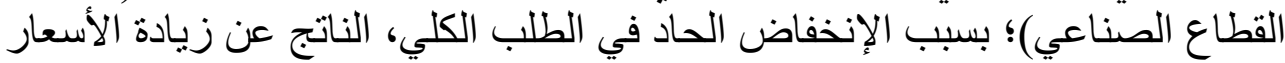

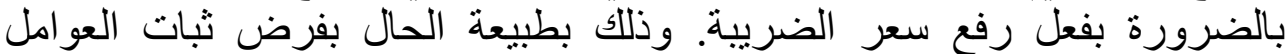
الأخري، أي في ظل افتر اض أن الحكومة لن تغير من نفقاتها العامة مثنلاً. بـات

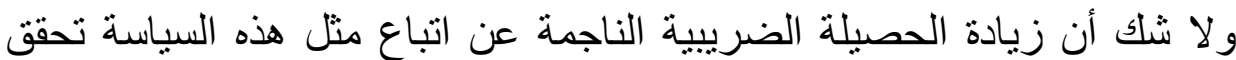

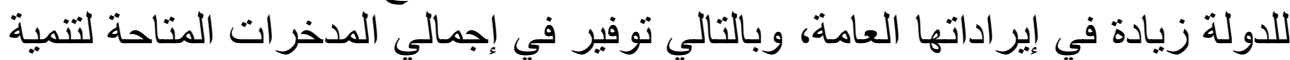

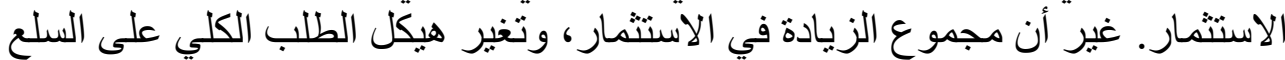

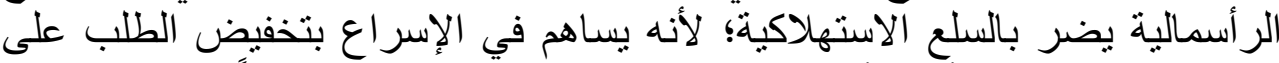

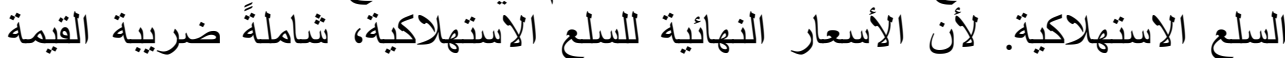

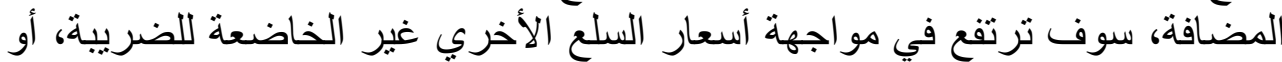

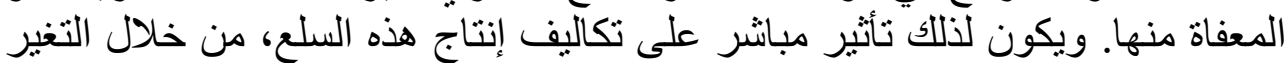
في أسعار المدخلات.؛ وعلي الجانب الآخر تقلل هذه السياسة من تكاليف الإنتاج

' - Dorothée Boccanfuso, Céline de Quatrebarbes and Luc Savard: Can the removal of VAT Exemptions support the Poor? The Case of Niger, Working Paper I _. \&, May Y.10. p. r.

-Claudio A. Agostini: The Effect of Sales Tax Rates on Food Exemptions, Department of Economics, Universidad Alberto Hurtado, Santiago, Chile. November Y.. ¿. P. r.

r - Dorothée Boccanfuso, Céline de Quatrebarbes and Luc Savard: Can the removal of VAT Exemptions support the Poor? The Case of Niger, Working Paper I... \&, May Y.10.p. r.

-Claudio A. Agostini: The Effect of Sales Tax ... Op. Cit. P. r.

${ }^{r}$ - Dorothée Boccanfuso, Céline de Quatrebarbes and Luc Savard: Can the removal of VAT Exemptions support ... Op. Cit. p. 10.

Claudio A. Agostini: The Effect of Sales Tax Rates ... Op. Cit. P. ₹.

- Dorothée Boccanfuso, Céline de Quatrebarbes and Luc Savard: Can the removal of VAT Exemptions ... Op. Cit. p. ${ }^{10}$. 
الإيتمان الضريبي وآثارة الإقتصادية والمالية "دراسة مقارنة"

بالنسبة للمنتجين بخصوص السلع المعفاة، ولكنها تزيد من أسعار المدخلات الخاضعة

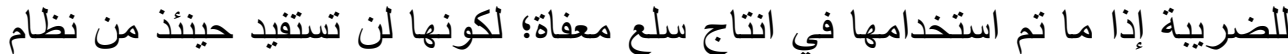

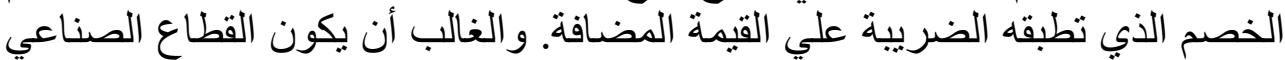

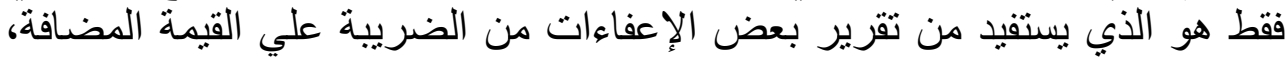

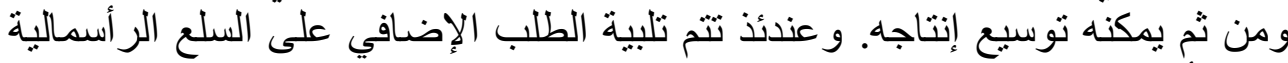
بشكل أساسي من خلال زيادة الطلب على المنتجات المحلية.

وأوضحت هذه الدراسة أن المزارعين بمثلون بح٪ من إجمالي سكان البلاد في

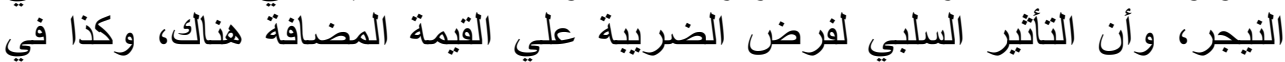

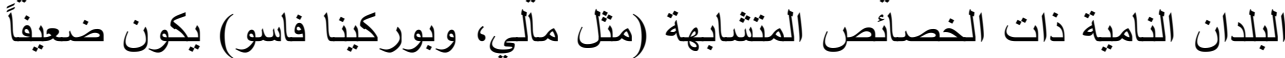

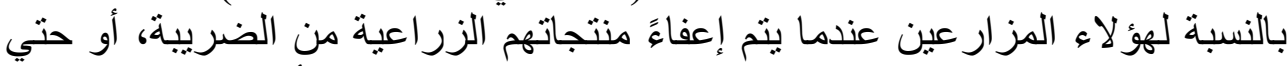

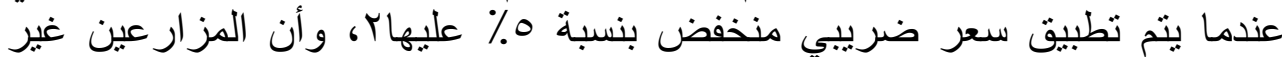

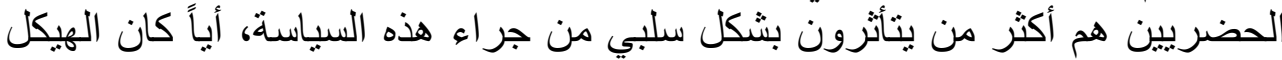

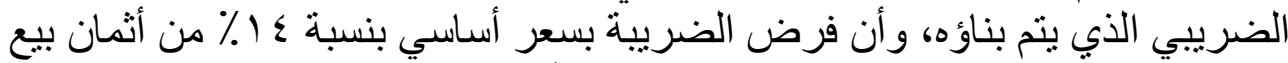

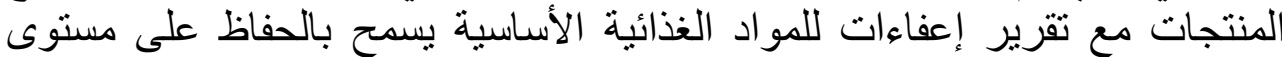

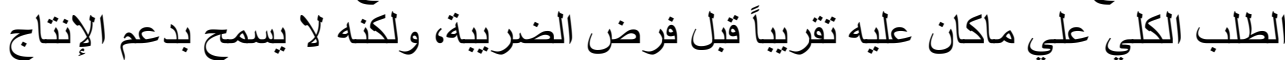

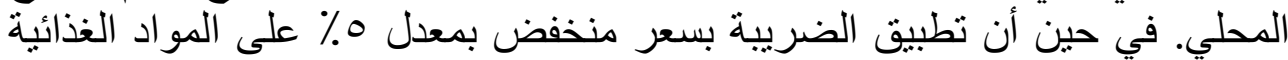

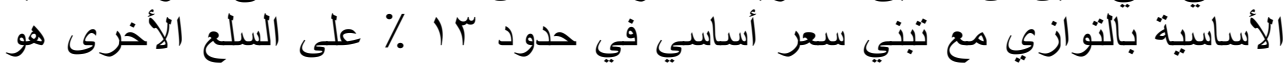

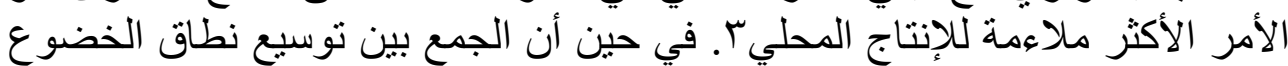

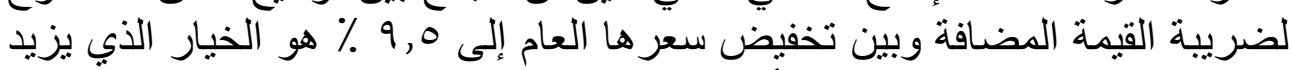
الإير ادات الضريبية، ويقلل من التأثنير السلبي على الناتج المحلي الإجماليع. و هكذا أبرزت هذه الدراسة أن تصميم هيكل الضريبة علي القيمة المضافة الأكثر

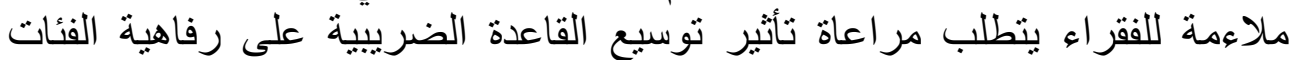

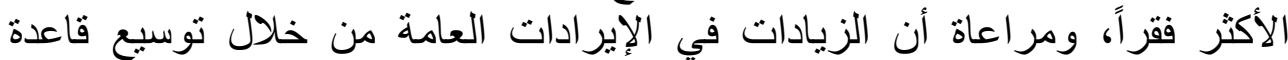

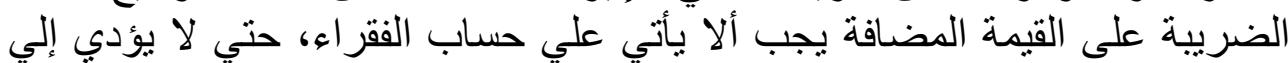
زيادة أعدادهم، وأنه يمكن تحقيق نفس المستوى من الإيرادات الضريبية من خلئي خلابل

- Claudio A. Agostini: The Effect of Sales Tax ... Op. Cit. P. ร.

' - Dorothée Boccanfuso, Céline de Quatrebarbes and Luc Savard: Can the removal of VAT Exemptions support ... Op. Cit. p. 10.

Claudio A. Agostini: The Effect of Sales Tax ... Op. Cit. P. 0.

r - Dorothée Boccanfuso, Céline de Quatrebarbes and Luc Savard: Can the removal of VAT Exemptions support ... Op. Cit. p. r .

Claudio A. Agostini: The Effect of Sales Tax ... Op. Cit. P. ○.

$r$ - Dorothée Boccanfuso, Céline de Quatrebarbes and Luc Savard: Can the removal of VAT Exemptions support ... Op. Cit. r .

Claudio A.: The Effect of Sales Tax Rates on Food Exemptions, ... Op. Cit. P. 0 .

- Dorothée Boccanfuso, Céline de Quatrebarbes and Luc Savard: Can the removal of VAT Exemptions ... Op. Cit. Yч. 


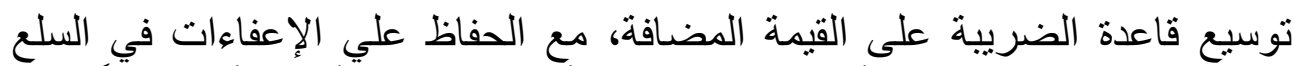

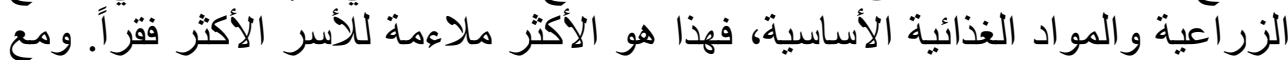

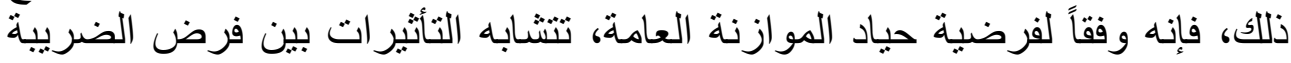

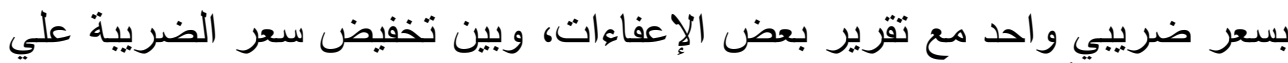
بعض السلع الأساسية وبخاصة المو اد الغذائية. وخلصت الدراسة إلي أهمية تقرير بعض الإعفاءات من الضريبة علي القيمة

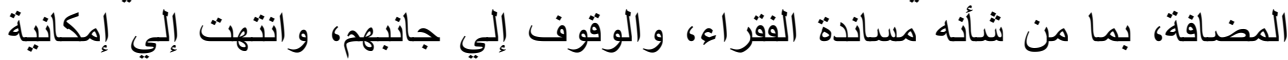

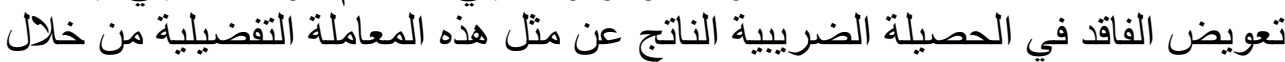

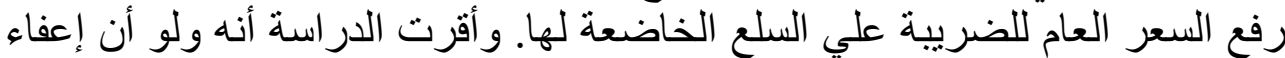

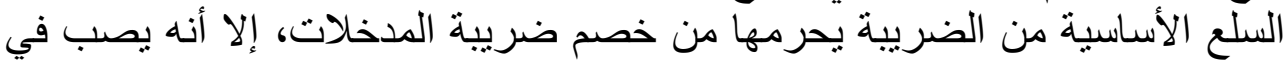

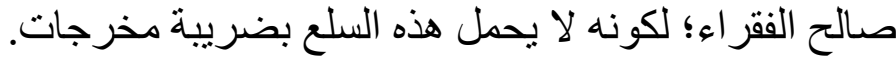

و هكذا يحرم المكلفون- بحسب الأصل- من خصم ضريبة المدخلات المتعلقة

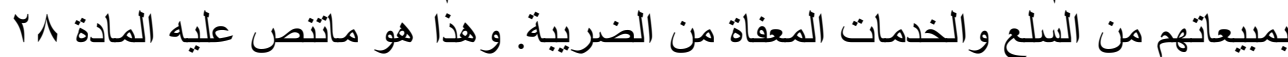

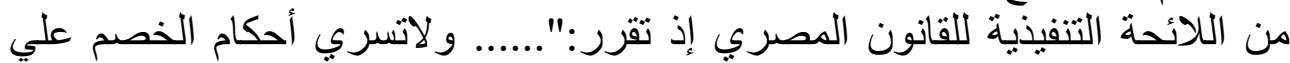

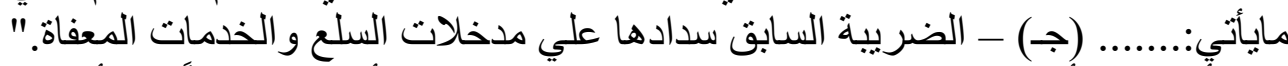

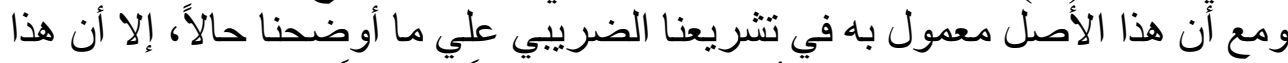

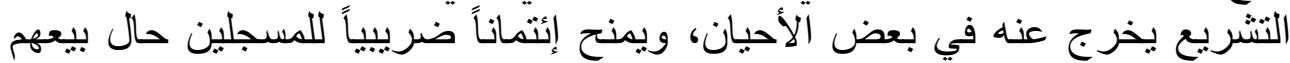

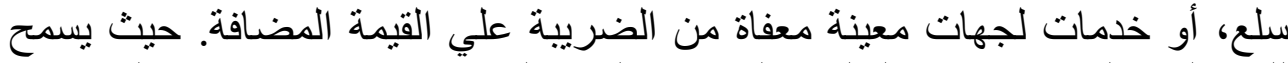

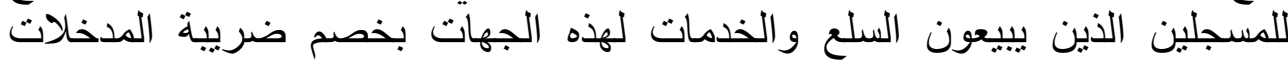
المتعلقة بهذه السلع و الخدمات، رغن رغم عدم استحقاق ضريبة مخرجات عليها، ورهذه

التعاملات هي به به:

' - Dorothée Boccanfuso, Céline de Quatrebarbes and Luc Savard: Can the removal of VAT Exemptions support ... Op. Cit. Y 7 .

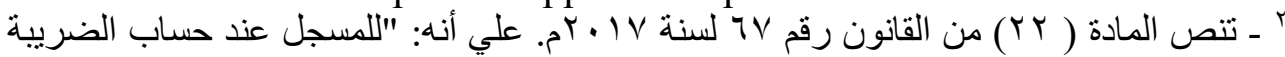

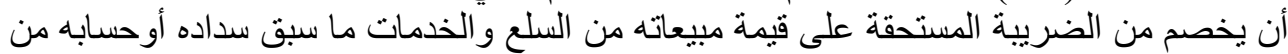

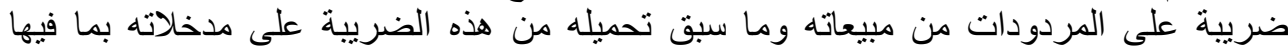

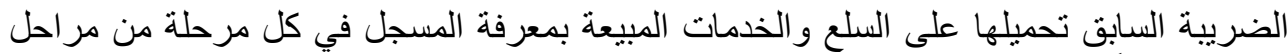

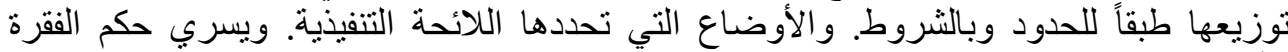

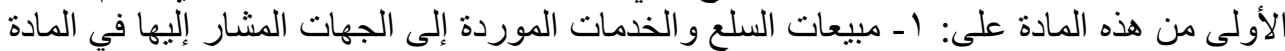

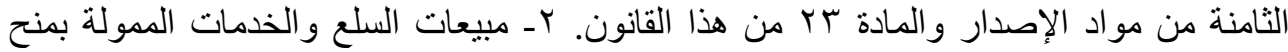
صدر قانون بإعفائها من الضريبية....".

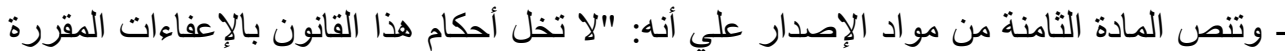

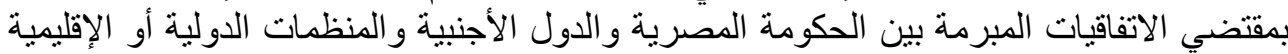

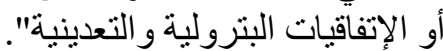

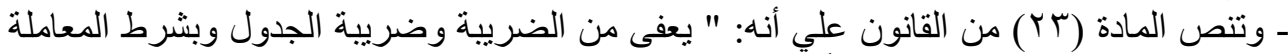

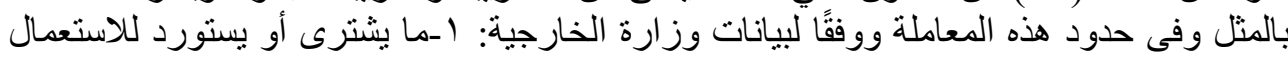

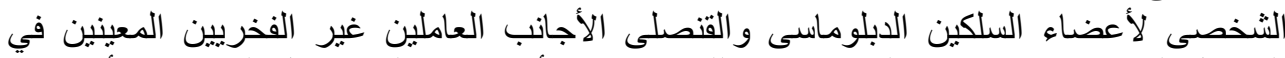

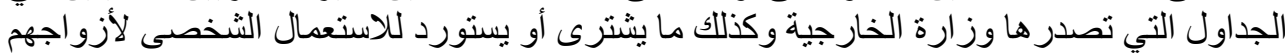
وأو لادهم القصر. Y - ما يشترى أو يستورد للسفارات و المفوضيات و القنصليات غير الفخرية 
الإعتمان الضريبي وآثارة الإقتصادية والمالية "دراسة مقارنة"

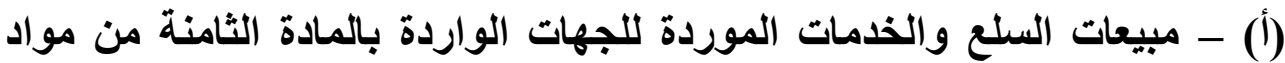

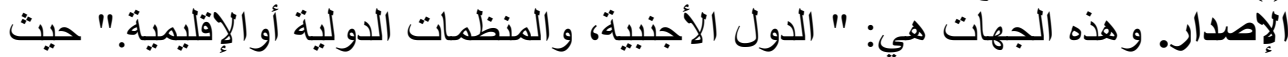

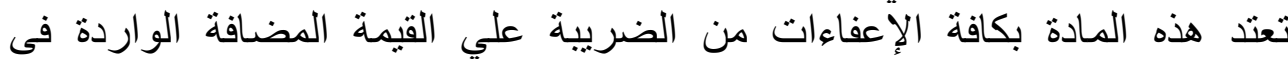

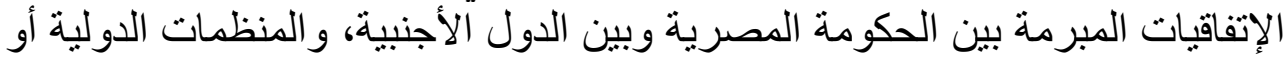

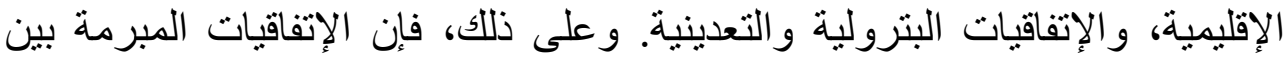

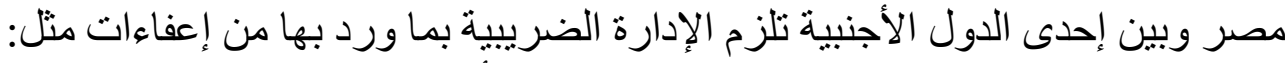

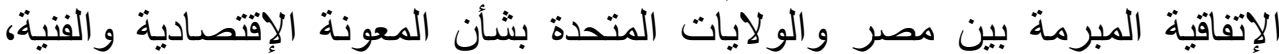
والصادر بشأنها القرار الجمهورى رقم

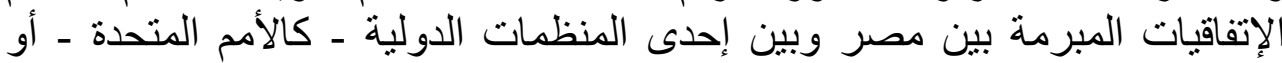

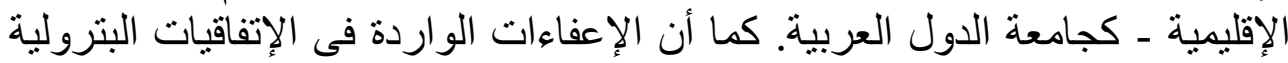

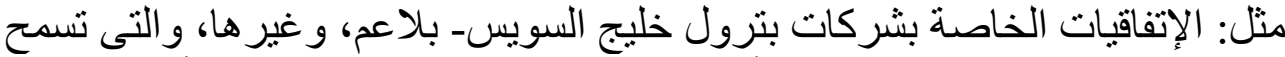

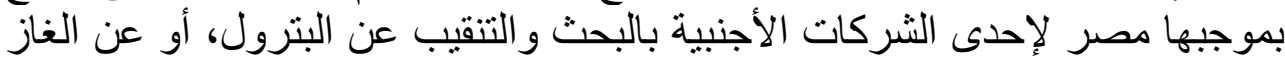

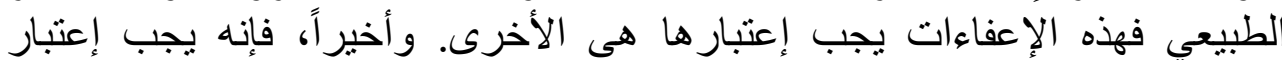

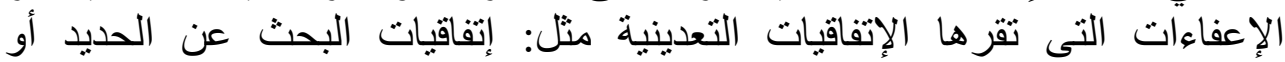
الذهب...إلخ. ويسمح تشريعنا الضريبي للمسجلين بخصم ضريبة الإتية الدذخلات التي التي

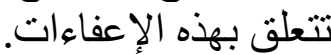

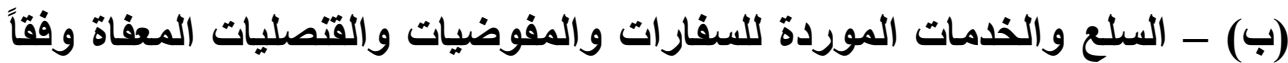

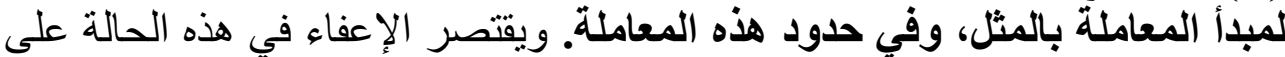

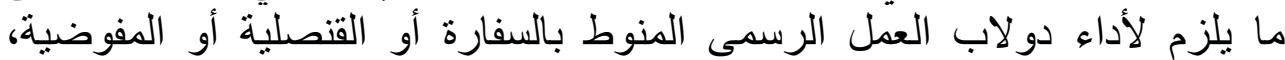

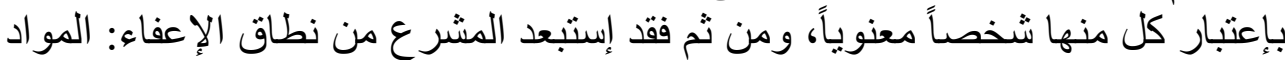

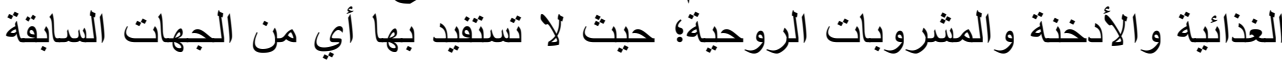

للاستعمال الرسمى عدا المواد الغذائية و المشروبات الروحية والأدخنة. ويحدد عدد السيار ات التيات التي

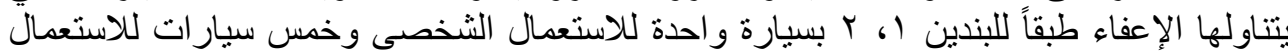

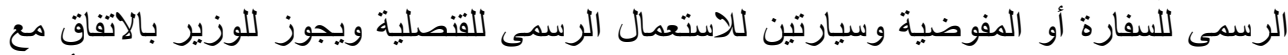

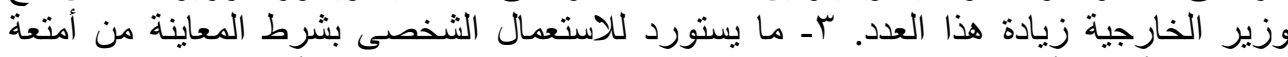

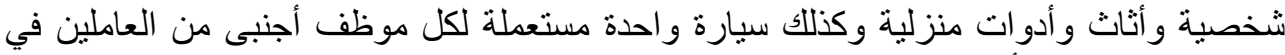

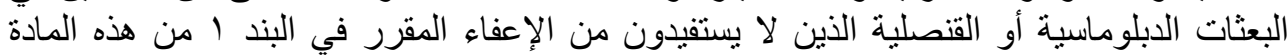

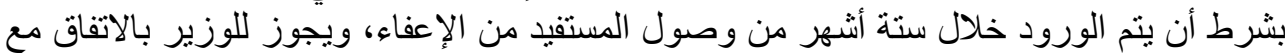

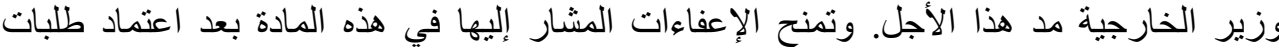

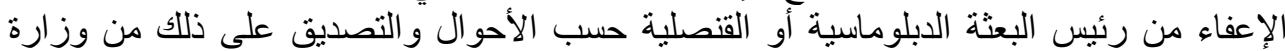

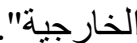

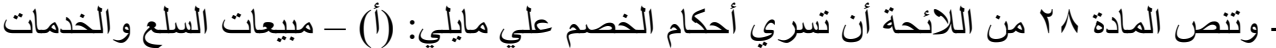

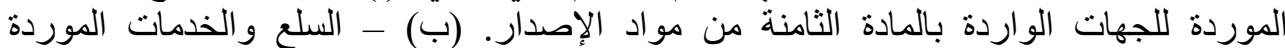

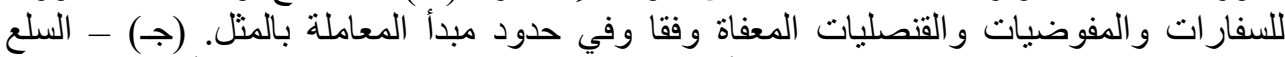

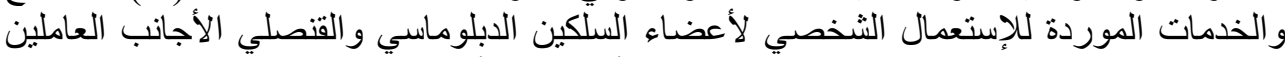

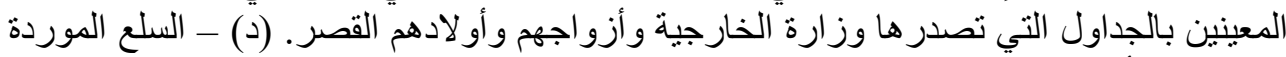

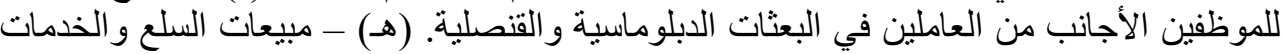

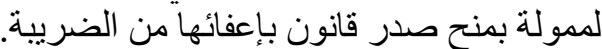
' ـ أنظر : مصلحة الضر ائب على المبيعات، القانون الضريبى... مرجع سابق، صـه. 
كثخص معنوي. كما أنه قصر الإعفاء بالنسبة للسيار ات على عدد معين هو خمس إلى إنى

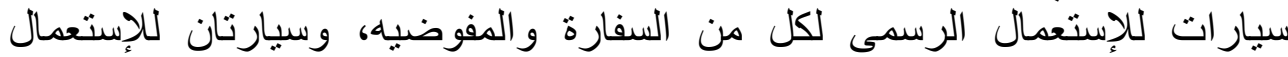
الرسمى للقنصليه.

(ج)-- السلع والخدمات الموردة للإستعمال الشخصي لأعضاء السلكين الابلوماسي

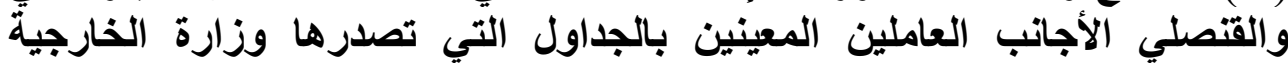

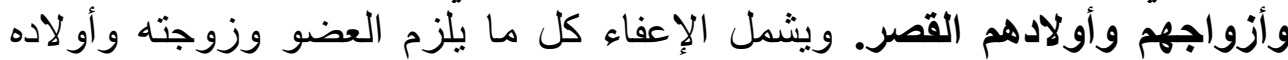

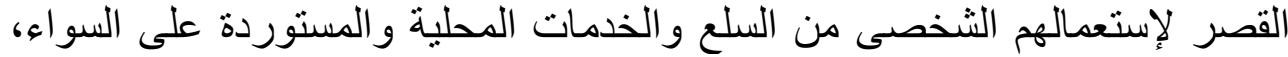

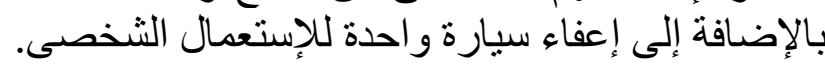

(د) - السلع الموردة للموظفين الأجانب من العاملين في البعثات الابلوماسية

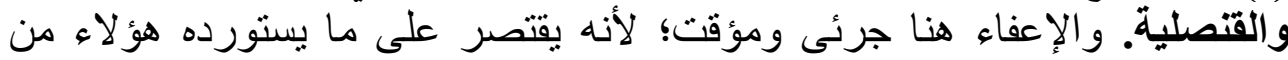

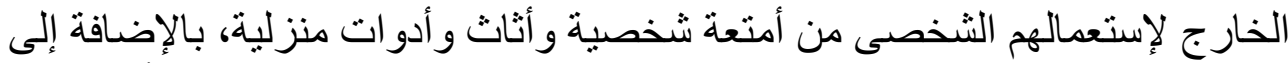

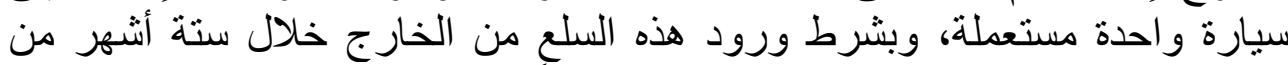

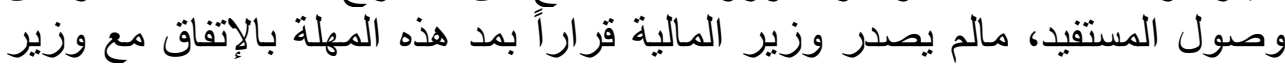
الخارجية.'

و لا يجوز منح الإعفاء فى الحالات الثلاث المتقدمة إلا بعد إعتماد طلبات الإعفاء

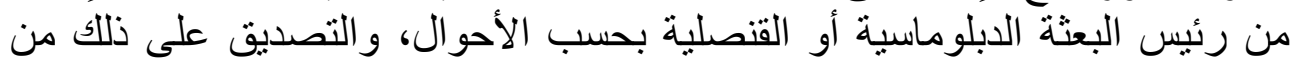
وزير الخارجية.

(ه) - مبيعات السلع والخدمات الممولة بمنح صدر قانون بإعفائها من الضريبة. معني ذلك أن المشرع سمح للمسجلين الذين يتعاملون في السلع أو الخدمات

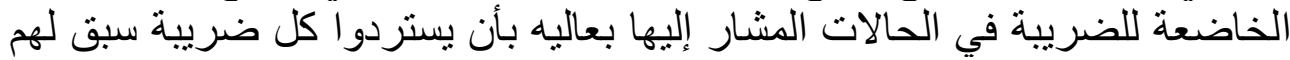

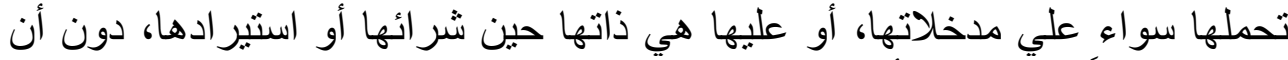

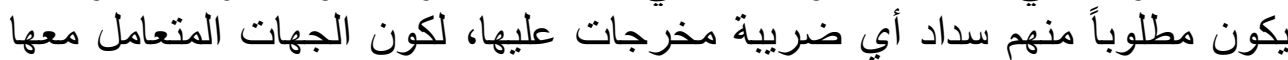

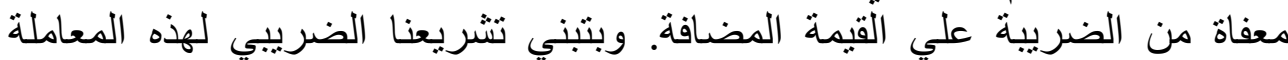

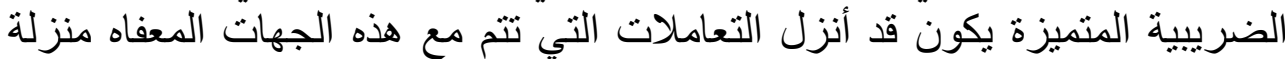

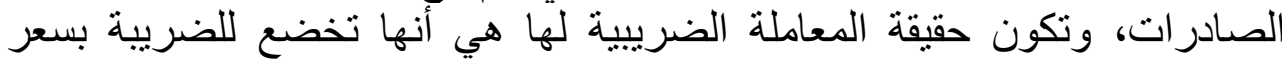

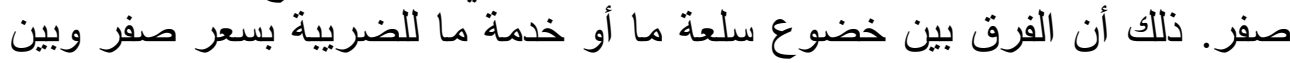

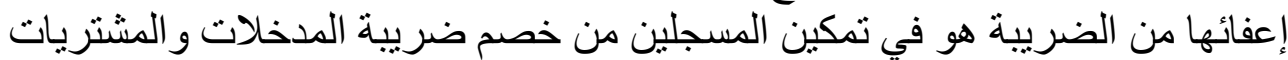

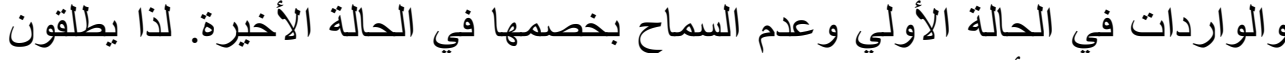

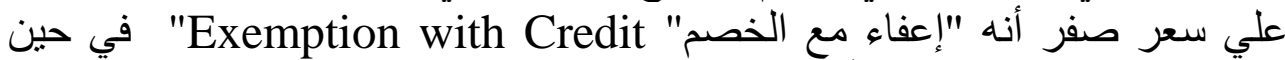
يطلقون علي الإعفاء مجرداً أنه "إعفاء بدون خصم

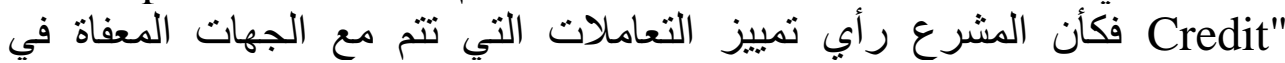
الفروض المشار إلبها بعاليه بمنحها ما هو أكثر من الإئتمان. وما هو أكثر الكثر من تطهير

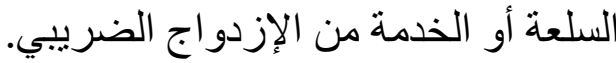

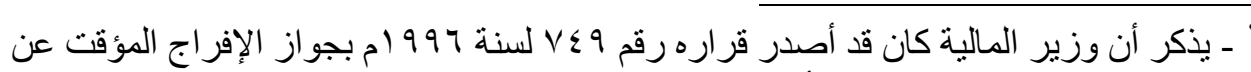

$$
\begin{aligned}
& \text { السيار ات التى ترد زيادة عن حد الأعفاء. }
\end{aligned}
$$


الإيتمان الضريبي وآثارة الإقتصادية والمالية "دراسة مقارنة"

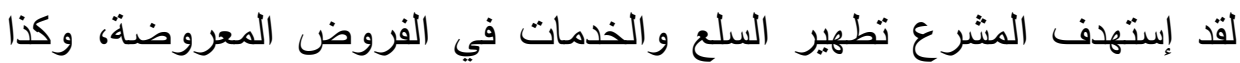

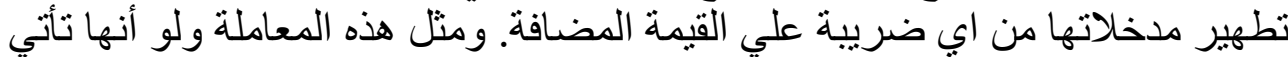

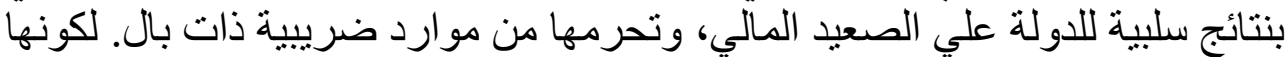

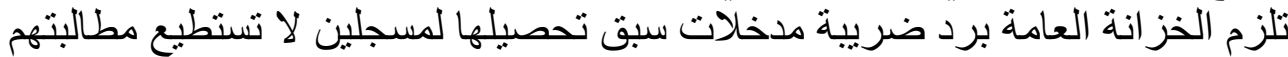

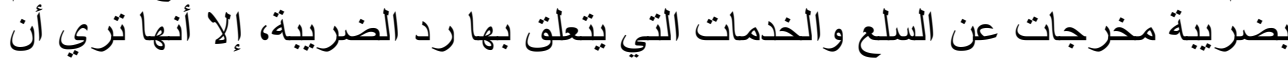
الأغر اض الأخري الإقتصادية والدبلوماسية جديرة بالإعتبار:

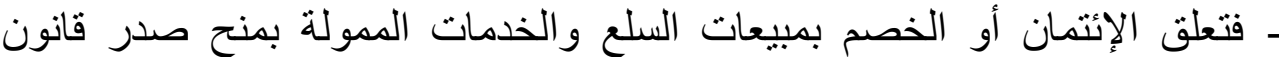

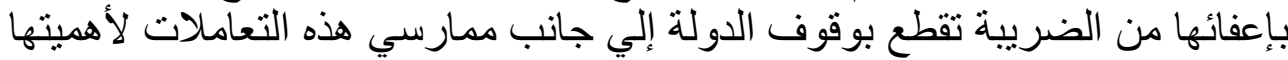

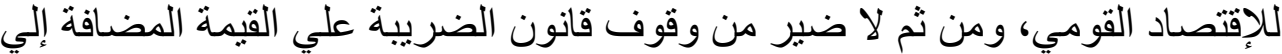

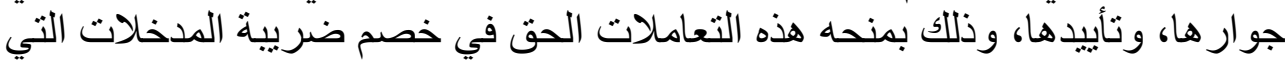

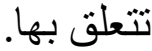

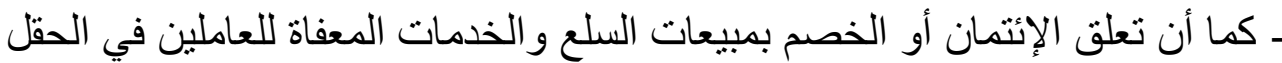

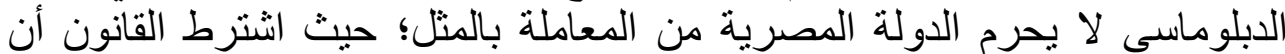

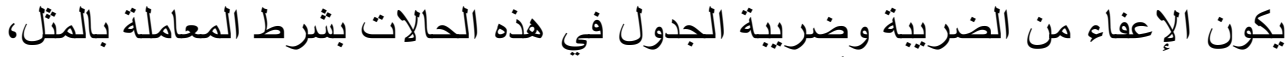

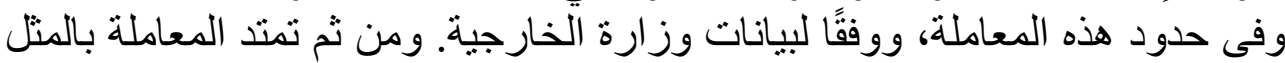

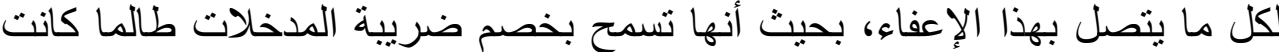
هناك معاملة بالمتل للابلو ماسيين المصريين في هذا الإطار.

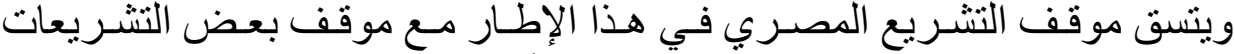

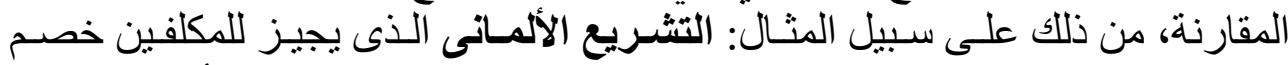

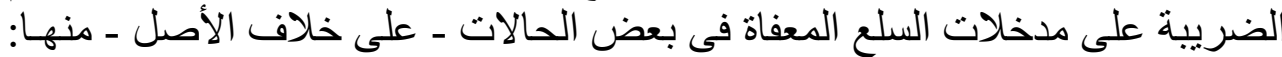

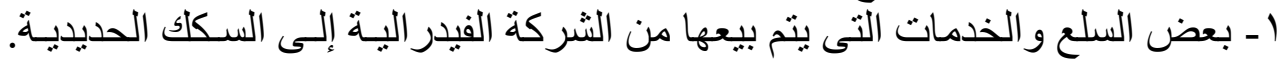

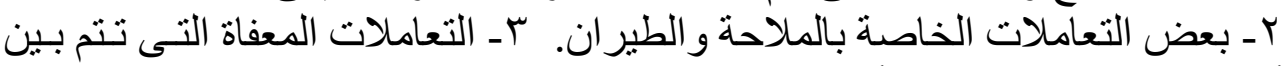

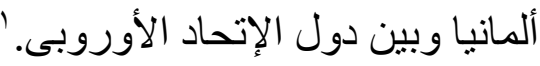

\section{ـ موقف الإعفاعات المقررة للجهات المنوط بها الدفاع عن الوطن:}

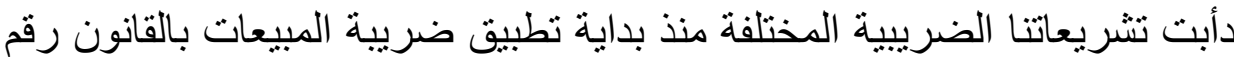

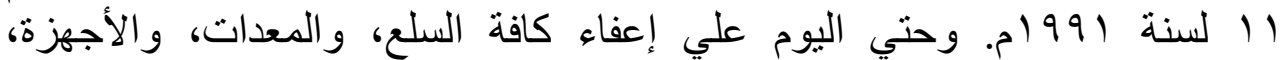

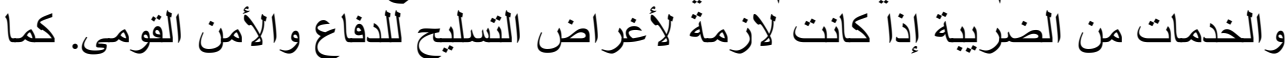

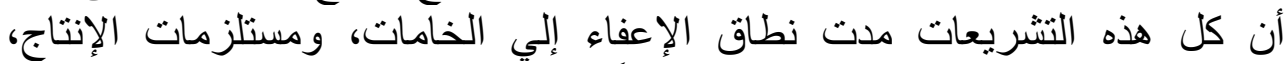

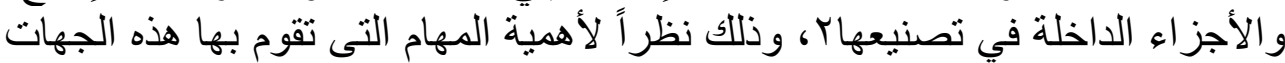

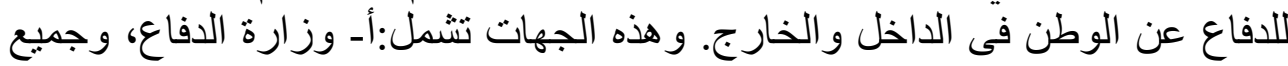

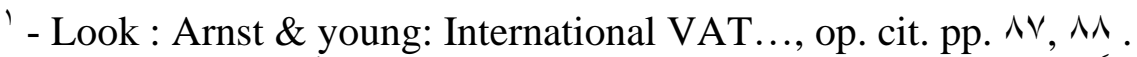

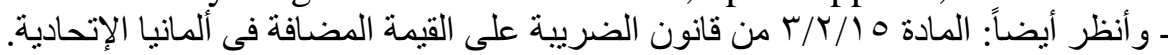

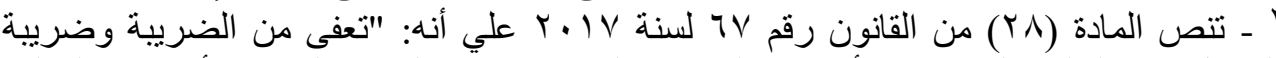

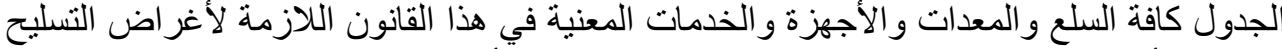
للافاع و الأمن القومى وكذللك الخامات ومستلزمات الإنتاج و الأجزاء الداخلة في تصنيعها." 


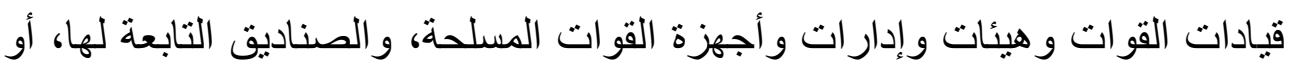
الملحقة بها. بـ وزارة الداخلية. جــ الهيئة العربية للتصنيع. دـ هيئة الأمن القومى.

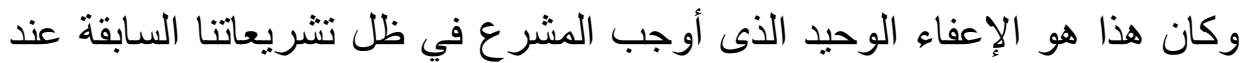

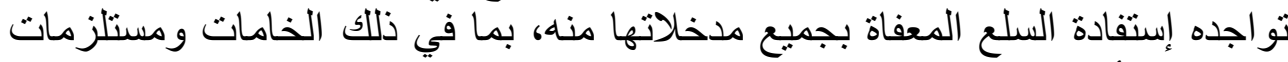

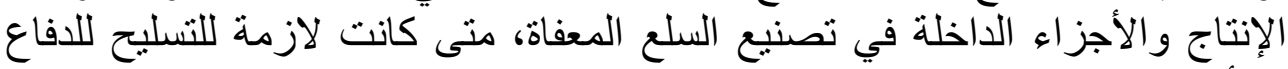

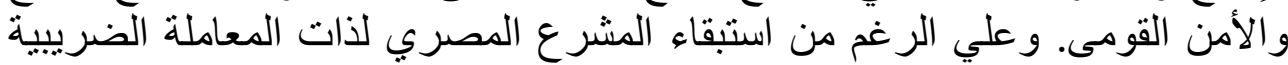

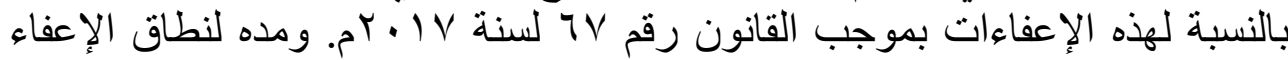

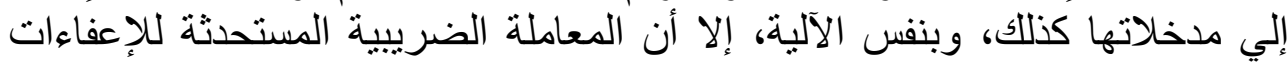

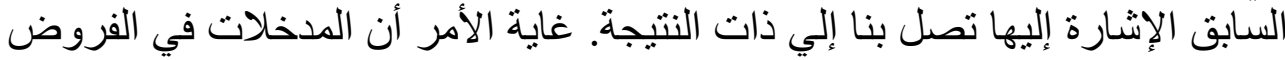

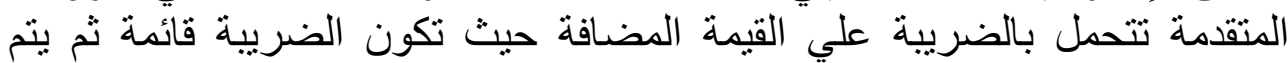

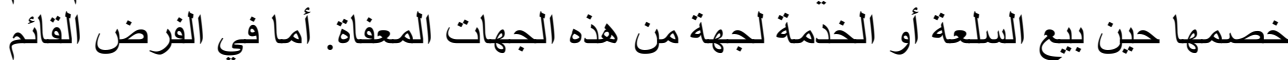

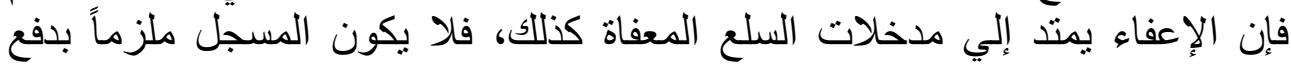
ضريبة ما علي الدخلات إبتداءً حتي يكون من حقه المطالبة بخصمها إنتهاءً.

\section{المبحث الثاني}

\section{تطبيقات خاصة للإنتمان المرغوب و آثاره الإقتصادية والمالية}

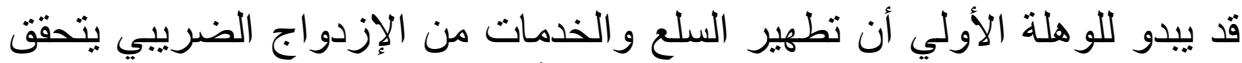

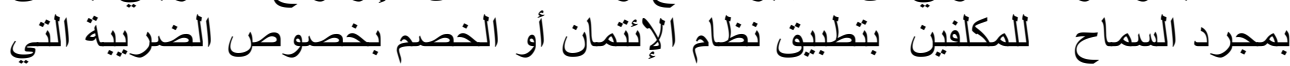

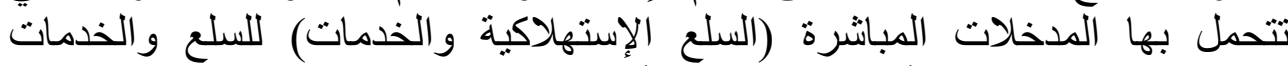

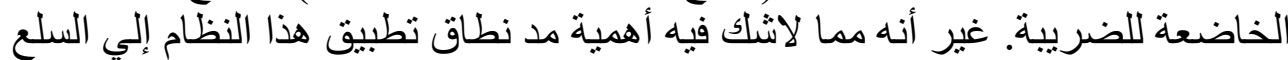

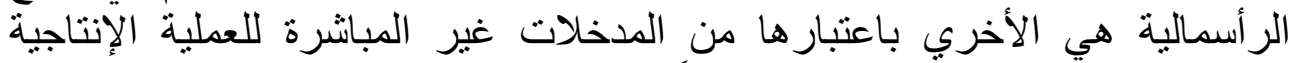

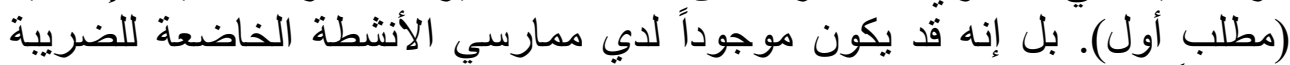

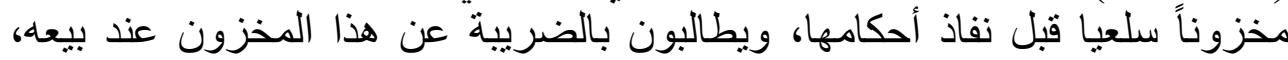

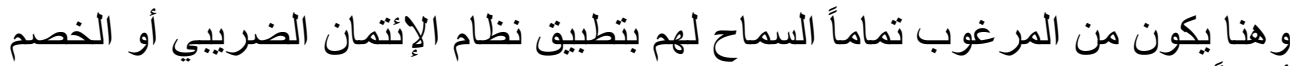
أيضاً علي هذا المخزون؛ لما يحققه ذللك من آثار مالية و إقتصادية حميدة (مطلب ثان).

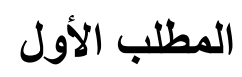

\section{تطبيق الإنتمان علي السلع الرأسمالية وآثاره الإقتصادية والمالية}

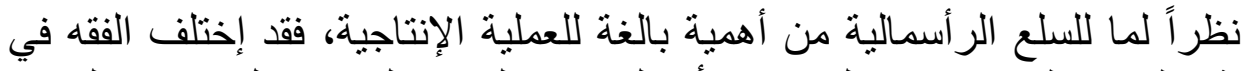

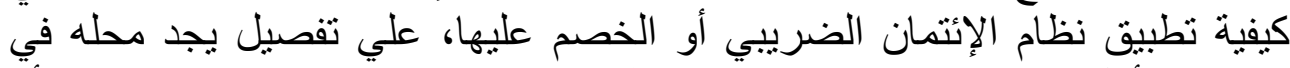

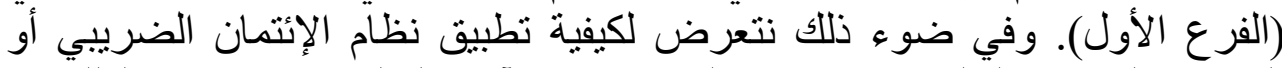
الخصم علي هذه السلع في تشريعنا الضريبي، والآثار المالية والإقتصادية لذانلك في لني 


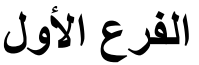

\section{موقف الفقه من أهمية الإتنمان الضريبي للسلع الرأسمالية}

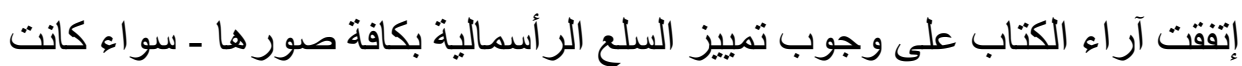

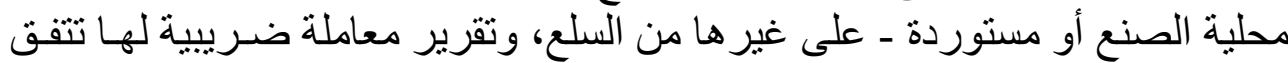

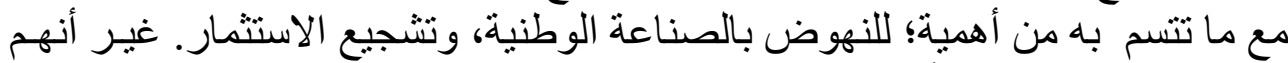

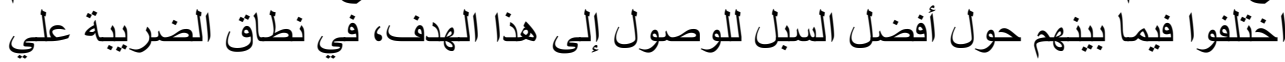

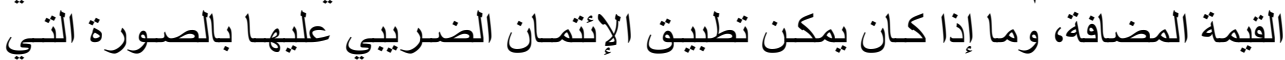
تحقق هذه الغاية إلى ثلاثة اتجاهات، نتعرض لهان لها تباعاً فيما يلي:

\section{الإتجاه الأول: إعفاء السلع الر أسمالية من الضريبة:}

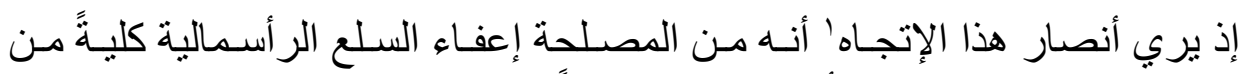

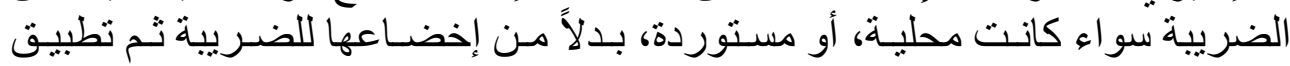
الإثتمان أو الخصم الضريبي عليها، مؤيدين وجهة نظر هم فى ذللك بـالحجج و الأسـانيد الطيد

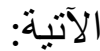

أو لاً: " أن الأصل فى هذه الضريبة أنها تفرض على منتج يتم بيعه فى السوق المحلية،

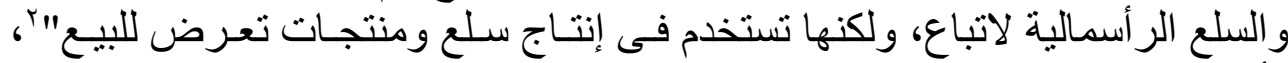

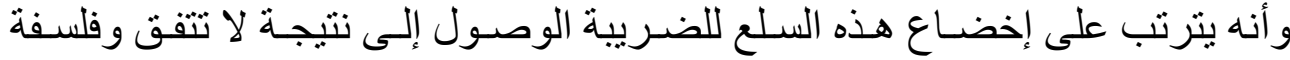

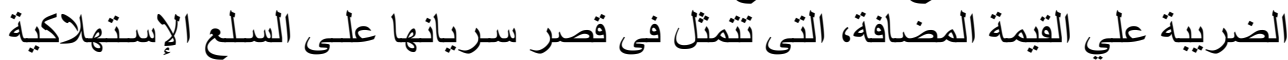

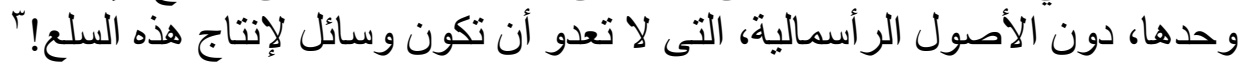

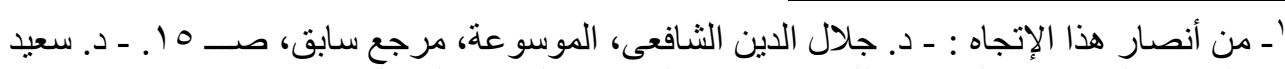

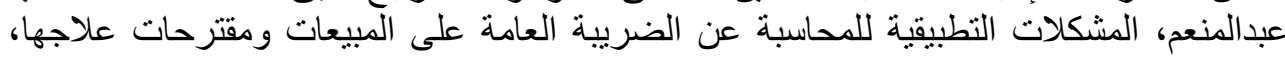

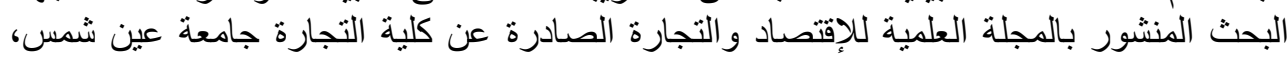

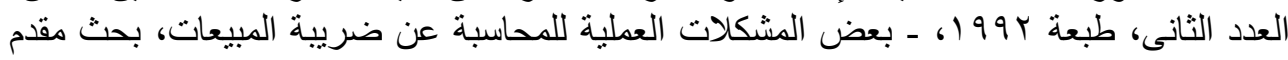

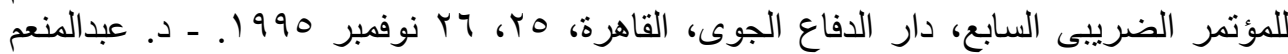

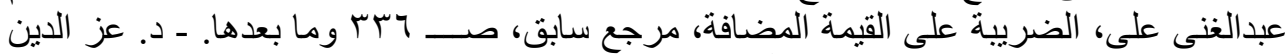

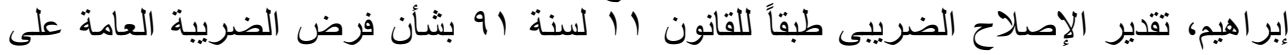

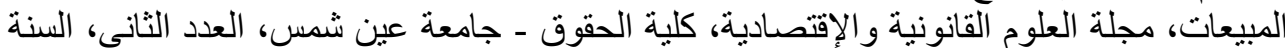

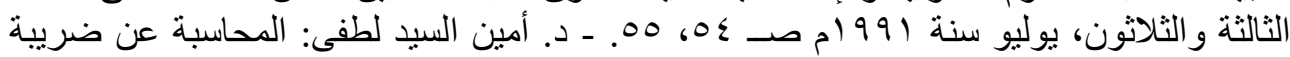

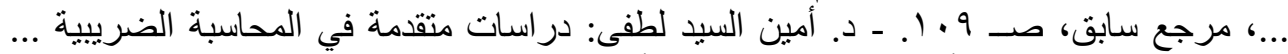

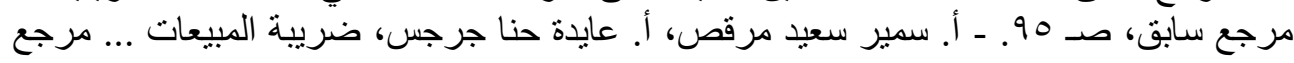

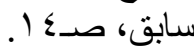

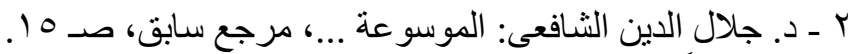

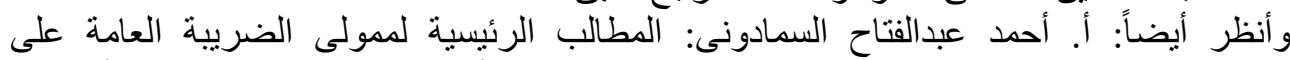

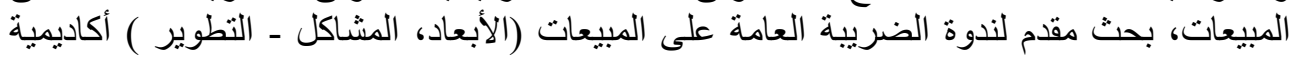

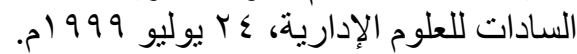

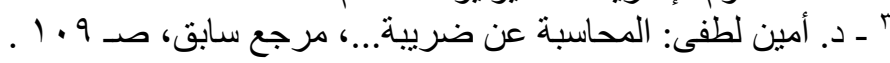




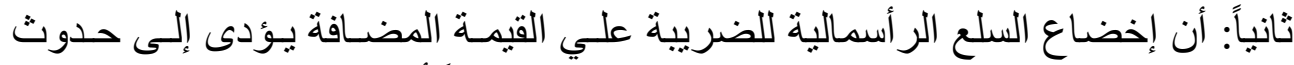

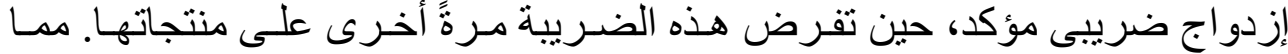

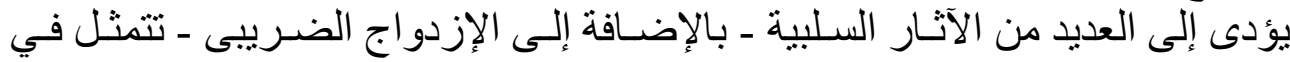

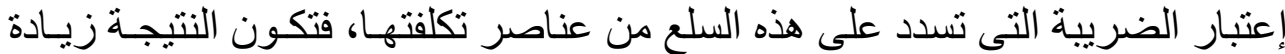

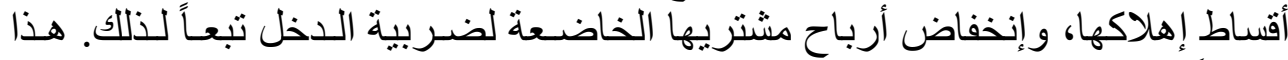

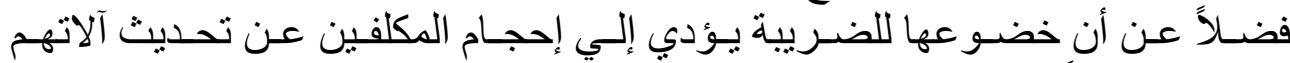

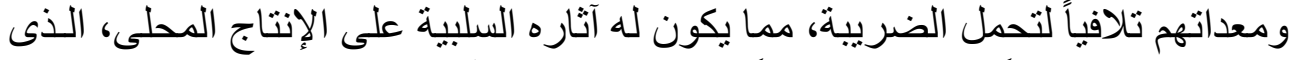
تسعى الدولة جاهدةً إلى تعظيم دورةً في عملية التنمية.'

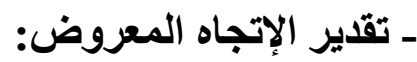

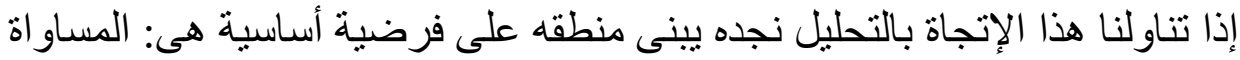

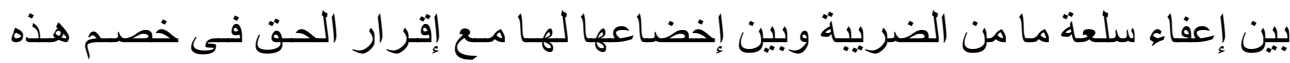

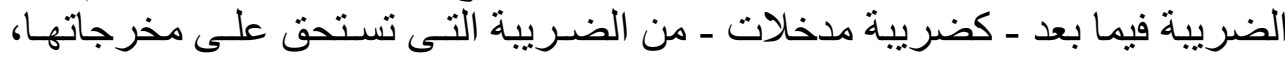

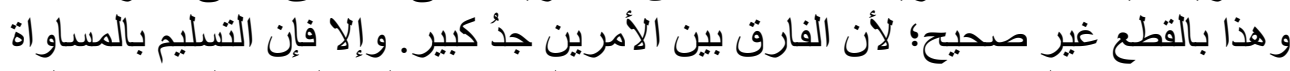

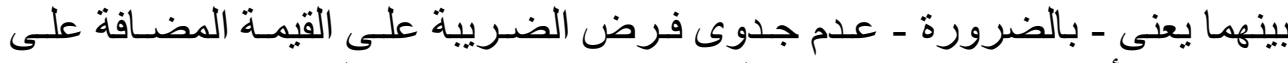

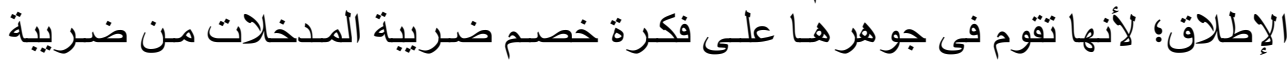

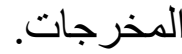

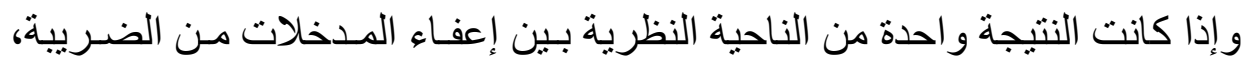

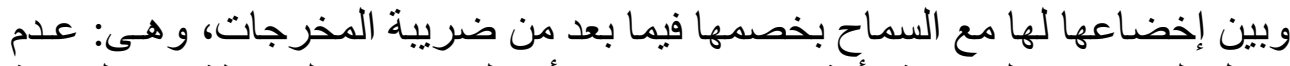

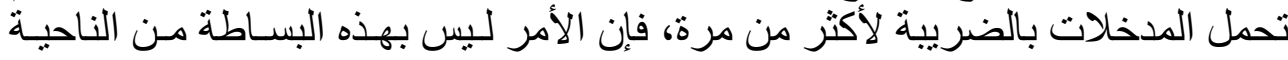

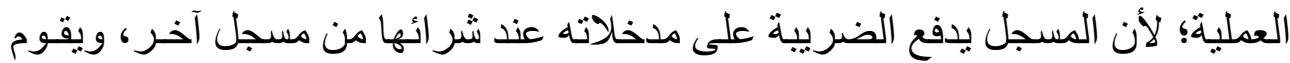

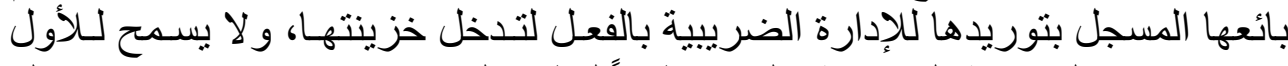

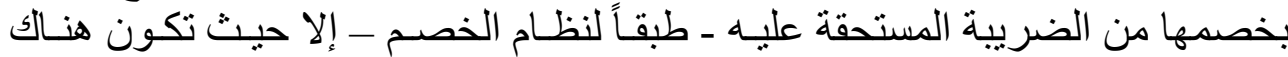

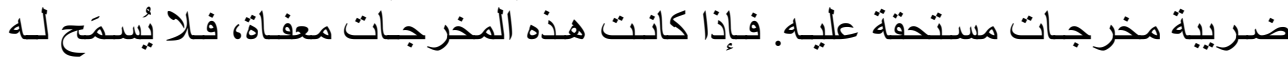

بخصمها.

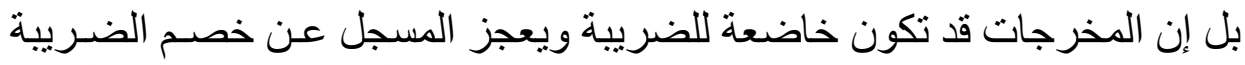

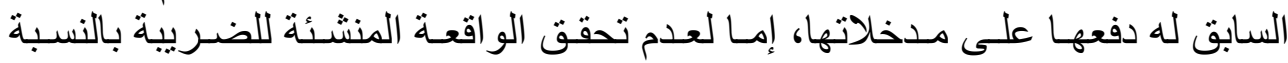

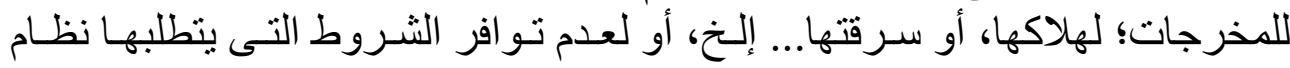

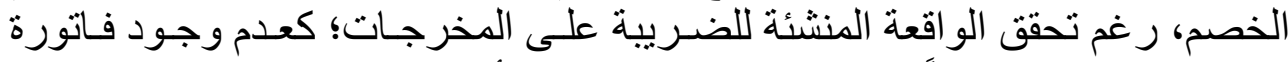

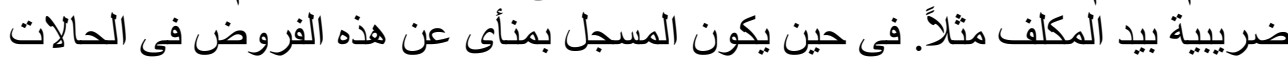

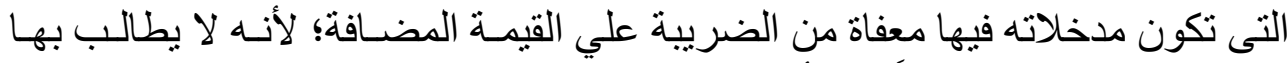

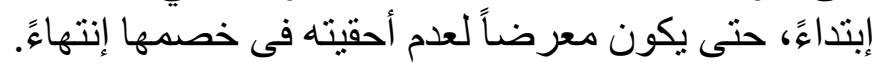

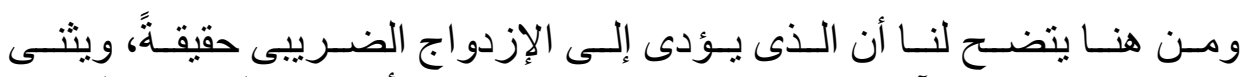

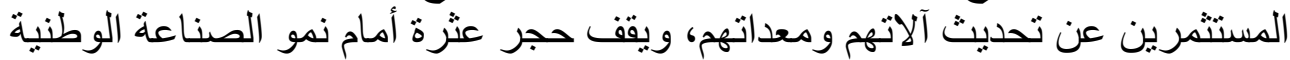

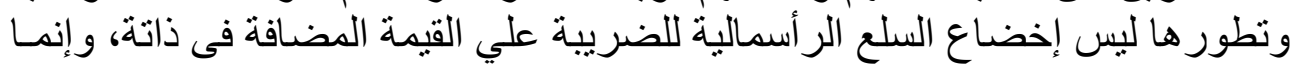

$$
\text { 'ـ د. عز الدين إبر اهيم: تقدير الإصلاح الضريبى، مرجع سابق، صـ Or، Or. }
$$


الإعتمان الضريبي وآثارة الإقتصادية والمالية "دراسة مقارنة"

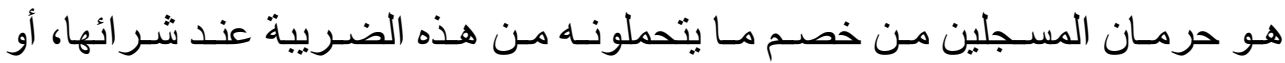

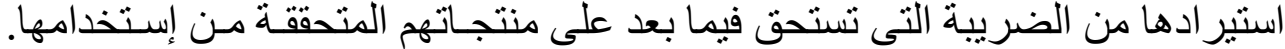

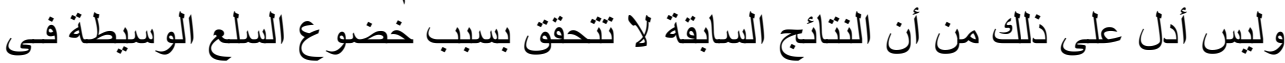

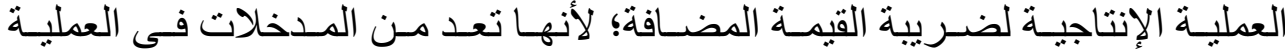

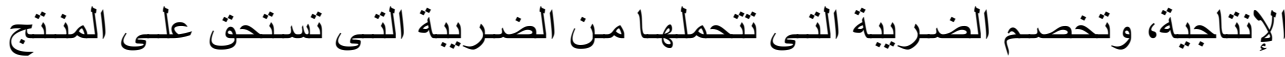

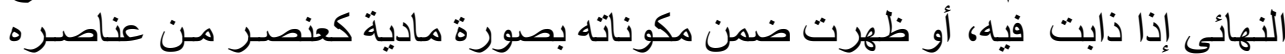

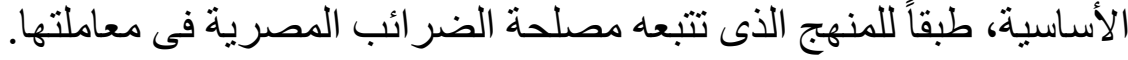

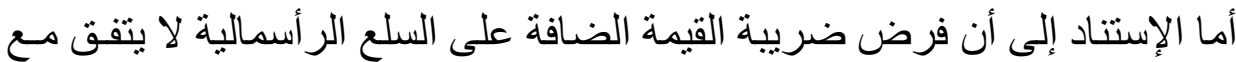

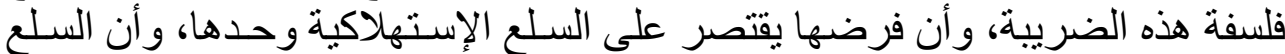

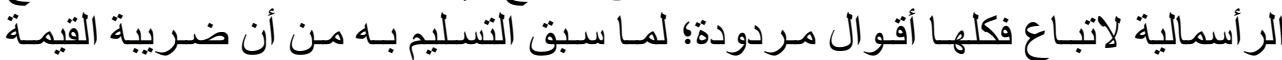

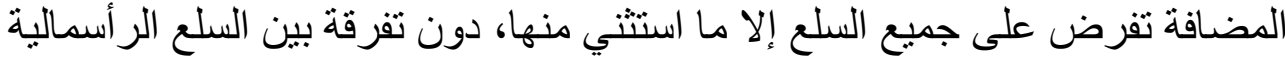

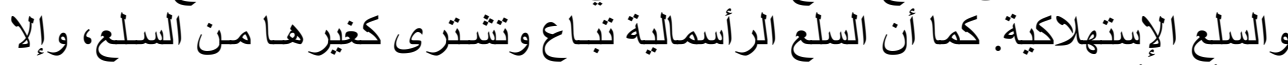

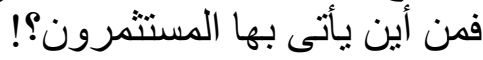

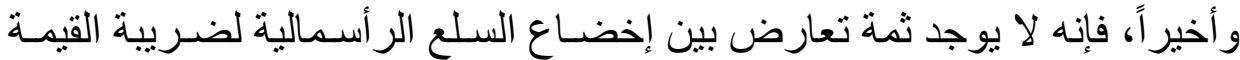

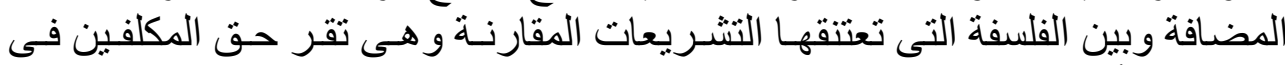

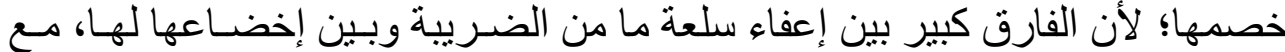

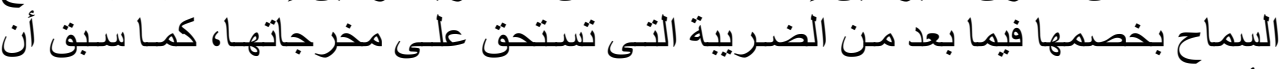
رأينا.

الإتجاه الثانى: إعفاء السلع الرأسمالية المستوردة وإخضاع ميثلتها المحلية لسعر

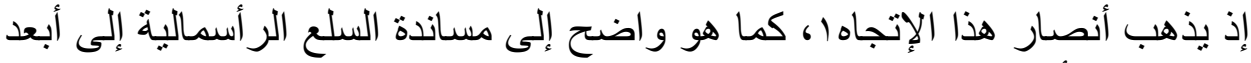

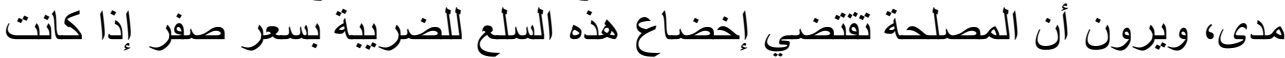

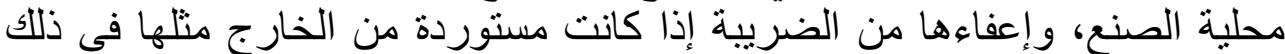

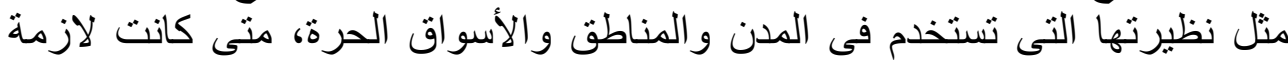

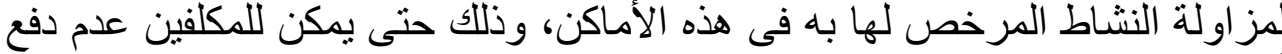

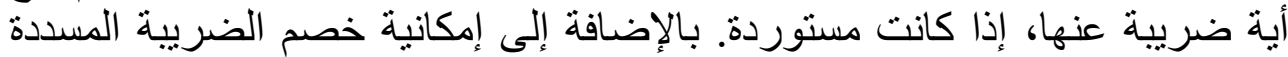

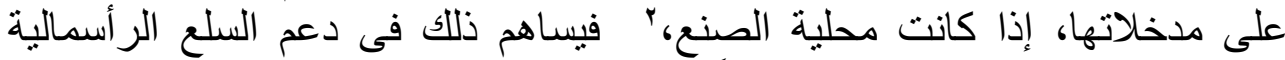

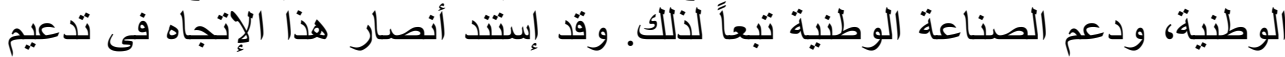

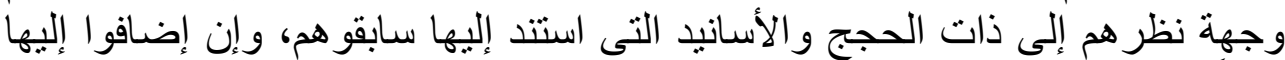

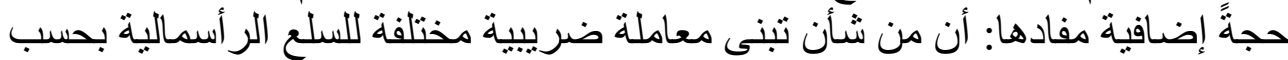

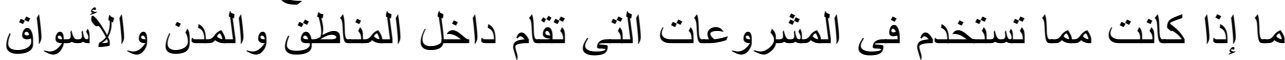

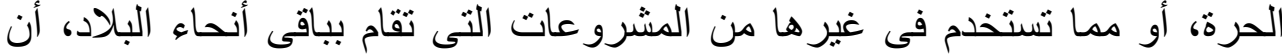
يؤدى إلى تفضيل النوع الأول من هذه المشرو عات على النوعات النى الأخير منها.

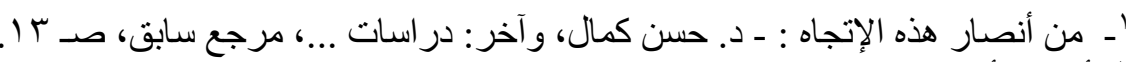

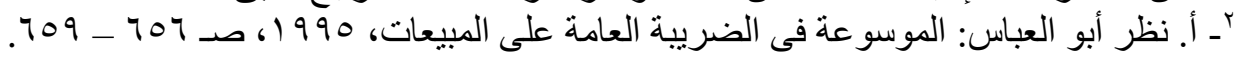




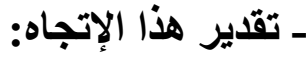

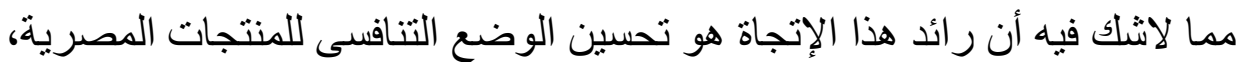

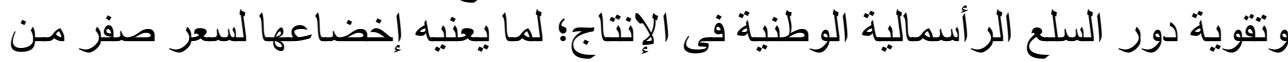

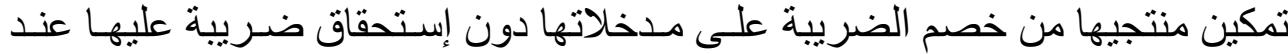

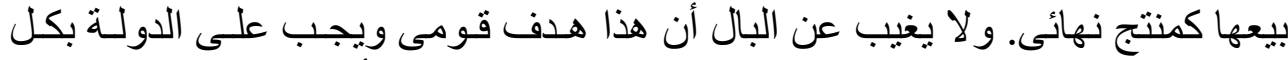

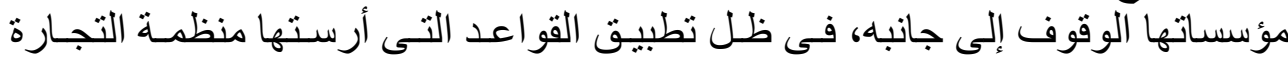

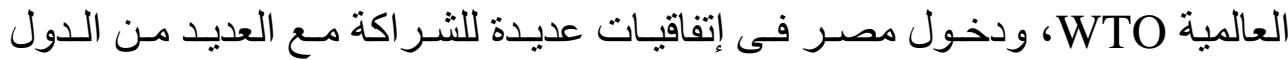

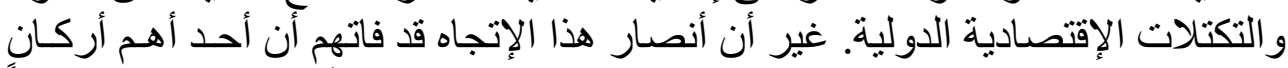

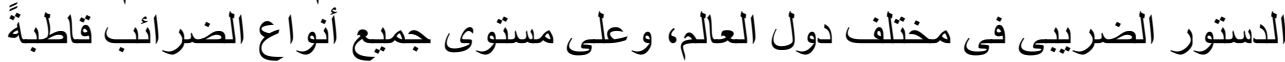

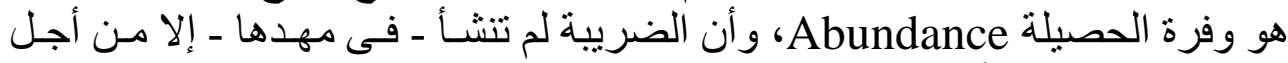

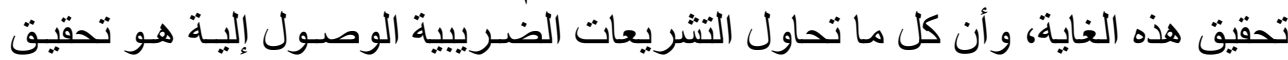

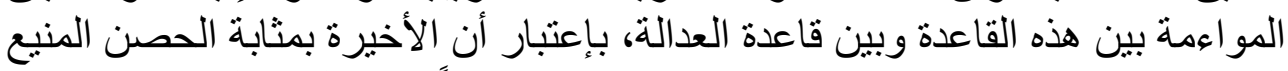

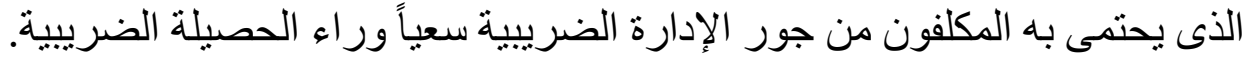

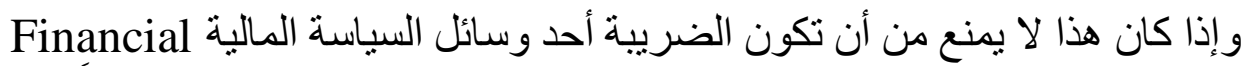

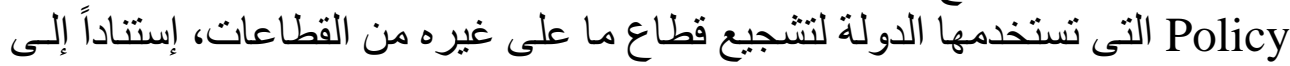

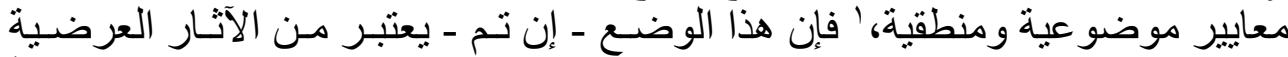

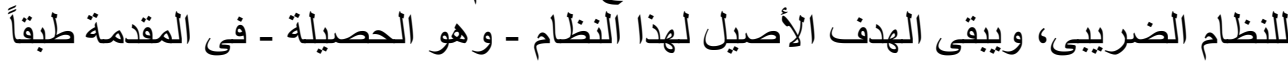

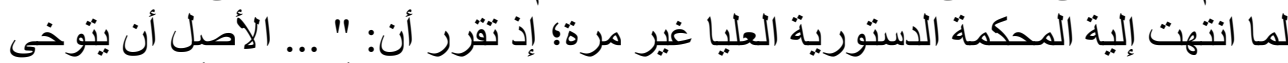

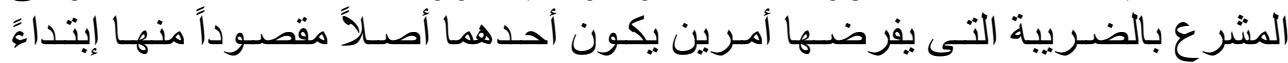
Primary Motive

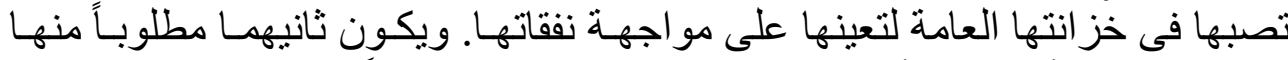

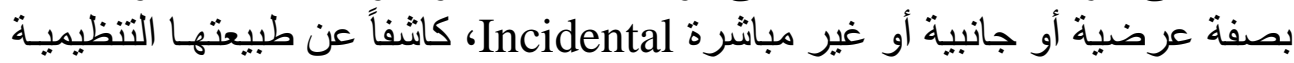
Regulatory Motive

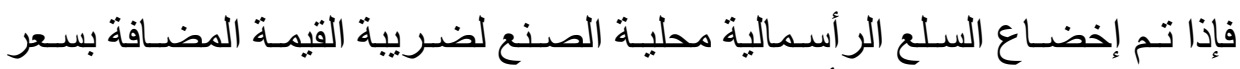

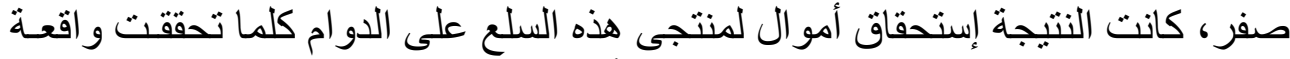

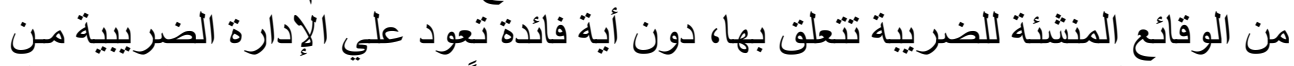

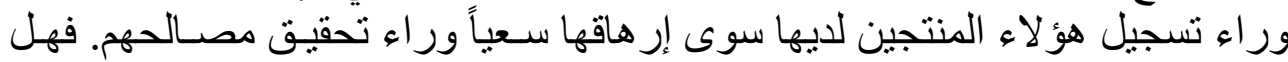

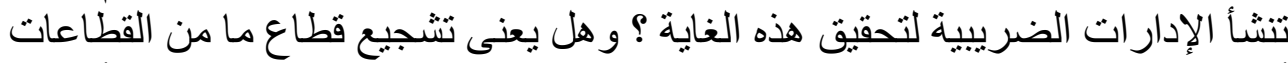

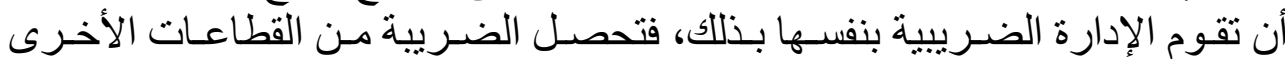

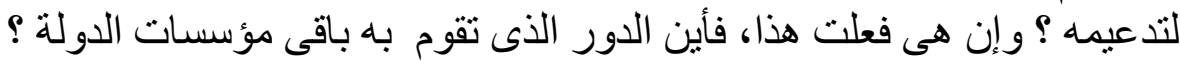

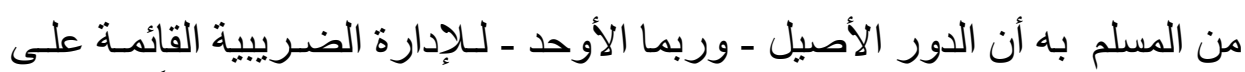

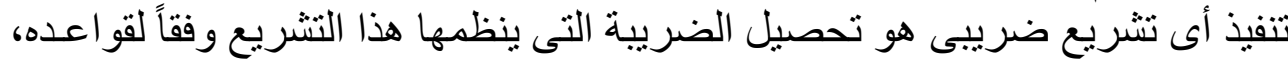

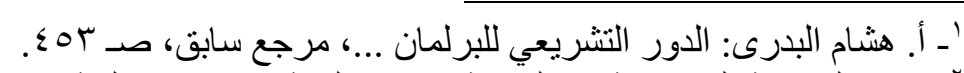

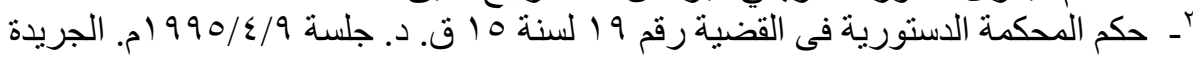

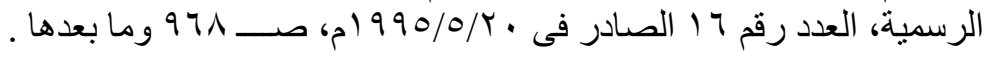


الإيتتمان الضريبي وآثارة الإقتصادية والمالية "دراسة مقارنة"

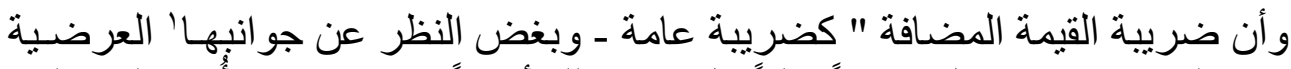

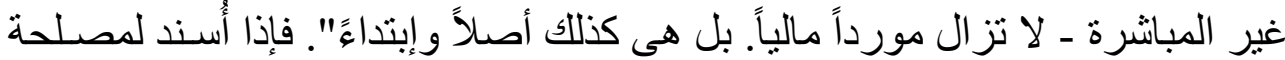

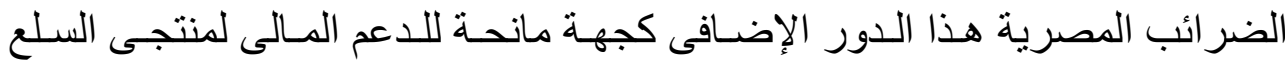

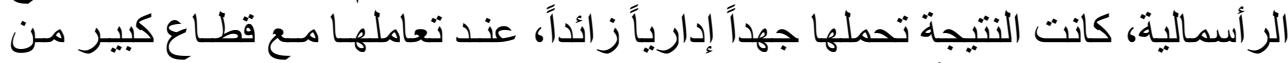

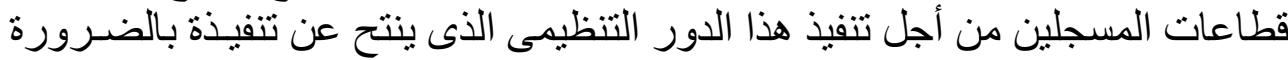

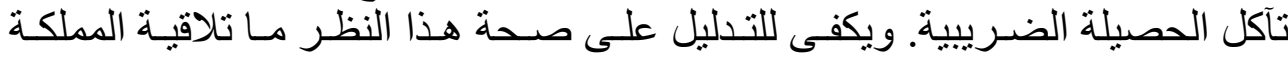

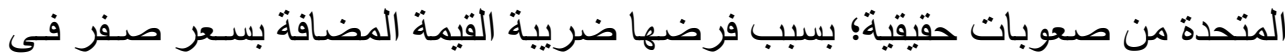

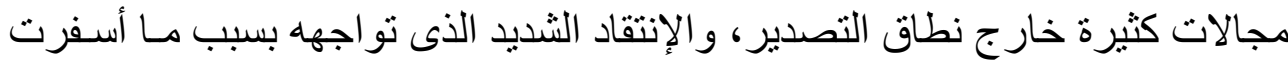

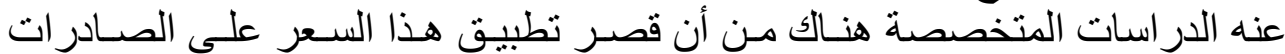

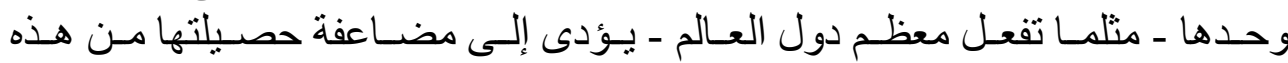
الضريبة.

الإتجاة الثالث: إخضاع السلع الرأسمالية للضريبة بسعر r\% مع حرمانها من نظام

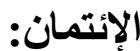

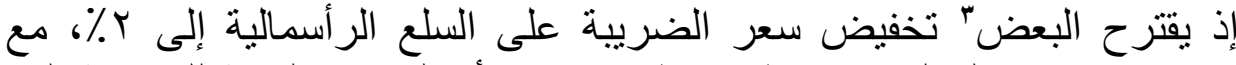

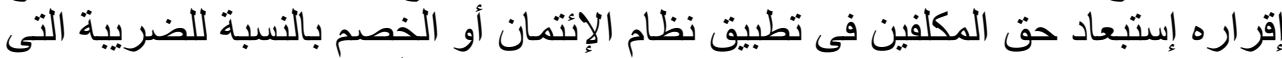
تسدد عنها من الضريبة التى تستحق على منتجاتها، مبرراً ذلك بأن من شأنه تسهيل

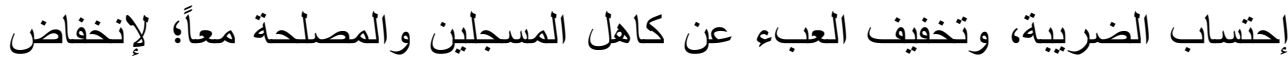

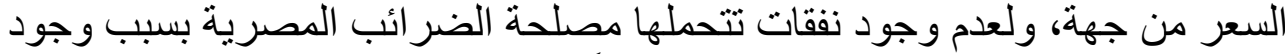

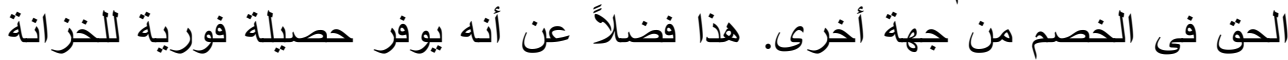

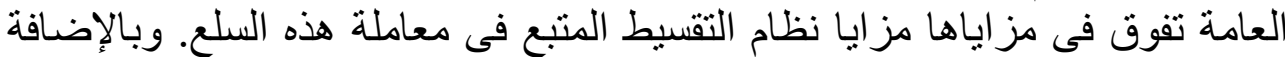

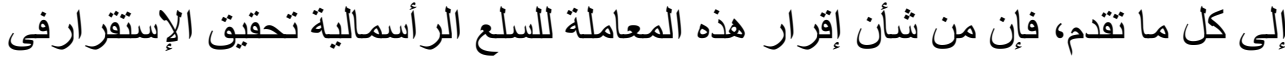
المعاملات، وتحديد تكلفة الإنتاج لدى المكلفين بصورة قطعية، وتجنيب الخز النة العامة المانة

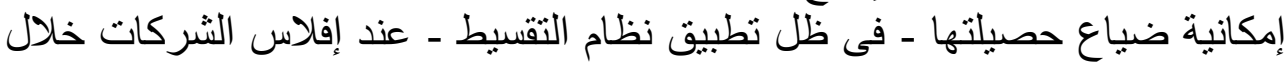

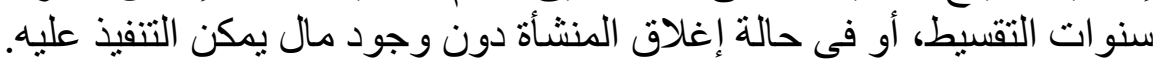

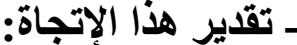

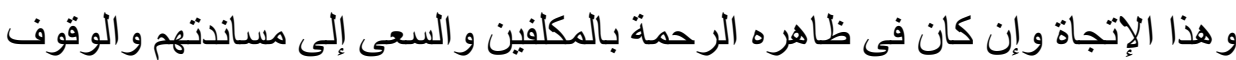

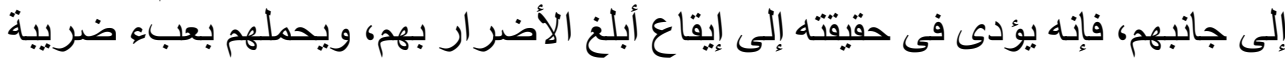
القيمة المضافة أكثر من مرة: ذلك أن سلب المكلفين حقهم الأصيل في خصم الضــيبية

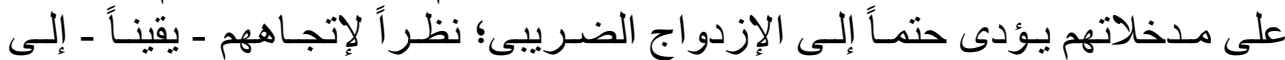

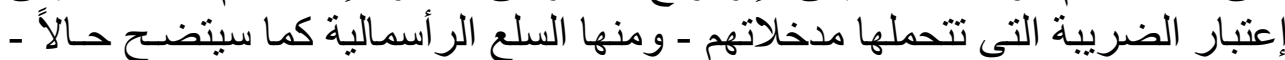

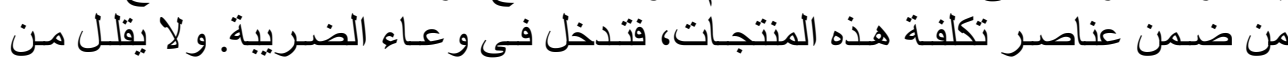

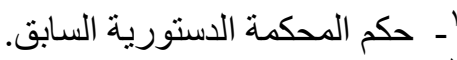

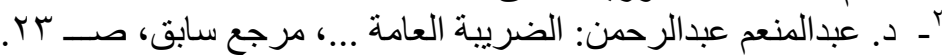

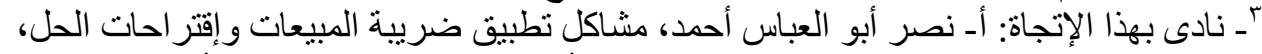

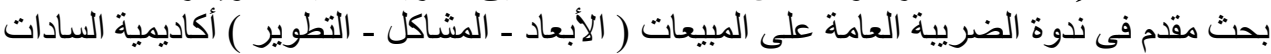

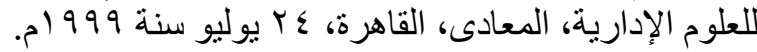


خطورة ذللك إنخفاض سعر الضريبة إلى بـ. ويكفى للتدليل على خطورة هذه النتيجـة

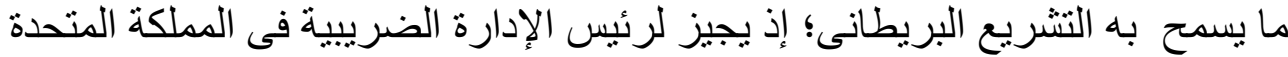

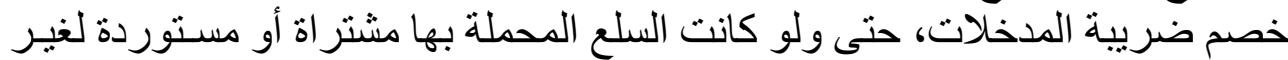

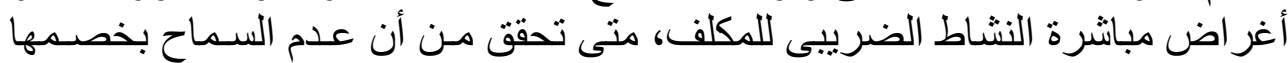

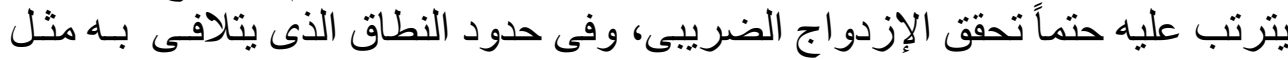

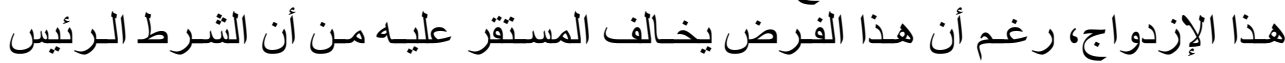

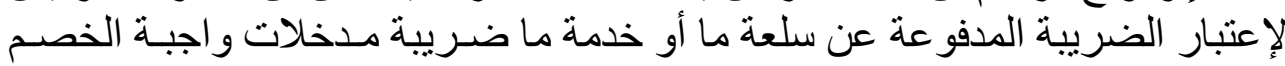

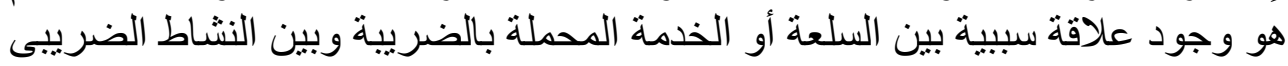

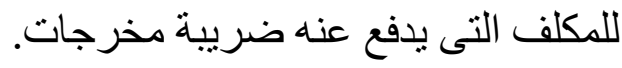

و هكذا تباينت آر اء الفقهاء فيما يتعلق بالمعاملة الضـريبية المثلـي للســـع الر أســالية

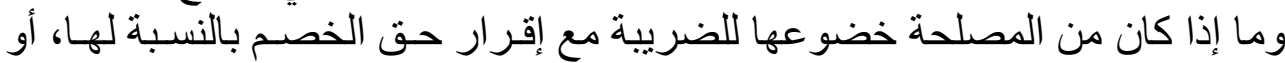

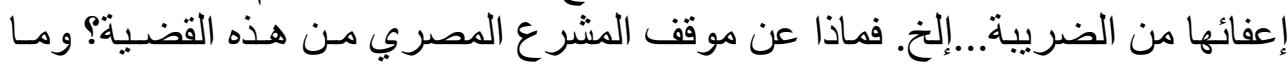
هي آثاره المالية و الإقتصادية؛؟ هذا هو موضع در اسة الفر الفرع التالي:

\section{الفرع الثاني}

\section{الإنتمان الضريبي والسلع الرأسمالية في التشريع المصري و آثاره}

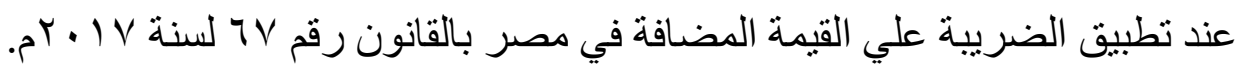

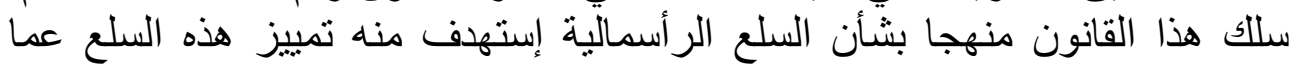

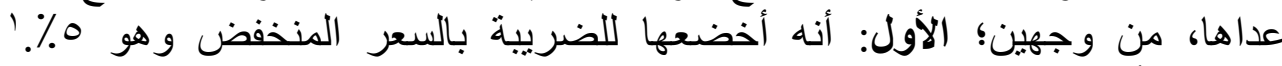

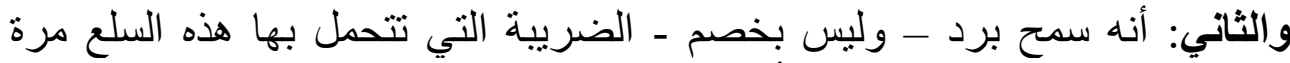

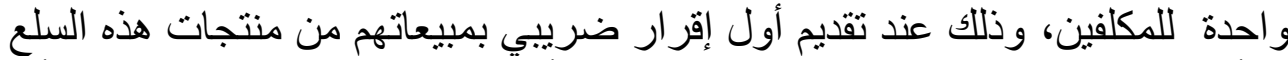

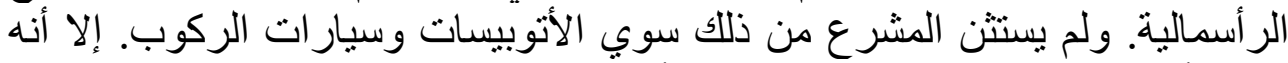

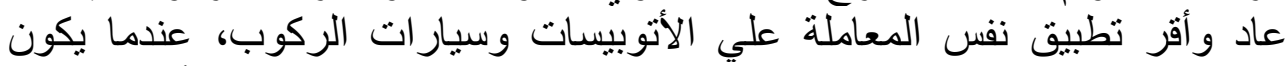

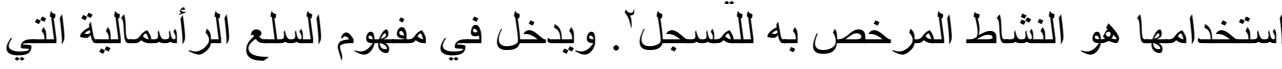

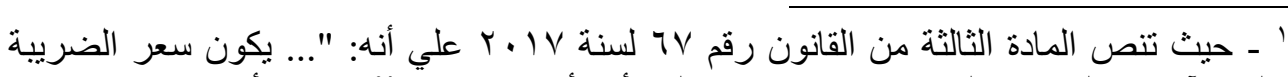

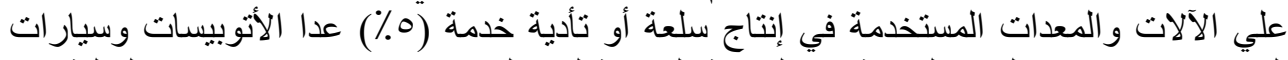

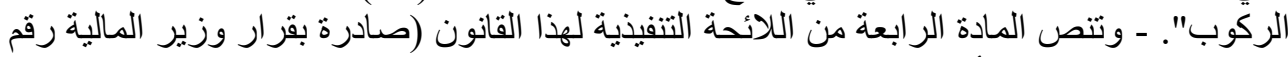

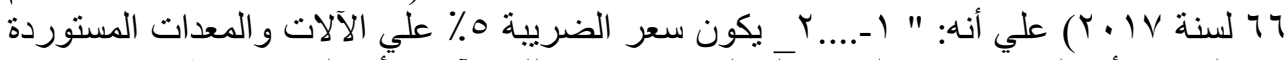

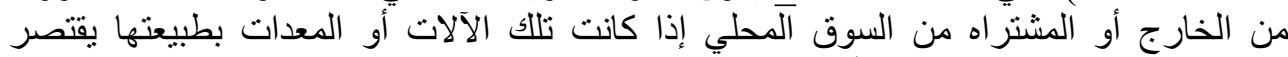

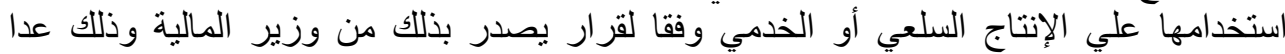
الأتوبيسات وسيارات الركوب. ........................ ويطبق السعر العار العام للضريبة علي أجزاء الآلات

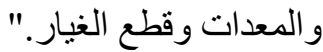

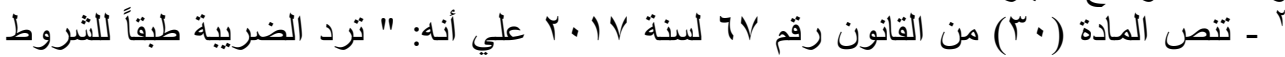

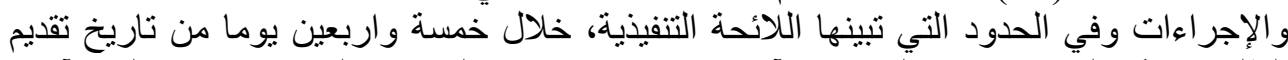

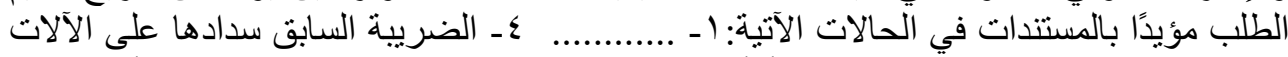

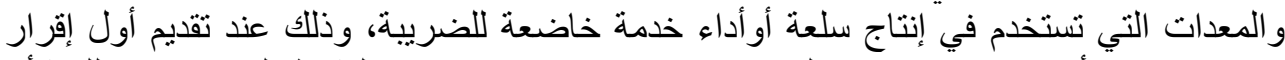

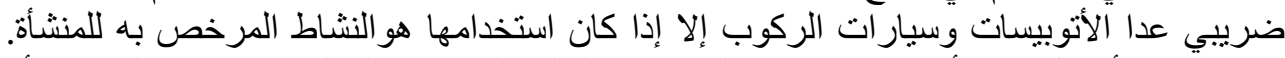

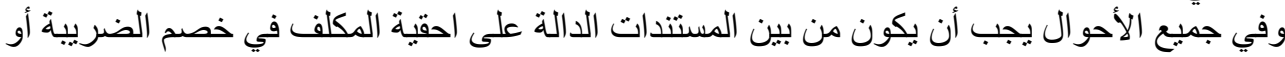
ردها شهادة موقعة من محاسب مقيد بجدول الاحن المحاسبين و المر اجعين تفيد ذلك". 
الإئتمان الضريبي وآثارة الإقتصادية والمالية "دراسة مقارنة"

تستففيد من هذه المعاملة الضرييية الجديدة: "... الآلات والمعدات وخطوط الإنتاج

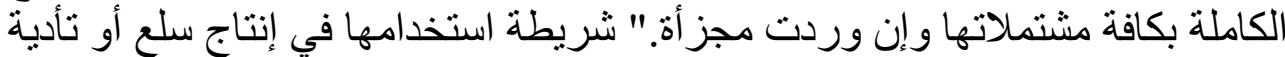

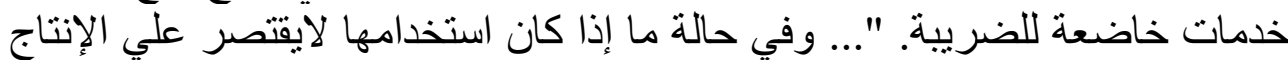

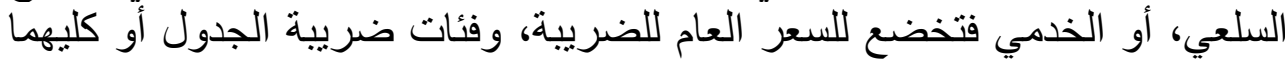

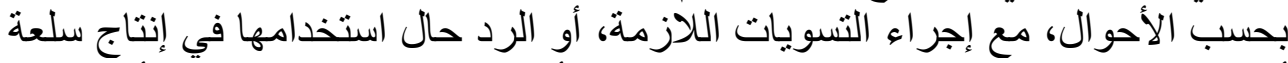

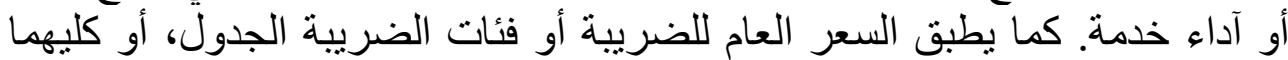

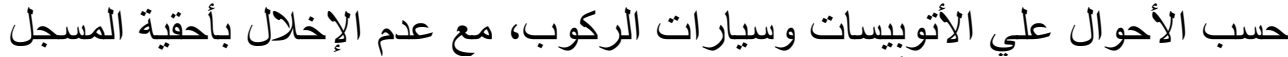

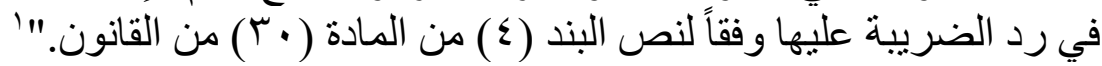

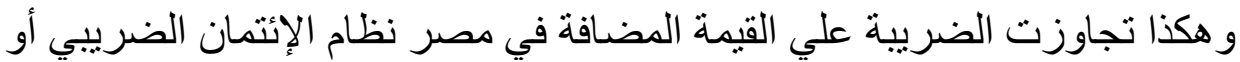

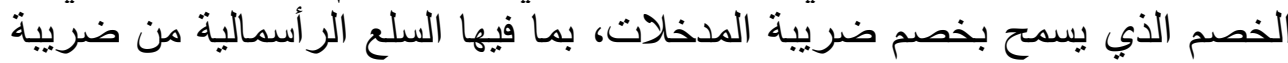

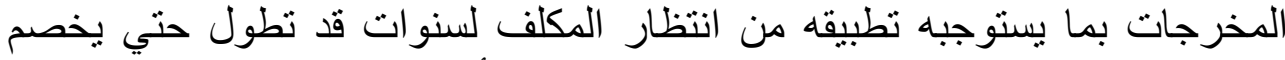

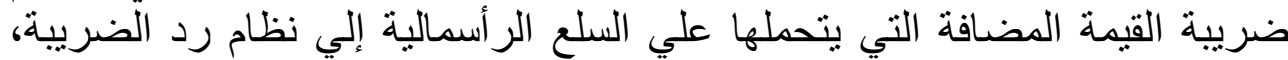

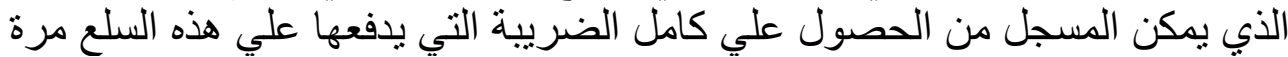

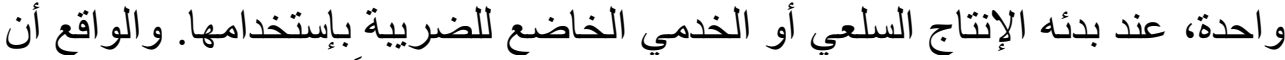

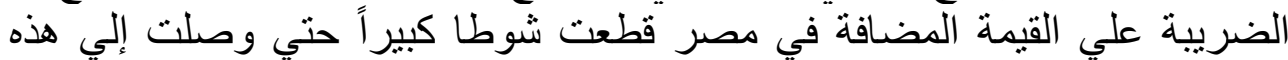

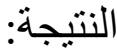

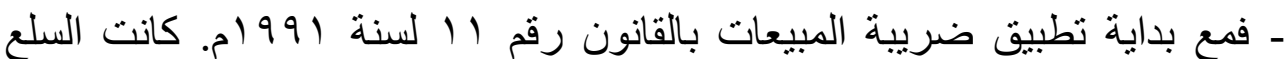

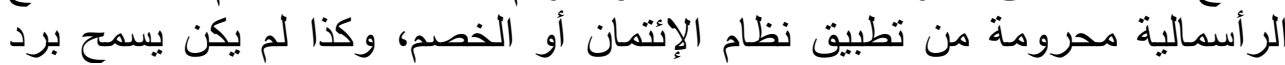
الضريبة المسددة عنها. وكانت تخضع للضريبة وقتها بالسعر العام وكان • (1).

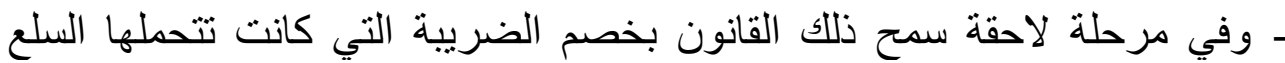

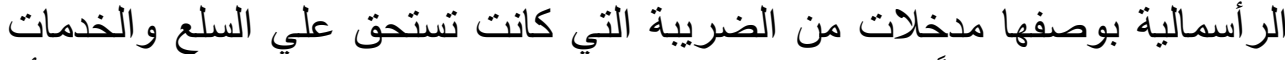

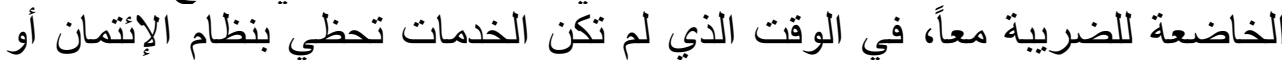

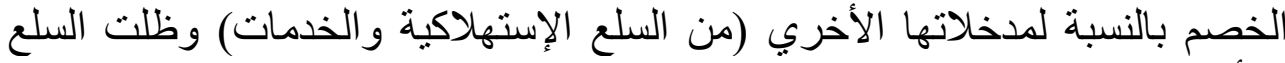
الر أسمالية تخضع للضريبة بالسعر العام كذلك.

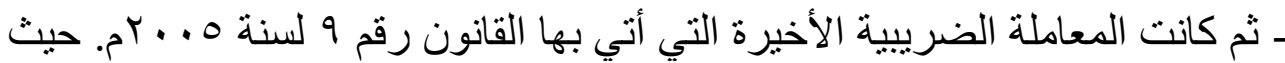

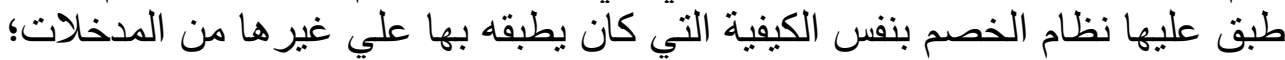

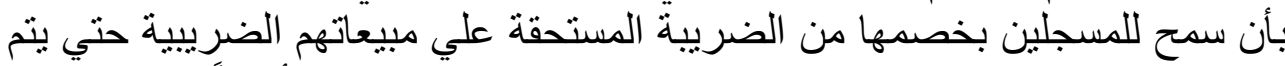
استنفاذها. وظلت هذه السلع خاضعة للضريبة بالسعر العام (• (1\%) أيضاً.

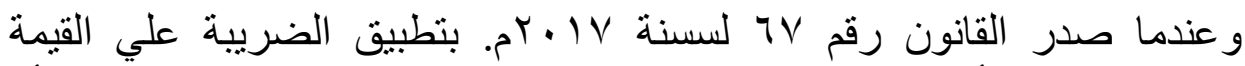

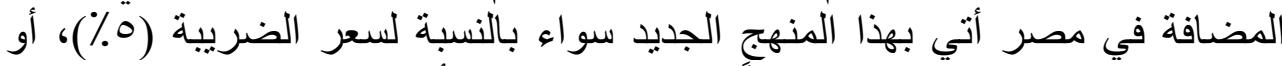

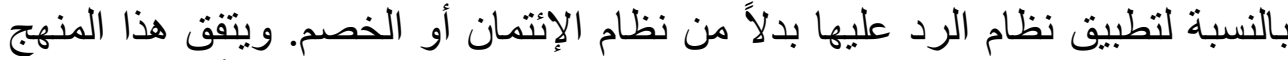

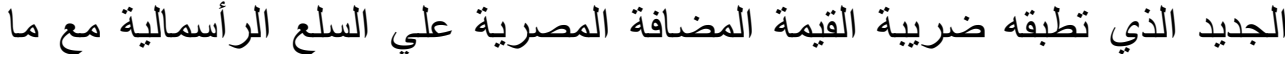
تطبقه بعض التشريعات المقارنة في الدول المتقدمة:

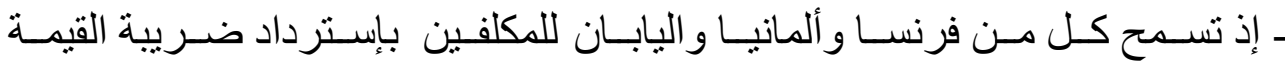




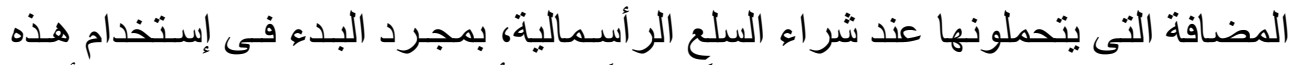

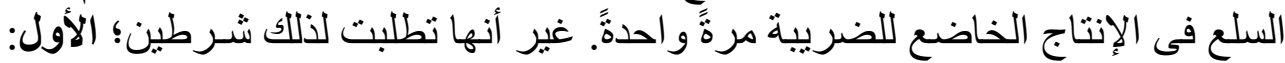

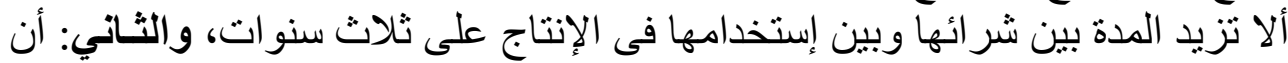

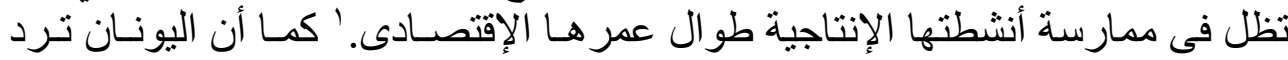

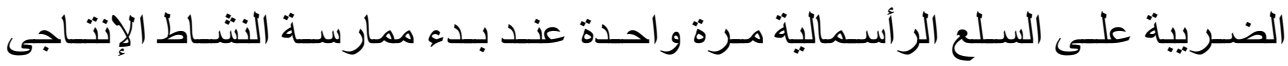

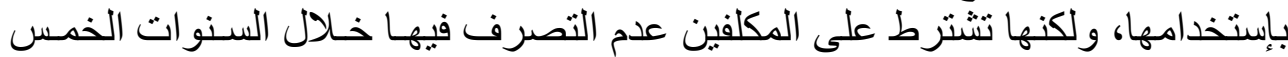

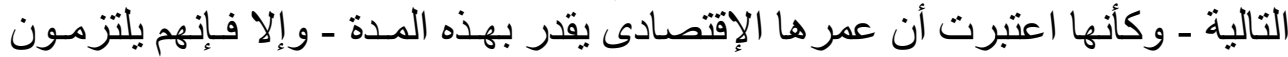

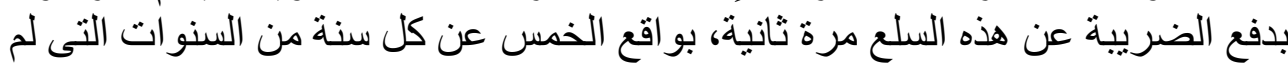

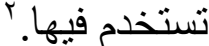

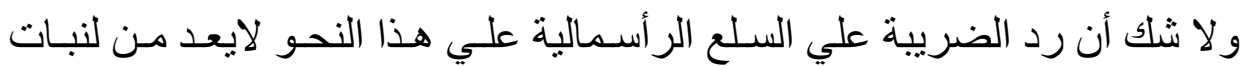

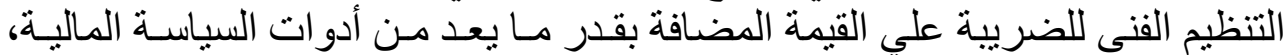

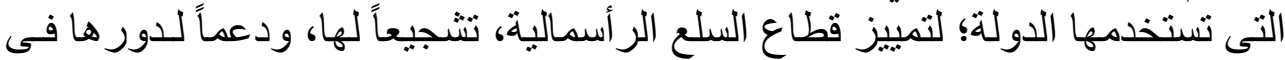

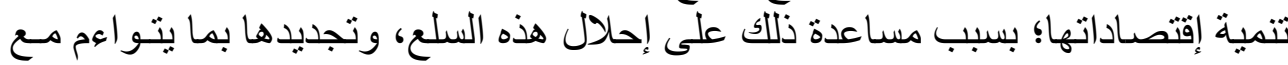

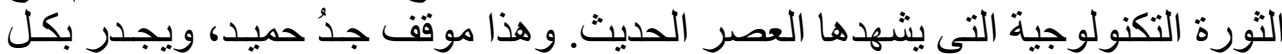

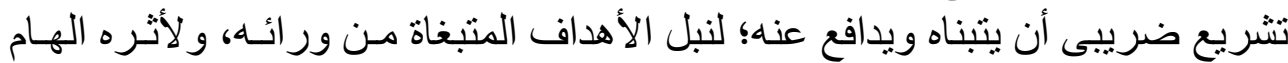

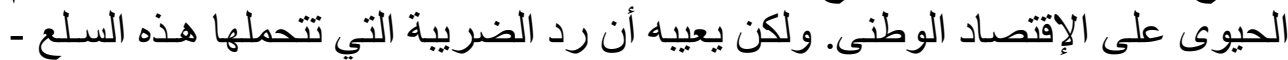

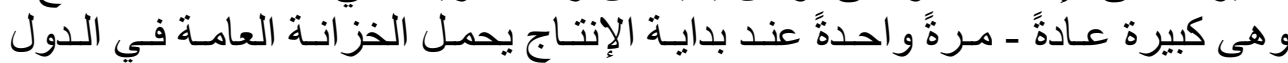
النامية، ومنها مصر أعباءً ماليةًً كبيرةً

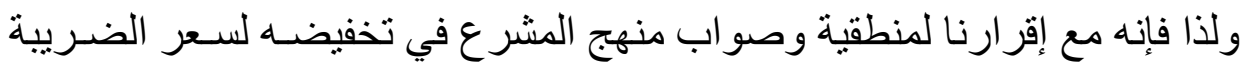

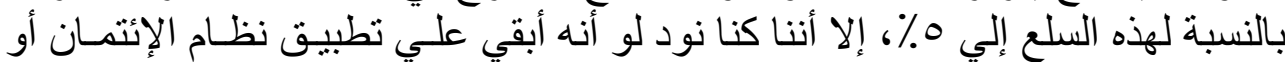

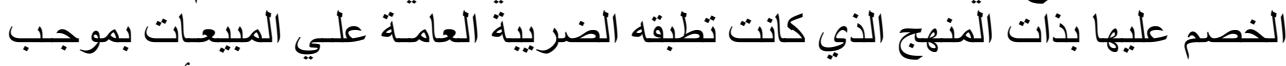

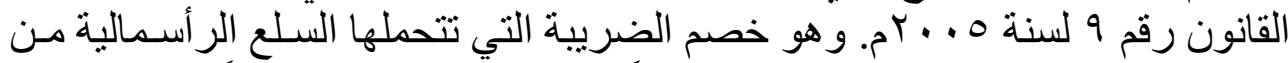

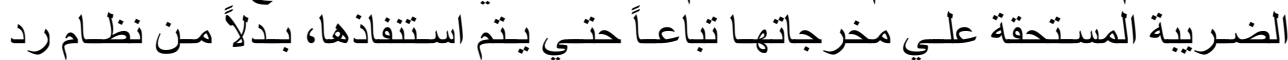
الضريبة؛ للعديد من الأسباب:

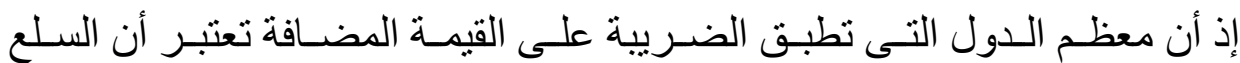

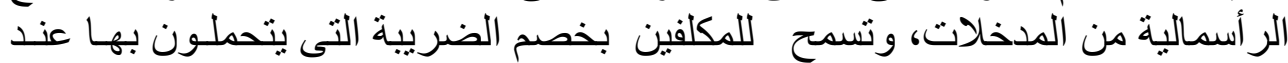

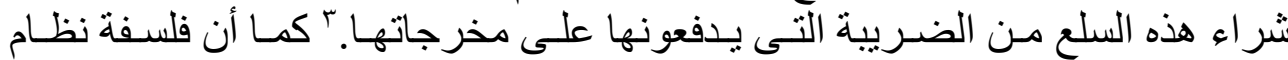

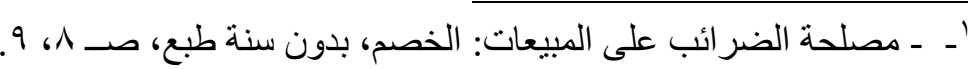

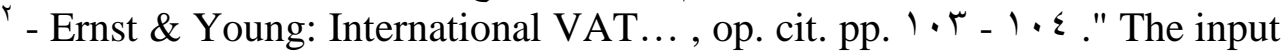
VAT recovered on capital assets to be adjusted if, the assets are soled within five years Repayment of the input VAT will be one - fifth for each year the assets were not used by the entrepreneur "

- Regardez aussi: Georges Egret, que sais - je?... op. cit. p. Vฯ .

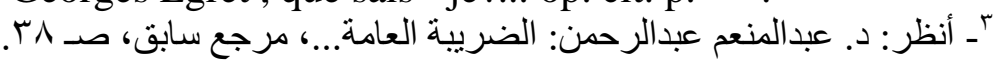

- Ernst \& young: Intentional VAT..., op. cit. p. 00.

" In principle, all input VAT on purchases including VAT : حيث ورد ما نصة (وللمزيد من on investments made during a VAT period is recoverable " 
الإيتتمان الضريبي وآثارة الإقتصادية والمالية "دراسة مقارنة"

الخصم فى الضريبة علي القيمة المضافة تقوم على أساس خصـم ضـريبة سبق دفعها

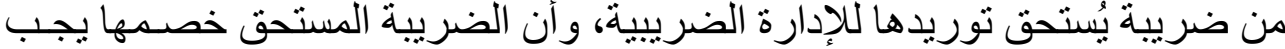

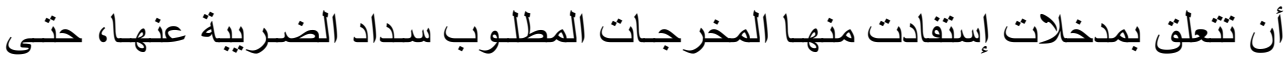

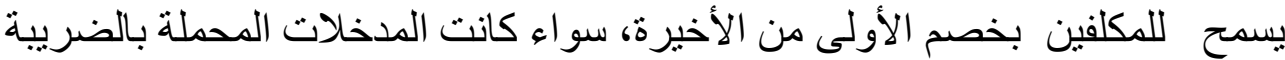

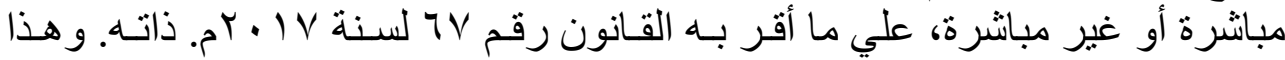

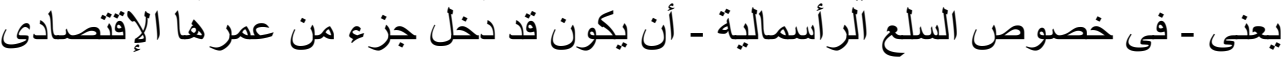

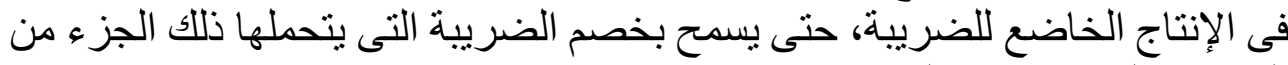
الضريبة النى تستحق على مخرجاته.

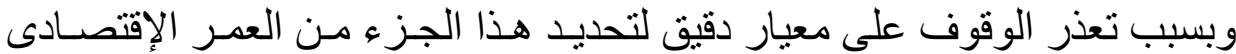

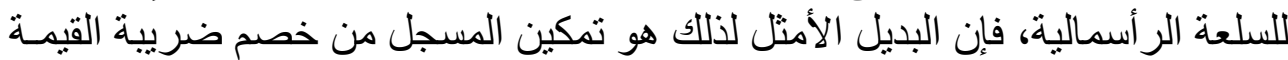

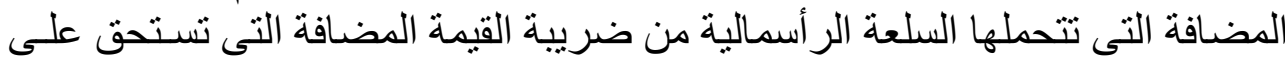

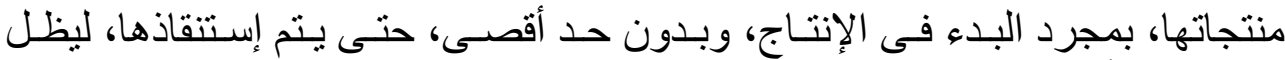

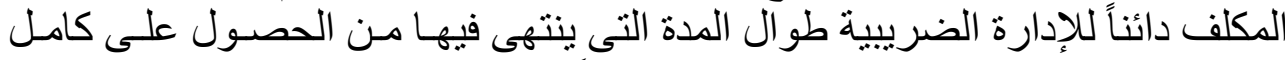

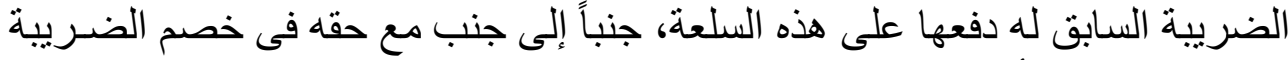

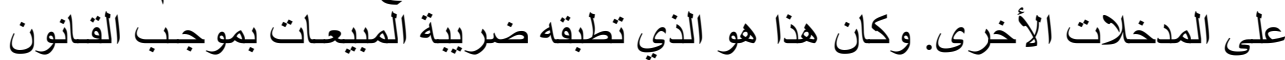

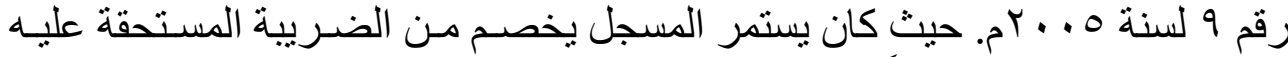

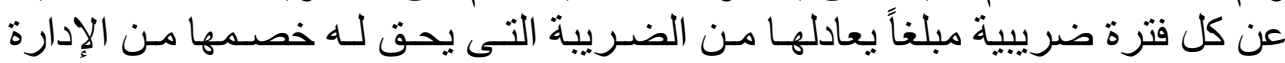

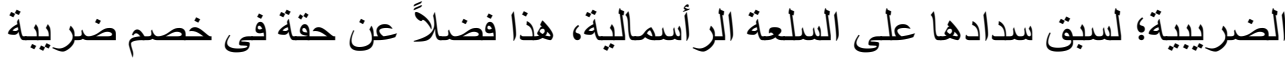
المدخلات الأخرى التى تتو افر الثروط القانونية لإعمال الحق فى الخصم بالنسبة لها.

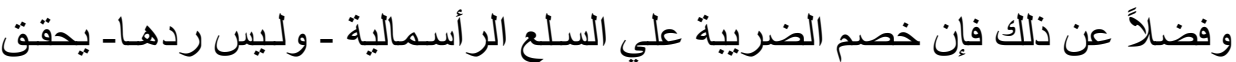

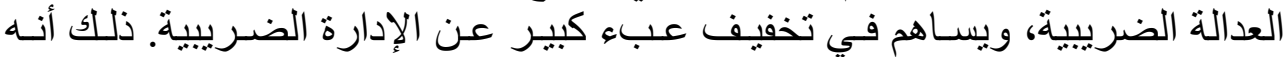

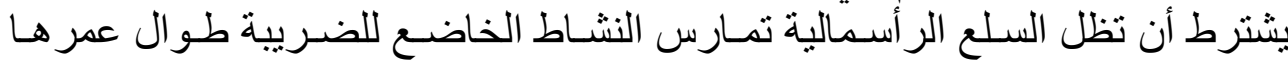

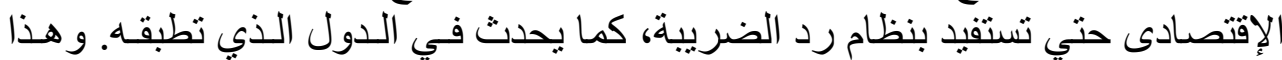

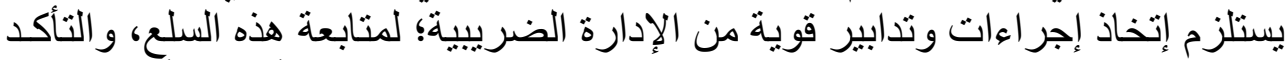
من تمام إهلاكها فى مشرو عات تخضع للضرئة الضية. وهو ما يمثل عبئًاً إضافياً يجنبنا إياه

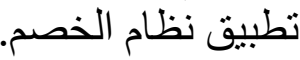

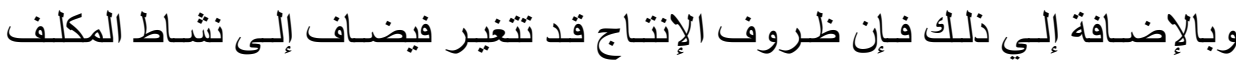

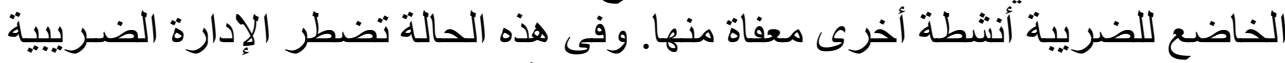

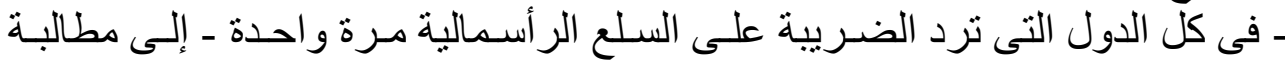

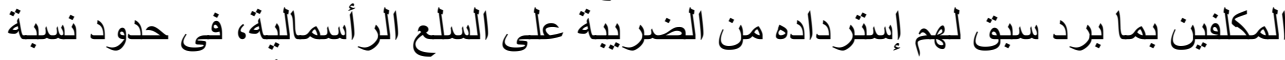

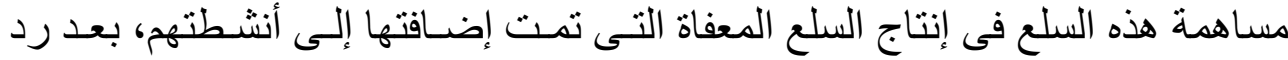

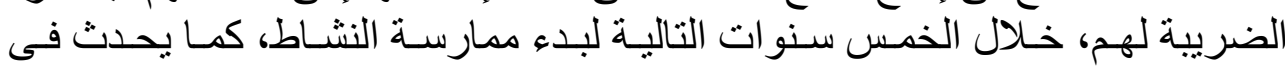

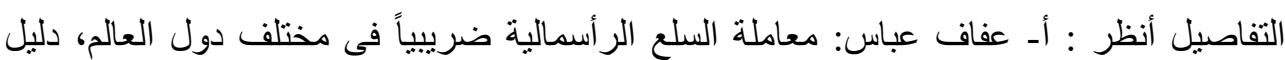

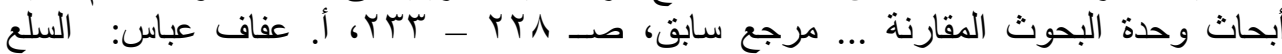
الر أسمالية بين الضريبة على القيمة المضافة والضريبة على المبية المبيعات، ... مرجع سابق، صــ 7 ـ. 


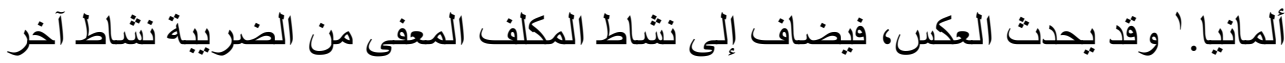

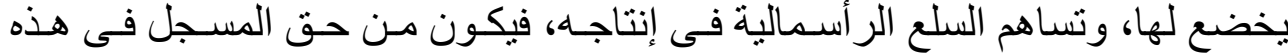

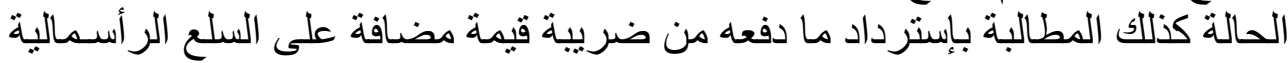

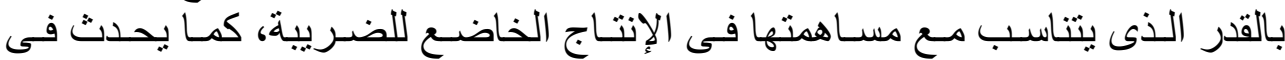
فرنسا.

وفضلاً عن كل ماتقدم فإنه قد يكون النشاط الإقتصادى للمكلف ذو طبيعة مزدوجـة الإنها

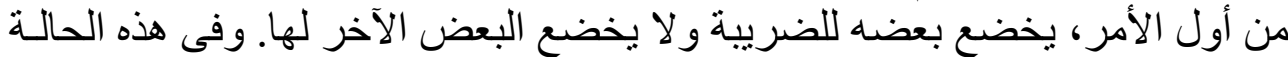

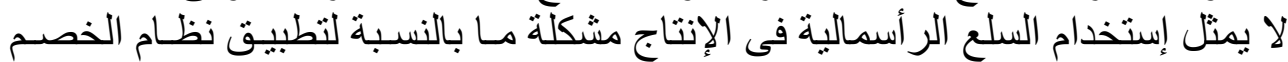

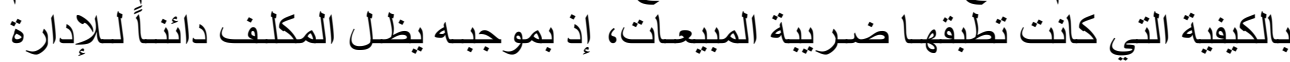

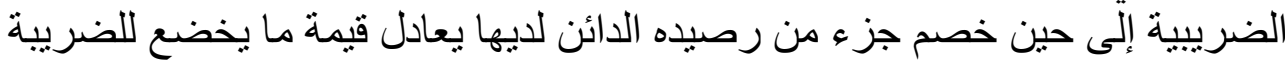

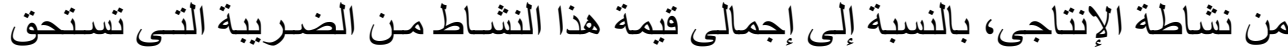

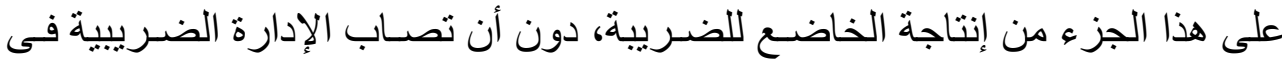

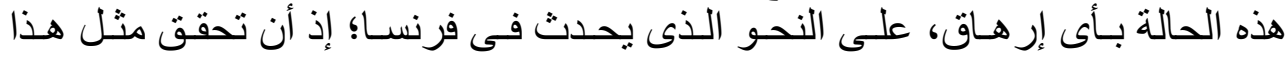

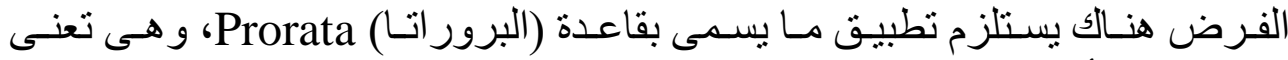

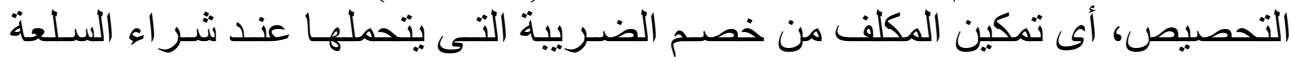

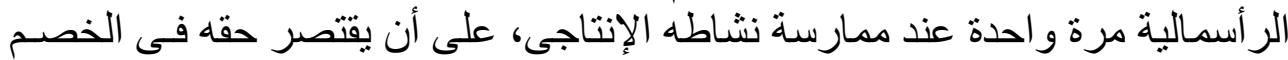

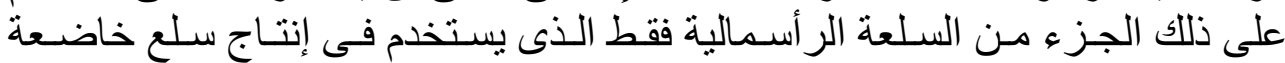

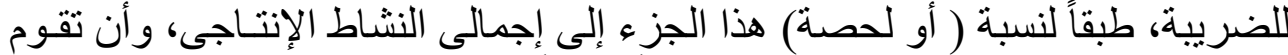

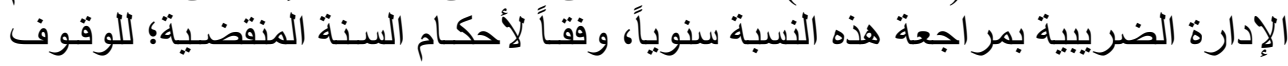

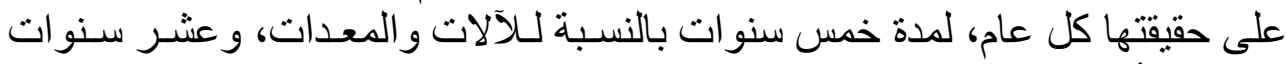

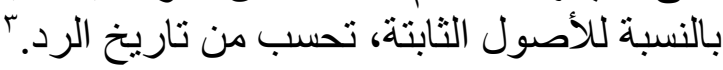

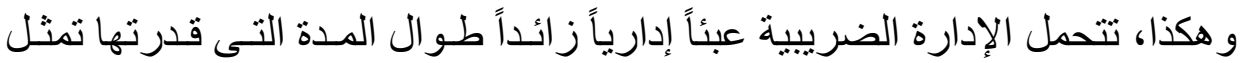

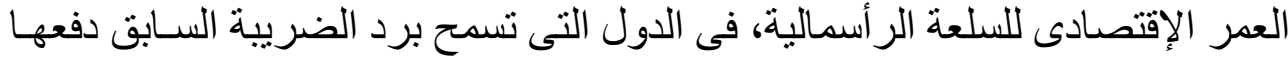

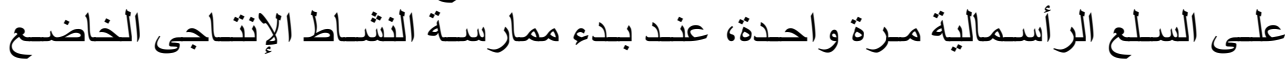

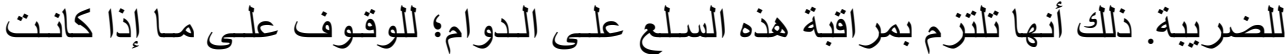

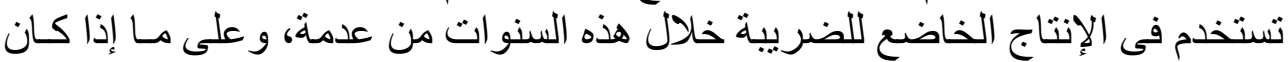

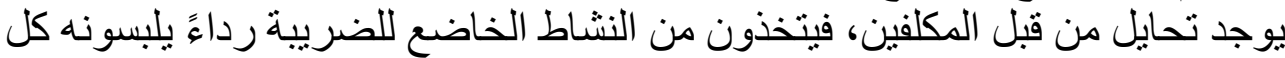

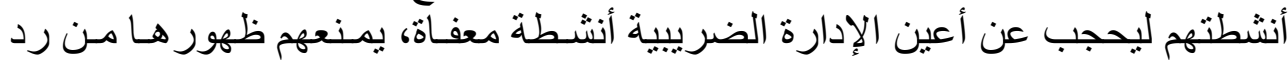

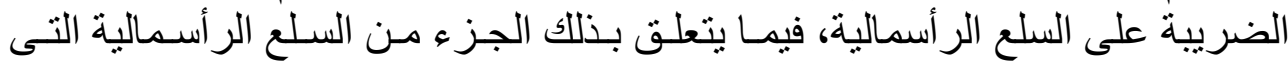

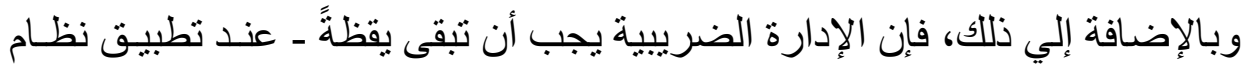

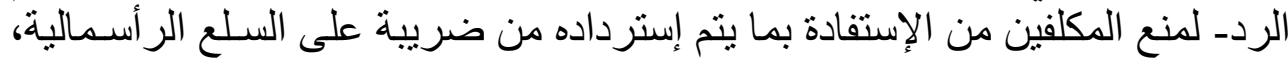

' - Ernst \& Young: International VAT..., op. cit. p. ${ }^{\wedge}$.

$r$ - Ibid. pp. ${ }^{Y}, V^{\prime}$.

$r$ - Ibid, p. $\vee$ T.

- Look too: Encyclopedia of value added tax..., op. cit. p. $0 . r r$. 
الإيتتمان الضريبي وآثارة الإقتصادية والمالية "دراسة مقارنة"

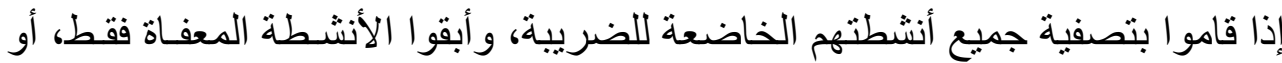

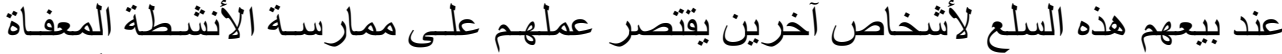

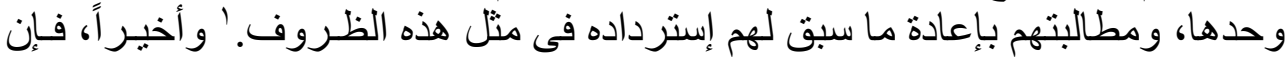

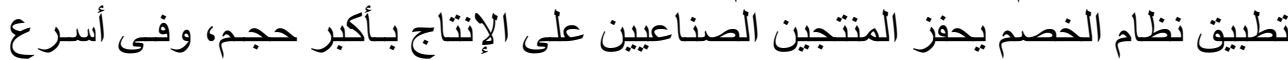

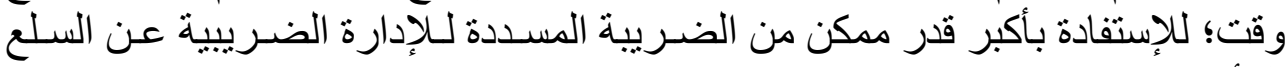

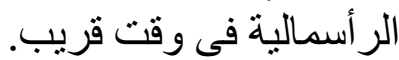

\section{المطلب الثاني}

\section{تطبيق الإنتمان الضريبي وآثاره علي تعاملات ما قبل الخضوع للضريبة}

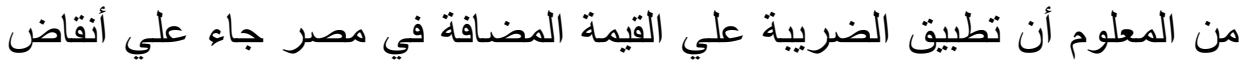

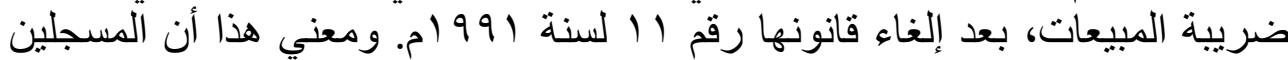

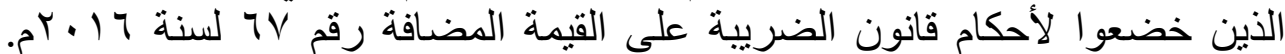

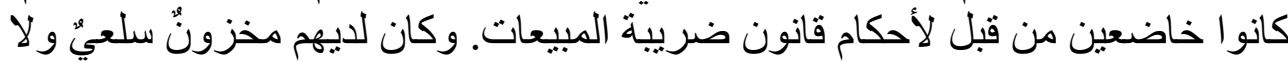

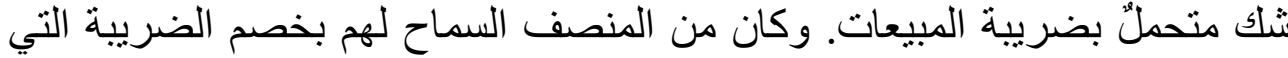

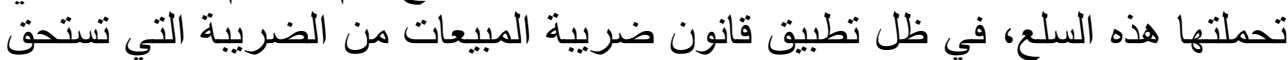

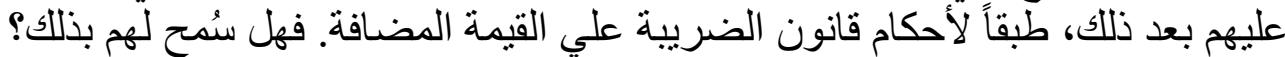

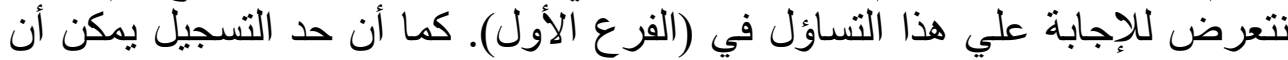

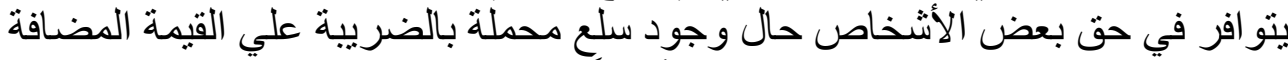

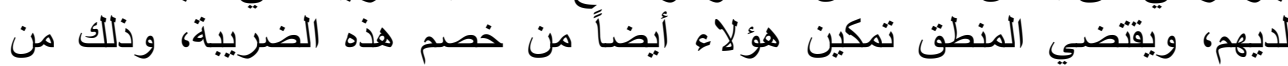

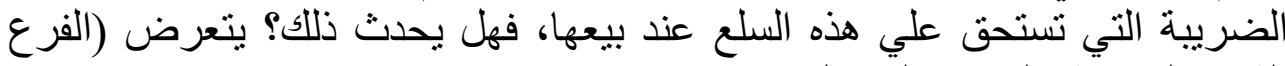
الثاني) للإجابة علي هذا التساؤل.

\section{الفرع الأول}

\section{تطبيق الإئتمان الضريبي وآثاره علي المشتريات المحملة بضريبة المبيعات الملغاة}

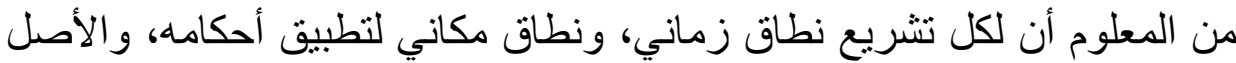

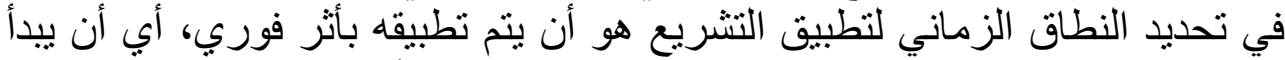

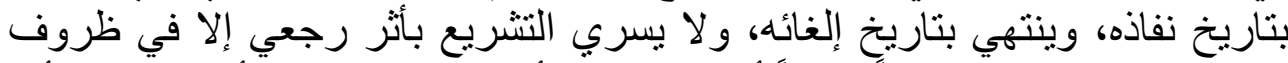

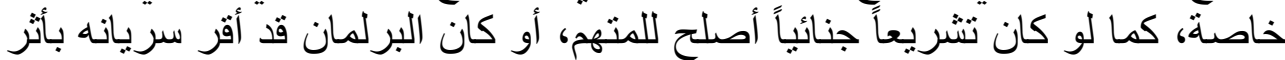

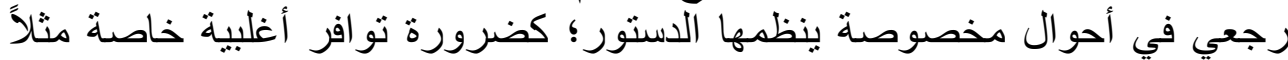

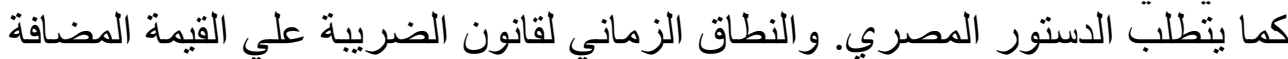

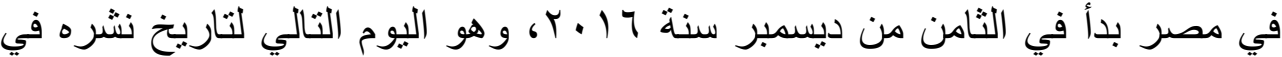

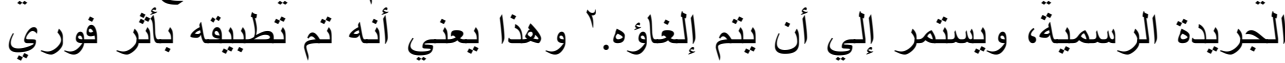

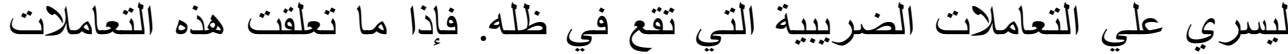

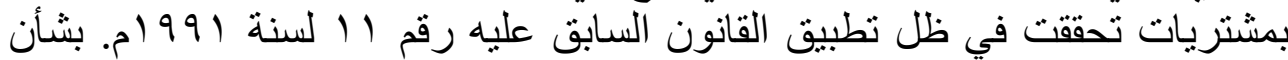

' - Ernst \& Young, international VAT, op. Cit. p. V) .

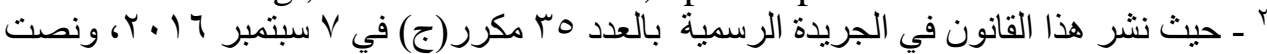

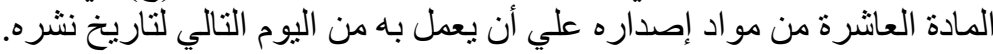


ضريبة المبيعات، فمن الطبيعي أن بطالب المسجل بضريبة القيمة المضافة المستحقة

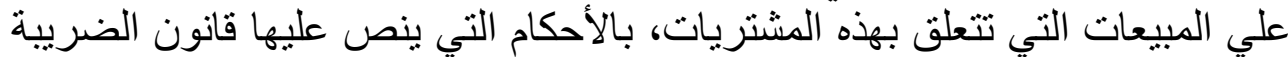

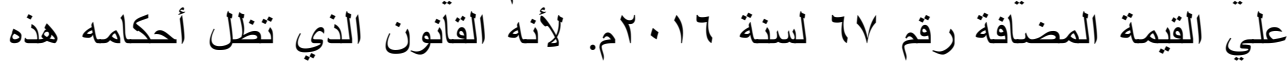
التعاملات؛ لاستحقاق الضريبة بتحقق و اقعة البيع باعتبار ها الواقعة المنشئة لها. وهنا لأها

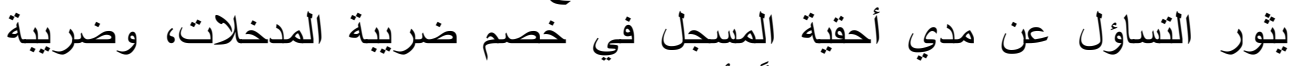

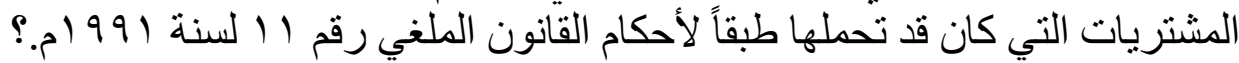

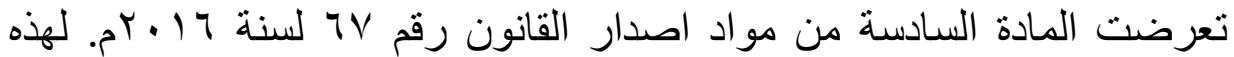
القضية، فنصت علي أنه: "للمسجل في ظل العمل بأحكام هذا القانون خصم قيمة الضريبة العامة على المبيعات الواجبة الخصم التي يعبر عنها الرصبد الدائن له قبل

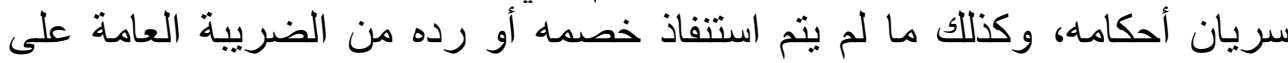

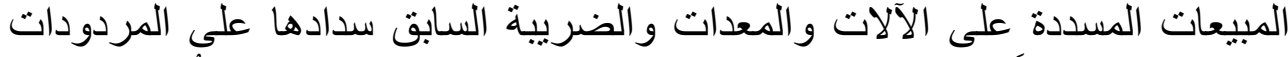

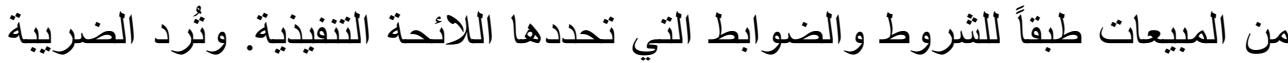

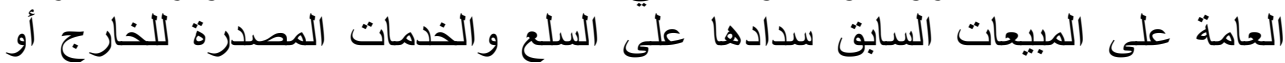

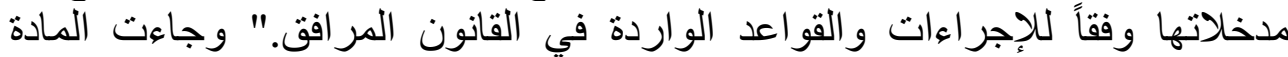

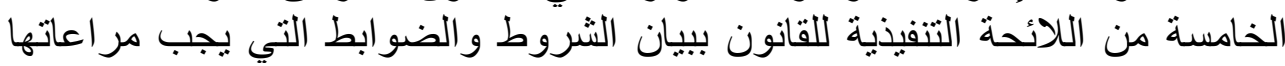
عند تطبيق الأحكام السابقة، فحددت هذه الشروط فيما يلي:

1 - إمساك دفاتر وسجلات محاسبية منتظمة.

r- حيازة أصول الفو اتير الضريبية أو شهادة الإجراءات الجمركية، وإيصال سداد الضريبة العامة علي المبيعات بالجمرلك الفراتير المختص.

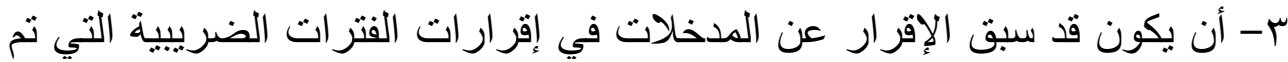

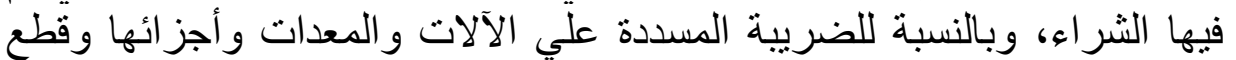

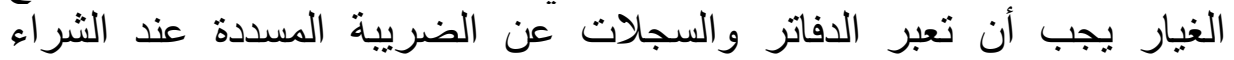
و الرصيد المتبقي بعد استبعاد ماتم خصمه بالإقر ار ات الثهرية الثرية.

ع - ألا تكون ضريبة المبيعات قد تم إدر اجها ضمن التكلفة.

ه- بالنسبة لمردودات المبيعات يجب ألا يخصم إلا ما سبق سدادة من ضريبة علي السلع المرتدة.

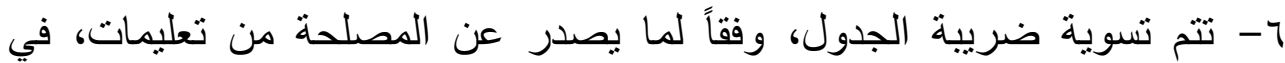

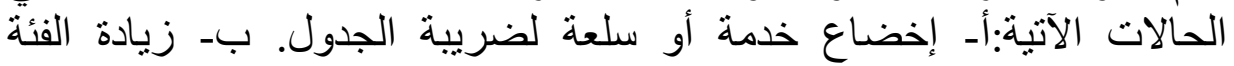

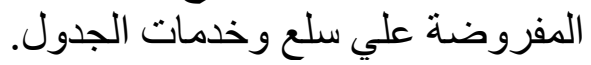

V- وفي جميع الأحوال لايسري حكم البند (r) من المادة (•r) من القانون علي الرصيد المذكور.

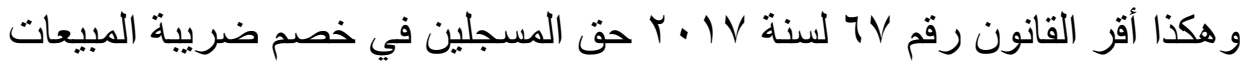

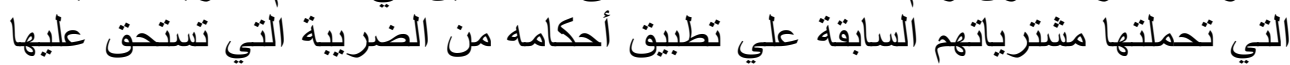


الإئتمان الضر يبي وآثارة الإقتصادية والمالية "دراسة مقارنة"

بالتطبيق لهذه الأحكام عند بيعها، بما في ذللك الضريبة المسددة علي السلع الر أسمالية.

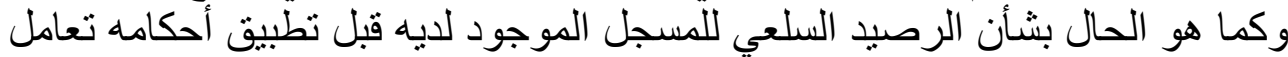

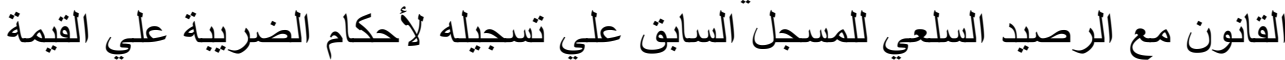

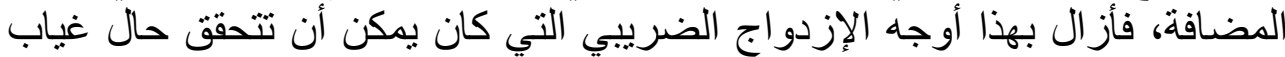
هذه المعالجة. ونفرد الفرع التالي لبيان ذللك.

\section{الفرع الثاني}

\section{تطبيق الإيتمان الضريبي وآثاره علي المخزون السلعي للمكلف قبل التسجيل}

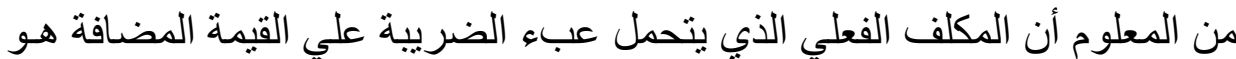

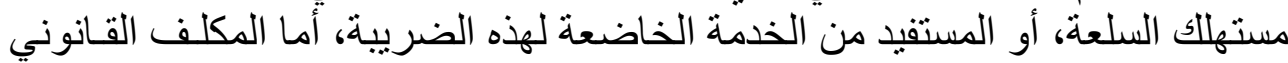

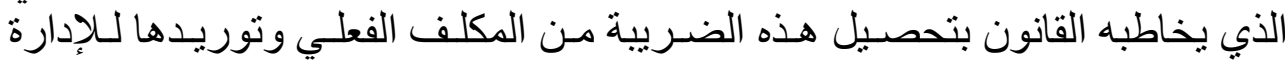

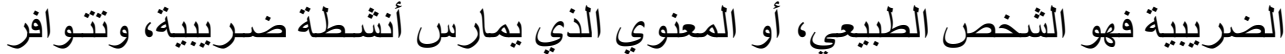

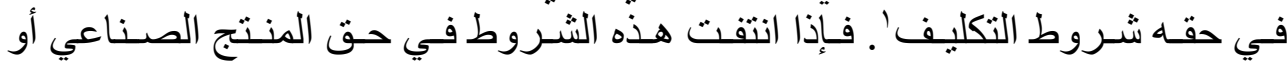

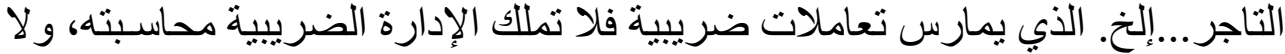

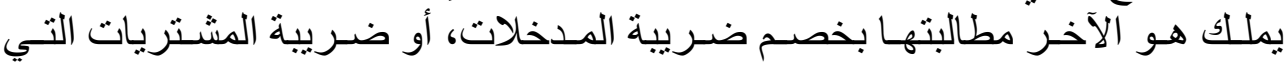
تتحملها تعاملاته الضريبية.

فإذا تو افرت شروط التكليف في حق المنتج الصناعي، أو التاجر مثلاً فبلغت قيمة فئهة

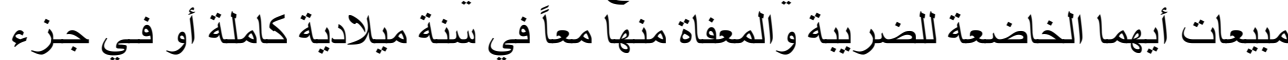

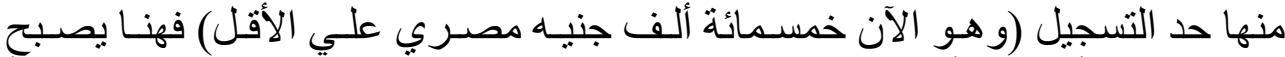

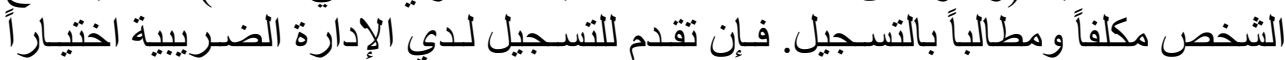

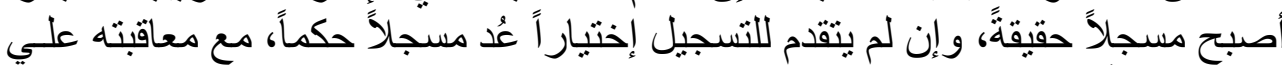

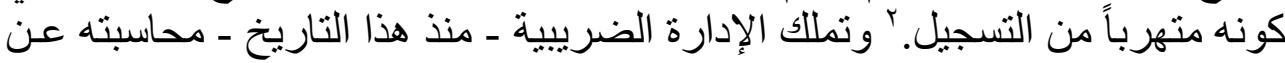

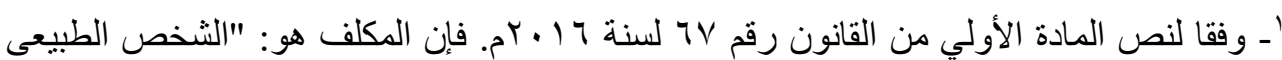

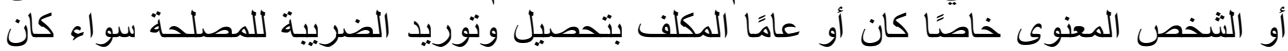

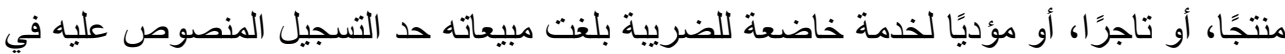

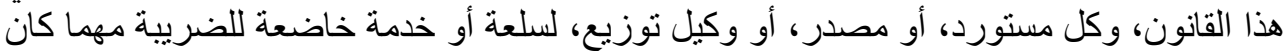

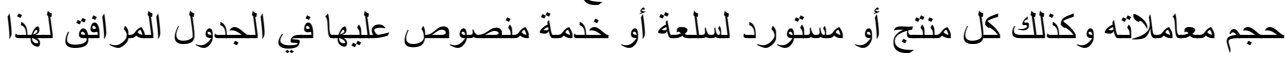

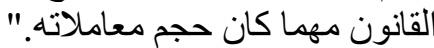

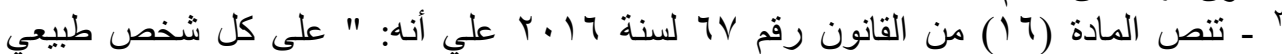

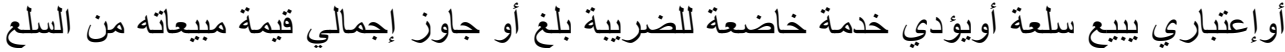

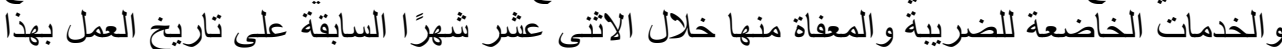

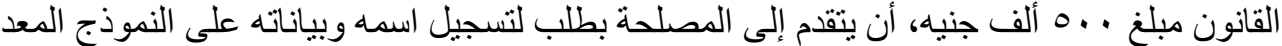

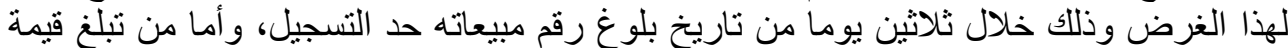

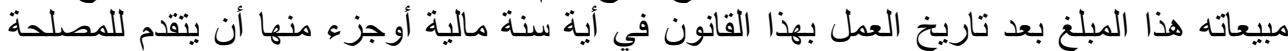

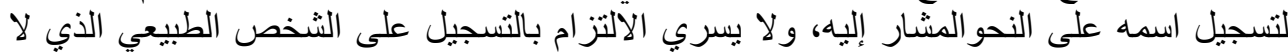

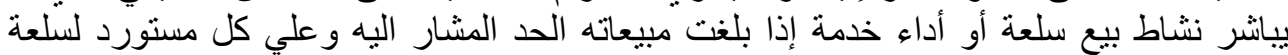

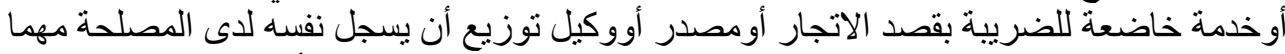

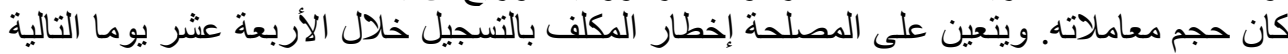
لتاريخ طلب التسجيل وتسري عليه احكام هذا القانون من تاريخ التسجيل. وفي حالة عدم تقدم 


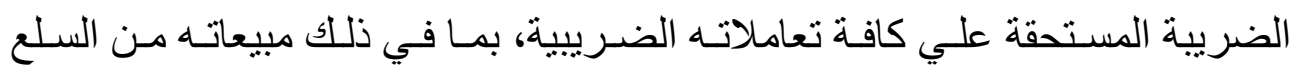

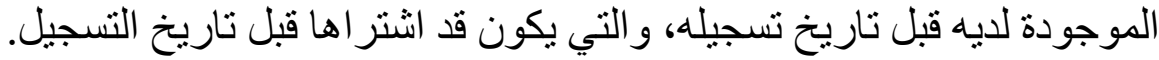

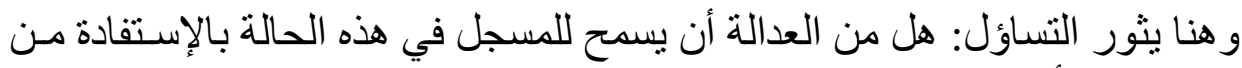

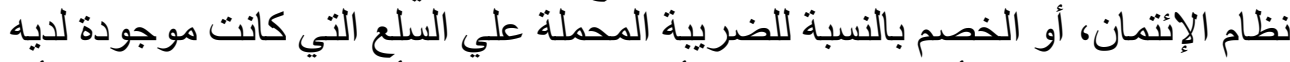

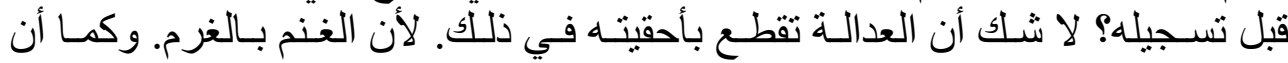

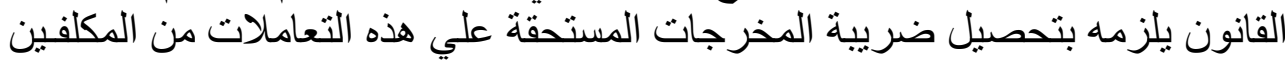

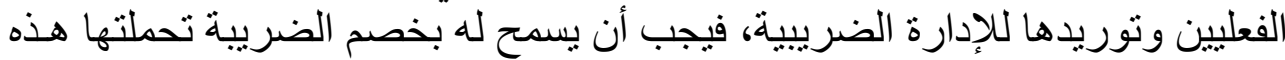

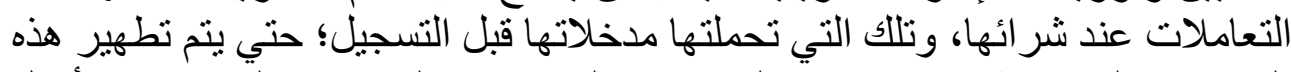

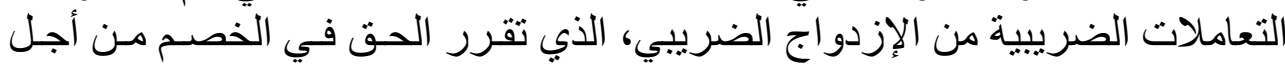

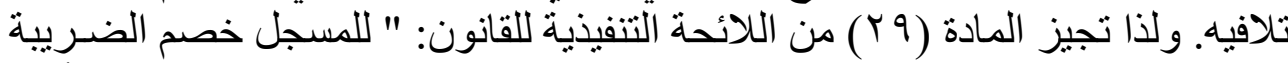

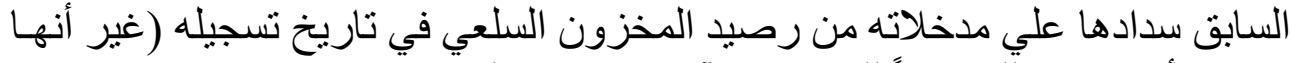

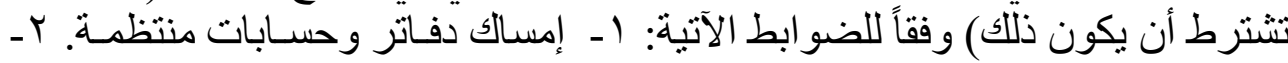

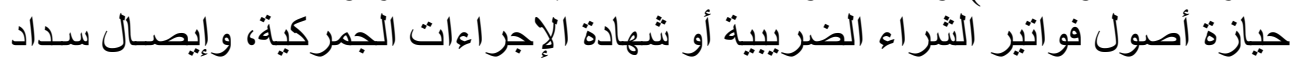

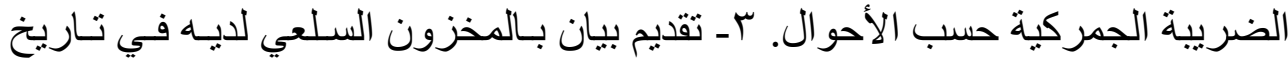

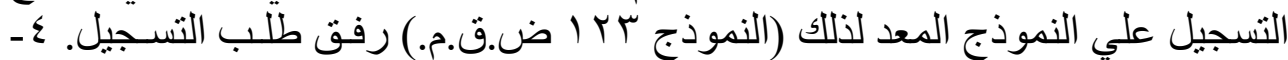

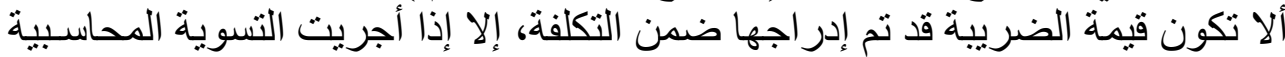

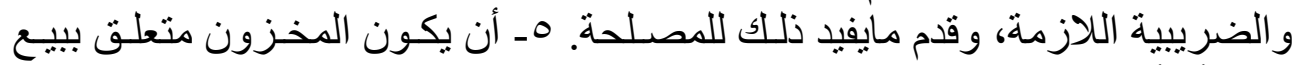
سلعة أو أداء خذمة خاضعة للضريبة ولغية.

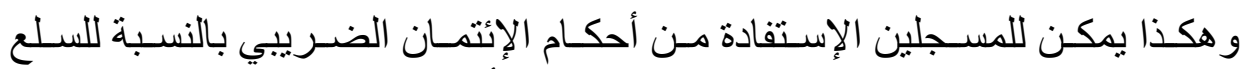

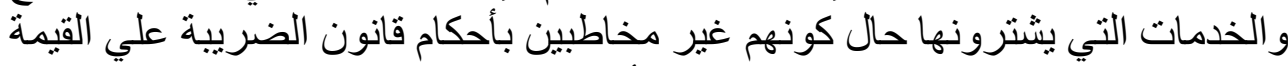

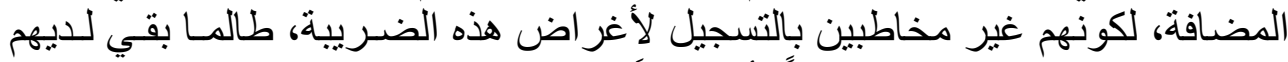

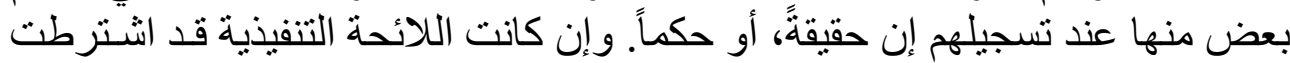

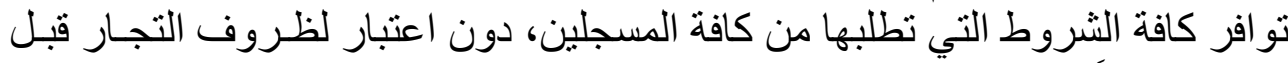

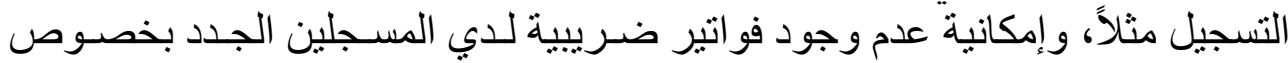

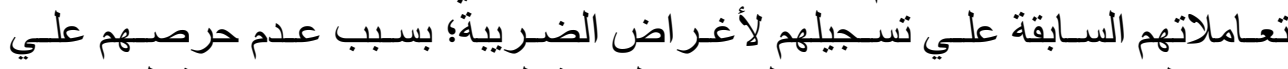

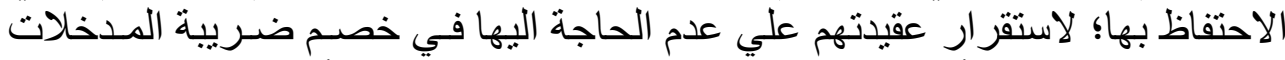

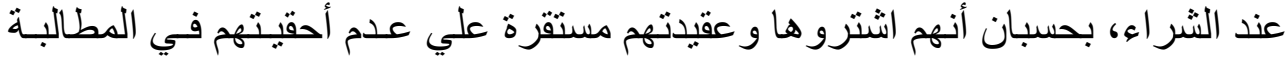

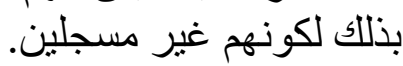

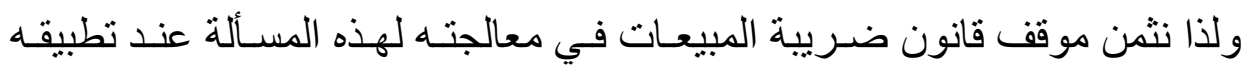

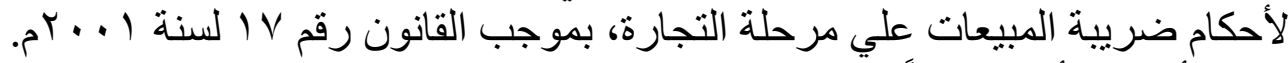

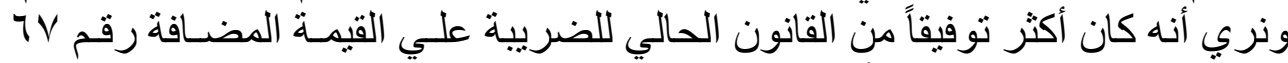

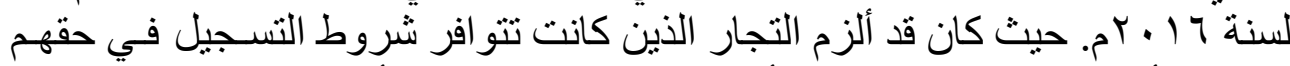

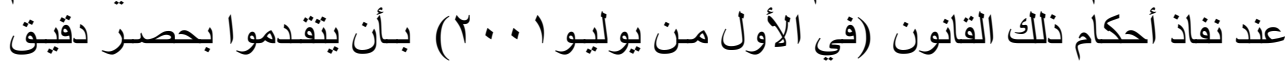

المكلف للصلحة للتسجيل بعد مسجلا بحكم القانون وتسري عليه أحكامه من تاريخ بلوغ ونام قيمة مبيعاته

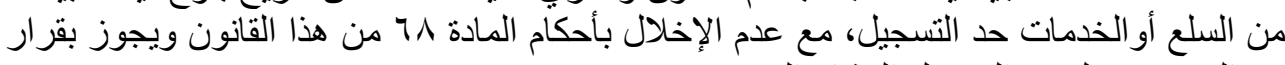
من الوزير تعديل حد التسجيل المشار اليه". 
الإئتمان الضريبي وآثارة الإقتصادية والمالية "دراسة مقارنة"

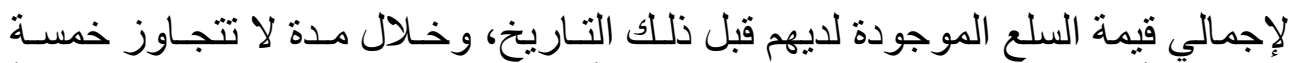

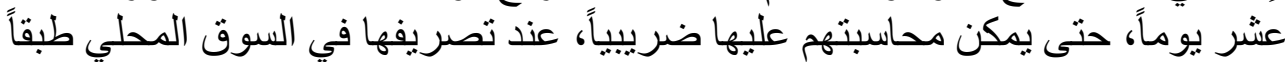

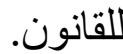

ولكن نظر اً لإستقر ارعقيدة ذلك القانون علي أن مجتمع التجـار يتميز بعدم إنتطسام

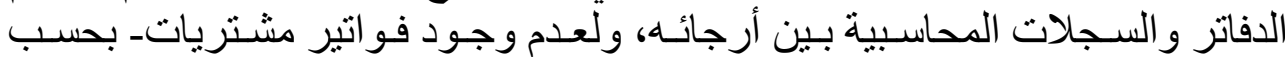

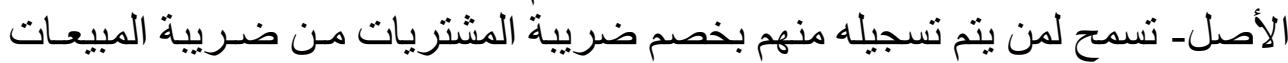

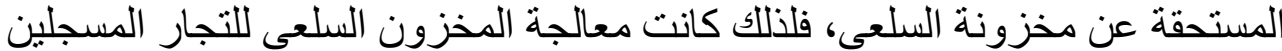

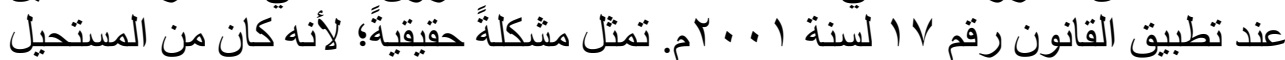

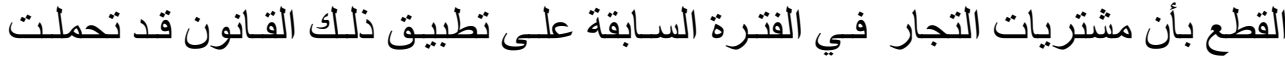

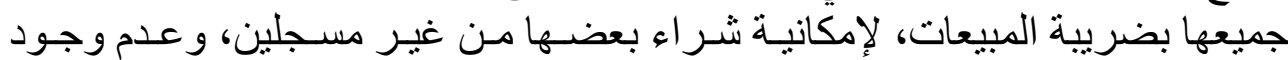

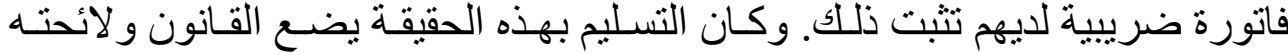
التنفيذية أمام عدة خيار ات:

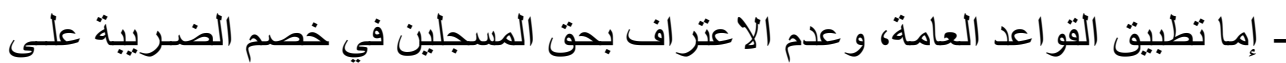

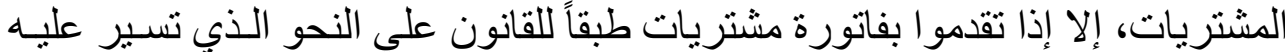

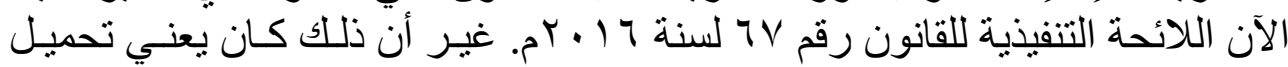

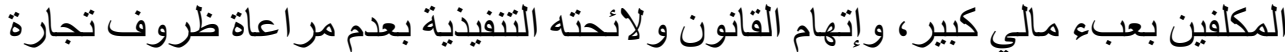
التجزئة.

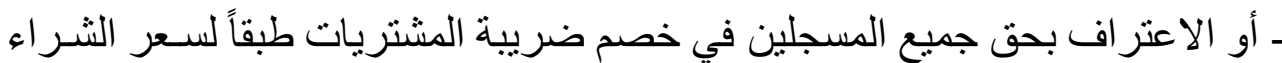

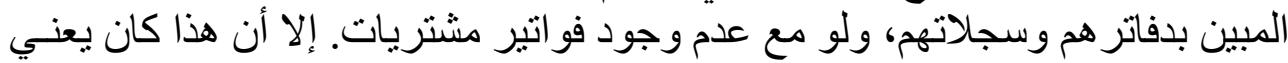

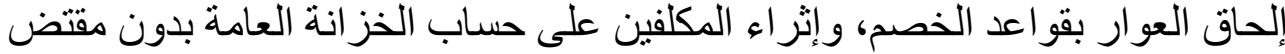

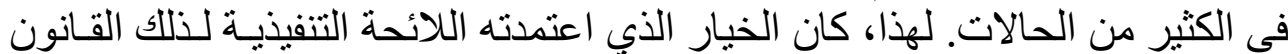
لمعالجة هذه المشكلة هو التفرقة بين حالتين:

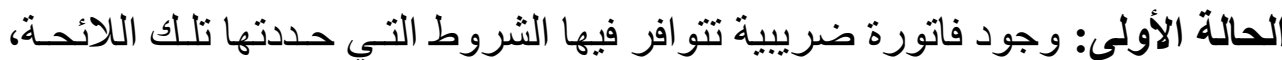

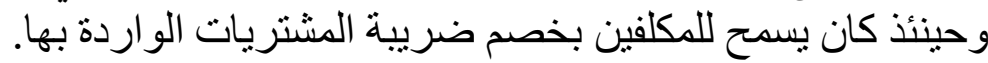

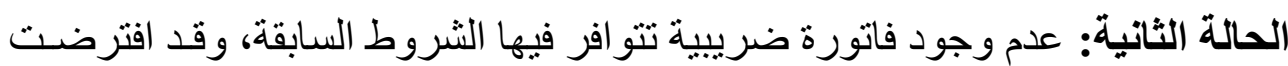

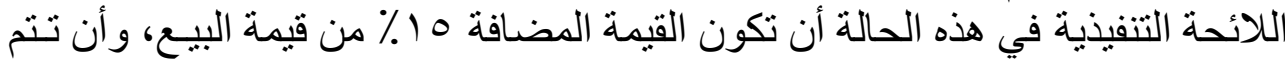

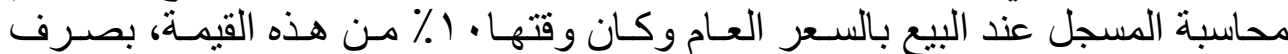

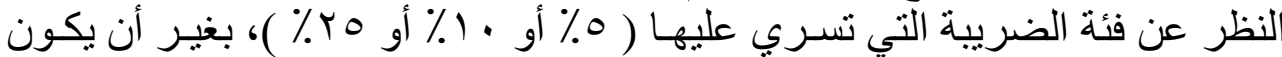

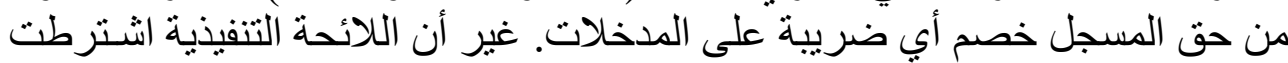

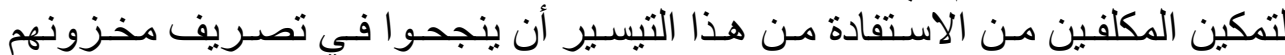

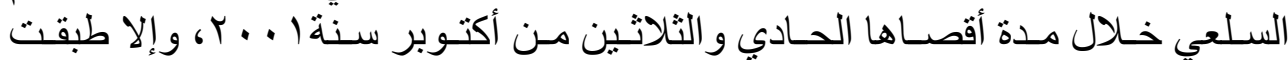

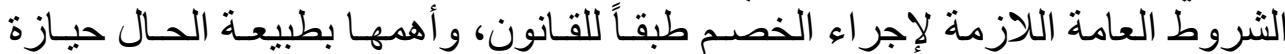
فاتورة ضريبية تثبت حقهم في خصم ضرية الترية المدخلات.

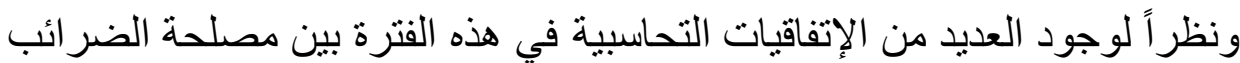

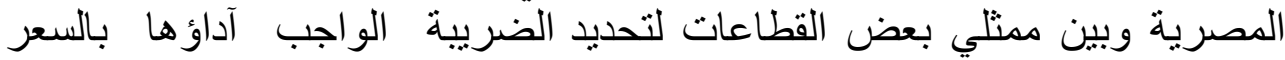


المحدد قانوناً من القيمة المضافة الافتر اضية التي قد تزيد أو تقل عن القيمة المضافة

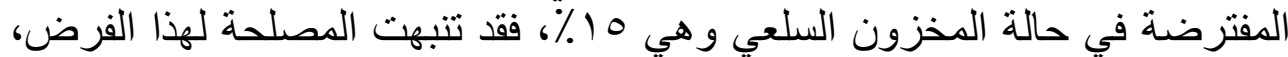

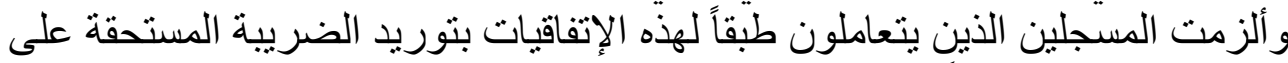

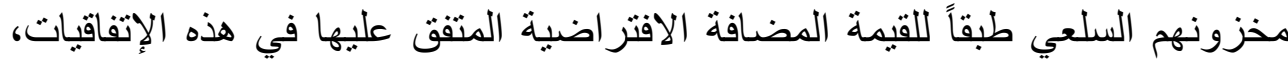

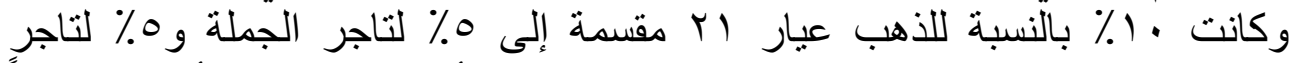

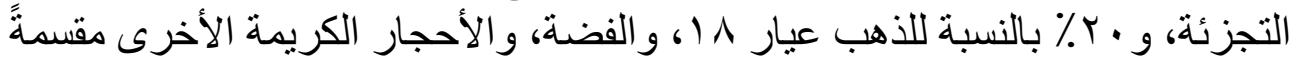

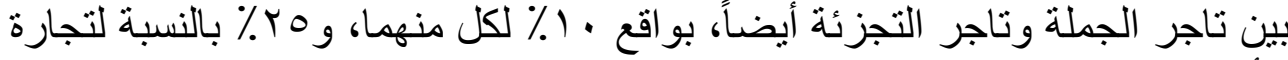
الأحذية و المنتجات الجلدية يخص تاجر الجملة منها ه٪؛ و الباقي لتاجر التجزئة ...

و لا شك أن هذا المنطق كان محموداً، ذلك أن القيمة المضافة المفترضة محل

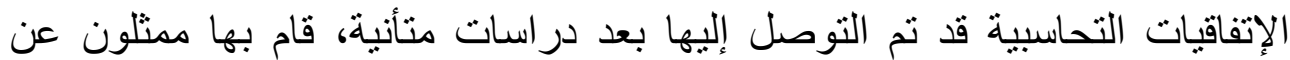

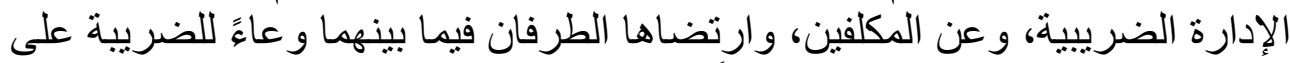

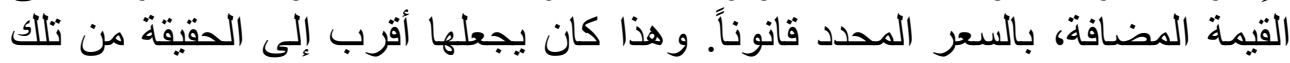

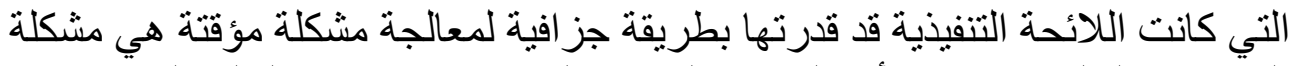

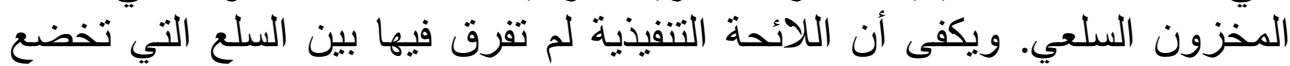

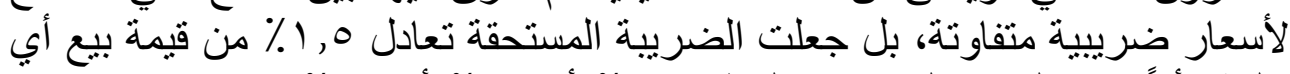

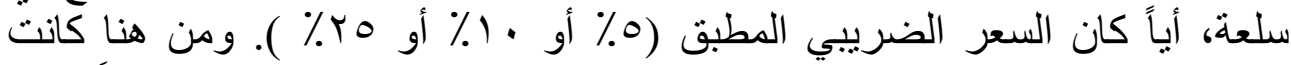

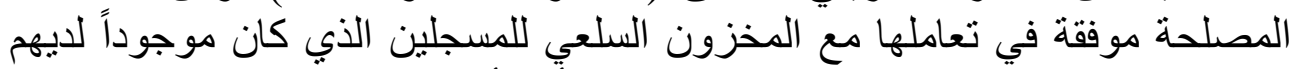

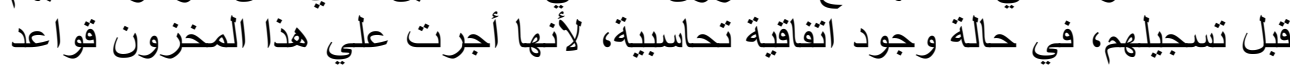

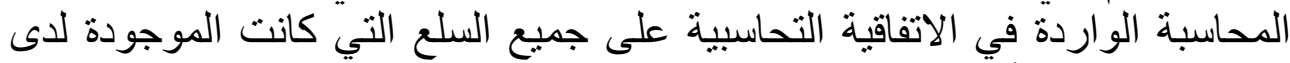
التجار سواء قبل، أو بعد سريان الضريبة الفائة على مرحلة التجارة.

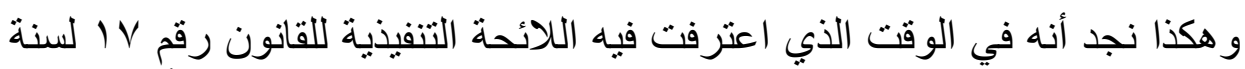

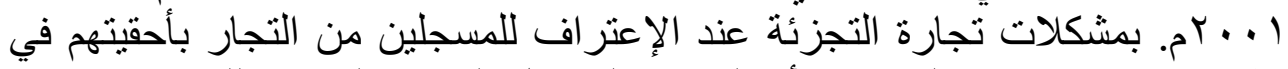

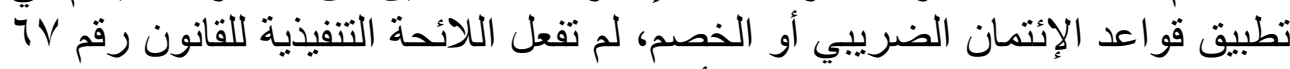

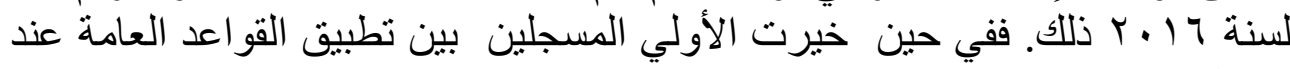

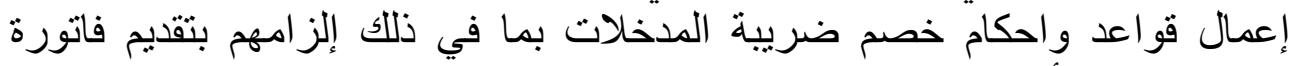

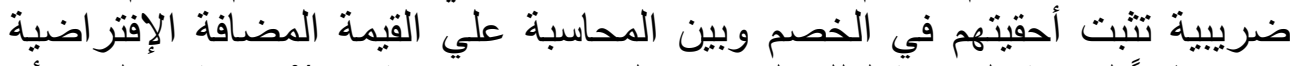

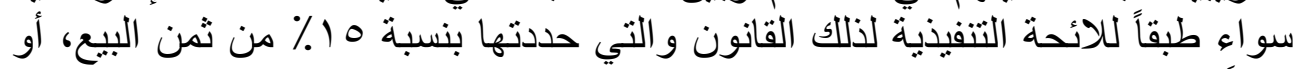

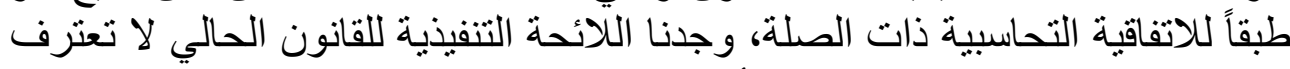

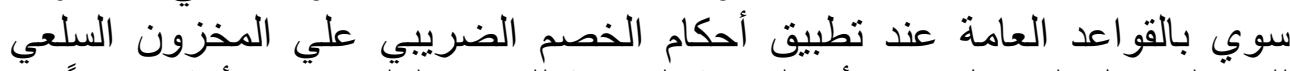

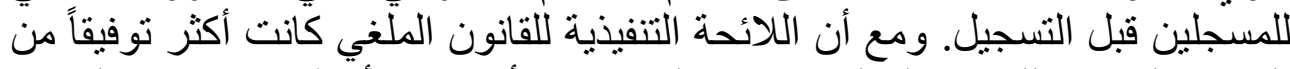

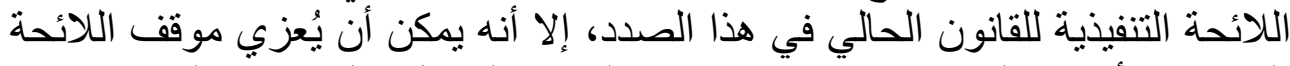

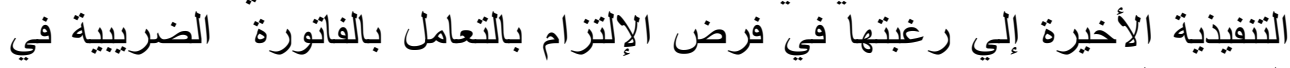
المجتمع الضريبي.

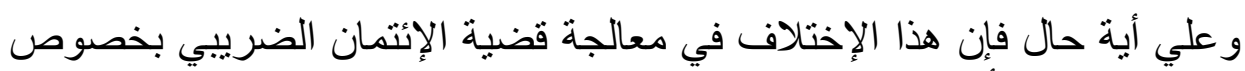

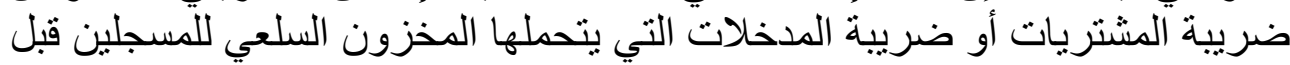

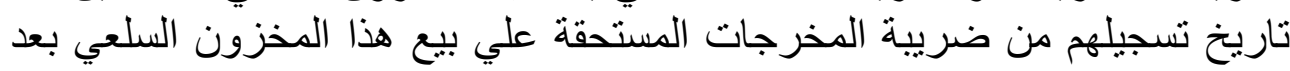


الإيتمان الضريبي وآثارة الإقتصادية والمالية "دراسة مقارنة"

تاريخ التسجيل لا يمنع من صو اب موقف كلتا اللائحتنين حين سمحتا للمسجلين بتطبيق

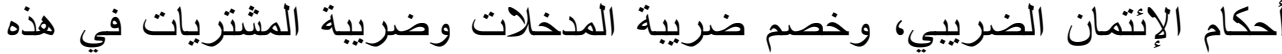

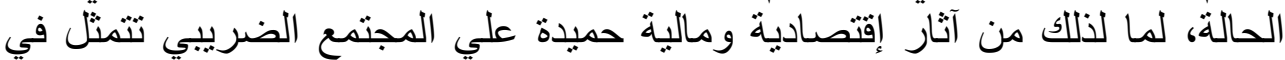
إزالة كافة أوجه الإزدواج الضريبي، حتي النانشئ منها عن التعاملات النية النسابقة علي فئي

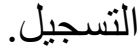

و هكذا فإنه كما أن الفصل الأول من هذا البحث قد ألقي الضوء علي الضي الإنتمان

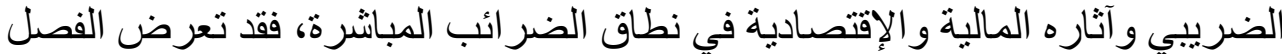

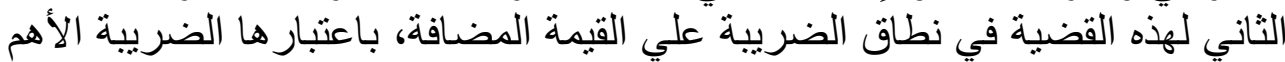

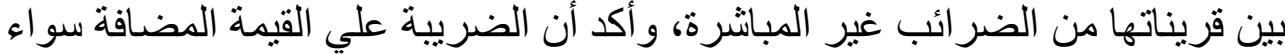

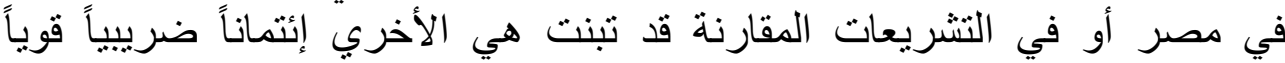

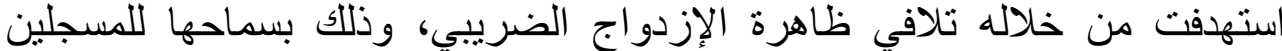

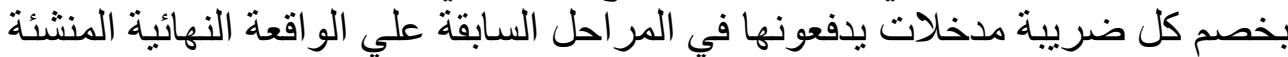

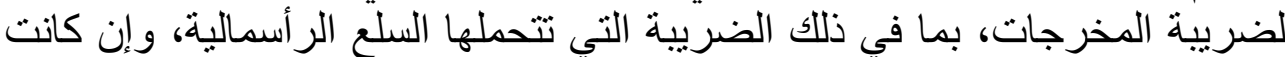

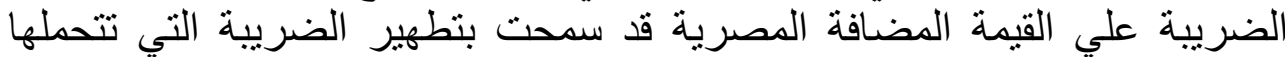

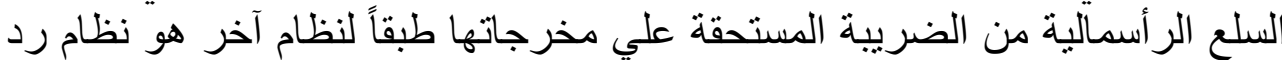

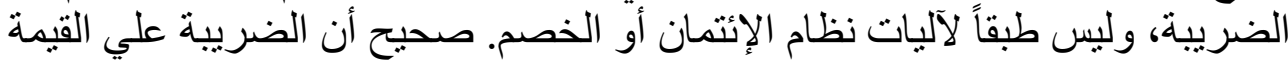

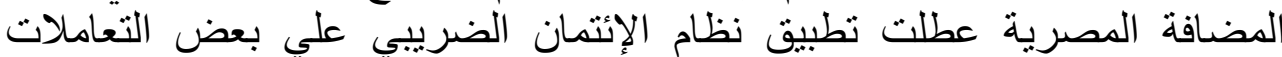

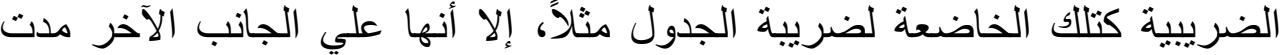

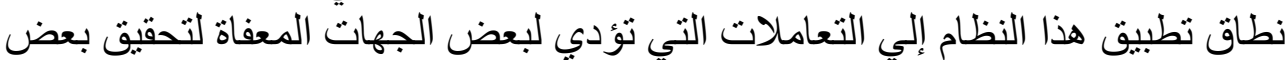

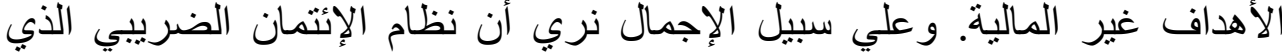

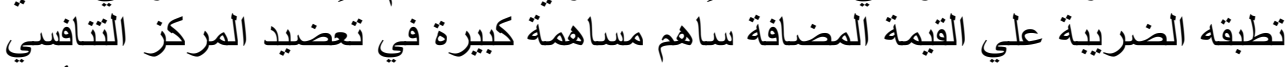

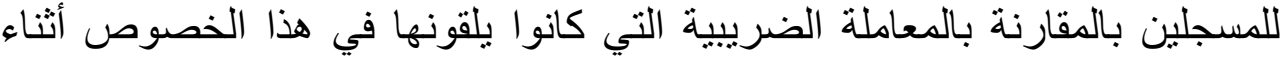
سريان الضريبة العامة علي المبيعات السابقة عليها.

\section{الخاتمة}

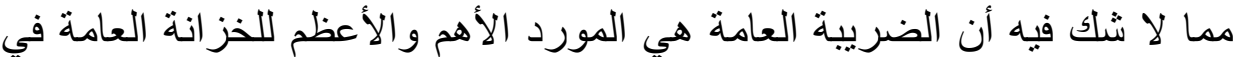

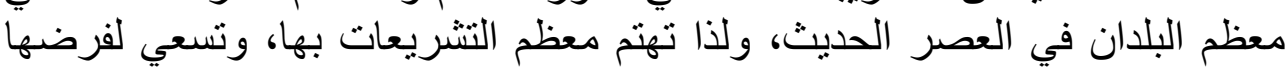

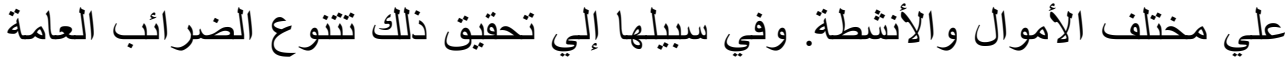

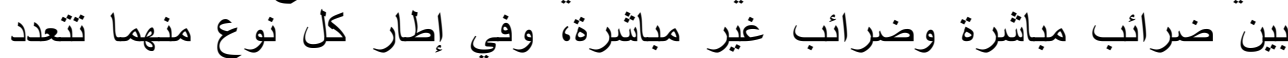

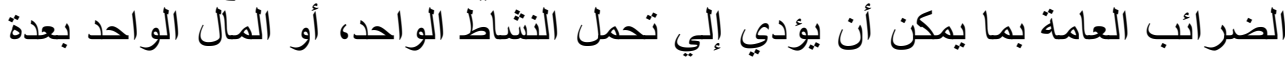

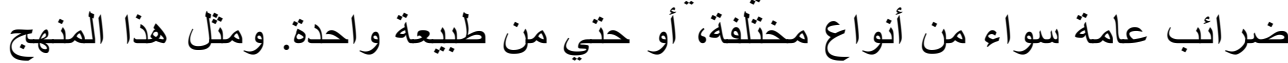

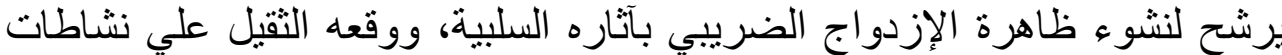

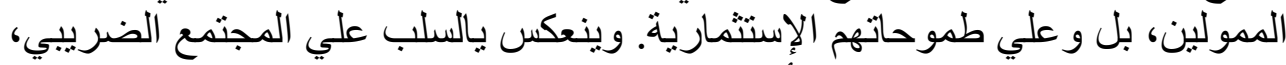

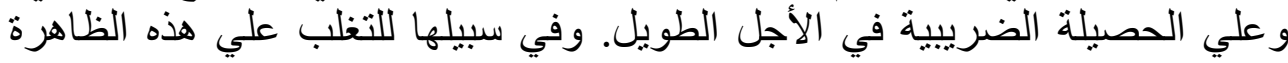

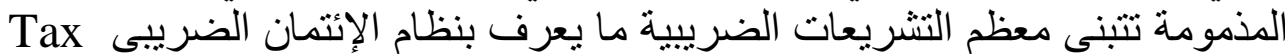

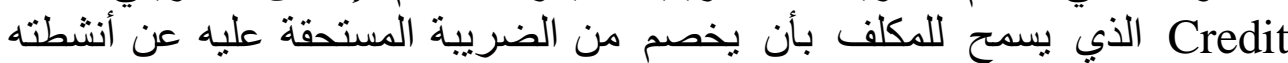

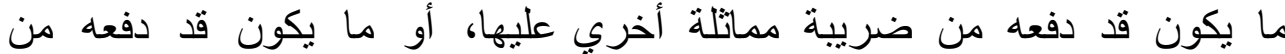
ضريبة من جنسها خلال مر احل سابقة من ممارسته لهذه الأنشطة. 
وقد تعرض البحث للإئتمان الضريبي بهذا الوصف سواء في نطاق الضرائب

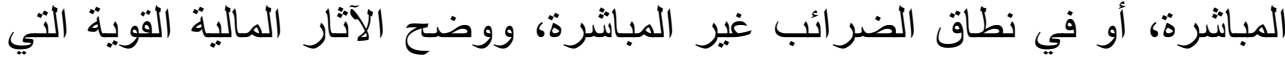

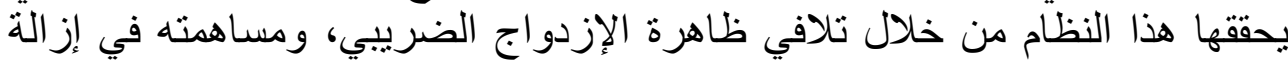

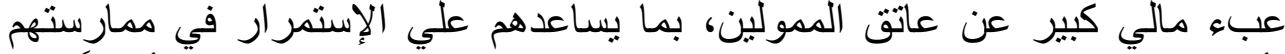

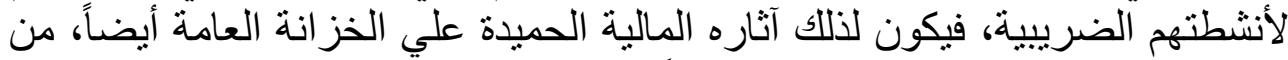

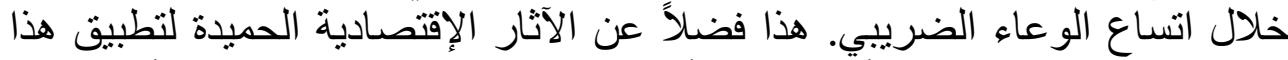

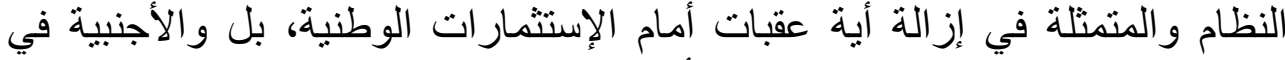

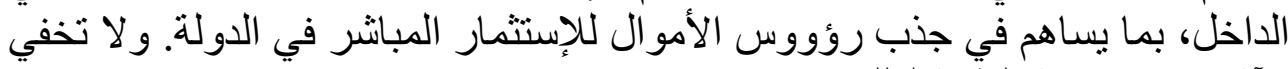
الآثار الإقتصادية الطيبة لذلك.

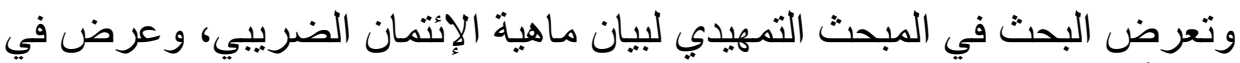
عجالة لأهم الفروق بينه وبين غيره من المفاهيم الضريبية المشابهة له؛ كالعفو

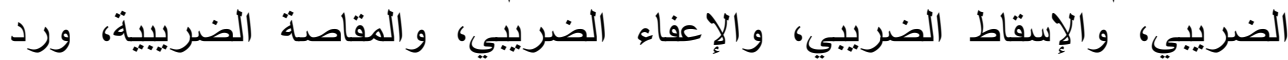

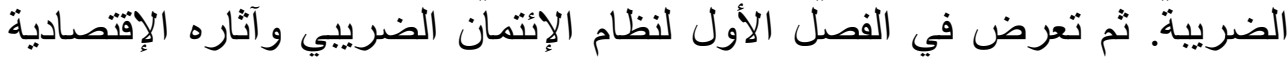

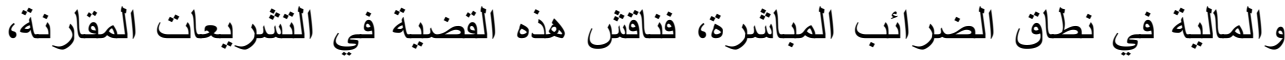

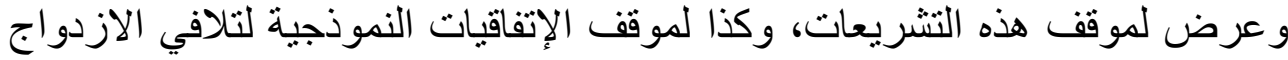

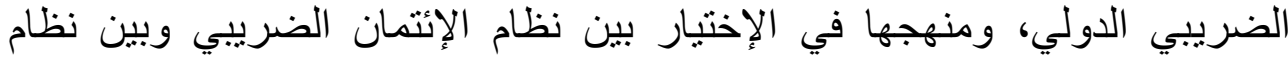

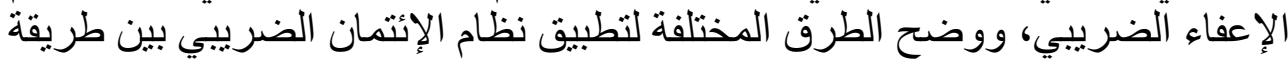

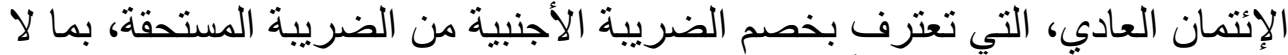

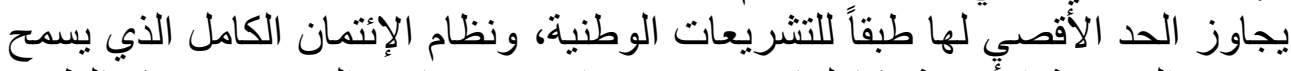

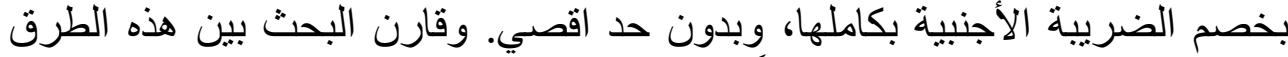

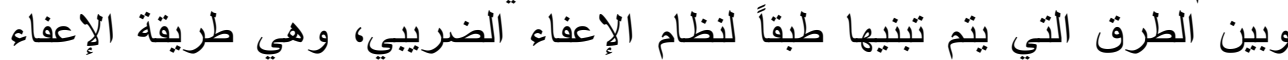

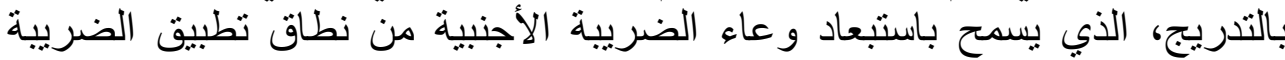

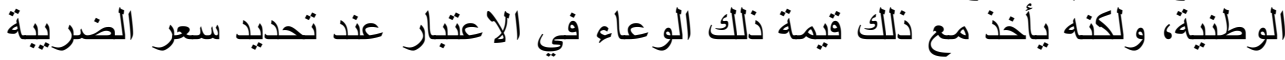
الوطنية. وطريقة الإعفاء الكامل، التي تسقط من حسبان الضريبة الوطنية الواءية كامل و عاء الضريبة الأجنبية.

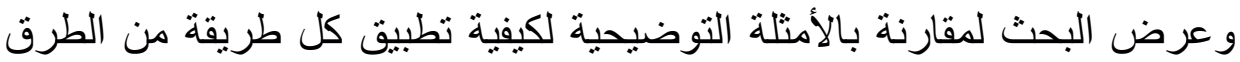

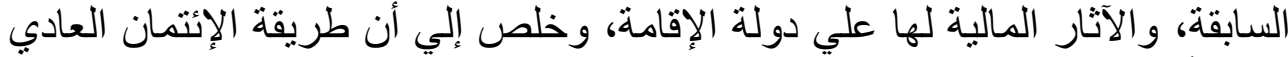

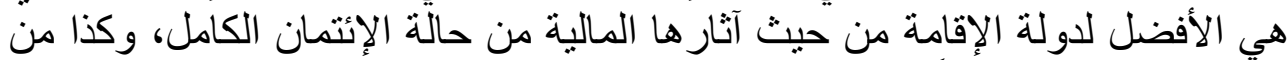

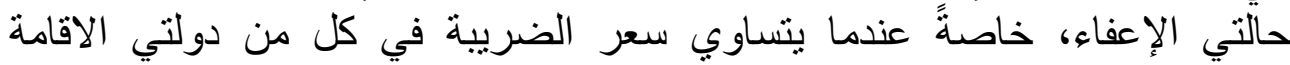

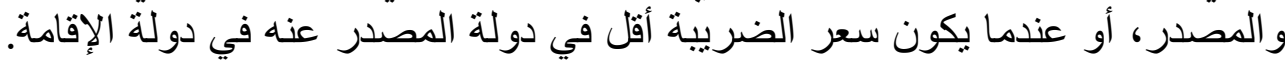

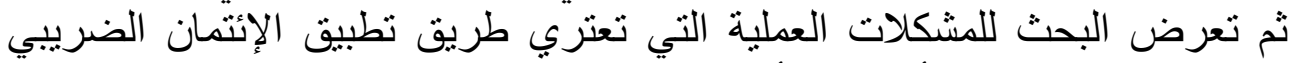

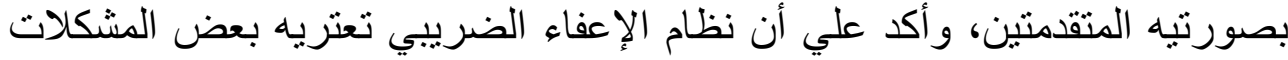
العملية هو الآخر.

وفي ضوء إعتياد التشريعات الضريبية، وبخاصة في الدول النامية، علي تطبيق

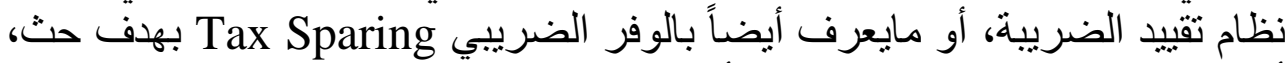

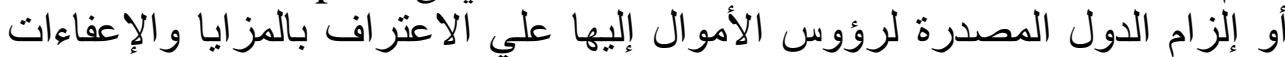

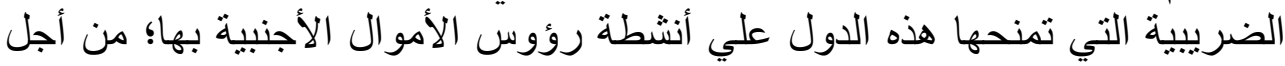


الإيتمان الضريبي وآثارة الإقتصادية والمالية "دراسة مقارنة"

تحفيز ها علي الإستثمار فيها، بحيث تتعامل الدول المصدرة لرؤوس الامو ال مع هذه فئه

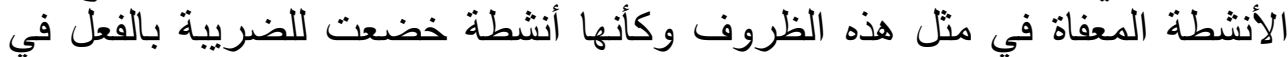

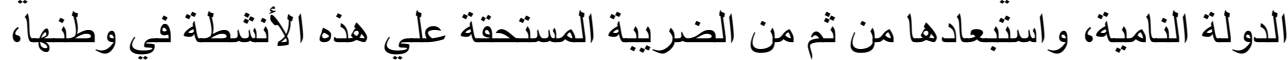

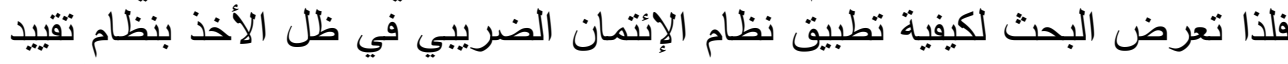

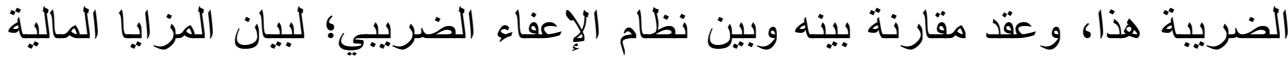

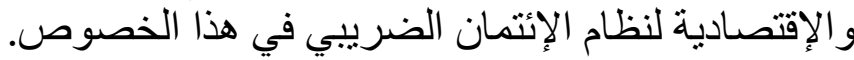

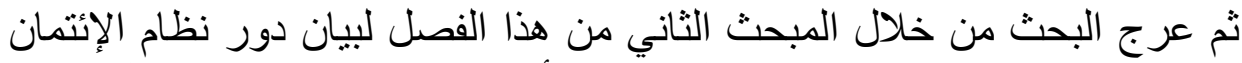

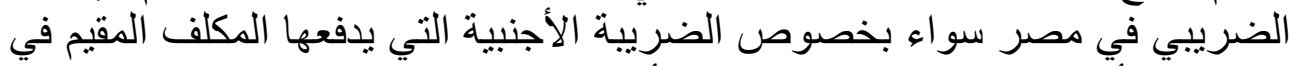

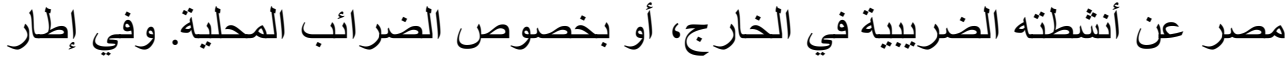

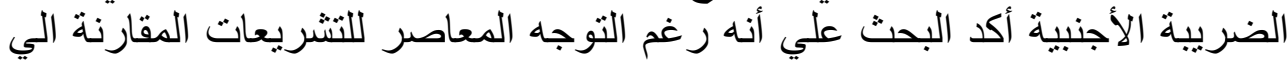

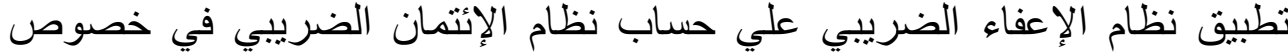

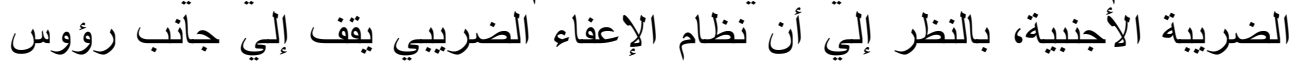

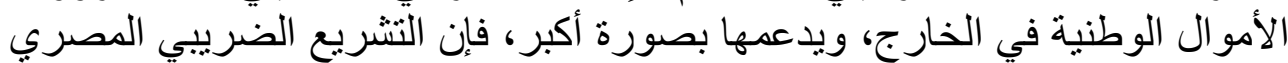

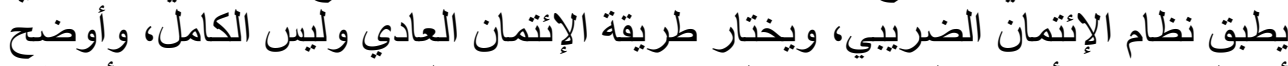

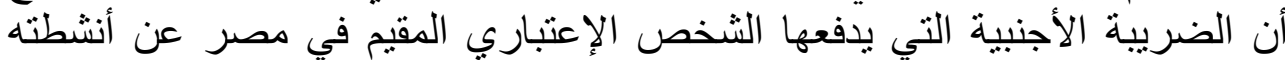

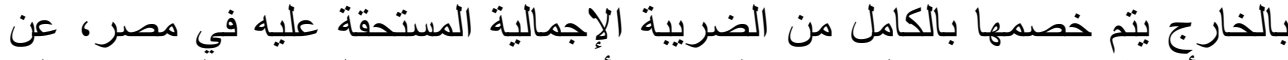

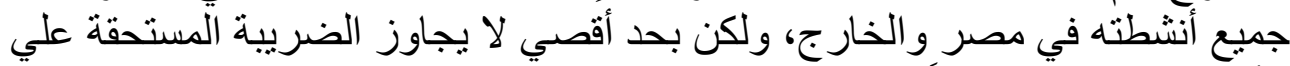

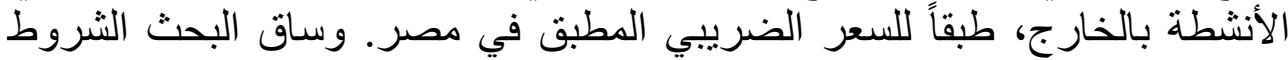

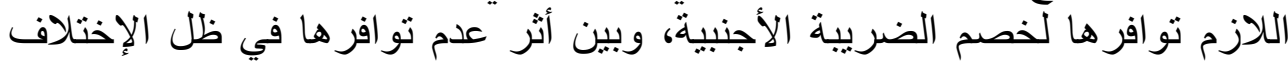
الفقهي بهذا الخصوص، والآنار المالية لذلك.

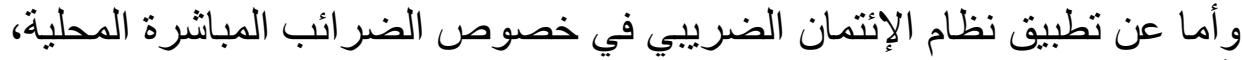

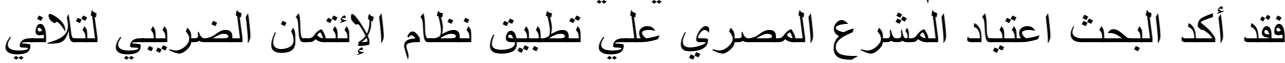

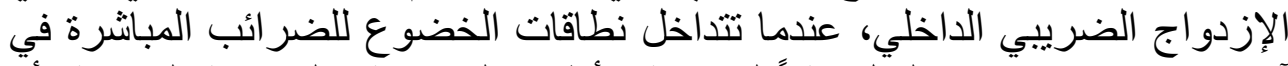

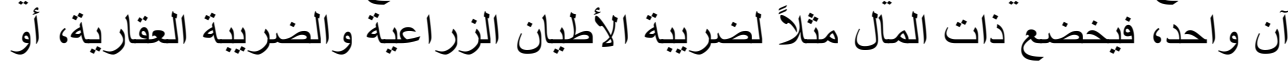

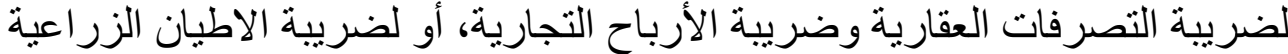

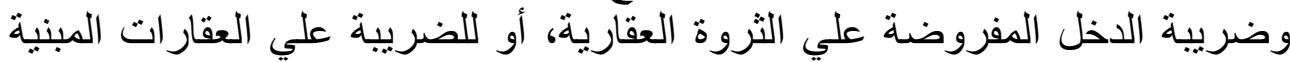

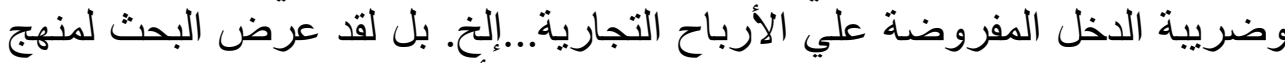

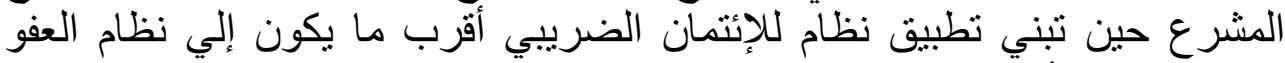

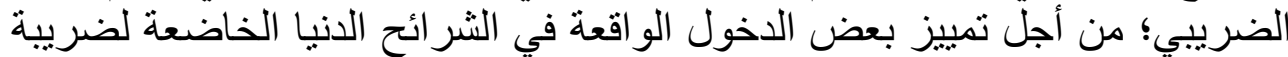
الاخل. وساق الأمثلة التوضيحية لبيان ذلك، ووضح الآثار المالية والاقتصادية التئية السلبية

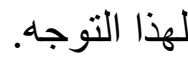

ثم جاء الفصل الثاني من البحث ليلقي الضوء علي نظام الإيتمان الضريبي كما

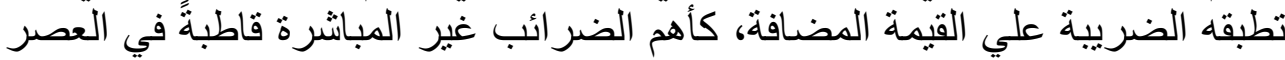

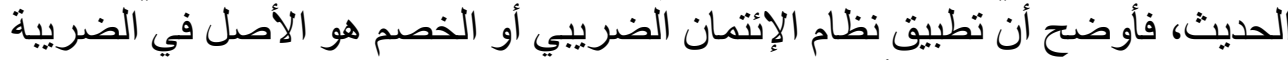

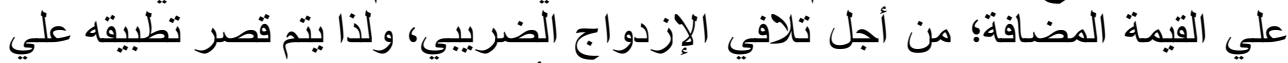

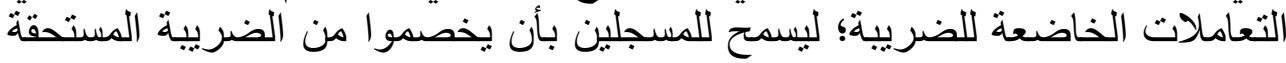

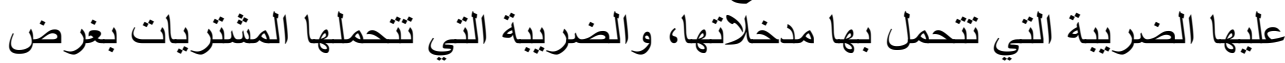




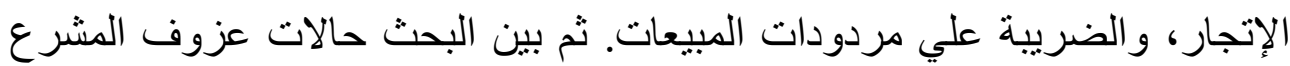

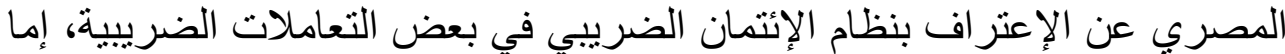

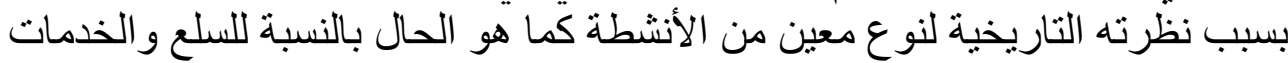

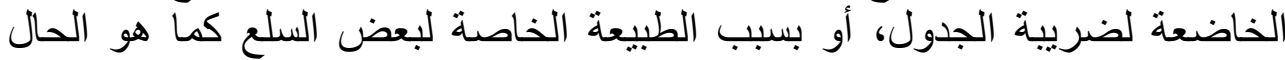

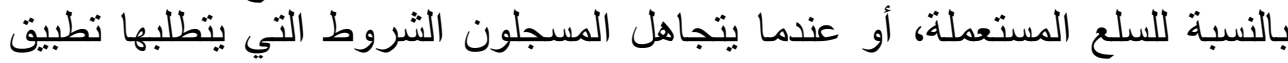

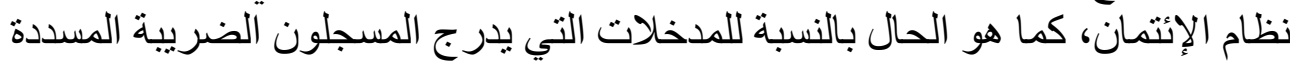

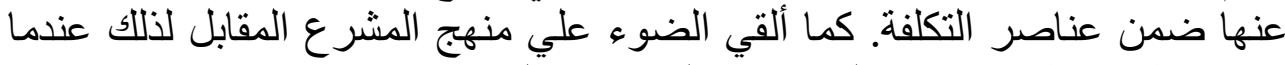

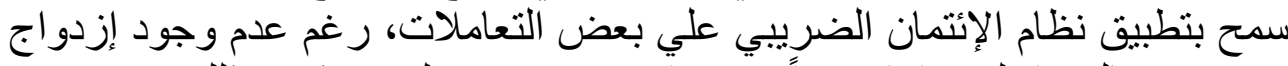

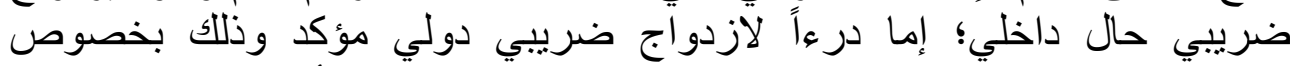

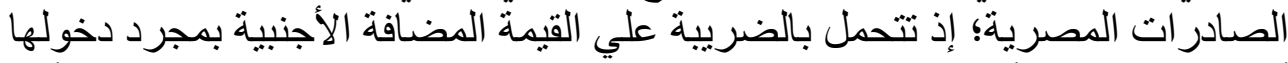

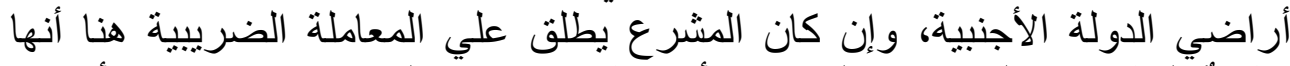

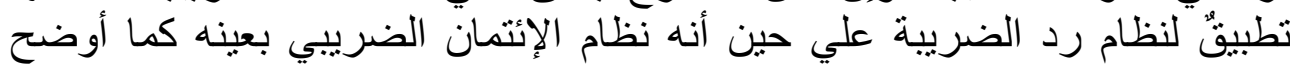

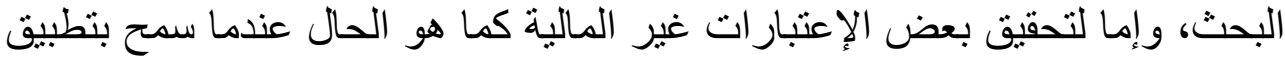

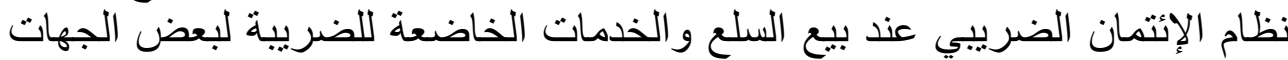

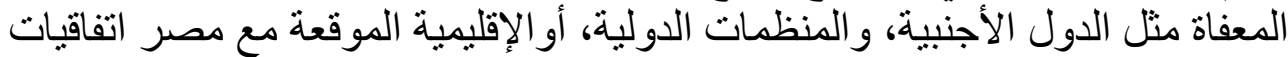

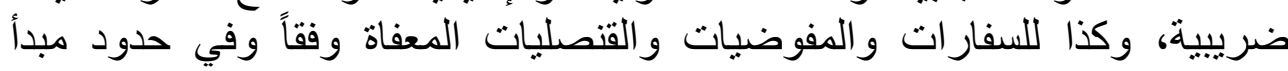

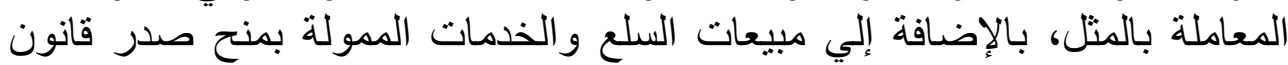

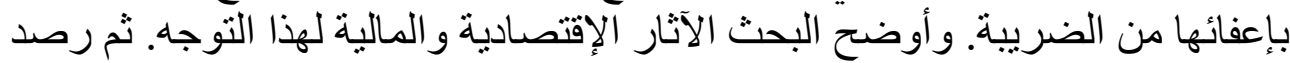

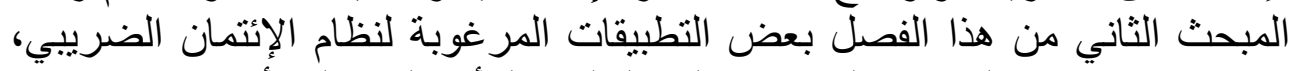

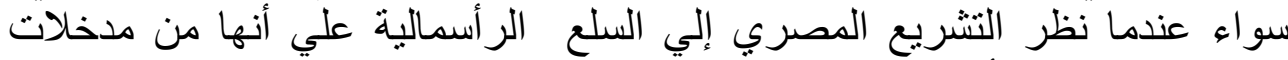

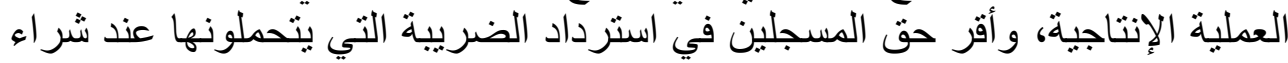

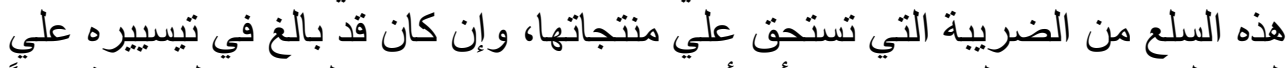

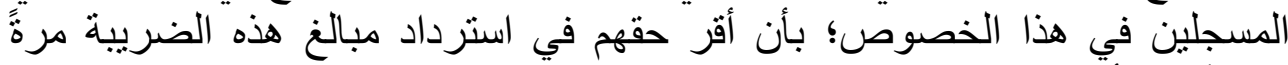

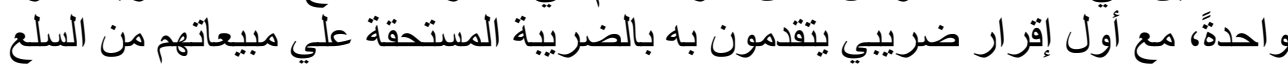

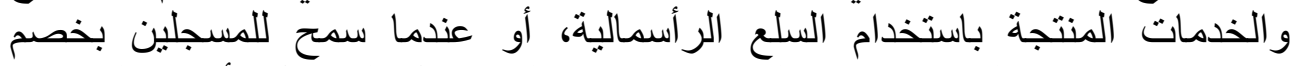

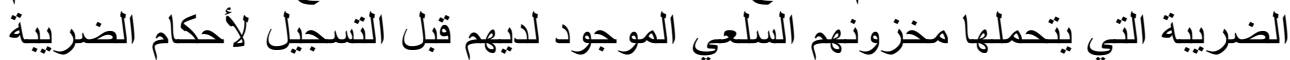

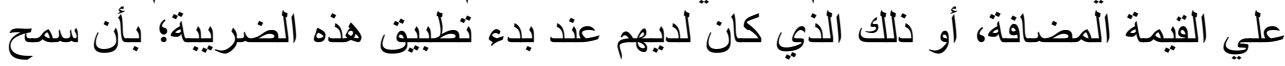

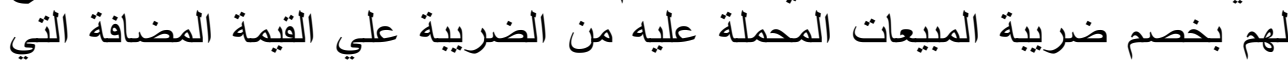
تستحق عليهم عند بيعهم لهذا المخزون السلعي فيما بعد، والآثار المالية والإقتصادية الفية الئية

وهكذا يكون هذا البحث قد ألقي الضوء علي نظام الإنتمان الضريبي كما تطبقه

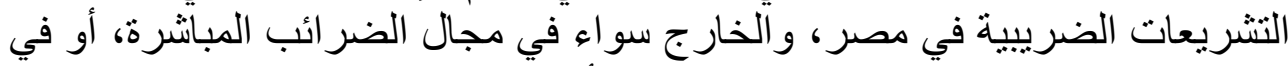

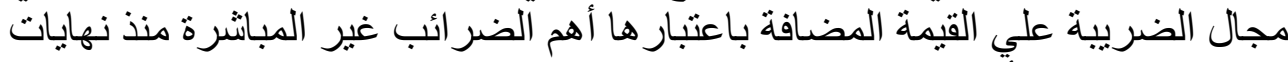

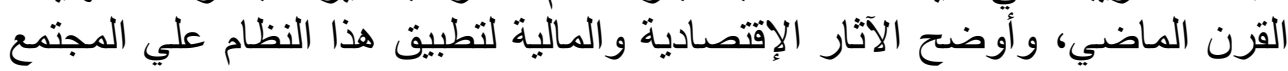
الضريبي، و علي الخز انة العامة للأولة في ذات الإنة الوقت.

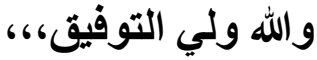




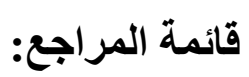

أولاً: المراجع باللغة العربية: إيز

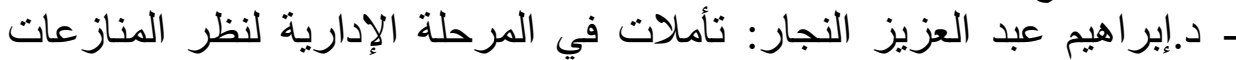

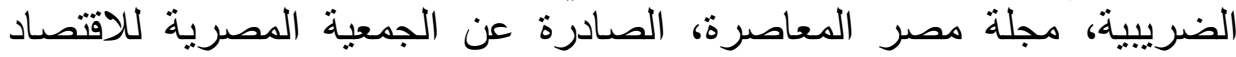

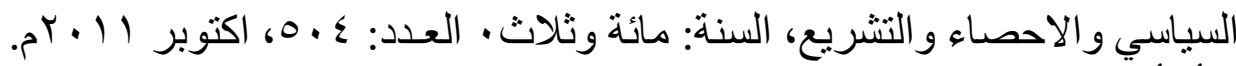

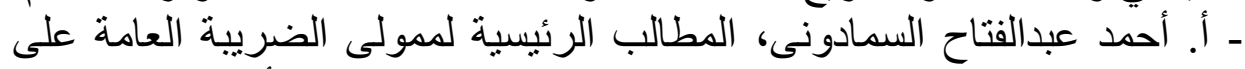

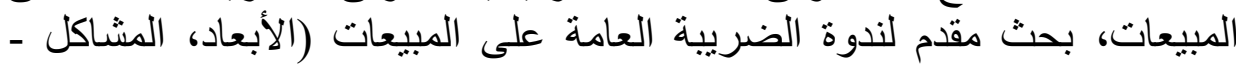

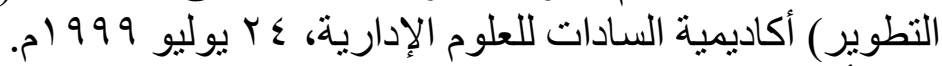

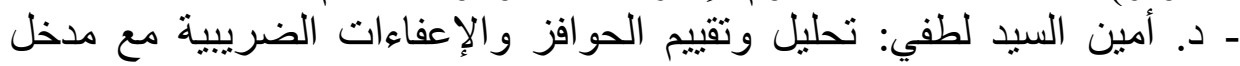

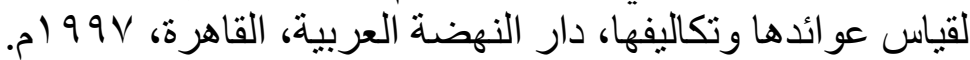

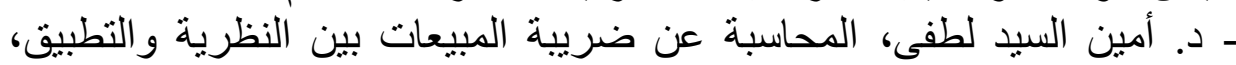

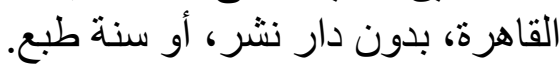

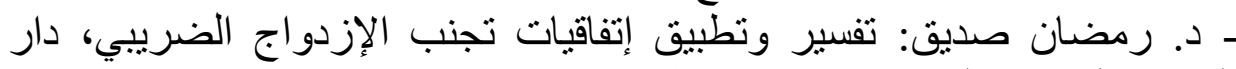
النهضة العربية، القاهرة، بدون سنة فئن طبع.

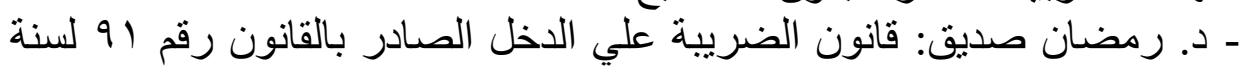

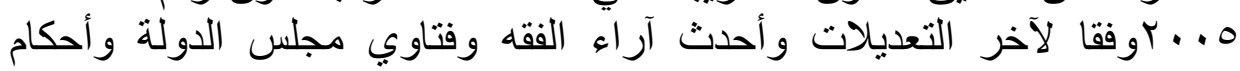

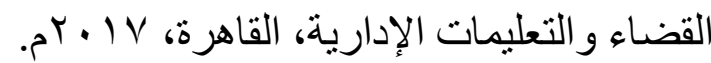
ـ د. رمضان صديق محمد: المعاملة الضريبية للإنشركات الإستخر اجية، رسالة

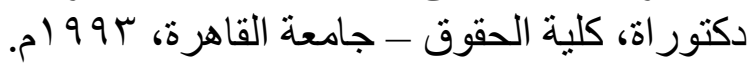

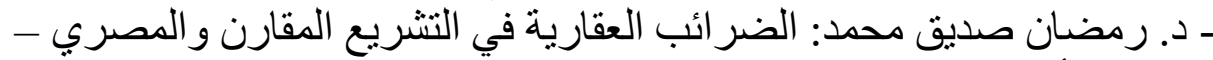

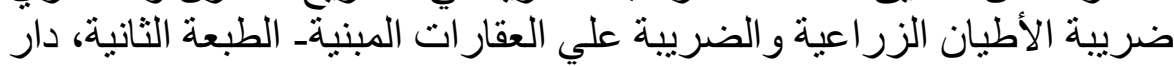

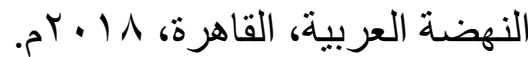
ـ د. زكريا محمد بيومي: موسوعة مانمة المناز عات الضريبية الوطنية و الدولية، الطبعة

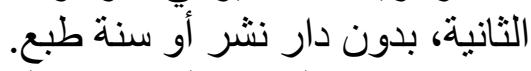

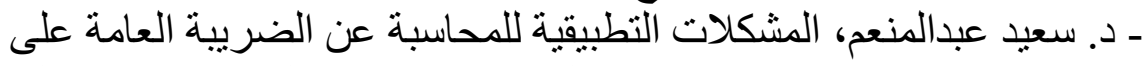

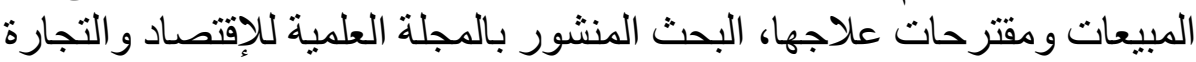

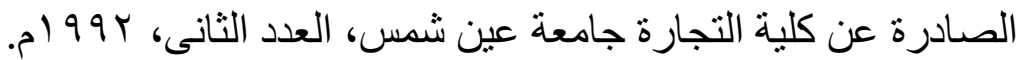

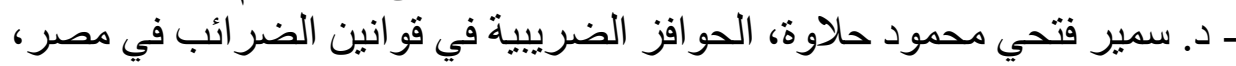

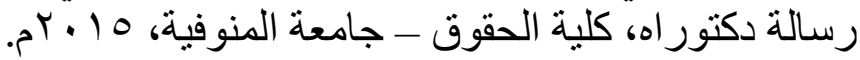

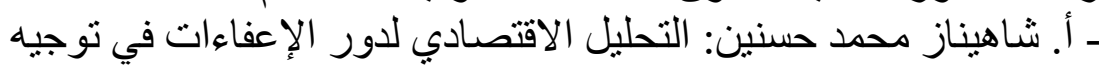

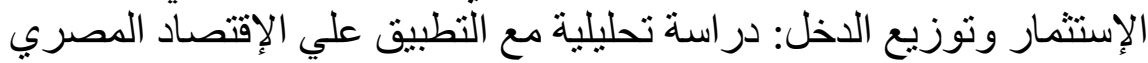

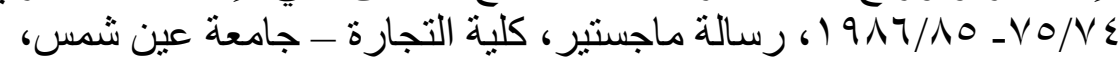


ـ ـ. عبد الهادي مقبل: در اسة تحليلية انتقادية لقانون الضريبة علي العقار ات ات الترات

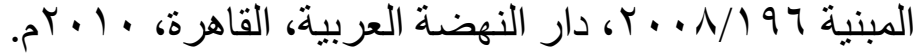

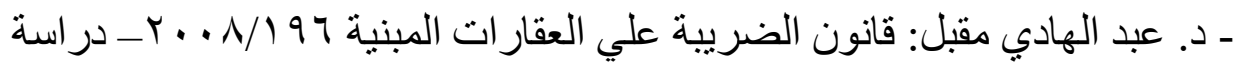

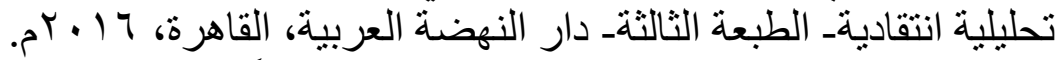

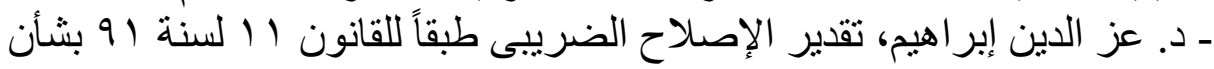

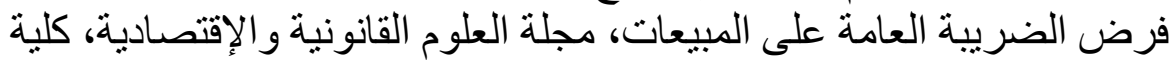

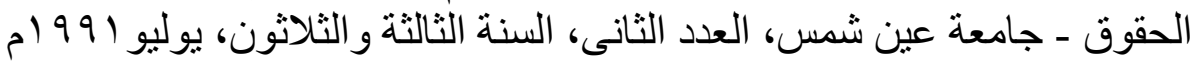

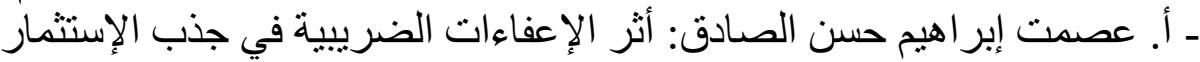

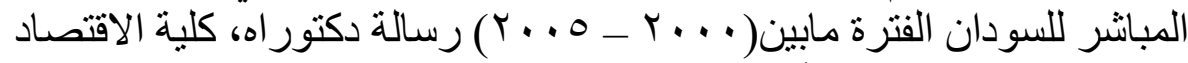

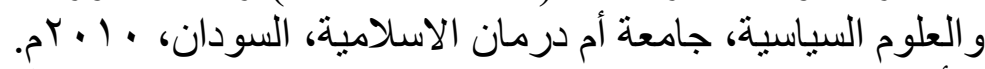

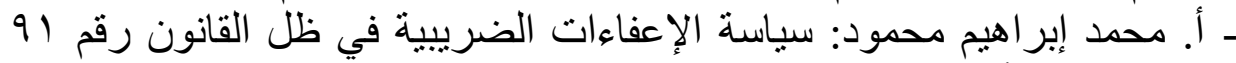

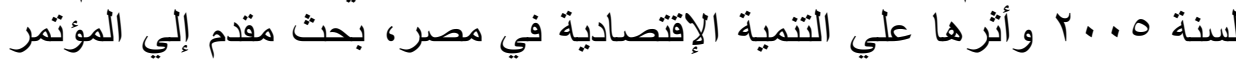

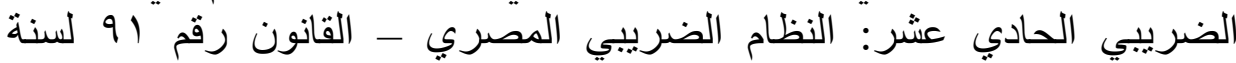

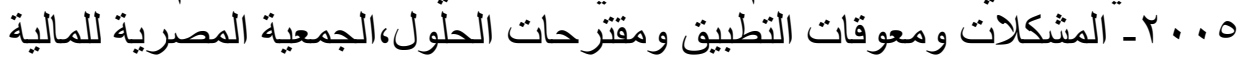

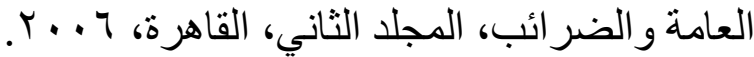

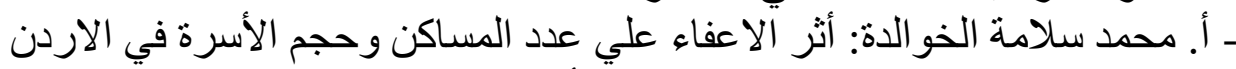

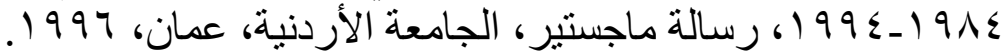

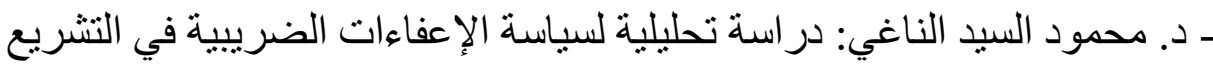
المصري، المجلة العلمية للإقتصساد و التجارة، كلية التجارة - جامعة عين شعس.

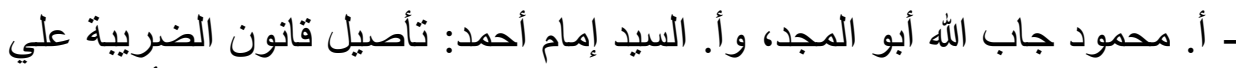

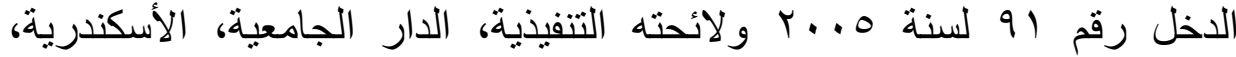

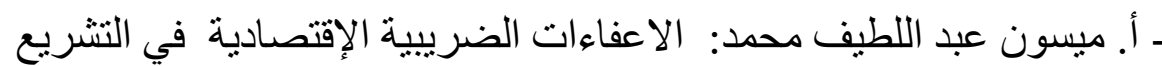

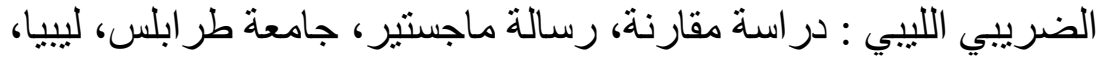

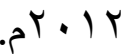

المستشار الدكتور / وائل راضي: المجمو عة التجارية، المكتب الفني، محكمة الفئية

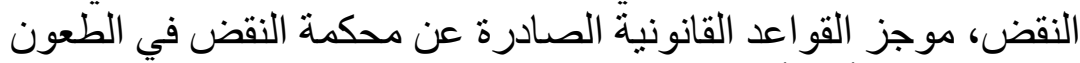

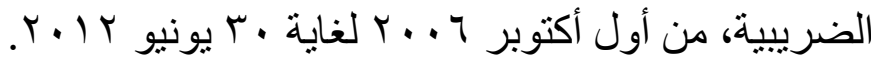


الإئتمان الضريبي وآثارة الإقتصادية والمالية "دراسة مقارنة"

Secondly, References in Forigen Languages:

- A. Farman , PKF , tax Handbook, $r \ldots . r \ldots$, Allied Dumber, Great Britain, $r$...

- Alan A. Tait, value Added Tax international, practice and problems , 1911 IMF, Washington, D.C. 1911.

- Ana Agúndez-García: THE DELINEATION AND

APPORTIONMENT OF AN EU CONSOLIDATED TAX BASE FOR MULTI-JURISDICTIONAL CORPORATE INCOME TAXATION: A REVIEW OF ISSUES AND OPTIONS, Working paper No ${ }^{9}$ - October $\Upsilon^{\prime}$. ? .

- Celine Azemar and Andrew Deliosy: The Tax Sparing Provision In uence: A Credit versus, Exempt Investors Analysis, University of Glasgow, UK, July $r$.. $V$

- Claudio A. Agostini: The Effect of Sales Tax Rates on Food Exemptions, Department of Economics, Universidad Alberto Hurtado, Santiago, Chile. November Y..

- Dennis Parkinson, Volue Added Tax in the E E C, Graham \& trotman L T d, London, 1911.

- Dorothée Boccanfuso, Céline de Quatrebarbes and Luc Savard: Can the removal of VAT Exemptions support the Poor? The Case

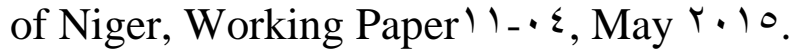

-Edmund Tirbutt, VAT and the small business, Biddls

Limited,Guildford, Great Britain, 199 .

- Encyclopedia of value Added Tax, London, U.K.

-Ernst \& Young: International VAT, Aguide to practice and pracedures in $r$ ) Countries, Ernst \& young international, London, 1991

- Harry Grubert: Enacting Dividend Exemption and Tax Revenue, Tax Analysis, International Taxation, Washington, DC r.r. . National Tax Journal, Vol. LIV, No. «.

- James Alm: The Role of Tax Exemptions and Credits, Tulane University Economics Working Paper Series, New Orleans, USA, Working Paper 10r 4 , December $r \cdot 10$

- James R. Hines Jr., Lawrence H. Summers: How Globalization Affects Tax Design, Tax Policy and the Economy, Volume $r$ r (Chapter pages in book $1 Y r-10 V$ ), University of Chicago Press,

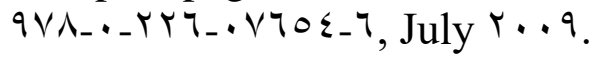

- John Brooks and Andrew Copp, How to live with VAT, Third Edition, London, 1919 
العدد الثامن والثمانون - الجزء الأول - إصدار أكتوبر 19 •

- Juan Carlos Conesa, Sagiri K. and Dirk Krueger: TAXING CAPITAL? NOT A BAD IDEA AFTER ALL!, Working Paper 1 YA^., NATIONAL BUREAU OF ECONOMIC RESEARCH, Massachusetts Avenue, Cambridge MA $\cdot r / r \wedge$, January $r \cdot . r$.

- Lawrence W. Kenny- University of Florida and Stanley L. WinerCarleton University: Tax Systems in the World: An Empirical Investigation into the importance of Tax Bases, Collection Costs, and Political Regime, May Y... .

- Luc Behaghel, Adrien Lorenceau and Simon Quantin: Replacing Churches and Mason Lodges? Tax Exemptions and Rural Development IZA DP No. $\vee \wedge \cdot \wedge$, D I S C U S S I O N P A P E R S E R I E S, Paris, France, December $r \cdot 1 r$.

- MARILYN R. FLOWERS: COSTS OF COLLECTIVE DECISIONS, CHOICE OF TAX BASE, AND MEDIAN VOTER EQUILIBRIUM, University of Oklahoma, PUBLIC FINANCE QUARTERLY, Sage Publications, Inc. Vol ${ }^{\top}$ No $r$, July $19 \vee \wedge$

- OECD $(r \cdot 1 \varepsilon)$, Model Tax Convention on Income and on Capital: Condensed Version $r \cdot 1 \leqslant$, OECD Publishing.

(http://dx.doi.org/ $/$, I $\vee$ A $\left./ / m t c \_c o n d-r \cdot I \leqslant-e n\right)$

- PAUL EKINS and STEFAN SPECK: Competitiveness and Exemptions From Environmental Taxes in Europe, Environmental and Resource Economics 1r: r79_r97, 1999. () 1999 Kluwer Academic Publishers. Printed in the Netherlands, April 1991.

- Paul Krugman and Martin Feldstein, "International trade effects of value Added Taxation " NBER Working paper N. Y I r ( National. Bureau of Economic Research, cambridge , November 1919 .

- Peter Egger, Valeria Merlo, Martin Ruf \& Georg Wamser: Consequences of the New UK Tax Exemption System: Evidence from Micro-level Data, CESIFO WORKING PAPER NO. $r q \leqslant r$, CATEGORY 1 : PUBLIC FINANCE, SEPTEMBER $r \cdot 1 r$.

- Peter Fortune: TAX-EXEMPT BONDS REALLY DO SUBSIDIZE MUNICIPAL CAPITAL!, Federal Reserve Bank of Boston, USA.

- RICHARD L. PFISTER: A REEVALUATION OF THE JUSTIFICATIONS FOR PROPERTY TAX EXEMPTION, Indiana University, India, PUBLIC FINANCE QUARTERLY, Vol. « No. $\varepsilon$, October, 19vч.

- Roger H. Gordon and Wojciech K.: THE CHOICE OF THE PERSONAL INCOME TAX BASE, NATIONAL BUREAU OF ECONOMIC RESEARCH 1.0 . Massachusetts Avenue, 
الإيتمان الضريبي وآثارة الإقتصادية والمالية "دراسة مقارنة"

Cambridge, MA · r Ir^, Working Paper r. rrv, June $r \cdot 1 \varepsilon$

- Salvatore B. Jens Suedekum: Voting on income tax exemptions, Public Choice, $r$.. 9 .

-Harry de Gorter and David R. Just: The Welfare Economics of an Excise-Tax Exemption for Biofuels, Cornell University, Working Paper, Department of Applied Economics and Management Cornell

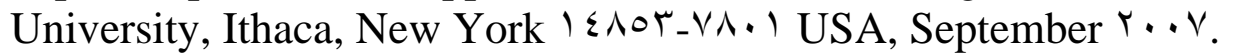
-Helmut Dietl, Christian Jaag, Markus Lang, Martin Lutzenberger and Urs Trinkner Impact of VAT Exemptions in the Postal Sector on Competition and Welfare, Institute for Strategy and Business Economics, University of Zurich, Working Paper Series, ISSN $174 .-110 \mathrm{~V}$, Working Paper No. $1 \leqslant 0$, November $r .1 \cdot$.

-James M. Poterba: TAX REFORM AND THE MARKET FOR TAX-EXEMPT DEBT, NBER WORKING PAPER SERIES, Working Paper No. $r q .$. NATIONAL BUREAU OF ECONOMIC RESEARCH, USA, Massachusetts, Cambridge, MA • rIrA, March 1919 .

-JOHANNES BECKER \& CLEMENS FUEST: CORPORATE TAX POLICY AND INTERNATIONAL MERGERS AND ACQUISITIONS - IS THE TAX EXEMPTION SYSTEM SUPERIOR? CESIFO WORKING PAPER NO. $1 \wedge \wedge \varepsilon$, CATEGORY ।: PUBLIC FINANCE, JANUARY $r \cdots \vee$.

-John N. Brown and Suzanne Chadwick, A guide to VAT in the UK, Ernst \& young, London, 199.

-Jr-Tsung Huang: The Personal Tax Exemption and Married Women's Birth Spacing in the United States, National Chengchi University Cross-Strait Interflow Prospect Foundation, Public

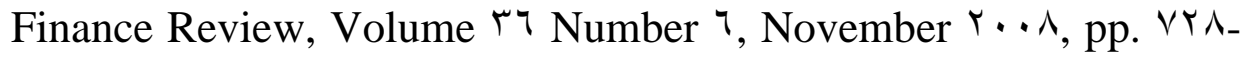
$V \leqslant$.

-S.O'ConnoraTerrence M.O'Connorbc: Tax exemption as a marketing tool: The Irish Republic and profits derived from artistic creativity. Journal of Business Research, Volume Tr, Issue 1., October $r \ldots q$, Pages $1 \ldots Y-1 \ldots r$ 
العدد الثامن والثمانون - الجزء الأول - إصدار أكتوبر 19 ب

YASUSHI IWAMOTO \&AKIHISA SHIBATA: Foreign Tax Credit and the Current Account, International Tax and Public Finance, $7,1 \% 1-1 \leqslant \wedge$ (1999), Institute of Economic Research, Kyoto University, Kyoto $7.7 \_\wedge 0.1$, Japan. 1999. 